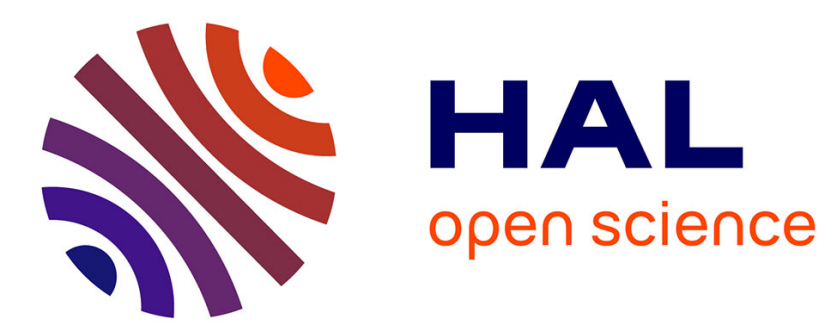

\title{
Mouvement féministe et droit de vote en Bolivie (1920-1952)
}

María Elvira Alvarez

\section{To cite this version:}

María Elvira Alvarez. Mouvement féministe et droit de vote en Bolivie (1920-1952). Histoire. 2011. dumas-01275966

\section{HAL Id: dumas-01275966 https://dumas.ccsd.cnrs.fr/dumas-01275966}

Submitted on 18 Feb 2016

HAL is a multi-disciplinary open access archive for the deposit and dissemination of scientific research documents, whether they are published or not. The documents may come from teaching and research institutions in France or abroad, or from public or private research centers.
L'archive ouverte pluridisciplinaire HAL, est destinée au dépôt et à la diffusion de documents scientifiques de niveau recherche, publiés ou non, émanant des établissements d'enseignement et de recherche français ou étrangers, des laboratoires publics ou privés. 
Université Paris 1 Panthéon - Sorbonne

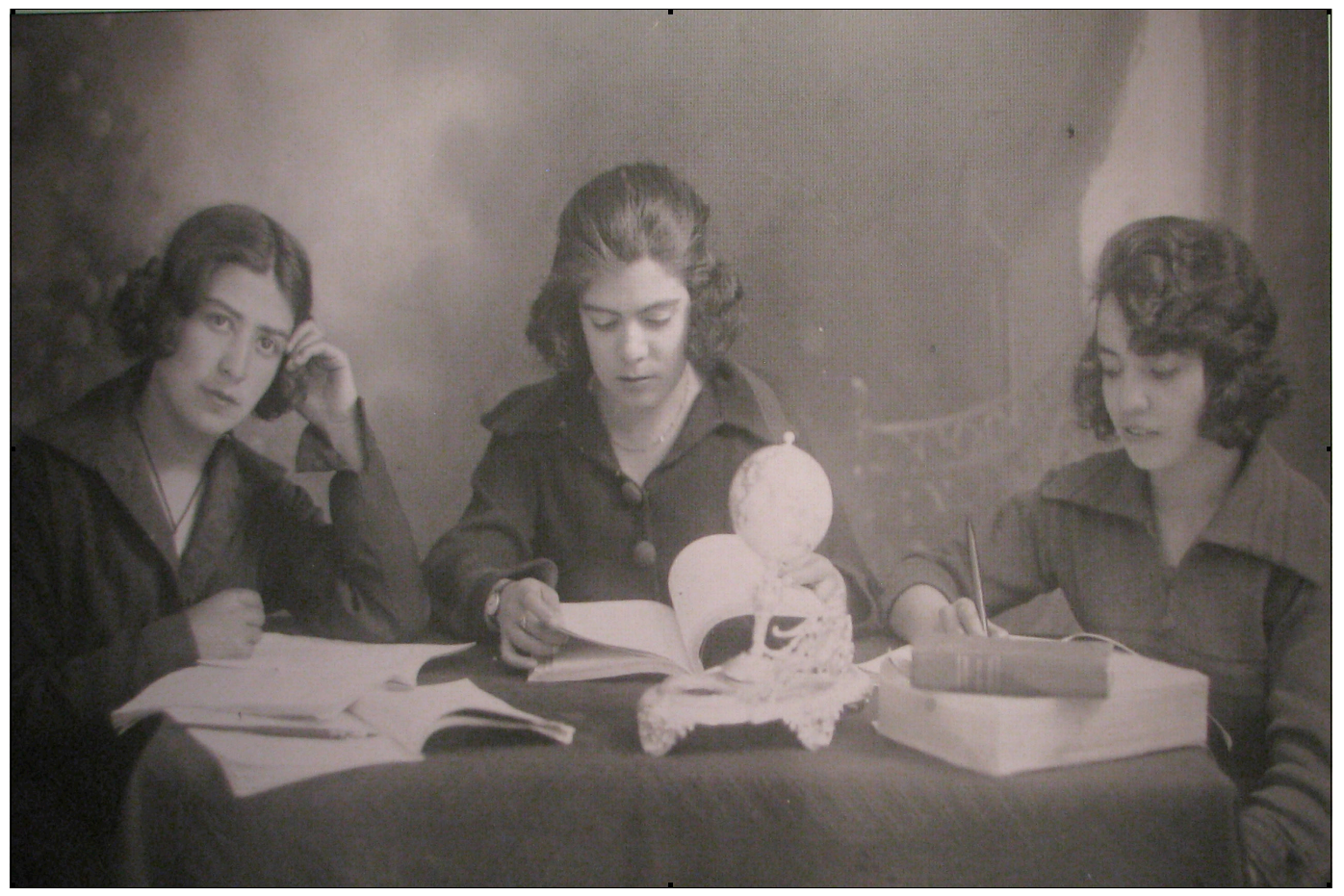

\title{
Mouvement féministe et droit de vote en Bolivie (1920-1952)
}

\author{
ALVAREZ María Elvira
}

Master 2 Histoire

Sous la direction de Annick Lempérière 


\title{
Mouvement féministe et droit de vote en Bolivie (1920-1952)
}

ALVAREZ María Elvira

\author{
Master 2 Histoire \\ Sous la direction de Annick Lempérière
}


Aux protagonistes de cette Histoire 
“... Nous qui sommes sans passé, les femmes,

Nous qui n'avons pas d'histoire

Depuis la nuit des temps, les femmes,

Nous sommes le continent noir..."

- Les Femmes, Christine de Pisan, 1364-1430 


\section{$\underline{\text { Table des matières }}$}

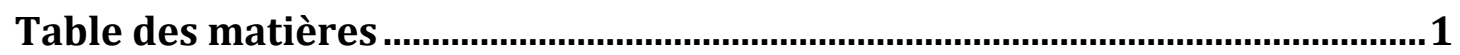

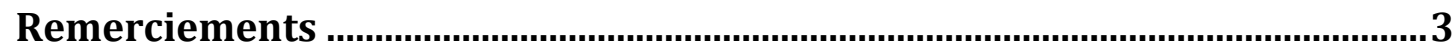

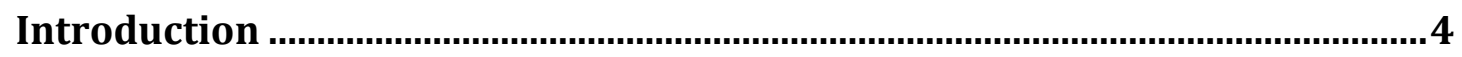

I) Émergence du mouvement féministe en Bolivie (années 1920)............... 13

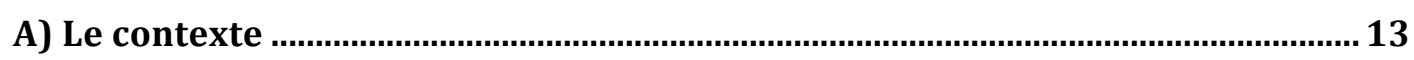

a) Développement de l'éducation des femmes au début du XXe siècle .........................13

b) La situation légale des femmes dans les années 1920 en Bolivie..............................19

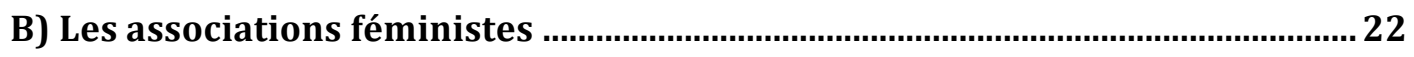

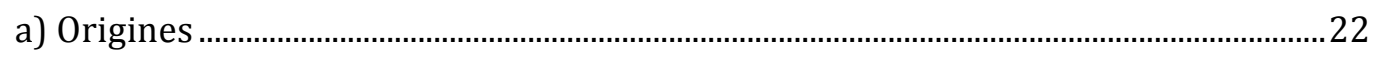

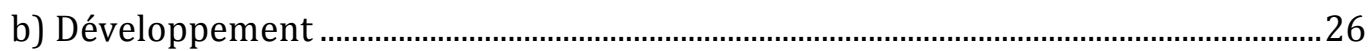

c) L'«Ateneo Femenino » de La Paz et les réseaux féministes .........................................32

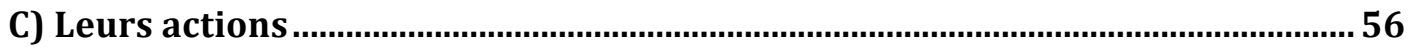

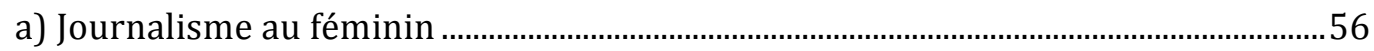

b) Congrès Nationaux et participation aux Congrès Internationaux..............................83

D) Quel féminisme, quelles demandes et quels projets ? .........................................104

a) Le type de féminisme revendiqué .................................................................................. 104

b) Quelles demandes ? ................................................................................................. 131

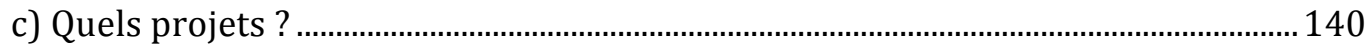

II) Femmes et mouvement féministe pendant et après la Guerre du Chaco

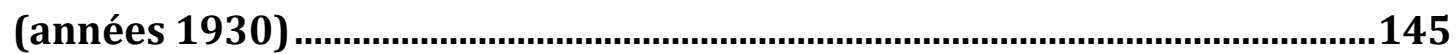

A) L'impact de la Guerre du Chaco dans la société bolivienne...............................145

a) L'impact politique, social et culturel de la Guerre du Chaco ...................................... 145

b) La participation des femmes à l'effort de guerre........................................................... 152

B) Mouvement féministe pendant et après la guerre ............................................161

a) Le mouvement féministe pendant la guerre ……………………………………....... 161

b) Le mouvement féministe de post guerre.................................................................... 183

C) Quelques pas vers l'octroi des droits civils et politiques aux femmes... qui ne

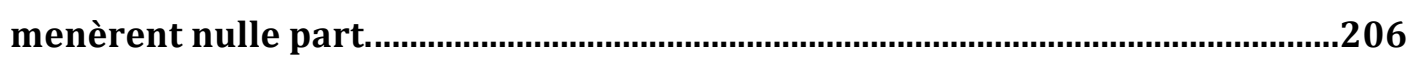

a) Le décret-loi de David Toro octroyant les droits civils aux femmes jamais mis en application 
b) La Convention de 1938 et le débat sur le suffrage féminin

III) Les premières expériences des femmes en politique (années 1940) .232

A) La Convention de 1944-1945 : réformes dans la législation de la famille et obtention du suffrage féminin limité

a) Les réformes dans la législation de la famille

b) L'obtention du suffrage féminin limité.

B) La première participation électorale des femmes : les élections municipales de 1947 et de 1949

a) La préparation pour les comices

b) La participation des femmes aux élections municipales et la réception de cet événement par la société

c) Les femmes du MNR, la Révolution et le suffrage universel.

a) Les « Barzolas » : les commandos féminins du MNR.

b) La Révolution Nationale et le Suffrage Universel

Conclusion

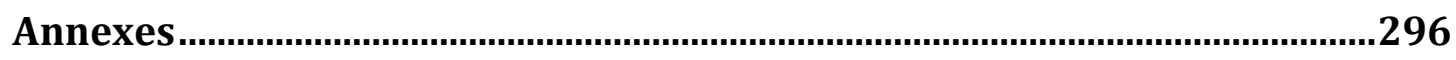

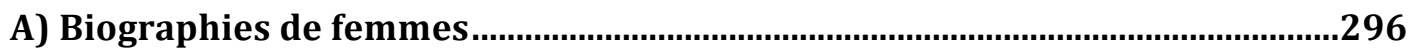

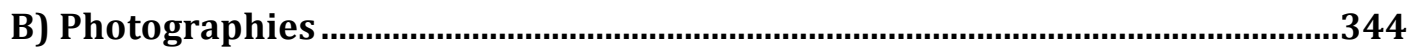

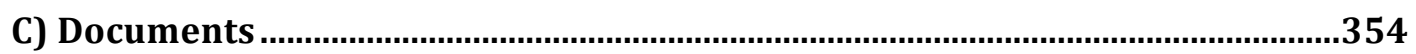

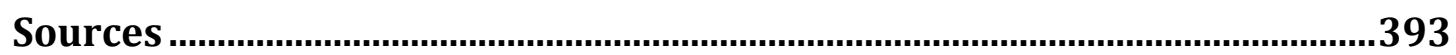

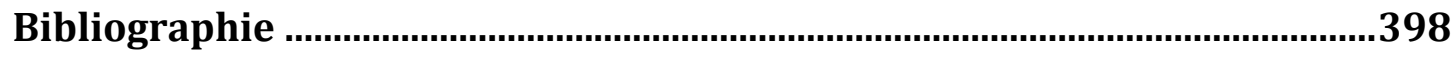




\section{$\underline{\text { Remerciements }}$}

Je veux remercier d'abord mes parents Gonzalo Alvarez Chávez et Rosario Gimenez Olmos pour leur soutien inconditionnel pendant toute la réalisation de ce travail et de mes études en France. Ma mère a été ma collaboratrice la plus importante en Bolivie pour la recherche et l'obtention d'informations lorsque je me trouvais à Paris. Je la remercie pour son aide qui m'a facilité considérablement la réalisation de ce mémoire.

Ensuite je veux remercier toutes les personnes en Bolivie, qui d'une manière ou d'une autre m'ont fourni des informations précieuses pour cette étude: Marie Danielle-Démélas, Salvador Romero Ballivián, Pilar Mendieta, Ana María Seoane, Florencia Durán Jordán, María Isabel Arauco, Gloria Ardaya, Lourdes Peñaranda, Teresa Rosazza, Rossana Barragán, Amalia Decker, Roxana Ybarnegaray, Dunia Mokrani, Luis Oporto Ordoñez, Marcela Inch, Martha Nardín de Urioste, Franklin et Guido Antezana, Ximena Medinaceli, Nohora de Beltrán et Luis Ramiro Beltrán qui a démontré un très grand intérêt pour ce travail et m'a proportionné un nombre considérable d'informations.

Je veux remercier aussi le personnel de l'archive de périodiques de l'Universidad Mayor de San Andrés (UMSA), celui des Archives du Congrès de la ville de La Paz, et celui des Archives Nationales de la ville de Sucre.

A Paris, je veux remercier surtout Mme. Annick Lempérière pour ses conseils et son aide pour la réalisation de ce travail, et Mme. Véronique Hébrard pour son aide et ses conseils pratiques.

Je veux remercier également Manoel Castello Branco pour son soutien pendant toute la période de rédaction de ce travail et son aide à la relecture et révision de celui-ci. 


\section{Introduction}

"Plus de lumière!"

- Goethe, 1832.

Que les femmes aient le droit de vote nous semble une évidence frappante de nos jours. Or, cette évidence n'en était pas une un siècle auparavant. Le suffrage féminin, ainsi que le mouvement féministe pour l'obtenir, sont une nouveauté du $\mathrm{XX}^{\mathrm{e}}$ siècle et ils possèdent une histoire propre. C'est cette histoire que je veux raconter pour mon mémoire de Master en me plaçant dans une aire géographique et un temps bien précis : la Bolivie de 1920 à 1952.

Ce projet a commencé il y a deux ans, en 2009, lorsque je me suis mise à la recherche de bibliographie et de sources en rapport à ce qu'à l'époque j'avais vaguement défini comme «les femmes et le vote en Bolivie ». Après un séjour dans ce pays pendant l'été 2009 qui m'a permis de constituer une première bibliographie et un premier corpus de sources, j'ai commencé une année de Master 1 qui m'a permis d'affiner le sujet et de le définir plus clairement. Ceci a abouti à l'énonciation du sujet de recherche en tant que «Mouvement féministe et droit de vote en Bolivie, 19201952 ». Cette avance quant à la précision du sujet de recherche est allée de pair avec tout un travail de recherche historiographique par rapport à ce qui avait été fait au sujet de l'histoire des élections, de la citoyenneté, de l'histoire des femmes, et plus précisément de l'histoire des femmes en Bolivie. Ce travail, conjugué également avec un dépouillement et une première analyse des sources, a abouti à la réalisation du mémoire de Master 1 que j'ai soutenu à la fin du mois de juin $2010^{1}$. Un deuxième séjour en Bolivie pendant l'été 2010 m'a permis de compléter et d'enrichir le corpus de sources dont je disposais déjà, ainsi que d'ajouter de nouveaux éléments bibliographiques sur 1'histoire des femmes en Bolivie. L'analyse de ces sources s'est avérée d'une très grande richesse et d'un très grand intérêt historique; le résultat en est ce mémoire de Master 2.

\footnotetext{
${ }^{1}$ ALVAREZ Maria Elvira, Mouvement féministe et droit de vote en Bolivie (1920-1952), mémoire de master 1 d'Histoire réalisé sous la direction de Annick Lempérière, Université Paris 1 Panthéon Sorbonne, Paris, juin 2010.
} 
Le corpus de sources dont on dispose est assez divers. Il est d'abord composé de lois, décrets de loi, texte des Constitutions de 1880, 1938 et 1945, et études sur la condition juridique des femmes qui nous permettent de connaître en détail les dispositions établies par l'État Bolivien de 1920 à 1952 concernant directement ou indirectement les femmes. L'on dispose également de débats parlementaires sur le divorce absolu en 1932 et en 1944, et sur le suffrage féminin dans les Conventions de 1938 et 1945 qui nous permettent de connaître en détail l'avis des hommes politiques de l'époque sur ces questions. Les articles de presse dont on dispose sont également une source riche en informations. Ils nous permettent de connaître l'opinion publique sur divers événements tels que la promulgation de la loi du divorce absolu, les débats parlementaires qui discutent du suffrage féminin, les premières élections où participent les femmes, les actions des organisations féministes, etc. Par ailleurs, les revues féminines - féministes publiées par les diverses organisations féministes sont une source précieuse pour connaître en détail la structure et organisation des associations féministes, leurs actions, activités, leurs réflexions sur le féminisme, sur la condition des femmes, leurs revendications, les membres qui les composaient, les réseaux féministes auxquels elles appartenaient, etc. En outre, les entretiens vidéos de certaines féministes réalisés à la fin des années 1980, ainsi que les entretiens que j’ai réalisé aux membres de leurs familles sont une source qui nous permet de connaître en détail la vie de ces femmes, leur pensées, leurs actions, ainsi que des anecdotes diverses. Finalement, quelques livres publiés par les femmes féministes sont une source précieuse pour connaître les organisations auxquelles elles appartenaient et quelques détails de la dimension subjective de leurs expériences.

Les femmes Boliviennes ont obtenu le droit de vote en 1952 dans le cadre d'une révolution qui mit à bas un régime de gouvernement oligarchique qui était en place depuis la fin du XIX ${ }^{\mathrm{e}}$ siècle. Ce fut la «Révolution Nationale » dirigée par le « Mouvement Nationaliste Révolutionnaire » (MNR) qui éclata le 9 avril 1952 et qui fut un des moments historiques les plus importants dans l'histoire de ce pays. Cette révolution tient ses racines de la Guerre du Chaco (1932-1935) qui signifia un bouleversement majeur dans le pays politiquement, socialement et culturellement puisqu'elle déclencha le début de l'écroulement du régime oligarchique qui fut 
finalement détruit en $1952^{2}$; mais cette révolution fut aussi l'effet direct d'un fait qu'eut lieu un an auparavant: le non respect du résultat des élections présidentielles que le MNR avait gagnées démocratiquement en mai 1951. Sous prétexte que le résultat de ces élections était un danger pour le pays, puisque le MNR était suspecté d'être affilié au Parti Communiste de la Bolivie, Mamerto Urriolagoitia réalisa un « auto-coup » d'Etat, qui fut qualifié plus tard comme « Mamertazo », en renonçant à la présidence et en transférant illégalement la charge au chef de l'État Major, qui, à son tour, nomma comme président Hugo Ballivián. Le nouveau gouvernement annula les élections et mit le MNR hors la loi. Ce dernier n'avait dès lors qu'une seule voie possible pour accéder au pouvoir : la révolution. Peu de temps après son arrivée au pouvoir, le MNR mit en place des réformes d'une importance considérable pour la Bolivie: la réforme agraire, la nationalisation des mines, et le suffrage universel. C'est à travers cette dernière réforme, par un décret-loi en date du 21 juillet 1952, que les femmes Boliviennes acquirent le droit de vote, en même temps que la plus grande partie de la population. En effet, avant cette date et depuis 1839, le type de suffrage existant en Bolivie avait été: direct, masculin, censitaire et restreint à ceux qui étaient alphabétisés. Par conséquent, une infime partie de la population pouvait participer aux comices : pour les élections de 1951, sur une population de 3.019.031 d'habitants, seuls 204.649 électeurs étaient inscrits pour voter, c'est-à-dire, 6, 78\% de la population $^{3}$.

Les premières questions générales que je m'étais posées lorsque j'abordais pour la première fois la problématisation du sujet «mouvement féministe et droit de vote en Bolivie » étaient : est-ce que l'octroi du droit de vote pour les femmes en Bolivie avait été le résultat d'un processus évolutif? Ou avait-il été décidé par la classe politique sans que les femmes l'aient vraiment demandé et sans qu'il y ait eu de débat préalable dans la société ? Il s'agissait en effet de savoir si le mouvement féministe avait joué un rôle prépondérant pour créer le débat au sein de la société sur la question du suffrage féminin et préparé un contexte favorable dans les sphères politique et sociale pour que la réforme soit mise en place, ou si cette réforme avait été décidée

\footnotetext{
${ }^{2}$ KLEIN, Herbert S., Orígenes de la revolución nacional boliviana. La crisis de la generación del Chaco, Librería Editorial G.U.M., La Paz, (n.d.)

${ }^{3}$ LEAÑO ROMÁN Eduardo, Sistemas electorales en Boliva. La Conversión de votos del Ejecutivo y Legislativo, Unidad de Análisis e Investigación del Area de Educación Ciudadana de la Corte Nacional Electoral, Corte Nacional Electoral, La Paz - Bolivia, 1ère édition février 2005, p. 37.
} 
« d'en haut » sans débat préalable et reçue avec une certaine indifférence de la part de la population et des femmes en général. Ces questions me paraissaient d'autant plus pertinentes que les femmes ont reçu le droit de vote dans le cadre d'une révolution et par décret de loi, c'est-à-dire sans débat préalable au sein d'un Parlement, et dans le cadre d'une réforme qui concernait d'autres secteurs de la population et pas seulement les femmes, puisqu'il s'agissait de la proclamation du suffrage universel.

Or, je me suis rendue compte plus tard que poser ces questions, et surtout la première, était partir d'un postulat téléologique, évolutif : c'était se demander s'il y avait eu ou pas une évolution dans le temps qui aurait permis aux femmes de créer un débat au sein de la société et de faire pression sur le gouvernement pour qu'il leur accorde le droit de vote ; c'était partir d'un point (le surgissement du mouvement féministe) pour arriver à un résultat en ligne droite (l'octroi du droit de vote). Or, c'est en analysant les sources que je me suis aperçue que le mouvement féministe, tout du moins en Bolivie, ne peut pas être compris de manière téléologique ni évolutive ; il ne s'agit pas d'une histoire linéaire. Comme l'affirme Michelle Perrot : « Le féminisme agit par poussées, par vagues. C'est un mouvement intermittent, syncopé, mais résurgent, parce qu'il ne s'appuie pas sur des organisations stables capables de le capitaliser (...) Il s'appuie sur des personnalités, des regroupements éphémères, des associations fragiles. ${ }^{4}$ L'histoire du mouvement féministe en Bolivie est strictement liée au contexte politique et social dans lequel il se développe : ses triomphes, défaites et même la priorité donnée à certaines de ses revendications, sont liées à ce qui se passe dans les sphères politique et sociale du pays.

La période sur laquelle nous travaillons est très longue marquée par des contextes politiques très différents qui constituent donc autant de «sous - périodes ». La longueur de la période a été une difficulté majeure, non pas tant dans la problématisation du sujet que dans le domaine pratique de réalisation du mémoire, puisqu'il fallait trouver des sources pour chaque décennie (1920, 1930, 1940, début des années 1950), ce qui représente un travail colossal pour une recherche de Master, et surtout pour ce qui concerne l'analyse et le dépouillement d'un corpus très vaste de sources qui correspondent à des périodes différentes et qui méritent donc d'être comprises, traités et analysées de manière différente en fonction de la période qu'elles représentent. Cependant, la période choisie se justifie pleinement en relation au sujet

\footnotetext{
${ }^{4}$ PERROT Michelle, Mon histoire des femmes, Editions du Seuil, 2006, p. 212.
} 
« mouvement féministe et droit de vote en Bolivie », puisque le surgissement de ce que l'on qualifie de «mouvement féministe » a lieu dans la décennie des années 1920 et le droit de vote est accordé aux femmes en 1952, et même s'il n'y a pas d'histoire linéaire entre ces deux faits, il y a une logique difficile à briser entre le mouvement féministe et l'acquisition du droit de vote qui constitue un des objectifs essentiels du mouvement féministe (même s'il n'est pas le seul comme on le verra plus tard). Cette logique relève donc non pas d'une relation de cause à effet (action féministe donc suffrage féminin) qui impliquerait une histoire linéaire, mais de la définition même de « mouvement féministe » qui implique parler de ses objectifs, dont le droit de vote.

Ceci nous oblige à poser la question de la définition même de « féminisme » et de « mouvement féministe ». Définir le féminisme n’est pas une question évidente. En raison de problèmes de définition, ce concept a fait et fait toujours polémique au sein de la société et parmi les militantes; mais aussi au sein de la communauté des historiens qui travaillent sur l'histoire des femmes et sur l'histoire du féminisme. Comme l'affirme Sylvie Chaperon dans L'Histoire sans les femmes est-elle possible ?: «Définir le féminisme est un acte politique, il s'agit de dire sa position politique et bien souvent dans le même mouvement d'affirmer que c'est la meilleure qui soit. Définir le féminisme n'est pas neutre, il s'agit souvent de désigner le "vrai" ou le "bon" féminisme, ou encore le seul qui vaille $»^{5}$ Puisque le féminisme est un objet historique et ne peut être défini que par rapport au contexte spatial et temporel où il prend place et se développe, la définition du féminisme dont se réclamaient les féministes boliviennes fera l'objet d'analyses spécifiques dans chacune des «souspériodes », consacrées à essayer de le cerner, de le définir et de le comprendre dans ses changements et continuités tout au long de la période sous un angle entièrement historique. On verra comment la définition du féminisme que proclamaient les féministes boliviennes change en fonction du contexte politique et social, tout comme ses stratégies d'action et même la priorité donnée à certain de ses objectifs. Suivant l'idée que « prédéfinir le féminisme, c'est peut-être s'interdire d'étudier les étapes qui $\mathrm{y}$ mènent, ou les modifications qui affectent son sens $»^{6}$, dans cette introduction on se limitera seulement à définir ce qu'on qualifie de «mouvement féministe » et de le

\footnotetext{
${ }^{5}$ CHAPERON Sylvie, “1945-1970, Reprendre l'Histoire du Féminisme”, dans SOHN Anne-Marie et THÉLAMON Françoise (sous la direction de), L'Histoire sans les femmes est-elle possible?, Perrin, 1997.

${ }^{6}$ Idem.
} 
distinguer de «féminisme ». La définition du féminisme dont se réclamaient les féministes boliviennes sera dévoilée tout au long de l'analyse.

Le féminisme concerne l'idéologie, la théorie avec des concepts et des principes fondateurs, les dimensions littéraire, philosophique, éthique et politique de ce qui peut s'exprimer comme une affirmation tout aussi bien individuelle et marginale, que collective. Le "mouvement féministe» fait appel à une affirmation collective et donc à une action collective d'une plus ou moins grande ampleur. Qui dit action collective, dit organisation collective formée de plusieurs acteurs individuels ou collectifs groupés et organisés autour de principes fondateurs (dans ce cas, le féminisme qu'ils revendiquent) mais aussi autour d'objectifs concrets à atteindre pour lesquels ils créent des stratégies d'action collective. Comme l'exprime Florence Rochefort dans L'Histoire sans les femmes est-elle possible? : «Un des enjeux méthodologiques importants de l'histoire du féminisme est justement d'opérer des distinctions et de montrer le passage d'une idée marginale portée par quelques individus à la constitution d'une mobilisation collective. Il est ainsi important de distinguer le «féminisme » $\mathrm{du}$ 《mouvement féministe », l'analyse des concepts fondateurs et celle d'une organisation collective, pour faire apparaître la dimension philosophique, éthique, littéraire, politique du féminisme d'une part, et son corpus de revendications d'autre part, dont peuvent s'emparer d'autres acteurs sociaux. ॥ ${ }^{7} \mathrm{De}$ sorte que l'objet de ce travail ce sont les organisations collectives de femmes qui se disent féministes et qui en fonction des principes fondateurs du féminisme qu'elles proclament et autour duquel elles se réunissent, se mobilisent et organisent des actions diverses afin d'atteindre plusieurs de leurs objectifs, dont le suffrage féminin. Ces organisations collectives de femmes seront étudiées dans les différentes décennies (1920, 1930, 1940). Les premières d'entre elles surgissent dans les années 1920, et plusieurs d'entre elles disparaissent dans les années 1930 et 1940, tandis que d'autres apparaissent à cette époque, notamment dans les années 1930. Une seule de ces organisations subsiste tout au long de la période qui va de 1920 à 1952. Dans ce cas, s'il y a plusieurs organisations avec des durées de vie différentes, pourquoi parler de «mouvement féministe» au singulier et pas de «mouvements féministes» au

\footnotetext{
${ }^{7}$ ROCHEFORT Florence, "Réflexions à propos de l'histoire du féminisme", dans SOHN Anne-Marie et THÉLAMON Françoise (sous la direction de), L'Histoire sans les femmes est-elle possible?, Perrin, 1997.
} 
pluriel ? Parler de «mouvements féministes » signifierait qu'il y a eu différentes mobilisations dans le temps (ce qui est le cas) menées par des organisations différenciées par le type de féminisme dont elles se réclamaient, c'est-à-dire que leurs concepts et principes fondateurs pour se mobiliser seraient différents et par conséquent leurs objectifs seraient distincts (ce qui n'est pas le cas). Cela pourrait impliquer l'existence de plusieurs générations de féministes se succédant dans le temps et revendiquant un féminisme qui n'est pas le même de l'une à l'autre, les nouvelles générations s'opposant aux premières par exemple. Ou cela pourrait impliquer tout simplement des organisations proclamant un féminisme très différent s'opposant l'un à l'autre par exclusion, sans aucun type de liens de coopération entre elles et même avec un certain degré de concurrence, ce qui n'est pas du tout le cas en Bolivie. Même si le féminisme dont se réclament ces organisations n'est pas le même tout au long de la période et connaît des changements en relation aux stratégies d'action et priorité donnée à certains objectifs en fonction du contexte social et politique dans lequel il se développe, il y a une certaine unité et homogénéité entre toutes ces organisations. Notamment par le fait que les femmes qui les composent et les recomposent sont toujours les mêmes. Certes des femmes nouvelles apparaissent, notamment dans la décennie des années 1930, mais elles travaillent avec des femmes qui appartenaient aux premières organisations féministes des années 1920 par exemple. Les objectifs de base : l'amélioration de l'éducation des femmes, ainsi que l'obtention des droits civils et politiques, restent toujours les mêmes tout au long de la période, même si les organisations ont des stratégies différentes en fonction des périodes pour les atteindre. On ne voit donc pas s'opposer des générations différentes de féministes; tout au contraire, les nouvelles organisations qui surgissent sont toujours composées de femmes d'anciennes organisations. On constate donc des liens étroits dans le temps et dans l'espace entre toutes ces femmes qui composent les diverses organisations. Il n'y a donc pas de concurrence, puisqu'elles reconnaissent que les objectifs de base entre les différentes organisations auxquelles elles appartiennent sont les mêmes. Elles essayent alors de coopérer entre elles pour créer une mobilisation collective. A cette unité et homogénéité contribue non seulement le fait que ces femmes sont presque toujours les mêmes, mais aussi le fait qu'elles appartiennent toutes aux classes moyennes et élevées de la société et qu'elles partagent les mêmes conceptions sur le rôle des femmes dans la société et sur ce dont les femmes ont besoin. Par contre, de grandes divergences se manifestaient entre elles 
et les femmes des classes populaires qui ne se considéraient pas féministes, et avec lesquelles elles n'ont jamais pu s'unir véritablement, en raison justement, comme on le verra plus tard, des conceptions très différentes qu'elles avaient des nécessités des femmes et du rôle qu'elles devaient jouer dans la société. Il s'agit donc d'un mouvement féministe qui possède une certaine unité et homogénéité dans le temps et dans l'espace qui justifie sa qualification au singulier.

L'objectif de ce travail de recherche est de connaître et d'analyser les organisations féministes en Bolivie de la période qui va de 1920 à 1952, c'est-à-dire depuis leur surgissement jusqu'à l'obtention du droit de vote, pour comprendre comment leurs modes d'organisation, leurs stratégies d'action, et la priorité donnée à certains objectifs se sont modifiées en fonction du contexte social et politique dans lequel elles se sont développées. Dans ce sens, trois périodes distinctes, dotées chacune d'une certaine unité, ont été identifiées pour analyser les différents moments dans lesquels a pris place le «mouvement féministe » en Bolivie: la décennie des années 1920 marquée par le surgissement et le développement des organisations féministes; la décennie des années 1930 marquée par les bouleversement sociaux, politiques et culturels que signifia la Guerre du Chaco, qui entraînèrent des changements considérables par rapport à la condition des femmes et par rapport aux mentalités, mutations que les organisations féministes prirent en compte dans leurs stratégies d'action et la priorité donnée à leurs objectifs; la décennie de 1940 jusqu'en 1952, marquée par l'obtention de quelques concessions de la part des hommes politiques, notamment le droit de vote pour les femmes qui savaient lire et écrire dans le cadre des élections municipales et par conséquent la première participation des femmes en politique. Il s'agira concrètement d'analyser et de connaître dans chaque décennie (1920, 1930 1940) quelles étaient ces organisations féministes? Qui étaient leurs membres? Quelles étaient les relations (sociales, familiales) entre les féministes et les hommes politiques de l'époque ? Quels étaient les liens qu'elles entretenaient entre elles? Dans ce sens, il s'agira de voir quelles étaient leurs actions et leurs stratégies pour atteindre leurs objectifs (dont le suffrage féminin était un des plus importants). Quel était le type de féminisme dont ces organisations féministes se réclamaient? Quel lien entretenaient-elles avec le féminisme international et quelle était leur position par rapport à celui-ci ? Il s'agira également de tenter de cerner tout au long de la période les principes fondateurs du féminisme que ces organisations revendiquaient pour essayer d'en donner une 
définition prenant en compte les changements qui se sont produits par rapport aux stratégies d'action et à la priorité donnée à certains de leurs objectifs. Quelles étaient leurs demandes concrètes et leurs projets en fonction du contexte social et politique dans lequel elles se développaient ? On étudiera de la même manière, dans chacune des décennies quelle fut la réception des organisations féministes au sein de la société et de la sphère politique. Les hommes politiques prirent-ils en compte leurs revendications lorsqu'ils débattaient sur les droits civils et politiques des femmes ?

L'analyse pour répondre à ces questions suivra les trois moments qu'on a déjà identifiés pour étudier le «mouvement féministe en Bolivie». Ainsi, la première partie sera consacrée au surgissement et au développement du mouvement féministe en Bolivie dans la décennie des années 1920. La deuxième partie abordera l'impact de la guerre du Chaco sur la société bolivienne et sur la vie des femmes, ainsi que sur le féminisme qui prit en compte ces changements sociaux, politiques et culturels pour s'y adapter (années 1930). Enfin, la troisième partie analysera l'obtention du suffrage féminin limité aux femmes qui savaient lire et écrire pour les élections municipales, leur première participation électorale, et le rôle joué par les femmes au sein du MNR avant la Révolution et l'obtention du suffrage universel (1940-1952). 


\section{I) Émergence du mouvement féministe en Bolivie (années 1920)}

\section{A) Le contexte}

\section{a) Développement de l'éducation des femmes au début du $\mathrm{XX}^{\mathrm{e}}$ siècle}

Pendant le dix-neuvième siècle l'éducation des filles des classes élevées et moyennes avait été assurée par l'Eglise Catholique et les congrégations religieuses. Il s'agissait le plus souvent d'une éducation primaire de base qui les préparait surtout à être de bonnes épouses et femmes au foyer pour bien s'occuper des tâches ménagères. Cette éducation était pauvre et superficielle avec un important fondement religieux ; d'après les idées de l'époque, les femmes n'avaient pas besoin de savoir plus. Avoir trop de connaissances était « dangereux » pour les femmes qui n'avaient pas de critère raisonnable pour pouvoir juger du mieux les livres qui tombaient entre leurs mains. Elles devaient conserver donc leur pureté à travers de l'innocence, qui était considérée comme une «vertu» chez elles. L'éducation des femmes, si elle avait lieu, était uniquement réservée aux filles des classes élevées et à quelques filles des classes moyennes; la plus grande partie de la population et parmi celle-ci les femmes, et surtout les femmes indigènes, était analphabète.

Cependant, à partir des années 1870 la question de l'éducation et de l'émancipation des femmes en Bolivie commence à être débattue non seulement dans les cercles intellectuels de l'époque, qui étaient au courant des avances dans ce domaine en Europe et aux Etats-Unis, mais aussi dans la presse écrite où l'on voit s'exprimer des idées «d'avant-garde» quant à la nécessité d'amélioration de l'éducation des femmes ${ }^{8}$. Ce thème commence à prendre une certaine importance à la fin du dix-neuvième siècle au sein des cercles intellectuels et politiques.

\footnotetext{
${ }^{8}$ ROSSELS, Beatriz, Las mujeres en la Historia de Bolivia. Imágenes y realidades del siglo XIX, Anthropos, La Paz - Bolivia, 2001.
} 
C'est ainsi qu'au début du $\mathrm{XX}^{\mathrm{e}}$ siècle, les critiques sévères de la part des intellectuels

Boliviens de l'époque se font sentir par rapport à une éducation insatisfaisante pour les femmes, qui faisait d'elles des êtres « frivoles » et « superficiels » :

«L'idée la plus courante dans les foyers est que les filles ne doivent savoir que l'indispensable pour jouer un rôle séducteur dans la vie sociale ; et on les éduque seulement à cette fin. Les jeunes femmes possèdent une culture très rudimentaire, mais elles sont habiles pour commenter tous les évènements du jour (...) Peu importe aux parents que leurs filles soient cultivées. On leurs exige, de préférence aux connaissances générales, une collection diverse de prières, à travers desquelles, pour faire mieux, on défigure et transforme l'idée de divinité à tel point que Dieu devient un jaloux gardien de nos actes et un complice de nos misères. - «Les hommes ne cherchent que le plaisir » - disent les parents; et ils deviennent des gardiens extrêmement sévères de la vertu de leurs filles. Ils leur cachent soigneusement les connaissances et valeurs des choses et des actions, et par rapport à tout ils leur font voir l'enchaînement des faits qui tâcheront de provoquer leur chute. Les jeunes femmes sont réservées jusqu'à arriver à la niaiserie, non pas par conviction, mais par peur au péché d'abord, et au châtiment ensuite. De cette lamentable conception pédagogique, de pareil abandon spirituel naît le manque d'inquiétudes intellectuelles chez la femme Bolivienne, dont le seul souhait est de séduire par les extériorités ostensibles dans la richesse des chiffons ou des plumes (...) Et naît ainsi le besoin de simulation d'abord, qui engendre celui de l'apparence... et toute apparence se paie. Celui-ci, de la même manière, est le résultat de l'éducation donnée dans les écoles religieuses (...) Une fois sorties de ces écoles, les filles arrivent au foyer avec une maigre et pauvre culture. Celle-ci est composée d'un peu de géographie, un autre peu d'histoire, un peu de mathématiques, quelques phrases de français dont généralement elles ne comprennent pas le sens ; deux ou trois mouchoirs brodés, non pas par elles mais par les professeures, trois ou quatre exercices de piano, et en complément naturel, un amour propre exagéré et un fanatisme étroit; fermé, intolérant, lequel, conservé au foyer, est perpétué dans les coutumes rigides, cristallisées, d'un quiétisme désespérant. Il n'y a pas d'acte, il n'y a pas de situation dans la vie d'une femme dans lequel ne soient mêlés, sinon la religieuse, au moins le confesseur... ${ }^{9}$

\footnotetext{
${ }^{9}$ «Idea corriente en el hogar, es esa de que las hijas no deben saber sino lo indispensable para desempeñar seductor papel en la vida social; y se las educa solo para ese fin. Las jóvenes poseen una cultura muy rudimentaria, pero son diestras en comentar los acontecimientos menudos del día (...) Poco se les da a los padres que sean cultas sus hijas. En ellas exigen, con preferencia a conocimientos de orden general, variada colección de oraciones, de esas en que, por hacerlo mejor, se desfigura y deforma la idea de divinidad y se convierte a Dios en celoso guardián de nuestros actos y cómplice de nuestras miserias. - "Los hombres no buscan más que el placer"- dicen los padres; y conviértense en severísimos guardianes de la virtud de sus hijas. Les ocultan cuidadosamente el conocimiento y valor de las cosas y acciones, y en todo les hacen ver encadenamiento de hechos tendientes a procurar su caída. Las jóvenes son recatadas hasta la ñoñería, no por convicción, sino por temor al pecado, primero, y al castigo después. De esta lamentable concepción pedagógica, de semejante abandono espiritual, nace la falta de preocupaciones intelectuales en la mujer boliviana, cuyo solo anhelo es
} 
Cependant, des changements importants commencèrent à prendre place à partir de 1899 avec l'accession des libéraux au pouvoir. Ce début du $\mathrm{XX}^{\mathrm{e}}$ siècle en Bolivie est une période de changements importants dans les sphères politique et économique. C'est une période d'apogée économique grâce à l'essor de l'étain, métal qui atteignit des prix exorbitants dans le marché mondial à cette époque. La Bolivie devint un des principaux producteurs mondiaux d'étain en ce début de siècle qui fut nommé le « siglo del estaño» («Siècle de l'étain »). Cet essor économique permit la modernisation du pays avec le développement de la construction des voies ferrées, de l'urbanisation publique, de la construction de routes et également de la construction d'écoles et de lycées dans les principaux centres urbains du pays ${ }^{10}$. Pour la première fois en Bolivie, l'Etat prit en main l'éducation des femmes. Désormais, il était obligatoire pour les filles des classes moyennes et élevées d'apprendre à lire et à écrire. Un événement marquant dans ce sens fut la fondation en 1906 par le président Ismael Montes du Collège Primaire de filles («Colegio primario de Niñas ») à La Paz. L'administration de ce collège fut d'abord prise en charge par des professeures étrangères, chiliennes, allemandes et belges, et plus tard par des professeures Boliviennes qui étaient parties au Chili en 1906 pour se former dans les Ecoles Normales de ce pays avec une bourse du gouvernement Bolivien (voir annexe B ${ }^{\circ} 1$ ). Parmi ces femmes on peut citer à Elena Smith (voir annexe A nº1). En 1909 fut fondée à Sucre la première Ecole Normale Supérieure, qui forma les professeures qui allaient servir dans les divers collèges et lycées pour filles qui furent fondés quelques années plus tard. En même temps, le Collège Primaire de filles de La Paz devint de plus en plus prestigieux. Ceci encouragea le gouvernement à lui octroyer le titre de Lycée en 1912, et donc le statut d'établissement secondaire dont les cours secondaires

seducir por las exterioridades ostensibles en la riqueza del trapo o de la pluma (...) Y nace la necesidad de la simulación primero, la cual engendra la de la apariencia... y toda apariencia se paga. Este de igual modo, es resultado de la educación dada en los colegios religiosos (...) Al salir de estos colegios, las niñas llevan al hogar de sus padres pobre y flaca cultura. Se compone de un poco de geografía, otro poco de historia, algo de matemáticas, pocas frases de francés cuyo significado generalmente no comprenden; dos o tres pañuelos bordados, no por ellas sino por las maestras, tres o cuatro ejercicios de piano, y como natural complemento, un amor propio exagerado y un fanatismo estrecho; cerrado, intolerante, el cual, conservado en el hogar, es perpetuado en las costumbres rígidas, cristalizadas, de un quietismo desesperante. No hay acto, no hay situación en la vida de una mujer en que no se mezcle, sino la madrecita, el confesor..." Alcides Arguedas, La Mujer Boliviana. Su Rol Social (1909), tiré de OPORTO ORDOÑEZ, Luis, Las mujeres en la Historia de Bolivia. Imágenes y realidades del siglo XX (1900-1950), Antología, Anthropos, La Paz - Bolivia, 2001.

${ }^{10}$ KLEIN, Herbert S., Orígenes de la revolución nacional boliviana. La crisis de la generación del Chaco, Librería Editorial G.U.M., La Paz, (n.d.) 
et d'humanités prirent une valeur universitaire ${ }^{11}$. Les portes des Universités furent ouvertes aux femmes en 1912. De la même manière, en 1914 fut fondée à Oruro un collège primaire pour filles. Sur la base des élèves de ce lycée fut fondée la première brigade de filles « Scouts » en Bolivie en 1915 sous l'initiative de María Gutierrez de Medinaceli (voir annexe $\mathrm{A} \mathrm{n}^{\circ} 2$ ). Cette brigade fut l'entité antécédente de la Croix Rouge Bolivienne, qui fut fondée en 1917 à La Paz par le Dr. Juan Manuel Balcázar en prenant comme modèle la Croix Rouge qui travailla en Europe pendant la Première Guerre Mondiale.

Dans les villes où n'étaient pas encore instaurés des Lycées secondaires pour filles comme à Oruro, les femmes qui voulaient poursuivre des études secondaires durent assister aux Lycées de garçons, qui les reçurent plutôt avec sympathie et curiosité malgré les résistances des administrateurs qui refusaient d'admettre des femmes dans les Lycées de garçons. Ces femmes, dont on peut citer l'exemple de Nelly López Rosse (voir annexe A n³), durent envoyer une pétition signée au Recteur du «Colegio Nacional Bolívar» et au Ministère de l'Education pour qu'il leur soit permit d'assister en cours avec les garçons. Finalement, l'autorisation leur fut accordée et elles purent suivre une éducation secondaire et obtenir le baccalauréat avec les garçons. Plus tard, en 1922 fut fondé le «Liceo de Señoritas Pantaléon Dalence » dans cette ville. Les femmes de Oruro purent passer ainsi le baccalauréat tout comme leurs camarades du « Liceo de Señoritas » de La Paz qui passèrent les examens avec les garçons. Parmi les bachelières de ce Lycée, on peut citer le témoignage de Betshabé Salmón Fariñas (voir annexe A n ${ }^{\circ}$ ), qui se souvient de cet événement ainsi:

«Je ne suis pas issue de la première promotion de femmes bachelières; je suis issue de la troisième ou quatrième promotion je crois. Parmi mes camarades d'études seulement 6 femmes d'entre nous arrivâmes jusqu'au baccalauréat, mais nous fûmes seulement 4 femmes à nous présenter aux examens : Carmen Rosa Torres Ballivián, Esther Lanza, Rosa Aparicio et moi. On réalisa l'examen au «Colegio Ayacucho ", au milieu de milliers de garçons. On ne passa pas les épreuves toutes seules, mais entourées de tout le lycée qui était en expectative. On était vraiment un rare spectacle pour eux. Cependant les professeurs avaient une main de fer, ils voulaient démontrer aux élèves que ce n'était pas parce qu'on était des femmes qu'ils allaient être plus tolérants; au contraire, ils furent encore plus rigides. Je

\footnotetext{
${ }^{11}$ OPORTO ORDOÑEZ, Luis, Las mujeres en la Historia de Bolivia. Imágenes y realidades del siglo XX (1900-1950), Antología, Anthropos, La Paz - Bolivia, 2001.
} 
réussis les épreuves, contente, à l'exception de l'examen de Mathématiques que j'ai failli ne pas passer parce que je n'ai jamais aimé les chiffres. ${ }^{12}$

Le témoignage de Betshabé, nous montre à quel point c'était nouveau de voir des femmes passer des examens de baccalauréat : il s'agissait d'un véritable spectacle de par sa rareté. De plus, ce témoignage nous laisse entrevoir que seules quelques femmes arrivaient jusqu'à la fin des études du cycle secondaire, et parmi ces femmes une très petite minorité décidait de passer les examens. Il y avait donc une certaine résistance encore de la part des jeunes femmes et probablement de leurs parents à les laisser aller jusqu'au bout de leurs études. D'ailleurs, dans les cercles de la bourgeoisie, il était souvent mal vu que les filles étudient puisque ça signifiait qu'elles voulaient chercher un travail. Si elles étaient dans la nécessité de trouver un travail c'était parce que la famille manquait d'argent. D'où la phrase prononcée par les parents avec un certain orgueil : «Ma fille n'a pas étudié parce qu'elle n'en a pas besoin. »

D'autre part, malgré l'impulsion de la part du gouvernement libéral de Montes pour développer l'éducation des femmes, il y avait encore des grosses différences quant au soutien financier que les collèges et lycées des femmes recevaient par rapport à ceux des garçons :

«Une des causes déterminantes du manque d'activité et d'enthousiasme au sein des Lycées... est l'inégalité totale des budgets économiques des Lycées des jeunes femmes par rapport à ceux des garçons et l'inégalité est encore plus accrue entre les Lycées des femmes, malgré le fait que le travail est absolument le même. » ${ }^{13}$

\footnotetext{
12 «Yo no salí de la primera promoción de mujeres; creo que salí de la tercera o cuarta. De mis compañeras sólo quedamos 6 hasta el bachillerato, pero al examen nos presentamos solo cuatro: Carmen Rosa Torres Ballivián, Esther Lanza, Rosa Aparicio y yo. Dimos el examen en el Colegio Ayacucho, en medio de miles de muchachos. No nos tomaron las pruebas a solas sino rodeadas de todo el colegio que había puesto expectativa en ello. Pero los profesores tenían mano férrea, querían demostrar a los alumnos que no porque éramos mujeres ellos eran más tolerantes; más bien nos apretaron peor. Yo pasé bien, contenta, sólo en matemáticas por poco me aplazo porque nunca me han gustado los números." Témoignage tiré de la transcription d'un entretien vidéo avec Bethsabé Salmón par Eva Urquidi, filmé et édité par Miriam Ernst et Miguel Cusicanqui à Quito - Equateur à la fin des années 1980. La transcription partielle de l'entretien fut réalisée par C. de Vega Magalí et FLORES Bedregal Teresa, et incluse sous le titre de «Con el periodismo en las venas. Testimonio de la jefe de redacción Bethsabé Salmón de Beltrán», dans l'ouvrage de BELTRAN Luis Ramiro (comp.), "Feminiflor" Un hito en el periodismo femenino de Bolivia", CIMCA, Círculo de Mujeres Periodistas, CIDEM, (n.d.).

${ }^{13}$ « Una de las causas determinantes de la falta de actividad y entusiasmo dentro de los Liceos... es la total desigualdad en los presupuestos económicos de los Liceos de Señoritas, con relación a los colegios de varones y aún más todavía entre los mismos liceos, no obstante de que el trabajo es
} 
Cette contradiction manifestée dans le fait d'encourager et d'impulser l'éducation des femmes et en même temps d'attribuer à cet effort un budget restreint qui la limitait, est visible également dans la tentative du gouvernement de promulguer un décret visant à instaurer le célibat des professeures :

«Le Ministre dit que le décret n'interdisait pas le mariage, mais il établissait seulement une alternative entre se marier et prendre soin du foyer ou ne pas se marier et servir au lycée. Il ajouta que si un homme se marie, il le fait sûrement avec l'intention de soutenir sa famille et il ne permettrait pas que sa femme travaille. Il ajouta que lorsqu'une femme se marie elle est victime de perturbations organiques de caractère physiologique. $»^{14}$

Les femmes subissaient des préjugés de la part des hommes politiques qui leur accordaient une fonction purement «maternelle» que ce soit au sein de leurs foyers ou au sein de la société. Elles ne pouvaient pas combiner ces deux «maternités », et elles devaient choisir entre le travail en tant que professeures ou se consacrer à prendre soin de leurs enfants et de leurs époux. Il n'y avait pas de compromis possible.

Plus tard dans les années 1920, encore plus de possibilités s'ouvrirent aux femmes pour son instruction et éducation. Ainsi, en 1928 l'on parlait de la possibilité de créer une Ecole Commerciale de Femmes comptant des disciplines comme le commerce, la comptabilité, et l'arithmétique. De la même manière, une autre voie leur fut ouverte avec les cours de secouristes qui furent offerts en 1924 dans l'hôpital de Miraflores à La Paz. Les femmes pouvaient étudier également dans le Conservatoire National de Musique où la plupart des élèves étaient des femmes et à l'Ecole des Beaux Arts, qui offrait des cours de peinture, musique et déclamation ${ }^{15}$.

Avec le développement de l'éducation des femmes en ce début de siècle toute une génération des femmes issues des classes moyennes et élevées de la société furent éduquées et cultivées et formèrent une première intellectualité féminine en Bolivie.

\footnotetext{
absolutamente igual », (La Enseñanza Nacional Femenina, 1927, p. 45), tiré de MEDINACELLI, Ximena, Alterando la rutina. Mujeres en las ciudades de Bolivia 1920 - 1930, CIDEM, La Paz Bolivia, 1989, p. 36.

14 «El Ministro dijo que el decreto no prohibía el matrimonio, sino solamente establecía una disyuntiva entre el casarse y atender el hogar o no casarse y atender la escuela. Añadió que si un hombre se casa, seguramente lo hará con intenciones de sostener su hogar y no permitiría a su mujer que trabaje. Agregó que cuando una mujer se casa es víctima de perturbaciones de carácter físiológico." (La República, 01/01/1924) tiré de MEDINACELLI, Ximena, Alterando la rutina. Mujeres en las ciudades de Bolivia 1920 - 1930, CIDEM, La Paz - Bolivia, 1989, p.38.

${ }^{15}$ MEDINACELLI, Ximena, Alterando la rutina. Mujeres en las ciudades de Bolivia 1920 - 1930 , CIDEM, La Paz - Bolivia, 1989.
} 
Ce seront ces femmes, élèves et professeures dans las premiers collèges et lycées pour filles, qui seront à l'origine de la création des premières organisations féministes au début des années 1920.

De par leur éducation et leur travail, ces femmes se trouvaient en décalage par rapport aux droits que la loi leur conférait : en plus d'être exclues de la vie politique du pays, elles étaient assujetties à leurs maris par la loi et le Code Civil du pays qui leur attribuait un statut de mineures une fois mariées.

\section{b) La situation légale des femmes dans les années 1920 en Bolivie}

Le Code Civil bolivien fut promulgué en 1831. Il était une copie fidèle du Code Napoléonien de 1804 avec quelques modifications et omissions pour s'adapter aux réalités du pays. Ce Code qui subit quelques modifications dans les années 1880, régit jusqu'en 1976. Il régissait les droits civils des femmes Boliviennes qui avaient un statut de mineures et devaient donc être soumises à l'autorité des hommes, que ce soit leurs pères ou leurs maris.

En effet, dans le Code Civil Bolivien de 1831 le mari était considéré comme le chef de la société conjugale et il exerçait en tous droits la patria potestad (la puissance paternelle) sur ses enfants et domestiques qui en respect de celle-ci lui devaient obéissance et soumission. La patria potestad lui donnait le pouvoir de correction sur ceux-ci, ainsi que l'usufruit légal des biens matériaux de la famille et la direction des affaires de celle-ci. La femme exerçait la patria potestad sur ses enfants, de manière beaucoup plus restreinte. D'ailleurs, le Code ne déclarait à aucun moment que la patria potestad était attribuée aux deux parents. Etant donné que le mari était le chef de la société conjugale, la patria potestad lui était attribuée uniquement à lui, qui pouvait l'exercer pleinement; la patria potestad n'était exercée par la femme que subsidiairement. Si le mari était vivant elle était complètement assujettie à l'autorité de celui-ci. Ainsi, d'après la loi du $1^{\text {er }}$ octobre 1890, la femme n'exerçait la patria potestad que si le mariage était dissout : «Le fils est sous l'autorité du père légitime ou naturel et dans son absence sous l'autorité de la mère jusqu'à sa majorité ou son 
émancipation ». ${ }^{16}$ De la même manière, l'article 130 du Code Civil bolivien instituait: «Le mari doit protection à sa femme, la femme lui doit obéissance ${ }^{17}$. D'après cet article, le mari en tant que chef de famille avait sous sa responsabilité le soutien matériel et moral du foyer et il devait donc protection à sa femme. Celle-ci, était complètement sous son autorité et entièrement soumise à la volonté de son mari. La loi l'obligeait à lui obéir en toutes circonstances. Le mari apparaît ainsi comme une sorte de «deuxième père » exerçant sa puissance paternelle sur sa femme qui devait lui obéir de par son statut de mineure et de par sa présupposée « infériorité ».

En outre, d'après l'article 131, la femme était obligée à habiter avec son mari et à le suivre partout où le mari jugeât convenable d'habiter. Le mari était obligée à recevoir sa femme dans son domicile, et à lui donner tout ce qui était nécessaire pour la vie, selon ses facultés et son état. Ainsi, l'article 53 instituait : « La femme mariée n'a d'autre domicile que celui de son mari. ${ }^{18}$

En ce qui concerne la nationalité des femmes Boliviennes, l'article 11 du Code Civil s’exprimait ainsi : «La femme Bolivienne mariée avec un étranger adopte la nationalité de son mari. $\gg{ }^{19}$ La femme Bolivienne perdait donc sa nationalité une fois mariée avec un étranger.

D'autre part, d'après l'article 132, les femmes ne pouvaient pas comparaître dans un procès sans l'autorisation de leurs maris. Néanmoins, l'article suivant affirme que les femmes n'avaient pas besoin de cette autorisation lorsque elles étaient poursuivies en matières criminelles.

Au sujet de l'administration des biens matériaux, l'article 134 instituait que la femme ne pouvait ni donner, ni aliéner ni acquérir à titre gratuit ou onéreux des biens sans le concours de son mari à l'acte, ou sans son consentement, ou sans sa ratification postérieure. D'après l'article 133, «si le mari est infirme ou absent, le

\footnotetext{
16 "Está el hijo bajo la autoridad del padre legítimo o natural y en su defecto de la madre hasta la mayoridad o emancipación.”, tiré de MACEDONIO Urquidi José Antonio, La Condición Jurídica o Situación legal de la mujer en Bolivia, 3e Edition, Cochabamba, 1937, p.18.

17 "El marido debe protección a su mujer, y ésta obediencia a su marido", tiré de MACEDONIO Urquidi José Antonio, La Condición Jurídica o Situación legal de la mujer en Bolivia, 3e Edition, Cochabamba, 1937, p. 19.

18 « La mujer casada no tiene otro domicilio que el de su marido. », tiré de MACEDONIO Urquidi José Antonio, La Condición Jurídica o Situación legal de la mujer en Bolivia, 3e Edition, Cochabamba, 1937, p.25.

19 "La mujer boliviana casada con un extranjero sigue la condición de su marido." tiré de MACEDONIO Urquidi José Antonio, La Condición Jurídica o Situación legal de la mujer en Bolivia, 3e Edition, Cochabamba, 1937, p. 20.
} 
juge, en connaissance de causes peut autoriser la femme à comparaître dans un procès, ou à passer un contrat. ${ }^{20}$ Ainsi, en cas d'absence du mari la femme passait sous la tutelle d'un juge qui prenait la place du mari pour lui accorder ou non son autorisation. D'autre part, le mari avait l'usufruit des biens dotaux avec les obligations que cela impliquait. Il pouvait les aliéner sans autorisation de sa femme, à exception des biens immeubles qui n'étaient pas aliénables, sauf dans les cas de nécessité prévus par la loi et avec le consensus des deux conjoints. En outre, la femme mariée pouvait administrer ses propres biens ; il s'agissait des biens qui n'étaient pas compris dans la dot («bienes parafernales »). Cependant, elle ne pouvait pas les aliéner ni comparaître dans un procès en raison d'eux, sans la licence du mari, ou dans son absence, sans la licence du juge rattaché au domicile conjugal.

La femme majeure et célibataire pouvait administrer ses biens et les aliéner dans le cours de ses affaires et de sa vie civile; la femme mariée pouvait agir de même seulement lorsque le mariage était dissout par la mort du mari ou par divorce.

L'article 136 attribuait à la femme la capacité de faire appel au juge dans le cas où le mari refusait de donner son autorisation. Le juge pouvait dans cas autoriser la femme en remplacement du mari.

D'après l'article 155 , les profits réalisés pendant le mariage devaient être divisées entre les deux conjoints; cependant, si la cause de divorce était l'adultère de la femme, celle-ci perdait tous les profits ainsi que la dot constituée par le mari. De même, d'après l'article 974, les acquêts du mariage appartenaient aux deux conjoints, mais seulement le mari pouvait les aliéner, même sans le consentement de sa femme. D'autre part, les époux pouvaient faire des testaments librement sur leurs biens propres, leurs «bienes parafernales», leurs bien patrimoniaux, dotaux, et leurs acquêts, en suivant les dispositions établies par la loi sur les droits des héritiers et des parts légitimes. L'article 459 instituait que les garçons âgés de moins de 14 ans, et les filles âgées de moins de 12 ans ne pouvaient pas faire des testaments. Cependant, après avoir dépassé cette limite d'âge ils pouvaient faire des testaments librement comme s'ils étaient hors de la patria potestad. D'après, l'article 140, la femme

\footnotetext{
20 "Si el marido está impedido o ausente, el juez, con conocimiento de causa puede autorizar a la mujer, sea para comparecer en juicio sea para contratar." tiré de MACEDONIO Urquidi José Antonio, $L a$ Condición Jurídica o Situación legal de la mujer en Bolivia, 3e Edition, Cochabamba, 1937, p. 20.
} 
pouvait faire un testament librement sans l'autorisation de son mari ${ }^{21}$. C'était finalement la seule chose que la femme pouvait faire sans l'autorisation de celui-ci.

La condition juridique des femmes des années 1920 était la même que celle des femmes de 1831, c'est-à-dire, quelques années après que la Bolivie se soit constituée comme pays indépendant, un siècle auparavant. Et ce, malgré le fait que la condition et la vie des femmes avaient changé notamment au début du siècle avec le développement de leur éducation et par conséquent l'entrée progressive des femmes des classes moyennes et élevées dans le marché du travail. Il y avait donc un décalage important entre leur condition juridique et les changements qui étaient en train de s'opérer par rapport à leurs conditions de vie; décalage qui fut dénoncé par les premières féministes qui firent leur apparition au début des années 1920.

\section{B) Les associations féministes}

\section{a) Origines}

Une première génération importante des femmes bénéficiaires du développement de l'éducation au début de siècle fait son apparition dans la vie publique au début des années 1920 avec la création et la formation de ce qu'elles avaient baptisé le plus souvent comme les «Centros Artísticos e Intelectuales de Señoritas » («Centres Intellectuels et Artistiques de jeunes femmes »). Il s'agissait à l'origine d'organisations destinées à accueillir les expressions artistiques, littéraires et intellectuelles de jeunes femmes cultivées des classes moyennes et élevées de la société, qui se réunissaient pour lire les poèmes et contes qu'elles avaient écrit, pour déclamer leurs poèmes favoris, commenter des livres, jouer au piano, exposer leurs peintures, et enfin faire la fête entre amis.

La première de ces organisations à apparaître en Bolivie, fut le «Centro Artístico e Intelectual de Señoritas de Oruro » fondée en 1920 par trois jeunes femmes (voir annexe B n²): Laura Graciela de La Rosa Torres (voir annexe A n5), Bethsabé Salmón Fariñas (voir annexe A n4) et Nelly López Rosse (voir annexe A n³). Il ne

\footnotetext{
${ }^{21}$ MACEDONIO Urquidi José Antonio, La Condición Jurídica o Situación legal de la mujer en Bolivia, 3e Edition, Cochabamba, 1937.
} 
s'agissait pas d'une organisation féministe au début, et elle était née de manière assez informelle comme s'en souvient Laura Graciela de la Rosa Torres :

«C'était un groupe informel. Au lieu de passer les dimanches seulement à se reposer ou à s'entretenir, on préférait les passer à lire des livres, et à commenter des affaires diverses. D'où le nom qu'on lui a donné de centre intellectuel $»^{22}$.

Bethsabé Salmón rapporte le même témoignage quant à la fondation de l'organisation :

«Le centre en réalité naquit par pure frivolité ; on voulait danser, on voulait passer le temps avec nos amoureux, on voulait réciter des poèmes, chanter. Nous nous réunîmes avec tout un groupe de jeunes femmes de la société d'Oruro et nous formâmes cette organisation afin de faire de l'art, des lectures, des commentaires et aussi, pourquoi ne pas le mentionner, pour converser avec nos copains et petits amis. Dans ce sens nous nous réunissions dans différentes maisons de famille chaque dimanche. Là on récitait, on chantait. On était trois amies à réciter toujours des poèmes, combien de vers n'ai-je appris.... ${ }^{23}$

L'organisation était formée d'un groupe assez important de jeunes femmes des classes moyennes et élevées de la société d'Oruro de l'époque qui se réunissaient avec leurs amis et petits amis (voir annexe $\mathrm{B} \mathrm{n}^{\circ} 3$ ) :

«Dans le centre on était quarante ou cinquante personnes plus ou moins. Toutes étaient de très bonnes amies, loyales, sincères. Il y avait quelques unes avec lesquelles on avait une camaraderie unique... ${ }^{24}$

\footnotetext{
22 «Era una agrupación informal. En vez de pasar los domingos solo en reposo o recreaciónm preferíamos pasarlo leyendo libros, comentando diferentes asuntos. De ahí que le pusimos el nombre de centro intelectual. » Entretien réalisé avec Laura Graciela de la Rosa Torres à Cochabamba Bolivie en 1987 par Sandra Aliaga Bruch, et inclus sous le titre de "Eramos audaces" Testimonio de la Directora Laura G. de La Rosa Torres » dans l'ouvrage de BELTRAN Luis Ramiro (comp.), "Feminiflor" Un hito en el periodismo femenino de Bolivia", CIMCA, Círculo de Mujeres Periodistas, CIDEM, (n.d.).

${ }^{23}$ «El centro nació en realidad de pura frivolidad; queríamos bailar, queríamos enamorar, queríamos recitar, cantar. Nos reunimos todo un grupo de niñas de la sociedad de Oruro y formamos esta organización con la idea de hacer arte, lecturas, comentarios y también, por qué no decirlo, para departir con amigos y enamorados. En ese sentido, nos reuníamos en distintas casa de familia cada domingo. Allí recitábamos, cantábamos. Tres amigas éramos las recitadoras de siempre, qué versos no me aprendía... ». Témoignage tiré de la transcription d'un entretien vidéo avec Bethsabé Salmón par Eva Urquidi, filmé et édité par Miriam Ernst et Miguel Cusicanqui à Quito - Equateur à la fin des années 1980. La transcription partielle de l'entretien fut réalisée par C. de Vega Magalí et FLORES Bedregal Teresa, et incluse sous le titre de «Con el periodismo en las venas. Testimonio de la jefe de redacción Bethsabé Salmón de Beltrán», dans l'ouvrage de BELTRAN Luis Ramiro (comp.), "Feminiflor" Un hito en el periodismo femenino de Bolivia", CIMCA, Círculo de Mujeres Periodistas, CIDEM, (n.d.).

${ }^{24}$ «En el centro éramos más o menos unas cuarenta o cincuenta personas. Todas eran amigas leales, sinceras. Habían algunas de camaradería única... » Entretien réalisé avec Laura Graciela de la Rosa Torres à Cochabamba - Bolivie en 1987 par Sandra Aliaga Bruch, et inclus sous le titre de «"Eramos audaces" Testimonio de la Directora Laura G. de La Rosa Torres » dans l'ouvrage de BELTRAN Luis
} 
D'une organisation quasi - informelle au début formée par des amies qui voulaient s'amuser et s'entretenir intellectuellement elle devint progressivement une organisation où s'exprimèrent aussi les souhaits de ces jeunes femmes en tant que femmes. Ainsi, elles commencèrent à réfléchir sur la condition réelle des femmes et la place qu'elles devaient occuper dans la société. Elles considéraient que les femmes devaient jouer un rôle important dans cette dernière à travers les fonctions et qualités qui lui étaient dévolues. Elles devaient donc s'occuper de la charité, de l'éducation, de la protection de l'enfant, etc. Et ce, surtout si elles avaient eu la chance de s'éduquer. En tant que femmes privilégiées de par leur culture et éducation, elles s'interrogeaient sur l'accès général des femmes à l'éducation et sur la nécessité d'améliorer celle-ci et de l'élargir à d'autres catégories de femmes. Les femmes devaient être instruites pour pouvoir offrir une bonne éducation à leurs enfants et par conséquent former des bons citoyens pour le progrès de la patrie. De même, elles considéraient, que l'émancipation des femmes se faisait d'abord et avant tout par l'éducation, ensuite par le travail et l'indépendance économique. Le moyen que ces femmes utilisèrent pour exprimer toutes ces idées et inquiétudes qui commencèrent à surgir par le débat et l'échange entre elles, fut la publication en 1921 d'une revue nommée Feminiflor, qu'on étudiera beaucoup plus en détail ultérieurement. Ce fut à travers cette revue que s'exprimèrent les premiers souhaits et revendications féministes des femmes du « Centro Artístico e Intelectual de Señoritas de Oruro ».

Bethsabé Salmón raconte comment naquit l'impulsion pour la publication de cette revue et comment l'organisation acquit une orientation féministe:

«Lorsqu'on se réunissait on emmenait toujours des livres qui venaient d'être publiés comme ceux de Alfonsina Storni ; enfin, d'autres. On les commentait et on les lisait, et un jour on s'est dit pourquoi on n'en fait pas des résumés et des compositions pour dimanche prochain (...)

On se réunissait religieusement mais tout n'était pas fête. L'ambiance commença à changer. On commença à se demander qu'est-ce qu'on voulait en tant que femmes, qu'est-ce qu'on cherchait, où est-ce qu'on allait. On orienta petit à petit nos inquiétudes jusqu'à arriver à exprimer nos demandes. Ainsi, s'incarna la nécessité de revendications de la femme bolivienne, on réussit à apercevoir la place qu'elle devait avoir dans notre société. Le fait d'être nées femmes n'allait pas faire de nous des êtres inférieurs. On devait lutter pour nous surpasser, pour être

Ramiro (comp.), "Feminiflor" Un hito en el periodismo femenino de Bolivia”, CIMCA, Círculo de Mujeres Periodistas, CIDEM, (n.d.). 
égales aux hommes, avec les mêmes privilèges, les mêmes droits, la même instruction et pour gagner le même espace dont jouissaient les hommes. $»^{25}$

Le Centre prit donc une allure beaucoup plus formelle, surtout à partir de mai 1921 avec la fondation de la revue Feminiflor. Le Centre comptait désormais d'un règlement qui régissait son organisation et fonctionnement. Différentes charges administratives étaient attribuées aux membres de l'organisation. Le renouvellement des personnes aux différentes charges était réglé par statuts. On n'a malheureusement pas pu trouver le règlement, mais l'on sait par les informations publiées dans la revue Feminiflor, que la Direction devait être renouvelée après un temps spécifique. La Direction était composée de différentes charges : Présidence, Vice-Présidence, $2^{\text {ème }}$ Vice-Présidence, Secrétariat, Pro Secrétariat, Trésor. Plusieurs membres faisaient partie du Conseil (voir annexe $\mathrm{C} \mathrm{n}^{\circ} 1$ ). Les autres femmes qui composaient l'organisation avaient le statut de membres actifs. Les membres se réunissaient chaque dimanche pour les sessions ordinaires. Des sessions extraordinaires pouvaient avoir lieu pendant d'autres jours de la semaine, pour aborder probablement des affaires qui n'étaient pas prévues dans les sessions ordinaires. Le Centre ne possédait pas de local propre : les membres se réunissaient donc dans les maisons de famille de chacune des membres. Si l'on en croit les souvenirs de Laura Graciela de La Rosa Torres, le Centre aurait compté entre 40 et 50 membres à une période donnée.

Les activités principales de l'association étaient bien évidemment la rédaction et publication de Feminiflor, mais aussi l'organisation de soirées littéraires - musicales ouvertes au public à l'occasion de fêtes patriotiques par exemple. Dans ces occasions les membres présentaient leur travail artistique que ce soit en jouant du piano, en

25 «Cuando nos seguíamos reuniendo, llevábamos libros que recién se publicaban como los de Alfonsina Storni; en fin, otros. Comentábamos y leíamos, y un día dijimos por qué no hacemos un resumen y una composición para el próximo domingo (...) Nos reuníamos religiosamente pero no todo era baile. El ambiente empezó a cambiar. Comenzamos a preguntarnos qué queríamos como mujeres, qué buscábamos, a dónde íbamos. Fuimos encauzando poco a poco nuestras inquietudes y llegamos a expresar nuestros reclamos. Así, llegamos a hacer carne la necesidad de reivindicaciones de la mujer boliviana, alcanzamos a percibir, el lugar que debía tener ésta en nuestra sociedad. El haber nacido mujeres no nos iba a hacer seres inferiores. Teníamos que luchar para superarnos, para ser iguales que los hombres, con los mismos privilegios, los mismos derechos, la misma instrucción y para ganar el mismo espacio del que los hombres gozaban. » Témoignage tiré de la transcription d'un entretien vidéo avec Bethsabé Salmón par Eva Urquidi, filmé et édité par Miriam Ernst et Miguel Cusicanqui à Quito Equateur à la fin des années 1980. La transcription partielle de l'entretien fut réalisée par C. de Vega Magalí et FLORES Bedregal Teresa, et incluse sous le titre de «Con el periodismo en las venas. Testimonio de la jefe de redacción Bethsabé Salmón de Beltrán », dans l'ouvrage de BELTRAN Luis Ramiro (comp.), "Feminiflor" Un hito en el periodismo femenino de Bolivia", CIMCA, Círculo de Mujeres Periodistas, CIDEM, (n.d.). 
récitant des poèmes, ou en faisant des discours sur une question artistique ou intellectuelle.

Le Centre Artistique et Intellectuel de Oruro eut une durée de vie assez courte (3 ans environ). Il cessa de fonctionner lorsque les jeunes femmes qui l'avaient fondé cessèrent de publier la revue «Feminiflor» en 1923. Ceci non pas parce qu'elles manquèrent de lecteurs, mais parce que la plupart des membres commencèrent à se marier et ne pouvaient plus s'occuper de leur organisation et de leur revue comme avant. Ce fut donc une association éphémère, mais la première du genre. Elle contribua à insuffler l'élan pour continuer l'expérience dans d'autres villes du pays.

\section{b) Développement}

En novembre 1921 un Centre artistique et culturel nommé «Iris » fut fondé à Cochabamba, inspiré et stimulé par son homologue d'Oruro. On n'a pas autant d'informations sur cette organisation puisque l'on n'a malheureusement pas pu trouver la revue homonyme qu'elle publiait. Cependant, on a réussi à trouver certaines informations grâce à la revue Feminiflor n $^{\circ} 7$ de novembre 1921, qui lui consacre plusieurs articles de félicitation pour informer au public d'Oruro de l'apparition de ce Centre et de sa revue. D'ailleurs, les membres de celui-ci envoyèrent un article et une lettre aux rédactrices de Feminiflor annonçant leur nouvelle entreprise. Il semblerait que les fondatrices du Centre de Cochabamba avaient des liens d'amitié antérieurs avec les membres du Centre Artistique d'Oruro. Inspirées et stimulées par leurs amies d'Oruro, elles décidèrent de fonder une organisation homologue dans leur ville. Ainsi, l'on lit dans leur article :

«Stimulées par nos sœurs de la ville du Pagador (Oruro) et encouragées par leur exemple, on essaye un travail complètement nouveau pour nous. $»^{26}$

L'orientation féministe de leurs objectifs est annoncée clairement depuis le début :

« Peut-être notre enthousiasme est supérieur à nos aptitudes ; mais l'on croit accomplir notre mission en contribuant au noble travail d'exalter la femme, malheureusement si déprimée dans notre pays, en raison de préjugés si profondément enracinés, qu'il est déjà temps de corriger. En démontrant que nous les femmes pouvons autant que les

\footnotetext{
${ }^{26}$ « Estimuladas por nuestras hermanas de la ciudad de Pagador y alentadas con su ejemplo, ensayamos una labor completamente nueva para nosotras. » dans Feminiflor n`7, Novembre 1921, Oruro. Archivo Nacional de Bolivia, Sucre - Bolivie.
} 
hommes ; que cet être fragile et délicat, comme ils nous appellent, peut lutter avec autant d'acharnement et de persévérance qu'eux. $»^{27}$

Cette organisation s'inspira donc du contenu des orientations féministes du Centre d'Oruro déjà établies, et contrairement à ce dernier, elle naquit et justifia son existence par les objectifs féministes qu'elle s'était donnés. Elle ne fut pas fondée seulement comme une organisation de distractions intellectuelles, comme son homologue d'Oruro à ses origines, mais comme une organisation artistique et intellectuelle aux orientations féministes qui allaient être exprimées dans la revue Iris. Les membres du Centre Artistique d'Oruro furent invités à l'inauguration du Centre de Cochabamba. Laura Graciela de La Rosa Torres se trouvait présente à l'inauguration et prononça un discours de félicitations qui fut transcrit dans Feminiflor. Le discours concluait ainsi :

«IRIS : au nom de la jeunesse féminine d'Oruro, et au nom de Feminiflor votre grande sœur, je vous salue comme à nos sœurs spirituelles, tes vaillantes et courageuses Rédactrices, à qui on souhaite le plus franc succès, dans le difficile travail qu'elles ont entrepris.

Balnéaire de Cala- Cala, 14 novembre 1921.

Laura G. De la Rosa T. ${ }^{28}$

En nommant Feminiflor comme la «grande sœur» de la revue Iris, la directrice du Centre Artistique d'Oruro établit une filiation directe entre les deux organisations, et par ce geste elle établit également une communauté d'objectifs et une lutte commune entre les deux organisations. Cette filiation et communion de luttes et d'objectifs sont également établies par le Centre de Cochabamba dans la lettre qu'elles envoient aux rédactrices de Feminiflor :

« Aux distinguées rédactrices de Feminiflor.

Chères amies :

En faisant écho à la voix lancée par Feminiflor, les filles du Tunari (Cochabamba) nous nous sommes courageusement lancées à la carrière du journalisme. Voilà la toute petite Iris.

\footnotetext{
27 «Quizás nuestros entusiasmos son superiores a nuestras aptitudes; pero creemos cumplir nuestra misión contribuyendo a la noble labor de enaltecer a la mujer, desgraciadamente tan deprimida en nuestro país, por prejuicios tan profundamente arraigados, que es tiempo ya de corregir. Demostrando que las mujeres podemos tanto como los hombres; que ese ser frágil y delicado, como nos llaman, puede luchar con tanto ahínco y perseverancia como ellos. » Idem.

28 «IRIS: en nombre de la muchachada femenina de Oruro, y a nombre de "Feminiflor", vuestra hermana mayor, yo os saludo, como así, a nuestras hermanas espirituales, tus valientes y esforzadas Redactoras, para quienes deseamos el más franco éxito, en la difícil tarea que hoy han empezado. Balneario de Cala-Cala, 14 de Noviembre de 1921.
}

Laura G. De la Rosa T. » Idem. 
Elle voit le jour aujourd'hui pour la première fois. Quel effet aura-telle?

On ne le sait pas.

Cependant, nous croyons que lors de son arrivée à Oruro, Feminiflor l'accueillera de manière bénévole et démontrera une véritable joie envers sa nouvelle sœur qui est surgie à la lumière du jour pour être sa fidèle compagne que ce soit dans les luttes comme dans les triomphes.

A cette occasion on est très heureuses de vous manifester notre profonde sympathie et adhésion au travail efficace que vous réalisez avec Feminiflor.

Et en vous saluant affectueusement, nous vous présentons notre plus sincère amitié.

Elena Gutierrez Reza, María Antonia Careaga, María Teresa Urquidi R. (voir annexe $\mathrm{A} \mathrm{n}^{\circ} 6$ ).

Corps de rédaction.

Cochabamba, 14 novembre 1921. » ${ }^{29}$

Directement inspirée par l'organisation d'Oruro, le centre de Cochabamba était organisé exactement de la même manière que son homologue avec les mêmes charges constituant la Direction. Ainsi, la Présidente était María Antonia Careaga, la VicePrésidente María Teresa Urquidi R. (voir annexe A nº), la 2e Vice-Présidente Elena Gutierrez Reza, la Secrétaire Alcira Velarde Guzmán, la Pro-Secrétaire Mercedes Oblitas Velarde, et la Trésorière Blanca del Granado.

Malheureusement, on ne sait pas plus sur cette organisation ni sur ses activités ; mais étant donné qu'elle était directement inspirée par l'association d'Oruro, on peut supposer que son fonctionnement était très semblable. De même les activités et les idées féministes revendiquées dans la revue Iris étaient probablement très similaires à celles de leur homologue d'Oruro. On ne sait pas exactement quand est-ce que le centre cessa ses activités, mais au $1^{\text {er }}$ avril 1924 le Centre était toujours en activité,

\footnotetext{
${ }^{29}$ « A las distinguidas redactoras de Feminiflor.

Estimadas señoritas:

Haciendo eco a la voz lanzada por Feminiflor, las hijas del Tunari valientemente nos hemos lanzado a la carrera del periodismo. Ahí va la diminuta "Iris".

Hoy ve la luz por vez primera ¿qué efecto les causará?

No lo sabemos.

Sin embargo, creemos que a su llegada a Oruro, Feminiflor la acogerá benévolamente y demostrará francamente a su nueva hermana que ha surgido a la luz para ser su adicta compañera ya en las luchas como en los triunfos.

Con este motivo nos es grato también manifestar a ustedes nuestra profunda simpatía y adhesión por la labor eficaz que despliegan en Feminiflor.

Y al saludarlas cariñosamente presentamos a ustedes nuestra más sincera amistad.

Elena Gutierrez Reza, María Antonia Arteaga, María Teresa Urquidi R.

Cuerpo de redacción.

Cochabamba, 11 de noviembre de 1921. » Idem.
} 
malgré le fait que la revue n'était plus publiée. En effet, à cette date les membres du centre « Iris » envoyèrent une lettre pour féliciter les rédactrices d'une nouvelle revue féministe apparue à Potosí sous le nom de Venas de Plata («Veines d'argent »). Cette revue, dont on parlera plus en détail ultérieurement, était du même genre que Feminiflor ou Iris, c'est-à-dire une revue créée par des femmes et destinée particulièrement aux femmes, dont l'objectif était l'amélioration de leurs conditions de vie ainsi que la lutte pour leurs droits civils et politiques. En guise de féliciter l'initiative des rédactrices de Venas de Plata les dirigeantes d' « Iris » laissent savoir que leur revue n'était plus en circulation en raison d'un environnement défavorable :

« Cochabamba, 6 mars 1924, Mlles les rédactrices de Venas de Plata, Potosí.

Mesdemoiselles distinguées :

On vous remercie de nous avoir envoyé le premier numéro de la revue Venas de Plata, qu'on vient de recevoir.

La lecture de Venas de Plata a été une surprise très agréable pour nous. Ses articles démontrent clairement la pureté d'idéaux sur lesquels se sont inspirées leurs rédactrices.

Les femmes de Cochabamba se sont confrontées à un obstacle dans l'environnement, insurmontable immédiatement, et c'est pour cela qu'Iris ne s'édite plus. Mais on se maintient toutes plein d'espoir, en luttant pour pouvoir reprendre notre travail.

Le conseil d'administration d'Iris vous envoie des salutations fraternelles, en souhaitant que Feminiflor, Iris, Ideal Femenino, et Venas de Plata soient les liens qui unissent Oruro, La Paz, Potosí, Cochabamba et que bientôt l'on voie surgir des championnes féminines dans les départements de notre patrie aimée qui manque encore d'elles.

Vos très humbles et très obéissantes servantes.

María Teresa Urquidi R. Directrice

Marina Montenegro Quiroga. Administratrice $\gg{ }^{30}$

\footnotetext{
${ }^{30}$ « Cochabamba, 6 de marzo de 1924.

Srtas. Redactoras de Venas de Plata, Potosí.

Distinguidas señoritas:

Agradecemos a Uds. Por el envío del primer número de la revista Venas de Plata, que acabamos de recibir.

Ha sido una sorpresa gratísima para nosotras la lectura de Venas de Plata. Sus artículos muestran claramente la pureza de ideales en que se han inspirado sus redactoras.

Las muchachas cochabambinas han encontrado un obstáculo, insalvable de inmediato en el ambiente y es por ello que Iris ha dejado de editarse. Pero todas se mantienen llenas de esperanza, luchando para poder reanudar sus labores.
} 
Iris eut donc une vie assez éphémère comme la plupart des revues de ce type. Le message de cette lettre, laisse entrevoir que l'accueil de la revue ne fut pas très favorable. Etait-ce par manque de lecteurs? Tant qu'on n'aura pas plus d'informations sur cette organisation et sa revue, la question reste ouverte.

D'autres organisations du même type surgirent suivant l'exemple du Centre Artistique et Intellectuel d'Oruro, telles que le « Centro Intelectual» de Cochabamba qui édita la revue Reflejos à partir d'octobre 1922. Cette information nous est procurée par le numéro 16 de la revue Feminiflor d'octobre 1922 :

\section{« Journalisme}

Le « Centre Intellectuel» de la ville de Cochabamba a fondé une revue avec le nom de Reflejos.

Nous envoyons à ses rédactrices nous plus sincères félicitations et applaudissements.

Nous rétribuons avec plaisir l'échange. ${ }^{31}$

Nous n'avons malheureusement pas d'autres informations sur ce centre puisque l'on n’a pas trouvé la revue.

La lettre antérieure envoyée par la Direction «d'Iris », mentionne une autre revue publiée à La Paz: Ideal Femenino. Cette revue était éditée par l'organisation « Centro Ideal Femenino » dont la directrice était Ana Rosa Tornero (voir annexe A $\mathrm{n}^{\circ} 7$ ). On n'a pas beaucoup d'informations sur cette organisation puisque leur revue est introuvable. Cependant, à l'occasion du deuxième anniversaire de Feminiflor en mai 1923, Ana Rosa Tornero envoya une lettre aux rédactrices de la revue pour les féliciter. Cette dernière fut publiée dans l'édition spéciale d'anniversaire de la revue,

La mesa directiva de Iris envía a Uds. un fraternal saludo, anhelando que Feminiflor, Iris, Ideal Femenino y Venas de Plata, sean los lazos que unan a Oruro, La Paz, Potosí, Cochabamba y que pronto veamos surgir paladines femeninos en los departamentos de nuestra amada patria que aún carecen de ellos.

Somos de Uds. attas. servidoras.

María Teresa Urquidi,

Directora.

Marina Montenegro Quiroga,

Administradora. » Dans Venas de Plata $n^{\circ} 2$, $1^{\mathrm{er}}$ avril 1924, Potosí, Archivo Nacional de Bolivia, Sucre.

31 « Periodismo.

El "Centro Intelectual" de la ciudad de Cochabamba ha fundado una revista con el nombre de Reflejos.

Enviamos a sus Redactoras nuestras sinceras felicitaciones y aplausos.

Retribuimos gustosas el canje. » Dans Feminiflor n¹6, octobre 1922, Oruro. Hemeroteca de la Universidad Mayor de San Andrés, La Paz - Bolivie. 
$\mathrm{n}^{\circ}$ 22, de mai 1923. Dans cette lettre, Ana Rosa Tornero établit une filiation entre les deux organisation en parlant de Feminiflor comme étant le précurseur du journalisme féminin - feministe, et en évoquant une lutte et des objectifs communs à atteindre :

« Au lever du jour du 25 mai, au milieu d'une souriante aurore et d'effluves de lumière, s'annonce un jour glorieux pour nos sœurs du Pagador (Oruro). Feminiflor atteint deux années de vie, ce qui implique un nouvel triomphe, deux années d'une lutte ardue dans le sentier accidenté du journalisme, deux années de travail constant dans l'horizon intellectuel.

Lors de la célébration de cette date, sonnent victorieuses les cloches du droit et de la justice annonçant l'anniversaire du champion de beaux sentiments qui émanent d'un boucaro de fleurs ravissantes dont les idéaux aromatiques enivrent les campagnes féminines. Au souvenir de ce jour l'écho de la joie répercute dans les cœurs de ses sœurs d'aspirations et de lutte.

Feminiflor qui donna le premier coup de clairon du journalisme féminin, sent aujourd'hui la fierté des vainqueurs; cette aube de la jeunesse entoure son front de l'auréole de la gloire.

De même que la fleur meurt avec poésie, le soldat avec héroïsme aux côtés de son fusil et le pilote en défiant le condor, de la même manière celles qui manions la plume, nous devons sacrifier si c'est possible nos vies dans l'autel de nos aspirations en défendant avec courage les privilèges de l'héroïsme féminin.

Vous, camarades de journalisme, avez plaidé avec l'arme de la réalité en face de ces esprits rongés par le pessimisme; aujourd'hui dans le domaine de la culture flambe le drapeau de la victoire. Sous ses plis se trouve gravé en lettres d'or le nom de Feminiflor. Un nouveau soleil éclaire le jardin fleuri, soleil qui reflète la persévérance et vivifie les boutons qui entrouvrent ses pétales aux activités de la vie.

Ideal Femenino s'associe à la joie de Feminiflor et ses rédactrices vous envoient des mots véhéments de félicitation, et en formulant de la prospérité pour leurs sœurs, elles répètent : Luttons jusqu'à vaincre et jusqu'à mourir glorieuses impulsées par les mots d'un célèbre écrivain qui dit : « Là où il n'y a pas de combat, il n'y a pas de victoire. »

Ana Rosa Tornero A. Directrice de Ideal Femenino $»^{32}$

\footnotetext{
32 «El amanecer del 25 de mayo, en medio de una aurora sonriente y de efluvios de luz anuncia un día glorioso para nuestras hermanas del Pagador. Feminiflor llega a los dos años de vida, lo que implica un nuevo triunfo, dos años de ardua lucha en el escabroso sendero del periodismo, dos años de constante trabajo en el horizonte intelectual.

Al celebrar esta fecha suenan victoriosas las campanas del derecho y de la justicia anunciando el aniversario del paladín de bellos sentimientos que emanan de un búcaro de primorosas flores cuyos aromáticos ideales embriagan el campo femenino. Al recordar este día el eco del regocijo, repercute en los corazones de sus hermanas de anhelos y combate.

Feminiflor que dio el primer clarinazo de periodismo femenino siente hoy el orgullo de los triunfadores; esa alborada de la juventud ciñe su frente con la aureola de la gloria.

Así como la flor muere con poesía, el soldado con heroísmo al lado de su fusil y el piloto desafiando al cóndor, del mismo modo las que esgrimimos la pluma debemos sacrificar si es posible nuestra vida en aras de nuestras aspiraciones defendiendo con valor los fueros del heroísmo femenino.
} 
A travers cette lettre, on observe que les objectifs du "Centro Ideal Femenino » étaient les mêmes que ceux de son homologue de La Paz. La durée de vie de sa revue, Ideal Femenino, dut être assez courte puisqu'à partir de septembre 1923, les membres de ce centre commencèrent à éditer une nouvelle revue : Aspiración, dont on parlera plus en détail postérieurement. Il s'agissait d'une revue dans la lignée de toutes les autres : une revue féminine culturelle et féministe à travers laquelle s'exprimaient les demandes et les idées des femmes féministes qui appartenaient au centre qui la publiait. La Directrice de cette revue était Rosa Viscarra Heredia, la Rédactrice en chef était Matilde Carmona Rodo (voir annexe $\mathrm{A} \mathrm{n}^{\circ} 8$ ) et l'Administratrice était Ana Rosa Vázquez (voir annexe A $n^{\circ} 9$ ). On ne sait pas exactement quand est-ce que le «Centro Ideal Femenino » cessa ses activités, mais la revue Aspiración n'atteignit que 5 numéros de septembre 1923 à février 1924.

Par ailleurs, la plupart des membres du «Centro Ideal Femenino », dont Ana Rosa Tornero, Matilde Carmona Rodo et Ana Rosa Vázquez participèrent à la fondation de l'organisation qui allait être la plus importante, solide et durable de toutes : l'« Ateneo Femenino » de La Paz.

\section{c) L'«Ateneo Femenino » de La Paz et les réseaux féministes}

\section{Origines}

Cette organisation fut fondée en avril 1923 par l'initiative de celle qui allait être sa Directrice pendant plusieurs périodes et années : María Luisa Sánchez Bustamante de Urioste (voir annexe $A n^{\circ} 10$ ). Elle fut fondée en tant que section féminine d'un centre intellectuel d'hommes déjà existant à La Paz, « l'Ateneo de la Juventud ».

\footnotetext{
Vosotras, compañeras de periodismo, habéis abogado con el arma de la realidad a esos espíritus carcomidos por el pesimismo; hoy en el terreno cultural flambea la bandera de la victoria, bajo cuyos pliegues se halla grabado el nombre de Feminiflor. Un nuevo sol alumbra el huerto florido, sol que refleja la perseverancia y vivifica los capullos que entreabren sus pétalos a las actividades de la vida. Ideal Femenino se asocia al júbilo de Feminiflor y sus redactoras os envían palabras vehementes de felicitación, y al formular prosperidad por sus hermanas repiten: Luchemos hasta vencer y morir gloriosas impulsadas por las palabras de un célebre escritor que dice: "Donde no hay combate no hay victoria."

Ana Rosa Tornero A.

Directora de Ideal Femenino. » Dans Feminiflor n²2, 25 mai 1923, Oruro, Hemeroteca de la Universidad Mayor de San Andrés, La Paz - Bolivie.
} 
Le numéro 22 de la revue Feminiflor (mai 1923) nous rapporte l'événement ainsi :

«"Ateneo de la Juventud"

Dans cet important centre culturel de La Paz, vient de se fonder une section spéciale féminine qui tend à cultiver les arts.

Dignement présidé par Madame Bustamante Urioste, ce centre d'esprits selects a donné un pas de plus vers le progrès féminin; entouré d'une ambiance intellectuelle de grande valeur, qui sera un stimulant pour contribuer à son progrès, on ne peut attendre que des jours remplis de véritables triomphes pour « l'Ateneo de la Juventud » qui élèveront le statut de la femme bolivienne.

Feminiflor qui ne peut pas être indifférente à rien qui signifie évolution et progrès dans les sphères féminines, a le plaisir d'envoyer à «l'Ateneo de la Juventud» à travers de Madame Bustamante, ses chaleureuses félicitations en leur augurant un brillant succès dans leur travail innovateur. $»^{33}$

Cependant, «l'Ateneo Femenino » se constitua comme une organisation totalement autonome et indépendante de son centre d'origine. Les hommes n'avaient aucun pouvoir de décision sur celui-ci, et l'orientation féministe de cette organisation fut visible et claire depuis ses origines. María Luisa Sánchez Bustamante raconte s'être inspirée d'une organisation de femmes au Chili pour la création de l'« Ateneo ». Elle se souvient de sa création ainsi:

« Je vais vous expliquer les origines de sa fondation. J'habitai au Chili pendant longtemps et je vis que les femmes travaillaient beaucoup pour leur pays et pour leur culture, pendant qu'ici, celle qui apprenait quelque chose restait à la maison.

Je suis venue avec l'idée de fonder une institution de femmes similaire au «Club de Señoras de Santiago » au Chili qui était très beau à l'époque; mais bien sûr là bas il y a des fortunes immenses, alors qu'ici on est très pauvres...

Je rencontrai quelques amis qui avaient crée l'«Ateneo de la Juventud» deux ans auparavant pendant que j'étais en voyage. Cette institution me plus bien et nous convînmes que je fonderai l'« Ateneo Femenino », mais bien sûr, ils voulurent s'immiscer dans notre «Ateneo », et étant donnée que je suis essentiellement féministe je leur

\footnotetext{
${ }^{33}$ «El Ateneo de la Juventud.

En este importante centro cultural de La Paz, acaba de fundarse una sección especial femenina, tendiente a cultivar las artes.

Dignamente presididas por la señora Bustamante Urioste este núcleo de selectos espíritus, ha dado un paso más en el progreso femenino; rodeadas de un ambiente intelectual de gran valía, que sabrá darles estímulo, y contribuir a su progreso, es de esperar que llegue para Ateneo de la Juventud, días de verdaderos triunfos, que elevarán a la mujer boliviana.

Feminiflor que no puede ser indiferente a nada de lo que signifique evolución y adelanto en las esferas femeninas, se complace en enviar en la persona de la señora Bustamante al Ateneo de la Juventud, su calurosa felicitación augurándoles brillante éxito en su innovadora tarea. » Dans Feminiflor n²2, mai 1923, Oruro. Hemeroteca de la Universidad Mayor de San Andrés, La Paz - Bolivie.
} 
dis que non ; qu'on allait faire un pacte pour collaborer entre nous mais que les hommes n'interviendraient pas dans nos affaires. Je ne voulais pas que les hommes s'en mêlent -non pas parce que je sois ennemie d'eux - au contraire - j'ai eu de très bons amis et jamais les hommes ne m'ont nui - mais j'avais déjà expérimenté la discrimination envers les femmes de la part d'eux antérieurement, c'est-à-dire, je ne pouvais pas accepter cette intrusion. Je créai un dicton un peu drôle qui disait : " Laissez-nous les femmes écrire des sottises, ne nous censurez pas. » Dans notre «Ateneo » on fit de la culture et surtout du féminisme ; la première chose qu'on voulut furent les droits civils et puis les droits politiques. La première institution en Bolivie qui se mit à demander les droits politiques fut l'« Ateneo ». Et les garçons -qui étaient tellement en retard- nous sifflaient en disant «Ces folles, veulent être députés ». Je n'ai jamais été député jusqu'à maintenant, pas parce que je ne l'ai pas voulu mais parce que j'ai toujours été dans les partis de l'opposition, et bien sûr, ils ne gagnent jamais ; mais je me suis bien portée candidate. ${ }^{34}$

L'«Ateneo Femenino » fut l'organisation de plus longue durée de vie parmi toutes les autres. On sait qu'au début des années 1980 elle était toujours en activité. C'est-à-dire qu'elle fonctionna pour plus de 60 ans, dont 28 furent dirigés par sa fondatrice María Luisa Sánchez Bustamante. Il fut donc une exception entre les associations féministes qui existèrent tout au long de la période qui va de 1920 à 1952, qui avaient une durée de vie assez éphémère. Ce fut également le premier

\footnotetext{
34 «Le voy a explicar los orígenes de su fundación. Yo viví en Chile mucho tiempo y vi que las mujeres trabajaban mucho por su país y su cultura, mientras que acá la que aprendía algo se quedaba en su casa.

Yo vine con la idea de fundar una institución de mujeres al estilo del Club de Señoras de Santiago de Chile que era muy hermoso en ese tiempo, claro que allá hay fortunas inmensas, acá somos tan pobres...

Me encontré con unos amigos que habían creado el Ateneo de la Juventud hacia dos años mientras yo estaba de viaje. Me gustó esta institución y convinimos en que yo fundaría el Ateneo Femenino, pero claro, ellos se quisieron meter a nuestro Ateneo, y como yo soy esencialmente feminista, les dije que no; que haríamos un pacto de colaborarnos pero los hombres no intervendrían en nuestros asuntos. Yo no quería que se metan los hombres - no porque era enemiga de ellos - al contrario - yo he tenido grandes amigos y nunca los hombres me han hecho daño alguno - pero anteriormente había tenido la experiencia de la discriminación hacia las mujeres por parte de ellos o sea que NO podía aceptar esa intromisión. Yo creé un dicho un poco chistoso que decía: "Déjenos escribir a las mujeres disparates, no nos censuren."

En nuestro Ateneo hicimos cultura y sobretodo feminismo; lo primero que quisimos fueron los derechos civiles y luego los políticos. La primera institución en Bolivia que se atrevió a reclamar los derechos políticos fue el Ateneo. Y los muchachos - tan atrasados que eran - nos silbaban diciendo "Estas locas, habían querido ser diputadas". Yo hasta ahora no he sido diputada, no porque no haya querido, sino que siempre estuve en partidos de oposición, y claro, nunca salen; pero si he candidateado. » Entretien réalisé à María Luisa Sánchez Bustamante par Mariana Baptista Alvarez à La Paz, en 1979 et inclus dans l'article «Evolución de la mujer boliviana en los últimos 50 años » dans l'édition « Bodas de Oro » du journal Ultima Hora, avril 1979.
} 
Centre qui organisa une campagne constante pour l'obtention des droits civils et politiques des femmes.

L'«Ateneo Femenino » publia deux revues : Eco Femenino de septembre 1923 à la fin de 1925, et Indice qui fut éditée à partir de décembre 1927 et qui atteignit seulement 3 numéros. La plupart des informations qu'on possède sur cette organisation datent des années 1920 puisqu'elles nous ont été procurées à travers ces revues. La publication de la revue Eco Femenino fut annoncée en septembre 1923 dans la revue Aspiración annonçant des objectifs communs entre les deux revues :
«"Eco Femenino"
Organe de l'« Ateneo Femenino », dont l'apparition s'annonce pour les jours qui suivent, sera dirigé par Mlle Ana Rosa Tornero. On ne doute pas qu'avec le nouveau collègue féminin on sera liés par des sentiments identiques de progrès et d'idéaux élevés, qui tendent à une fin primordiale et urgente: l'union et l'harmonie de la famille bolivienne.
Aspiración félicite avec effusion l'« Ateneo Femenino » à travers de sa digne et distinguée représentante, Madame M. Luisa B. de Urioste, pour cette innovation dans son enthousiaste travail pour le bien de la culture féminine. $»^{35}$

Le fait qu'une grande partie des membres qui composaient le «Centro Ideal Femenino » et qui administraient la revue Aspiración soient également membres fondateurs de l'«Ateneo Femenino» renforçait l'union et les liens entre ces deux organisations.

L' «Ateneo Femenino » avait été formé comme une organisation féministe, mais aussi comme une organisation sociale dont les objectifs étaient le «progrès social ». Pour atteindre ce progrès social, l'amélioration de l'éducation des femmes, la protection de leur travail et l'obtention de ses droits civils et politiques étaient des objectifs primordiaux.

\footnotetext{
35 «"Eco Femenino".

Órgano del "Ateneo Femenino", cuya aparición se anuncia para estos días y que será dirigido por la Srta. Ana Rosa Tornero. No dudamos que con el nuevo colega femenino, nos ligará idénticos sentimientos de progreso e ideales elevados, que tiendan a un fin primordial e inaplazable: la unión y armonía de la familia boliviana.

Aspiración felicita efusivamente al "Ateneo Femenino" en su digna representante la distinguida Sra. M. Luisa B. de Urioste, por ésta innovación en su entusiasta labor en bien de la cultura femenina. » Dans Aspiración, n ${ }^{\circ}$, septembre 1923, La Paz. Centro de Informaciôn y Desarrollo de la Mujer (CIDEM), La Paz - Bolivie.
} 


\title{
Objectifs
}

L'«Ateneo Femenino » était régit par statuts dont on connaît uniquement le chapitre premier qui traite des fins de l'association. Elle se présente comme une organisation intellectuelle et artistique avec des objectifs sociaux, dont le principal était l'amélioration de la condition civile et juridique des femmes, ainsi que leur développement culturel et protection de leur travail. Elle annonce dans le même sens les projets qu'elle prétend entreprendre pour atteindre ses fins :

\author{
$\ll \quad$ Statuts \\ De l' «Ateneo Femenino » de La Paz \\ Chapitre 1 \\ Fins de la société
}

$1^{\circ}$.- Est organisé dans la ville de La Paz dans le mois d'avril 1923, une société féminine autonome avec des fins intellectuelles, artistiques et de bien public, elle admettra dans son sein l'étude de tous les problèmes sociaux et particulièrement ceux qui concernent la femme dans sa condition civile et juridique.

$2^{\circ}$.- La société travaillera pour l'amélioration culturelle féminine dans les diverses sphères sociales; elle encouragera le réveil, développement et perfectionnement des intelligences; elle protègera le professionnalisme et travail des femmes.

$3^{\circ}$.- Cette société aura comme nom «ATENEO FEMENINO» et en elle toutes les femmes boliviennes et étrangères trouveront la liberté de développer leurs idées. De même, ses portes seront ouvertes à toutes les sociétés qui travaillent pour le progrès du bien public; elles recevront collaboration morale et effective et pourront avoir des délégués formant partie de la Direction, en qualité de membres du Conseil.

$4^{\circ}$.- Pour atteindre le meilleur succès de ses fins, l'association soutiendra, avec ses propres moyens une "Bibliothèque Publique ", une «Caisse de Fonds et de Secours » pour la femme professionnelle et intellectuelle, la publication de revues et annales, elle organisera des conférences et des concours féminins et pour enfants, des cours d'éducation complémentaire, etc., etc. ${ }^{36}$

\footnotetext{
${ }^{36}$ « Estatutos

del "Ateneo Femenino" de La Paz.

Capitulo I.

Fines de la sociedad.

$1^{\circ}$.- Se organiza en la ciudad de La Paz, en el mes de abril de 1928, una sociedad femenina autónoma con fines intelectuales, artísticos y de bien público, dará cabida en su seno al estudio de todos los problemas sociales y en especial a los que atañen a la mujer en su condición civil y jurídica.

2. ${ }^{\circ}$ - La sociedad trabajará por el mejoramiento cultural femenino en las distintas esferas sociales; fomentará el despertar, desarrollo y perfeccionamiento de las inteligencias; protegerá el profesionalismo y trabajo de la mujer.
} 
Il est intéressant de noter que l'association se présente d'abord comme une organisation sociale aux fins de «progrès social». Englobée dans celles-ci se trouve la condition des femmes de toutes les classes sociales. Ainsi, l' « Ateneo Femenino » montre bien que c'est une organisation dont les inquiétudes concernent non seulement les femmes mais l'ensemble de la société : leurs objectifs vont au delà de l'obtention des droits civils et politiques des femmes. Ceci s'inscrit dans le sens que donnent ces femmes au féminisme qu'elles revendiquent : il inclut des inquiétudes sociales pour le progrès de la patrie dans son ensemble dans lequel les femmes devaient jouer un rôle prépondérant. En vue d'essayer de donner une définition du féminisme que proclamaient les femmes boliviennes, on analysera plus en détail leurs projets sociaux ultérieurement.

\section{Les membres ${ }^{37}$}

Les membres de l'«Ateneo Femenino » avaient différents statuts selon le rôle qu'elles jouaient dans l'organisation. Ainsi, il y avait 4 catégories d'associées : les membres honoraires, les membres actifs, les correspondantes et les membres passifs. Les membres honoraires étaient directement nommés par la Direction qui prenait en compte le travail de notoriété dans le domaine scientifique, didactique, littéraire, artistique ou humanitaire des personnes proposées à cette nomination. L'on connait uniquement deux personnes qui avaient ce statut: la célèbre poétesse uruguayenne Juana de Ibarbourou nommée membre honoraire en mai $1925^{38}$ (voir annexe C n²) et María Luisa Sánchez Bustamante, nommée présidente honoraire de l’organisation en

3. ${ }^{\circ}$ - Esta sociedad se llamará ATENEO FEMENINO y en ella encontrarán libertad para desarrollar sus ideas todas las mujeres bolivianas y extranjeras. Así mismo, estarán abiertas sus puertas para las sociedad que laboren por el progreso público, las que recibirán colaboración moral y efectiva y las que podrán tener delegados, que formen parte del directorio, en calidad de Miembros de su Consejo.

4. ${ }^{\circ}$ - Para llegar al mejor éxito de sus fines, la asociación sostendrá, por cuenta propia una "Biblioteca Pública", una "Caja de Fondos y Auxilio" para la mujer profesional e intelectual, la publicación de revistas y anales, propiciará conferencias, concursos femeninos e infantiles, cursos de educación complementaria, etc., etc. » Dans Indice $\mathrm{n}^{\circ} 3$, s.d.,1928. Collection privée de Martha Nardín Rivas, belle-fille de María Luisa Sánchez Bustamante.

${ }^{37}$ Indice $\mathrm{n}^{\circ} 1$, décembre 1927, La Paz. Centro de Informaciôn y Desarrollo de la Mujer (CIDEM), La $\mathrm{Paz}$ - Bolivie.

${ }^{38}$ Eco Femenino ${ }^{\circ}$ 13, mai 1925, La Paz. Hemeroteca de la Universidad Mayor de San Andrés, La Paz - Bolivie. 
juillet 1925 lors du renouvellement de la Direction où Rosa Infante (voir annexe A $\mathrm{n}^{\circ} 11$ ), fut élue la nouvelle présidente ${ }^{39}$.

Pour être associée active, correspondante ou passive il fallait qu'un membre de la Direction ou du Conseil présente par écrit dans l'une des réunions, le nom et prénom de la candidate ainsi que sa biographie, indiquant le type d'activité intellectuelle ou sociale qu'elle réalisait, ainsi que la profession ou les titres qu'elle avait. Pour devenir associée active il fallait présenter une thèse d'admission qui devait être lue dans l'une des sessions publiques de l' «Ateneo » ou publiée dans la revue de celui-ci. Ainsi, par exemple Ana Rosa Vázquez (voir annexe A $n^{\circ}$ 9) présenta sa thèse d'admission en octobre 1923. Elle portait sur la nécessité de réaliser un Congrès féminin international à l'occasion des fêtes du centenaire de la Bolivie en $1925^{40}$.

Les associées passives étaient les personnes qui souhaitaient collaborer avec l'«Ateneo Femenino ». Leur admission n'était pas conditionnée à la présentation d'une thèse, mais elles n'avaient pas les mêmes privilèges que les associées actives. Les associées passives pouvaient participer aux Assemblées plénières et aux sessions de la Direction, où elles avaient le droit de vote mais elles n'avaient pas le droit de discussion ni le droit de pouvoir être élues aux charges de la Direction.

Les associées correspondantes avaient surtout une fonction de publicité des revues et des publications du centre. Toutes les associées actives qui se trouvaient hors de La Paz ou hors du pays pouvaient être des associées correspondantes. Leur rôle était de représenter l' «Ateneo Femenino » et de le mettre en contact avec les différentes sociétés féminines boliviennes et étrangères. Elles devaient envoyer des articles et des renseignements pour les publications et le travail de l'association. La Direction devait nommer toutes les associées correspondantes dans toutes les villes importantes du monde et devait prendre soin de maintenir une communication constante avec chacune d'entre elles.

Lorsque la Direction considérait qu'il était convenable de recevoir dans son sein de manière occasionnelle des littéraires, des scientifiques, des artistes, etc., hommes ou femmes, il organisait des sessions extraordinaires à l'honneur de ces personnes, en leur attribuant le titre d' « hôtes honoraires ». Par exemple, une session extraordinaire

\footnotetext{
${ }^{39}$ Eco Femenino n¹4, juillet 1925, La Paz. Hemeroteca de la Universidad Mayor de San Andrés, La Paz - Bolivie.

${ }^{40}$ Eco Femenino n`2, octobre 1923, La Paz. Hemeroteca de la Universidad Mayor de San Andrés, La Paz - Bolivie.
} 
eut lieu à l'honneur de María Lía Suárez, déléguée du « Consejo Nacional de Mujeres de la Argentina » («Conseil National de Femmes d'Argentine ») en mai 1925. Cette dernière promit d'être l'intermédiaire pour le rapprochement des femmes boliviennes et argentines $^{41}$. L'écrivain espagnol Francisco Villaespesa fut également nommé « hôte honoraire » en session extraordinaire en juillet 1925 lorsqu'il se trouvait en visite dans le pays ${ }^{42}$.

De 1923 à 1927 les membres actifs, correspondants et passifs étaient obligés à payer des frais de mensualité et d'admission. A partir de 1927, en remplacement de ces frais les membres devaient avoir une action dans la «Caisse de Fonds et de Secours ». À défaut d'avoir rempli cette condition, les femmes ne pouvaient pas avoir le statut d'associées du centre.

L'appartenance politique, sociale ou religieuse n'était pas prise en compte pour être acceptée ou être appelée au sein de l'«Ateneo » en tant que membre active, passive ou encore correspondante.

Cependant, dans la pratique l'«Ateneo Femenino» était uniquement composé de femmes des classes moyennes et élevées de la société. Les restrictions pour y accéder telles que la rédaction d'une thèse d'admission ainsi que les frais d'admission, les mensualités à payer et plus tard, la possession d'une action dans la « Caisse de Fonds et de Secours », limitaient l'accès à celles qui avaient reçue pour le moins une éducation secondaire et qui avaient les moyens financiers pour payer ces frais.

Les membres qui formèrent partie de 1' «Ateneo Femenino » dans ses débuts en 1923 furent $^{43}$ : María Luisa Sánchez Bustamante de Urioste (voir annexe $\mathrm{A} \mathrm{n}^{\circ} 10$ ), Irene Gutierrez V. M., Elodia Baldivia de Ligerón (voir annexe A no12), Carmen Guillermina Dalens, Enriqueta Castillo Nava, Enriqueta C. de Luna O., Isabel Calvo, Raquel Carmona (voir annexe A n58), María Cristina Sotomayor, Stael Gómes, Elvira Benguria A. (voir annexe A n 13 ), Sally Gutierrez V.M., Sofía Berdecio, Carmen Sánchez Bustamante C. (voir annexe A nº14), Alicia Belmont, Elena Alvarez D., T. Granier, Lindaura Paz Campero, Arminda Aparicio S., Eduviges G. v. de Hertzog (voir annexe A n¹5), Julia Iturralde, Adela Reyes Ortiz, María Luisa de

\footnotetext{
${ }^{41}$ Eco Femenino ${ }^{\circ} 13$ mai 1925, La Paz. Hemeroteca de la Universidad Mayor de San Andrés, La PazBolivie.

${ }^{42}$ Eco Femenino ${ }^{\circ} 14$ juillet 1925, La Paz. Hemeroteca de la Universidad Mayor de San Andrés, La Paz-Bolivie.

${ }^{43}$ Feminiflor $\mathrm{n}^{\circ}$ 25, novembre 1923, Oruro. Hemeroteca de la Universidad Mayor de San Andrés, La Paz - Bolivie.
} 
Ballivián, María V. v. de Estivariz, Leonor Díaz Romero y G. (voir annexe A nº16), Ana Rosa Vázquez (voir annexe A n9), Quica Estenssoro (voir annexe A n¹7), Hortensia Sanjinés Montes, Amalia Villa de La Tapia (voir annexe A n¹8), Raquel Valverde, María Bonel Urriolagoitia, A. Valverde.

En septembre 1924 les charges de la Direction (voir annexe B n4) étaient distribuées de la manière suivante ${ }^{44}$ :

Présidente : María Luisa Sánchez Bustamante (voir annexe A nº10).

Vice-Présidente : Rosa Infante (voir annexe A n 11 ).

Directrice de la Bibliothèque: Emma Perez de Carvajal (voir annexe A n¹9). Secrétaire : Carmen Rosa Torres.

Pro-Secrétaire : Raquel Carmona (voir annexe $\mathrm{A} \mathrm{n}^{\circ} 58$ ).

Trésorière : Enriqueta Castillo.

Membres du Conseil (« Vocales ») : Eduviges G. v. de Hertzog (voir annexe A n¹5), Isabel B. v. de Haillot (voir annexe A n²0), Irene Gutiérrez V. M.

Comme on peut le constater, les charges de la direction sont exactement les mêmes que celles du « Centro Intellectuel et Artistique » d'Oruro, ce qui nous laisse supposer que l' « Ateneo Femenino » s'était inspiré de celui-ci dans sa création et organisation. D'après le règlement, la Direction devait être renouvelée au bout de deux ans. Ainsi, en juillet 1925 la Direction fut rénovée ainsi ${ }^{45}$ :

Présidente honoraire : María Luisa Sánchez Bustamante (voir annexe A nº10).

Présidente : Rosa Infante (voir annexe $\mathrm{A} \mathrm{n}^{\circ} 11$ )

Vice-Présidente : M. Cristina S. G. de Suazo.

Secrétaire : Isabel B. v. de Haillot (voir annexe A n²0).

Pro-Secrétaire : Cristina Iturralde de Zalles (voir annexe $\mathrm{A} \mathrm{n}^{\circ} 21$ ).

Trésorière : Raquel Carmona (voir annexe A n58).

Directrice de la Bibliothèque : Eduviges G. de Hertzog (voir annexe A n ${ }^{\circ}$ ).

\footnotetext{
${ }^{44}$ Eco Femenino n ${ }^{\circ}$, septembre 1924, La Paz. Hemeroteca de la Universidad Mayor de San Andrés, La Paz - Bolivie.

${ }^{45}$ Eco Femenino n ${ }^{\circ}$, juillet 1925, La Paz. Hemeroteca de la Universidad Mayor de San Andrés, La $\mathrm{Paz}$ - Bolivie.
} 
Membres du Conseil («Vocales ») : Elodia B. de Ligerón (voir annexe A n ${ }^{\circ} 12$ ), Carmen Rosa Torres, Carmen Sánchez Bustamante (voir annexe A n¹4), Anhélica Estenssoro, Ana Rosa Tornero (voir annexe A nº ${ }^{\circ}$.

Une grande partie des membres de l'«Ateneo Femenino» étaient des femmes intellectuelles : écrivaines, poétesses, artistes, professeures normaliennes, des classes moyennes et élevées de la société. Certaines d'entre elles, étaient connues dans la société en raison de leur travail littéraire ou artistique telles que Leonor Díaz Romero, Quica Estenssoro; ou encore en raison de leurs exploits telles que Amalia Villa de La Tapia. Au fil des années, l'«Ateneo Femenino» a compté parmi ses membres des femmes artistes, intellectuelles, professeures normaliennes de La Paz et de la Bolivie. Il s'agissait donc d'un groupe constitué des femmes appartenant à l'élite sociale et intellectuelle du pays. Elles remplissaient les conditions essentielles pour devenir citoyennes à l'époque : savoir lire et écrire et avoir un capital minimum qui ne provienne pas du travail domestique. Elles considéraient donc que le droit de vote ainsi que les droits civils des femmes étaient des demandes légitimes.

\section{Activités}

L' «Ateneo Femenino » au contraire du « Centre Intellectuel et Artistique d'Oruro, possédait un local propre où se réunissaient les membres. Celui-ci fut inauguré en octobre 1923 avec une soirée littéraire - musicale, où eurent lieu des lectures de conférences et de thèses d'admission, ainsi que la présentation de spectacles de chant, de violon, de piano et la représentation humaine d'une allégorie (voir annexe $\left.\mathrm{B} \mathrm{n}^{\circ} 5\right)^{46}$. Le nouveau local se trouvait dans la rue «Ladislao Cabrera » au «Prado », avenue résidentielle où habitaient les familles de l'élite de $\mathrm{La} \mathrm{Paz} \mathrm{de} \mathrm{l'époque}{ }^{47}$ et très probablement une grande partie de femmes qui composaient l' « Ateneo Femenino ».

Dans ce local avaient lieu toutes les activités de l'organisation : les sessions ordinaires et extraordinaires, les réunions de la Direction, des Assemblées, les soirées littéraires-

\footnotetext{
${ }^{46}$ Eco Femenino n`2, octobre 1923, La Paz. Hemeroteca de la Universidad Mayor de San Andrés, La Paz - Bolivie.

${ }^{47}$ BARRAGÁN Rossana, QAYUM Seemin, SOUX María Luisa, De terratenientes a amas de casa. Mujeres de la élite de La Paz en la primera mitad del siglo XX. Serie "Protagonistas de la Historia", Editores: Ministerio de Desarrollo Humano, Secretaría de Asunto Étnicos, de Género y Generacionales, Subsecretaría de Asuntos de Género, La Paz - Bolivia, 1997.
} 
musicales où les membres lisaient des travaux ou démontraient leurs qualités artistiques en faisant de la musique ou en déclamant des poèmes, où encore en présentant avec l'«Ateneo de la Juventud» des pièces de théâtres historiques produites par les membres, appelées « Évocations historiques» (voir annexe $\mathrm{B} \mathrm{n}^{\circ}$ ). Dans ce local se tenaient également les conférences bimensuelles qu'offrait l'«Ateneo » et qui étaient gratuites et ouvertes au public. Elles avaient lieu tous les premiers et troisièmes lundis du mois ${ }^{48}$. Les conférences pouvaient être réalisées par les membres de l'organisation sur des thèmes divers: ainsi, par exemple, la conférence donnée par Adela Reyes Ortiz Canedo sur Beethoven en septembre $1924^{49}$, ou la conférence donnée par Fidelia Corral Zambrana (voir annexe A n²2) sur le «Journalisme en tant que preuve du féminisme» en juillet $1925^{50}$. Les conférences étaient données également par des experts hommes ou femmes, qui n'étaient pas nécessairement des membres de l'organisation, sur leur thème de spécialité. Ainsi, le cycle de conférences scientifiques réalisées le 28 avril, et le 5 et 12 mai 1924, par le botaniste bolivien Martín Cárdenas sur l'expédition Rusly réalisée avec des botanistes états-unien dans l'Amazonie bolivienne. Ou encore la conférence réalisée par l'écrivain espagnol Francisco Villaespesa dans laquelle il procéda à la lecture et à l'analyse d'un de ses contes ${ }^{51}$. En plus de ces conférences, l' «Ateneo » offrait des cours gratuits donnés par ces membres. L'on ne sait pas à qui étaient destinées ces cours ni sur quoi ils portaient, mais l'on peut supposer qu'ils étaient donnés aux femmes des classes populaires qui ne savaient pas lire ni écrire.

L' « Ateneo Femenino » possédait une « Bibliothèque Publique », dans son local, dont le fonds s'enrichissait par des donations (voir annexe $\mathrm{C} \mathrm{n}^{\circ} 3$ ).

Cependant, il semblerait que les dons n'étaient pas très fréquents et que par conséquent la bibliothèque disposait d'un fonds assez modeste. C'est ce dont se plaint Rosa Infante (voir annexe A n¹1), présidente de $1^{\prime}$ « Ateneo Femenino » de 1925 à

\footnotetext{
${ }^{48}$ Eco Femenino n 7 , juin 1924, La Paz. Hemeroteca de la Universidad Mayor de San Andrés, La Paz - Bolivie.

${ }^{49}$ Eco Femenino ${ }^{\circ}$ 9, septembre 1924, La Paz. Hemeroteca de la Universidad Mayor de San Andrés, La Paz - Bolivie.

${ }^{50}$ Eco Femenino n¹4, juillet 1925, La Paz. Hemeroteca de la Universidad Mayor de San Andrés, La $\mathrm{Paz}$ - Bolivie.

${ }^{51}$ Eco Femenino n¹4, juillet 1925, La Paz. Hemeroteca de la Universidad Mayor de San Andrés, La Paz - Bolivie.
} 
1927, lorsqu'elle fait le bilan de son travail, à l'occasion de la rénovation de la Direction en août 1927 :

«BIBLIOTHEQUE : Depuis la fondation de l'« Ateneo », on a fait des grands efforts pour accroître le fonds de notre bibliothèque, car on la considère de grande utilité non seulement pour boire des sources saines du savoir, la rénovation d'idées; mais aussi pour former un centre de lecture et l'offrir aux dames qui nous honorent en assistant à ce foyer. Le fonds s'est enrichi avec quelques ouvrages; néanmoins, il est encore réduit, peu de personnes enthousiastes ont contribué à la demande que 1 'on a fait... $»^{52}$

A partir de la fin de 1927 surgit le projet de construction d'un local qui serait aussi un «Hogar Internacional » («Foyer International») où les femmes provenant d'institutions féminines internationales affiliées au foyer, pourraient se loger lors de visites dans le pays. Ce projet avait comme but principal de favoriser les échanges avec d'autres institutions féminines de la Bolivie et du monde entier pour faire sortir la Bolivie de l'isolement où elle se trouvait en raison de sa position méditerranéenne.

María Luisa Sánchez Bustamante explique le projet ainsi:

«Les foyers internationaux, réussissent à faire une publicité profitable au pays dans lequel ils sont implantés; ils envoient des renseignements, réalisent des échanges précieux avec les sociétés analogues et établissent un courant de communication avec toutes les nations. Ils offrent également les opportunités pour envoyer des déléguées ou des groupes de spécialistes qui à titre d'amitié, trouvent un vaste champ d'instruction et de distractions.

En ce qui concerne les autres coins de la république, l'établissement d'un Foyer Féminin aurait en Bolivie, des prérogatives sympathiques, puisqu'aucun pays comme le nôtre a autant besoin de travailler pour l'unité nationale. Tous les ans on aurait des visites de commissions interdépartementales et aussi, de femmes qui en raison d'affaires professionnelles, artistiques ou d'études se verraient dans la nécessité d'arriver toutes seules. Pourvu qu'elles appartiennent à des sociétés ayant de pactes et de relations avec le Foyer féminin, elles trouveraient toujours un logement protégé et une coopération effective. $\gg{ }^{53}$

\footnotetext{
52 «BIBLIOTECA: Desde la fundación del Ateneo, se ha perseguido con insistencia para incrementar nuestra biblioteca, porque la conceptuamos de gran utilidad, no solo para beber en las fuentes sanas del saber, la renovación de ideas; sino también formar un centro de lectura y ofrecer a las damas que nos honran asistiendo a este hogar. Se ha incrementado con algunas obras; sin embargo, es reducida todavía, pocas personas entusiastas han contribuido al pedido que hemos hecho... » dans Indice $\mathrm{n}^{\circ} 1$, décembre 1927, La Paz. Hemeroteca de la Universidad Mayor de San Andrés, La Paz - Bolivie.

${ }^{53}$ «Los Hogares Internacionales consiguen una propaganda beneficiosa par el país que los posee; envían datos, realizan canjes valiosos con sociedades análogas y establecen una corriente de comunicación con todas las naciones, así como también ofrecen oportunidades de poder enviar delegadas o grupos estudiosos que a título de amistad, encuentran un campo amplio de instrucción y recreo.
} 
Ce local, servirait également à accueillir toutes les activités courantes de l'organisation ainsi que des cours complémentaires universitaires pour les femmes de Droit public, Économie Politique, Droit International, et d'hygiène sociale ${ }^{54}$. Il y aurait un petit théâtre pour les fêtes de l'institution, un grand vestibule, des salles de conférences et de cours, et la Bibliothèque Publique. Un croquis de la façade de cet édifice, réalisé par l'artiste Emilio Amoretti ${ }^{55}$, fut publié dans le numéro 2 de la revue Indice de janvier 1928 (voir annexe $\mathrm{C} \mathrm{n}^{\circ} 5$ ).

On ne sait pas si ce local fut finalement construit ou non. Il est probable que non puisque l' « Ateneo Femenino » avait des problèmes d'argent. La revue Eco Femenino cessa d'exister en raison de difficultés financières. C'est ce qu'explique Rosa Infante (voir annexe $\mathrm{A}^{\circ} 11$ ) lorsqu'elle fait le bilan de son travail en tant que présidente de 1925 à 1927 :

«REVUE ECO: Le manque de ressources de l'institution a été une des causes primordiales de la suspension de la revue Eco, qui bénéficia d'une grande circulation et de prestige à l'extérieur comme à l'intérieur de la république. Celle-ci était le porte-parole de nos idéaux, celle qui reflétait le travail des membres, dans chaque page étaient imprimées leurs idées selon leurs penchants artistiques, littéraires, historiques, qui s'écrivaient avec une véritable ferveur. $\rangle^{56}$

Néanmoins, l'«Ateneo Femenino» recevait des subventions de la part du Gouvernement qui semblent avoir été modestes, mais qui servirent pour faire face aux nécessités les plus urgentes de l'organisation.

\footnotetext{
Respecto a los demás puntos de la república, el establecimiento de un Hogar Femenino sería, en Bolivia, de simpáticas prerrogativas, ya que ningún país como el nuestro necesita trabajar por la unidad nacional. Todos los años se nos harían visitas de comisiones inter - departamentales y también, las mujeres que por asuntos profesionales, artísticos o de estudio se verían en la necesidad de llegar solas, encontrarían siempre que pertenecieran a sociedades con relaciones y pactos con el Hogar Femenino, alojamiento resguardado y cooperación efectiva. » Indice $\mathrm{n}^{\circ} 2$, janvier 1928 , La Paz. Centro de Informaciôn y Desarrollo de la Mujer (CIDEM), La Paz - Bolivie.

${ }^{54}$ Indice $\mathrm{n}^{\circ} 1$, décembre 1927, La Paz. Centro de Informaciôn y Desarrollo de la Mujer (CIDEM), La Paz - Bolivie.

${ }^{55}$ Indice $\mathrm{n}^{\circ}$ 1, décembre 1927, La Paz. Centro de Informaciôn y Desarrollo de la Mujer (CIDEM), La Paz - Bolivie.

56 «REVISTA ECO: La falta de recursos que carece la institución, ha sido una de las causas primordiales para que se suspenda la edición de la Revista Eco, la que llegó a tener mucha circulación y prestigio tanto en el exterior como en el interior de la República; ésta era la porta-voz de nuestros ideales, la que reflejaba el trabajo de las socias, en cada página estaban estampadas sus ideas según sus aficiones a lo artístico, literario, histórico que se escribía con verdadero fervor. »Indice $\mathrm{n}^{\circ} 1$, janvier 1928, La Paz. Centro de Informaciôn y Desarrollo de la Mujer (CIDEM), La Paz - Bolivie.
} 
C'est ce qu'affirme Rosa Infante en 1927 :

«FONDS : Grâce aux démarches de la méritoire présidente honoraire María Luisa de Urioste, qui a toujours collaboré avec moi dans toutes les affaires de l'« Ateneo », qui est d'ailleurs l'âme qui l'anime et lui donne vie, on a réussi à ce que le suprême gouvernement assigne à cette institution, un petit lot, avec lequel on a pu faire face aux nécessités les plus urgentes. De même, María Luisa, solicita à l'expréfet, monsieur Arturo Prudencio, une autre subvention, qui fut satisfaite avec beaucoup de gentillesse, qui quoique limitée, a été un auxiliaire puissant car elle a stimulé nos activités. Nous avons acquis un piano, qui manquait pour donner de l'éclat à nos sessions publiques et avec ce motif, s'est formée la section musicale artistique, composée de distinguées mesdemoiselles et dirigée par la compétente et enthousiaste associée, Madame Matilde de Bruno... » ${ }^{57}$

Même avec ces aides la situation financière de l'organisation en 1927 n'était pas dans le meilleur état, ce qui expliquerait que la revue Indice n'atteignît que 3 numéros :

« Il est porté à la connaissance des associées que l'état économique de la société laisse beaucoup à désirer. Cependant on attend qu'avec les dispositions prises, l'année prochaine apporte des grandes améliorations dans la section.

La Trésorière. $»^{58}$

Malgré toutes ces difficultés, l'«Ateneo Femenino » fut l'organisation la plus active et importante en termes de création de réseaux avec les organisations féministes de la Bolivie et du monde entier.

\section{Les réseaux féministes en Bolivie et dans le monde}

Depuis sa fondation 1'«Ateneo Femenino » se chargea de prendre contact avec toutes les organisations féministes de la Bolivie, d'établir des liens pour créer un

\footnotetext{
57 «FONDOS: Merced a las gestiones de la meritoria presidenta Honoraria, señora María Luisa de Urioste, que siempre me ha colaborado en todos los asuntos del Ateneo, como que es, el alma que la anima y le da vida; ha conseguido que el supremo Gobierno le asigne, a esta institución, una pequeña partida, con la que ha podido hacer frente a las necesidades de mayor urgencia. Así mismo la suscrita, por su parte solicitó al ex-prefecto, Sr. Arturo Prudencio, otra subvención, la que fue atendida con toda gentileza, aunque limitada, se la consideró como un auxiliar poderoso pues impulsó nuestras actividades. Se ha adquirido un piano, el que hacía falta para dar realce a nuestras sesiones públicas y con este motivo, se ha formado la sección musical artística, compuesta por distinguidas señoritas y dirigida por la competente y entusiasta ateneísta señora Matilde Bruno... » Indice $\mathrm{n}^{\circ} 1$, janvier 1928, La Paz. Centro de Informaciôn y Desarrollo de la Mujer (CIDEM), La Paz - Bolivie.

${ }^{58}$ « Se pone en conocimiento de las asociadas que el estado económico de la sociedad deja mucho que desear, esperándose sin embargo, que con los disposiciones tomadas se ingresará al próximo año con grandes mejoras de la sección. La Tesorera. » Indice $n^{\circ} 1$, janvier 1928, La Paz. Centro de Informaciôn y Desarrollo de la Mujer (CIDEM), La Paz - Bolivie
} 
véritable réseau féministe dans le pays, mais aussi au-delà des frontières avec les féministes de l'Amérique Latine et de l'Europe.

Toutes les organisations féministes créées au début des années 1920 avaient des liens entre elles, et toutes surgirent plus ou moins en même temps sous l'inspiration de la première d'entre elles, le «Centro Artístico e Intelectual de Señoritas de Oruro », comme on a pu le constater. Elles se reconnaissaient comme ayant des objectifs communs à atteindre. Cependant, elles ne réalisèrent pas des actions concrètes communes afin d'atteindre leurs objectifs. Ceci peut être expliqué par le fait qu'elles étaient des organisations éphémères et qu'elles ne disposèrent donc pas $d u$ temps nécessaire pour créer des réseaux solides. L'« Ateneo Femenino », l'organisation la plus durable de toutes, fut la seule à essayer d'avoir une véritable politique de création de réseaux féministes non seulement avec les féministes de la Bolivie, mais aussi avec les féministes du monde entier.

Quelques mois après sa fondation, en novembre 1923 l' «Ateneo Femenino » envoya un message de fraternité au «Centro Artístico e Intelectual de Señoritas de Oruro » à travers sa représentante Ana Rosa Tornero (voir annexe A n7) qui visita Oruro. L'écho de cet événement fut publié dans les revues respectives de chacune des organisations : Eco Femenino et Feminiflor. Pour recevoir son hôte provenant de La Paz, le «Centro Artístico e Intelectual de Señoritas de Oruro » réalisa une fête littéraire - musicale à l'Ecole de Beaux Arts, où le président de l'Ecole, ainsi que les représentantes de chacune des organisations prononcèrent des discours sur la communion d'idéaux des deux organisations et la nécessité de faire avancer le mouvement de femmes pour leur amélioration culturelle, sociale et politique. Le discours d'Ana Rosa Tornero représentante de l' «Ateneo Femenino » commençait ainsi :

«Dans la ville de La Paz s'est formé un «Ateneo Femenino » qui aujourd'hui est en pleine activité et ses efforts pro femme promettent donner des fruits vigoureux et sains.

En ayant tracé un programme de nationalisme et de vaste travail culturel dans toute la République, il se dirige aujourd'hui aux femmes de l'illustre terre du Pagador (Oruro) pour qu'en faisant écho à cet appel, elles travaillent aussi pour l'élévation de la Patrie, en faisant que ses femmes se réveillent de la léthargie dans laquelle elles ont été 
plongées jusqu'à aujourd'hui par manque d'initiatives et d'idées propres. $\gg 5$

L' «Ateneo Femenino » demandait également la création d'un « Ateneo Femenino » à Oruro autonome par rapport à celui de $\mathrm{La} \mathrm{Paz} \mathrm{:}$

«En demandant que soit fondé à Oruro, un nouveau «Ateneo Femenino » autonome du nôtre, nous voulons resserrer les liens d'union sacrée, avec nos sœurs d'Oruro avec lesquelles on aura désormais une seule et même cause, les mêmes idéaux et une seule volonté pour lutter et aller après le triomphe. ${ }^{60}$

La réponse du « Centro Artístico e Intelectual de Señoritas de Oruro », très favorable se fit entendre à travers le discours de Bethsabé Salmón Fariñas (voir annexe $\mathrm{A} \mathrm{n}^{\circ} 4$ ):

« Une signification spirituelle nous réunit dans cette demeure de l'Art, l'«Ateneo Femenino » de la Paz, groupe de selectes cultures, envoie aux femmes de cette terre un message de fraternité.

L'inquiétude constante et universelle pour l'amélioration de la femme qui inquiète tous les esprits studieux et supérieurs ne pouvait pas être soustraite de la jeunesse du Nord, et logiquement cette mission s'est imposée un groupe de dames cultivées de cette ville, qui en joignant leur travail et effort à celui de plusieurs institutions de la République, souhaite pour la femme un progrès culturel maximal qui en l'arrachant du cadre de préjugés ancestraux l'élève à un plan supérieur avec une valeur sociale active. $»^{61}$

\footnotetext{
59 «En la ciudad de La Paz se ha formado un "Ateneo Femenino" el que hoy está en plena actividad y sus esfuerzos en pro de la mujer prometen dar frutos vigorosos y sanos.

Habiendo trazado un programa de nacionalismo y amplia labor cultural en toda la República, se dirige hoy a las mujeres de la ilustre tierra del Pagador que haciendo eco a este llamamiento trabajen también ellas por el engrandecimiento de la Patria, haciendo que sus mujeres despierten del letargo del que hasta hoy han estado sumidas por falta de iniciativas e ideas propias. " Feminiflor, n²5, novembre 1923, Oruro. Hemeroteca de la Universidad Mayor de San Andrés, La Paz - Bolivie.

${ }^{60}$ "Al pedir que se funde en Oruro, un nuevo "Ateneo Femenino" autónomo del nuestro, queremos estrechar vínculos de unión sagrada con nuestras hermanas orureñas con las que de hoy en adelante tendremos una misma causa, los mimos ideales y una sola voluntad para luchar e ir tras el triunfo. » Feminiflor, $\mathrm{n}^{\circ} 25$, novembre 1923, Oruro. Hemeroteca de la Universidad Mayor de San Andrés, La Paz - Bolivie.

${ }^{61}$ «Una significación espiritual nos congrega en esta mansión del Arte, el Ateneo Femenino de La Paz, agrupación de selectas culturas, en vía a las mujeres de esta tierra un mensaje de fraternidad.

La constante y universal preocupación para el mejoramiento de la mujer y que inquieta todas las mentes estudiosas y superiores no podía ser sustraída del espiritualismo que anima a la juventud del norte, y lógicamente esa misión se ha impuesto un grupo de cultas damas de aquella ciudad, que sumando su labor y esfuerzo al de varias instituciones similares de la República, anhelan para la mujer un progreso cultural máximo que arrancándole del marco de ancestrales prejuicios la eleve a un plano superior, con un valor social activo. » Eco Femenino n²4, janvier 1924, La Paz. Hemeroteca de la Universidad Mayor de San Andrés, La Paz - Bolivie.
} 
La filiation et l'union des deux organisations dans leurs idéaux, objectifs et lutte fut symbolisée avec la remise d'un bouquet de fleurs de la part de Bethsabé Salmón (voir annexe $\mathrm{A} \mathrm{n}^{\circ}$ 4) à Ana Rosa Tornero (voir annexe $\mathrm{A} \mathrm{n}^{\circ} 7$ ):

"L" "Ateneo Femenino" de La Paz, encore de courte vie, mais d'intense et d'efficace travail est sans doute la première institution culturelle de la République.

De ce temple vient à nous l'une de ses vestales en nous apportant le lien cordial qui en nouant nos cœurs donnera un seul rythme à nos efforts.

Heureuse messagère d'idéalisme : Retournez dans votre auvent et dites aux femmes de votre terre, qu'ici aussi nous avons l'âme pleine de nobles souhaits et d'idéaux, d'aspirations vers un lendemain meilleur, et que si on marcha péniblement toutes seules une longue distance du parcours, avec vous, et avec toutes les femmes de la Bolivie, nous forgerons un avenir plus juste pour toutes les générations à venir, en ayant comme devise : abnégation et persévérance.

Retournez et dites à nos sœurs, que la femme d'Oruro n'est pas indifférente, ni lâche et que sa grande âme nourrit la même aspiration que vous. Elle travaillera, elle luttera pour triompher un jour et poursuivre une voie plus égalitaire, plus consciente et plus noble.

Et en vivant dans l'Art, dans le devoir et dans le patriotisme, la Bolivie sera puissante.

Je dépose en vous face à 1'“Ateneo Femenino" de La Paz, ces fleurs, modestes, des liens qui signifieront une seule et même volonté, une seule et même âme entre les femmes boliviennes. " ${ }^{62}$

La fête en l'honneur d'Ana Rosa Tornero fut un évènement social où assista une partie de l'élite intellectuelle d'Oruro (voir annexe B n7). L'événement fut décrit dans la presse d'Oruro comme un acte très « significatif et sympathique » dans lequel il y eut «une véritable profusion d'art et d'enthousiasme». Des présentations musicales furent réalisées, tout comme la lecture de poèmes, dont celle d'Amalia

\footnotetext{
${ }^{62}$ «El Ateneo Femenino de La Paz, de corta vida aún, pero de intensa y eficiente lavbor es sin duda la primera institución cultural femenina de la República.

De aquel templo viene a nosotros una de sus vestales trayéndonos el lazo cordial que anudando nuestros corazones ha de dar un solo ritmo a nuestros esfuerzos.

Feliz mensajera de idealismo: Volved a vuestro alero y decid a las mujeres de vuestra tierra, que también aquí tenemos el alma rebozante de nobles anhelos e ideales, de aspiración hacia una mañana mejor, y que si sola andamos trabajosamente un largo trecho ya del camino, y con vosotras, y con todas las mujeres de Bolivia, forjaremos un provenir más justo para todas las generaciones venideras, teniendo por lema: abnegación y perseverancia.

Volved y decid a nuestras hermanas que la mujer orureña, no es una indiferente, no una cobarde y que su alma grande, abriga el mismo anhelo que vosotras. Que trabajará, que luchará, para un día triunfar y seguir una senda más igualitaria, más conciente y más noble. Y viviendo en el Arte, en el deber y el patriotismo Bolivia, será poderosa.

En vos deposito ante el Ateneo Femenino de La Paz, estas flores, sencillos lazos que significarán, una sola alma, entre la mujer boliviana. » Eco Femenino ${ }^{\circ} 4$, janvier 1924, La Paz. Hemeroteca de la Universidad Mayor de San Andrés, La Paz - Bolivie.
} 
Villa de La Tapia (voir annexe $\mathrm{A} \mathrm{n}^{\circ} 18$ ) qui se trouvait présente à l'événement ${ }^{63}$. En outre, les associées du «Centro Artístico e Intelectual de Señoritas de Oruro » envoyèrent une carte de salutations aux membres de l'«Ateneo Femenino » (voir annexe $\left.\mathrm{C} \mathrm{n}^{\circ} 6\right)$.

L' «Ateneo Femenino » envoya des représentantes dans d'autres villes du pays telles que Sucre, Cochabamba, et Potosí, dans le but de former d'autres «Ateneos » autonomes par rapport à celui de La Paz. On sait que cet objectif fut réalisé uniquement dans la ville de Cochabamba où un «Ateneo» fut formé ${ }^{64}$. Malheureusement, on n'a pas d'autres informations sur ce centre.

La tentative de créer un véritable réseau national féministe se développa avec l'existence des membres correspondants de l'«Ateneo Femenino» dans d'autres villes de la Bolivie. Comme on l'a vu, ces membres devaient faire la publicité de l'organisation et de ses publications, ainsi que mettre celle-ci en contact avec les sociétés féminines des villes où ils se trouvaient. En juin 1924, 1'«Ateneo Femenino » possédait des correspondantes uniquement dans deux villes du pays : Ana Rosa Tornero (voir annexe $\mathrm{A} \mathrm{n}^{\circ} 7$ ) à Cochabamba et María v. de Estivarez à Oruro ${ }^{65}$. Quelques mois plus tard, en septembre 1924, l'«Ateneo Femenino» avait 5 correspondantes : Carmen Sánchez Bustamante (voir annexe A n¹4) en Europe, Ana Rosa Tornero (voir annexe $\mathrm{A} \mathrm{n}^{\circ}$ ) ) à Cochabamba, María v. de Estivarez à Oruro, Josefina Goitia à Sucre et Laura Córdova (voir annexe $\mathrm{A} \mathrm{n}^{\circ} 25$ ) à Potosí. Carmen Sánchez Bustamante, la sœur de María Luisa Sánchez Bustamante, était partie en voyage en Europe avec l'objectif de mettre en contact l'organisation avec les groupes féminins et féministes d'Europe. Un « thé littéraire » fut organisé à l'occasion de son départ, le 5 avril 1924. Eco Femenino rapporte l'événement ainsi :

« Le 5 avril dernier l'« Ateneo Femenino » offrit un thé littéraire à ses membres, mesdemoiselles, Sánchez Bustamante, en raison de leur voyage en Europe (...)

Mademoiselle Carmen S. Bustamante reçut la nomination de membre correspondant de l'«Ateneo Femenino » et la mission d'établir des

\footnotetext{
${ }^{63}$ La Patria, 11 novembre 1923, Oruro. Tiré de Eco Femenino nº 4, janvier 1924, La Paz. Hemeroteca de la Universidad Mayor de San Andrés, La Paz - Bolivie.

${ }^{64}$ Eco Femenino n4, janvier 1924, La Paz. Hemeroteca de la Universidad Mayor de San Andrés, La $\mathrm{Paz}$ - Bolivie.

${ }^{65}$ Eco Femenino n ${ }^{\circ}$, juin 1924, La Paz. Hemeroteca de la Universidad Mayor de San Andrés, La Paz

- Bolivie.
} 
communications entre la dite institution et les groupes féminins d'Europe. ${ }^{66}{ }^{66}$

Les objectifs et le message que devaient être portés par Carmen aux femmes d'Europe furent exprimés ainsi dans le discours d'Emma Perez del Castillo de Carvajal (voir annexe $\left.\mathrm{A} \mathrm{n}^{\circ} 19\right)$ :

« Et au delà des mers, en brisant le fil de vos rêves souvenez-vous que vous êtes correspondante de l'«Ateneo». Communiquez-nous les impressions d'art et de beauté dans lesquelles sera trempée votre âme, mais surtout parlez-nous de l'idéal, de la culture et de la libération de la Femme. Étudiez ses nouvelles orientations pour que, lorsque vous serez de retour du voyage, vienne avec vous un abondant contingent d'idées bonnes et nouvelles qui nous servent de guide dans le noble sentier que nous avons tracé.

Dites à nos sœurs du vieux continent, qu'ici aussi la femme est en train de se réveiller au balbutiement de la doctrine féministe et dites leurs au nom de cette Maison culturelle, dites leur, je répète, que la femme bolivienne regarde très haut et très loin, car à force de contempler nos cimes argentées intouchées et l'horizon bleu de nos pampas sans fin, sa rétine et son âme se sont habituées à la pureté des neiges et à la liberté infinie; mais faites quelque chose de pratique également: demandez leur aide pour la réussite de notre plus grand idéal : la MER. » ${ }^{67}$

Ce discours laisse entrevoir la volonté de suivre l'exemple du féminisme européen dont les idées serviraient de «guide» au travail entrepris par les féministes en Bolivie. Le féminisme européen apparaît donc comme un modèle à suivre et il y a là une volonté de connaître en détail les idées féministes des femmes en Europe pour enrichir l'idéologie féministe que les Boliviennes étaient en train de construire. De même, il est intéressant de voir que les féministes boliviennes voyaient dans les

\footnotetext{
${ }^{66}$ «El 5 de abril pasado el Ateneo Femenino ofreció un té literario a sus consocias señoritas Sánchez Bustamante con motivo de su viaje a Europa (...) La señorita Carmen S. Bustamante recibió el nombramiento de socia corresponsal del Ateneo y la misión de establecer comunicación entre dicha institución y las agrupaciones femeninas de Europa.» Eco Femenino n7, juin 1924, La Paz. Hemeroteca de la Universidad Mayor de San Andrés, La Paz - Bolivie.

${ }^{67}$ «Y allende los mares, rompiendo el hilo de vuestros ensueños acordaos que sois Corresponsal del Ateneo. Comunicadnos las impresiones de arte y belleza en que se halle empapada vuestra alma, pero sobretodo habladnos del ideal, la cultura y liberación de la Mujer. Estudiad sus nuevas orientaciones para que al retornar del viaje venga con vos un abundante contingente de ideas buenas y nuevas que nos sirvan de guía en el noble sendero que nos hemos trazado.

Decid a nuestras hermanas del continente viejo, que aquí también la mujer está despertando al balbuceo de la doctrina feminista y decidles más en nombre de esta Casa cultural, decidles, repito, que la mujer boliviana mira muy alto y muy lejos, porque a fuerza de contemplar nuestras plateadas cimas intocadas y el horizonte azul de nuestras pampas sin fin, se han habituado su retina y alma a la pureza de las nieves y a la libertad infinita; pero haced algo práctico igualmente: pedidles su ayuda a la consecución de nuestro magno ideal: el MAR. » Eco Femenino n7, juin 1924, La Paz. Hemeroteca de la Universidad Mayor de San Andrés, La Paz - Bolivie.
} 
groupes féminins d'Europe un potentiel soutien international pour résoudre le problème du littoral perdu contre le Chili lors de la Guerre du Pacifique (1879-1883). En effet, elles tenaient comme un des objectifs essentiels de leur mouvement «le progrès de la Patrie », et c'est dans ce sens qu'elles considéraient que les femmes devaient être éduquées et devaient pouvoir participer en politique, puisqu'elles contribueraient de manière essentielle « au progrès de la Patrie », comme on le verra plus tard. Récupérer la mer était le premier pas dans ce sens pour les femmes et la société de l'époque (et même encore pour la société d'aujourd'hui).

En mai 1925, l'«Ateneo Femenino » avait étendu les réseaux féministes dans d'autres pays de l'Amérique du Sud, puisqu'il avait désormais 7 correspondantes dans différentes villes du pays mais aussi dans les pays voisins: María Lía Suárez en Argentine (elle était venue à La Paz en mai 1925 en tant que déléguée du « Consejo Nacional de Mujeres de la Argentina» et nommée hôte honoraire de l'«Ateneo Femenino »), Lidia Cárdenas à Lima - Pérou, María Teresa Urquidi R. (voir annexe A n ${ }^{\circ}$ ) à Cochabamba, María v. de Estivarez à Oruro, Josefina Goitia à Sucre, Laura Córdova (voir annexe $\mathrm{A} \mathrm{n}^{\circ} 25$ ) à Potosí et María Vaca Diez à Santa $\mathrm{Cruz}^{68}$. Un mois plus tard, en juillet 1925 les réseaux s'étaient étendus à l'Italie avec Blanca Gismondi comme correspondante, et Ana Rosa Tornero joignit María Lía Suárez en tant que correspondante à Buenos Aires ${ }^{69}$.

En mars 1927, 1'«Ateneo Femenino » se fédéra au Conseil International de Femmes («International Council of Women ») fondé en 1888 à Washington :

«Étant donné que la fédération de 1'«Ateneo Femenino » au Conseil International de Femmes a été décidée en session spéciale en mars de cette année, l'on croit convenable faire connaître les conclusions du Congrès International Féminin, célébré à Génève du 7 au 11 juin dernier.

Étant donné les nombreuses communications reçues, demandant notre fédération, et les intéressantes publications envoyées, 1'“ATENEO FEMENINO" accueillit enthousiaste son union au Conseil International de Femmes; en plus, il décida d'élargir son programme de travail pour offrir plus de coopération sociale, tout ce qui a été opportunément communiqué à la présidente du conseil cité, Lady Aberdeen et Temair, qui en communication du 18 juillet dernier,

\footnotetext{
${ }^{68}$ Eco Femenino n`13, mai 1925, La Paz. Hemeroteca de la Universidad Mayor de San Andrés, La Paz - Bolivie.

${ }^{69}$ Eco Femenino n ${ }^{\circ} 14$, juillet 1925, La Paz. Hemeroteca de la Universidad Mayor de San Andrés, La $\mathrm{Paz}$ - Bolivie.
} 
encourage les membres de 1"“ATENEO FEMENINO" de La Paz à arriver bientôt à une étroite harmonie d'activités. ${ }^{70}$

Cette union au Conseil International de Femmes signifia un pas important de l'intégration de l'«Ateneo Femenino» au mouvement féministe international. L' « Ateneo » non seulement créait des réseaux autour de lui dans les autres villes de la Bolivie et dans d'autres pays du monde, mais il s'intégrait aussi aux réseaux féministes internationaux. En intégrant le mouvement féministe de la Bolivie au mouvement féministe international, l'«Ateneo » le dota de plus de solidité et de légitimité tant à l'intérieur qu'à l'extérieur du pays. Grâce à cette union, d'autres membres correspondants furent nommés en Europe en 1927, tels que Luisa van Eeghen aux Pays Bas, qui travaillait au sein du Conseil International de Femmes et visita la Bolivie en 1928.

En outre, une nouvelle correspondante fut nommée en Amérique Latine : Esther N. de Calvo au Panamá.

En Bolivie d'autres correspondantes furent nommées dans les différentes villes du pays : Eduviges v. de Hertzog (voir annexe $\mathrm{A} \mathrm{n}^{\circ} 15$ ) à Oruro, María Isaura Guzmán à Potosí, Leonor de Ugarte à Cochabamba et Carmen Sánchez Bustamante (voir annexe $\left.\mathrm{A} \mathrm{n}{ }^{\circ} 14\right)$ à Buenos Aires. Les nominations de toutes les autres correspondantes furent ratifiées $^{71}$.

En outre, en octobre 1927 l'«Ateneo Femenino »se fédéra au Conseil National de Femmes Argentines :

«Le 22 septembre la Présidente de l'institution, reçut une communication du Conseil National de Femmes Argentines, demandant la fédération de l' "Ateneo Femenino » pour unir avec des liens solides le travail féminin et féministe des femmes latinoaméricaines. La communication fut soumise à l'Assemblée du 17

\footnotetext{
${ }^{70}$ «Como en sesión especial llevada a cabo en marzo del presente año, se resolvió la federación del ATENEO FEMENINO de La Paz al Consejo Internacional de Mujeres, creemos muy oportuno dar a conocer algunas conclusiones del Congreso Internacional Femenino, celebrado en Ginebra del 7 al 11 de junio próximo pasado.

En vista de numerosas comunicaciones recibidas, pidiendo nuestra federación y de interesantes publicaciones enviadas, el ATENEO FEMENINO, acogió entusiasta su unión al Consejo Internacional de Mujeres; además resolvió ampliar su programa de trabajo para ofrecer mayor cooperación social, todo lo que fue oportunamente comunicado a la presidenta del citado Consejo, Lady Aberdeen y Temair, quién en comunicación del 18 de Julio pasado, anima a las socias del ATENEO FEMENINO de La Paz, para llegar pronto a una estrecha armonía de actividades. » Indice, nº 1 , décembre 1927, La Paz. Centro de Informaciôn y Desarrollo de la Mujer (CIDEM), La Paz - Bolivie.

${ }^{71}$ Indice, ${ }^{\circ} 1$, décembre 1927, La Paz. Centro de Informaciôn y Desarrollo de la Mujer (CIDEM), La $\mathrm{Paz}-$ Bolivie.
} 
octobre dernier, ayant été décidé d'accepter une si honorable et importante coopération. $)^{72}$

Cette fédération fut de même un pas très important de l'intégration du mouvement féministe bolivien au mouvement féministe latino-américain de l'époque. Avec une union si importante, et la présence de correspondantes dans différents pays de l'Amérique Latine tels que l'Argentine, le Pérou, et le Panamá, l'«Ateneo Femenino » avait créé et s'était intégré solidement à des réseaux féministes latinoaméricains.

La volonté et les propositions pour la création de réseaux et de liens de coopération avec l'« Ateneo Femenino » s'annonçaient ainsi dans la revue Indice :

«On souhaite avoir dans toutes les villes importantes des correspondantes femmes qui se dédient à n'importe quelle activité sociale ou professionnelle. Envoyez-nous votre portrait et renseignements pour que votre carnet de correspondante de INDICE vous soit expédié.

On est prêts à entamer des relations et à réaliser des pactes d'amitié avec toutes les sociétés du monde qui aient un programme similaire au notre.

Nous fournissons des renseignements sur la Bolivie en matière administrative, politique, pédagogique, bibliographique, etc., à qui le sollicite et nous sommes engagées à aider les étrangers pour connaître notre pays et leur servir de guide dans les voyages qu'ils réalisent dans le territoire bolivien.

Nous pouvons nous charger de l'envoi de livres nationaux et de l'échange de publications au bénéfice de la bibliothèque publique de 1 ' "Ateneo Femenino". " ${ }^{73}$

Au début de 1928, les réseaux féministes et féminins de l' «Ateneo » s'élargirent davantage permettant des liens de collaboration et d'échange avec

\footnotetext{
72 «Con fecha 22 de Septiembre recibió la Presidenta de la institución, un oficio del Consejo Nacional de Mujeres Argentinas, pidiendo la federación del Ateneo Femenino para unir con sólidos lazos la labor femenina y feminista de las mujeres latino-americanas. La comunicación fue sometida a la asamblea del 17 de Octubre último, habiéndose resuelto aceptar tan honrosa como importante cooperación. » Indice, ${ }^{\circ} 1$, décembre 1927, La Paz. Centro de Informaciôn y Desarrollo de la Mujer (CIDEM), La Paz - Bolivie.

73 « Deseamos en todas las ciudades importantes, corresponsales mujeres que se dediquen a cualquier actividad social o profesional. Mándenos su retrato y datos para remitirle el carnet de corresponsal de INDICE.

Estamos dispuestos a entablar relaciones y a realizar pactos amistosos con todas las sociedades del mundo que tengan programa de trabajo similar al nuestro.

Subministramos datos sobre Bolivia en materia administrativa, política, pedagógica, bibliográfica etc., a quien lo solicite y estamos empeñadas en ayudar a los extranjeros a conocer nuestro país y servirles de guía en viajes que realicen en territorio boliviano.

Podemos encargarnos del envío de libros nacionales y de canje de publicaciones en beneficio de la biblioteca pública del Ateneo Femenino. » Indice, n¹, décembre 1927, La Paz. Centro de Informaciôn y Desarrollo de la Mujer (CIDEM), La Paz - Bolivie.
} 
d'organisations de type divers. En plus des membres correspondants que l' « Ateneo » avait dans les principales villes du pays, des correspondants se trouvaient dans des villes plus petites. Ainsi, Sara Baldivieso à Tupiza, María Baldivieso à Chulumani (Yungas) et Raquel Lucuy à Tarija. En ce qui concerne les pays voisins de nouvelles correspondantes apparurent telles que Octavia Alaje à Camargo (Chili) et Zoila Rosa Cárdenas à Lima - Pérou. Toutes ces femmes furent nommées agents de la revue Indice.

Celle-ci fut en outre distribuée au sein des associations féminines qui, au début de 1928, entretenaient de liens d'amitié ou étaient fédérées à l' «Ateneo Femenino »: «Sociedad Protectora de la Infancia » de La Paz, Société de Bienfaisance des Dames de La Paz, Conseil International de Femmes (fixé à Londres), Bureaux de Bibliographie, d'Émigration, Conseil National de Femmes de la République d'Argentine, Revue féminine Nosotras à Caracas - Venezuela, Conseil National de Femmes du Pérou, Société Interalliée de Femmes du Panamá, Société de dames de Lima "Entre nous" ("Sociedad de damas limeñas "Entre nous"”), «Ateneo Femenino » de Cochabamba. En plus, la revue Indice fut envoyée aux associations féministes fédérées et non fédérées au Conseil International de Femmes, qui représentaient 45 sociétés de tous les continents; elle fut également envoyée à toutes les correspondantes du pays, aux rédactions de la presse et aux amis intellectuels de la société qui avaient donné des livres pour la Bibliothèque Publique.

L' «Ateneo Femenino » avait créé ainsi des réseaux non seulement avec des associations féministes du pays, de l'Amérique Latine et du monde entier, mais aussi avec d'autres types de sociétés féminines. La revue Indice bénéficiait de cette manière d'une très large distribution au sein de toutes ces institutions qui maintenaient de liens de coopération et d'échange avec l'«Ateneo Femenino ». A ce titre, par exemple la revue vénézuélienne Nosotras était distribuée au sein de l’ Ateneo Femenino » ${ }^{74}$.

De par sa solidité et sa durée de vie, l' «Ateneo Femenino» fut la société féministe la plus active et dynamique de toutes et la seule à créer un véritable réseau féministe dans le pays, et à l'intégrer aux réseaux internationaux féministes latinoaméricains et mondiaux.

\footnotetext{
${ }^{74}$ Indice n², janvier 1928, La Paz. Centro de Informaciôn y Desarrollo de la Mujer (CIDEM), La Paz - Bolivie.
} 
Le développement de l'éducation des femmes au début du $\mathrm{XX}^{\mathrm{e}}$ siècle permit l'apparition de plusieurs générations de femmes éduquées et cultivées des classes moyennes et élevées de la société qui s'organisèrent d'abord pour partager leurs expressions artistiques et culturelles dans des associations féminines qu'elles créèrent entre amies pour s'entretenir et se cultiver. Ce fut le cas du «Centro Artístico e Intelectual de Señoritas de Oruro » qui devenait plus formel au fur et à mesure que ces femmes prenaient conscience du rôle qu'elles pouvaient et devaient jouer dans la société en raison de leur éducation. S'éduquer était donc une première étape vers l'émancipation des femmes, ce qui était accompagnée de devoirs envers la société et envers la patrie. Les femmes, une fois éduquées devaient contribuer au « progrès de la patrie » d'abord à travers l'éducation des enfants pour les convertir en bons citoyens, et ensuite à travers l'action sociale (charité, enseignement, etc.) dans le cadre des rôles qui étaient naturellement dévolus aux femmes. Pour ce faire, les femmes devaient obtenir les droits civils et politiques qui leur permettraient de jouer un rôle important dans la société et dans le pays. Cette prise de conscience prit place dans d'autres villes du pays où se développèrent plusieurs associations féministes qui prirent comme modèle le Centre d'Oruro et sa revue Feminiflor. La plus importante de ces organisations fut l'«Ateneo Femenino» de La Paz, en raison de son dynamisme et de sa durabilité, les autres organisations ayant eu une courte durée de vie.

En vue d'atteindre leurs objectifs, les organisations féministes des années 1920 développèrent des stratégies d'action leur permettant sinon de faire pression sur les hommes politiques, au moins de faire connaître leurs demandes par la société et la sphère politique. Comme on le verra, les actions de ces femmes avaient place dans un cadre complètement légal et pacifique: elles publiaient des revues féminines féministes afin de faire connaître leurs demandes et projets, elles participaient à des Congrès de femmes internationaux et organisaient des Congrès dans le pays en même temps qu'elles établissaient des réseaux avec les féministes de l'étranger, elles proposaient des projets de lois pour réformer le Code Civil et elles avaient des projets sociaux. Elles ne sortaient pas dans la rue ni réalisaient des actes violents ou spectaculaires comme les «suffragettes» anglaises, desquelles elles voulaient absolument se démarquer afin de donner une définition propre de leur type de féminisme. 


\section{C) Leurs actions}

\section{a) Journalisme au féminin}

La première et principale activité des associations féministes des années 1920 fut la publication de revues féminines - féministes qui leur servaient de porte-parole pour faire connaître non seulement leurs expressions artistiques et intellectuelles à travers la publication de poèmes, de contes, d'essais historiques, etc., mais aussi leurs idées en relation à divers thèmes concernant la condition des femmes : leur éducation, le rôle qu'elles devaient jouer dans la société et dans le pays, l'obtention de ses droits civils et politiques, le féminisme en Bolivie et ailleurs, le travail des femmes, etc. Ces revues étaient donc un moyen de s'exprimer et de faire connaître à la société leurs inquiétudes et leurs demandes en tant que femmes qui avaient pris conscience de la place qu'elles devaient avoir dans la société et dans le pays. Par la rédaction, édition et publication de ces revues ces femmes accédaient à un domaine qui leur avait été interdit auparavant: le journalisme.

Les premières publications destinées aux femmes en Bolivie surgirent dans la deuxième moitié du $\mathrm{XIX}^{\mathrm{e}}$ siècle. La première d'entre elles fut Mistura para el bello sexo, apparue à Sucre en 1873, destinée aux "femmes de la classe cultivée », à savoir, au nombre réduit des femmes des classes élevées de l'époque qui savaient lire et écrire. L'autre publication de ce type apparue à la même époque, fut $E l$ Jardincito de María, qui devint plus tard El Semanario Católico, publiée par les prêtres Bernardo González et V. Roqui, et dirigée par Modesta Sanjinés (voir annexe A n²6) de 1874 à 1876. Ces publications étaient cependant dirigées ou rédigées par des hommes. Il fallut attendre la fin du XIX ${ }^{\mathrm{e}}$ siècle pour que des revues destinées aux femmes et dirigées par elles apparaissent. La première de ces revues fut El Album, apparue à Sucre en 1889. Elle fut dirigée par Carolina Jaimes Freyre (voir annexe A $\mathrm{n}^{\circ} 27$ ), mère du poète bolivien Ricardo Jaimes Freyre. Il s'agissait d'une revue destinée aux femmes des classes élevées de la société de Sucre de l'époque. Ce fut la première revue féminine à traiter de la nécessité d'améliorer l'éducation des femmes dans le pays et participa aux débats intellectuels de l'époque sur ce sujet. Une autre revue de ce type, fut $L a$ Rosa en circulation à Cochabamba entre 1895 et 1897.

Ces revues furent les premières revues féminines à être dirigées par des femmes et destinées aux femmes; elles furent ainsi les prédécesseurs des revues féminines - 
féministes qui surgirent dans les années 1920 dans le cadre de l'émergence du mouvement féministe.

\section{Feminiflor}

\section{La publication}

La première de ces revues fut Feminiflor (voir annexe $\mathrm{C} \mathrm{n}^{\circ}$ ) du « Centro Artístico e Intelectual de Señoritas de Oruro », publiée à partir de 1921. Comme on l'a vu auparavant, cette revue fut le moyen par lequel les membres de cette association féminine commencèrent à exprimer leur prise de conscience selon laquelle les femmes devaient jouer un rôle primordial dans la société et par conséquent dans le pays. Toutes leurs réflexions sur la condition et la situation des femmes boliviennes furent exprimées dans cette revue. Ainsi s'en souvient sa rédactrice en chef Bethsabé Salmón Fariñas (voir annexe A nº4) de Beltrán:

«Feminiflor surgit au sein du «Centro Artístico e Intelectual de Señoritas de Oruro » qui fut fondé à Oruro aux environs de 1921 par l'initiative de Laura de La Rosa, admirable amie. Les membres de cette organisation, nous sentîmes la nécessité de compter sur un véhicule de presse propre pour divulguer nos inquiétudes civiques et culturelles pour lutter pour la cause de la femme. Et, sans aucune expérience et sans beaucoup de prolégomènes, nous nous mîmes à écrire et à publier.

On était une coopérative animée de gamines. Chacune faisait ce qu'elle pouvait. Souligner des informations d'importance pour les femmes. Choisir des vers. Applaudir certaines mesures. Commenter des problèmes et proposer des solutions. Critiquer ce qui nous paraissait indésirable. Donner place aussi aux distractions et à la bonne humeur. Fournir des renseignements utiles pour la vie de la maison. Et, bien sûr, mendier des avertissements et inventer des concours pour attirer le public. On travailla beaucoup, mais on s'amusa encore plus avec les efforts de notre jeunesse et de notre aventure. ${ }^{75}$

\footnotetext{
75 «Feminiflor surgió en el seno del Centro Artístico e Intelectual de Señoritas que la iniciativa de Laura de La Rosa, admirable amiga, fundó en Oruro allá por 1921. Sentimos las socias la necesidad de contar con un vehículo de prensa propio para divulgar nuestras inquietudes cívicas y culturales y para luchar por la causa de la mujer. Y, sin ninguna experiencia ni muchos prolegómenos, nos echamos a escribir y a publicar.

Era una bulliciosa cooperativa de chiquillas. Cada una hizo lo que pudo. Destacar noticias de importancia para las mujeres. Escoger versos. Aplaudir ciertas medidas. Comentar problemas, proponer soluciones. Criticar lo que nos parecía indeseable. Dar paso también al entretenimiento y al buen humor. Brindar datos útiles para la vida del hogar. Y, por supuesto, mendigar avisos e inventar concursos para atraer al público. Trabajamos mucho pero disfrutamos todavía mucho más en los afanes de nuestra juventud y aventura. » Discours de Bethsabé Salmón Fariñas de Beltrán lors de l'hommage rendu aux fondatrices de Feminiflor par le Cercle de Femmes Journalistes de La Paz en 1977, et publié dans BELTRAN Luis Ramiro (comp.), "Feminiflor" Un hito en el periodismo femenino de Bolivia", CIMCA, Círculo de Mujeres Periodistas, CIDEM, (n.d.).
} 
Le premier numéro de la revue fut publié en mai 1921 autour d'une ambiance d'enthousiasme au sein des femmes qui voyaient le produit de leurs efforts et réflexions voir la lumière du jour pour la première fois. L'enthousiasme de cette journée perdura chez Bethsabé Salmón (voir annexe A nº ${ }^{4}$ ) qui se souvenait de cet évènement ainsi :

«Plus d'un demi-siècle est déjà passé depuis lors, mais je me souviens encore vivement de ce matin ensoleillé et joyeux dans lequel sortit notre premier numéro. Nous arrivâmes comme des abeilles pour nous poser sur les meubles de l'imprimerie Teller, en contemplant remplies de joie comment nos articles passaient du papier à une forme tangible. Tâchées de noir et impatientes mais pleines de joie, nous fêtâmes et nous allions donner l'édition aux crieurs de journaux, lorsque nos copains et petits amis envahirent l'atelier. Habillés avec des vestes obscures et des pantalons clairs, ils nous surprirent en s'offrant comme des vendeurs de la revue. Ils se lancèrent dans les rues de ce Oruro doré en criant : "Feminiflor ! Feminiflor d'aujourd'hui !"

La ville s'étonna de voir les jeunes garçons de l'élite vendant des revues, et plus encore, de voir de garçons servant de crieurs de journaux pour une revue de femmes. Cependant, par curiosité ou par sympathie, les acheteurs épuisèrent cette première édition en quelques heures, en payant à 20 centimes l'exemplaire. Imaginez-vous notre émotion? ${ }^{76}$

Feminiflor se publiait mensuellement, mais pas de manière complètement régulière puisqu'il y avait quelques mois où la revue n'était pas publiée. Au début, la revue fut financée par les jeunes femmes, membres du Centre Artistique et Intellectuel d'Oruro. Ensuite, elle se maintenait avec la vente des avertissements :

«Au début nous payâmes toutes une petite cotisation. Ensuite celui qui nous maintenait et convertit notre idéal en réalité fut le commerce d'Oruro qui nous reçut avec les bras ouverts ; jamais un avertissement ne manqua. Les avertissements couvraient le prix du journal, parfois nous avons de l'argent en plus. $\gg{ }^{77}$

\footnotetext{
${ }^{76}$ « Ha pasado más de medio siglo desde entonces, pero todavía recuerdo vívidamente aquella mañana de sol y alegría en que salió nuestro primer número. Caímos como abejas sobre los chivaletes de la imprenta Teller, contemplando con alborozo cómo nuestros artículos pasaban del papel a la forma tangible. Tiznadas y ansiosas pero llenas de gozo, festejamos a punto de entregar la edición a los canillitas cuando invadieron el taller amigos y enamorados nuestros. Uniformados con sacos oscuros y pantalones claros, nos sorprendieron brindándose a la revista como suplementeros. Y se lanzaron a las calles de aquel dorado Oruro voceando: “FFeminiflor! ¡Feminiflor de hoy díaaa!”

La ciudad se asombró de ver a los jóvenes "pitucos" vendiendo revistas y, más aún, de ver a varones sirviendo de canillitas a una revista de mujeres. Sin embargo, por curiosidad o por simpatía, los compradores agotaron esa primera edición en pocas horas, pagando a veinte centavos el ejemplar. ¿Se imaginan nuestra emoción?» Idem.

77 «Nos acuotamos al principio todas con pequeñas sumas. Después quien nos mantuvo e hizo que nuestro ideal se volviera realidad fue el comercio de Oruro que nos recibió con los brazos abiertos;
} 
La revue fut publiée pendant trois ans, de 1921 à 1923 ce qui déjà était un temps assez long pour la plupart des revues de l'époque qui avaient le plus souvent des vies éphémères. La revue eut donc un relatif succès qui lui permit d'avoir une durée de vie relativement longue.

D’après les souvenirs de Bethsabé Salmón, 500 exemplaires de la revue étaient tirés au début, et 1.500 au bout de trois ans ${ }^{78}$, ce qui représente un chiffre énorme puisque le tirage le plus élevé à l'époque était de 1000 exemplaires pour le journal El Diario, du parti Libéral fondé en $1904^{79}$. Les chiffres donnés par Bethsabé Salmón doivent donc être nuancés. Dans le meilleurs des cas, il est probable, qu'une centaine d'exemplaires aient été publiés au début, et quelques centaines au bout de trois ans.

\section{Être femme journaliste : critiques et accueil}

D'après les souvenirs des rédactrices de Feminiflor, la revue reçut un accueil favorable de la part du public et de la société en général.

C'est ce qu'affirme Laura Graciela de La Rosa Torres :

«La collaboration, l'accueil que nous offrit le public... On pensait qu'il pourrait y avoir de la collaboration d'un nombre très réduit de personnes, n'est-ce pas ? Mais non, tout le monde contribua à ce qu'on continue, à ce que la femme accède au domaine du journalisme et à d'autres domaines, à ce qu'elle ne soit pas uniquement soumise à ses caprices et aux choses féminines. Beaucoup de personnes comprirent, que sans cesser d'être féminines, on pouvait embrasser d'autres domaines. ${ }^{80}{ }^{8}$

nunca nos hizo fallar un aviso. Los avisos cubrían el importe del periódico, a veces nos sobraba algún dinero. » Témoignage tiré de la transcription d'un entretien vidéo avec Bethsabé Salmón par Eva Urquidi, filmé et édité par Miriam Ernst et Miguel Cusicanqui à Quito - Equateur à la fin des années 1980. La transcription partielle de l'entretien fut réalisée par C. de Vega Magalí et FLORES Bedregal Teresa, et incluse sous le titre de «Con el periodismo en las venas. Testimonio de la jefe de redacción Bethsabé Salmón de Beltrán », dans l'ouvrage de BELTRAN Luis Ramiro (comp.), "Feminiflor" Un hito en el periodismo femenino de Bolivia”, CIMCA, Círculo de Mujeres Periodistas, CIDEM, (n.d.). ${ }^{78}$ Idem.

${ }^{79}$ CRESPO R. Alberto, «El periodismo boliviano de los años 20 », dans BELTRAN Luis Ramiro (comp.), "Feminiflor" Un hito en el periodismo femenino de Bolivia", CIMCA, Círculo de Mujeres Periodistas, CIDEM, (n.d.).

${ }^{80}$ «La colaboración, la acogida que nos brindó el público... Pensábamos que podía haber colaboración de alguno que otro, pero como un anís ¿no? Pero, todo el mundo contribuyó a que siguiéramos adelante, a que la mujer accediera al campo periodístico y a otros campos, a que ella no se someta solamente a sus caprichos y a las cosas femeninas. Muchos comprendieron que, sin dejar de ser femenina, una podía abarcar otros campos. » Entretien réalisé avec Laura Graciela de la Rosa Torres à Cochabamba - Bolivie en 1987 par Sandra Aliaga Bruch, et inclus sous le titre de "Eramos audaces" Testimonio de la Directora Laura G. de La Rosa Torres » dans l'ouvrage de BELTRAN Luis Ramiro 
Le journalisme était, comme l'exprime Laura Graciela de La Rosa, un domaine nouveau pour les femmes. Quelques revues publiées et dirigées par des femmes étaient apparues à la fin du $\mathrm{XIX}^{\mathrm{e}}$ siècle, comme on l'a vu, mais il s'agissait d'un phénomène exceptionnel. Les rédactrices de Feminiflor accédaient ainsi dans un domaine dévolu exclusivement aux hommes, et par conséquent des critiques pouvaient être attendues, surtout en relation à une potentielle «masculinisation » des femmes accédant aux espaces professionnels des hommes. C'est pour se défendre de ce type de critiques que Laura Graciela de La Rosa affirme que «... sans cesser d'être féminines, on pouvait embrasser d'autres domaines ».

Les souvenirs de Bethsabé Salmón sont similaires à ceux de sa collègue quant aux critiques et à l'accueil du public:

«-Est-ce qu'il y eut des réactions adverses envers la revue?

- Quelques unes, très peu de choses. Presque tous la lisaient avec beaucoup de sympathie. Toutes les rédactrices étaient un peu moins âgées que moi, des gamines qui inspiraient de la sympathie, de l'intérêt, et je crois que c'était pour cela que les gens nous aidaient beaucoup avec ce qu'ils pouvaient. ${ }^{81}$

Cependant, lorsqu'on lit les articles qu'elles rédigèrent à cette époque sur son travail en tant que journalistes, on voit qu'elles semblaient moins optimistes à l'époque vis-àvis des critiques et de l'accueil du public, que dans leurs souvenirs plus de 50 ans plus tard. Ainsi, dans le numéro spécial d'anniversaire de deux ans de la revue, Bethsabé Salmón s'exprime ainsi:

« Rares sont ceux qui donnent du mérite, ceux qui comprennent au moins l'intention de notre effort; la plupart sont indifférents ou hostiles à nos buts, mais est-ce que ces esprits intransigeants et myopes savent au moins pourquoi ?... Est-ce qu'on fait du mal à souhaiter pour la femme de notre patrie une amélioration morale et intellectuelle ? Nos tendances ne s'acheminent-elles pas vers un bien être commun,

(comp.), "Feminiflor" Un hito en el periodismo femenino de Bolivia”, CIMCA, Círculo de Mujeres Periodistas, CIDEM, (n.d.).

81 «- Hubo reacciones adversas a la revista?

- Alguna que otra, muy poca cosa. Casi todos la leían con mucha simpatía. Todas las redactoras eran algo menores que yo, chiquillas que inspiraban simpatía, interés, y creo por eso nos ayudaban mucho en lo que podían. » Témoignage tiré de la transcription d'un entretien vidéo avec Bethsabé Salmón par Eva Urquidi, filmé et édité par Miriam Ernst et Miguel Cusicanqui à Quito - Equateur à la fin des années 1980. La transcription partielle de l'entretien fut réalisée par C. de Vega Magalí et FLORES Bedregal Teresa, et incluse sous le titre de «Con el periodismo en las venas. Testimonio de la jefe de redacción Bethsabé Salmón de Beltrán», dans l'ouvrage de BELTRAN Luis Ramiro (comp.), "Feminiflor" Un hito en el periodismo femenino de Bolivia", CIMCA, Círculo de Mujeres Periodistas, CIDEM, (n.d.). 
vers une morale supérieure ? Une femme qui ait gagné en culture et éducation, ne mérite pas à cause de cela, ses parents, époux et enfants ? N'est-il pas bien pour l'homme même, ce progrès ? Et avec tout, on ne s'inquiète pas trop que les masses ne nous comprennent pas, le nombre s'annule en face de la qualité, et l'avis sain et le conseil mûr nous suffisent, ceux que les véritables valeurs intellectuelles veuillent nous donner pour nous redresser lorsque notre sentier sera faux, ou nous donner de la lumière quand elle manquera, avec cet aide, et surtout avec notre foi dont les vœux sont renouvelés aujourd'hui comme on l'a fait hier et comme on le fera dans d'autres jours comme celui-là, nous continuerons à monter la montagne malgré nos détracteurs et peu importent les incrédules. $»^{82}$

Il semble que la revue reçut un certain nombre de critiques n'ayant pas donc eu un accueil aussi favorable comme le laissent imaginer les souvenirs marqués d'optimisme de ces rédactrices. Le fait de voir des jeunes femmes accéder à un champ qui leur avait été interdit auparavant ne pouvait pas aller sans critiques à la fois des journalistes hommes et de la société.

Parmi les critiques à l'encontre de Feminiflor, nous avons connaissance d'une seule de la part d'un homme caché sous le pseudonyme de « Caballero Quijano » qui publia un article dans un journal d'Oruro, El Quijote, soulignant de manière moqueuse les fautes d'orthographe et de grammaire des rédactrices de la revue Feminiflor. Ces dernières s'en défendirent très bien, dans le numéro 16 de la revue, à travers plusieurs articles servant à expliquer les raisons, souvent typographiques de ces erreurs, et à donner des leçons d'orthographe et de grammaire pour montrer qu'elles maîtrisaient très bien la langue espagnole.

\footnotetext{
82 «Pocos, contados son los que dan mérito, los que comprenden la intención al menos de nuestro esfuerzo; los más son indiferentes u hostiles a nuestros propósitos, pero, ¿saben siquiera acaso esos espíritus intransigentes y miopes por qué?... ¿Hacemos mal tal vez en anhelar para la mujer de esta nuestra patria un mejoramiento moral e intelectual? Nuestras tendencias no se encaminan a un bienestar común, a un elevamiento moral superior? Una mujer que haya ganado en cultura y educación, desmerecerá por ello a sus padres, esposos e hijos? No será bien para el hombre mismo este progreso? Y con todo, no nos preocupa demasiado el que las masas nos comprendan, el número se anula ante la calidad y nos basta la opinión sana y el consejo maduro que verdaderos valores intelectuales quieran darnos para enderezar cuando nuestra senda esté errada o darnos luz cuando nos falte ella, con esa ayuda y más que todo con nuestra fe cuyos votos renovamos hoy como lo hicimos ayer y lo haremos en otros días como éste, seguiremos ascendiendo cuesta arriba la montaña pese a nuestros detractores y no importe a los incrédulos. » Feminiflor, n²2, mai 1923, Oruro. Hemeroteca de la Universidad Mayor de San Andrés, La Paz - Bolivie.
} 


\section{Contenu}

La revue avait un format tabloïd au début et demi - tabloïd ensuite, et le numéro de pages augmenta avec le temps ${ }^{83}$. En général la moyenne de pages était une vingtaine, à l'exception de l'édition spéciale pour l'anniversaire de deux ans de la revue, qui comptait 64 pages (Feminiflor $n^{\circ} 22$, mai 1923). La revue se publiait en noir et blanc avec des photographies et des illustrations. La couverture comportait des renseignements sur les responsables de la revue, le numéro et la date.

Comme on l'a déjà signalé antérieurement, la Directrice de la revue était Laura Graciela de La Rosa Torres (voir annexe A n ${ }^{\circ}$ ), la Rédactrice en chef était Bethsabé Salmón Fariñas (voir annexe $\mathrm{A} \mathrm{n}^{\circ} 4$ ) et l'Administratrice était Nelly López Rosse (voir annexe $\mathrm{A} \mathrm{n}^{\circ} 3$ ).

Feminiflor couvrait un champ de sujets assez vaste comme on peut le voir dans le tableau $\mathrm{A}^{84}$ (voir aussi l'annexe $\mathrm{C} \mathrm{n}^{\circ} 8$ pour le sommaire détaillé de chacun des numéros de la revue). En ce qui concerne les thèmes généraux, l'on constate que l'Histoire et la Littérature sont les disciplines sur lesquelles il y avait le plus d'articles, avec 15 et 36 articles respectivement au total, sur 6 exemplaires étudiés. En effet, la revue Feminiflor pouvait être considérée comme une revue littéraire où les membres du Centre Artistique et Intellectuel d'Oruro, ainsi que les écrivains et écrivaines boliviens ou étrangers, parfois célèbres, de l'époque publiaient leurs poèmes, leurs contes, leurs essais littéraires, qui occupaient une place très importante dans le contenu de la revue. Des poèmes de poètes ou poétesses célèbres étaient également choisis et publiés par les rédactrices.

La plupart de ces travaux littéraires étaient fortement influencés par le courant romantique : la nature était toujours évoquée pour exprimer les sentiments et les émotions de l'être humain.

Plusieurs articles d'Histoire étaient également publiés dans la revue, le plus souvent sur des évènements historiques du pays et de son indépendance pour célébrer les jours patriotiques. Une place importante était consacrée aux femmes remarquables de l'Histoire que ce soit en politique ou en littérature. Celles-ci apparaissaient toujours

\footnotetext{
${ }^{83}$ Idem.

${ }^{84}$ Ce tableau concerne tous les numéros disponibles de la revue à l'exception du numéro 7, qui n'a sûrement pas pu être trouvé lorsque le tableau a été réalisé.

Ce tableau nous permettra de faire une brève analyse du contenu thématique de la revue.
} 
comme des modèles à suivre et comme la preuve des réussites auxquelles pouvaient aspirer les femmes.

Presque tous les numéros avaient une «page masculine » où les hommes pouvaient envoyer leurs poèmes, leurs travaux et leurs réflexions sur des sujets divers. Cette page était une référence amusante et quelque peu sarcastique à la «page féminine » qu'avaient la plupart des revues de l'époque, seul espace où les femmes pouvaient s'exprimer. Dans, Feminiflor, revue de femmes et faite par des femmes, la page masculine était le seul espace où les hommes pouvaient s'exprimer.

Des concours étaient organisées «pour attirer le public »d'après Bethsabé Salmón, tels que le concours de «l'homme le plus laid d'Oruro », référence quelque peu sarcastique aux concours de beauté des femmes. Ou encore le concours de «l'homme le plus estimé d'Oruro par ses qualités morales ».

En ce qui concerne le sujet de «la femme», il y a plusieurs thèmes qui ressortent comme on peut le voir dans le tableau A : l'éducation et le féminisme avec 16 et 13 articles qui leur sont respectivement consacrés. L'éducation des femmes est le sujet le plus récurrent dans la revue. Ceci montre la part que ce sujet avait dans les préoccupations et réflexions de ces femmes, premières bénéficiaires $\mathrm{du}$ développement de l'éducation pour les femmes au $\mathrm{XX}^{\mathrm{e}}$ siècle. Elles considéraient que l'éducation pour les femmes devait s'améliorer continuellement et être élargie à d'autres catégories de femmes. L'éducation était la voie première pour l'émancipation de femmes et pour son indépendance. C'était en effet grâce à l'éducation que les femmes avaient pu sortir de la «léthargie» dans laquelle elles se trouvaient et que leurs conditions de vie avaient commencé à changer. Les femmes devaient être éduquées pour être de bonnes épouses et de bonnes mères au sein de leur foyer. Elles devaient être éduquées également pour pouvoir contribuer au « progrès » de la société et de leur pays. Pour cela, elles devaient acquérir les droits civils et politiques. Cette dernière inquiétude explique la récurrence du thème «féminisme ». Les articles sur l'obtention des droits civils ont été inclus dans ce thème, qui est une constante préoccupation chez les rédactrices. Elles s'interrogent sur sa définition, et ce que signifie être féministe afin d'en donner une définition qui leur soit propre. 


\section{Tableau $A^{85}$}

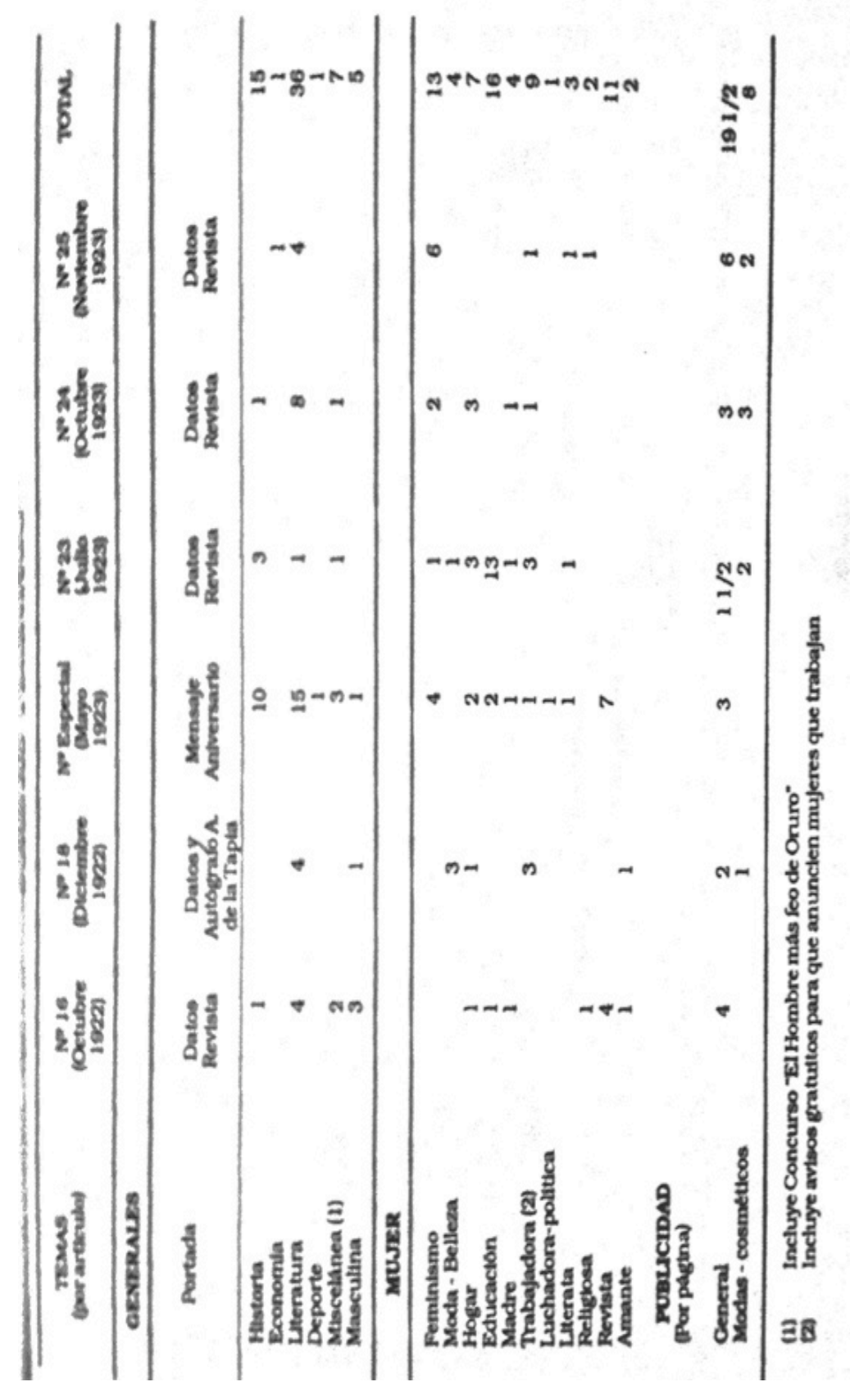

${ }^{85}$ Tableau tiré de CAJÍAS Lupe, “¿Qué escribían ellas? Análisis de contenido.”, dans BELTRAN Luis Ramiro (comp.), "Feminiflor" Un hito en el periodismo femenino de Bolivia", CIMCA, Círculo de Mujeres Periodistas, CIDEM, (n.d.). 
Dans ce sens, elles publient toujours les nouvelles concernant les avances $d u$ féminisme à l'étranger (voir exemple dans annexe $\mathrm{C} \mathrm{n}^{\circ} 9$ ), ainsi que l'apparition de nouvelles associations et revues féministes dans le pays. De même, plusieurs collaborateurs hommes envoient des articles de réflexion sur le féminisme. Il y a donc une continuelle réflexion sur ce thème et sur la nécessité d'obtenir notamment les droits civils : il s'agissait de continuer le progrès déjà entamé avec le développement de l'éducation des femmes et d'adapter les lois aux réalités des femmes du début du $\mathrm{XX}^{\mathrm{e}}$ siècle.

On analysera plus en détail ultérieurement les réflexions sur le féminisme, proposées par les femmes des associations féministes de l'époque afin d'essayer de cerner la définition qu'elles en donnaient pour se proclamer elles mêmes féministes.

Les thèmes du «foyer » et de la « maternité » devraient être mis ensemble puisqu'ils font partie d'un thème plus général qui concerne la famille et qui les inclut tous les deux. Dans ce cas là, le thème de la famille (qui inclut maternité et foyer) serait constitué de 11 articles au total (4+7), ce qui montre qu'il s'agissait d'un thème assez récurrent. La famille était en effet au centre des réflexions des rédactrices sur l'éducation, le féminisme, et l'obtention des droits civils et politiques. Les femmes devaient être éduquées pour être de bonnes épouses, cela impliquait être de bonnes « compagnes » pour les hommes sur le plan intellectuel et sentimental. Les femmes devaient également être éduquées pour être de bonnes mères et pouvoir éduquer de bons futurs citoyens.

La famille était une patrie en échelle plus petite : les progrès dans la famille étaient des progrès dans la patrie. Etant donné que les conditions de vie des femmes avaient changé grâce à leur éducation, les droits qui leurs étaient accordées étaient en décalage avec leur réalité de tous les jours. Les lois devaient être donc réformées afin de leur accorder les droits civils et les droits politiques pour qu'elles puissent contribuer au « progrès » du pays.

Les articles sur la revue occupent un espace important, 11 articles au total. Ils concernent en général des informations sur la revue, sur le Centre Artistique et Intellectuel, les progrès de la revue, etc. Ceci explique le fait que 7 articles lui soient consacrés dans le numéro spécial à l'occasion du deuxième anniversaire de la revue.

Le thème du travail occupe 9 articles au total, dont des pages consacrées aux annonces des femmes travailleuses d'Oruro. En effet, cette page permettait aux femmes d'Oruro qui travaillaient en tant que couturières, fleuristes, modistes de 
chapeaux, etc., de publier leurs annonces gratuitement (voir annexe $\mathrm{C} \mathrm{n}^{\circ} 10$ ). Des articles étaient aussi publiés sur la nécessité des femmes d'avoir une indépendance économique à travers de leur travail. Celle-ci était indispensable à l'émancipation des femmes. De plus en plus de femmes travaillaient: les lois devaient donc être réformées afin qu'elles puissent être capables de disposer du produit de leur travail, mariées ou non. Il est intéressant de noter que Bethsabé Salmón, (voir annexe A n4) avait été une de premières femmes à travailler dans un bureau à Oruro avec Isabel Barrenechea. Il était mal vu pour une femme issue de la classe moyenne ou élevée, de travailler; cela signalait la mauvaise situation économique de la famille. Bethsabé se souvient des critiques qu'elle et sa mère recevaient lorsque elle répond à la question suivante dans un entretien:

« - Est-ce qu'on vous critiqua d'aller travailler dans un bureau ?

- Oui, beaucoup. C'était surtout ma mère qui endurait les critiques ; parfois elle en pleurait, mais moi je lui disais qu'elle ne souffre pas, que j'allais étudier et travailler, que les femmes aussi nous avions le droit; les hommes étudiaient et travaillaient; pourquoi pas nous ? J'étais une rebelle. ${ }^{86}$

Dans ce sens, elle se souvient aussi d'une anecdote concernant le port du chapeau :

«A cette époque là, le luxe pour la femme était le chapeau. Ceux qui avaient un sens de leur estime et dignité, ne pouvaient pas sortir sans chapeau. Mais nous, Isabel et moi, on sortait avec le chapeau dans la main pour dire « j'ai un chapeau mais je ne le mets pas ». C'était une autre révolte, et après nous, toutes les femmes enlevèrent leur chapeau, et à la fin personne n'embêtât plus avec ce détail. " ${ }^{87}$

Les rédactrices de Feminiflor et membres du Centre Artistique et Intellectuel d'Oruro étaient des femmes d'avant-garde (premières bachelières, premières à travailler dans un bureau, premières à enlever leur chapeau, premières femmes

\footnotetext{
${ }^{86}$ « - La criticaron por haber ido a trabajar en una oficina?

- Sí, mucho. Mi madre era la que padecía las críticas; a veces hasta lloraba, pero yo le decía que no sufriera que yo iba a estudiar y a trabajar, que las mujeres también tenemos derecho; los hombres estudian y trabajan; por qué nosotras no? Era una rebelde. » Témoignage tiré de la transcription d'un entretien vidéo avec Bethsabé Salmón par Eva Urquidi, filmé et édité par Miriam Ernst et Miguel Cusicanqui à Quito - Equateur à la fin des années 1980. La transcription partielle de l'entretien fut réalisée par C. de Vega Magalí et FLORES Bedregal Teresa, et incluse sous le titre de «Con el periodismo en las venas. Testimonio de la jefe de redacción Bethsabé Salmón de Beltrán », dans l'ouvrage de BELTRAN Luis Ramiro (comp.), "Feminiflor" Un hito en el periodismo femenino de Bolivia”, CIMCA, Círculo de Mujeres Periodistas, CIDEM, (n.d.).

${ }^{87}$ « En ese tiempo el lujo de la mujer era el sombrero. Nadie que se apreciaba podía salir sin sombrero. Pero nosotras, Isabel y yo, íbamos con el sombrero en la mano, para decir "tengo sombrero pero no me lo pongo". Era otra rebeldía y tras de nosotras todas las mujeres se quitaron el sombrero y al final la gente dejó de molestar con ese detalle. » Idem.
} 
journalistes). Leurs expériences personnelles à cet égard, les avaient poussé à se poser des questions sur leur place dans la société en tant que femmes dans le cadre des changements culturels et sociaux qu'étaient en train de s'opérer dans le pays, tels que le développement de l'éducation des femmes, leur accès progressif au marché $d u$ travail, etc. Le contenu de leur revue reflète ces inquiétudes et réflexions, qui viennent de leurs propres expériences en tant que femmes d'avant-garde, bénéficiaires des premiers progrès et changements concernant les conditions de vie des femmes. C'est en cela que les thèmes de l'éducation, du féminisme, de l'obtention des droits civils et politiques, la famille et le travail, apparaissent comme les sujets prépondérants de leurs réflexions, de leurs inquiétudes, et de leurs revendications. C'est en cela également que la place accordée aux thèmes de la beauté et de la mode est minime, puisque le but principal de la revue était d'exprimer leurs réflexions sur le rôle et la place des femmes dans la société et dans le pays, en même temps que de pouvoir partager leurs créations artistiques et leur goût pour l'art.

Feminiflor insuffla ainsi l'élan pour la création de revues similaires dans le reste du pays.

\section{Aspiración ("Toujours en avant!", Marden) ${ }^{88}$}

La revue Aspiració (voir annexe $\mathrm{C}^{\circ}{ }^{\circ} 11$ ) fut publiée à partir de septembre 1923 à La Paz, par celles qui avaient été les membres de l'association «Centro Ideal Femenino ». Elle eut une durée de vie assez courte puisqu'elle n'atteignit que 5 numéros. La directrice de la revue était Rosa Viscarra Heredia, la Rédactrice en chef était Matilde Carmona Rodo (voir annexe $\mathrm{A} \mathrm{n}^{\circ} 8$ ) et l'Administratrice était Ana Rosa Vázquez (voir annexe $\mathrm{A} \mathrm{n}^{\circ}$ 9). Ces dernières participèrent également à la fondation de 1' «Ateneo Femenino » et en tant que telles collaborèrent comme rédactrices dans la revue Eco Femenino. De même, les rédactrices de cette revue collaboraient avec des articles et des poèmes dans la revue Aspiración. Il y avait donc un échange constant de travaux et d'articles entre les rédactrices de chacune des revues, qui appartenaient aux deux associations.

Tout comme Feminiflor et Eco Femenino, Aspiración était le moyen par lequel celles qui avaient été les membres du «Centro Ideal Femenino » exprimaient leurs idées et

\footnotetext{
${ }^{88}$ « Siempre adelante ! », Marden. Devise de la revue.
} 
réflexions quant à la place que devaient occuper les femmes dans la société et dans le pays. L'idée que les femmes étaient appelées à jouer un rôle primordial dans le progrès de la patrie se laisse entendre dès le premier article intitulé «Pour la Patrie » du premier numéro :

« Nous aimons vraiment la Bolivie et dans cette petite revue vous avez notre première contribution comme la preuve efficace de cela. La Bolivie est le mobile de nos actions et la lumière qui illumine notre idéal de progrès.

Nous souhaitons qu'Aspiración comble nos désirs d'être promotrices de nobles idéaux d'exaltation féminine et nous aspirons à ce qu'elle soit le tiède foyer où se retrouvent les âmes sincères, impatientes de lumière, de beauté et de bonté provenant de toute la République. $\gg{ }^{89}$

L'idée de contribuer au "progrès de la Patrie » apparaissait donc comme l'objectif premier des rédactrices de la revue, qui pour cela voulaient favoriser à tout prix l'amélioration et le développement de la culture des femmes à travers de leur revue :

«En hissant le labarum de tout ce qui signifie altruisme, elles (les rédactrices d'Aspiración) ont dirigé leur pensée vers la réalisation des plus nobles idéaux poursuivis par la femme.

Conséquentes avec ce principe, elles feront tout ce qui sera à portée de leurs mains pour élever sa culture, réveiller ses activités et stimuler là où le courage manque. ${ }^{90}$

C'est dans ce sens que l'on comprend la devise de la revue "Siempre Adelante » («Toujours en avant »).

Les objectifs de la revue ne différaient donc pas des autres revues de ce type qui cherchaient le dépassement culturel, intellectuel, social et politique des femmes pour qu'elles puissent contribuer au « progrès de la patrie ».

La revue était publiée mensuellement. Elle avait un format demi tabloïd. Elle était composée d'une vingtaine de pages pour chaque numéro. Elle était publiée en noir et

\footnotetext{
${ }^{89}$ «Amamos de verdad a Bolivia y en ésta pequeña revista tenéis nuestro modesto concurso como prueba eficiente de ello. Bolivia es el móvil de nuestras acciones y la luz que alumbra nuestro ideal de progreso.

Anhelamos que Aspiración, colme nuestros deseos de ser propulsora de los nobles ideales de enaltecimiento femenino y aspiramos a que sea el tibio nido a donde se reconcentren de toda la República, almas sinceras, ansiosas de luz, de belleza y bondad. » Aspiración, n ${ }^{\circ}$, septembre 1923, La Paz. Centro de Informaciôn y Desarrollo de la Mujer (CIDEM), La Paz - Bolivie.

90 «Al levantar el lábaro de cuanto signifique altruismo, han dirigido su pensamiento hacia la realización de los más nobles ideales que persigue la mujer.

Consecuentes con este principio, harán cuando esté a su alcance por levantar su cultura, despertar sus actividades y estimular allá donde se vea que falte el aliento. »Aspiración, n¹, septembre 1923, La Paz. Centro de Informaciôn y Desarrollo de la Mujer (CIDEM), La Paz - Bolivie.
} 
blanc avec des illustrations et des photographies. Les couvertures portaient toujours des illustrations ou des photographies.

Elle avait 4 sections fixes : "Activités Féminines », « Frivolités », « Cuisine » et « Jardinage » en raison de «l'intérêt que toutes ces sections avaient pour la culture féminine » car d'après les rédactrices :

«La femme d'idéaux supérieurs ne doit pas limiter ses connaissances et croire que sa finalité est réalisée en arborant un diplôme résonnant, non. Elle doit être aussi qualifiée pour utiliser la plume qui cristallise ses sentiments, que pour prendre le balai qui laisse sa maison propre ; pour cuisiner des plats appétissants, que pour pouvoir triompher dans le terrain de tennis; pour cultiver les plantes avec amour que pour discuter consciencieusement sur des affaires transcendantales. Cette complexité d'aspirations sera incarnée dans notre revue. $)^{91}$

La section «Activités Féminines » couvrait un champ assez vaste de sujets tels que «L'art d'être à la maison $»^{92}$, «Le féminisme français - La femme turque » ${ }^{93}$, « La femme et les sports $»^{94}$, etc. Les avances du féminisme à l'étranger, ainsi que le féminisme en soi, étaient des sujets de réflexions important pour les rédactrices. La place de la femme dans la société faisait aussi l'objet de plusieurs articles de la revue, qui traitaient de la Croix Rouge Bolivienne ${ }^{95}$, l'éducation des filles dans les écoles ${ }^{96}$, le progrès des femmes ${ }^{97}$, la nécessité de donner de la confiance aux femmes ${ }^{98}$, etc. La section « Frivolités » traitait comme son titre l'indique de sujets «légers » tels que la mode. La section cuisine était destinée à donner des recettes et des conseils de cuisine, et la section jardinage, des conseils par rapport aux soins de jardins et de

\footnotetext{
91 « La mujer de superiores ideales no debe limitar sus conocimientos y creer que su finalidad está realizada con ostentar un resonante título, no. Debe ser tan capacitada para levantar la pluma que cristalice sus sentimientos, como para coger la escoba que ponga límpida su casa; para guisar apetitosos platos, como para triunfar en la cancha de tenis; para cultivar las plantas con amor como para discutir concienzudamente asuntos trascendentales. Esta complejidad de aspiraciones encarnará nuestra revista. " Aspiración, ${ }^{\circ} 1$, septembre 1923, La Paz. Centro de Informaciôn y Desarrollo de la Mujer (CIDEM), La Paz - Bolivie.

${ }^{92}$ Idem.

${ }^{93}$ Aspiración, n², octobre1923, La Paz. Centro de Informaciôn y Desarrollo de la Mujer (CIDEM), La Paz - Bolivie.

${ }^{94}$ Aspiración, n`3, novembre 1923, La Paz. Centro de Informaciôn y Desarrollo de la Mujer (CIDEM), La Paz - Bolivie.

${ }^{95}$ Aspiración, n`2, octobre1923, La Paz. Centro de Informaciôn y Desarrollo de la Mujer (CIDEM), La Paz - Bolivie.

${ }^{96}$ Aspiración, n5, février 1924, La Paz. Centro de Informaciôn y Desarrollo de la Mujer (CIDEM), La Paz - Bolivie.

${ }^{97}$ Idem.

${ }^{98}$ Idem.
} 
plantes. Aspiración accordait donc beaucoup plus d'importance aux tâches ménagères que les autres revues.

Outre ces sections fixes, la revue accordait un espace très important à la publication de poèmes, contes, essais littéraires, etc. Dans ce sens elle pouvait être également considérée comme une revue littéraire au même titre que Feminiflor. Elle n'avait pas, une page masculine, mais les hommes collaboraient continuellement envoyant des articles, des poèmes, des essais, etc. Des articles courts étaient consacrés à la célébration des fêtes patriotiques de chacune des villes du pays. La section «Galerie Sociale » publiait les photographies et portraits de personnages importants dans la société de l'époque. Parfois, des articles étaient consacrés à la santé et à la puériculture.

A partir de décembre 1923, les seules femmes qui se chargèrent de la revue furent Rosa Viscarra Heredia et Carmela Zalles Iturralde ; Ana Rosa Vázquez laissa la revue en raison de motifs de santé et Matilde Carmona Rodo pour se vouer complètement à ses études. Ces départs expliqueraient peut être que la revue eut une vie aussi éphémère.

L'accueil de la revue semble avoir été assez favorable puisque plusieurs lettres de félicitations d'hommes publics et politiques et de dirigeants de journaux furent publiées dans la revue. La liste des personnes envoyant des félicitations fut également publiée ; celle-ci incluait entre autres: Julia B. de Saavedra, épouse du Président à l'époque ; J. Gabino Villanueva, Ministre d'Instruction et d'Agriculture à l'époque ; Felipe Guzmán, sénateur de La Paz à l'époque, appartenant au Parti Républican (il fut président du pays de septembre 1925 à août 1926) ; José M. Baldivia, directeur de l'Ecole de Beaux Arts; Juan Manuel Balcázar, directeur de la Croix Rouge Bolivienne ; Teodosio Saenz aumônier de l'Armée ; Antonio González B., directeur du Conservatoire National de Musique ; Elena Schmidt (voir annexe A $n^{\circ} 1$ ) directrice du « Liceo de Señoritas » de La Paz (elle avait été la professeure des rédactrices de la revue); María Luisa Sánchez Bustamante (voir annexe A ${ }^{\circ} 10$ ), Présidente de l'«Ateneo Femenino » de La Paz; Cristina Iturralde de Zalles (voir annexe A n ${ }^{\circ} 21$ ); Enrique Baldivieso, homme politique (il fut Vice-Président de la République sous le gouvernement de Germán Busch (1938-1939)); Gregorio Reynolds, un des trois plus grands poètes modernistes de la Bolivie avec Franz Tamayo et Ricardo Jaimes Freyre; Humberto Viscarra, écrivain. Les dirigeants des journaux : La República 
(Journal du Parti Républicain de Saavedra, président du pays à l'époque), «Page féminine » de La República, La Reforma, Nueva Era, El Deber de Corocoro, La Luz d'Arequipa, El Porteño de Mollendo, envoyèrent également des lettres de félicitations.

Parmi ces lettres on peut citer un extrait de celle de Felipe Guzmán, sénateur de La Paz. Cet homme politique semble avoir été un fervent défenseur des droits civils et politiques des femmes:

«La femme ne doit plus être ignorante, la femme qu'elle soit célibataire ou mariée doit jouir de la plénitude de ses droits civils et aller résolument à la conquête des droits politiques; la femme finalement doit envahir le domaine de la propagande écrite, à travers de la presse, pour réclamer les garanties que la société lui doit en raison de sa faiblesse et de son manque de défense.

Elle doit principalement demander la réforme de nos lois qui représentent la plus abominable injustice en mettant sur elle le poids de tous les devoirs et aucun des droits pour retourner pour le respect de sa vie à son honneur et à sa fortune.

C'est à vous qui correspond la gloire de rompre en Bolivie les préjugés cristallisés, en vous lançant dans l'entreprise journalistique qui aura sûrement d'efficaces résultats.

Je veux que cette lettre soit un encouragement pour cette noble tâche, qui sera complètement finie le jour où la femme bolivienne se trouvera, comme la femme anglaise, entourée de garanties de tout genre par la loi et par la société. $\gg{ }^{99}$

Parmi les lettres de la presse on peut citer celle envoyée par La República:

"On a reçu le premier numéro de cette revue féminine, qui nous apporte dans ses pages de très jolis et attrayants articles littéraires et d'information locale, en plus d'un abondant matériel graphique, qui révèle sans aucun doute l'intérêt de la rédaction à présenter une revue qui soit en accord avec notre milieu social. L'acceptation qu'elle aura sûrement dans notre public lecteur et notamment dans le sexe féminin dont les idéaux sont défendus par la revue, en tendant vers leur progrès,

\footnotetext{
99 « La mujer ya no debe ser ignorante, la mujer sea soltera o casada debe gozar de la plenitud de sus derechos civiles e ir resueltamente a la conquista de los derechos políticos; la mujer finalmente debe invadir el campo de la propaganda escrita, mediante la prensa, para reclamar las garantías que la sociedad le debe en orden a su debilidad, a su indefensión.

Principalmente debe pedir la reforma de nuestras leyes que representan la más abominable injusticia al poner sobre ella el peso de todos los deberes y ninguno de los derechos para volver por el respeto a su vida, a su honor y a su fortuna.

A Uds. les corresponde la gloria de romper en Bolivia los prejuicios cristalizados, acometiendo una empresa periodística que seguramente ha de tener eficaces resultados.

Esta carta quiero que sea un estímulo para esa noble tarea, que no podrá ser perfectamente cumplida sino cuando la mujer boliviana se halle, como la mujer inglesa, rodeada de todo género de garantías por la ley y por la sociedad. » Aspiración, n², octobre1923, La Paz. Centro de Informaciôn y Desarrollo de la Mujer (CIDEM), La Paz - Bolivie.
} 
culturel et patriotique, sera une juste rétribution à l'effort de ses rédactrices.

Nos paroles d'encouragement et de félicitations vont au corps de rédaction personnifié par Rosa Viscarra Heredia, Matty Carmona Rodo, et Ana Rosa Vázquez G., et nous espérons que leurs louables enthousiasmes préconisateurs de la marche du féminisme consciente de ses droits et devoirs dans la société ne soient pas déchus. $\gg{ }^{100}$

On voit donc qu'une partie d'hommes politiques, ainsi que quelques hommes et femmes du milieu artistique et culturel du pays, et surtout de la presse répondirent favorablement au surgissement de cette revue malgré le fait que celle-ci eut une vie très courte.

La revue eut aussi des répercussions dans la presse péruvienne. El Comercio de Lima et El Heraldo de Puno louèrent la mission patriotique que s'étaient données les rédactrices de la revue. Ces journaux mentionnèrent surtout l'article rédigé par Ana Rosa Vázquez intitulé "N'oublions pas le littoral”, qui incitait les mères de famille à parler constamment aux enfants des territoires côtiers perdus dans la Guerre du Pacifique (1879-1883) contre le Chili, afin qu'un jour ils soient récupérés par les nouvelles générations. Ces journaux péruviens louèrent les sentiments patriotiques des femmes boliviennes qui contribuaient ainsi au «progrès » de leur patrie. Ils étaient sensibles à la question de la Guerre du Pacifique, puisque le Pérou allié à la Bolivie, fut également vaincu par le Chili et perdit une grande partie de son territoire. Avec El Tropical du Cuzco, ils louèrent également la mission culturelle et intellectuelle que les femmes boliviennes avaient commencée dans leur pays avec la publication de la revue.

Presque en même temps qu'Aspiración surgit la revue représentante de 1' «Ateneo Femenino » avec une durée de vie plus longue et avec des compromis encore plus solides pour l'obtention des droits civils et politiques.

\footnotetext{
100 «Hemos recibido el primer número de esta revista femenina, que nos trae en sus páginas muy bonitos y atrayentes artículos literarios y de información local, a más de abundante material gráfico, que revela a todas luces el interés de la redacción en presentar una revista que esté de acuerdo con nuestro medio social y la aceptación que seguramente tendrá en nuestro público lector y en especial en el sexo femenino cuyos ideales defiende, tendiendo a su mayor adelanto cultural y patriótico, será una justa retribución al esfuerzo de sus redactoras.

Vaya nuestra palabra de aliento y felicitación al cuerpo de redacción personificado por las señoritas Rosa Viscarra Heredia, Matty Carmona Rodo y Ana Rosa Vázquez G., y esperamos no decaigan sus laudables entusiasmos preconizadores de la marcha del feminismo consciente de sus deberes y derechos en la sociedad. » Aspiración, n², octobre1923, La Paz. Centro de Informaciôn y Desarrollo de la Mujer (CIDEM), La Paz - Bolivie.
} 


\section{Eco Femenino (“Aimer le devoir et reconnaître le droit", Montesquieu) ${ }^{101}$}

La revue Eco Femenino (voir annexe C n¹2) fut publiée par 1' «Ateneo Femenino » mensuellement de 1923 à 1925 ; elle eut donc une durée de vie beaucoup plus longue que son homologue Aspiración. La première directrice de la revue fut l'ancienne présidente de l'association « Centro Ideal Femenino », Ana Rosa Tornero (voir annexe $\mathrm{A} \mathrm{n}^{\circ} 7$ ). En juillet 1925, la direction fut prise en charge par María Teresa Solari (voir annexe A n²9) La rédactrice en chef était Carmen Sánchez Bustamante (voir annexe A n¹4), et l'administratrice était Irene Gutierrez V. M. A partir de juin 1924, les tâches d'administration de la revue s'élargirent et se complexifièrent. Désormais, il y avait des personnes chargées du secrétariat, des reportages, de la rédaction, et de la correspondance. A partir de mai 1925 la revue avait une dessinatrice.

La revue atteignit 15 numéros, dont uniquement 7 sont disponibles aujourd'hui. Elle avait un format demi tabloïd. Elle se publiait mensuellement, en noir et blanc, avec des photographies et des illustrations. En moyenne elle avait une vingtaine de pages. Elle se vendait à 30 centimes l'exemplaire; des abonnements pouvaient se faire tant en Bolivie qu'à l'étranger à des prix différents selon la durée de l'abonnement (voir annexe $\mathrm{C} \mathrm{n}^{\circ} 13$ ).

Le contenu de la revue ne différait pas beaucoup des autres revues : un espace très important était accordé à la littérature avec la publication de poèmes, contes, essais littéraires, etc., des membres de l'«Ateneo Femenino », ainsi que d'écrivains et écrivaines, parfois célèbres de l'époque. Les intellectuels et écrivains les plus importants de l'époque, tels que Alcides Arguedas ${ }^{102}$ et Alberto Ostria Gutiérrez

\footnotetext{
${ }^{101}$ «Amar el deber y reconocer el derecho », Montesquieu. Devise de la revue.

${ }^{102}$ Ecrivain et historien, il fut l'un des plus importants intellectuels du début du $\mathrm{XX}^{\mathrm{e}}$ siècle en Bolivie. Homme politique, il remplit plusieurs missions diplomatiques en Europe, et fut également sénateur et député. Il est surtout connu par ses réflexions et travaux sur la condition des indigènes dans le pays. La question de l'intégration des indigènes dans la Nation était l'un des sujets les plus importants et débattus dans la société à cette époque. Alcides Arguedas publia plusieurs ouvrages, dont les plus connus sont Pueblo Enfermo (1909) et Raza de Bronce (1919), dans lesquels il fait une description « psychologique » des indigènes du pays et essaie de démontrer que leur manque d'intégration à la nation, était l'une des causes les plus importantes du retard et sous-développement du pays.
} 
parmi d'autres, collaborèrent dans la revue, avec des essais sur la condition des indigènes du pays ${ }^{103}$.

Des articles historiques et patriotiques étaient également publiés. Des photographies des membres de l'«Ateneo Femenino » étaient très souvent incluses dans la revue.

Les activités de l'«Ateneo Femenino » avaient un espace prépondérant dans la revue où se publiaient les conférences bi-mensuelles organisées par l' «Ateneo », les thèses d'admission des nouvelles membres, les fêtes et soirées organisées par l'association, les discours prononcées par les membres dans diverses occasions, les bilans participation des membres aux Congrès Internationaux de femmes, etc. La revue consacrait de même un espace très important aux avances du féminisme à l'étranger, ainsi qu'aux réflexions sur les définitions de féminisme ailleurs et dans le pays. Des nouvelles sur les autres organisations féministes du pays étaient souvent publiées. La place et le rôle des femmes dans la société faisait l'objet de plusieurs réflexions de la part des membres de 1' "Ateneo ». Celui-ci organisa un concours sur le thème : « Les devoirs de la femme ». Elodia Ballivián de Ligerón (voir annexe A n ${ }^{12}$ ) remporta le premier prix et Casta Muñoz le deuxième prix ${ }^{104}$.

La revue accordait également une place essentielle à la question de l'obtention des droits civils et politiques des femmes avec plusieurs articles sur la question (voir annexe $\left.\mathrm{C} \mathrm{n}^{\circ} 14\right)$. Eco Femenino fut la première revue où apparut une claire et solide détermination de «lutte » pour l'obtention des droits civils et politiques des femmes. Les autres revues montraient cette préoccupation également, mais de manière beaucoup plus prudente et timide: les articles insistaient beaucoup plus sur le développement de l'éducation de femmes, et sur l'obtention des droits civils que sur les droits politiques. Il semblerait que les rédactrices de ces revues considéraient qu'il fallait d'abord une amélioration et un élargissement de l'éducation de femmes et l'obtention des droits civils pour que les droits politiques, dont le droit de vote, leur soient accordés ensuite. La position plus déterminée exprimée dans Eco Femenino, s'explique aussi par le fait que l' « Ateneo Femenino » fut la seule organisation parmi toutes les autres à avoir une durée de vie longue et par conséquent à atteindre un niveau d'organisation beaucoup plus développé. Ce fut la seule association qui

\footnotetext{
${ }^{103}$ Eco Femenino n ${ }^{\circ} 13$, mai 1925, La Paz. Hemeroteca de la Universidad Mayor de San Andrés, La Paz- Bolivie.

${ }^{104}$ Eco Femenino n7, juin 1924, La Paz. Hemeroteca de la Universidad Mayor de San Andrés, La PazBolivie.
} 
prépara un projet de loi pour réformer le Code Civil afin que les droits civils soient accordés aux femmes, et qui organisa le premier Congrès de femmes dans le pays, comme on le verra plus tard.

Eco Femenino cessa d'être publiée en 1925 en raison de problèmes économiques que dut affronter l'« Ateneo Femenino » et qui ne lui permettaient plus d'éditer la revue.

Une autre revue fut donc publiée deux ans plus tard par cette organisation : Indice.

\section{Indice}

La revue Indice (voir annexe $\mathrm{C}^{\circ} 15$ ) fut publiée à partir de décembre 1927 et n'atteignit que 3 numéros, très probablement en raison de problèmes financiers que l'«Ateneo Femenino » n'avait pas pu résoudre. Elle eut donc une vie beaucoup plus éphémère que son prédécesseur.

La directrice de la revue était María Luisa Sánchez Bustamante de Urioste (voir annexe $\mathrm{A} \mathrm{n}^{\circ} 10$ ), l'administratrice était Ana Rosa Vázquez (voir annexe A nº 9 ), et la secrétaire de presse était Marina Montes de Rada.

La revue était publiée mensuellement en format tabloïd, le texte de la revue ayant une couleur bleu clair. Comme on peut le voir dans l'annexe $\mathrm{C} \mathrm{n}^{\circ} 14$, les couvertures étaient très sobres, sans aucune illustration ni photographie. La revue avait en outre, une vingtaine de pages en moyenne.

Le contenu de celle-ci était presque identique à celui de la revue Eco Femenino. Un espace très important était accordé aux activités de 1' «Ateneo Femenino »: informations sur son organisation, activités et travail réalisé par l'association, discours prononcées par les membres à différentes occasions, etc. Une place très importante était également donnée aux avances du féminisme dans le pays et surtout à l'étranger, notamment par le fait que 1' «Ateneo Femenino» avait déjà créé des réseaux féministes dans le pays et s'était intégré à des réseaux féministes internationaux, comme on le verra plus tard. Des articles étaient dans ce sens consacrés au féminisme et à sa signification. Comme dans toutes les autres revues, Indice, consacrait une partie à la publication de poèmes, contes, travaux littéraires, mais l'espace accordé à ceux-ci était plus réduit que dans Eco Femenino et les autres revues. En effet, Indice accordait beaucoup plus d'importance aux activités de l' «Ateneo » et au féminisme (définition, avances à l'étranger) que toutes les autres revues. Ceci pourrait s'expliquer par le fait que 1'«Ateneo Femenino » était une organisation beaucoup 
plus mûre déjà (elle existait depuis presque 4 ans) et par conséquent son positionnement idéologique était beaucoup plus défini qu'auparavant. Les articles d'Eco Femenino, laissent entrevoir des réflexions sur le féminisme et sur les stratégies d'action à entreprendre qui sont encore dans l'état de réflexion et de construction, alors que dans Indice on aperçoit un positionnement beaucoup plus solide et mûr qu'auparavant ainsi qu'une organisation beaucoup plus développée de l'association.

En outre, la revue publiait des articles sur des sujets divers tels que la condition des indigènes $^{105}$, la puériculture ${ }^{106}$, l'art colonial au Pérou ${ }^{107}$, etc., et sur des sujets d'actualité tels que les conflits frontaliers entre la Bolivie et le Paraguay ${ }^{108}$.

La revue avait des agents et des correspondants dans différentes villes du pays, de l'Amérique Latine et d'Europe. Elle était envoyée à tous ces agents et distribuée dans toutes les organisations affiliées à l'« Ateneo Femenino », comme on l'a déjà vu. Elle bénéficiait d'une large distribution, malgré le fait qu'elle eut une durée de vie extrêmement courte. La revue développa un service commercial de vente à travers des stratégies publicitaires. Dans ses pages, sa publicité informait du contenu de la revue et des objectifs de 1' «Ateneo Femenino » en tant qu'organisation féministe au service du développement de la culture, des femmes ainsi que de leurs conditions juridiques et sociales. L'on apprend également que la revue n'avait aucun intérêt commercial et qu'elle ne produisait pas des profits; elle se maintenait donc avec

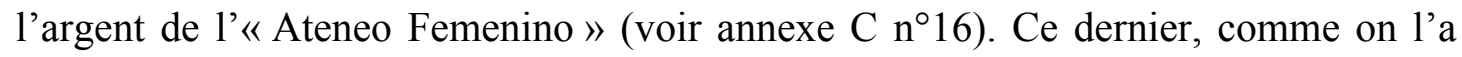
vu, n'était pas dans une très bonne situation financière. Il est donc très probable que la revue cessa d'être publiée par des raisons financières.

D’autres revues féminines - féministes furent publiées dans la décennie 1920 dans les villes du pays, non pas au sein d'associations féministes concrètes, mais par des femmes qui s'organisèrent pour la publication de ces revues et qui d'une manière ou d'une autre s'intégrèrent au mouvement féministe des années 1920 en Bolivie.

\footnotetext{
${ }^{105}$ Indice, $\mathrm{n}^{\circ} 3$, s.d., 1928, La Paz. Collection personnelle de Martha Nardín Rivas.

${ }^{106}$ Indice, ${ }^{\circ} 1$, décembre 1927, La Paz. Centro de Informaciôn y Desarrollo de la Mujer (CIDEM), La Paz - Bolivie.

${ }^{107}$ Indice, n², janvier 1928, La Paz. Centro de Informaciôn y Desarrollo de la Mujer (CIDEM), La Paz - Bolivie.

${ }^{108}$ Indice, ${ }^{\circ} 1$, décembre 1927, La Paz. Centro de Informaciôn y Desarrollo de la Mujer (CIDEM), La Paz - Bolivie.
} 


\section{Venas de Plata ("Plus de lumière !", Goethe) ${ }^{109}$}

La revue Venas de Plata (voir annexe $\mathrm{C} \mathrm{n}^{\circ} 17$ ) fut publiée à Potosí, à partir de février 1924. On ne sait pas combien de numéros furent éditées, mais uniquement les deux premiers sont encore disponibles aujourd'hui.

Elle n'était pas publiée au sein d'une association féministe telle que le «Centro Artístico e Intelectual de Señoritas de Oruro » ou l’ « Ateneo Femenino », mais par de jeunes femmes de la ville de Potosí qui se réunirent et s'organisèrent afin de faire $\mathrm{du}$ journalisme dans cette ville. Il s'agissait de publier une revue qui soit le moyen par lequel elles exprimeraient leurs souhaits de dépassement culturel, social et politique en tant que femmes. La directrice de la revue était Laura Córdova (voir annexe A $\mathrm{n}^{\circ} 25$ ), la rédactrice en chef était Raquel Saavedra N., et l'administratrice était Peregrina Ríos R. Les rédactrices étaient Emma Mendoza M., Fanny Berríos V., Lia Salas L. et Aimée Marie Hardy. La revue comptait en outre avec la collaboration d'une douzaine de femmes.

La revue était publiée mensuellement en noir et blanc. Elle avait un format demi tabloïd. Des photographies de villes du pays étaient parfois incluses. La moyenne de pages était une vingtaine. Le titre de la revue faisait bien évidemment référence au passé historique de la ville de Potosí, qui avait été un des centres miniers d'argent les plus importants de l'Empire Espagnol à l'époque coloniale.

Les objectifs et le contenu de la revue ne différaient pas des autres : il s'agissait de contribuer au développement culturel, social et politique des femmes pour atteindre le "progrès de la patrie ». L'apparition de la revue fut clairement inspirée par le développement du journalisme féminin dans les autres villes du pays avec la publication de revues telles que Feminiflor (Oruro), Iris, Reflejos (Cochabamba), Aspiración, et Eco Femenino (La Paz) :

«Vers la culture féminine

En obéissant à un désir de culture et à une aspiration de perfectionnement, nous faisons aujourd'hui de la publicité à cette feuille imprimée qui porte le sceau de l'effort et de la volonté d'un groupe de jeunes demoiselles qui, en défiant le milieu et l'indifférentisme général, avancent vers la réalisation d'un idéal : la culture féminine.

\footnotetext{
109 « Luz más luz », Goethe. Devise de la revue.
} 
Dans plusieurs centres de la république se sont déjà faits sentir d'impulsions similaires qui ont atteint un relatif succès. L'absolue réalisation de leurs buts requiert ce qu'on appelle persévérance. Avec beaucoup de volonté le travail sera complété.

L'apparition de cette revue n'est pas tardive, elle n'obéit pas à un désir d'imitation, et moins encore à une forme d'exhibitionnisme. Nos tendances vont plus loin de ce que peuvent nous attribuer certains lecteurs : nous désirons l'échange intellectuel, nous voudrions exposer nos idées, si pauvres qu'elles semblent; nous allons vers la culture féminine si négligée hier comme aujourd'hui.

Nous allons aussi rectifier un faux concept, une appréciation erronée lancée contre la femme de Potosí, à qui il semble qu'on qualifie de peu préparée - pour le travail journalistique. ${ }^{110}$

Les dirigeantes de la revue maintenaient des échanges avec les rédactrices des revues des autres villes du pays : des numéros des revues Aspiración, et Eco Femenino leur étaient envoyées ${ }^{111}$.

La revue annonçait des objectifs clairement patriotiques et féministes:

« Nous voulons seulement l'élévation et le progrès de la Bolivie, et pour cela nous nous apprêtons fortes de cœur, avec ces sentiments nobles et purs que la savante nature a donné à la femme.

Nous n'apportons pas une mine de connaissances, seulement un effort propre nous guide vers la conquête d'une place culminante dans le monde civilisé. Notre travail sera un travail d'étude, de persévérance dans le journalisme, en souhaitant que d'autres feuilles surgissent aussi en tant que porte-paroles éloquents des pensées et des sentiments de la femme.

Peuple de Potosí, accueillez notre Revue qui ne poursuit pas l'éloge ni l'applaudissement niais de ceux qui sont rétrogrades dans tous les actes de la vie.

Accueillez-la, même si ce petit ouvrage est dirigé par des jeunes femmes enthousiastes, qui remplies de la plus fervente aspiration, désirent contribuer à la grande date bolivienne, avec un mot de plus qui

\footnotetext{
110 « Hacia la cultura femenina.

Obedeciendo a un deseo de cultura y a un anhelo de perfeccionamiento, damos hoy a la publicidad esta hoja impresa que lleva el sello del esfuerzo y de la voluntad de un grupo de señoritas que, desafiando el ambiente y el indiferentismo general, avanzan hacia la realización de un ideal: la cultura femenina.

Ya en varios centros de la república se han sentido iguales impulsos que han logrado un relativo éxito y cuya absoluta realización de propósitos requiere aquello que llamamos perseverancia. Con mucha voluntad se completará la obra.

No es tardía la aparición de esta Revista, no obedece a un deseo de imitación, menos a una forma de exhibicionismo. Nuestras tendencias van más allá de lo que pueden atribuirnos algunos lectores: deseamos el intercambio intelectual, quisiéramos exponer nuestras ideas, por muy pobres que parezcan; vamos hacia la cultura femenina tan descuidada ayer como hoy.

Vamos también a rectificar un falso concepto, una errónea apreciación lanzada a la mujer potosina a la que parece se la califica de poco preparada - para las faenas periodísticas. »Venas de Plata, $\mathrm{n}^{\circ} 1$, février 1924, Potosí. Archivo Nacional de Bolivia, Sucre - Bolivie.

${ }^{111}$ Venas de Plata, ${ }^{\circ}$ 2, avril, 1924, Potosí. Archivo Nacional de Bolivia, Sucre - Bolivie.
} 
sort d'un de ses départements, pour qu'il soit le bastion du progrès féministe.

Accueillez-la au moins pour nous encourager.

Laura Córdova. $»^{112}$

La « grande date » à laquelle se réfère cet extrait est le Centenaire de l'Indépendance de la Bolivie qui allait être célébré en 1925. En effet, un des objectifs des rédactrices de la revue était que leur ville compte avec une publication féminine qui contribue au progrès des femmes pour la célébration du Centenaire, afin de montrer que Potosí n'était pas en retard par rapport au développement de la culture féminine.

La plus grande partie des articles de la revue concernaient des réflexions sur la condition des femmes dans tous les domaines. Ainsi, l'on trouve des articles tels que "L'idéal que nous poursuivons : l'éducation de la femme ", "Le progrès dans la condition de la femme », «D'où résulte (l'idée de) l'“infériorité" (féminine) ? »113, «La femme dans le $\mathrm{XX}^{\mathrm{e}}$ siècle ${ }^{114}$, etc. Une autre grande partie des articles étaient consacrés à des essais historiques remémorant des dates patriotiques pour le pays. D'autres articles étaient consacrés à des sujets divers d'actualité tels que le développement de l'aviation en Bolivie ${ }^{115}$, la déclaration des droits de l'enfant à Genève $^{116}$, etc. Contrairement aux autres revues, Venas de Plata ne publiait pas des articles littéraires tels que des poèmes, contes, ou essais. Par contre, des citations d'écrivains célèbres étaient incluses dans la revue.

Venas de Plata ne fut pas la seule revue à être publiée hors d'une association féministe, par des femmes qui s'organisèrent afin d'exprimer leurs souhaits et

\footnotetext{
112 «Solo queremos el engrandecimiento y el adelanto de Bolivia, y para esto nos aprestamos fuertes de corazón, con esos sentimientos nobles y puros, que la sabia naturaleza ha dotado a la mujer.

No aportamos un gran caudal de conocimientos, solo un esfuerzo propio nos guía a la conquista de un puesto culminante en el mundo civilizado. Nuestra labor será de estudio, de perseverancia en el periodismo, deseando que surjan también otras hojas como el portavoz elocuente del pensar y sentir de la mujer.

Pueblo potosino, acoged nuestra Revista que no persigue el elogio ni el fatuo aplauso de los que son retrógrados en todos los actos de la vida.

Acogedla, aunque esta pequeña obra fuere dirigida por muchachas entusiastas, que llenas del más ferviente anhelo, desean contribuir a la magna fecha boliviana, con una letra más que sale de uno de sus departamentos, para que sea el baluarte del progreso feminista.

Acogedla siquiera para nuestro estímulo. Laura Córdova. » Idem.

${ }^{113}$ Idem.

${ }^{114}$ Venas de Plata, n², avril, 1924, Potosí. Archivo Nacional de Bolivia, Sucre - Bolivie.

${ }^{115}$ Venas de Plata, ${ }^{\circ} 1$, février 1924, Potosí. Archivo Nacional de Bolivia, Sucre - Bolivie.

${ }^{116}$ Venas de Plata, n², avril, 1924, Potosí. Archivo Nacional de Bolivia, Sucre - Bolivie.
} 
demandes en tant que femmes. On a un autre exemple dans la revue Anhelos de Cochabamba.

\section{Anhelos ("Pour l'élévation morale et culturelle de la femme") ${ }^{117}$}

La revue Anhelos fut publiée à partir du $1^{\text {er }}$ juillet 1929 jusqu'à la fin de l'année 1930. On ne sait pas exactement combien de numéros furent édités, mais on dispose uniquement de 5 aujourd'hui. Ce fut la dernière revue de ce type à être publiée en Bolivie dans les années 1920.

Les directrices de la revue étaient María Quiroga de Montenegro (voir annexe A $\mathrm{n}^{\circ}$ 30) et Mercedes Anaya de Urquidi (voir annexe A n³1).

La revue avait un format demi tabloïd et se publiait en noir et blanc mensuellement (même si pas de manière totalement régulière). Elle avait une quinzaine de pages en moyenne.

Le contenu ne diffère pas des autres revues : les objectifs des rédactrices étaient l'amélioration et développement de l'éducation des femmes pour leur contribution essentielle au « progrès de la patrie ». L'emphase des articles est mise notamment sur l'éducation des femmes qui apparaît comme le sujet le plus important de tous. Un article est également dédié à la nécessité d'obtention des droits civils des femmes. Par contre, la revue et ses collaboratrices semblent assez prudentes par rapport à l'utilisation du mot « féministe » et parfois s'en défendent. Ainsi le premier article de la revue qui porte sur les objectifs de celle-ci annonce :

«... Le moment est arrivé pour que la femme de Cochabamba assume une attitude, non pas féministe dans toute l'acception du terme, pour laquelle elle n'est pas suffisamment préparée, mais qui lui permette de se faire connaître comme aimante de l'instruction et de l'éducation intégrale avec un critère élevé, propre et serein, la douce, la cultivée et religieuse sans fanatisme; la fille et la sœur exemplaire, la femme du foyer qui soit la première maîtresse modèle de ses enfants, celle qui soit une épouse avec laquelle le mari partage tous ses idéaux, en trouvant en elle une collaboratrices consciente et assidue; celle qui lègue à sa patrie des enfants utiles. $)^{118}$

\footnotetext{
117 «Por la elevación moral y cultural de la mujer ». Devise de la revue.

118 «Es llegado el momento en que la mujer cochabambina asuma una actitud, no feminista en toda la acepción de la palabra, para lo cual no está lo bastante preparada, pero sí, de darse a conocer como amante de la instrucción y educación integral, de criterio elevado, propio y sereno, la dulce, la culta y religiosa sin fanatismo; la hija y hermana ejemplar, la mujer del hogar que sea la primera maestra
} 
Il est intéressant de voir comment les directrices et collaboratrices de cette revue nient une position féministe, ou tout du moins, la définition communément donnée de celle-ci pour élaborer une réflexion sur les définitions du féminisme et en donner une qui leur soit propre dans d'autres articles. On analysera cet aspect plus en détail ultérieurement.

Comme dans la plupart des autres revues, un espace important était accordé à la littérature : des poèmes, contes, essais, étaient publiés. Le premier numéro de la revue fut dédié à la célèbre poétesse Adela Zamudio (voir annexe $\mathrm{A} \mathrm{n}{ }^{\circ 28}$ ), qui était morte un an auparavant. Des articles furent également dédiés à d'autres femmes boliviennes « illustres » dans la littérature ou dans l'histoire. Des articles historiques et patriotiques, ou sur le folklore du pays occupaient de même une place importante dans la publication. La revue comptait de même avec une section sociale dans laquelle étaient annoncés tous les évènements sociaux de la ville de Cochabamba.

La première action des féministes des années 1920 en Bolivie fut la publication de revues féminines - féministes à travers laquelle elles exprimèrent leur prise de conscience sur la nécessité de développer et améliorer l'éducation des femmes, ainsi que leurs conditions sociales, juridiques et politiques. Suivant l'exemple de Feminiflor, plusieurs revues de ce type surgirent dans les principaux centres urbains du pays tels que Oruro, Cochabamba, Potosí, et La Paz que ce soit comme porte-paroles d'associations culturelles et féministes, ou de femmes réunies pour faire du journalisme et exprimer leurs souhaits en tant que femmes éduquées et cultivées. Ces revues étaient surtout lues et connues des femmes des classes moyennes et élevées de la société qui partageaient les mêmes idées avec les femmes qui les publiaient. Elles étaient lues et connues également des hommes intellectuels de l'époque qui par leurs éventuelles collaborations soutenaient les souhaits et demandes exprimés dans ces publications. Les revues circulaient donc au sein des cercles intellectuels de femmes et d'hommes qui appartenaient à l'élite intellectuelle du pays. Les demandes, souhaits et revendications exprimés dans ces revues représentaient une infime fraction des femmes du pays : celles qui avaient été les premières bénéficiaires

modelo de sus hijos, la que sea una esposa con quien departa el marido todos sus ideales, hallando en ella una coadyuvadora consciente y asidua; aquella que legue a su patria hijos de provecho. » Anhelos, $\mathrm{n}^{\circ} 1$, juillet 1929, Cochabamba. Centro de Informaciôn y Desarrollo de la Mujer (CIDEM), La Paz Bolivie. 
du développement de l'éducation des femmes dans les principaux centres urbains de la Bolivie, à savoir, les femmes des classes moyennes et élevées de la société. Il n'y a pas de chiffres concernant le nombre de femmes qui savaient lire et écrire, ou de femmes bachelières, professionnelles ou travaillant dans le secteur tertiaire de l'économie dans les années 1920 qui nous donneraient un ordre de grandeur sur la présence de ces femmes au sein de la société bolivienne.

Les seuls chiffres démographiques qui sont disponibles sur la première moitié du $\mathrm{XX}^{\mathrm{e}}$ siècle en Bolivie, sont ceux proportionnés par les recensements de 1900 et de 1950 et par les études statistiques réalisées après, qui concernent uniquement l'année 1950. D'après ces études, sur une population de 3.019.031 d'habitants en 1950, la population active était de 1.350 .782 , dont la population féminine était de 579.894 , c'est-à-dire $42 \%$ du total. A cette époque l'axe économique était formé par les départements de La Paz, Cochabamba et Santa Cruz (qui avait commencé à dépasser Oruro). Cet axe regroupait $71.72 \%$ du total de la population féminine économiquement active.

Parmi la population féminine économiquement active, $75.94 \%$ avait comme occupation principale l'agriculture et l'élevage, c'est-à-dire, 440.371 femmes ; seulement $8.98 \%$, entraient dans la catégorie « Professionnelles, services domestiques et personnels », c'est-à-dire 52.074 femmes $^{119} ; 7.76 \%$ travaillait dans l'industrie de transformation, notamment dans les secteurs textiles et alimentaires, c'est-à-dire 44.999 femmes; $4.19 \%$ s'occupait du commerce, des crédits et des assurances, c'està-dire, 24.297 femmes. 268.758 femmes et 439.755 hommes de tous les âges savaient lire et écrire en 1950, faisant un total de 708,513 personnes. Le pourcentage de femmes de tous les âges sachant lire et écrire était donc de $9 \%$ de la population totale en 1950.

Ces chiffres qui concernent la fin de notre période, nous permettent seulement d'imaginer l'ordre de grandeur de femmes des classes moyennes et élevées qui étaient

\footnotetext{
${ }^{119}$ La dénomination de cette catégorie est extrêmement vague et prête à confusion. Il semblerait qu'elle englobe les femmes ayant un titre professionnel ainsi que les femmes qui travaillaient comme femmes de ménage. D'après Luis, OPORTO ORDOÑEZ dans Las mujeres en la Historia de Bolivia. Imágenes y realidades del siglo XX (1900-1950), Antología, Anthropos, La Paz - Bolivia, 2001, cette catégorie concerne les femmes ayant un titre professionnel des classes moyennes et élevées de la société. Cependant, d'après María Isabel Arauco dans Mujeres en la Revolución Nacional: Las Barzolas, Distribución CINCO, La Paz, 1984, cette catégorie concerne surtout les femmes de ménage. Par le dénomination de la catégorie il semblerait que celle-ci englobe les deux : femmes ayant un titre professionnel et femmes travaillant dans les services domestiques. Il est donc difficile de savoir combien de femmes avaient un titre professionnel en 1950.
} 
professionnelles et qui travaillaient dans les années 1920. Il est très difficile et risqué d'avancer des chiffres. On peut seulement supposer que le nombre de femmes professionnelles en 1920 était extrêmement réduit, tenant compte du fait que l'éducation des femmes avait commencé à se développer moins de 20 ans auparavant, et que les premières femmes professionnelles étaient apparues dans la décennie 1910. Il s'agissait donc d'un groupe infime de femmes au sein duquel on trouvait les femmes féministes et journalistes des années 1920.

La diffusion et l'influence de ces revues étaient donc limitées à ces cercles très restreints de femmes cultivées et d'hommes intellectuels qui constituaient l'élite intellectuelle de la Bolivie. La grande majorité des femmes du pays, dont les femmes indigènes habitant la campagne et les femmes métisses («cholas») des centres urbains du pays étaient étrangères à ces publications et au développement général $d u$ mouvement féministe dans le pays.

Les revues féminines - féministes des années 1920 ne répondaient pas à des stratégies pour faire pression sur le gouvernement, mais à des stratégies de communication d'idées et d'objectifs des associations et des femmes féministes du pays. Elles leur servaient donc à faire connaître à la société et aux hommes politiques, leurs demandes et leurs revendications.

Outre ces publications, les organisations féministes développèrent d'autres types d'action qui servaient non seulement à faire connaître leurs demandes, mais aussi à formuler des propositions concrètes de réformes légales dans le pays.

\section{b) Congrès Nationaux et participation aux Congrès Internationaux}

L'organisation d'un Congrès national de femmes est une idée qui surgit assez tôt au sein de l'« Ateneo Femenino » de La Paz.

La première femme à proposer ce projet fut Ana Rosa Vázquez, dans sa thèse d'admission à l'« Ateneo » qui fut publiée dans la revue Eco Femenino d'octobre 1923. Ce projet devait avoir lieu à l'occasion de la célébration du Centenaire de la Bolivie en 1925. L'idée était inspirée des Congrès féminins qu'avaient déjà eu lieu dans d'autres pays d'Europe et d'Amérique du Sud : 
«Désignée en assemblée par le centre intellectuel «Ateneo Femenino », pour la conférence de cette après-midi, je vous prie de bien vouloir écouter les points que j'indiquerai, sur la nécessité de convoquer un Congrès Féminin à l'occasion de la célébration du Centenaire de la Bolivie dans sa vie d'Indépendance.

Je ne ferai pas l'histoire des congrès réalisés dans des centres européens et sud-américains à l'occasion du mouvement féminin qui se développe dans le monde entier, plaidant pour les droits civils et politiques de la femme, et qui sont assez connus. ${ }^{120}$

Les objectifs que devaient être atteints par la réalisation d'un tel Congrès étaient divers. Il s'agissait d'abord de faire connaître les souhaits et demandes du « mouvement féminin » qui était apparu en Bolivie :

« Je vais seulement vous manifester qu'il est d'urgente nécessité morale et intellectuelle de faire connaître le mouvement féminin, qui a commencé dans notre monde social, à l'occasion de faire comprendre ses aspirations de culture féminine et d'aspirations patriotiques. ${ }^{121}$

Ensuite il s'agissait de revendiquer des réformes dans la législation afin que les droits civils soient accordés aux femmes :

«Dans un Congrès National on demanderait le changement de la législation des lois qui pèsent sur nous de manière si onéreuse et déprimante (...) En comptant heureusement avec un centre social et intellectuel comme 1'« Ateneo Femenino », celui-ci appellerait des talents particulièrement reconnus dans toute la république, qui en organisant des commissions, étudieraient les lois qui devraient être réformées. Voici la liste de quelques femmes à qui on pourrait confier cette tâche : María Luisa B. de Urioste (voir annexe A n¹0), Ugarte de Salamanca (voir annexe A $n^{\circ} 32$ ), Adela Zamudio (voir annexe A $\mathrm{n}^{\circ} 28$ ), María Gutierrez de Rubin de Celis, Eduviges v. de Hertzog (voir annexe $\left.\mathrm{A} \mathrm{n}^{\circ} 15\right)$, et plein d'autres encore. ${ }^{122}$

\footnotetext{
120 «Designada en junta, por el centro intelectual “Ateneo Femenino", para la conferencia de esta tarde, he de rogaros prestéis vuestra bondadosa atención a los ligeros apuntes que indicaré, acerca de la necesidad de convocar un Congreso Femenino, con motivo de recordar y festejar el Centenario de Bolivia en su vida de Independencia.

No he de hacer historia de los congresos realizados en centros europeos y sudamericanos, con motivo del movimiento femenino que se realiza en todo el mundo, abogando por los derechos civiles y políticos de la mujer, y que son bastante conocidos. » Eco Femenino, n², octobre 1923, La Paz. Hemeroteca de la Universidad Mayor de San Andrés, La Paz - Bolivie.

121 «Tan solo he de manifestaros, que es de urgente necesidad moral e intelectual, dejar conocer el movimiento femenino, que se ha iniciado en nuestro mundo social, con motivo de hacer comprender sus aspiraciones de cultura femenina y anhelos patrióticos. » Idem.

122 «En un Congreso Nacional, pediríamos que cambien la legislación de las leyes, que pesan sobre nosotros en forma tan onerosa y deprimente (...) Contando felizmente con un centro social e intelectual como el "Ateneo Femenino", este centro, llamaría a talentos particularmente reconocidos de toda la república, quiénes, organizando comisiones, estudiarían las leyes que se podría pedir sean reformadas. He aquí algunas de las señoras de quienes podíamos confiar: María Luisa B. de Urioste, Ugarte de
} 
Le projet pouvait également s'élargir à d'autres pays et devenir un Congrès International de femmes auquel participeraient les femmes intellectuelles et féministes des pays sud-américains. Dans ce cas, il s'agirait aussi de faire connaître les demandes de la Bolivie pour récupérer son territoire côtier perdu lors de la Guerre du Pacifique (1879-1883) contre le Chili :

«Vous me direz peut-être, comment peut-on réunir un Congrès et qu'est-ce qu'on demanderait dans celui-ci ?

On pourrait réunir un congrès, pas seulement national, mais aussi international, avec l'aide des pouvoirs publics, qui, connaisseurs des fins recherchées par le mouvement féminin, devraient collaborer; subventionner et faciliter les transports, aux femmes intellectuelles des républiques sœurs invités à nous honorer dans les sessions du Congrès, en célébrant notre vie d'indépendance.

Ainsi elles verraient de près nos justes aspirations de sortie vers la mer, en vivant jusqu'aujourd'hui entre des rochers et des montagnes enneigées; pour élever ensemble, nos prières au Dieu de la justice, depuis le moment où, en tant que filles, épouses ou mères, nos enfants, époux et pères seraient les victimes du sacrifice de s'offrir à l'holocauste, en protégeant les sentiments d'intégrité nationale (...) Il est dans tous les aspects nécessaire d'établir des liens d'union intellectuelle avec les nations sœurs, en nommant des commissions de propagande féminine... ${ }^{123}$

Il est intéressant de voir que, d'après ce projet, un Congrès international de femmes aurait des objectifs diplomatiques non seulement en relation aux demandes d'accès au littoral de la Bolivie, mais aussi pour éviter une guerre entre les pays sud-américains, comme le sous-entend Ana Rosa Vázquez. Les femmes joueraient ainsi le rôle d'intermédiaires entre les gouvernements.

Salamanca, Adela Zamudio, María Gutiérrez de Rubín de Celis, Eduviges v. de Hertzog y muchas otras más. » Idem.

${ }_{123}$ «Me diréis tal ves, ¿y cómo se puede reunir un Congreso; y qué pediríamos en él?

Se podría reunir un congreso, no sólo nacional, sino hasta internacional, con la ayuda de los poderes públicos, quiénes, conocedores de los fines que persigue el movimiento femenino, deberían colaborar, subvencionar y facilitar los transportes, a las mujeres intelectuales de las repúblicas hermanas invitadas a honrarnos en las sesiones del Congreso, festejando nuestra vida de independencia.

Así verían de cerca nuestras justas aspiraciones de salida al mar, viviendo como hasta ahora, entre breñas y nevados; para elevar juntas, nuestras oraciones al Dios de la justicia, desde el momento, que como hijas, esposas o madres, nuestros hijos, esposos o padres, serían las víctimas del sacrificio de ofrecerse en holocausto, amparando los sentimientos de integridad nacional (...) Es de todo punto necesario establecer lazos de unión intelectual con las naciones hermanas, nombrando comisiones de propaganda femenina... » Idem. 
Ce projet ne fut finalement pas réalisé en 1925 comme il était prévu. Cependant, la même année les membres de 1'« Ateneo Femenino » eurent l'occasion de participer à la Seconde Conférence Panaméricaine de Lima qui eut lieu en janvier 1925. Les membres de l'«Ateneo Femenino » qui participèrent à cet événement furent Ana Rosa Tornero (voir annexe $\mathrm{A} \mathrm{n}^{\circ}$ ) ) et Eduviges v. de Hertzog (voir annexe A $\left.n^{\circ} 15\right)$. La presse du Pérou publia plusieurs articles sur la visite de ces deux représentantes boliviennes et notamment sur la visite d'Ana Rosa Tornero ${ }^{124}$. Sur cette participation, on connaît uniquement les 4 projets présentés par Eduviges v. de Hertzog qui portaient sur: l'éducation secondaire des femmes, le droit de vote des femmes, la création d'une Banque Protectrice des Femmes Travailleuses, et l'alphabétisation des indigènes. On a des informations sur le premier et le deuxième projets de manière indirecte, à travers le commentaire sur ceux-ci réalisé par $\mathrm{M}$. Teresa Solari (voir annexe A n²9) publié dans la revue Eco Femenino de septembre 1925. Il semblerait que Hertzog insista sur la nécessité qu'avaient les femmes d'avoir une éducation secondaire, qui ne serait pas contradictoire avec le rôle de femmes au foyer qu'elles devaient remplir avec « abnégation ». Dans ce sens, les femmes étaient «professeures de leur propre foyer ». En cultivant leurs esprits, elles ne devaient pas s'éloigner des sciences domestiques et devaient pouvoir combiner les deux activités. Les écoles et lycées devraient donc éduquer les femmes de manière à ce qu'elles puissent être des femmes cultivées et en même temps de bonnes femmes au foyer.

Concernant le droit de vote, les connaissances que l'on a sur ce projet viennent également du commentaire réalisé par M. Teresa Solari. Le droit de vote était revendiqué pour les femmes qui savaient lire et écrire car elles étaient dans une situation «d'égalité intellectuelle et morale » avec les hommes. De plus, les femmes, en tant que «dépositaires de sentiments », devaient collaborer aux hommes dans l'élaboration des lois. Si les hommes étaient le «cerveau», les femmes étaient l'« âme»; les lois avaient besoin d'âme pour être véritablement justes. Les femmes devaient, en plus, pouvoir élaborer des lois qui soient en accord avec leurs propres intérêts pour leur progrès et celui de la société ${ }^{125}$.

\footnotetext{
${ }^{124}$ Eco Femenino, nº 13, mai 1925, La Paz. Hemeroteca de la Universidad Mayor de San Andrés, La $\mathrm{Paz}$ - Bolivie.

${ }^{125}$ Eco Femenino, ${ }^{\circ} 15$, septembre 1925, La Paz. Hemeroteca de la Universidad Mayor de San Andrés, La Paz - Bolivie.
} 
Le troisième projet sur la création d'une Banque Protectrice des femmes travailleuses fut publié dans la revue Eco Femenino de mai 1925. Il s'agissait de créer une Banque ou «Maison de Prêts » pour les femmes pauvres (mères d'enfants ou veuves) qui travaillaient ou qui voulaient travailler. Cette Banque prêterait de l'argent avec de bas intérêts annuels aux femmes qui auraient des projets professionnels divers. Les intérêts ne dépasseraient pas le 6\% annuel. Pour la création de cette Banque, les femmes à l'aise économiquement, donneraient un capital et deviendraient des actionnaires. Ces Banques seraient établies dans chaque capitale de département formant un réseau. Le personnel des Banques serait constitué par des jeunes femmes récemment diplômées d'Instituts de Commerce, dirigées par des hommes qui les initieraient dans le travail des Banques. Les actionnistes des Banques gagneraient le $2 \%$ annuel pour son capital fondateur. Les Banques seraient complètement indépendantes des Banques spéculatrices. L'argent prêté aux femmes pauvres serait surveillé afin de contrôler son bon emploi.

Il est très probable que ce projet n'ait jamais eu lieu ; lorsqu'il fut présenté à Lima, la déléguée des femmes travailleuses au Conseil Supérieur du travail ne le considéra pas viable $^{126}$.

Le quatrième et dernier projet présenté par Eduviges v. de Hertzog, concernait l'alphabétisation des indigènes au Pérou et en Bolivie. En effet, la question de l'intégration des indigènes à la Nation était une constante réflexion à l'époque en Bolivie, et dans d'autres pays comme le Pérou, dans les cercles politiques et intellectuels de l'époque. Des intellectuels comme Franz Tamayo, Alcides Arguedas en Bolivie et Carlos Mariátegui au Pérou, s'occupèrent de cette question dans plusieurs de leurs ouvrages. La plus grande partie de la population en Bolivie était constituée d'indigènes qui habitaient surtout dans les campagnes, le pays ayant une population majoritairement rurale. D'après le recensement réalisé en 1900, la Bolivie avait une population d'indigènes de 903,126 personnes, une population de métis ou « cholos» de 485,293 personnes, et une population de blancs ou «criollos» de 231,088 personnes $^{127}$. Ceux qui dirigeaient le pays depuis son indépendance et qui constituaient l'élite politique, économique et intellectuelle du pays étaient

\footnotetext{
${ }^{126}$ Eco Femenino, n 13 , mai 1925, La Paz. Hemeroteca de la Universidad Mayor de San Andrés, La Paz - Bolivie.

${ }^{127}$ KLEIN, Herbert S., Orígenes de la revolución nacional boliviana. La crisis de la generación del Chaco, Librería Editorial G.U.M., La Paz, (n.d.), p. 34.
} 
essentiellement les blancs. Une grande partie des indigènes aymaras et quechuas travaillaient en conditions semi féodales dans les «haciendas» (exploitations agricoles) en tant que colons. Ils recevaient un lot de terre en échange de leur travail dans l'exploitation agricole du patron. Le système du «pongueaje » était en place à cette époque : le colon devait rendre des services gratuits au patron pendant deux semaines de l'année dans l' «hacienda » ou en ville. Le patron, à cette occasion pouvait louer le pongo à d'autres personnes qui avaient besoin de son travail ${ }^{128}$.

$\mathrm{Au}$ début du $\mathrm{XX}^{\mathrm{e}}$ siècle, un des problèmes essentiels était la «question indigène »: que faire de la masse d'indigènes qui habitaient les campagnes et qui constituaient la plus grande partie de la population? Il était nécessaire de trouver une réponse à cette question puisque, selon les idées de l'époque, l'une des principales causes du retard du pays était sa composition raciale. D'après cette conception, les indigènes, étaient complètement « indifférents » et étrangers non seulement à ce qui se passait dans le pays, mais aussi aux coutumes occidentales et donc à la « civilisation ».

Les réponses à la question des indigènes furent diverses. Il y en avait ceux qui soutenaient qu'il fallait faciliter la venue de migrants «blancs» d'Europe pour « blanchir » la population. D'autres, considéraient qu'il fallait intégrer les indigènes à la nation pour en faire une force de « progrès » : il fallait donc les alphabétiser et les éduquer aux valeurs chrétiennes et occidentales afin qu'ils deviennent de «bons citoyens ».

C'est dans ce contexte que s'inscrit le projet présenté par Eduviges v. de Hertzog. Les représentantes de $1^{\prime}$ «Ateneo Femenino» appartenaient toutes aux classes moyennes et élevées de la société et à l'élite «blanche » intellectuelle du pays, comme on l'a déjà vu. Elles partageaient donc les idées et conceptions qui circulaient au sein des cercles intellectuels de l'époque quant à la question des indigènes et de leur intégration au pays. Ainsi, elles considéraient que leur alphabétisation était le premier pas vers leur intégration à la nation. Celui-ci était un des principaux projets « sociaux » de l'organisation (le sujet occupe plusieurs articles dans leurs revues Eco Femenino et Indice).

\footnotetext{
128 BARRAGÁN Rossana, QAYUM Seemin, SOUX María Luisa, De terratenientes a amas de casa. Mujeres de la élite de La Paz en la primera mitad del siglo XX. Serie "Protagonistas de la Historia", Editores: Ministerio de Desarrollo Humano, Secretaría de Asunto Étnicos, de Género y Generacionales, Subsecretaría de Asuntos de Género, La Paz - Bolivia, 1997.
} 
Le projet présenté à la Seconde Conférence Panaméricaine de Lima apparaît comme une mission «civilisatrice» que devait être entreprise par les femmes cultivées de la Bolivie et du Pérou, pays partageant une «composition raciale» similaire :

«Les indigènes semi civilisés des républiques sud-américaines, se consacrent dans sa majeure partie à l'agriculture et aux travaux d'édification (...) Je pense que les femmes cultivées du Pérou et de la Bolivie ont une grande mission d'Humanité à étudier et à mettre en pratique pour attirer et fondre dans la Civilisation le puissant élément autochtone, qui constitue la plus grande partie de la population de ces nations (...) Je pense que le Comité Éxécutif de la Seconde Conférence Panaméricaine de femmes doit établir les bases pour la réorganisation de l'Instruction dans les pays où la race indigène est presque une

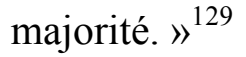

Le projet prévoyait l'institution d'écoles dans toutes les exploitations agricoles pour les enfants. Les adultes analphabètes assisteraient à l'école trois fois par semaine. Le projet prévoyait également l'amélioration des conditions de vie des indigènes habitant les « haciendas ». Le patron devait avoir de l'eau potable et une habitation avec un équipement médical basique au cas où les indigènes ne pourraient pas être emmenés aux hôpitaux. Le patron devait également faire venir un médecin deux fois par an pour qu'il vaccine tous les colons des « haciendas ». De même, il devait prendre soin de l'état de sobriété ce ces derniers, pour qu'ils puissent travailler plus efficacement. Le patron avait le droit d'emmener les indigènes rebelles en justice, mais il ne pouvait pas les flageller. Le patron était également chargé de payer les salaires du médecin et du professeur de l'école. Si l'année était mauvaise pour les produits agricoles le patron devait donner des graines à ses colons et leur procurer les moyens de vie essentiels.

\footnotetext{
129 « Los indios semi-civilizados de las Repúblicas Sud-Americanas, en su mayor parte se dedican a la agricultura y a los trabajos de edificación (...) Creo que las mujeres cultas del Perú y Bolivia tienen una grande misión de Humanidad que estudiar y poner en práctica para atraer y confundir en la Civilización al poderoso elemento autóctono parte muy grande de la población de estas naciones (...) Yo creo que el Comité Ejecutivo de la Segunda Conferencia Pan-Americana de Mujeres, debe sentar las bases para la reorganización de la Instrucción en los países donde la raza indígena casi es mayoría. » Eco Femenino, n¹4, juillet 1925, La Paz. Hemeroteca de la Universidad Mayor de San Andrés, La Paz - Bolivie.
} 
L'esprit paternaliste du projet fut clairement exprimé par Hertzog à la fin de sa présentation:

«La sueur versée par l'indigène fructifie la terre du patron et il est juste que ce dernier soit le père de ses colons lorsqu'il y a des malheurs à déplorer. ${ }^{130}$

On ne sait pas quel fut le sort des projets présentés par les représentantes boliviennes de l'«Ateneo Femenino» au sein de la Conférence de Lima, mais leur participation constitua un premier pas vers la création de liens et de réseaux avec les femmes intellectuelles et féministes de l'Amérique du Sud. Par ailleurs, suite à sa participation au Congrès, Ana Rosa Tornero fut invitée à participer à la «Liga Internacional de Mujeres Ibéricas e Hispanoamericanas » qui eut lieu au Mexique en $1925^{131}$. Malheureusement, on n'a pas pu trouver des informations sur sa participation à ce Congrès.

Les actions des femmes de l'«Ateneo Femenino » en 1925 ne se limitèrent pas à la participation aux Congrès internationaux de femmes. Même si elles ne réussirent pas à organiser un Congrès national de femmes pour le Centenaire de la Bolivie, elles se chargèrent de présenter au gouvernement un projet de modification du Code Civil afin que les femmes puissent obtenir les droits civils. En effet, en juin 1925 elles firent appel à Benjamín H. Gallardo, jurisconsulte, civiliste et Recteur de l'Université Mayor de San Andrés de La Paz, (voir annexe B nº) pour qu'il réalise un projet de réforme du Code Civil bolivien qui accorde les droits civils aux femmes. Ce projet devait être présenté au Parlement en hommage au Centenaire du pays. Des commissions de femmes devaient être réunies pour élaborer le projet de modification sous la direction de Benjamín H. Gallardo:

" À l'occasion de la réalisation de l'intéressante idée du docteur Benjamín H. Gallardo présentée à 1'“Ateneo Femenino", de demander au Congrès la réforme législative sur les droits des femmes, ce Centre culturel a résolu former des commissions organisatrices du projet.

On espère que tous les Centres féminins de la République, et chaque femme en particulier, participera avec son adhésion à la cause, à l'appel que fera 1"“Ateneo Femenino", car il s'agit d'une idée que travaillée avec effort sera le germe de bons résultats.

\footnotetext{
${ }^{130}$ «El sudor vertido por el indio fructifica la heredad del patrón y es justo que este sea padre de sus colonos cuando hay desgracias que lamentar. » Idem.

${ }^{131}$ Eco Femenino, n¹3, mai 1925, La Paz. Hemeroteca de la Universidad Mayor de San Andrés, La $\mathrm{Paz}-$ Bolivie.
} 
L'espoir nous encourage car nous avons confiance que l'intelligence des Chambres sera favorable au projet, dont les points étudiés avec un critère juste et désintéressé par le docteur Gallardo, constituent la demande la plus digne faite par la femme par rapport à ses droits. ॥ ${ }^{132}$

Le projet qui était nommé « Projet de réintégration des droits civils de la femme » fut finalement présenté à l' "Ateneo Femenino » par le docteur Benjamín H. Gallardo dans une conférence réalisée le 11 juillet 1925 dans les salons de 1'Université Mayor de San Andrés de La Paz ${ }^{133}$. L'objectif du projet présenté par Gallardo dans son discours à l'occasion de cet événement était celui de «mettre à jour » un Code Civil « archaïque » qui n'était plus en accord avec les réalités de vie de tous les jours des femmes boliviennes. Il était donc nécessaire qu'à l'occasion des célébrations de son Centenaire, la Bolivie puisse rénover sa législation en considérant les réformes du Code Civil présentées dans ce projet :

« Mademoiselle la Présidente de l' « Ateneo Femenino » Mesdames, Messieurs :

Nous arrivons à la première centurie de vie républicaine, et en examinant notre législation en ce qui concerne les droits civils de la femme, l'on voit avec un sentiment profond, que le législateur bolivien ne s'est absolument pas occupé du sexe féminin, en le laissant dans un état d'abandon et d'infériorité relative à l'homme et dans un quasi esclavage.

Notre Code Civil qui reconnaît comme origine le Code Napoléon; informé dans les principes du Code Romain, considère la femme non pas comme une personne absolument capable de l'exercice et de la jouissance des droits civils, mais, moins que relativement comme quelque chose d'intermédiaire entre la personne et la chose, et de là émane son infériorité, la prééminence et la supériorité de l'homme et son droit d'autorité.

Lorsqu'on observe nos coutumes sociales, le rang que la femme occupe en elles, le niveau auquel on l'a placé avec la culture méthodique de son esprit et de son intelligence, les considérations desquelles elle est digne en tant que fille, épouse ou mère, on voit qu'il

\footnotetext{
132 « Con motivo de llevarse a cabo la interesante idea del doctor Benjamín H. Gallardo, presentada al Ateneo Femenino, con objeto de pedir al H. Congreso de este la reforma legislativa en cuanto a los derechos de la mujer incumbe, ha resuelto este Centro cultural formar sus comisiones organizadoras de este proyecto.

Es de esperar que todos los Centros femeninos de la República, y cada mujer en particular, concurra con su adhesión a la causa, al llamado que hará el Ateneo Femenino, ya que se trata de una idea que laborada con el esfuerzo ha de ser germen de benéficos resultados.

La esperanza nos alienta porque confiamos en que la inteligencia de la H. H. Cámaras ha de ser asequible al proyecto, cuyos puntos estudiados, con criterio justo y desinteresados por el doctor Gallardo, constituyen el reclamo más digno que hará la mujer de sus derechos. » Eco Femenino, n ${ }^{\circ}$, juillet 1925, La Paz. Hemeroteca de la Universidad Mayor de San Andrés, La Paz - Bolivie.

${ }^{133}$ Indice, ${ }^{\circ} 1$, décembre 1927, La Paz. . Centro de Informaciôn y Desarrollo de la Mujer (CIDEM), La Paz - Bolivie.
} 
y a une différence très profonde entre la femme sociale et la femme envisagée légalement.

Cela veut dire et manifeste très clairement, que l'harmonie qui doit régner entre la loi et les coutumes sociales a disparu et n'existe plus ; que les dispositions de nos codes en ce qui concerne les femmes, pèchent par archaïques et vieilles, qu'elles ne s'adaptent pas à notre environnement et qui réclament à cor et à cri une réforme radicale réintégrant la femme à ses droits civils qui furent réduits autrefois. ${ }^{134}$

Il est intéressant de constater que la demande de réforme du Code Civil était basée sur l'idée qu'il n'était plus adapté aux conditions sociales des femmes des années 1920 ; c'est-à-dire que dans les conceptions de Gallardo et des membres de l'«Ateneo Femenino » la réforme du Code Civil ne répondait pas à une nécessité de provoquer des changements dans la condition sociale des femmes à travers la modification des lois, mais au contraire, d'adapter les lois aux changements qu'avaient subi les coutumes sociales. D'après Gallardo, celles-ci plaçaient les femmes à un très haut niveau. Les changements des coutumes sociales entre le début de la vie républicaine du pays et les années 1920 étaient dûs bien évidemment au développement de l'éducation des femmes des principaux centres urbains entreprit au début du XX $\mathrm{X}^{\mathrm{e}}$ siècle. Dans la conception de Gallardo, et des membres de l'« Ateneo » les femmes des années 1920 n'étaient pas les femmes des premières années de l’Indépendance, puisqu'elles étaient désormais des femmes éduquées et cultivées. Les

134 « Señorita Presidenta del Ateneo Femenino:

Señoras, Señores:

Llegamos a la primera centuria de vida republicana, y al examinar nuestra legislación en lo que se refiere a los derechos civiles de la mujer se ve con profundo sentimiento, que el legislador boliviano no se ha ocupado absolutamente del sexo femenino, dejándolo en estado de abandono y de inferioridad relativamente al varón y en una cuasi esclavitud.

Nuestro Código Civil que reconoce como origen el Código Napoleón, informado en los principios del Derecho Romano, considera a la mujer no como una persona absolutamente capaz del ejercicio y goce de los derechos civiles, sino, menos que relativamente, como algo intermediario entre la persona y la cosa, y de ahí emana la inferioridad de ella, la preeminencia y superioridad del varón y su derecho de señorío.

Cuando se observan nuestras costumbres sociales, el rango que la mujer ocupa en ellas, la altura a que la hemos colocado con el cultivo metódico de su espíritu y de su inteligencia, las consideraciones a que es acreedora como hija, como esposa y como madre, se ve que hay una diferencia muy profunda entre la mujer social y la mujer legalmente contemplada.

Quiere decir esto y manifiesta muy a las claras, que ha desaparecido y no existe la armonía que debe reinar entre la ley y las costumbres sociales; que las disposiciones de nuestros códigos en lo referente a la mujer, pecan de arcaicas y añejas, que no se adaptan a nuestro medio ambiente y que reclaman a voces una reforma radical reintegrándola a la mujer en sus derechos civiles que otrora fueron mermados. » Exposición de motivos y proyecto de ley de Reintegración de los derechos civiles de la mujer. Conferencia que tuvo lugar en el Ateneo Femenino, en el mes de Julio de 1925, por el jurisconsulto y Civilista Dr. Benjamín H. Gallardo, Rector de la Universidad Mayor de San Andrés. Talleres "La República", La Paz - Bolivia. Centro de Informaciôn y Desarrollo de la Mujer (CIDEM), La Paz - Bolivie. 
lois qui régissaient leur vie sociale n'étaient donc plus adaptées à leurs conditions de vie, et ce décalage entre le social et le légal exigeait une rénovation à travers des réformes. Dans ce sens, le social était en avance par rapport au légal d'après Gallardo et les femmes de l'«Ateneo». C'est ce qu'exprime Rosa Infante, présidente à l'époque de l' "Ateneo Femenino », dans son discours de remerciement à Gallardo pour le projet de réforme présenté par celui-ci :

« D'après l'exposition de motifs du projet que nous venons d'entendre de la part du remarquable civiliste et jurisconsulte docteur Gallardo, nous voyons de manière claire et manifeste qu'en tant qu'aimant de la justice et du droit, il a su encadrer dans sa réforme si profondément étudiée, et il a su harmoniser la position sociale qu'occupe la femme, où elle est respectée, exaltée et considérée au même niveau que l'homme dans sa capacité mentale et même supérieure à celui-ci dans ses sentiments délicats et sensibles prédisposés à réaliser des actes d'abnégation et de sacrifice pour le bien de ses semblables; pendant que légalement on la déprime car on la croit incapable de pouvoir exercer avec un critère satisfaisant les droits que la loi lui confère ; ainsi le projet a pour objet le nivellement social et légal de la femme. $\gg{ }^{135}$

La célébration du Centenaire était pour eux l'occasion parfaite d'entreprendre des réformes dans la législation puisqu'il s'agissait d'un moment de « refondation » du pays. Il fallait donc prendre en compte toutes les évolutions sociales du siècle de vie indépendante afin d'obtenir un Code Civil qui soit adéquat aux réalités sociales $\mathrm{du}$ pays.

S'il est vrai que les conditions des femmes urbaines des classes moyennes et élevées de la société s'étaient transformées avec le développement de leur éducation, l'idée qu'il y avait une « exaltation » de la femme et qu'on la considérait égale à l'homme intellectuellement, répond plus à un idéal imaginée par les membres de l' «Ateneo Femenino » qu’à une véritable réalité dans le pays, parce que la grande majorité des femmes, n'avaient pas été bénéficiaires du développement de l'éducation au début du $\mathrm{XX}^{\mathrm{e}}$ siècle, et que par conséquent, la proportion de femmes éduquées et cultivées,

\footnotetext{
135 «Según la exposición de motivos del proyecto que acabamos de escuchar al destacado civilista y jurisconsulto doctor Gallardo, vemos de una manera clara y manifiesta que, amante de la justicia y del derecho, ha sabido encuadrar en su reforma tan profundamente estudiada, y ha logrado armonizar la posición social que ocupa la mujer, donde es respetada, enaltecida y considerada al nivel del hombre en su capacidad mental y aun superior a éste en sus sentimientos delicados y sensibles y predispuestos a realizar actos de abnegación y sacrificio, en bien de sus semejantes; mientras que legalmente, se la deprime porque se la cree incapaz de poder ejercer con suficiente criterio los derechos que la ley otorga; luego el proyecto tiene por objeto nivelarla social y legalmente. » Idem.
} 
dans le pays, était infime. Ces changements concernaient donc une petite portion des femmes, de laquelle faisaient partie les membres de l' «Ateneo». En tant que femmes éduquées et cultivées, celles-ci considéraient qu'il était logique et juste qu'elles puissent obtenir les droits civils et ne plus être considérées comme des mineures devant la loi une fois mariées.

Le projet présenté par Gallardo était inspiré du Code Civil brésilien élaboré en 1916, qu'il considérait comme le plus «moderne, scientifique et méthodique » de tous. D'après Gallardo, le Code Civil bolivien n'avait pas besoin d'être refait, car cela prendrait trop de temps, il fallait donc qu'il soit modifié selon les stipulations du projet et harmonisé avec la législation bolivienne. Une réforme totale du Code Civil pourrait venir postérieurement, reprenant les réformes qui seraient déjà entreprises concernant les droits civils des femmes.

Le projet de « réintégration des droits civils des femmes » instituait dans son article premier que les femmes avaient la pleine jouissance de leurs droits civils, qu'elles pouvaient exercer profession ou industrie licite, ainsi qu'exercer les charges civiles pour lesquels la Constitution n'exigeait d'autre condition que la « idoneidad». Cependant, l'article 2 délimitait leurs capacités au régime matrimonial choisi :

«Article 2.- L'extension de la capacité de la femme mariée sera déterminée par le régime matrimonial des biens $\gg{ }^{136}$

Tout comme dans le Code Civil en vigueur, lorsque les femmes se mariaient, leurs droits civils étaient réduits. Ainsi, même si l'article $1^{\text {er }}$ leur accorde la pleine jouissance de leurs droits civils, l'article 2 limite ceux-ci au type de régime matrimonial choisi par les époux. La femme mariée continuait donc à avoir des limitations par rapport à l'exercice de ses droits civils.

Cependant, le projet instituait des changements qui, non sans contradictions, accordaient certaines capacités aux femmes mariées qu'elles n'avaient pas avec le Code Civil en vigueur.

\footnotetext{
136 «Artículo 2.- La extensión de la capacidad de la mujer casada se determinará por el régimen matrimonial de los bienes. » Idem.
} 
Ainsi, d'après l'article 3 du projet, une fois mariée, la femme bolivienne ne perdait plus sa nationalité.

D'après l'article 4, les témoins dans les procès devaient être âgés de plus de 21 ans et pouvaient être élus par les intéressés.

En ce qui concerne la patria potestad, le projet modifiait ce qui était considéré comme une absurdité d'après Gallardo. En effet, dans le Code Civil les enfants étaient sous l'autorité du père légitime ou naturel, et en son absence, sous l'autorité de la mère jusqu'à la majorité ou l'émancipation. L'article 197 du Code instituait qu'après la dissolution du mariage par la mort d'un des époux, la tutelle des enfants mineurs et non émancipés appartenait par droit au survivant. D'après Gallardo, ce dernier article était absurde car, la patria potestad appartenait aux deux parents et était établie par les liens de sang entre ceux-ci et leurs enfants. Si l'un des parents mourrait ces liens de sang n'étaient pas dissous entre le survivant et ses enfants. Le survivant devait donc exercer la patria potestad en tous droits et non pas la tutelle. Cette dernière devait être exercée uniquement lorsque les deux parents étaient morts. Ainsi, l'article 5 du projet présenté par Gallardo, instituait que si l'un des parents s'absentait en laissant des enfants mineurs, la patria potestad et l'administration des biens devaient être exercées par le conjoint présent. De même, l'article 22 établissait que si le mariage était dissout par la mort d'un des conjoints, l'exercice de la patria potestad correspondait au conjoint survivant.

L'article $130 \mathrm{du}$ Code Civil d'après lequel l'homme devait protection à sa femme, et celle-ci lui devait obéissance, était remplacé par :

"Les conjoints se doivent réciproquement respect, protection et assistance. ${ }^{137}$

Cet article abolissait la situation inégale et hiérarchique existante entre les deux époux dans le Code Civil en vigueur, et la remplaçait avec une situation égalitaire et réciproque.

Néanmoins, le projet de Gallardo présentait quelques contradictions avec cette stipulation d'égalité: il établissait que l'homme était le chef de la société conjugale et que par conséquent il avait la représentation légale de la famille, ainsi que l'administration des biens communs, des acquets, des biens patrimoniaux de la femme si l'administration de ces derniers avait été accordé au mari en vertu du régime

\footnotetext{
${ }^{137}$ « Los cónyuges se deben recíprocamente respeto, protección y asistencia. » Idem.
} 
matrimonial adopté. L'homme avait également le droit de fixer et de changer le domicile de la famille, ainsi que le droit d'autoriser la profession de la femme et sa résidence hors du foyer conjugal. Il avait de même l'obligation de subvenir aux dépenses de la famille. La femme devait participer assister à ces dépenses avec les rentes de ses biens en proportion à leur valeur et relativement à ceux du mari, sauf s’il y avait une disposition contraire dans les capitulations matrimoniales. L'obligation qu'avait le mari de subvenir aux besoins de la femme cessait lorsqu'elle abandonnait sans juste motif le foyer et qu'elle refusait d'y retourner.

Comme on peut le constater, le mari était toujours considéré comme le responsable des besoins économiques de la famille, il devait donc travailler par obligation afin de subvenir aux besoins de celle-ci. Si la femme contribuait à ces besoins ce n'était que de manière auxiliaire. Ainsi, si elle travaillait, son salaire ne pouvait être considéré que comme un revenu d'appoint.

Les droits civils de la femme mariée se limitaient au régime matrimonial adopté, et l'homme conservait plusieurs charges et privilèges qui lui étaient déjà accordés dans le Code Civil, tels que la fixation du domicile, et le droit d'autoriser la profession de la femme.

Une des nouveautés introduites par le projet est la «licence uxoriale »: la licence ou autorisation accordé par la femme au mari. Cette licence suivait le principe selon lequel il y avait des droits et des devoirs corrélatifs au mari et à la femme. Si l'épouse était copropriétaire des acquêts, elle avait le droit d'avis sur l'administration de ceux-ci. D'après l'article 974 du Code Civil en vigueur, malgré le fait que la femme était copropriétaire des acquêts, seulement le mari pouvait les aliéner, et ce même sans le consentement de la femme. La licence uxoriale vient modifier cet article en établissant que le mari ne pouvait ni aliéner, ni hypothéquer ni mettre en garantie les biens immeubles ou les droits sur les immeubles de la femme. Il ne pouvait pas non plus faire un procès en tant qu'acteur sur ces mêmes biens ou droits. Il ne pouvait pas déposer une caution qui compromette la partie des acquêts de la femme, ou faire une donation avec les biens ou les profits communs avec la femme, sauf s'il s'agissait d'une donation rémunératrice ou de petite valeur. Il pouvait cependant, faire des donations nuptiales aux filles ou des donations aux fils en raison de leur mariage ou de leur établissement économique séparé. En l'absence du consentement de la femme, que ce soit parce qu'elle refusait de consentir et parce qu'elle était dans l'impossibilité de le faire, le juge pouvait la remplacer pour donner 
l'autorisation au mari. L'autorisation du juge, donnait de la validité aux actes du mari mais ne compromettait pas les biens de la femme. L'annulation des actes du mari réalisés sans la licence uxoriale ou sans celle du juge, pouvait être demandée uniquement par la femme et ses héritiers.

L'article $131 \mathrm{du}$ Code Civil en vigueur qui obligeait la femme à habiter avec le mari et de le suivre partout où il jugeât convenable, et qui obligeait le mari à recevoir la femme dans son domicile et à lui donner tout ce qui était nécessaire pour la vie, selon ses facultés et son état, fut modifié par : « Le mari et la femme doivent habiter le domicile conjugal et tous les deux ont le droit à ce que l'autre le reçoive dans celuici ». Par le mariage la femme devait prendre le nom de famille de l'époux précédé de la particule « de » et assumer la condition de sa compagne et de son auxiliaire dans les charges de la famille.

D'après l'article 10 du projet, la femme ne pouvait sans l'autorisation du mari : 1) pratiquer les actes que celui-ci ne pouvait exercer sans le consentement de la femme ; 2) aliéner ou mettre en garantie les immeubles de son domaine particulier, quel que soit le régime matrimonial; 3) aliéner ses droits sur les immeubles de l'autre ; 4) accepter ou renoncer à un héritage ou un legs ; 5) accepter de devenir tutrice ou curatrice ou accepter une autre charge publique ;6) entrer dans un procès civil ou commercial sauf dans les cas indiqués dans les articles 13 et 17 du projet ; 7) exercer une profession ; 8) contracter des obligations qui impliquaient l'aliénation des biens du patrimoine. La participation du mari à l'acte, ainsi que sa confirmation ou exécution postérieure valaient comme autorisation tacite. Le manque d'autorisation du mari pouvait être remplacé par un juge dans les cas 1 à 5 de l'article 10, et dans les cas 7 à 8 pourvu que le mari ne fournisse pas les moyens de subsistance à sa femme et à ses enfants.

D'après l'article 12 du projet, la femme qui exerçait une profession, industrie ou acte lucratif, ou qui travaillait en tant qu'ouvrière, avait le droit de pratiquer tous les actes inhérents à son exercice et à sa défense, tout comme le droit de disposer librement du produit de son travail.

D'après l'article 13, la femme était présumée autorisée par le mari pour : 1) l'achat à crédit des choses nécessaires à la vie domestique ; 2) obtenir des prêts afin d'obtenir l'argent nécessaire à l'achat de ces choses ; 3) contracter les obligations concernant la profession, industrie, art ou travail qu'elle exerçait avec l'autorisation du mari ou celle du juge. D'après Gallardo, cet article rendait légale une pratique courante dans 
les coutumes sociales, car lorsque les femmes achetaient à crédit ce qui était nécessaire pour le ménage, les commerçants ne leur demandaient jamais l'autorisation du mari, puisqu'ils supposaient qu'elles étaient autorisées par celui-ci. Il est intéressant de constater que le projet n'institue pas que les femmes n'avaient pas besoin de l'autorisation de leurs maris pour ces actes, sinon qu'elles étaient présumées autorisées par leurs maris. Cela veut dire, que l'autorisation du mari pour ces actes était toujours valable et nécessaire, mais que pour des raisons pratiques les femmes devaient être présumées autorisées par leurs maris. Les actes des femmes dans ces cas, restaient dépendant de l'autorisation du mari, ne serait-ce que de manière symbolique.

D'après l'article $14 \mathrm{du}$ projet, la femme mariée pouvait indépendamment de l'autorisation de son mari : 1) exercer les droits qui lui correspondaient sur les personnes et biens de ses enfants naturels ou d'un mariage antérieur;2) libérer ou revendiquer les immeubles du mariage que le mari ait mit en garantie ou aliéné, sans le consentement de sa femme ou du juge ; 3) annuler les cautions et les donations faites par le mari ; 4) revendiquer les biens communs, meubles ou immeubles donnés ou transférés par le mari à sa concubine. La femme pouvait également sans l'autorisation du mari proposer l'annulation du mariage, l'action de divorce, demander les aliments qui lui correspondaient, et faire un testament ou disposition de dernière volonté. D'après l'article 17, la femme avait la direction et l'administration du mariage lorsque le mari se trouvait absent en lieu lointain ou pas connu, s'il était en prison pour plus de deux ans, ou s'il était judiciairement déclaré interdit. Dans ces cas, l'administration des biens communs était accordée à la femme. Par conséquent, celle-ci pouvait disposer de ses biens particuliers ainsi qu'aliéner les biens communs et ceux du mari. Elle pouvait aliéner les biens immeubles communs et ceux du mari avec une autorisation spéciale du juge. Le manque d'autorisation du mari ou du juge invalidait les actes de la femme, et cette nullité pouvait être demandée par le mari ou ses héritiers jusqu'à deux années après la dissolution de la société conjugale.

En ce qui concerne, le type de régime matrimonial, le projet introduisait quatre types de régimes (qui n'existaient pas dans le Code Civil en vigueur): communauté universelle, communauté partielle, séparation et régime dotal. Les époux pouvaient stipuler avant le mariage le régime qui leur serait convenable.

Le régime de communauté universelle établissait la communication de tous les biens présents et futurs des conjoints ainsi que de leurs dettes. La propriété et possession 
des biens étaient communes aux deux conjoints, cependant le seul qui pouvait les administrer était le mari.

Le régime de communauté partielle, excluait de la communauté les biens que chaque conjoint possédait au moment du mariage et ceux obtenus pendant le mariage par donation ou succession. Ce régime excluait également les biens acquis avec des valeurs appartenant exclusivement à l'un des conjoints ou en subrogation des biens patrimoniaux. Il excluait de même les obligations antérieures au mariage, et celles en provenance d'actes illicites ou de quasi délits. Les biens qui entraient dans la communauté étaient: ceux acquis pendant le mariage à titre onéreux même si seulement au nom de l'un des conjoints ; les biens acquis par donation, héritage ou legs à faveur d'un des conjoints; les améliorations des biens propres de chaque conjoint réalisées avec des fonds communs ; les fruits des biens communs ou ceux des biens propres de chaque conjoint perçus pendant le mariage ; les fruits civils de travail ou d'industrie de chaque conjoint ou des deux. L'administration des biens du mariage correspondait au mari, et les dettes contractées par celui-ci engageaient les biens communs, et faute de ceux-ci, les biens particuliers de chaque conjoint en proportion du profit obtenu par chacun d'entre eux.

Dans le régime de séparation, les biens de chaque conjoint étaient sous l'administration exclusive de chacun d'entre eux, qui pouvaient les aliéner librement, s'il s'agissait de meubles. La femme était obligée à contribuer aux dépenses du mariage avec les rendements de ses biens, en proportion à leur valeur, sauf stipulation contraire dans le contrat « antenupcial ».

Dans le régime dotal, chacun des conjoints décrivait séparément dans le contrat « antenupcial» les biens qui constituaient la dot, avec la déclaration qu'ils se soumettaient à ce régime. La dot pouvait être constituée par la future épouse ou par d'autres. La dot pouvait comprendre en tout ou en partie les biens présents et futurs de la femme. Les conjoints ne pouvaient pas augmenter la dot. Une fois la société dotale en vigueur le mari avait le droit d'administrer les biens dotaux, de percevoir les fruits de ceux-ci, et de faire usage des actions judiciaires éventuelles par rapport à ceux-ci. La femme pouvait demander la séparation de la dot, lorsque la mauvaise administration du mari compromettait les biens de celui-ci et de sa femme. Une fois la dot séparée, la femme en exerçait l'administration, mais la dot était toujours inaliénable. La dot devait être restituée par le mari à la femme, ou à ses héritiers dans le mois qui suivait la dissolution de la société conjugale. La femme conservait la 
propriété et l'administration des «bienes parafernales », sans pouvoir aliéner les biens immeubles.

Le projet présenté par Gallardo, accordait des droits civils à la femme mariée qu'elle n'avait pas dans le Code Civil en vigueur. Ainsi, par exemple, elle ne perdait plus sa nationalité lorsqu'elle se mariait à un étranger et ne devait plus « obéissance » à son mari. Cependant, plusieurs limitations restaient toujours en vigueur dans le projet, car celui-ci confirmait le mari en tant que chef de la société conjugale, et lui accordait par conséquent plusieurs privilèges dont par exemple, l'administration des biens, la fixation du domicile, et le pouvoir d'autoriser ou non sa femme à réaliser d'actes divers. La nouveauté introduite dans le projet, était la licence uxoriale, qui limitait les actes du mari. Cependant, cette limitation était également appliquée à la femme qui en plus avait d'autres limitations que le mari n'avait pas. Il s'agissait donc d'un projet avec des réformes modérées qui ne remettait pas en question radicalement la place de la femme au sein du mariage. Celle-ci, une fois mariée, était toujours une mineure puisqu'elle nécessitait de l'autorisation de son mari pour la réalisation de plusieurs actes de la vie civile. Le mari nécessitait de l'autorisation de sa femme mais uniquement dans l'administration des biens appartenant à celle-ci.

Le projet fut envoyé le 24 août 1925 au pouvoir législatif pour qu'il soit étudié et appliqué par les législateurs. Cependant, l'étude de ce projet fut reléguée pour l'année suivante. En 1926, les membres de 1' «Ateneo Femenino » envoyèrent une deuxième demande, sans avoir de réponse de la part du pouvoir législatif. Des projets indépendants concernant l'octroi des droits civils aux femmes, furent présentés au Parlement par les députés Ugarte, Hernandez et Herrero, mais il semblerait qu'ils ne furent jamais débattus dans l'Assemblée. Face à cette indifférence de la part du pouvoir législatif, une conférence sur les droits civils des femmes fut réalisée à l'Université Mayor de San Andrés par Betshabé Levy qui envoya une pétition au Parlement signée par toutes les femmes qui participèrent à l'acte. De même, Raquel Ichazo Vázquez, inspectrice de l'instruction secondaire de la République se chargea de la distribution du projet dans toutes les sociétés culturelles du pays lors d'une tournée d'inspection dans le pays. Néanmoins, le pouvoir législatif de la deuxième moitié de la décennie 1920 se montra complètement indifférent au projet ainsi qu'aux 
demandes réalisées par les membres et les collaboratrices de l'«Ateneo Femenino ${ }^{138}$.

Le projet de cette organisation concernant la réalisation d'un Congrès National de femmes devint finalement une réalité en 1929. En effet, la première Convention Nationale féminine fut convoquée et organisée en mai 1929 à La Paz par l'« Ateneo Femenino ».

Les informations que l'on a sur cette Convention sont malheureusement très limitées et proviennent uniquement de sources secondaires bibliographiques ${ }^{139}$. Cependant, l'on sait que cette Convention eut lieu dans les salons de l'Université Mayor de San Andrés, et que plusieurs organisations féminines de tout le pays y assistèrent, notamment des organisations culturelles et de bienfaisance. Participèrent de même, des syndicats ouvriers. Ainsi, y assistèrent des déléguées de la «Federación Obrera del Trabajo» («FOT»), telles que Angélica Azcui (voir annexe A n²4), et Carmen Guillén. La première présenta une communication intitulée « Organisation ouvrière » et la deuxième un «Projet de législation ouvrière pour garantir le travail des femmes de ménage ». Participèrent également les membres de la «Federación Obrera Femenina » («FOF), tels que Susana Rada, Catalina Mendoza et Rosa Calderón, et des déléguées du « Sindicato Femenino de Oficios Varios ».

Très rapidement, les différences de classe et par conséquent de conceptions et demandes entre les femmes appartenant aux sociétés culturelles et de bienfaisance et celles appartenant aux syndicats ouvriers se firent sentir. Les premières, qui appartenaient aux classes moyennes et élevées de la société concentraient leurs expositions sur la nécessité d'acquérir les droits civils et politiques des femmes et traitaient des questions sociales de manière très paternaliste, faisant appel aux valeurs chrétiennes de la charité. Les deuxièmes concentraient leurs demandes sur des problèmes de classe, tels que la lutte pour la journée de huit heures de travail, la construction de marchés, le soutien à ses «camarades" hommes ouvriers, etc. Il y avait donc un abîme entre les conceptions de ces femmes sur le rôle que devaient jouer les femmes dans la société, et entre les demandes qu'elles avaient pour

\footnotetext{
${ }^{138}$ Indice $\mathrm{n}^{\circ} 1$, décembre 1927, La Paz. Centro de Informaciôn y Desarrollo de la Mujer (CIDEM), La Paz - Bolivie.

${ }^{139}$ MEDINACELLI, Ximena, Alterando la rutina. Mujeres en las ciudades de Bolivia 1920 - 1930, CIDEM, La Paz - Bolivia, 1989.
} 
améliorer la condition des femmes dans le pays. Les femmes syndicalistes accusèrent les femmes des classes moyennes d'être influencées par les curés :

«À l'occasion de la Convention Nationale de femmes réalisée à La Paz, Bolivie, le syndicat féminin de La Paz édita un manifeste dans lequel il expose ses points de vue par rapport au problème de l'émancipation féminine. Ce syndicat qui a une orientation libertaire, se présenta à cette convention, et manifesta d'immédiat qu'il se trouvait seulement dans l'opposition, car les autres délégations avaient été façonnées par les curés et avaient organisé la convention, non pour lutter pour l'amélioration des conditions de la moitié du genre humain, de la femme vilement dominée par l'homme et exploité par le capitalisme, mais pour exalter la religion et introniser le cœur de Jésus dans les foyers et dans les écoles de la Bolivie. ${ }^{140}$

Les femmes syndicalistes finirent par se retirer de la Convention en signe de protestation et organisèrent une manifestation de répudiation contre celle-ci dans laquelle participèrent des hommes et des femmes des différents syndicats, qui prononcèrent des discours en aymara, manifestant ainsi non seulement des différences de classe avec les femmes des organisations culturelles et de bienfaisance mais aussi des différences de culture.

La première Convention Nationale de femmes organisée par l'«Ateneo Femenino » fut un échec. Les différences de classe et les différences culturelles entre les différentes femmes présentes à cet événement étaient irréconciliables: les conceptions sur le rôle que devaient jouer les femmes dans la société, les demandes qu'avaient les divers groupes étaient complètement différentes et reflétaient leur position de classe dans la société. Les intérêts des femmes des classes moyennes et élevées et ceux des femmes des classes populaires n'étaient pas du tout les mêmes. Une union entre ces deux secteurs pour lutter pour l'amélioration des conditions de vie des femmes en général semblait donc impossible. Le premier effort réalisé vers une union interclassiste de femmes n'eut donc aucun résultat.

\footnotetext{
140 «Con motivo de la convención nacional de mujeres realizada en La Paz, Bolivia, el sindicato femenino de La Paz editó un manifiesto en que expone sus puntos de vista frente al problema de la emancipación femenina. Dicho sindicato que tiene orientación libertaria, hízose presente en dicha convención, y se puso de manifiesto de inmediato que se hallaba sólo en la oposición, pues las demás delegaciones eran hechura de los curas y habían organizado la convención, no para luchar por mejorar las condiciones de la mitad del género humano, de la mujer vilmente dominada por el hombre y explotada por el capitalismo, sino para exaltar la religión y entronizar el corazón de Jesús en los hogares y en las escuelas de Bolivia. »Tiré de MEDINACELLI, Ximena, Alterando la rutina. Mujeres en las ciudades de Bolivia 1920 - 1930, CIDEM, La Paz - Bolivia, 1989.
} 
Les actions réalisées par les associations féministes des années 1920 s'inscrivaient dans un cadre complètement légal et pacifiste. Au lieu de sortir dans les rues pour manifester afin de faire connaître leurs demandes à la société et aux hommes politiques, les femmes des organisations féministes des années 1920 publiaient des revues féminines culturelles et littéraires. A côté de poèmes et d'essais historiques, se publiaient des articles sur l'éducation des femmes, des réflexions sur leur place dans la société, des articles parlant de la nécessité d'obtenir les droits civils et politiques. C'était le moyen que les femmes cultivées appartenant aux classes moyennes et élevées de la société et qui se proclamaient féministes avaient trouvé pour communiquer leurs réflexions, inquiétudes et revendications par rapport à la condition de femmes dans le pays. Etant donnée la durée de vie éphémère de la plupart de ces organisations, la publication de revues féminines - féministes fut la seule action réalisée par ces organisations éphémères qui disparurent assez vite avec leurs revues. La seule organisation qui réussit à réaliser d'autres actions fut l' « Ateneo Femenino », de par sa durée de vie beaucoup plus longue et la solidité de son organisation. Celui-ci réussit la création de réseaux féministes dans le pays, mais aussi au delà des frontières avec la présence de membres correspondantes dans les différentes villes du pays, d'Amérique du Sud et d'Europe. Il s'intégra au mouvement féministe international de l'époque en formant partie du Conseil International de femmes et du Conseil National de femmes argentines. En outre, il participa aux Congrès internationaux de femmes réalisés au Pérou et au Mexique en 1925. Mais son action ne se limita pas à cela, des projets furent concrétisés par cette organisation afin d'obtenir les droits civils et politiques des femmes tels que la création du « projet de réintégration des droits civils des femmes » en 1925 et l'organisation de la première Convention féminine en 1929. Même si ces dernières actions échouèrent en raison de l'indifférence des hommes politiques à l'égard des projets sur l'octroi des droits civils des femmes et en raison des différences culturelles et de classe des femmes réunies dans la Convention féminine, elles créèrent des précédents pour les organisations à venir dans les décennies suivantes.

Ces actions que l'on a étudiées nous informent sur le mouvement féministe en tant qu'organisation collective réunissant plusieurs associations féministes en vue d'atteindre des objectifs communs. Mais qu'en est-il de l'idéologie de ce mouvement? Qu'en est-il des motifs et des objectifs qui poussaient ces femmes à agir et à se mobiliser ? Quels étaient les fondements théoriques, éthiques et philosophiques 
sur lesquels se basaient ces femmes pour donner sens à leurs actions ? Les motifs et les objectifs des femmes appartenant aux organisations féministes ont été entrevus rapidement lors de l'analyse des organisations en elles mêmes et de leurs actions. Il s'agira désormais d'analyser en détail quels étaient les fondements théoriques, éthiques et philosophiques construits par les associations féministes des années 1920. En d'autres termes, il s'agira de comprendre quel était le type de féminisme qu'elles proclamaient et auquel elles s'adhéraient. Comment envisageaient-elles le mouvement féministe international ? Comment s'appropriaient-elles les principes du féminisme international afin de créer un féminisme propre auquel elles pouvaient s'identifier ? Ces questions présupposent que l'on étudie quelles étaient exactement les demandes des différentes associations féministes mais aussi comment elles inscrivaient leurs actions et leur travail dans la société.

\section{D) Quel féminisme, quelles demandes et quels projets ?}

\section{a) Le type de féminisme revendiqué}

Les fondements théoriques du féminisme revendiqués par les organisations féministes peuvent être appréhendés à travers de la lecture des revues qu'elles publiaient. En effet, un grand nombre d'articles sont consacrés à la définition du féminisme, avec des réflexions sur le féminisme international de l'époque et sur ce que signifiait être féministe. Les femmes qui écrivaient pour ces revues se proclamaient elles mêmes féministes et essayaient de donner une définition de ce qu'elles entendaient pour «féminisme». Les principes éthiques, philosophiques, littéraires et politiques de ce qui était l'idéologie de leur organisation collective se dégagent de la lecture de ces publications nous permettant de comprendre et de cerner ce qui donnait sens à leur mobilisation.

Les féministes des années 1920 en Bolivie, montraient une constante préoccupation sur les avances du féminisme international à l'époque. Elles publiaient très souvent des articles consacrés aux Congrès de femmes qu'avaient lieu dans d'autres pays, les actions qu'avaient réalisées les associations féministes dans d'autres pays, les triomphes des féministes de l'étranger avec l'obtention des droits civils et politiques, etc. Les avances du féminisme à l'étranger occupaient donc une place 
prépondérante dans leurs publications. En même temps, les féministes boliviennes considéraient qu'elles répondaient à l'appel lancé par les féministes des autres pays afin de lutter pour les droits des femmes dans leur pays. Elles voyaient dans les EtatsUnis par exemple, un des pays à l'origine du mouvement féministe qui se répandit dans les pays d'Amérique du Sud, dont la Bolivie. Elles admettaient ainsi que le féminisme international avait une influence directe sur leur mobilisation, même si elles considéraient que le féminisme en Bolivie était encore dans ses débuts et qu'il y avait un long chemin à faire encore. C'est ce qui est exprimé dans un article de la revue Feminiflor d'octobre 1923 :

«C'est avec une grande satisfaction qu'on reçoit les nouvelles qui arrivent jusqu'à nous des avances que réalise dans le monde entier le Féminisme. - La femme s'est mise en action et bientôt elle verra ses rêves réalisés et ses justes aspirations accomplies. - Le nombre de dames cultivées et intelligentes qui forment le «Féminisme» est considérable.

Ce fut en Amérique du Nord où la femme fit entendre sa voix de protestation, ce fut là-bas où s'entendit le premier coup de clairon du Féminisme, où la femme réclame les justes droits qui lui correspondent; où la femme ne faiblit pas et continue à lutter pour un idéal commun ; c'est là où le Féminisme avance et où «La Femme » occupera bientôt sa véritable place.

La voix lancée par la femme nord-américaine a répercuté dans presque tous les pays de l'Amérique du Sud en réveillant les femmes de la léthargie où elle se trouvaient, elles ont entendu au loin la voix de protestation demandant justice pour la femme et elles ne sont pas restées indifférentes, elles se sont également mises en action et aujourd'hui le «Féminisme» avance dans quelques pays de l'Amérique du Sud; où les femmes luttent pour un même idéal (...)

En Bolivie, le Féminisme s'oriente résolument, il reste encore beaucoup à faire, mais on réussira, un jour viendra où le Féminisme triomphera, non pas ce Féminisme batailleur et politique, mais le vrai féminisme, conscient de devoirs et de droits qui place la femme dans la véritable place qui lui correspond. Il n'y a pas longtemps que la femme bolivienne vivait dans l'infériorité mentale par rapport à l'homme ; elle restait indifférente. Aujourd'hui la jeunesse féminine s'illustre, lutte pour un idéal, réclame les droits pour la femme. Et le jour arrivera dans lequel la femme Bolivienne verra ses justes aspirations accomplies. \" 141

\footnotetext{
141 «Con gran satisfacción recibimos las noticias que llegan hasta nosotras de los avances que en todo el mundo está haciendo el Feminismo.- La mujer se ha puesto en acción y muy pronto ha de ver realizados sus sueños y cumplidas sus aspiraciones.- Es considerable el número de damas cultas e inteligentes que forman el "Feminismo".

Fue en América del Norte donde la mujer hizo escuchar su voz de protesta, fue allí donde se escuchó el primer clarinazo del Feminismo, donde la mujer reclama los justos derechos que a ella le corresponden;
} 
En même temps que les rédactrices de Feminiflor admettaient l'influence du féminisme états-unien comme étant à l'origine du «réveil» du féminisme en Amérique du Sud, et qu'elles établissaient par conséquent une filiation, une lignée directe entre les deux, elles se démarquaient de ce féminisme qu'elles qualifiaient de « batailleur et politique » pour proclamer le « vrai » féminisme: celui « conscient de devoirs et de droits ». Une contradiction surgit alors puisqu'en même temps qu'elles légitimaient le féminisme états-unien en le considérant le point d'origine de la « voix de protestation » de femmes en Amérique, elles le délégitimaient en impliquant qu'il s'agissait d'un faux féminisme par opposition au «vrai» féminisme. En effet, lorsqu'elles parlaient des fondements du féminisme à l'étranger, c'était toujours pour s'en démarquer et donner une définition propre de leur féminisme en contraste.

Contrairement au type de féminisme qu'elles revendiquaient, elles considéraient que celui des Etats Unis était « batailleur» et « excessif ». D’après elles, ceci pouvait être expliqué par la longue histoire d'oppression sur les femmes de ce pays avec les dogmes du puritanisme. Tout un article est consacré à ce sujet dans le numéro 22 de la revue Feminiflor :

«Contrairement à ce qu'on pense hors des Etats-Unis, la femme de ce pays ne jouit pas depuis toujours de la liberté. Au contraire. Dans leur cas s'applique bien l'idée selon laquelle la liberté est pour ceux qui la méritent, pour ceux qui savent lutter pour elle.

La liberté dont jouit la femme nord-américaine n'est pas un de ces héritages providentiels que l'on gaspille par pure ignorance de ce que ça a coûté de la gagner. Les prérogatives féminines sont au contraire dans ce pays un droit encore en train d'être conquis, qui doit être affirmé avec emphase par la même génération qui le conquit. En un mot, même les excès d'aujourd'hui s'expliquent par l'oppression d'hier, et la «flapper» d'aujourd'hui n'est rien d'autre que cela, la

donde la mujer no desmaya y sigue luchando por un común ideal; es allí donde el Feminismo avanza y donde pronto ha de ocupar "La Mujer" su verdadero puesto.

La voz lanzada por la mujer Norteamericana ha repercutido en casi todos los países de Sud América despertando a la mujer del letargo en que se hallaba, han escuchado a lo lejos la voz de protesta pidiendo justicia para la mujer y no han permanecido indiferentes, se han puesto también en acción y hoy el "Feminismo avanza en algunos países de Sur América; donde las mujeres luchan por un mismo ideal (...)

En Bolivia el Feminismo viene orientándose decididamente, aún falta mucho por hacer, pero se conseguirá, día llegará en que triunfe el Feminismo, no ese Feminismo batallador y político, sino el verdadero feminismo; consciente de deberes y derechos que coloca a la mujer en el verdadero puesto que a ella le corresponde. Hasta hace pocos años la mujer Boliviana ha vivido en inferioridad mental con respecto del hombre; permanecía indiferente.- Hoy la juventud femenina se ilustra, lucha por un ideal, reclama para la mujer sus derechos. Y día llegará en que la mujer Boliviana vea cumplida sus justas aspiraciones. » Feminiflor, n²4, octobre 1924, Oruro. Hemeroteca de la Universidad Mayor de San Andrés, La Paz - Bolivie. 
réaction personnifié des aspirations contenues dans la femme coloniale par une discipline sociale et religieuse de fer (...)

Ce n'est pas par hasard que la rébellion féministe commença dans cette Nouvelle Angleterre, où les puritains avaient fondé une théocratie pas moins exclusivement masculine que la mosaïque (...) Les Pèlerins avaient des femmes, l'idée théologique d'un être impur et fatalement faible en volonté. Leurs prédicateurs la maintenaient dans une constante terreur de l'enfer... » ${ }^{142}$

Les rédactrices de la revue Feminiflor cherchaient à comprendre les causes du caractère «excessif » du féminisme états-unien et elles en conclurent que plus les femmes avaient été reléguées et opprimées dans le passé par des raisons culturelles et religieuses, plus leur rébellion était « excessive», car réalisée en réaction à cette oppression. D'où, d'après elles, le modèle de la «flapper» apparue aux Etats-Unis dans les années 1920, symbole de la femme masculinisée par son comportement (elle buvait, fumait, fréquentait les clubs de jazz, conduisait des voitures, faisait du sport et avait des mœurs libérées) et par son apparence physique (port de cheveux courts ; silhouette androgyne et longiligne, où n'étaient plus marquées ni la poitrine, ni la taille). Ainsi, dans le même article les rédactrices expliquent que le féminisme en France était beaucoup plus modéré. Cela s'expliquait par le fait que la femme française avait toujours joué un rôle d'importance dans la société :

«Comme un moyen terme d'une société qui n'a pas passé des extrêmes de l'oppression à ceux du suffragisme, nous avons la société française, où la femme occupa pendant des siècles une position propre ; de directrice de cérémonies dans la vie sociale, de vestale dans les cercles intellectuels et de chef du foyer dans la famille en ce qui concerne sa gestion interne. Aux Etats-Unis c'est autre chose. ${ }^{143}$

\footnotetext{
142 «Contrariamente a lo que se cree fuera de Estados Unidos, la mujer de este país no gozó siempre de libertad. Por el contrario. En su caso queda bien aplicado aquello de que la libertad es para aquellos que la merecen, para los que saben pelear por ella.

La libertad de que goza la mujer norteamericana no es ninguna de esas herencias providenciales que se derrocha por pura ignorancia de lo que ha costado ganarla. Las prerrogativas femeninas son por el contrario en este país un derecho todavía conquistado, el que debe ser afirmado con énfasis por la misma generación que lo conquistó. En una palabra, hasta los excesos de hoy se explican por la opresión de ayer, y la "flapper" del día de hoy no es más que eso, la reacción personificada de los anhelos contenidos en la mujer colonial por una férrea disciplina social y religiosa (...)

No en balde la rebelión feminista comenzó en esa Nueva Inglaterra donde los puritanos habían fundado una teocracia no menos exclusivamente masculina que la mosaica (...) Los Peregrinos tenían de la mujer la idea del ser impuro y fatalmente flaco de voluntad. Sus predicadores la mantenían en perpetuo terror del infierno... » Feminiflor,n ${ }^{\circ} 22$, mai 1923, Oruro. Hemeroteca de la Universidad Mayor de San Andrés, La Paz - Bolivie.

143 "Como un término medio de una sociedad que no ha tenido que pasar de los extremos de la opresión a los del sufragismo, tenemos la sociedad francesa, donde la mujer ha ocupado por siglos una posición propia; de directora de ceremonias en la vida social, de vestal en los círculos intelectuales y de
} 
Le féminisme français était beaucoup plus modéré par rapport à celui des Etats-Unis car d'après les rédactrices de Feminiflor, les françaises n'avaient pas été aussi opprimées dans le passé comme les femmes états-uniennes. Les grandes distinctions entre le féminisme anglo-saxon des Etats-Unis, et le féminisme français, pouvaient s'expliquer d'après les rédactrices de Feminiflor par l'histoire de chacun des pays et le rôle qu'avaient joué les femmes dans le passé. Elles étaient en train de distinguer et de caractériser deux types de féminisme existant dans le monde par l'histoire culturelle et religieuse des pays d'où ils provenaient.

Ces distinctions qu'elles réalisaient entre le féminisme états-unien et le féminisme français nous donnent les moyens pour proposer deux catégories de féminisme qui nous permettront d'essayer de comprendre où est-ce que les féministes boliviennes des années 1920 se situaient et quel type de féminisme elles revendiquaient. S'il est vrai que les féminismes sont extrêmement divers et qu'il est très difficile de leur attribuer des catégories qui les fixeraient de manière artificielle en supprimant toutes leurs subtilités dans le temps et dans l'espace, on peut tout de même essayer de distinguer deux catégories générales d'analyse qui nous permettent de distinguer et caractériser deux types généraux de féminisme dans le monde occidental. Cet exercice répond à un enjeu méthodologique essentiel qui est celui d'essayer de donner une définition de l'objet de recherche étudié. Ces catégories d'analyse nous permettront de situer le type de féminisme revendiqué par les féministes des années 1920 en Bolivie, et nous permettront par conséquent d'essayer d'en donner une définition. Karen Offen et Marisa Ferrandis Garayo, proposent deux catégories d'analyse pour cerner les féminismes surgis dans le monde occidental dans le $\mathrm{XIX}^{\mathrm{e}}$ et $\mathrm{XIX}^{\mathrm{e}}$ siècles. La première catégorie est celle du féminisme « relationnel» et la deuxième celle du féminisme «individualiste». Comme elles l'expriment: « Desde una perspectiva histórica, los argumentos de la tradición feminista relacional proponían una visión de la organización social fundada en el género pero igualitaria. Como unidad básica de la sociedad, defendían la primacía de una pareja, hombre/mujer, no jerárquica y sustentada en el compañerismo, mientras que los argumentos individualistas presentaban al individuo, con independencia del sexo o género, como la unidad básica. El feminismo relacional ponía el énfasis en los 
derechos de las mujeres como mujeres (definidas principalmente por sus capacidades de engendrar y/o criar) respecto de los hombres. Insistía en la distinta cualidad, en virtud de esas funciones, de la contribución de las mujeres al resto de la sociedad y reclamaba los derechos que le confería dicha contribución. Como contraste, los argumentos feministas de tradición individualista hacían hincapié en los conceptos más abstractos de los derechos humanos individuales y exaltaban la búsqueda de la independencia personal (o autonomía) en todos los aspectos de la vida, a la vez que descalificaban, desaprobaban o rechazaban por insignificantes todos los roles definidos socialmente y minimizaban la discusión de las cualidades o contribuciones relacionadas con el sexo, incluidas las responsabilidades de engendrar y sus concomitantes. ${ }^{144}$

Bien évidemment, ces définitions des catégories proposées ne se trouvent jamais de manière aussi claire et distincte dans la réalité. Il s'agit donc de catégories d'analyse et non pas de définitions fixes sur deux types de féminisme des $\mathrm{XIX}^{\mathrm{e}}$ et $\mathrm{XX}^{\mathrm{e}}$ dans le monde occidental. A l'intérieur de chacune de ces catégories on peut trouver des idées et des fondements empruntés à l'autre. Comme les auteures affirment : «En los siglos anteriores podemos encontrar a menudo testimonios de ambos en las palabras de un solo individuo, o entre los miembros de un grupo concreto... ${ }^{145}$ Même si ces deux catégories pourraient être critiquées en tant que reflets de la pensée dualiste et binaire occidentale, il est vrai qu'elles sont des catégories utiles pour appréhender les féminismes dans le monde occidental : «Para que no se piense que los dos enfoques que aquí cito son sólo otro lamentable ejemplo de la tantas veces censurada lógica binaria, endémica en el pensamiento occidental, o una forma de reduccionismo, permítaseme indicar que hay razones sociológicas importantes para proponer dos y nada más que dos categorías en lugar de "variedades" o "grados relativos" de feminismo. Es cierto que estos dos modos de razonamiento reflejan el dualismo yo/otro característico del pensamiento occidental, pero continúan siendo operativos porque también reflejan las profundas diferencias de opinión que durante tanto tiempo han existido en el discurso occidental sobre las cuestiones estructurales básicas de la organización social y, en particular, sobre la relación de los individuos y

\footnotetext{
144 OFFEN Karen et FERRANDIS Garayo Marisa, «Definir el feminismo : Un análisis historico comparativo », Historia Social, n9 (Winter 1991), p.103-135.

${ }^{145}$ Idem.
} 
de los grupos familiares con la sociedad y el estado. Si se piensa que el feminismo tiene que entenderse históricamente, deben abordarse los dos. » ${ }^{146}$

D'après Karen Offen et Marisa Ferrandis, le féminisme « relationnel » aurait dominé le féminisme européen au $\mathrm{XIX}^{\mathrm{e}}$ siècle et se trouverait notamment représenté en France, alors que le féminisme « individuel» concernerait le monde anglo-saxon et serait apparu à la fin du XIX ${ }^{\mathrm{e}}$ siècle avec la publication en 1869 du livre de Stuart Mill The Subjection of Women. Le féminisme « individuel» en outre, aurait marqué l'Europe pendant tout le $\mathrm{XX}^{\mathrm{e}}$ siècle. Il est clair que, comme on l'a déjà dit, ces catégories ne reflètent pas de manière exacte la réalité : le féminisme anglo-saxon ne peut pas être réduit uniquement à la catégorie de féminisme «individuel» ni le féminisme français à la catégorie de féminisme «relationnel». Des fondements de tous les deux se trouvent dans toute l'Europe tant au XIX ${ }^{\mathrm{e}} \mathrm{qu}^{\prime} \mathrm{au} \mathrm{XX}^{\mathrm{e}}$ siècle. Cependant, ces catégories nous permettent de comprendre et de distinguer à grands traits les fondements théoriques de deux types de féminisme dans le monde occidental dans lequel s'inscrit le féminisme revendiqué par les féministes boliviennes des années 1920. Dans les articles sur le féminisme qu'elles publient dans leurs revues on retrouve clairement les fondements théoriques qui caractérisent le féminisme « relationnel ». La vision de l'organisation sociale fondée sur le genre de manière égalitaire se retrouve dans plusieurs des articles de ces revues, ainsi que le concept de couple comme unité de base, avec des relations égalitaires de «compañerismo ». La femme devait s'éduquer pour pouvoir être la « compañera », (« la compagne ») de l'homme non seulement dans le domaine intellectuel, mais dans tous les aspects de la vie. De même, les droits revendiqués par les féministes boliviennes sont revendiqués pour les femmes en tant que femmes et non pas en tant qu'individus neutres. Le rôle social des femmes en tant qu'êtres capables d'engendrer des enfants et de les élever est constamment exalté par les féministes boliviennes, qui considéraient que le domaine principal de la femme était le foyer (« Hogar») avec la famille. La maternité est ainsi toujours exaltée et mise en avant comme argument pour l'obtention des droits sociaux, civils, politiques, car la mère jouait un rôle essentiel dans la société à travers de la reproduction et de l'éducation des futurs citoyens. Dans ce sens, les « qualités féminines » propres aux femmes n'étaient pas niées, mais au contraire, elles étaient défendues et utilisées comme des arguments pour prouver que les femmes

\footnotetext{
${ }^{146}$ Idem.
} 
devaient obtenir leurs droits. Les femmes ayant une sensibilité beaucoup plus développée que les hommes, elles étaient «pur sentiment», tandis que les hommes étaient «pure raison». Les lois devaient être élaborées avec «sentiment» et « raison» et c'est pour cette raison que les femmes devaient avoir le droit de participer aux comices par exemple. Cette exaltation des qualités féminines s'inscrivait dans la conception essentialiste qu'avaient les féministes boliviennes des années 1920 sur « La Femme ». Comme on a pu déjà le voir, elles parlent toujours de « la femme » au singulier et jamais « des femmes » au pluriel. Elles considéraient donc « la femme » de manière essentialiste comme une entité aux qualités immuables dans le temps et dans l'espace. «La femme » avait toujours les mêmes qualités peu importent les classes sociales auxquelles elle appartenait où le temps et l'espace qu'elle habitait. Dans ce sens, la femme avait une «essence» immuable qu'elle devait à son sexe biologique. Le genre et le sexe étaient une seule et même chose dans les conceptions des féministes boliviennes des années 1920.

Ainsi, même si à aucun moment elles ne s'identifient avec le féminisme d'un certain pays en particulier, elles se démarquent véritablement du féminisme « individualiste » anglo-saxon qu'elles considéraient comme « violent» « excessif », et « masculin » en faisant souvent référence aux actions des «suffragettes»qu'elles condamnaient clairement. C'est ce qu'exprime Bethsabé Salmón Fariñas (voir annexe A n4) en novembre 1923:

«Et notre féminisme est celui-là, pas celui qui arbore des haillons dans les comices électoraux à travers les rues et les places. Loin de ce féminisme grotesque il y a quelque chose de plus sacré et de plus noble : le foyer (« el Hogar»). Et à ce foyer la femme doit apporter sa part de spiritualisme et de culture qui fasse d'elle un être conscient et non pas une estampe décorative comme jusqu'à aujourd'hui. ») ${ }^{147}$

Face à ce féminisme anglais « excessif » elles présentaient le féminisme français comme un modèle à suivre auquel elles s'identifiaient beaucoup plus:

«Le féminisme français continue à imprimer sur son œuvre une direction plus humaine et utile que son congénère anglais. Pendant que celui-ci vota pour l'obtention du vote politique au milieu du feu, des bombes, de la destruction des auvres d'art et de manifestations

\footnotetext{
${ }^{147}$ «Y ese es nuestro feminismo, no aquel que enarbola harapos en los comicios electorales por calles y plazuelas. Lejos de ese feminismo grotesco hay algo más sagrado y más noble: el Hogar. Y a ese hogar debe la mujer llevar su acuotación de espiritualismo y cultura, que hagan de ella un ser consciente y no una estampa decorativa como hasta hoy. " Feminiflor, n²5, novembre 1923, Oruro. Hemeroteca de la Universidad Mayor de San Andrés, La Paz - Bolivie.
} 
scandaleuses, le féminisme français combat pour l'amélioration sociale de la femme et de l'enfant, et se traduit par des organisations de protection et d'aide. ${ }^{148}$

La défense des qualités féminines propre aux femmes faisait partie du féminisme proclamé par ces femmes. Il s'agissait en même temps de se défendre des critiques de l'époque selon lesquelles les féministes « reniaient» leur sexe et leurs obligations au sein du foyer et de la famille. Dans le même article Bethsabé se défend de ces critiques ainsi :

«Il est temps déjà d'offrir une compréhension plus ample de nos intentions. Il est nécessaire que l'on comprenne qu'on n'est pas des renégates de notre sexe, de notre mission sacrée dans le foyer («hogar »). On veut seulement un peu de justice. Que la femme soit éduquée et instruite pour que la patrie soit grande. ${ }^{149}$

L'affiliation au féminisme international ainsi que la critique du féminisme « extrémiste » anglo-saxon représenté à travers des « suffragettes » sont également claires dans les écrits de l'« Ateneo Femenino» :

« L'action féminine dans le monde est déjà si répandue, qu'aucun pays ne peut se soustraire à son influence civilisatrice. Pour cela, l'ensemble des associations féminines représente une véritable institution sociale qui joue un rôle très important dans la société, non seulement en Europe et aux Etats-Unis, mais aussi dans plusieurs nations sudaméricaines.

Ce souffle de culture est arrivé jusqu'à nous pas très tôt, certes, mais il n'est jamais tard pour entreprendre la croisée de santé qu'un jour se traduira par des œuvres d'impondérable bienfaisance.

Et quel est notre Nord, l'aspiration, l'idéal que nous devons poursuivre? Il y eut un temps où le mot «féminisme» inspirait une certaine inquiétude dans les grandes sociétés et représentait une notion inacceptable dans les petites nations, où il était considéré comme une voie égarée et étrangère au destin de la femme. Ne parlons pas du féminisme extrémiste, celui de la vieille fille suffragiste avec des accès de fanatisme anarchiste qui est la risée du monde. Mais parlons du féminisme sage, raisonnable, fruit de la charité chrétienne et de l'amour à la culture de la femme et de l'enfant, futur représentant du progrès national; du féminisme conseil du foyer et barrière contre le

\footnotetext{
148 «El feminismo francés continúa imprimiendo a su obra otra dirección más humana y más útil que su congénere el inglés. Mientras éste luchó por el voto político por medio del fuego, de las bombas de la destrucción de las obras de arte y de las manifestaciones escandalosas, el francés combate por el mejoramiento social de la mujer y del niño, y se traduce en organizaciones de protección y de ayuda. » Aspiración, n², octobre 1923, La Paz. Centro de Informaciôn y Desarrollo de la Mujer (CIDEM), La Paz - Bolivie.

149 «Es tiempo ya de dar una comprensión más amplia a nuestras intenciones. Es necesario que se comprenda que no somos renegadas de nuestro sexo, de nuestra sacra misión en el hogar. No queremos sino un poco de justicia. Que se eduque y se instruya a la mujer para que la patria sea grande. » Idem.
} 
vice (...) L' « Ateneo Femenino » commence ses premiers pas dans cet ouvrage et un augure de confiance dans le triomphe semble venir de tous les domaines du monde et habiter dans tous les cœurs, malgré toutes les vieilles inquiétudes, car en franchissant les portes du foyer pour chercher des nouveaux horizons pour son activité, la femme n'oublie pas ses obligations sacrées de mère et d'épouse ; une longue expérience a démontré que la femme intellectuelle est moins frivole et plus consciente de sa mission dans la société et dans la famille.

Est-ce que ces idéaux sont trop grands pour notre force ? Le cœur humain s'alimente d'eux et un esprit d'action collective dans les femmes boliviennes, facilitera le grand ouvrage, au service duquel je mets la modeste participation de ma foi. $)^{150}$

Les membres de 1' «Ateneo Femenino » voyaient également comme nécessaire se défendre des accusations selon lesquelles les féministes perdaient leurs «qualités féminines »:

«Pour nous, le féminisme est le résumé d'égal accueil des lois pour l'homme et pour la femme et nous ne croyons pas que pour avoir les droits qui lui correspondent, la femme, perde sa féminité, car celle-ci réside dans le cœur, dans l'âme; et des simples accidents de la vie extérieure ne peuvent pas tuer un esprit : 1'esprit ne meurt pas. ${ }^{151}$

«La femme » était féminine par essence, avoir des droits ne changerait jamais son essence ni ses qualités féminines. Dans les conceptions des femmes de l'époque il

150 «La acción femenina en el mundo es ya tan extensa, que ningún país pudiera sustraerse a su influencia civilizadora. Por ello, el conjunto de las asociaciones femeninas representa, no solamente en Europa y Estados Unidos, sino también en muchas naciones sud-americanas, una verdadera institución social que juega rol importantísimo en la sociedad.

Ese hálito de cultura ha llegado hasta nosotros no muy temprano, ciertamente, pero nunca tarde para emprender la cruzada de salud que un día se traducirá en obras de imponderable beneficio.

Y ¿cuál es nuestro Norte, la aspiración, el ideal que debemos perseguir? Hubo un tiempo en que la palabra "feminismo" inspiraba cierta inquietud en las grandes sociedades y algo como una noción inaceptable en las pequeñas, donde se le consideraba como un camino extraviado y ajeno al destino de la mujer. No hablemos del feminismo extremista, el de la solterona sufragista con arranques de fanatismo anarquista que mueve a risa en el mundo. Hablemos sí del feminismo cuerdo, razonador, fruto de la caridad cristiana y del amor a la cultura de la mujer y del niño, futuro exponente del adelanto nacional; del feminismo, consejo del hogar y barrera contra el vicio (...) El Ateneo Femenino inicia sus primeros pasos en esa obra y un augurio de confianza en el triunfo parece venir de todos los ámbitos del mundo y vivir en todos los corazones, a pesar de todas las preocupaciones antiguas, porque al franquear las puertas del hogar para buscar nuevos horizontes a su actividad la mujer no abandona sus sagradas obligaciones de madre y de esposa; larga experiencia ha demostrado que la mujer intelectual es menos frívola y más consciente de su misión en la sociedad y en la familia.

¿Son estos ideales demasiado grandes para nuestra fuerza? De ellos vive el corazón humano y un espíritu de acción colectiva en las mujeres bolivianas facilitará la grande obra, en servicio de la cual, yo pongo el escaso concurso de mi fe. » Eco Femenino, n4, janvier 1924, La Paz. Hemeroteca de la Universidad Mayor de San Andrés, La Paz - Bolivie.

151 «Para nosotros feminismo es el resumen de igual acogida por las leyes al hombre y a la mujer y no creemos que por tener los derechos que le correspondan, la mujer. Pierda su feminidad, pues, ella reside en el corazón, en el alma; y meros accidentes de la vida exterior no pueden matar un espíritu: el espíritu no muere. » Eco Femenino, n , septembre 1924, La Paz. Hemeroteca de la Universidad Mayor de San Andrés, La Paz - Bolivie. 
était donc absurde et ridicule de vouloir se dégager de sa féminité. «La femme » ne devait pas sortir de son rôle de femme ni de la sphère féminine dans laquelle elle se trouvait inscrite. C'est ce qu'affirment les rédactrices de Aspiración :

« Il semble qu'il y a un point sur lequel nous sommes toutes d'accord: la femme, en sachant plus, n'est pas moins femme ; mais bien entendu, elle ne doit pas tomber dans l'erreur signalé par De Maistre dans la célèbre lettre envoyée à sa fille dans laquelle il lui disait : "Certaines femmes croient que pour être distinguées elle doivent se comporter à la manière des hommes. La femme ne peut pas être supérieure sinon en tant que femme ; lorsqu'elle prétend imiter l'homme elle devient une guenon $(. .$.

Les femmes nous devons être quelque chose pour nous mêmes, des vraies femmes dans le sens plein et meilleur du terme... » ${ }^{152}$

\section{C'est ce qu'affirment également les rédactrices de Venas de Plata:}

«Le féminisme a été interprété de manière diverse, la noblesse de ses intentions a été très faussée. La femme en réclamant et en défendant ses droits ne fait que demander la part qui lui correspond dans le droit et la lutte pour la vie. Elle ne prétend pas abandonner le foyer pour se lancer à l'érudition et à la tribune; mais sans méconnaître les obligations domestiques (qui dans ce cas cessent d'être routinières) aussi agréables comme subtiles, elle veut avoir participation en ce qui concerne les diverses connaissances, si elle a éduqué et développé son intelligence, son critère et son jugement, pourquoi on lui niera qu'elle travaille intellectuellement dans la sphère qu'elle maîtrise ? » ${ }^{153}$

Les femmes devaient être éduquées et cultivées pour être de bonnes compagnes ( « compañeras ») des hommes, mais elles devaient aussi être de bonnes mères, des bonnes femmes au foyer. Les femmes ne devaient surtout pas délaisser les tâches ménagères et leur place au sein du foyer et au sein de la famille, pour se cultiver. La

\footnotetext{
152 «Parece que hay un punto en el que todas estamos conformes: el de que la mujer, por saber más, no es menos mujer; pero bien entendido, que no debe incurrise en el error señalado por De Maistre en la famosa carta a su hija, cuando le decía: "Ciertas mujeres creen que para ser distinguidas deben ser a la manera de los hombres. La mujer no puede ser superior sino como mujer; desde que pretende emular al hombre se convierte en mona (...)

Las mujeres debemos ser algo por nosotras mismas, verdaderas mujeres en el sentido pleno y mejor de la palabra... » Aspiración, n², octobre 1923, La Paz. Centro de Informaciôn y Desarrollo de la Mujer (CIDEM), La Paz - Bolivie.

153 «El feminismo ha sido interpretado diversamente, mucho se ha falseado la nobleza de sus intenciones. La mujer al reclamar y defender sus derechos no hace sino pedir la parte que le corresponde en el derecho y la lucha por la vida. No pretende abandonar el hogar, para lanzarse al doctorismo y a la tribuna; pero sin desconocer las obligaciones domésticas (que en este caso dejan de ser rutinarias), tan agradables como sutiles, quiere tener participación en lo que respecta a los diversos conocimientos, si ha educado y desarrollado su inteligencia, su criterio y juicio ¿por qué se le ha de negar que trabaje intelectualmente en la esfera que domina? »Venas de Plata, n², avril 1924, Potosí. Archivo Nacional de Bolivia, Sucre - Bolivie.
} 
femme cultivée, devait se vouer aux sciences, aux arts et au travail sans cesser de « régner » au sein de son foyer:

«C'est le bon jugement qui doit guider la jeune femme dans le chemin étendu du progrès, ce chemin sera trouvé avec les études, la culture, avec une éducation vaste et solide. Celles qui sont douées avec des conditions exceptionnelles, qu'elles aillent vers la lutte des sciences, des arts et des professions libres, sans laisser de côté le ciel du foyer, pour une fausse gloire, sans perdre l'idéal selon lequel dans les devoirs de la maison, dans le travail, dans l'art et dans tous les actes elles doivent élever leur niveau intellectuel et moral ; car la femme est la base de l'humanité, l'éducatrice et en tant que compagne elle ne doit pas être inférieure à l'homme en connaissances et en culture.

La femme du foyer d'âme bonne, simple et modeste, avec des sentiments d'artiste, doit se consacrer aux professions manuelles, car en elles, elle trouvera les charmes qui correspondent à son caractère : les divisions sont plusieurs qui comprennent les œuvres de dames si indispensables pour la maison (...) Aucune femme n'a le droit de mépriser les besognes (féminines), surtout si elles ont été ennoblies par l'aristocratie, comme Minerve, la déesse de la guerre et des savoirs, qui ne dédaigna jamais de broder, les filles de Charles le Grand, avec leurs mains elles filèrent et brodèrent, la célèbre reine Isabel I d'Espagne, Marie Antoinette, Marie Stuart, les femmes les plus célèbres par sa beauté nous léguèrent le souvenir de leurs travaux, comme Beatriz, Victoria Coloma et la Comtesse Gucolí, les muses de Michel Ange et Bayron: toutes les déesses souveraines sont liées dans les ébauches vulgaires à la création féminine. ${ }^{154}$

Cette défense des «qualités féminines » et du fait que se cultiver et demander les droits des femmes ne signifiait pas cesser d'être féminine et ne devait pas signifier l'abandon de ses devoirs au sein de la famille, allait de pair avec une exaltation de la maternité et du rôle social que la femme remplissait en tant que reproductrice de

\footnotetext{
154 «Es el buen juicio el que debe guiar a la joven por el amplio camino del progreso, este camino será hallado con el estudio, la cultura, con una educación vasta y sólida. Las que están dotadas de las condiciones excepcionales vayan a la lucha de las ciencias, artes y profesiones libres, sin dejar el cielo de su hogar, por una falsa gloria, sin perder el ideal de que dentro de los deberes de la casa, en el trabajo, en el arte y en todos sus actos deben elevar su nivel intelectual y moral; porque la mujer es la base de la humanidad, la educadora y como compañera no debe ser inferior al hombre, en conocimientos y en cultura.

La mujer del hogar de alma buena, sencilla y modesta, con sentimientos de artista, debe consagrarse a las profesiones manuales, porque en ellas hallará los encantos que a su carácter se encuadren: son varias las divisiones que comprenden las obras de damas, tan indispensables para la casa (...) Ninguna mujer tiene derecho a despreciar las labores, mucho más si estas han sido ennoblecidas por la aristocracia, como Minerva, la diosa de la guerra y la sabiduría que jamás desdeñó bordar, las hijas de Carlo Magno, con sus reales manos hilaron y bordaron, la célebre Reina Isabel I de España, María Antonieta, María Stuart, las mujeres más célebres por su hermosura, nos legaron el recuerdo de sus trabajos como Beatriz, Victoria Coloma y la Condesa Gucolí, las musas de Miguel Angel y Bayron; todas las diosas soberanas están enlazadas en los bosquejos vulgares a la creación femenina. » Feminiflor, $\mathrm{n}^{\circ} 25$, novembre 1923, Oruro. Hemeroteca de la Universidad Mayor de San Andrés, La Paz - Bolivie.
} 
l'humanité et en tant qu'éducatrice des générations à venir. Les femmes devaient jouer un rôle essentiel à travers l'éducation de leurs enfants, et pour cela elles devaient s'éduquer et se cultiver :

«Précisément à cela tend le féminisme : à libérer la femme du réseau de préjugés qui l'emprisonnent. Il est indispensable que la femme soit bien éduquée, sérieusement; qu'elle s'accoutume à l'observation honnête et courageuse des divers phénomènes sociaux et familiaux, afin d'acquérir expérience dont les fruits pourront être utiles aux autres. Oui, parce que nous sommes dans l'obligation de retourner les connaissances acquises, en les améliorant autant que possible, sans égoïsme, sans malice, sans hypocrisie (...)

Madame Stael demanda à l'Empereur Napoléon, qui était, d'après lui, d'après son avis, la femme la plus grande du monde. Napoléon répondit avec fermeté : «Celle qui a eu le plus d'enfants. » Pour moi, la femme la plus grande du monde, n'est pas précisément, celle qui a eu le plus d'enfants, sinon celle qui a su les éduquer mieux que n'importe quelle autre. La mission de la femme moderne consiste, non seulement à procurer être une excellente épouse, une fille utile, un élément de progrès pour la société, mais aussi, plus que tout, à être une bonne mère, mère dans le concept le plus élevé et authentique du vocable. La femme doit alors, bien s'illustrer dans tout ordre de choses pour modeler habilement l'âme de ses enfants. ॥ ${ }^{155}$

Un deuxième article dans Eco Femenino va dans le même sens :

«Des femmes, qui savent ! - c'est ce que disent, les égoïstes, ceux qui pensent que nous sommes encore les esclaves du travail vulgaire. Je suis la première à comprendre, l'haute mission de la femme, surtout, dans son destin en tant que mère. Femme, qui en étant mère est encore plus obligée à être comprise, dans toute l'étendue intellectuelle, et en plus; être maîtresse de la volonté, qui l'induise à l'action, ouvre le sentier, pour les générations futures; et celui-ci sera un grand travail pour la patrie. La mère, telle une artiste, modèlera l'âme forte de ses

\footnotetext{
155 «Precisamente a eso tiende el feminismo: a liberar a la mujer de las redes de prejuicios que la aprisionan. Es indispensable que la mujer se eduque bien, seriamente; que se acostumbre a la observación honrada y valiente de los diversos fenómenos sociales y familiares, con el objeto de adquirir experiencia cuyos frutos podrán ser útiles a las demás. Sí, porque estamos en la obligación de devolver los conocimientos adquiridos, mejorándolos en lo posible, sin egoísmo, sin malicia, sin hipocresía (...)

Madame Stael preguntó al Emperador Napoleón, cuál era, según su concepto, la mujer más grande del mundo. Napoleón contestó con firmeza: "La que ha tenido más hijos." Para mí, la mujer más grande del mundo, no es precisamente aquella que ha tenido más hijos, sino la que ha sabido educarlos mejor que ninguna otra. La misión de la mujer moderna consiste, no sólo en procurar ser una excelente esposa, una hija útil, un elemento de progreso para la sociedad, sino también, más que nada, en ser una buena madre, madre en el concepto más alto y genuino del vocablo. La mujer debe, pues, ilustrarse bien en todo orden de cosas para modelar hábilmente el alma de sus hijos. » Eco Femenino, n ${ }^{\circ} 13$, mai 1925, La Paz. Hemeroteca de la Universidad Mayor de San Andrés, La Paz - Bolivie.
} 
enfants ; l'âme qui, avant de demander, cherchera, avant de pleurer, agira. ॥ 156

Cette exaltation de la maternité et du rôle des femmes en tant qu'éducatrices de leurs enfants se retrouve également dans la revue Venas de Plata de Potosí :

« Sous ces aspects doit s'imposer à la femme le concept élevé suivant : Qu'il y a trois choses qui la dignifient. Maternité, Illustration et Amour.

Ainsi elle réussira à être une bonne mère, exemplaire épouse, prévenante sœur, fille attentive et obéissante, en un seul mot elle devra constituer l'apprécié petit bijou des vertus que demain formeront la sage gouvernante de sa maison et la bonne éducatrice de ses enfants... » 157

«...Que cette sainte enceinte où elle remplit la mission auguste de la maternité, devienne un foyer de lumière qui arrache sans pitié même les derniers brouillards de l'erreur. ${ }^{158}$

A la fin de l'année 1927, la conception de la maternité que les membres de l'" Ateneo Femenino » avaient, était un peu plus distanciée que celle exposée quelques années auparavant dans Eco Femenino. Cette conception accordait encore une place essentielle à la maternité et au rôle d'éducatrice de la mère, mais la fonction procréatrice n'était plus exaltée en tant que telle; c'était surtout l'éducation proportionnée aux enfants par la mère comme rôle social et culturel qui était mise en avant. Dans ce sens, María Luisa Sánchez Bustamante de Urioste (voir annexe A $\mathrm{n}^{\circ} 10$ ), distingue ce qui constitue le sexe biologique de la femme servant à la procréation, «fonction » qu'elle partage avec les autres êtres vivants, et le rôle social et culturel que la mère exerce en tant qu'éducatrice qui doit être mis en valeur et

\footnotetext{
156 «- Mujeres, que saben! - esto dicen, los egoístas, los que piensan que, aún somos, esclavas del trabajo vulgar. Yo soy la primera en comprender, la alta misión de la mujer, sobre todo, en su destino, como madre. Mujer, que al ser madre, está más obligada a ser comprendida, en toda la extensión intelectual; y además; dueña de la voluntad, que la induzca a la acción abra la senda, para las generaciones futuras; y esta será labor grande para la patria. La madre, cual artista, modelará el alma fuerte de sus hijos; el alma, que, antes de pedir busque, antes de llorar obre. » Eco Femenino, n ${ }^{\circ} 13$, mai 1925, La Paz. Hemeroteca de la Universidad Mayor de San Andrés, La Paz - Bolivie.

157 « Bajo estos aspectos se debe imponer en la mujer el siguiente elevado concepto: Que hay tres cosas que la dignifican. Maternidad, Ilustración y Amor.

Así llegará a ser buena madre, ejemplar esposa, hermana solícita, hija atenta y obediente, en una palabra, deberá constituir el preciado joyel de virtudes que mañana formarán a la sabia gobernadora de su casa y a la buena educadora de sus hijos... »Venas de Plata, $\mathrm{n}^{\circ} 1$, février 1924, Potosí. Archivo Nacional de Bolivia, Sucre - Bolivie.

${ }^{158}$ «...y que ese recinto santo donde ella desempeña la misión augusta de la maternidad, se convierta en un foco de luz que desgarre sin piedad hasta las últimas nieblas del error. » Idem.
} 
exalté. Pour bien remplir ce rôle, les mères devaient être éduquées et avoir une « morale supérieure » :

« On peut argumenter que dans son rôle de mère, elle s'acquitte envers la nature et reste, de fait, investie d'une haute mission. Il faudrait mettre quelques parenthèses ; en premier lieu, signaler que la maternité physique de l'espèce ne peut jamais être une noble mission, car à celleci sont destinées tous les groupes du règne animal; mais s'il s'agit de l'influence morale et sociale qu'en tant que mère elle peut exercer, c'est autre chose et dans cette vertu ressort la nécessité de que sa préparation civique, intellectuelle et morale soit supérieure, car on lui a confié la tâche de façonner depuis les plus tendres années, la nature et le caractère des individus utiles. Pourra-t-elle être précurseur de super éléments sociaux, sans avoir formé avec une solide doctrine sa conscience citoyenne, sa morale privée et ses compétences intellectuelles? ${ }^{159}$

Dans cette même revue est publié un article écrit par une écrivaine états-unienne, Dorothi Dumbar Bromley, qui, en critiquant le féminisme anglo-saxon américain, « violent», « grotesque » et «masculin», proclame les nouveaux dogmes de ce qu'elle appelle le «Féminisme Nouveau» («Feminismo al Nuevo Estilo»). La nouvelle féministe était la femme cultivée, qui travaillait et était donc indépendante économiquement, mais qui ne laissait pas de côté ni sa féminité ni ses devoirs au sein du foyer, ni son rôle de mère éducatrice de ses enfants :

«Il n'est pas déjà temps qu'on abandonne le fantasme appelé féministe ? Le «Féminisme » est devenu un vocable d'opprobre pour la femme moderne, car le mot suggère, soit l'ancienne école de batailleuses féministes qui utilisaient des talons bas et possédaient peu de charme féminin, soit l'espèce populaire qui lutte contre l'homme avec sa clameur constante sur la conservation de leurs noms de jeunes filles, l'égalité des droits, la place de la femme dans le monde et beaucoup d'autres choses. Si un homme insensé assume qu'une femme est féministe par le simple fait qu'elle a un travail ou une profession, celle-ci se considérera à juste titre insultée.

Lorsque l'homme courant critique la "femme nouvelle » il travaille sous l'illusion selon laquelle il existe seulement deux types de femmes, la créature d'instinct qui se conforme avec le fait "d'avoir un foyer", et la «stérile intellectuelle» qui s'inquiète uniquement «pour elle»,

\footnotetext{
159 «Puede argüirse que en su rol de madre ella cumple con la naturaleza y queda, de hecho, investida de una alta misión. Habría que hacer algunos paréntesis; en primer término, señalar que la maternidad física de la especie no puede nunca ser una noble misión, ya que a ella están destinadas todos los grupos del reino animal; pero que si se trata de la influencia moral y social que como madre puede ejercer, es otra cosa y en tal virtud resalta la necesidad de que su preparación cívica, intelectual y moral sea superior, ya que en ella está encomendado el plasmar desde los tiernos años, la índole y carácter de individuos útiles. ¿Y podrá ella ser precursora de súper-elementos sociales, sin tener formada con sólida doctrina su conciencia ciudadana, su moral privada y su competencia intelectual? »Indice, $\mathrm{n}^{\circ} 1$, décembre 1927, La Paz. Centro de Informaciôn y Desarrollo de la Mujer (CIDEM), La Paz - Bolivie.
} 
même si le foyer et les enfants en souffrent. Mais, que doit-on penser du nombre constamment croissant de jeunes femmes qui admettent qu'une vie complète requiert le mariage et les enfants et en plus une carrière ou profession? Ces femmes, si elles réussissent à se marier, sont désireuses d'atteindre un grand succès dans leur mariage, et font de l'éducation de leurs enfants un art. Mais elles sont en même temps poussées par une inéluctable compulsion intérieure de devenir des personnes dans leur propre droit. Et dans cette ère de simple gestion du foyer, elles voient leur opportunité, car il est évident qu'une femme qui s'organise intelligemment peut économiser du temps pour ses propres recherches. Qui plus est, elles sont convaincues qu'elles seront des meilleures épouses et mères par l'exercice qu'elles acquièrent dans leurs fonctions hors du foyer.

Puisque les choses doivent être signalées en noir et blanc à l'homme, nous nous permettons d'énoncer ici les dogmes du credo de la femme moderne. Appelons-la « Feministe Nouvelle ».

Premier dogme. Il y a trois bonnes raisons pour lesquelles la Féministe Nouvelle s'inquiète d'obtenir une carrière ou un travail : la première, elle peut appartenir à ce type de personnes qui persistent dans un art particulier, science ou profession qui sera une partie inévitable de leurs vies ; la deuxième, elle peut sentir la nécessité d'une flatteuse sortie pour ses énergies; la troisième, il se peut qu'elle n'ait aucun autre moyen pour obtenir son indépendance économique (...)

Deuxième dogme. Malgré tout, elle ne vivra pas pour son travail uniquement, car elle considère qu'une femme qui parle uniquement de son travail a un horizon aussi étroit que celle qui parle seulement du foyer et de ses enfants. Elle refusera, par conséquent, d'abandonner tous ses intérêts personnels pour le bien de son travail (...)

Troisième dogme. Elle n'est pas hostile à l'autre sexe. Au contraire, elle aime travailler avec les hommes plus qu'avec les femmes, car leurs méthodes sont plus directes et leur vision plus ample; et elle découvre qu'elle peut traiter avec eux sur la base d'une véritable confraternité (...)

Quatrième dogme. Par le même corollaire, la Féministe Nouvelle ne professe aucune loyauté envers la femme dans son ensemble, même si elle croit fortement dans la femme individuelle (...)

Cinquième dogme. La Féministe Nouvelle est aussi loin des féministes primitives, qu'elle se trouve contrariée avec la psychologie qui a guidé certaines d'entre elles à renoncer à l'homme en même temps qu'elles l'imitent avec leurs cheveux courts et leur vêtements masculins. Elle n'est pas aussi élégamment vêtue que la femme de société, mais malgré tout elle est chaque année mieux habillée et soignée que la femme professionnelle d'affaires. En ce qui concerne les manières et le maniérisme elle n'a le moindre désir d'imiter l'homme. Au contraire, elle préfère conserver les modulations de sa voix, la qualité de ses gestes purement féminins, tels quels la nature voulut qu'ils furent.

Sixième dogme. Des cris de combat vides semblent à la Féministe Nouvelle d'un aussi mauvais goût que les costumes et les manières masculines (...) 
Huitième dogme. Elle admet qu'un époux et des enfants sont nécessaires pour le complet développement de la femme courante, même si elle sait que la femme est douée de manière diverse de degrés de passion et d'instinct maternel (...) » ${ }^{160}$

\section{Le féminisme que proclamaient les féministes boliviennes était donc très distancié $d u$}

féminisme « individuel » anglo-saxon, dont le modèle de femme féministe était la suffragette, « vieille fille », « violente » et « masculine ». Les féministes boliviennes ne voulaient pas du tout être comprises et vues ainsi. Elles s'efforçaient de démontrer

160 « ¿No es ya tiempo de que abandonemos el fantasma llamado feminista? El "Feminismo" se ha convertido en un vocablo de oprobio para la mujer moderna, puesto que la palabra sugiere, o la antigua escuela de batalladoras feministas que usaban tacones bajos y poseían poco del encanto femenino o la popular especia que antagoniza al hombre con su constante clamor acerca de la conservación de sus nombres de doncellas, la igualdad de derechos, el lugar de la mujer en el mundo y muchas otras causas. Si un desatinado varón asume que una mujer es feminista por el mero hecho de que posee un empleo o una profesión, ésta se considerará justificadamente insultada.

Cuando el hombre corriente critica a la "nueva mujer" trabaja bajo la ilusión de que existen solamente dos tipos de mujeres, la criatura de instinto que se contenta con "tener un hogar", y la "estéril intelectual" que solamente se preocupa de "ella misma", aunque el hogar y los hijos padezcan. Pero ¿qué debemos pensar acerca del constantemente creciente grupo de mujeres jóvenes que admiten que una vida completa reclama el casamiento e hijos, y además una carrera o profesión? Estas mujeres, si llegan a casarse, están deseosas de llegar a un gran éxito en su casamiento, y hacen de la crianza de sus hijos un arte. Pero a la vez, son movidas por una inescapable compulsión interior de ser personas en su propio derecho. Y en esta era de sencillo manejo del hogar ven ellas su oportunidad, pues es obvio que una mujer que traza sus planes inteligentemente puede ahorrar algún tiempo para sus propias investigaciones. Es más, están convencidas de que serán mejores esposas y madres por el ejercicio que adquieren en sus funciones fuera del hogar.

Puesto que al hombre han de señalársele las cosas en blanco y negro, nos permitimos enunciar aquí los dogmas del credo de la mujer moderna. Llamémosla "Feminista al Nuevo Estilo".

Primer dogma. Hay tres buenas razones por que la Feminista al Nuevo Estilo se preocupa por obtener una carrera o un trabajo: primera, puede pertenecer a esa clase de personas que persisten en que cierto arte, ciencia o profesión ha de ser parte inevitable de sus vidas; segundo, puede sentir la necesidad de una halagadora salida para su energía; tercera, puede que no tenga oro medio de obtener su independencia económica (...)

Segundo dogma. Con todo, ella no ha de vivir para su trabajo solamente, pues cree que una mujer que solamente habla de su trabajo tiene un horizonte tan estrecho como la que habla solamente del hogar y de sus hijos. Rehusará, por tanto, abandonar todos sus intereses personales en bien de su trabajo (...) Tercer dogma. No es hostil al otro sexo. Por el contrario, le agrada trabajar con los hombres más que con las mujeres, pues sus métodos son más directos y su visión más amplia; y descubre que puede tratar con ellos sobre la base de una franca confraternidad (...)

Cuarto dogma. Por el mismo corolario, la Feminista al Nuevo Estilo no profesa lealtad ninguna a la mujer en conjunto, aunque aferradamente cree en la mujer individual (...)

Quinto dogma. La Feminista al Nuevo Estilo está tan lejos de las feministas primitivas, que se encuentra contrariada con la psicología que ha guiado a algunas de ellas a renunciar del hombre a la vez que lo imitan con su pelo corto y ropa masculina. No estará tan elegantemente vestida como la mujer de sociedad, con todo cada año está mejor vestida y mejor arreglada que la mujer profesional de negocios. En lo que respecta a las maneras y manierismo no tiene el menor deseo de imitar al hombre. Por el contrario, prefiere conservar las modulaciones de su voz y la calidad de sus gestos puramente femeninos, tal cual la naturaleza quiso que fueran.

Sexto dogma. Gritos vacíos de combate parecen a la Feminista al Nuevo Estilo de tan mal gusto como el traje y las maneras masculinas (...)

Octavo dogma. Concede que un esposo e hijos son necesarios para el completo desarrollo de la mujer corriente aunque sabe que la mujer está dotada muy variadamente en grado de pasión e instinto maternal (...) » Indice, $\mathrm{n}^{\circ}$ 2, janvier 1928, La Paz. Centro de Informaciôn y Desarrollo de la Mujer (CIDEM), La Paz - Bolivie. 
que leur féminisme, qui était le seul vrai et légitime pour elles, ne proclamait pas l'abandon du foyer, de la famille ni la perte de l'essence des femmes : leurs vertus et qualités féminines. Au contraire, elles voulaient démontrer que les féministes étaient des femmes éduquées, cultivées, qui lorsqu'elles travaillaient, savaient concilier parfaitement une vie professionnelle et indépendante avec l'accomplissement de devoirs conjugaux et familiaux au sein du foyer, où les femmes vouaient une grande partie de leur énergie à éduquer leurs enfants dans les connaissances et les vertus morales pour former d'excellents citoyens pour l'avenir. L'homme était non pas un concurrent, mais un compagnon dans la vie. Les femmes ne devaient pas envahir l'espace masculin ni par leur comportement ni par la volonté de réaliser des tâches et des travaux purement masculins. Elles devaient rester purement féminines et exceller dans les domaines féminins. C'était par leurs qualités essentiellement féminines que les femmes pouvaient contribuer au «progrès de la patrie » puisqu'elles avaient un sens de la morale et une sensibilité plus développés que les hommes. Il est clair que, pour les féministes boliviennes des années 1920, qui appartenaient toutes aux classes moyennes et élevées de la société, ces fondements théoriques constituaient un idéal de vie qui pouvait leur être accessible par leur position de classe. Il est très probable que la plupart d'entre elles étaient secondées à la maison par des domestiques qu'elles dirigeaient ayant le temps d'assister à d'activités culturelles et de se charger de l'organisation de leurs associations. Combiner la vie intellectuelle avec celle de la maison semblait un mode de vie faisable pour ces femmes, même si elles appréhendaient les contradictions et difficultés de la tâche avec humour (voir annexe $\left.\mathrm{C} \mathrm{n}^{\circ} 19\right)$.

De telles proclamations n'allaient pas sans contradictions puisque souvent en même temps que les rédactrices se proclamaient féministes, elles publiaient dans leurs revues, des collaborations masculines qui exprimaient clairement leur opposition au féminisme. Ainsi, la revue Feminiflor qui pour son édition d'anniversaire publia les collaborations de deux hommes qui se montraient non seulement opposés au féminisme mais aussi à l'existence de femmes intellectuelles. Le premier, qui signa sous le pseudonyme de Nolo Beas s'exprimait ainsi :

« L'état de grâce du monde s'appelle femme.

Le féminisme a un peu de force. La féminité n'a que grâce.

Ô, oui! La femme doit d'abord être femme, deuxièmement être femme, et troisièmement elle doit être un cœur. 
Ces femmes qui utilisent des lunettes sont très dangereuses, tout comme ces hommes qui se maquillent avec du rimmel et de la poudre de riz.

La femme, pour être femme, elle doit être charmante, féminine et pour être aimée, elle doit être deux fois féminine. C'est-à-dire belle, avec une addition indispensable : qu'elle ait honte d'être jolie.

L'organe de la beauté chez les femmes est le cœur. On voit très laides les femmes dont le cœur leur est monté dans la tête. La pensée est comme la fumée, elle salit terriblement la cheminée.

Je ne sais pas quoi faire entre une femme adorablement belle et une femme délicieusement pensante. C'est fatal, la femme belle séduit, et celle qui pense nous fait dire : admirable ! Je préfère que la femme séduise, car finalement tous les hommes on est tous plus ou moins des Adams, et on n'a pas coupé le cordon ombilical de la tradition biblique. La femme n'est pas «sauvée » en mangeant la pomme de la science, après avoir mangé le fruit « interdit» elle continue à être une femme : cela est la féminité (...)

Pour cela; le féminisme est bon pour les féministes. Par contre, la féminité fait danser des enthousiasmes dans mon cœur et sur la douceur de mon cerveau, en son honneur réalisent une grande fête la beauté, l'amour, la culture. ${ }^{161}$

Les féministes étaient clairement vues comme des êtres masculins ; elles n'étaient ni hommes ni femmes, mais des êtres d'une « espèce à part » dont l'utilité était mise en question. C'est ce qu'exprime Fabián Vaca Chávez, directeur du journal El Diario, avec sa collaboration dans la même revue :

«Plusieurs fois, je me suis mis à méditer sur ce que signifie le féminisme, sur ce qu'on doit faire en faveur des femmes, les hommes qui présumons d'être avancés, et ceux qui par galanterie ou par conviction, nous voulons bien nous conduire avec le beau sexe.

Et, même avant d'entrer dans l'analyse du problème, je n'ai pas pu me soustraire de la suggestion d'examiner ce qui représente en face de

\footnotetext{
161 « El estado de gracia del mundo se llama mujer.
}

El feminismo tiene algo de fuerza. La feminidad solo tiene gracia.

¡Oh, sí! La mujer primero debe ser mujer, segundo debe ser mujer, y tercero debe ser un corazón.

Son muy peligrosas esas mujeres que se ponen lentes, tan peligrosas como esos hombres que se maquillan con rimel y polvos de arroz.

La mujer, para ser mujer, encantadora, femenina; y para ser amada, dos veces femenina. Es decir, bella, con el aditamento indispensable que tenga vergüenza de ser linda.

El órgano de la belleza en las mujeres es el corazón. A las mujeres que se les ha subido el corazón a la cabeza se las mira muy feas. El pensamiento como el humo, tizna terriblemente la chimenea.

Yo no sé que hacer entre una mujer adorablemente bella, y una mujer deliciosamente pensadora. Es fatal, la mujer bella seduce y la mujer que piensa nos hace decir: ¡admirable! Prefiero que la mujer seduzca, porque al fin y al cabo todos los hombres somos más o menos Adanes, y aún no hemos roto el cordón umbilical de la tradición bíblica. A la mujer no la "salva" el que coma la manzana de la ciencia, después de comer el fruto "prohibido" sigue siendo mujer: eso es la feminidad (...)

Por eso; el feminismo es bueno para las feministas. En cambio la feminidad me hace bailar entusiasmos en el corazón, y sobre la tersura de mi cerebro en su honor realizan una gran fiesta la belleza, el amor, la cultura.» Feminiflor, n²2, mai 1923, Oruro. Hemeroteca de la Universidad Mayor de San Andrés, La Paz - Bolivie. 
l'esthétique la femme féministe: Grande, robuste, musclée et solide, très masculine dans la voix, la démarche, le geste et l'expression, la femelle leader appartient à un genre intermédiaire entre l'homme et la femme, qui en n'étant ni l'un ni l'autre, elle n'est pas neutre non plus, mais elle appartient à une espèce à part.

Est-ce que le meilleur et seul argument qu'existe en faveur du féminisme, de ses droits et prérogatives; de ses égalités et de ses rébellions est l'existence des hommes inférieurs, sans volonté, sans intelligence et sans cœur. Mais, est-ce que la femme a besoin de la loi, de la démocratie ou du droit pour être égale et même supérieure à l'homme, pour légiférer et pour diriger les destins de son foyer et même ceux de son peuple? J'ai vu des sourires qui valaient plus qu'une péroraison ; j'ai entendu des mots plus efficaces qu'un code ; et j'ai senti l'influence décisive et irrémédiable d'une larme ou d'une caresse. Et tout cela loin du forum, du parlement et des comices, où pour gouverner il est nécessaire d'imposer et où pour vaincre il est souvent nécessaire de faire semblant. ${ }^{162}$

Ces contradictions semblent également visibles à travers le seul groupe de femmes qui niait une position ouvertement féministe dans les premiers numéros de leur revue, et en même temps assumait exactement les mêmes revendications que leurs homologues, en réclamant, entre autres, l'obtention des droits civils des femmes. C'est le cas des rédactrices d'Anhelos qui dans le premier numéro de leur revue se montrent assez prudentes quant à l'utilisation du terme « féministe » :

«... Le moment est arrivé pour que la femme de Cochabamba assume une attitude, non pas féministe dans toute l'acception du terme, pour laquelle elle n'est pas suffisamment préparée, mais qui lui permette de se faire connaître comme aimante de l'instruction et de l'éducation intégrale avec un critère élevé, propre et serein, la douce, la cultivée et religieuse sans fanatisme; la fille et la sœur exemplaire, la femme du foyer qui soit la première maîtresse modèle de ses enfants, celle qui soit une épouse avec laquelle le mari partage tous ses idéaux, en

\footnotetext{
162 «Muchas veces me he puesto a meditar sobre lo que significa el feminismo, sobre lo que debemos hacer a favor de las mujeres los hombres que presumimos de avanzados y los que, por galantería o por convicción queremos quedar bien con el bello sexo.

Y, aún antes de entrar en el análisis del problema, no he podido sustraerme a la sugestión, de examinar lo que representa ante la estética la mujer feminista: Alta, fornida, musculosa y recia, con mucho de varón en la voz, en el andar, en el gesto y en la expresión, la hembra líder pertenece a un género intermedio entre el hombre y la mujer, que sin ser lo uno ni lo otro tampoco es neutra, sino que pertenece a una especie aparte.

Acaso el mejor u el único argumento que existe a favor del feminismo, de sus derechos y prerrogativas, de sus igualdades y de sus rebeldías, es la existencia de los hombres inferiores, sin voluntad, sin inteligencia y sin corazón. Pero ¿acaso necesita la mujer de la ley, de la democracia o del derecho para ser igual o hasta superior al hombre, para legislar y para dirigir los destinos de su hogar y aún los de su pueblo? Yo he visto sonrisas que valían más que una peroración; he oído palabras más eficaces que un código; y he sentido influencia decisiva e inapelable de una lágrima o de una caricia. Y todo esto lejos del foro, del parlamento y de los comicios, donde para gobernar es necesario imponer, y donde para vencer es muchas veces preciso fingir. » Idem.
} 
trouvant en elle une collaboratrice consciente et assidue; celle qui lègue à sa patrie des enfants utiles. ${ }^{163}$

" "Je ne suis pas féministe", nous disait il y a peu madame Charlotte Perkins Gilman, distinguée auteure de L'indépendance économique de la femme (The Economic Independence of Women) et d'autres ouvrages aussi inspirateurs qu'originaux sur le rôle de la femme dans la société.

Telle révélation pourrait être déconcertante pour beaucoup de personnes qui en étant informées de l'œuvre étendue de madame Gilman ne se sont pas rendues compte encore de la véritable signification de la lutte pour l'émancipation intellectuelle, morale et économique de la femme. Pour la majorité un tel effort se traduit par le mot «féminisme » et c'est pour cela que nous voulons déclarer $q u$ 'il $n$ 'y a pas des femmes féministes. Toutes celles qui jouissons de la triple émancipation à laquelle on a fait référence, nous travaillons pour que nos sœurs les moins privilégiées peuvent un jour profiter des mêmes privilèges que nous, non pas parce qu'on désire les faire conscientes de leurs droits et de leurs devoirs en tant que membres d'un sexe, mais parce que nous croyons qu'elles doivent sentir la responsabilité de la bonne marche de la communauté dans laquelle elles vivent et de la nation à laquelle elles appartiennent. Et en sentant une telle responsabilité nous voulons qu'elles soient suffisamment qualifiées pour contribuer au progrès de leur peuple dans la forme qui soit le plus en accord avec leurs habiletés.

La femme communément désignée comme féministe, n'est pas une telle, mais plutôt une humaniste, si avec ce mot l'on peut décrire la sphère de ses intérêts dans tout le bien qu'elle désire non seulement pour les femmes, mais aussi pour les enfants et les hommes de toutes les couleurs et races. Sa dévotion pour la cause de la femme se base dans sa croyance selon laquelle l'humanité ne peut atteindre la plénitude de son développement véritable que lorsque les hommes et les femmes travaillent comme des égaux, et que lorsque la femme, qui a détenu la marche du progrès prenne sa place non pas pour profiter de droits, mais pour servir. Féministes ? Quelle absurdité ! Nous ne pouvons concevoir rien de pire qu'un monde gouverné et dirigé exclusivement par des hommes, à moins qu'il soit un monde régit par des femmes, car celui-ci n'appartient à aucun des sexes en particulier.

\footnotetext{
163 « Es llegado el momento en que la mujer cochabambina asuma una actitud, no feminista en toda la acepción de la palabra, para lo cual no está lo bastante preparada, pero sí, de darse a conocer como amante de la instrucción y educación integral, de criterio elevado, propio y sereno, la dulce, la culta y religiosa sin fanatismo; la hija y hermana ejemplar, la mujer del hogar que sea la primera maestra modelo de sus hijos, la que sea una esposa con quien departa el marido todos sus ideales, hallando en ella una coadyuvadora consciente y asidua; aquella que legue a su patria hijos de provecho. » Anhelos, $\mathrm{n}^{\circ}$ 1, juillet 1929, Cochabamba. Centro de Informaciôn y Desarrollo de la Mujer (CIDEM), La Paz Bolivie.
} 
Il a été fait pour les deux, et dans sa marche les idéaux de l'homme et de la femme doivent s'unir pour l'améliorer. ${ }^{164}$

Cependant, un peu plus tard, dans le numéro 4 de la revue Anhelos, leurs rédactrices exprimèrent la volonté de lutter pour l'obtention des droits civils des femmes, en faisant référence aux avances réalisées dans ce domaine non seulement dans les pays où le féminisme était actif, mais aussi dans d'autres pays du monde. Elles mentionnèrent également le Congrès Panaméricain de la Havane, réuni en 1928, avec le but de lutter pour l'obtention des droits civils et politiques des femmes du continent américain.

Ces apparentes contradictions dans les publications des féministes boliviennes des années 1920 font preuve non pas d'un manque de rigueur et de logique dans leurs écrits, mais plutôt du fait que leur idéologie est en train de se construire et d'être réfléchie. Leurs articles, souvent rédigés par différentes collaboratrices, sont plus des réflexions sur ce que constituait le féminisme à l'étranger et le féminisme en Bolivie, sur ce que signifiait être féministe, etc., que des manifestes avec des programmes clairs et bien définis. Néanmoins, ce qui reste clair est leur différentiation avec le féminisme «individualiste» anglo-saxon. Leurs principes et fondements appartiennent à la catégorie du féminisme « relationnel », avec la mise en avant du

\footnotetext{
164 «"No soy feminista”, nos decía hace poco la señora Charlotte Perkins Gilman, distinguida autora de La Independencia Económica de la Mujer (The Economic Independence of Women) y de muchas obras tan inspiradoras como originales sobre la actuación de la mujer en la sociedad.

Tal revelación podría ser desconcertante para muchas personas que estando informadas de la obra tan extensa de la señora Gilman no se han dado aún cuenta del verdadero significado de la lucha por la emancipación intelectual, moral y económica de la mujer. Para la mayoría tal esfuerzo se traduce en la palabra "feminismo" y por tal razón queremos declarar que no hay mujeres feministas. Todas aquellas que gozamos de la triple emancipación a que hemos hecho referencia, trabajamos porque nuestras hermanas menos afortunadas puedan algún día disfrutar de los mismos privilegios que nosotras, no porque deseamos hacerlas conscientes de sus derechos y deberes como miembros de un sexo, sino porque creemos que deben sentir la responsabilidad por la buena marcha de la comunidad en que viven y por la nación a la que pertenecen. Y sintiendo tal responsabilidad queremos que estén debidamente capacitadas para contribuir al adelanto de su pueblo en la forma que más esté de acuerdo con sus habilidades.

La mujer comúnmente designada como feminista no es tal, sino más bien humanista, si con esa palabra podemos describir la esfera de sus intereses en todo lo bueno que desea no solamente para las mujeres sino también para los niños y los hombres de todos colores y razas. Su devoción a la causa de la mujer se basa en la creencia de que la humanidad no puede llegar a la plenitud de su desarrollo verdadero hasta que los hombres y mujeres trabajen como iguales, hasta que la mujer que ha detenido la marcha del progreso tome su lugar no para disfrutar de derechos, sino para servir. ¿Feministas? ¡Qué absurdo! No podemos concebir nada peor que un mundo gobernado y dirigido exclusivamente por hombres a menos que sea un mundo regido por mujeres, pues este no pertenece a ninguno de los dos sexos en particular. Fue hecho para los dos, y en su marcha los ideales del hombre y de la mujer deben por necesidad unirse para mejorarlo. » Anhelos, n² , agosto 1929, Cochabamba. Centro de Informaciôn y Desarrollo de la Mujer (CIDEM), La Paz - Bolivie.
} 
couple égalitaire comme unité de base de la société, leur insistance sur le « compañerismo» dans les relations de couple, les revendications des droits des femmes en tant que femmes, avec une mise en avant des qualités essentiellement féminines et des rôles «naturels » de la femme telles que la maternité et l'éducation des enfants.

Les rédactrices d'Anhelos, tout comme leurs homologues critiquaient le féminisme « individualiste » anglo-saxon, mais au lieu de redéfinir leur propre féminisme, elles refusèrent d'utiliser ce terme et préférèrent de le remplacer par «humanisme », car elles ne désiraient pas que leur lutte soit réduite à la lutte des droits des femmes mais $\mathrm{au}$ « progrès » social et au « progrès » de la nation en général.

L'objectif de contribuer au «progrès de la nation » était partagé par toutes les autres féministes boliviennes des années 1920. Le "patriotisme» de la femme bolivienne était un thème récurrent dans leurs écrits. Ainsi, la revendication des droits des femmes qu'elles proclamaient était toujours accompagnée de l'argument qu'il s'agissait de contribuer au " progrès de la patrie ». Si les femmes revendiquaient leurs droits c'était pour pouvoir contribuer au « progrès » de leur nation. La caractéristique propre au féminisme proclamé par les féministes boliviennes des années 1920 était donc d'exalter les «valeurs patriotiques» des femmes. Dans ce sens, les revendications des femmes ne prenaient sens que si elles contribuaient au « progrès de la patrie ».

La notion de «progrès » avancée par les femmes des années 1920 provient bien évidemment de l'idéologie «positiviste » de la fin du $\mathrm{XIX}^{\mathrm{e}}$ de laquelle s'étaient imprégnés les intellectuels et hommes politiques sud-américains de la fin du XIX ${ }^{\mathrm{e}}$ et $\mathrm{du}$ début $\mathrm{du} \mathrm{XX}^{\mathrm{e}}$ siècle. Le «progrès de la patrie » était donc un thème omniprésent dans les écrits de l'époque : le développement de l'industrie, des sciences et des technologies devraient faire avancer le pays vers le «progrès ». C'était un thème d'autant plus obsédant pour les intellectuels boliviens de l'époque, que leur pays était extrêmement pauvre et sous-développé et qu'ils s'interrogeaient continuellement sur les raisons de ce retard et les moyens de les résoudre. L'élite intellectuelle, économique et politique bolivienne voulait placer la Bolivie au sein des nations « civilisées » et «avancées » et non pas parmi les nations «sous-développées » et « sauvages ». Les féministes des années 1920, imprégnées de ces idées s'approprièrent cette notion de «progrès » pour l'inclure dans leur idéologie 
féministe. L'intégration des femmes à la vie politique de la nation, avec l'obtention des droits civils et politiques placerait la Bolivie au sein des nations «civilisées ». Une fois les femmes intégrées à la vie politique et sociale, elles pourraient contribuer $\mathrm{au}$ « progrès » de leur nation.

C'est ce qu'exprimaient les rédactrices de Feminiflor :

" Aucune de nous n'ignore le sentiment d'amour et de gratitude que couvre notre cœur envers notre patrie ; c'est un amour sublime, grand, comparable uniquement à l'amour maternel; ce sentiment qui n'a pas de limites, s'appelle patriotisme. Le vrai patriotisme consiste à améliorer notre pays autant que possible, en corrigeant tout ce qui est mauvais et imparfait et en encourageant tout ce qui est bon, en contribuant avec notre travail intellectuel ou manuel à faire notre patrie grande et heureuse.

Or, vous me demandez.

Comment pouvons-nous contribuer à l'amélioration et à l'honneur de notre patrie? Très facilement, en étudiant et en travaillant avec constance pour nous faire utiles plus tard, non seulement pour la patrie, mais aussi pour l'humanité, comme nos dignes professeures qui, où elles vont, sèment la semence vivifiante du bien et de l'instruction qui ouvre la porte du progrès de toute civilisation passée (...)

Ainsi demain, dans un jour pas lointain, notre patrie sera grande, heureuse et respectée par toutes les nations du monde, et toutes répéteront avec enthousiasme comme nous en ce moment :

VIVE LA BOLIVIE ! ${ }^{165}$

Dans ce même sens s'inscrivait l'idée que les femmes devaient se cultiver et s'éduquer afin de pouvoir former des « bons citoyens » pour l'avenir de la patrie. La maternité et l'éducation des enfants étaient exaltées pour pouvoir contribuer au «progrès de la patrie ». Ces idées furent par exemple exprimées dans la revue Eco Femenino :

«Qu'il n’y aient plus les éternelles responsables des foyers détruits par l'ignorance ou la maladresse de plusieurs mères. N'assistons plus à

\footnotetext{
165 « Ninguna de nosotras ignora el sentimiento de amor y gratitud que abriga nuestro corazón hacia nuestra patria; es un amor sublime, grande, comparable únicamente al amor materno, éste sentimiento que no tiene límites, se llama patriotismo. El verdadero patriotismo consiste en mejorar nuestro país lo más que se puede, corrigiendo todo lo malo e imperfecto que en él existe y fomentando todo lo bueno, contribuyendo con nuestro trabajo intelectual o manual a hacerla grande y feliz. Ahora me preguntan ustedes.

¿Cómo nosotras podemos contribuir a la mejora y honra de la patria? Muy fácilmente, estudiando y trabajando con constancia para hacernos más tarde útiles, no solo a la patria, sino a la humanidad, como nuestras dignas profesoras que por doquiera que pasan van sembrando la semilla vivificadora del bien y de la instrucción que abre la puerta del progreso de toda pasada civilización (...)

Así mañana, en día no lejano, nuestra patria será grande feliz y respetada por todas las naciones del mundo y todas repetirán con entusiasmo como nosotras en este momento: ¡VIVA BOLIVIA! » Feminiflor, $n^{\circ} 10$, février 1922, Oruro. Hemeroteca de la Universidad Mayor de San Andrés, La Paz Bolivie.
} 
l'irrémédiable angoisse d'enfants, à qui leur manque tendresse maternelle.

Finis les époux égarés et les citoyens sans foi ni convictions, - sans pureté ni valeurs propres.

La Patrie n'avancera plus cahin-caha, car ses hommes seront alimentés, avec des enseignements sublimes et des solides principes que seulement le concours d'une mère, une mère cultivée, peut donner (...) Préparons-la à la gloire sans paire d'être mères pour de vrai; -la mission la plus sacrosainte qu'elle a (...)

«Depuis que la première femme accoucha le deuxième homme sur terre, l'avenir de l'humanité est dans les mains des femmes. ${ }^{166}$

« Sur tous ces égoïsmes, et même au dessus de son amour, se trouve la patrie. Et si celui à qui elle aime est capable de l'élever; elle ne doit pas être un obstacle.

Mot qui encourage, stimule et réveille les énergies; amour qui donne foi et confiance. Cela doit être la femme bolivienne ! Car du sein de son amour sortiront les hommes qui feront grande et glorieuse la patrie. Et elle est déjà mère !

Alors, sa bonté, sa tendresse son amour infini sera le ciseau qui sculpte sur l'âme de ses enfants la forme de toutes les vertus.

Car la mère, et seulement elle, est responsable envers Dieu, et envers la patrie, de l'âme de ses enfants.

Car d'une femme noble et bonne, naît un enfant bon et noble, comme d'un rosier naît une rose. ${ }^{167}$

L'exaltation du rôle de la mère en tant que fondement de l'idéologie féministe des féministes des années 1920, ne prenait sens que dans les idéaux «patriotiques » de

\footnotetext{
166 «No hayan más, las eternas irresponsables de los destrozados hogares por la ignorancia o torpeza de muchas madres. No presenciemos ya, la irremediable congoja de hijos, a quienes faltó maternal ternura.

Acabaránse los descarriados esposos y los ciudadanos sin fe ni convicciones,- sin pureza ni valores propios.

La Patria no andará en los tumbos que hoy, porque serán alimentados sus hombres, con sublimes enseñanzas y sólidos principios que sólo el concurso de una madre, una madre culta, puede dar (...) Preparémosla a la sin par gloria de ser madres de verdad; - la misión más sacrosanta de ella (...) "Desde que la primera mujer echó al segundo hombre al mundo, el porvenir de la humanidad está en manos de las mujeres". » Eco Femenino, n9, septembre 1924, La Paz. Hemeroteca de la Universidad Mayor de San Andrés, La Paz - Bolivie.

167 « Por sobre todos sus egoísmos, y aún por encima de su amor, está la patria. Y si aquél a quien ama es capaz de engrandecerla; ella no debe ser un obstáculo.

Palabra que aliente; acicate que despierte las energías; amor que de fe y confianza. ¡Eso debe ser la mujer boliviana! ¡Porque del seno de su amor saldrán los hombres que harán grande y gloriosa la patria!

¡Y ya es madre!

Entonces, su bondad, su ternura, su infinito amor será el cincel que esculpa en el alma de sus hijos la forma de todas las virtudes. Que la madre, y solo ella, es responsable ante Dios, y la patria, del alma de sus hijos.

Que de una madre noble y buena, sale un hijo bueno y noble, como de un rosal sale una rosa. » Eco Femenino, n7, juin 1924, La Paz. Hemeroteca de la Universidad Mayor de San Andrés, La Paz Bolivie.
} 
«progrès ». La revendication de leurs objectifs était toujours accompagnée de cet appel au "patriotisme» et au "progrès de la nation ». Leurs revendications féministes s'inscrivaient donc dans cette exaltation de la «patrie », puisque leur plus grand objectif était son "progrès ». Leur idéologie féministe ne prenait sens que si elle était inscrite dans la volonté d'atteindre cet objectif.

C'est pourquoi les rédactrices de la revue Aspiración, intitulèrent le premier article du premier numéro de la revue « Pour la patrie» :

« Patriotisme saint que la femme bolivienne, ainsi nous le comprenons, est appelée à exalter et à diffuser chez les petits, dans le vaste champ du foyer et de l'école. Oui, femmes de Bolivie, insufflez-leur l'amour à la patrie, la réalisation de ses plus chères aspirations; apprenez-leur que notre patrie est pauvre car elle manque de l'Etoile plus riche de notre Blason, qui solitaire dans le lointain brille sans cesse pour le cœur bolivien et qu'ils sont les appelés à la reconquérir pour que la Bolivie soit prospère.

La femme qui aime véritablement son foyer, n'omet aucun dicton de son cœur qui tende à le rendre plus beau : elle ne méprise aucun détail qui le fasse aimable pour ceux qui dorment sous leur toit et dans son esprit elle a toujours l'image de sa petite maison. De la même manière, celles qui aimons véritablement la Bolivie nous ne devons pas omettre notre participation, si petite soit elle ; car un détail que l'on considère insignifiant, une action isolée, une initiative ou l'effort pour l'amélioration intellectuelle, morale et physique, sont des éléments qui constituent son prestige et qui tendent à conquérir son progrès. ${ }^{168}$

Les autres revues annonçaient également les mêmes objectifs dans les premiers numéros de leurs revues. Ainsi, Venas de Plata de Potosí:

«La femme bolivienne est destinée à remplir la mission la plus sublime, la plus dévouée et sainte ; former et fortifier le cœur avec de sages doctrines de moralité, en tant que mère, épouse ou fille de ceux

\footnotetext{
168 «Patriotismo santo que la mujer boliviana, así lo entendemos, está llamada a exaltar y a difundir en los pequeñuelos, en el vasto campo del hogar y de la escuela. Sí, mujeres de Bolivia infundidles con el amor a la patria, la realización de sus más caras aspiraciones; enseñadles que nuestra patria está pobre porque le falta la Estrella más rica de nuestro Escudo, que solitaria y en la lejanía efulge sin cesar para el corazón boliviano y que ellos son los llamados a reconquistarla para que Bolivia sea próspera.

La mujer que ama de veras su hogar, no omite ningún dictado de su corazón que tienda a embellecerlo: no desprecia ningún detalle que lo haga amable para los que su lecho cobija y en su mente siempre fija está la imagen de su casita. Del mismo modo las que amamos de veras a Bolivia, no debemos omitir nuestro concurso por pequeño que sea; porque ya un detalle que lo consideramos insignificante; ya una acción aislada; una iniciativa, o el afán de mejoramiento intelectual, moral o físico, son elementos que constituyen su prestigio y que tienden a conquistar su progreso. » Aspiración, n ${ }^{\circ}$, septembre 1923, La Paz. Centro de Informaciôn y Desarrollo de la Mujer (CIDEM), La Paz - Bolivie.
} 
qui demain sculpteront avec des lettres d'or le grand nom de notre patrie aimée. $\gg{ }^{169}$

Ou encore Anhelos de Cochabamba dans un article intitulé «Le patriotisme de la femme $»$ :

«Ces sentiments s'unissent à la promesse de demain et s'élève le patriotisme.

De ce connu amour au foyer, aveugle d'abord, réfléchi ensuite, avec les ans et l'expérience, naît l'amour à la patrie ; et cet amour constitue l'espoir des peuples; et cet espoir des peuples, marque le niveau moral du monde, à travers des époques qu'il traverse.

Sparte, la république inimitée de l'archipel hellénique, est la représentation la plus brillante de la femme au foyer, de la femme dans la patrie. $\gg{ }^{170}$

Le foyer («hogar») était souvent représenté comme la patrie à une plus petite échelle. Le travail des femmes dans leurs foyers se répercutait et projetait à l'échelle de la nation toute entière. C'est pour cette raison que le rôle de la maternité et de l'éducation des enfants avait une place centrale dans l'idéologie féministe des féministes boliviennes des années 1920, car c'était au sein du foyer que se formaient les citoyens de «l'avenir».

Les objectifs patriotiques énoncés dans les revues faisaient toujours référence à la nécessité de récupérer le littoral, comme on a déjà pu le voir dans plus d'une occasion. Un des rôles essentiels des mères était de parler aux enfants de ce territoire perdu contre le Chili dans la Guerre du Pacifique (1879-1883), pour que ce soit eux qui le récupèrent dans les années à venir. Les intellectuels et hommes politiques de l'époque considéraient que l'une des raisons du retard de la Bolivie, en plus de sa composition raciale, était son enclavement au milieu des terres. La Bolivie ne pourrait jamais atteindre le « progrès » si le territoire côtier perdu, n’était pas récupéré.

\footnotetext{
169 « La mujer boliviana está destinada a cumplir la misión más sublime, la más abnegada, y santa; formar y fortalecer el corazón con sabias doctrinas de moralidad, ya sea como madre, esposa o hija de los que mañana esculpirán con letras de oro el gran nombre de nuestra amada patria. » Venas de Plata, $\mathrm{n}^{\circ} 1$, février 1924, Potosí. Archivo Nacional de Bolivia, Sucre - Bolivie.

${ }^{170}$ «Esos sentimientos se unen a la promesa del mañana, y se levanta el patriotismo.

De ese tan conocido amor al hogar, ciego primero, reflexivo después, con los años y la experiencia, nace el amor a la patria, y ese amor es la esperanza de los pueblos; y esa esperanza de los pueblos marca el nivel moral del mundo, en las épocas que atraviesa.

Esparta, la república inimitada del Archipiélago helénico, es la representación más brillante de la mujer en el hogar, de la mujer en la patria. » Anhelos, n², août 1929, Cochabamba. Centro de Informaciôn y Desarrollo de la Mujer (CIDEM), La Paz - Bolivie.
} 
$\mathrm{Au}$ sein de ce féminisme «relationnel» dont les fondements et revendications s'inscrivaient dans l'objectif très large de "progrès de la patrie », des demandes étaient formulées par les associations féministes de l'époque afin d'atteindre l'émancipation sociale, culture et politique des femmes.

\section{b) Quelles demandes?}

En étudiant les associations féministes, leurs actions et le type de féminisme qu'elles proclamaient on a déjà pu entrevoir quelles étaient les demandes des féministes boliviennes des années 1920. Dans cette partie, il s'agira donc de connaître plus en détail comment ces demandes étaient formulées, quelle était la logique qui les liait et quelles étaient les demandes spécifiques de chaque association.

La demande qui apparaissait comme la plus importante de toutes et celle qui était partagée par toutes les associations féministes des années 1920 était celle de l'amélioration et développement de l'éducation des femmes. Bénéficiaires du développement de cette éducation au début du $\mathrm{XX}^{\mathrm{e}}$ siècle, ces femmes appartenant aux classes moyennes et élevées de la société étaient très souvent, comme on peut le voir dans les biographies en annexe, des professeures et proviseures de lycées de femmes dans le pays. L'amélioration de l'éducation des femmes était donc un objectif primordial pour elles, car elles considéraient que la voie première vers l'émancipation des femmes était leur éducation. Les femmes devaient d'abord être éduquées et ensuite acquérir les droits civils et politiques, car une femme ignorante ne pourrait jamais bénéficier des avantages procurés par l'obtention des droits civils et politiques. Une grande partie des articles des revues étaient consacrés au sujet de l'éducation des femmes : quelle était la meilleure éducation que les femmes pouvaient recevoir. Ces articles mettaient surtout l'accent sur l'importance que devait avoir l'éducation des femmes au sein des priorités du gouvernement car les femmes étaient les éducatrices des futures générations et le « progrès » dépendait de leur éducation :

«Si l'éducation de l'homme est utile et importante, l'est encore plus celle de la femme comme un puissant facteur social, c'est à elle qui est confié le progrès des nations et l'avenir de la race, et par conséquent, en tant que compagne et collaboratrice de l'homme, non seulement dans l'ordre pédagogique, mais aussi dans l'ordre sociologique et 
moral, un effort puissant de soin et d'énergie doit être dédié à l'éducation moderne de la femme. »" ${ }^{171}$

La revue Venas de Plata concevait son travail dans le but du progrès de l'éducation féminine. Les articles consacrés à présenter les objectifs de la revue s'intitulaient «Vers la culture féminine» et «Idéal que l'on poursuit: l'éducation de la femme $»^{172}$.

La revue Anhelos plaçait l'éducation de la femme comme son objectif principal.

L'éducation des femmes devait être améliorée et élargie à d'autres catégories de femmes:

« Voici un thème extrêmement important dans la vie d'un peuple et d'une société : l'éducation de la femme.

Il n'y pas longtemps qu'on considérait comme un danger cultiver les remarquables qualités intellectuelles de la belle moitié du genre humain : on considérait une utopie penser à des femmes médecins, avocats, journalistes, etc., etc., mais l'histoire de la civilisation du monde qui avance à grands pas, nous démontre, dans les faits, une belle réalité en ce qui concerne l'évolution du talent féminin.

C'était ainsi pendant le Moyen Âge et l'époque de la Renaissance. Deux ou trois siècles plus tard, les droits et privilèges de la femme sont reconnus en Espagne, France, Italie, Belgique ; les Etats-Unis étant un des premiers pays à déclarer solennellement les droits de la femme, en la considérant femme au foyer, et en même temps compagne et citoyenne consciente de ses devoirs et de son rôle dans la société. En effet, si nos sœurs de l'autre côté des mers, avec une meilleure chance que la notre, progressent et se développent, s'instruisent et proclament leurs droits ; est-ce qu'on va nous considérer inférieures et est-ce qu'on va s'immobiliser en nous privant des jouissances les plus saines et pures de la vie ? Nos facultés mentales sont les mêmes : la seule chose dont on a besoin est de compléter notre éducation de la manière la plus parfaite possible, nous développer culturellement et socialement pour être des véritables femmes au foyer: car la savante nature nous a signalé aussi nos obligations en tant que premières conseillères et amies des générations de l'avenir, premières à imprimer les qualités morales dans la psyché des enfants.

Tous les regards doivent, alors, être dirigés à cultiver notre intelligence; à ouvrir la voie dans les Lycées, dans les Universités, dans les Écoles Professionnelles, qui tendent a élargir nos connaissances, encourageant notre travail, notre effort personnel, sans

\footnotetext{
171 «Si la educación del hombre es útil e importante, lo es en más alto grado la de la mujer como poderoso factor social, a ella está encomendado el progreso de las naciones y el provenir de la raza, y por lo tanto, como compañera y colaboradora del hombre, no sólo en el orden pedagógico, sino también en el sociológico y moral, ha de dedicarse un poderoso esfuerzo de cuidado y energía en la moderna educación de la mujer. » Eco Femenino, n², octobre 1923, La Paz. Hemeroteca de la Universidad Mayor de San Andrés, La Paz - Bolivie.

${ }^{172}$ Venas de Plata, n¹, février 1924, Potosí. Archivo Nacional de Bolivia, Sucre - Bolivie.
} 
nous faire sortir de notre rôle féminin et des liens que nous avons pour former le sanctuaire sacré du foyer.

Il est nécessaire que l'on essaye de développer notre propre personnalité, en ouvrant une campagne contre l'ignorance, en luttant sans cesse pour la prospérité de notre patrie et la grandeur de l'humanité, traçons un programme simple dans sa forme, mais vaste dans ce qu'il comprend :

I- $\quad$ Solide campagne contre l'ignorance.

II- L'Éducation de la Femme, comme le problème le plus transcendantal pour la prospérité de la Nation bolivienne.

III- La femme doit recevoir une éducation élargie.

IV- Création et multiplication de Collèges, Lycées, Universités, Écoles Professionnelles, pour femmes : Esthétique - Musique et Peinture - Photographie, Statuaire, sont des arts propres à la femme.

V- Enseignement de Puériculture et Economie Domestique, Clinique pour femmes et enfants.

VI- Culture Physique de la Femme, Exercices gymnastiques et récréatifs, Hygiène.

VII- Connaissances d'Instruction Civique - Leur importance.

VIII- Méthodes et systèmes modernes d'enseignement.

IX- Cours d'hygiène dictés par un professionnel dans les écoles secondaires.

Lorsque nous aurons rempli le PREMIER POINT consigné dans ce programme, avec toute l'étendue et perfection qu'il requiert, étendant notre action vers la femme du peuple, jusqu'à arriver à l'indigène de nos petits villages, on pourra proclamer l'émancipation de la femme bolivienne à base d'éducation et culture. Pendant ce temps, il est nécessaire de travailler sans repos, étudier constamment tous les problèmes nous concernant et concernant notre environnement; solliciter la coopération des hauts Pouvoirs de l'Etat; faire comprendre aux pères de famille la nécessité d'éduquer les jeunes femmes, en bannissant les préjugés d'après lesquels l'instruction de la femme est d'importance secondaire et que les études pourraient la distraire de ses devoirs d'épouse et de mère. D'autre part, il existe l'idée selon laquelle nous ne sommes pas capables d'entreprendre des études aussi intenses que ceux des hommes; cependant, le grand cataclysme du Vieux Continent en 1914, a mis en évidence devant le monder entier, comment la Femme s'est tiré dans toutes les activités destinées exclusivement à l'homme. De telle manière que,la seule chose qui nous reste à faire est de travailler intensément pour l'Éducation et l'Instruction de la Femme bolivienne, en donnant ainsi le premier pas solide et sûr qui nous conduise à un avenir de vastes horizons ! » ${ }^{173}$

\footnotetext{
173 «He aquí un tema importantísimo en la vida de un pueblo y de una sociedad: la educación de la mujer.

Hasta hace muy pocos años, se conceptuaba un peligro cultivar las relevantes cualidades intelectuales de que está dotada la bella mitad del género humano: se consideraba una utopía pensar en mujeres médicos, abogados, periodistas, etc., etc., pero la historia de la civilización del mundo que avanza a pasos gigantescos, nos demuestra, con los hechos, una hermosa realidad en lo referente a la evolución del talento femenino.
} 
Dans son essai sur «Les devoirs de la Femme bolivienne» Elodia Ballivián de Ligerón place l'éducation des femmes indigènes comme une des obligations prioritaires à réaliser.

\title{
L'éducation des femmes devait donc non seulement être améliorée mais aussi élargie
} aux femmes des classes populaires urbaines et rurales.

\author{
Dans la logique des féministes de l'époque, seulement des femmes éduquées et \\ cultivées pouvaient profiter des avantages procurés par l'obtention des droits civils.
}

Así, durante la Edad Media y en la época del Renacimiento, dos o tres siglos más tarde, los derechos de la mujer son reconocidos en España, Francia, Italia, Bélgica; siendo Estados Unidos uno de los primeros países en declarar solemnemente los derechos de la mujer, considerándosela a la vez que ama de gobierno, compañera y ciudadana consciente de sus deberes y de su papel en la sociedad. En efecto, si nuestras hermanas de allende los mares, con mejor suerte que la nuestra progresan y se desarrollan, se instruyen y proclaman sus derechos; -nosotras- ¿nos conceptuaremos inferiores y nos inmovilizaremos privándonos de los goces más sanos y puros de la vida? Nuestras facultades mentales son las mismas, lo único que necesitamos es completar nuestra educación de la manera más perfecta posible, desarrollarnos cultural y socialmente para ser verdaderas mujeres de hogar; puesto que la sabia naturaleza, nos ha señalado también nuestras obligaciones como a las primeras consejeras y amigas de las generaciones del porvenir, como a las primeras que imprimimos las cualidades morales en la psiquis infantil.

Todas las miradas deben, pues, dirigirse a cultivar nuestra inteligencia; a abrirnos paso en los Liceos, en las Universidades, en las Escuelas Profesionales que tiendan a ampliar nuestros conocimientos, alentando nuestra labor, nuestro esfuerzo personal, sin sacarnos como algunos pretenden, de nuestro papel femenino y de los vínculos que tenemos para formar el santuario sagrado del hogar.

Preciso es que, tratemos de desarrollar nuestra propia personalidad, abriendo una verdadera campaña contra la ignorancia, luchando sin descanso por la prosperidad de nuestra patria y por la grandeza de la humanidad, tracémonos un programa sencillo en su forma, pero vasto en su comprensión:

I- Decidida campaña contra la ignorancia.

II- La Educación de la Mujer como el problema más trascendental para la prosperidad de la Nación Boliviana.

III- Debe darse a la mujer una Educación amplia.

IV- Creación y multiplicación de Colegios, Liceos, Universidades, Escuelas Profesionales para mujeres: Estética - Música y Pintura - Fotografía, Estatuaria, son artes propias a la mujer.

V- Enseñanza de Puericultura y Economía Doméstica, Clínica para mujeres y niños.

VI- Cultura Física de la Mujer, Ejercicios gimnásticos y recreativos. Higiene. V

II- Conocimientos de Instrucción Cívica. Su importancia.

VIII- Métodos y sistemas modernos de enseñanza.

IX-Cursos de higiene dictados por un profesional en los colegios secundarios.

Cuando hayamos llenado el PRIMER PUNTO consignado en este programa, con toda la amplitud y perfección que requiere, extendiendo nuestra acción hacia la mujer del pueblo, hasta llegar a la indígena de nuestras aldeas, podremos proclamar la emancipación de la mujer boliviana a base de educación y cultura. Entre tanto, es necesario trabajar sin descanso, estudiar constantemente todos los problemas referentes a nosotras y a nuestro medio ambiente; solicitar la cooperación de los altos Poderes del Estado; hacer comprender a los padres de familia, la necesidad de educar a las jóvenes, desterrando prejuicios de que la instrucción en la mujer es de importancia muy secundaria y que el estudio podría más bien distraerla de sus deberes de esposa y de madre. Por otra parte, existe la idea de que no somos capaces de emprender estudios tan intensos como los del hombre; sin embargo, el gran cataclismo del Viejo Continente en 1914, ha puesto de manifiesto, ante el mundo entero, cómo la Mujer se ha desenvuelto en todas las actividades destinadas exclusivamente al hombre. De manera, pues, que lo único que nos toca hacer es trabajar intensamente por la Educación e Instrucción de la Mujer Boliviana, dando así el primer paso firme y seguro que nos conduzca a un porvenir de vastos horizontes! » Anhelos, n 1, juillet 1929, Cochabamba. Centro de Informaciôn y Desarrollo de la Mujer (CIDEM), La Paz - Bolivie. 
L'obtention des droits civils était l'autre demande partagée par toutes les associations féministes des années 1920. Toutes les revues mentionnaient à un moment ou à un autre la nécessité qu'avaient les femmes d'obtenir leurs droits civils. Certaines revues accordaient plus d'importance à ce thème en lui consacrant plusieurs articles, telles que Eco Femenino (voir annexe $\mathrm{C} \mathrm{n}^{\circ} 14$ ) Indice, Anhelos, tandis que les autres revues comme Feminiflor, Aspiración, Venas de Plata l'englobaient souvent sous d'autres thèmes tels que l'éducation de la femme, la rôle que la femme jouait et devait jouer dans la société. Ces dernières revues plaçaient leurs priorités sur l'éducation des femmes et dans ce sens elles envisageaient l'obtention des droits civils à plus long terme, une fois que les femmes seraient émancipées déjà par l'éducation. La seule organisation qui donnait autant d'importance à l'obtention des droits civils qu'à celle de l'éducation des femmes était l'«Ateneo Femenino ». Les membres de cette organisation considéraient qu'il était déjà temps que les femmes obtiennent les droits civils car les lois qui régissaient leur vie sociale et civile étaient trop archaïques et en décalage complet avec la réalité de vie des femmes des années 1920. Ce fut pour cette raison qu'elles furent à l'origine de l'élaboration d'un projet de réforme du Code Civil, en vue d'obtenir les droits civils, comme on l'a déjà vu.

En étant la seule organisation toujours existante en 1926, 1' «Ateneo Femenino » fut de même la seule organisation à soutenir le projet de Loi du Divorce Absolu présenté pour la première fois en $1926^{174}$. Ce projet ne fut finalement pas débattu cette année mais 6 années plus tard, en 1932. Le projet fut approuvé alors sans beaucoup de débats au sein de la Chambre des députés. Cependant, lorsqu'il fut débattu au sein du Sénat, les débats se prolongèrent pendant plusieurs jours et ce fut un sujet extrêmement polémique non seulement au sein du Sénat mais aussi au sein de la société bolivienne. Les débats par rapport au sujet occupaient plusieurs pages des journaux. Il s'agissait d'une loi extrêmement polémique car très avancée pour l'époque : elle autorisait entre autres, le divorce par consentement mutuel après deux ans de mariage, le divorce par séparation de corps de trois ans, le divorce par

\footnotetext{
${ }^{174}$ OPORTO ORDOÑEZ, Luis, Las mujeres en la Historia de Bolivia. Imágenes y realidades del siglo XX (1900-1950), Antología, Anthropos, La Paz - Bolivia, 2001.
} 
séparation de fait de plus de 5 ans $^{175}$. Le divorce relatif existait en Bolivie avant 1932, et consistait en la séparation des corps et de biens; cependant, aucune dissolution juridique du lien conjugal n'avait lieu et par conséquent les conjoints ne pouvaient pas se remarier. Lorsque la loi du divorce absolu fut débattue en 1932 ceux qui la soutenaient argumentaient que le mariage était un contrat civil comme n'importe quel autre et en tant que tel il devait pouvoir être dissout ${ }^{176}$. Le divorce signifierait une libération pour les femmes habitant sous le joug de mauvais maris qui gaspillaient leurs fortunes. Ceux qui étaient en contre argumentaient qu'il s'agissait d'une loi qui allait à l'encontre des dogmes catholiques, et même si l'Etat bolivien permettait la liberté des cultes, l'article 2 de la Constitution proclamait l'Etat bolivien comme un pays catholique. Par le divorce les femmes seraient répudiées par leurs maris, laissées à l'abandon et dans la ruine économique sans d'autres possibilités de pouvoir se marier à nouveau, car il était facile pour un homme de se remarier, mais pas pour une femme qui avait «perdu ses charmes et sa virginité ». Le divorce signifiait la destruction des familles et par conséquent la destruction de la société bolivienne ${ }^{177}$. Plusieurs organisations de femmes catholiques s'opposèrent publiquement à la loi en envoyant des lettres demandant que cette loi, qui était une «atteinte contre la morale », ne soit jamais approuvée. Des conférences s'opposant à l'approbation de cette loi furent également réalisées par les femmes catholiques, dont des anciens membres de l'«Ateneo Femenino» telles que Leticia Antezana de Alberdi (voir annexe A $n^{\circ} 33$ ). La position officielle de $1^{\prime}$ «Ateneo Femenino » soutenait toujours cette loi car elle constituait, d'après la plupart de ces membres, une émancipation pour les femmes. Des conférences furent prononcées par les membres de cette association comme María Gutierrez de Medinaceli (voir annexe A n²) pour faire connaître aux femmes les avantages de cette $10 i^{178}$. Malheureusement, le contenu de ces conférences est introuvable. Néanmoins, la société, les femmes et même les féministes se

\footnotetext{
${ }^{175}$ Les autres causes permettant le divorce incluaient: l'adultère de l'un des conjoints, la tentative d'homicide de l'un des conjoints contre l'autre, la prostitution de la femme par le mari ou des enfants par l'un des deux conjoints, l'abandon volontaire de l'un des conjoints pour plus d'un an, l'ébriété habituelle, la folie ou les maladies contagieuses chroniques et incurables, sévices ou injures graves ou mauvais traitements qui fassent la vie à deux insupportable. Les conjoints divorcés pouvaient se remarier entre eux, mais ne pouvaient pas citer les causes du premier divorce dans une deuxième action de divorce.

${ }^{176}$ Le mariage civil existait en Bolivie depuis le 11 octobre 1911.

${ }^{177}$ Redactor del Senado, sesiones extraordinarias, 1932, p. 188-679, Archivo del Congreso, La Paz Bolivie.

${ }^{178}$ OPORTO ORDOÑEZ, Luis, Las mujeres en la Historia de Bolivia. Imágenes y realidades del siglo XX (1900-1950), Antología, Anthropos, La Paz - Bolivia, 2001.
} 
montrèrent complètement divisés par rapport à cette question. La loi fut finalement approuvée le 15 avril 1932, mais la polémique continua au sein de la société bolivienne pendant longtemps.

Peu de temps après sa promulgation les demandes de divorce explosèrent dans le pays. Les procès de divorce qui étaient publiés dans les journaux, montrent l'ampleur des chiffres car de 5 à 7 demandes de divorce avaient lieu par jour. Deux mois après la promulgation de la loi, 157 demandes de divorce furent traitées par les 5 tribunaux de La Paz, dont 88 de la part des hommes et 69 de la part des femmes. Au bout d'un an de la promulgation de la loi, 400 demandes de divorce furent traitées à La Paz, dont 55\% provenaient des femmes. Face de ces chiffres croissants, l'Église établit certaines mesures dans le but de limiter le nombre de divorcés au sein des fidèles catholiques. Un Congrès d'évêques fut réuni à Cochabamba, où l'on décida : d'instaurer l'usage obligatoire d'un carnet de profession catholique; de refuser tout service religieux aux divorcés et à leurs familles; d'entreprendre une campagne catholique contre le divorce dans tous les lycées catholiques. La loi provoquait autant plus de polémique au sein de la société, qu'elle fut proclamée quelques mois avant le début de la Guerre du Chaco (commencée en juillet 1932) et que les mobilisés craignaient devoir affronter les demandes de divorces de leurs femmes à leur retour $^{179}$. La polémique s'étendit pendant toute la décennie des années 1930 et même dans la première moitié des années 1940. En 1944, 12 ans plus tard, un projet d'abrogation de la loi fut présenté au Parlement qui finalement le rejeta. À cette occasion, les débats et la polémique se ravivèrent dans la société avec autant de force qu'en 1932: pour certains cette loi avait provoqué plusieurs dégâts dans la société et était responsable de la « crise morale » que traversait le pays.

En ce qui concerne les droits politiques, l’ «Ateneo Femenino » fut la seule organisation qui avait clairement comme l'une de ses priorités, en plus de l'obtention des droits civils, celle du suffrage féminin. Les revues Eco Femenino et Indice furent les seules à parler du sujet et à exprimer la nécessité de lutter pour atteindre cet objectif. Il semblerait donc que les autres revues et organisations voyaient l'obtention du suffrage féminin comme un objectif lointain car il viendrait logiquement après le

\footnotetext{
${ }^{179}$ DURÁN JORDÁN Florencia et SEOANE F. Ana María, El complejo mundo de la mujer durante la Guerra del Chaco, Editores: Ministerio de Desarrollo Humano, Secretaría de Asunto Étnicos, de Género y Generacionales, Subsecretaría de Asuntos de Género, La Paz - Bolivia, 1997.
} 
développement de l'éducation de femmes et après l'obtention des droits civils. Plusieurs de ces revues faisaient référence aux avances des autres pays par rapport à la question et parlaient de l'intégration de la femme dans la vie de la nation, mais ne mentionnaient pas à proprement parler la nécessité d'obtenir le suffrage féminin en Bolivie. Les rédactrices de ces revues se considéraient probablement en retard par rapport aux autres nations en ce qui concerne l'éducation féminine et le fait que les boliviennes n'avaient pas encore obtenu les droits civils. Le droit de vote n'apparaissait donc pas dans ses objectifs à court terme. Même si l'« Ateneo Femenino » donnait beaucoup d'importance au suffrage féminin, comme le montrent les articles publiés dans ses revues (voir par exemple l'annexe $\mathrm{C} \mathrm{n}^{\circ} 14$ ) et les projets présentés par Eduviges v. de Hertzog (voir annexe A n¹5) à la Seconde Conférence Panaméricaine de Lima en 1925, aucune action concrète en vue d'atteindre cet objectif ne fut réalisée par cette organisation dans les années 1920. Tout comme leurs collègues, les membres de l' «Ateneo Femenino » considéraient que l'éducation des femmes devait être développée avant d'obtenir le droit de vote, car les femmes devaient être préparées pour envahir d'abord les municipes et ensuite le Congrès. C'est-à-dire, que les membres de l' «Ateneo » envisageaient d'obtenir d'abord les droits civils, ensuitre le droit de vote pour les élections municipales, et plus tard le droit de vote pour les élections nationales. Cependant, contrairement à leurs collèges, les membres de l'«Ateneo Femenino » envisageaient l'obtention du suffrage féminin le « plus tôt possible » :

«On a déjà parlé et écrit sur des modifications législatives, on a demandé l'égalité en accordant à la femme personnalité, en la libérant de sa minorité au sein du mariage; on a considéré les possibilités d'atteindre le droit de vote.

Sur ce dernier point je pense que toutes les femmes boliviennes qui avons été contaminées du désir de résurgence personnelle et collective, dans cette ère mondiale de progrès et d'action, nous sommes toutes parfaitement d'accord sur le fond de ce problème et que nous marchons ensemble, avec un pas solide vers lui. Mais il y a certaines impatientes qui veulent atteindre la fin, avant de commencer par le début, et, à mon avis: le succès de notre campagne dépend d'avoir des justes et équilibrés débuts, de tracer le plan de combat.

Une exception ne peut pas faire une règle. Avant tout nous devons tâcher de travailler pour donner au pays un plus grand contingent de femmes préparées pour les chaires, la tribune et les sciences, et alors mobilisées avec ces puissantes armes de combat nous forcerons à gros coups les portes des municipes, d'abord, et celles du Congrès ensuite. 
Quand ? Le plus tôt possible, et soyons des ferventes travailleuses dans notre cause pour atteindre la culmination de notre perfectionnement intellectuel.

Seulement ainsi la femme bolivienne pourra se vanter d'avoir dépassé l'homme, dans le sens que, cultivée son intelligence, orientées ses buts et dominées ses passions, elle sera élément effectif, force dynamique dans la vie de notre démocratie, avec avantage elle pourra se placer, alors, à côté de tant de congressistes qui dans un siècle, bientôt, de vie indépendante, ont uniquement offert à la patrie des fruits médiocres et nuls.

Certaines de mes collègues pensent que pour entrer, de plein fouet dans les activités politiques, la femme se présentera seulement revêtue au début, d'honnêteté dans les buts et de bonne volonté, acquérant avec l'exercice, l'habileté professionnelle. Nous avons besoin, en plus des principales qualités citées et indispensables à tout citoyen, homme ou femme, envahir les universités et travailler beaucoup pour bannir de notre sexe l'accablante ignorance; former un milieu pour que les hommes et les femmes abandonnent les préjugés qu'ils ont, en considérant que la femme a seulement besoin d'étudier et de penser lorsque lui furent niés les biens de la fortune et de la beauté; lorsqu'elle n'est plus jeune ; lorsqu'elle ne s'est pas mariée.

Il faut remarquer que l'élément féminin le plus préparé pour le moment en Bolivie est le normalien. Tout ce groupe de femmes arriva aux salles de classe peut-être avec l'amertume de l'inégalité au sein de son propre sexe et ainsi commença la lutte et, ô prodige ! Beaucoup d'entre elles découvrirent, une fois tombé l'épais voile qui enveloppait leurs esprits, un beau et nouveau champ d'action qui leur était offert. ${ }^{180}$

\footnotetext{
${ }^{180}$ «Se ha hablado ya y escrito sobre modificaciones legislativas, se ha pedido la igualdad dando a la mujer personalidad, libertándola de su minoridad dentro del matrimonio, se han considerado las posibilidades de alcanzar el voto.

Sobre este último punto, todas las mujeres bolivianas que hemos sido contaminadas del deseo de resurgimiento personal y colectivo, en esta era mundial de progreso y acción, creo que estamos en el fondo de este problema de perfecto acuerdo y que marchamos de conjunto, con paso seguro hacia él. Solo que algunas impacientes quieren llegar al fin antes de comenzar por el principio, y en mi concepto: está el éxito de nuestra campaña en tener justos y equilibrados comienzos en trazar el plan de combate.

Una excepción no puede hacer una regla. Antes que nada debemos procurar, trabajar, por dar al país un mayor contingente de mujer preparadas para la cátedra, la tribuna y la ciencia, y entonces movilizadas con estas poderosas armas de combate forzaremos a golpe tendido las puertas de los municipios, primero, y luego las del Congreso.

¿Cuándo? Lo más pronto posible y seamos fervientes trabajadoras en nuestra causa para llegar luego a la culminación de nuestro perfeccionamiento intelectual. Sólo así la mujer boliviana podrá vanagloriarse de haber superado al hombre, en el sentido de que, cultivada su inteligencia, orientadas sus miras y dominadas sus pasiones, será elemento efectivo, fuerza dinámica en la vida de nuestra democracia, con ventaja podrá colocarse, entonces, al lado de tantos congresales que en un siglo, pronto, de vida independiente, sólo han ofrendado a la patria frutos de medianía y nulidad.

Algunas de mis compañeras, creen, que para entrar, la mujer de lleno en las actividades políticas, sólo ha de presentarse revestida, en el comienzo de honradez de miras y buena voluntad, adquiriendo con el ejercicio, la pericia profesional. Necesitamos además de las principales cualidades citadas e indispensables a todo ciudadano, hombre o mujer, invadir las universidades y trabajar mucho para desterrar de nuestro sexo la abrumadora ignorancia; formar un ambiente para que hombres y mujeres abandonen los prejuicios que tienen, considerando que una mujer sólo necesita estudiar y pensar
} 
Les membres de l' «Ateneo Femenino » envisageaient donc l'obtention du suffrage féminin dans son programme, mais elles considéraient que les femmes devaient d'abord se préparer pour être à la mesure des charges qu'elles auraient une fois élues dans les comices électoraux. Les femmes de l'«Ateneo Femenino », envisageaient le droit de vote dans le cadre libéral qui régissait les élections en Bolivie: c'est-à-dire qu'elles acceptaient les conditions requises pour devenir citoyennes telles que savoir lire et écrire. Elles n'avaient donc pas une conception démocratique du droit de vote qui inclurait la participation de toutes les femmes et/ou de tous les hommes aux comices. Leurs demandes s'inscrivaient dans le cadre libéral de démocratie qui était en place en Bolivie à l'époque.

Les programmes des organisations féministes n'étaient pas uniquement constitués de demandes mais aussi de projets sociaux. Les féministes boliviennes de l'époque considéraient que les femmes devaient prendre en considération, non seulement des droits, mais aussi des devoirs. Leurs idées de contribution au «progrès de la patrie » s'accompagnaient de projets sociaux de service à la communauté, à la société, et au pays.

\section{c) Quels projets ?}

Les membres des organisations féministes des années 1920 envisageaient plusieurs projets sociaux car elles considéraient qu'elles avaient le devoir de servir la société au bénéfice du «progrès » du pays. Sans être et sans se présenter comme des associations de bienfaisance, elles considéraient cependant qu'elles avaient un rôle à jouer dans le « progrès » social. C'est le cas de l' «Ateneo Femenino » qui comme on l'a déjà vu, dans ses statuts annonçait qu' « elle admettra dans son sein l'étude de tous les problèmes sociaux » et que toutes les associations « qui travaillaient pour le bien public $\gg$ trouveraient de la collaboration dans cette association ${ }^{181}$. Plusieurs projets

cuando le han sido negados los bienes de la fortuna y de la belleza; cuando ha dejado de ser joven; cuando no se ha casado.

Adviértase que el elemento femenino más preparado por el momento en Bolivia es el normalista. Todo ese grupo de mujer llegó a las aulas talvez con la amargura de la desigualdad dentro de su propio sexo y así comenzó la ruda lucha y ¡oh, prodigio!, muchas descubrieron, caído el tupido velo que envolvía sus mentes, un hermoso y nuevo campo de acción que se les ofrecía. » Eco Femenino, n 4 janvier 1924, La Paz. Hemeroteca de la Universidad Mayor de San Andrés, La Paz - Bolivie.

${ }^{181}$ Indice ${ }^{\circ} 3$, s.d.,1928. Collection privée de Martha Nardín Rivas, belle-fille de María Luisa Sánchez Bustamante. 
sociaux furent donc envisagés par ces organisations, et notamment par l'«Ateneo Femenino » qui de par sa durée de vie fut l'association la plus active de toutes.

La base sur laquelle se réalisaient et se justifiaient certaines des actions sociales de ces organisations était la valeur chrétienne de la charité. Celle-ci était considérée comme une vertu très importante particulièrement chez les femmes, qui avaient comme mission servir avec « abnégation » la société. Plusieurs des articles des revues féminines - féministes, mettaient en avant le rôle de service que la femme devait entreprendre au sein de la société et exaltaient des vertus «féminines » telles que l'« abnégation » et l' « amour ». C'est sur ces bases idéologiques et chrétiennes que se fondaient et se justifiaient les actions sociales des féministes de l'époque.

Le plus souvent les actions réalisées par ces organisations étaient ponctuelles, et ne relevaient donc pas de projets à long terme. C'est le cas par exemple, de la soirée littéraire - musicale réalisée par les membres du « Centro Artistico et Intelectual de Señoritas de Oruro » le 22 décembre 1922 pour collecter des fonds au bénéfice des orphelins du Chili suite à un tremblement de terre qui avait provoqué la destruction de plusieurs villages dans ce pays ${ }^{182}$.

Par ailleurs, les revues publiaient des informations sur les actions de charité réalisées par les membres de leurs associations, comme par exemple l'organisation d'une société de charité pour la «Protection de l'Enfant et des personnes âgées », réalisée par Isabel v. de Haillot (voir annexe A n`20), membre de l' «Ateneo Femenino », au sein de l'école « Lindaura Campero » qu'elle dirigeait ${ }^{183}$.

D'autres actions, non pas de charité, mais d'aide financière à d'autres institutions furent réalisées par l'«Ateneo Femenino» avec des buts patriotiques. Ainsi, par exemple, la collecte de fonds réalisée entre décembre 1927 et janvier 1928 pour le «Comité Pro-Aviation Chaco ». Ces fonds étaient destinés à contribuer au financement de l'aviation de la Bolivie qui serait mobilisée dans le cas d'une guerre éventuelle contre le Paraguay pour protéger le territoire du Chaco (Sud-Est du pays). En effet, les différends frontaliers avec le Paraguay commencèrent à la fin de 1926, et

\footnotetext{
${ }^{182}$ Feminiflor, $\mathrm{n}^{\circ} 18$, décembre 1922, Oruro. Hemeroteca de la Universidad Mayor de San Andrés, La $\mathrm{Paz}$ - Bolivie.

${ }^{183}$ Eco Femenino, n¹4, juillet 1925, La Paz. Hemeroteca de la Universidad Mayor de San Andrés, La Paz - Bolivie.
} 
la possibilité d'une guerre fut envisagée alors. Cependant, le Président à l'époque, Hernando Siles, résolut ces problèmes et évita la guerre en 1929. Ces conflits frontaliers conduisirent finalement les deux pays à la guerre en 1932 comme on le verra plus tard.

À part ces actions sociales souvent de charité et parfois patriotiques, l'« Ateneo Femenino » envisagea des projets sociaux à plus long terme. Ainsi, les projets présentés par Eduviges v. de Hertzog (voir annexe A n¹5) à la Seconde Conférence Panaméricaine de femmes à Lima en 1925 sur l'éducation secondaire des femmes, l'alphabétisation des indigènes et la création d'une Banque Protectrice des femmes travailleuses, qu'on a déjà étudiés.

D'autres projets furent envisagés, tels que la création d'une Ligue Antialcoolique pour combattre le vice de l'alcool qui était vu comme une plaie dans la société ${ }^{184}$, ou encore la création de Comité d'Hygiène Sociale destiné à combattre la prostitution. En outre, des projets récréatifs furent conçus tels que la création de parcs scolaires pour les enfants.

On ne sait pas si ces derniers projets furent finalement réalisés ou pas; il est probable que non par manque d'argent.

Pour mener à bien ses actions sociales, l'«Ateneo Femenino » était affiliée à diverses associations féminines telles que la Société de Bienfaisance de Dames («Sociedad de Beneficiencia de Señoras »), la Société Protectrice de l'Enfance et la Ligue d'Employées de Commerce et de l'Industrie. Les représentantes de ces associations faisaient partie de la Direction de 1' «Ateneo Femenino » en tant que membres du Conseil.

Si les organisations féministes des années 1920 envisageaient des œuvres de charité, de bienfaisance et des projets sociaux, c'était d'abord parce qu'elles considéraient qu'un des principaux rôles des femmes dans la société était le service voué aux autres. Les femmes devaient donc faire preuve de charité et d'abnégation envers la société. Ce service ne devait pas s'arrêter là car les féministes boliviennes considéraient qu'elles devaient contribuer en tant que femmes au «progrès social »

\footnotetext{
${ }^{184}$ Eco Femenino, n4, janvier 1924, La Paz. Hemeroteca de la Universidad Mayor de San Andrés, La Paz - Bolivie.
} 
pour le bénéfice du pays en général. Leurs projets s'inscrivaient donc dans les visions patriotiques de « progrès » qu'elles formulaient dans leur revue. Leurs associations ne devaient pas servir uniquement à lutter pour la cause des femmes mais elles devaient être aussi utiles et profitables à la communauté et à la nation afin de contribuer au «progrès de la patrie ». D'où la conception de projets à plus long terme tels que l'alphabétisation des indigènes.

Étudier les fondements idéologiques des organisations féministes des années 1920 en Bolivie, implique également étudier leurs demandes : comment celles-ci étaient formulées et quelle logique les liait afin de comprendre exactement quels étaient leurs objectifs et comment envisageaient-elles l'émancipation des femmes. Cela implique d'étudier de même comment ces organisations se concevaient et s'inscrivaient elles mêmes au sein de la société et du pays : quel était le rôle qu'elles considéraient qu'elles devaient jouer au sein de leur communauté. D'où l'étude des projets sociaux qu'elles envisageaient soit comme des œuvres de charité, soit comme des œuvres patriotiques pour contribuer au «progrès » non seulement de la société mais aussi de la patrie. De leur position de classe privilégié, ces femmes agissaient d'après les principes et valeurs chrétiens de la charité et de la compassion : l'aide au plus pauvre et au plus défavorisé. De par leur appartenance à l'élite intellectuelle et économique du pays, ces femmes partageaient les visions et idées courantes à l'époque sur l'intégration des indigènes à la nation. Sous des conceptions totalement paternalistes et guidées par des valeurs de charité et de compassion, ces femmes envisageaient l'intégration des indigènes au pays à travers l'alphabétisation et la « civilisation ». Aucune réforme de changements sociaux plus profonds ne fut jamais proposée ou envisagée par ces femmes qui partageaient le modèle libéral politique et économique qui s'était imposé à la fin du XIX ${ }^{\mathrm{e}}$ siècle dans le pays.

Les organisations féministes des années 1920 eurent une durée de vie assez courte tout comme les revues qu'elles publiaient. Elles furent des associations éphémères, dissoutes quelques années après leur création. Le peu de temps dont elles disposèrent limita énormément leur capacité d'action, qui la plupart du temps fut réduite à la publication de revues féminines - féministes. La seule organisation qui eut une durée de vie longue fut l' «Ateneo Femenino », ce qui lui permit de devenir une organisation plus solide intégrée au mouvement féministe international et ayant créé un réseau féministe en Bolivie. Sa durée de vie lui permit également de réaliser 
plusieurs actions concrètes telles que la participation aux Congrès Internationaux de femmes, l'organisation d'un Congrès National de femmes ou encore la réalisation de projets de modification de lois afin d'obtenir les droits civils des femmes. Ce fut finalement cette organisation qui guida le mouvement féministe des années 1920 en Bolivie.

Les femmes qui composaient ces organisations appartenaient toutes à l'élite sinon économique au moins intellectuelle du pays. Il s'agissait d'un secteur de la population féminine extrêmement restreint et réduit. Il est difficile d'avancer des chiffres, faute à l'existence de ceux-ci, mais l'on peut déduire en réfléchissant aux chiffres postérieurs, qu'il s'agissait d'un nombre infime de femmes organisées afin de lutter pour la cause féminine. L'influence et la diffusion de leurs publications étaient donc réduites aux cercles intellectuels de l'époque. La seule fois où une union avec les femmes des classes populaires fut tentée, fut un échec en raison des différences culturelles et sociales abyssales entre ces deux secteurs de la population.

Malgré le caractère éphémère de ces organisations, la plupart des femmes qui les fondèrent et en formèrent partie ne disparurent pas de la lutte pour la cause féminine dans les années suivantes. Une grande partie d'entre elles jouèrent un rôle important dans la Guerre du Chaco et fondèrent ou s'intégrèrent aux nouvelles organisations qui surgirent dans les années 1930 dans un contexte de guerre et de post guerre totalement différent à celui des années 1920 . 


\section{II) Femmes et mouvement féministe pendant et après la Guerre du Chaco (années 1930)}

\section{A) L'impact de la Guerre du Chaco dans la société bolivienne}

a) L'impact politique, social et culturel de la Guerre du Chaco ${ }^{185}$

La Guerre du Chaco contre le Paraguay eut lieu entre 1932 et 1935. Ce fut une guerre dévastatrice pour le pays, tant au niveau des pertes humaines qu'au niveau des pertes économiques. Elle signifia un bouleversement majeur pour le pays culturellement, socialement et politiquement. Elle fut l'élément déclencheur de l'écroulement progressif du régime de gouvernement oligarchique qui fut finalement détruit avec la Révolution Nationale de 1952. Elle provoqua également une effervescence politique sans précédents avec la création de nouveaux partis qui voulaient finir avec les partis traditionnels et le régime de gouvernement oligarchique en place depuis la fin du $\mathrm{XIX}^{\mathrm{e}}$ siècle. Les partis politiques ne récupéreraient plus jamais leur popularité ni les bases sur lesquelles ils reposaient malgré leurs divers efforts et tentatives dans ce but. La Bolivie qu'ils voulaient gouverner n'étaient plus la même : la culture, la société et même la politique avaient été transformées par cette guerre.

Les origines immédiates du conflit avec le Paraguay remontent à la fin de l'année 1926, lorsque se célébra à Buenos Aires une conférence dans laquelle le Paraguay réclama tout le territoire du Chaco (voir annexe $\mathrm{C} \mathrm{n}^{\circ} 20$ ). Début de décembre, des manœuvres furent réalisées par le Paraguay dans la zone de litige, ce qui provoqua la capture d'un officiel paraguayen. La réponse fut l'attaque du fortin bolivien «Vanguardia » le 8 décembre 1926. La Bolivie avait construit 11 fortins entre 1923 et

\footnotetext{
${ }^{185}$ La plupart des informations sur l'impact social, politique et culturel de la Guerre du Chaco ont été tirées de KLEIN, Herbert S., Orígenes de la revolución nacional boliviana. La crisis de la generación del Chaco, Librería Editorial G.U.M., La Paz, (n.d.) et de MESA (de) José, GISBERT Teresa, MESA Gisbert Carlos D., Manual de Historia de Bolivia, Editorial Gisbert, La Paz, 2008.
} 
1928 dans le territoire du Chaco, et «Vanguardia » était l'un d'entre eux ${ }^{186}$. La prise de ce fortin eut un impact très important dans le pays. Immédiatement le gouvernement reçut l'appui de tous les partis politiques, et des démonstrations populaires furent réalisées dans les rues pendant trois jours de suite. Le président à l'époque, Hernando Siles, annula les élections municipales qui devaient avoir lieu le 9 décembre, et rompit les relations diplomatiques avec le Paraguay. Cette décision reçut l'approbation des tous les dirigeants civils. Ensuite, Siles fit appel aux réserves militaires de 1926 et 1927 et accepta des volontaires pour l'armée. Cependant, il se nia à réaliser une mobilisation générale. En même temps il accepta la proposition de médiation du Secrétaire d'État des Etats-Unis, Kellog, et en représailles, l'armée bolivienne prit les fortins paraguayens «Boquerón» et «Mariscal López». Le Paraguay finit par se rétracter en face de cette ouverte position d'agression, et après des longues négociations, un acte de conciliation fut signée entre les deux pays en septembre $1929^{187}$. Le gouvernement de Siles évita la guerre, mais seulement pour quelques années.

En juin 1930 Siles fut renversé par des mouvements populaires où les étudiants jouèrent un rôle important. Une fois le gouvernement renversé, une «Junta Revolucionaria » militaire prit le pouvoir; elle fut dirigée par un cabinet civil à la tête duquel se trouvait, Daniel Sánchez Bustamante, père de María Luisa Sánchez Bustamante de Urioste (voir annexe A n¹0). Des élections eurent lieu en 1931: Daniel Salamanca fut élu président. Cependant, lors des élections du Congrès, son parti, le « Repúblicano Genuino », subit une grande défaite en face du parti libéral qui prit la plupart des sièges de l'Assemblée. Salamanca était donc un président minoritaire. La crise économique de 1930 eut un impact très fort dans le pays ; les mesures économiques prises, déclenchèrent une forte inflation qui provoqua un important mécontentement social et politique dans le pays. Salamanca, de plus en plus isolé, décida d'orienter ces mécontentements vers le Paraguay, en affirmant que la Bolivie devait «marcher fort sur le Chaco » («pisar fuerte en el Chaco »). Confiant, que le pays était suffisamment préparé pour affronter cette guerre, malgré les

\footnotetext{
${ }^{186}$ MESA (de) José, GISBERT Teresa, MESA Gisbert Carlos D., Manual de Historia de Bolivia, Editorial Gisbert, La Paz, 2008.

${ }^{187}$ KLEIN, Herbert S., Orígenes de la revolución nacional boliviana. La crisis de la generación del Chaco, Librería Editorial G.U.M., La Paz, (n.d.).
} 
avertissements de l'État Major affirmant le contraire, Salamanca ordonna la réalisation des premières opérations d'agression vers juillet 1932. La guerre avait commencé.

Cette guerre qui dura jusqu'en juin 1935 fut catastrophique pour les deux pays mais notamment pour la Bolivie qui avait subit une grande défaite avec la perte non seulement de l'intégralité du Chaco Boréal, mais aussi d'une grande partie de sa population. Dans cet aspect, la Guerre du Chaco fut comparable à la Première Guerre Mondiale pour les pays européens. La Bolivie perdit près de $25 \%$ de sa population : plus de 65.000 jeunes étaient morts, avaient déserté ou étaient morts en captivité. Ce chiffre n'inclut pas tous les handicapés et blessés qui résultèrent de la guerre.

La Bolivie avait perdu la guerre en raison de son manque de préparation pour un conflit de cette ampleur, d'une conduction militaire très déficiente, et d'une société incapable de conduire une guerre étrangère. La masse de l'armée était composée presque exclusivement par des indigènes aymaras et quechuas, dont la plupart d'entre eux étaient des colons qui travaillaient dans une situation de semi servilisme dans les grandes exploitations agricoles détenues par l'élite économique du pays. Ils combattaient dans un territoire très aride et hostile situé à des milliers de kilomètres de leurs lieux d'origine, l'Altiplano et les vallées du pays, contre une armée beaucoup plus homogène socialement. Les indigènes boliviens, complètement désintégrés de la nation ne comprirent même pas pourquoi ils étaient dans le Chaco. Leur présence dans l'armée ne signifia pas une amélioration de leur statut socio-économique car les «castes» furent rigoureusement maintenues pendant la guerre. Ils étaient donc complètement ségrégués des blancs et des métis, qui occupaient dans sa majorité les rangs supérieurs de l'armée.

La guerre eut un impact très profond chez ce dernier secteur de la population, les blancs et les métis, qui sortirent du conflit complètement frustrés et aigris par la défaite catastrophique. La mauvaise conduction de la politique, les erreurs militaires, la corruption administrative, l'absentéisme de l'élite économique, provoquèrent un grand sentiment de frustration au sein de cette population qui vivait pour première fois une situation de guerre. Un vétéran expliquait ce sentiment ainsi :

«...Le drame du Chaco fit une grande brèche dans les consciences. Les générations antérieures à 1932 parlent un langage; ceux qui viennent 
après en parlent un autre complètement différent. Pour ceux qui vivent cette insoutenable expérience, il y a une transmutation... de valeurs $»^{188}$.

Ce fut dans la situation de guerre que ces hommes se retrouvèrent pour la première fois face à face avec les réalités du pays : une extrême pauvreté ; une population indigène complètement désintégrée de la nation vivant dans un état de semi servilisme, complètement discriminée et reléguée par les minorités blanches. Ces hommes remirent complètement en question le système politique, économique et social sous lequel vivait le pays depuis la fin du $\mathrm{XIX}^{\mathrm{e}}$ siècle. Cette génération d'hommes qui vécurent la guerre fut appelée plus tard la «génération du Chaco »; ce fut de ses rangs que sortirent les hommes qui formèrent les nouveaux partis politiques de post guerre, dont le MNR qui dirigea la Révolution Nationale de 1952.

En effet, une fois la guerre finie, une effervescence politique eut lieu dans le pays avec la création de nombreux nouveaux partis politiques. On considérait que les partis traditionnels ne répondaient plus aux aspirations de la majorité et qu'ils avaient conduit le pays à une guerre inutile et absurde. Il fallait donc chercher dans des programmes idéologiques différents.

Les partis qui surgirent dans les années 1930 étaient sous l'influence de plusieurs idéologies et courants politiques tels que le marxisme dans toutes ses tendances (stalinisme et trotskisme en particulier), la pensée indigéniste sous l'influence de Mariátegui, le fascisme en pleine application en Italie et en Espagne, le nationalsocialisme allemand, et le nationalisme comme un courant éclectique et peu défini encore. Les partis traditionnels, essayèrent en même temps de s'adapter à ce nouvel échiquier politique. Ainsi, le parti républicain dirigé par Bautista Saavedra (président de la Bolivie entre 1920 et 1925), ajouta à son nom l'adjectif « socialiste », formant le « Partido de la Unión Republicana Socialista » (le «PURS » dans les années 1940). Cependant, cet ajout ne modifia en rien l'idéologie conservatrice de ce parti traditionnel. Le parti «Republicano Genuino» de Salamanca et le parti libéral maintinrent leur structure mais dans un clair procès de décadence. Carlos Víctor

\footnotetext{
188 «El drama del Chaco abrió una amplia brecha en la conciencia. Las generaciones anteriores a 1932 hablan un lenguaje; y los que vienen después otro completamente diferente. Para aquellos que viven esta insostenible experiencia, hay una transmutación de... valores. » KLEIN, Herbert S., Orígenes de la revolución nacional boliviana. La crisis de la generación del Chaco, Librería Editorial G.U.M., La Paz, (n.d.), p. 214.
} 
Aramayo un des trois «barons de l'étain ${ }^{189}$ tenta une recomposition des forces traditionnelles avec la création du «Partido Centrista », sans succès. Les partis de gauche qui étaient encore minoritaires et marginaux au début des années 1920, se développèrent à la fin de cette décennie : en 1927 furent fondés le «Partido Obrero » et le « Partido Laborista »; en 1928 fut fondé le Parti Communiste de Bolivie dans la clandestinité et sous la direction de Carlos Mendoza Mamani ; en 1929 fut fondé le « Partido Socialista Revolucionario » et en 1930 un nouveau «Partido Socialista ». Après la guerre, les partis de gauche prirent une force jamais vue auparavant. En 1935 surgirent les organisations « Beta Gama » et la «Confederación Socialista Boliviana » sous la direction de Enrique Baldivieso et d'un groupe de jeunes intellectuels, futurs fondateurs du MNR en 1940. De même, les groupes de gauche exilés tels que « Izquierda Bolivana » au Chili et «Exilados» au Pérou, s'unirent pour créer un nouveau parti politique : le «Partido Obrero Revolucionario» («POR »), fondé en 1935 par l'union de groupes de gauche exilés au Pérou et en Argentine sous la direction de Tristan Marof et José Aguirre ${ }^{190}$. Du côte de l'extrême droite, fut fondé en 1937 le parti «Falange Socialista Boliviana» sous l'influence du fascisme espagnol et sous la direction de Óscar Únzaga de la Vega.

Salamanca avait été renversé en plein milieu de la guerre en 1934 par les principaux dirigeants de l'État Major: Peñaranda, David Toro, Germán Busch, Moscoso et d'autres officiers. En effet depuis le début de la guerre, les relations entre l'État Major et le chef de l'État avaient été très tendues. En 1934, Salamanca avait destitué Peñaranda comme chef de l'État Major et nommé à sa place Lanza. Le président se rendit à Villamontes avec Lanza, et une fois là il fut obligé à renoncer à

\footnotetext{
${ }^{189}$ Les «barons de l'étain » étaient les trois hommes dont leurs entreprises contrôlaient $80 \%$ des industries d'étain et $80 \%$ des exportations en Bolivie pendant la première moitié du XX siècle. Avant 1941 leurs entreprises produisaient jusqu'à $1 / 4$ de la production totale d'étain dans le monde. Ces trois hommes étaient: Simón I. Patiño, Hoschild, et Aramayo. DUNKERLEY, James, Rebelión en las venas, Trad. Rose Marie Vargas Jastram, Plural Editores, La Paz - Bolivia, 2003.

190 Tristan Marof, dont le vrai nom est Gustavo Navarro, fut l'un des dirigeants les plus importants de la gauche bolivienne, car il refléta dans ses premières années de militance politique la radicalisation des intellectuels de années 1920 et 1930 qui poussèrent le changement de la société bolivienne de leur époque. Née à Sucre en 1889, il était à l'origine membre du parti républicain. Lors d'un voyage en Europe, il devint marxiste et écrivit un ouvrage important: La justicia del inca (1926) dans lequel il affirma : «Terre au peuple, mines à l'Etat». Il fut le fondateur du « Partido Obrero Revolucionario » en 1935. Cependant, en 1938 il rompit avec l'autre fondateur du parti, José Aguirre, et fonda le Partido Socialista Obrero Boliviano. MESA (de) José, GISBERT Teresa, MESA Gisbert Carlos D., Manual de Historia de Bolivia, Editorial Gisbert, La Paz, 2008.
} 
la charge de la présidence. Il fut remplacé par Luis Tejada Sorzano, qui mena les négociations de paix avec le Paraguay en 1935.

Une fois la guerre finie, plusieurs voix se dressèrent exigeant des éclaircissements par rapport à la conduction de la guerre et un éventuel procès contre les responsables. Face à ce danger, les jeunes officiers qui avaient participé à la guerre et qui avaient remis en question l'ordre traditionnel suite à la défaite, décidèrent de renverser le gouvernement de Tejada Sorzano le 16 mai 1936. Ce coup d'État fut dirigé par Germán Busch, qui plaça David Toro à la tête de la Présidence.

Toro avait été un des officiers les plus influents dans la guerre, mais sa participation dans le conflit contre le Paraguay fut beaucoup débattue au point qu'il fut obligé d'écrire un livre pour justifier ses actions pendant la guerre. Lorsqu'il fut élu président il annonça que sa mission était «d'implanter le socialisme d'État avec la participation des partis de gauche », et qualifia par conséquent son gouvernement de « socialisme militaire ». Cependant, ces affirmations n'avaient aucun véritable sens idéologique car son gouvernement n'entreprit jamais un programme socialiste. Il s'agissait plutôt d'un gouvernement populiste et réformiste.

Le gouvernement s'allia avec la «Confédération Socialiste Bolivienne » dirigée par Enrique Baldivieso. Pour se rallier le mouvement ouvrier, Toro créa le ministère du travail, ce qui représentait une nouveauté dans l'histoire bolivienne. Ce ministère fut placé sous la direction de Waldo Alvarez, le premier ouvrier en Bolivie à avoir un poste dans le cabinet des Ministres. De même, Toro proposa aux groupes réformistes une Assemblée Constituante pour rédiger une nouvelle Constitution afin de répondre aux nécessités de réforme du pays. Cependant, son gouvernement ne dura pas longtemps car le 13 juillet 1937 Germán Busch réalisa un coup d'état et se mit à la tête du pouvoir.

Les forces traditionnelles avaient beaucoup d'expectatives par rapport au gouvernement de Busch. En effet, la société dans son ensemble croyait que Busch suivrait une ligne beaucoup plus conservatrice que Toro et qu'il mettrait fin aux dérives radicales de Toro. Mais ce fut le contraire qui eut lieu : Busch approfondit les réformes déjà entreprises par Toro. Il rompit alors avec les partis traditionnels qui s'unirent pour former la «Concordancia», document d'union signé par Alcides Arguedas (chef du parti libéral à l'époque), Enrique Hertzog et Demetrio Canelas. En revanche, Busch s'allia avec les groupes nommés socialistes dont le groupe formé par Enrique Baldivieso, Augusto Céspedes et Carlos Montenegro, qui soutint le 
gouvernement dans le journal La Calle ${ }^{191}$. Le projet de former une Assemblée Constituante formulé sous Toro, se réalisa sous le gouvernement de Busch. Ce fut la Convention de 1938, qui rédigea une nouvelle Constitution en accord avec les changements politiques, sociaux et culturels déclenchés par la guerre. Cette Assemblée élut Busch comme président constitutionnel et Enrique Baldivieso comme Vice-Président. Le traité de paix avec le Paraguay fut finalement signé en juillet 1938. En avril 1939, Busch se déclara dictateur et entreprit les réformes les plus poussées de son gouvernement. Un nouveau Code du Travail fut promulgué avec plusieurs mesures favorables pour les travailleurs, dont la libre disposition de leurs salaires accordée aux femmes travailleuses. Il nationalisa la Banque Centrale, et par décretloi du 7 juin 1939 il déclara que le 100\% des divises obtenues par les exportations des minéraux devaient être données à l'État.

En août 1939, Busch se suicida. Carlos Quintanilla fut alors placé à la tête du pouvoir par les militaires ${ }^{192}$. L'ère du «socialisme militaire » était close, mais la germe de changements politiques et sociaux déclenchés par la guerre culminerait plus tard avec la Révolution de 1952.

La Guerre du Chaco et la terrible défaite que la Bolivie essuya contre le Paraguay, changèrent complètement la vision que les hommes qui participèrent de la guerre, appartenant surtout aux classes moyennes de la société, avaient par rapport au pays. Dans leur nouvelle vision, le régime de gouvernement oligarchique n'avait rien fait pour pallier la pauvreté et intégrer la grande majorité de la population dans la vie publique et politique du pays. De cette génération d'hommes sortirent les dirigeants qui formèrent les nouveaux politiques en quête de solutions nouvelles, et même les jeunes officiers de l'armée qui établirent, ce qu'ils qualifièrent de «socialisme militaire » pour répondre à la soif de changements dans la société. La Bolivie de post guerre n'était plus la même. Ces changements qui concernèrent l'ensemble de la société touchèrent bien évidemment les femmes qui participèrent à l'effort de guerre de manière très importante. De par leur contribution à l'effort de guerre, les femmes

\footnotetext{
${ }^{191}$ La Calle était au début des années 1930 le journal du Parti Socialiste qui était sous la direction de Carlos Montenegro. et Augusto Céspedes.

${ }^{192}$ MESA (de) José, GISBERT Teresa, MESA Gisbert Carlos D., Manual de Historia de Bolivia, Editorial Gisbert, La Paz, 2008.
} 
n'occupaient plus la même place au sein de la société et la perception que la société avait d'elles s'était forcément transformée.

\section{b) La participation des femmes à l'effort de guerre ${ }^{193}$}

Lorsque le Paraguay attaqua le fortin «Boquerón » le 8 décembre 1928, les femmes de toutes les classes sociales sortirent dans les rues pour manifester contre ce qu'elles considéraient une agression de la part du Paraguay. Elles accédèrent à la Plaza Murillo de La Paz (place principale de la ville où se trouvent les Palais exécutif et législatif) avec des drapeaux de la Bolivie en chantant contre l'« envahisseur ».

Cependant, quelques années plus tard, en 1932, lorsque la guerre avec le Paraguay semblait inévitable, plusieurs organisations féminines se prononcèrent contre la guerre. L'« Asociación Cristiana Femenina » fondée en 1931 organisa des discussions publiques d'opposition à la guerre et à la course mondiale aux armements. De même, le «Comité Boliviano de la Confederación Femenina de la Paz Americana », sous la direction de María Luisa S. de Siles et Victoria v. de Tejada, la « Sociedad Protectora de la Infancia », les dames de «San Vicente de Paul», l'association « Beneficiencia de Señoras », l'« Ateneo Femenino », la «Liga de Damas Católicas », et le « Centro Hispano Americano de Señoras » se prononcèrent contre la guerre devant la Société des Nations. Quelques journalistes isolées comme Martha Mendoza (voir annexe A $\mathrm{n}^{\circ} 34$ ) rédigèrent plusieurs articles d'opposition au conflit dans les journaux.

Pourtant, lorsque la guerre fut déclarée en juillet 1932, toutes ces organisations laissèrent de côté leurs positions pacifistes et tournèrent leurs efforts vers l'aide aux soldats et à leurs familles.

Immédiatement elles cherchèrent à coordonner le travail de la Croix Rouge bolivienne, du Rotary Club, des autorités du gouvernement, du Préfet de Département de La Paz qui était également le Président du Centre de Propagande et de Défense Nationale. La Croix Rouge bolivienne organisa le premier corps d'infirmières qui devaient partir aux zones d'opérations. De même, l' « Ateneo Femenino », qui à cette époque était sous la direction de Emma Pérez de Carvajal (voir annexe A nº19), se

\footnotetext{
${ }^{193}$ La plupart des informations sur la participation des femmes boliviennes à la Guerre du Chaco ont été tirées de l'ouvrage DURÁN JORDÁN Florencia et SEOANE F. Ana María, El complejo mundo de la mujer durante la Guerra del Chaco, Editores: Ministerio de Desarrollo Humano, Secretaría de Asunto Étnicos, de Género y Generacionales, Subsecretaría de Asuntos de Género, La Paz - Bolivia, 1997.
} 
joignit au travail de la Croix Rouge en organisant deux légions de femmes pour le service au Front ; la première était composée de jeunes femmes des classes moyennes et élevées de la société et la deuxième de femmes des classes populaires. De la même manière, l' «Ateneo » fit la donation de dix uniformes pour les dix premières infirmières qui partirent au centre d'opérations au Chaco.

Le 18 juillet 1932, plus de 150.000 personnes se réunirent à la Plaza Murillo pour faire ses adieux aux premiers soldats partant au Front. Les troupes boliviennes partirent de l'État Major jusqu'à la Plaza Murillo, où le Président, sa famille et la foule les attendaient. Au milieu d'applaudissements, de vivats et de fleurs qui leur furent lancées, les soldats se dirigèrent à la Gare pour partir. Les femmes les accompagnèrent en pleurant, avec l'espoir de les voir de retour ${ }^{194}$. Les femmes de l'association «San Vicente de Paul» leurs offrirent des cocardes avec le cœur de Jésus, ainsi que des cigarettes, des biscuits, et des objets d'usage personnel. Un autre groupe de femmes catholiques réalisa une procession avec la vierge « del Carmen » et le drapeau national, en poussant des vivats à la Patrie à l'armée.

Les élèves du Lycée «Instituto Americano », demandèrent au directeur de la Clinique Allemande, M. Beck, que des cours de secourisme soient tenus afin qu'elles puissent s'intégrer à la Croix Rouge le plus tôt possible.

La Proviseure de 1'Ecole Professionnelle Uruguay à La Paz, Ana Rosa Tornero (voir annexe $\mathrm{A}^{\circ} 7$ ), et les professeures de cet établissement, réalisèrent une manifestation contre le Paraguay à laquelle se joignirent d'autres établissements scolaires de la ville. Elles défilèrent en formant des colonnes qui couvraient plusieurs rues de la ville. Lorsqu'elles arrivèrent à la Plaza Murillo, elles furent ovationnées par la foule, et montèrent sur le balcon présidentiel pour prononcer plusieurs discours incitant la foule à remplir leurs devoirs patriotiques. Ana Rosa Tornero prononça une harangue interrompue plusieurs fois par de fervents applaudissements. Les parties les plus remarquables de ce discours furent exprimées ainsi:

«... Hier seulement, les femmes boliviennes nous demandions la paix (...) Aujourd'hui, en face de l'outrage causé à notre patrie et en

\footnotetext{
${ }^{194}$ Une « cueca» célèbre encore aujourd'hui, fut composée à cette époque évoquant les moments d'adieux entre les femmes et les soldats partant au «Vert Enfer », c'est-à-dire, le Chaco (« Infierno verde » titre de la cueca) (voir annexe $\mathrm{C} \mathrm{n}^{\circ} 21$ ). La « cueca» est un type de musique et une danse sudaméricaine à deux qui semble provenir de la «Jota» espagnole. Elle est reconnue comme danse typique de plusieurs pays tels que la Bolivie, l'Argentine, le Chili (qui la déclara « danse nationale ») et le Pérou avec des diverses variantes tant dans le rythme de la musique que dans les chorégraphies.
} 
sachant qu'un peuple sauvage appelé Paraguay, tel un chacal affamé a planté ses griffes dans le cœur de nos frères, nous sentons que notre esprit se contracte de rébellion car arrive jusqu'à nous le cri du sang (...) Et dans cette heure d'angoisse toutes les femmes nous nous enrôlons pour replier nos ailes et descendre jusqu'aux champs de bataille (...) si seulement il était possible de braquer les armes pour la défense de notre intégrité nationale. Que les paraguayens sachent que palpite dans nos veines le sang des héroïnes de la Coronilla (voir annexe $\left.\mathrm{A} \mathrm{n}{ }^{\circ} 35\right),(. .$.$) qu'illumine nos esprits le nom de Juana Azurduy$ de Padilla (voir annexe A $n^{\circ} 36$ ) et que se trouvent ici présentes les filles de Manzaneda (voir annexe $\mathrm{A} \mathrm{n}^{\circ} 37$ ) qui avec le «topo ${ }^{195}$ » dans la main feront trembler l'ennemi (...) Femmes boliviennes, répondez en cette heure d'action et promettez travailler dans les champs de bataille $(. .$.$) contribuons à défendre la souveraineté de notre Patrie. { }^{196}$

Le discours d'Ana Rosa Tornero, assez violent était un appel à la mobilisation des femmes pour participer à l'effort de guerre non seulement à l'arrière-garde mais aussi dans les champs de bataille à travers le secours des soldats. En faisant appel à des héroïnes de l'Histoire de la Bolivie elle établissait une lignée avec celles-ci, symboles $\mathrm{du}$ 《 patriotisme» et du courage de la «femme bolivienne» qui serait prête à se sacrifier pour l'honneur et la souveraineté de sa patrie. Le «patriotisme » des femmes boliviennes fut alors exalté ainsi que le rôle primordial qu'elles devaient jouer dans la guerre pour la défense de leur pays.

D’autres discours furent prononcés à cette occasion par différentes femmes dont la poétesse Olga Bruzzone (voir annexe $\mathrm{A} \mathrm{n}^{\circ} 38$ ) qui lit un poème dédié aux soldats (voir annexe $\mathrm{C} \mathrm{n}^{\circ} 22$ ).

\footnotetext{
${ }^{195}$ Le « topo » est une sorte de broche-épingle en argent servant à accrocher les «mantas » des «cholas» (femmes métisses) en Bolivie. La «manta» était un accessoire vestimentaire féminin typiquement espagnol qui se portait sur les épaules; il fut adopté comme un des accessoires vestimentaires essentiels de la « chola ». Ayant une forme pointue, le « topo » pouvait s'utiliser comme une arme.

${ }^{196}$ «... Ayer nomás las mujeres bolivianas pedimos la paz (...) Hoy frente al ultraje inferido a nuestra Patria y sabiendo que un pueblo salvaje llamado Paraguay cual chacal hambriento había hincado sus garras en el corazón de nuestros hermanos sentimos que nuestro espíritu se encoge de rebelión porque también llega hasta nosotros el grito de la sangre (...) Y en esta hora de angustia nos alistamos todas las mujeres para replegar nuestras alas y descender en los campos de batalla (...) Si posible fuera empuñar las armas en defensa de la integridad nacional. Sepan los paraguayos que palpita en nuestras venas, la sangre de las heroínas de la Coronilla, (...) que ilumina nuestros espíritus el nombre de Juana Azurduy de Padilla y que se hallan aquí presentes las hijas de la Manzaneda, que con el topo en la mano harán temblar al enemigo (...) Mujeres bolivianas, responded en esta hora con la acción y prometeos trabajar en los campos de batalla (...) ayudemos a defender la soberanía de la Patria. » Tiré de DURÁN JORDÁN Florencia et SEOANE F. Ana María, El complejo mundo de la mujer durante la Guerra del Chaco, Editores: Ministerio de Desarrollo Humano, Secretaría de Asunto Étnicos, de Género y Generacionales, Subsecretaría de Asuntos de Género, La Paz - Bolivia, 1997.
} 
En outre, les lycées féminins religieux convoquèrent toutes leurs élèves et anciennes élèves à s'organiser. Un «Comité Pro Patria de los Sagrados Corazones ${ }^{197}$ fut formé et dirigé par Leticia Antezana de Alberdi (voir annexe A $\mathrm{n}^{\circ} 33$ ). Celui-ci convoqua à une réunion générale d'organisations féminines à laquelle assistèrent : la Croix Rouge, l'«Ateneo Femenino », les Dames de «San Vicente de Paul », la « Liga Nacional Antituberculosa », « Las Hijas de Santa Ana ${ }^{198}$ », la « Liga de Damas Católicas », la « Sociedad Protectora de la Infancia », la « Sociedad de ExAlumnas de los Sagrados Corazones », « Entronización del Sagrado Corazón », École Professionnelle «Uruguay», École «Vicenta Eguino», parmi d'autres. Cette convocation réunit la plupart des associations féminines existantes à l'époque dont plusieurs de dames catholiques, ainsi que le personnel de plusieurs lycées et écoles de femmes de la ville de La Paz. Il s'agissait de s'organiser entre associations pour contribuer à l'effort de guerre.

Le lycée « Santa Ana » commença une campagne de collecte de médicaments et de vêtements. Le personnel et élèves de ce lycée envoyèrent une lettre au chef de l'Etat Major lui informant de leur décision de collaborer en confectionnant des uniformes, sous-vêtements, draps, et moustiquaires, et pour remplir cette tâche elles demandaient des pièces de tissu. Elles se montrèrent prêtes également à suppléer les professeurs d'instruction primaire absents et les religieuses parties dans la guerre, ainsi qu'à préparer des paquets de premiers secours individuels.

La plupart des femmes des classes moyennes et élevées de la société s'intégrèrent dans des associations féminines ou s'affilièrent à la Croix Rouge et à d'autres sociétés de secours. Plusieurs d'entre elles devinrent des infirmières, couturières, dactylographes et commencèrent ainsi une profession qui permit à plusieurs d'entre elles de pouvoir subvenir plus tard à leurs besoins et à ceux de leurs familles.

L'Académie de «Corte y Confección » organisa des ateliers pour confectionner des vêtements d'infirmières; 1' "Asociación Cristiana Femenina » sous la direction de Rosa Wilson de Zavala, fit une collecte de fonds pour acquérir des draps et des

\footnotetext{
197 «Sagrados Corazones » était un lycée catholique pour filles.

${ }^{198}$ « Santa Ana » était également un lycée catholique pour filles.
} 
vêtements, en même temps que les cours de secourisme demandés par les élèves du lycée « Instituto Americano » commencèrent à s'organiser.

La Croix Rouge joua un rôle très important en formant et envoyant des corps d'infirmières constamment au Front.

Des institutions de «marraines de guerre » se formèrent pour soutenir matériellement et moralement les soldats mobilisés et leurs familles. Les marraines de guerre et les infirmières étaient chargées de visiter les familles des mobilisées en portant un certificat conféré par la «Liga Nacional Antituberculosa» et validé par la «Croix Rouge ». Elles devaient donner aux familles des mobilisés des cours d'hygiène, des notions élémentaires de préparation d'aliments, de méthodes pour économiser de l'argent, combattre les vices et les mauvaises coutumes. Elles étaient en outre chargées de chercher des informations sur leurs parents au Front, ainsi que de rédiger ou lire des lettres pour les analphabètes. De la même manière, elles apprirent aux familles des mobilisés des notions d'histoire bolivienne, et elles leurs donnèrent des informations diverses telles que : les endroits où ils pourraient trouver du travail, de l'assistance médicale, des école gratuites, des vivres à bas prix, etc. Chaque infirmière ou marraine de guerre avait à sa charge un nombre déterminé de familles qu'elle devait visiter une fois par semaine. Elles devaient rédiger des rapports sur leur travail et les envoyer aux autorités supérieures.

Seulement à la fin du mois de juillet 1932, fut organisé de manière officielle le programme de «marraines de guerre » autorisé par le Ministère de Guerre, sous la direction de Bethsabé de Iturralde. L'organisation précédente des marraines de guerre avait été réalisée de manière spontanée par les différentes associations de femmes, dont la Croix Rouge. Le programme officiel des «marraines de guerre » établissait une responsable dans chaque département du pays, chargée d'organiser les réseaux de marraines de guerre dans son département. Les officiers et soldats qui souhaitaient avoir une marraine de guerre, devaient la contacter pour qu'une marraine leur soit attribuée. La marraine devait envoyer au soldat des paquets, des lettres d'encouragement, et se compromettait à prendre soin de sa famille. Pour financer leurs différentes activités, les marraines organisèrent plusieurs événements servant à collecter des fonds. Une kermesse fut par exemple organisée au Club de Tennis de La Paz où participèrent les femmes des classes moyennes et élevées de la société. Le travail des marraines de guerre fut intense et reconnu avec gratitude par les soldats qui exprimèrent leur reconnaissance de manière diverse selon leurs possibilités : en 
publiant leur reconnaissance dans les journaux, en leur offrant des moutons de leur régions, ou en leur offrant des dîners et des fêtes en leur honneur. La société reconnut également le travail des marraines qui fut décrit ainsi dans les journaux :

«... Les femmes sont en train de mener un travail dont la magnitude n'est pas encore possible de mesurer. Que cette puissante force spirituelle qui part de l'âme des femmes boliviennes, soit aussi l'arme formidable et non sanglante de la défense nationale. ${ }^{199}$

En même temps, les filles du Président Salamanca, Leonor et Raquel Salamanca réunirent dans le Palais de Gouvernement plusieurs femmes des classes élevées de la ville de La Paz dont: Bethsabé de Aguirre, Gloria Tejada, María René de Aramayo (épouse de Carlos Victor Aramayo, un des trois «barons de l'étain»), Esther de Carrasco (voir annexe A n³9), Rosa Iturralde de Ballivián, Felicidad de Muñoz, Ana Rosa Tornero (voir annexe $\mathrm{A} \mathrm{n}^{\circ}$ 7), entre autres. Cette réunion fut à l'origine de la création de la «Sociedad Patriótica de Señoras ». La direction de cette nouvelle organisation était composée de: Leonor Salamanca de Guzmán en tant que présidente, Lucila de Tejada Sorzano en tant que vice-présidente, Elia de Otero et María Luisa Sánchez Bustamante de Urioste (voir annexe A $n^{\circ} 10$ ) en tant que secrétaires. Peu de jours après la fondation de cette association, les femmes qui la composèrent réussirent à collecter une somme importante d'argent.

En outre, l'«Ateneo Femenino » et les associations qui étaient affiliés à cette organisation, firent un appel à travers du Conseil International de Femmes (auquel l'«Ateneo » était affilié) à toutes les femmes du monde pour qu'elles réfléchissent « avec calme et impartialité » sur la « justice » et le « droit» qui accompagnaient la Bolivie dans la guerre.

Ana Rosa Tornero (voir annexe A n7), créa des «Brigades Féminines » composées de groupes de femmes qui s'engageaient à aller périodiquement dans les zones d'opérations du Chaco afin de porter secours et du matériel (aliments, médicaments, vêtements, etc.) aux soldats. Les femmes qui s'engageaient devaient jouir d'une indépendance économique et rester pendant au moins trois mois dans les

\footnotetext{
199 «...Las mujeres están llevando una labor cuya magnitud no es posible todavía medir. Que esta poderosa fuerza espiritual que parte del alma de las mujeres bolivianas, sea también el arma formidable e incruenta de la defensa nacional. » El Diario, 7 novembre 1934. Tiré de DURÁN JORDÁN Florencia et SEOANE F. Ana María, El complejo mundo de la mujer durante la Guerra del Chaco, Editores: Ministerio de Desarrollo Humano, Secretaría de Asunto Étnicos, de Género y Generacionales, Subsecretaría de Asuntos de Género, La Paz - Bolivia, 1997.
} 
zones d'opérations. Le succès de l'action de ces brigades, poussa Ana Rosa Tornero à créer des filiales dans d'autres villes du pays, telles que Cochabamba et Santa Cruz. Pendant la guerre, Ana Rosa Tornero se rendit plusieurs fois au Chaco. À ses retours elle faisait part publique de ses voyages et de l'état des soldats au Front à travers la radio «Illimani », ou à travers des conférences publiques réalisées dans le théâtre municipal qui se remplissaient pour l'entendre. Ana Rosa Tornero était aussi correspondante de guerre du journal El Diario, dans lequel se publiaient ses reportages. A cette époque, elle fut l'unique femme parmi 9 représentants dans la direction de l'Association de Journalistes.

Deux fois par semaine dans le Palais législatif, les jeunes femmes étudiantes des lycées écrivaient des lettres pour les paysannes analphabètes, assistées d'un traducteur qui dictait aux jeunes femmes ce que les épouses, mères ou filles voulaient transmettre aux soldats au Front. De même, ces jeunes femmes cousaient des draps et stérilisaient et enroulaient des bandes deux fois par semaine au Collège Militaire.

À Oruro, fut fondée la « Liga Filial » par Laura Graciela de La Rosa Torres (voir annexe $\mathrm{A} \mathrm{n}^{\circ}$ 5), avec le but de rendre de services aux soldats et à leurs familles. Ainsi, par exemple, cette organisation, dans laquelle travailla également Bethsabé Salmón Fariñas de Beltrán (voir annexe $\mathrm{A} \mathrm{n}^{\circ} 4$ ), se chargea de faciliter les démarches de mariage pour les soldats qui voulaient se marier avant de partir au Front. Cette association se chargeait aussi de la rédaction de lettres (pour les analphabètes) et de leur envoi aux soldats. De même, l'association se chargea de donner des vêtements et le petit-déjeuner aux enfants des combattants. Les membres de cette association étaient marraines de guerre des soldats. Elles créèrent la première bibliothèque militaire à Villamontes.

Partie au Front avec d'autres femmes membres de la Liga Filial pour emmener des aliments et des vêtements aux soldats, L. Graciela de La Rosa, écrivit un livre sur son expérience au Front: «Mi visita a las trincheras y zanjas del velo », dont la plus grande partie du contenu fut censurée par le gouvernement.

Quelques femmes boliviennes jouèrent le rôle d'espionnes; ce fut le cas de Rosa Aponte Moreno, Adela Bello, Elsa Aguilera, Chabela Reyes, Zoraida Alcoreza, Cristina Velasco, et Liz Morales. Elles partaient au Paraguay ou au nord de 
l'argentine avec de fausses identités afin d'essayer d'avoir accès à des documents secrets sur les plans d'opération de guerre du Paraguay.

Les principales organisations à La Paz qui se mobilisèrent et qui réalisèrent des actions de toutes sortes pour contribuer à l'effort de guerre, furent: la «Liga de Damas Católicas » de Bolivie, sous la direction de Angélica Tapia S. de Méndez; la Croix Rouge bolivienne, sous la direction de Bethsabé Montes ; 1 '«Asociación Femenina Pro Defensores de la Patria» («ASFEDEPA»), sous la direction de Antonia Zalles Careaga (voir annexe A n40); le "Comité Patriótico de Señoras », sous la direction de Lucila F. de Tejada Sorzano ; 1'association de « Señoras de San Vicente de Paul», sous la direction de Julia B. de Saavedra; les «Marraines de guerre », sous la direction de Bethsabé Iturralde : la « Liga Antituberculosa », sous la direction de Victoria v. de Tejada; la «Beneficiencia de Señoras », sous la direction de M. Teresa de Gutiérrez; la « Sociedad Protectora de la Infancia », sous la direction de M. Teresa de Pachecho ; l'« Ateneo Femenino », sous la direction de Emma Perez de Carvajal (voir annexe A $\mathrm{n}^{\circ} 19$ ), les anciennes élèves du lycée «Sagrados Corazones », sous la direction de María Z. de Aramayo; les anciennes élèves du lycée «Santa Ana », sous la direction de Mercedes Z. de Velasco; les «Damas Católicas Bolivianas », sous la direction de Matilde Gutierrez de Crespo; les élèves du lycée «Sagrados Corazones », sous la direction de Graciela Matos Salinas ; la « Sociedad Cultural Colegio Santa Ana », sous la direction de Angélica Aldunate.

Toutes ces organisations étaient composées de femmes des classes moyennes et élevées de la société ; la Croix Rouge bolivienne, réformée dans chaque département pendant la guerre, finit par accepter des femmes des classes populaires dans ses rangs. Les femmes des classes populaires faisaient des donations d'aliments pour les familles pauvres des mobilisées et certaines d'entre elles demandèrent au Gouvernement une autorisation pour que les femmes puissent s'enrôler en tant que soldats dans l'armée. Cette autorisation ne leur fut jamais donnée.

$\mathrm{Au}$ fur et à mesure que la guerre avançait le travail d'assistance et de secours aux soldats devenait de plus en plus chargé : les hôpitaux de Sucre débordés, ne pouvaient plus recevoir des blessés. L'université de la ville, ainsi que d'autres bâtiments publics furent adaptés pour devenir des hôpitaux. 
$\mathrm{Au}$ début de la guerre certains propriétaires terriens firent des donations volontaires d'une partie de leur production; cependant, plus tard, l'État se vit dans la nécessité de leur exiger ces donations de manière obligatoire.

En raison de l'absence de leurs maris, la plupart des femmes étaient désormais chefs de famille et en tant que telles, devaient remplir toutes les obligations de la charge, dont principalement, subvenir aux besoins de la famille. La situation pour les femmes qui ne travaillaient pas et qui ne se trouvaient pas dans une bonne situation économique était très difficile, car malgré le fait qu'une loi fut promulguée en 1934 obligeant les employeurs à donner $50 \%$ du salaire des mobilisés à leurs familles, celle-ci ne fut presque jamais respectée. Une grande partie de femmes commencèrent donc à travailler au début de la guerre ou un peu plus tard. Plusieurs femmes cherchèrent à se former rapidement afin de trouver un travail le plus tôt possible. Il y eut une grande affluence de femmes dans les instituts de commerce et de secrétariat, qui ouvrirent plus de cours pour répondre à cette demande. Au début du conflit, l'Intendance de guerre sollicita la main d'œuvre féminine dans l'industrie textile pour la confection de vêtements. Il y eut une grande affluence de femmes pour ce type de travail, au point que, très vite, le secteur était saturé. Les femmes cherchèrent donc du travail dans d'autres secteurs : elles s'insérèrent dans l'administration publique, dans les banques, dans la poste, ou dans les entreprises privées. Dans les villes minières, les femmes trouvèrent du travail à l'extérieur ou à l'intérieur de la mine malgré la croyance populaire selon laquelle les femmes qui rentraient à l'intérieur des mines portaient malheur. Une fois la guerre finie, les femmes furent invitées à regagner leurs foyers et leur place au sein de la famille. On considérait que l'accès massif des femmes au travail avait été une mesure temporaire en raison de la situation de guerre ; une fois le confit terminé, il n'y avait plus de raison pour que les femmes conservent leur travail ; il fallait que les hommes démobilisés puissent récupérer les -leur. Ainsi, on leur exigea de rendre leurs postes aux démobilisés, et plusieurs femmes furent virées de leurs postes. Cependant, une autre partie d'entre elles conservèrent leurs postes après la guerre s'installant ainsi dans la sphère publique.

Les femmes boliviennes s'organisèrent immédiatement après la déclaration de la guerre. Les associations existantes essayèrent de coordonner leurs actions et collaborer dans tout ce qu'elles pouvaient, que ce soit en formant les premiers corps 
d'infirmières, en donnant des uniformes, en collectant des fonds, parmi d'autres actions. Des organisations comme la Croix Rouge jouèrent un rôle important avec l'envoi constant d'infirmières au Front, et l'organisation de marraines de guerre. D'autres organisations se formèrent dans la nécessité du moment telles que les Brigades Féminines, la «Liga Filial» d’Oruro, 1“"Asociación Femenina Pro Defensores de la Patria », la «Sociedad Patriótica de Señoras », etc., et jouèrent un rôle important que ce soit à l'arrière-garde ou au Front. Les femmes accédèrent massivement au marché du travail, et malgré le renvoi de plusieurs d'entre elles à la fin de la guerre, une grande partie d'entre elles conservèrent leur travail. Le rôle jour par les femmes ne passa pas inaperçu au sein de la société : les femmes avaient accédé à la sphère publique et avaient réalisé un travail de mérite à l'arrière-garde et au Front, en tant que secouristes, marraines de guerre, etc.; elles avaient prouvé qu'elles pouvaient jouer un rôle d'importance et utile dans la sphère publique. La perception que la société et que les femmes avaient d'elles mêmes s'était forcément transformée.

La mobilisation des femmes pendant la guerre ne concerna pas uniquement l'assistance et le secours, mais aussi la lutte pour l'obtention des droits civils et politiques.

\section{B) Mouvement féministe pendant et après la guerre}

\section{a) Le mouvement féministe pendant la guerre}

L'expression « féminisme de brèches », selon laquelle le mouvement féministe $s^{\prime}$ '《activerait » pendant des périodes de crise, peut s'appliquer à la Bolivie du début des années 1930 marquée par la guerre qu'elle était en train de mener contre le Paraguay. En effet, pendant le conflit, certaines femmes, conscientes du rôle qu'elles étaient en train de jouer dans la société pendant que les hommes se trouvaient dans le Front, et convaincues que l'importance de ce rôle devait s'accentuer après la guerre, commencèrent une campagne féministe pour l'obtention des droits civils et politiques. Une renaissance du mouvement féministe bolivien eut lieu à cette occasion, non pas dans le cadre des organisations féministes des années 1920, dont presque toutes à l'exception de l'«Ateneo Femenino », avaient disparu, mais dans le cadre d'une 
organisation qui avait comme seul but l'obtention des droits civils et politiques des femmes.

Les origines de cette renaissance commencèrent au début de la guerre et plusieurs facteur contribuèrent a raviver le débat dans l'opinion publique par rapport à ce sujet. En août 1932 la féministe péruvienne, Nina Flores, visitât le pays. Elle était une importante dirigeante du mouvement féministe dans son pays. Invitée par la Fédération Universitaire Locale, elle réalisa une conférence à La Paz sur «La femme bolivienne dans le moment tragique d'aujourd'hui ». Une autre femme qui visita le pays, en 1932 fut la journaliste anglaise Rose Forbes, qui donna des conférences sur la politique nationale et internationale de la Bolivie. Les deux femmes reçurent un accueil très favorable car les auditoriums se remplissaient de gens venus les écouter ${ }^{200}$.

La question d'octroyer les droits civils et politiques aux femmes fut une question qui se posait dans les journaux, et certains journalistes, écrivains et hommes politiques publièrent leurs avis sur la question. Ce fut le cas de Nazario Pardo Valle, journaliste, historien et homme politique qui défendit le suffrage féminin dans un article sous forme d'essai publié en plusieurs jours, intitulé « Le suffrage féminin : est-il possible et souhaitable de l'établir en Bolivie ?» et publié dans le journal La Calle. Pardo Valle, présentât plusieurs arguments historiques pour défendre sa position et fit surtout référence aux avances des pays à l'étranger par rapport à la question ${ }^{201}$.

Au début de l'année 1933 fut réalisée en Uruguay une Conférence Internationale de femmes à laquelle participèrent Ana Rosa Tornero (voir annexe $\mathrm{A} \mathrm{n} \mathrm{n}^{\circ}$ ) et Jael Oropeza (voir annexe $\mathrm{A} \mathrm{n}^{\circ} 41$ ). Cette Conférence avait comme objectif, réunir les femmes des pays du cône Sud afin d'harmoniser leurs luttes pour obtenir les droits civils et politiques dans leurs pays respectifs ${ }^{202}$.

Depuis le début de la guerre, plusieurs femmes journalistes publièrent dans les journaux du pays et dans des revues féminines internationales des articles sur la

\footnotetext{
${ }^{200}$ DURÁN JORDÁN Florencia et SEOANE F. Ana María, El complejo mundo de la mujer durante la Guerra del Chaco, Editores: Ministerio de Desarrollo Humano, Secretaría de Asunto Étnicos, de Género y Generacionales, Subsecretaría de Asuntos de Género, La Paz - Bolivia, 1997.

${ }^{201}$ La Calle, 21, 23, 27 et 28 décembre 1933, La Paz. Hemeroteca del Archivo del Congreso, La PazBolivie.

${ }^{202}$ DURÁN JORDÁN Florencia et SEOANE F. Ana María, El complejo mundo de la mujer durante la Guerra del Chaco, Editores: Ministerio de Desarrollo Humano, Secretaría de Asunto Étnicos, de Género y Generacionales, Subsecretaría de Asuntos de Género, La Paz - Bolivia, 1997.
} 
nécessité des femmes d'obtenir les droits civils et politiques. Ce fut le cas de Zoila Viganó Castañón (voir annexe A n²4), qui dirigeait depuis mars 1933 la section féminine du journal La Semana Gráfica, ainsi que les sections "Crónicas heroicas", "Problemas nacionales" et "Cuestiones Sociales". Dans ces sections, elle publiait constamment des articles sur la condition des femmes et sur leurs droits, ainsi que des articles sur le féminisme, la condition des femmes à l'étranger, le rôle joué par les femmes dans la guerre, etc. Quelques uns de ses articles étaient intitulés « Introduction à l'étude du Féminisme », «L'amour et le mariage soviétiques », « Les devoirs de la Femme envers les études », «La femme devant l'éducation civique », «Le vote de la femme brésilienne », «Les droits civils de la femme», « La femme face au problème du travail », «Mission de charité pendant la guerre », etc. Elle avait déjà écrit occasionnellement des articles dans les journaux sur la condition des femmes et leurs droit depuis 1930 alors qu'elle était encore étudiante à l'université.

Pendant la guerre, Zoila Viganó forma avec un groupe de femmes le «Comité de Acción Feminista ». On n'a pas beaucoup d'informations sur cette organisation et on ne sait pas exactement à quelle date elle fut fondée. On peut supposer cependant qu'elle fut fondée entre 1933 et 1934, c'est-à-dire, en pleine période de guerre. Il s'agissait d'une organisation qui avait comme but principal de réaliser une campagne féministe pour l'obtention immédiate des droits civils et politiques car des élections présidentielles allaient avoir lieu en novembre 1934. Le Secrétariat était composé par : Zoila Viganó, Etelvina Villanueva (voir annexe A n43), María Pardo de Vargas, María Gutierrez de Medinaceli (voir annexe A n²), Herminia Carmona et María C. Lara $^{203}$.

Cette organisation n'avait d'autre but que celui de réaliser une campagne pour l'obtention des droits civils et politiques des femmes avant les élections présidentielles de novembre 1934. Comme son nom l'indique il s'agissait d'un « comité », c'est-à-dire, un groupe de personnes chargées d'un sujet en particulier, en représentation d'une collectivité. Il ne s'agissait donc pas d'une organisation avec une structure durable qui avait d'autres activités culturelles, littéraires, musicales, etc., telles que les organisations féministes des années 1920, mais plutôt d'une

\footnotetext{
${ }^{203}$ La Razón, 21 octobre 1934, La Paz. Collection personnelle d'extraits de journaux de Zoila Viganó Castañón.
} 
organisation qui avait comme seul but l'obtention des droits civils et politiques des femmes de manière immédiate.

Le «Comité de Acción Feminista » commença sa campagne pour l'obtention des droits civils et politiques vers juin 1934. Celle-ci eut lieu à travers les moyens de communication publique tels que la presse et la radio. Plusieurs articles furent rédigés et publiés par Zoila Viganó et Etelvina Villanueva dans les journaux La Razón ${ }^{204}$, El Diario, La Gaceta de Bolivia, à La Paz, El Republicano à Potosí sur les motifs qui poussaient les femmes à demander les droits civils et politiques.

Dans un article intitulé «Pourquoi les femmes demandons nos droits?», Zoila Viganó s'exprima ainsi :

«...Le mouvement féministe que nous redémarrons aujourd'hui n'est pas une imitation des autres pays, mais, elle est l'effet des évènements actuels, c'est-à-dire, de la guerre qui comme tout conflit ou commotion grande amène avec soi des changements partiels ou radicaux dans la vie sociale, politique et économique des peuples, et comme telle, nous ne pouvons pas nous soustraire du devoir impératif de lutter pour nos droits, que le procès même de l'Histoire nous signale en ces moments graves de transition entre le présent et le futur du pays.

Aujourd'hui notre patrie, en raison de l'action belligérante au Chaco, s'affronte à d'énormes difficultés que la femme est en train de surmonter, ça se voit clairement dans les bureaux publics et privés, dans les ateliers et usines dans lequel les femmes travaillent de manière satisfaisante, ce qui nous permet d'arriver à la conclusion logique que si le sexe féminin se prête à réaliser de telles fonctions et si elles lui sont confiées sans observations, alors il est d'une stricte justice de leur confier aussi l'intervention dans les destins du pays, en leur octroyant les droits de citoyenneté pour intervenir dans le suffrage, ce qui doit nous être accordé en laissant de côté les préjugés sociaux qui s'opposent à la loi d'évolution qui forcément est en train de marquer la conquête des droits de la femme. En nous référant concrètement à notre pays, cela fait plusieurs années qu'on autorise la femme à occuper diverses charges dans l'administration, oubliant de manière biaisée que de telles fonctions sont inséparables de la citoyenneté, nous considérons que cette situation d'injustice ne peut pas continuer à régner, car si la femme est apte et permise à exercer de telles fonctions alors il est juste de lui reconnaître le droit de suffrage sans d'autres conditions que celles établies par la Constitution pour les hommes. Et dans ces moments de manque d'électeurs en raison de l'absence de citoyens pour les comices électoraux, peut-on nier à la mère, à l'épouse

\footnotetext{
${ }^{204}$ La Razón fut fondé en 1916 sous la direction financière de Bautista Saavedra, dirigeant du « Partido Rapublicano » et président de la Bolivie de 1920 à 1925. Le journal était dirigé par David Alvéstegui et passa à être le journal du « Partido Repúblicano Genuino » en 1921.
} 
ou à la fille de celui qui offre son sang pour la patrie, sa franche intervention qui décidera le sort du pays? $»^{205}$

Comme l'affirme Zoila Viganó, ce mouvement féministe était le résultat des changements politiques et sociaux que la guerre avait mis en place. Ceux-ci concernaient le rôle important que les femmes étaient en train de jouer pendant cette période de crise en affrontant toutes les difficultés d'un conflit d'une telle magnitude. La place que les femmes avaient dans la société était donc en train de se transformer : les femmes étaient en train de démontrer qu'elles pouvaient exercer les tâches auparavant dévolues exclusivement aux hommes. Il était donc juste que les femmes aient le droit de vote pour pouvoir décider du destin du pays. L'absence d'électeurs est un autre motif évoqué par Zoila Viganó pour justifier l'octroi du droit de vote aux femmes. S'il n'y avait pas d'électeurs pour voter dans les prochaines élections, car les hommes se trouvaient au Front, il était urgent d'accorder le droit de vote aux femmes. La guerre était un moment essentiel pour réclamer les droits civils et politiques, car les femmes étaient en train de prouver qu'elles pouvaient diriger le destin du pays. Zoila Viganó évoque de même l'hypocrisie des hommes politiques qui autorisaient les femmes depuis plusieurs années à travailler dans l'administration publique sans être citoyennes. En effet, d'après l'article 34 de la Constitution en vigueur à l'époque, les droits de la citoyenneté consistaient à participer en tant qu'électeur ou élu à la formation ou à l'exercice des pouvoirs publics et à être admissible dans les fonctions

\footnotetext{
205 «...El movimiento feminista que hoy reiniciamos no es imitación a otros países, sino, es el efecto de los acontecimiento actuales, es decir de la guerra, que como todo conflicto o conmoción grande trae consigo cambios parciales o radicales dentro de la vida social, política y económica de los pueblos, y como tal, nosotras no podemos sustraernos al imperativo deber de luchar por nuestros derechos, que el proceso mismo de la Historia nos señala en estos momentos graves de transición entre el presente y el futuro del país.

Hoy en día nuestra patria, debido a la acción bélica del Chaco se ve frente a enormes dificultades que la mujer las viene allanando, así quedaron claros en las oficinas públicas y fábricas que las mujeres desempeñan satisfactoriamente, llegando a la conclusión lógica que si el sexo femenino se presta para realizar estas funciones y si se le confía sin observaciones, entonces es de estricta justicia, también confiarles su intervención en los destinos del país, otorgándole los derechos de ciudadanía para intervenir en el sufragio, lo cual debe concedérsenos dejando a un lado los prejuicios sociales, que se oponen contra la ley de evolución que forzosamente va marcando la conquista de los derechos de la mujer. Refiriéndome concretamente a nuestros país, hace muchos años que se la autoriza a ocupar distintos cargos dentro de la administración, olvidándose tendenciosamente de que tales funciones son inseparables de la ciudadanía, nosotras consideramos que esta situación de injusticia palpable no puede seguir imperando, pues si la mujer es apta y permitida para tales funciones entonces es equitativo reconocerle el derecho al sufragio, sin más condiciones que las que establece la Constitución para los varones. Y en estos momentos de escasez de electores por la ausencia de ciudadanos para los comicios electorales puede negársele a la madre, a la esposa o a la hija de aquel que brinda su sangre por la patria su franca intervención que ha de decidir la suerte del país? » La Razón, 21 septembre, 1934. Collection personnelle d'extraits de journaux de Zoila Viganó Castañón.
} 
publiques. Cela voulait dire que seulement les citoyens avaient le droit d'accèder à des postes publiques ; or les femmes exerçaient ce droit sans être des citoyennes pour autant. Si les femmes exerçaient l'un des droits de la citoyenneté, elles devaient pouvoir exercer l'autre droit qui était celui de pouvoir participer aux élections.

Évoquant toujours ce qui était établit dans la Constitution Zoila Viganó, affirme dans le même texte :

«Quel précepte constitutionnel exclut la femme de ses droits légitimes? Aucun. Car il n'y pas d'article qui fasse des différences entre l'homme et la femme, le terme homme, employé comprend les deux sexes. De là l'ignominieuse réalité d'une injustice dans laquelle on exige à la femme devoirs et sacrifices dans la société ou collectivité et lui sont restreints les droits et garanties qui sont des facultés authentiquement inhérentes, depuis le moment où elle met son apport dans les activités diverses au développement général du pays... ${ }^{206}$

L'argument que la Constitution n'excluait pas les femmes explicitement de la citoyenneté et que le terme « homme » incluait les deux sexes, est une preuve que les droits de citoyenneté étaient réclamés par les femmes non pas en tant que femmes, avec leurs qualités « inhérentes » à leur sexe, mais en tant qu'individus neutres qui devaient participer aux décisions sur le destin du pays. Le citoyen n'était plus incarné par un être masculin, et les femmes ne devaient pas devenir citoyennes en tant que femmes, sinon en tant qu'individus neutres, car en incluant les deux sexes, le terme «homme» les annulait; aucun des deux sexes ne pouvait plus incarner la citoyenneté. En cela, les arguments utilisés par les femmes du «Comité de Acción Feminista » étaient tout à fait différents des arguments utilisées par les féministes des années 1920 qui réclamaient les droits politiques en tant que femmes, en mettant en avant les qualités et fonctions féminines qui seraient utiles à la patrie. Les femmes du «Comité de Acción Feminista » revendiquaient la citoyenneté non pas en tant que femmes, mais en tant qu'individus. Les fondements théoriques du féminisme qu'elles proclamaient se laissent entrevoir dans les articles publiés par Zoila Viganó, dans lesquels elle expose ses réflexions sur la définition du féminisme :

«Le féminisme est une attitude de lutte (...) L'on peut être féminine sans être féministe; et une féministe est un paradoxe, un contre-sens,

\footnotetext{
${ }^{206}$ «¿Qué precepto constitucional excluye a la mujer de sus legítimos derechos? Ninguno. Pues no hay artíiculo que haga diferencias entre el varón y la mujer, el término hombre, empleado, abarca a ambos sexos. De allí que la oprobiosa realidad de una injusticia en que se le exige a la mujer deberes y sacrificios dentro de la sociedad o colectividad y se le restringe los derechos y garantías que le son facultades genuinamente inherentes, desde el momento que pone su aporte en diversas actividades dentro del desarrollo general del país... » Idem.
} 
car la féminité est un attribut sexuel tandis que le féminisme est une position d'esprit pleinement révolutionnaire, précisément parce que son objectif est d'établir l'égalité des droits en face de ceux absolus de l'homme. Le Féminisme pourrait s'appeler, dans une acception sociale : antimasculinisme, car il tend à mettre fin à la tyrannie ancestrale de l'homme sur la femme humiliée. ${ }^{207}$

Cet extrait est extrêmement intéressant. Zoila Viganó distingue le féminisme de la féminité, c'est-à-dire qu'une féministe ne devait pas forcément être féminine, les deux étant des choses complètement distinctes. Comme elle l'explique elle même, la féminité n'était «qu'un attribut sexuel », c'est-à-dire un caractère propre au sexe féminin. Quant au féminisme, il s'agissait d'une «position d'esprit» c'est-à-dire d'une idéologie, d'un engagement idéologique au delà des caractères propres à un sexe déterminé. En cela, comme elle l'affirme « une féministe est un paradoxe, un contresens »; en effet si la féministe réclamait les droits pour un certain groupe de personnes en particulier, (dans ce cas les femmes avec toutes leurs qualités et attributions («féminité»)), au nom de l'égalité, elle entrait forcément dans un paradoxe car l'égalité impliquait l'absence de tout particularisme. C'est le paradoxe auquel se réfère Joan W. Scott dans son ouvrage La Citoyenne paradoxale. Les féministes françaises et les droits de l’homme: les féministes sont des «citoyennes paradoxales » car si elles réclament les droits pour les femmes en tant que femmes elles font appel à leur différence alors que le citoyen neutre excluait toute différence en étant théoriquement une abstraction des différences. De même, si les femmes réclamaient l'égalité en mettant en avant la neutralité des citoyens, le fait de réclamer des droits pour un groupe en particulier (les femmes) les mettait dans une position contradictoire car l'égalité et la notion d'individu neutre excluaient tout particularisme ${ }^{208}$. Zoila Viganó, consciente de ces paradoxes, définit le féminisme comme une lutte contre l'oppression masculine : un « antimasculinisme » comme le qualifie elle même, c'est-à-dire une lutte contre le «masculinisme» en tant qu'attributs donnés par la société et la culture au sexe masculin lui permettant de

\footnotetext{
${ }^{207}$ «El feminismo es actitud de lucha (...) Se puede ser femenina sin ser feminista; y una feminista es una paradoja, un contra sentido, simplemente porque la feminidad es atributo sexual mientras el feminismo es una posición de espíritu plenamente revolucionaria, precisamente porque su objetivo es establecer la igualdad de derechos frente a los absolutos del hombre. El Feminismo podría llamarse, en acepción social: antimasculinismo, pues tiende q dar fin con la tiranía ancestral del varón sobre la mujer humillada. » La Semana Gráfica, n.d, 1934, La Paz. Collection personnelle d'extraits de journaux de Zoila Viganó Castañón.

${ }^{208}$ SCOTT, Joan W., La citoyenne paradoxale. Les féministes françaises et les droits de l'homme, Albin Michel, Paris, 1998.
} 
dominer sur les femmes et avoir des droits « absolus ». Le « masculinisme » est ainsi appréhendé par Zoila Viganó comme des relations de pouvoir et de hiérarchie à travers lesquelles l'homme avait imposé sa «tyrannie » à la femme. Elle rejoint ainsi, au moins de manière intuitive, ce que Joan W. Scott entend par genre : «...gender is a constitutive element of social relationships based on perceived differences between the sexes, and gender is a primary way of signifying relationships of power. ${ }^{209}$

L'on constate donc que le type de féminisme proclamé par les femmes qui composaient le «Comité de Acción Feminista » était complètement différent à celui revendiqué par les féministes des années 1920 qui mettaient en avant la « féminité » des femmes comme une qualité justifiant leur inclusion dans la vie politique du pays. Ces dernières ne luttaient pas pour l'égalité des femmes avec les hommes mais plutôt pour la mise en valeur des femmes et de ce qui était «féminin » dans la société, et cette mise en valeur impliquait l'octroi de certains droits. Leur féminisme était totalement pacifiste et leurs actions s'inscrivaient dans un cadre légal, contrairement au féminisme anglo-saxon «violent ». Ici, Zoila Viganó définit le féminisme comme une «attitude de lutte» et comme «une position d'esprit pleinement révolutionnaire ». Par l'utilisation de ces expressions elle implique un certain degré de violence. Au moins en théorie, le féminisme proclamé par Zoila Viganó au nom du «Comité de Acción Feminista » n’était donc pas pacifiste, mais « révolutionnaire» en ce qu'elle voulait mettre fin à « la tyrannie ancestrale » des hommes. Le féminisme des membres de cette organisation, se rapprochait ainsi plus du féminisme anglosaxon. Par le fait de revendiquer «l'égalité des droits » il se rapproche également du féminisme « individualiste » puisque l'égalité était revendiquée par les femmes en tant qu'individus neutres hors des «attributs sexuels». En désincarnant le terme « homme » du sexe masculin employée dans la Constitution, elles faisaient appel à la notion d'individu neutre. Cela ne voulait pas dire que les féministes du «Comité de Acción Feminista » niaient leur « féminité », mais elles ne la mettaient pas en avant pour justifier leur inclusion dans la vie politique du pays :

«...avec le respect et accomplissement des droits des devoirs contractés avec la nation nous savons maintenir notre féminité. $»^{210}$

\footnotetext{
${ }^{209}$ SCOTT, Joan W., « Gender : A Useful Category for Historical Analysis », Vol. 91, n5, décembre 1986, p. 1067.

210 «... junto al respeto y cumplimiento de los deberes contraídos con la nación sabemos mantener nuestra feminidad. » La Gaceta de Bolivia, 29 septembre 1934, année I, n¹4, La Paz. Collection personnelle d'extraits de journaux de Zoila Viganó Castañón.
} 
Par ailleurs, le fait de réclamer les droits civils et politiques des femmes de manière immédiate dans le contexte de guerre, les différentiait des féministes des années 1920 qui envisageaient l'acquisition des droits par étapes : les femmes devaient d'abord être éduquées et une fois qu'il y aurait un contingent suffisamment important de femmes préparées pour la politique elles pourraient réclamer les droits civils et les droits politiques.

La campagne féministe du « Comité de Acción Feminista » se réalisa également à travers la radio. Des conférences sur l'obtention des droits civils et politiques furent réalisées dans lesquelles participa le docteur José María Gutiérrez, chef du Parti Libéral. Ce dernier fut le premier parti politique à soutenir de manière officielle en 1934 les demandes de femmes pour l'obtention de leurs droits civils et politiques. Le docteur José María Gutiérrez, qui avait eu la chaire de Droit Constitutionnel dans la faculté de Droit de l'Université Mayor de San Andres de La Paz, collabora dans la campagne du «Comité de Acción Feminista » en réalisant la première conférence du cycle de conférences diffusées dans la radio «Illimani » sur la nécessité qu'avaient les femmes d'obtenir les droits civils et politiques. Ce cycle commença vers octobre 1934 avec les paroles du docteur José María Gutiérrez qui s'exprima ainsi à propos de l'obtention des droits civils et politiques des femmes :

« Il y a des esprits pusillanimes et pessimistes, même parmi les femmes cultivées, qui considèrent que le moment n'est pas encore arrivé pour que leur soit reconnu l'exercice des droits politiques, comme si pour cela, une grande expérience et un formidable bagage de connaissances soient requis. De telles personnes oublient que la femme bolivienne, exerce depuis plusieurs années des charges publiques dans l'administration, qu'elle s'est consacrée à l'enseignement et qu'aujourd'hui elle remplace de manière satisfaisante à l'homme dans les activités commerciales et industrielles.

La guerre du Chaco a démontré de manière éloquente que la femme prête des services efficaces, car elle a organisé des associations philanthropiques, chargées de mitiger la douleur humaine, aidant les prisonniers, les invalides et blessés leur fournissant toute sorte de ressources; elle a fait une campagne incessante pour que la correspondance soit distribuée opportunément; des femmes distinguées servent en tant qu'infirmières dans le champ de bataille même et des commissions féminines sont allées visiter notre courageuse armée, en lui apportant l'affectueuse et respectueuse salutation des éléments de l'arrière-garde (...)

Ces circonstances auraient dû pousser le gouvernement à octroyer sans tarder l'exercice des droits politiques à la femme; octroyés ou 
reconnus ceux-ci, il serait plus facile que le Parlement se charge de modifier la loi civile, en corrigeant les énormes injustices relatives au régime des biens dans le mariage.

J'ai été et je suis un ardent défenseur de l'émancipation juridique et politique de la femme, je crois fortement que si le droit à intervenir dans les affaires publiques du pays lui est accordé, en lui octroyant la citoyenneté active et passive elle fera un usage très discret de cette prérogative, car elle n'oubliera jamais que la société et la famille réclament l'accomplissement de devoirs sacrés et inexcusables et elle ne cessera jamais d'être la Reine du foyer. " ${ }^{211}$

Par leur contribution à la vie sociale et culturelle du pays depuis plusieurs années et leur participation à l'effort de guerre, les femmes méritaient obtenir les droits civils et politiques. Le droit de vote devait leur être accordé d'abord et la législation civile serait modifiée plus facilement ensuite. Cependant, le docteur José María Gutiérrez ne remettait pas en question la place que les femmes devaient occuper au sein de la famille; au contraire cette place était exaltée. La politique ne devait pas distraire les femmes de leurs devoirs et obligations principales au sein du foyer.

En ce qui concerne le travail, le chef du parti libéral considérait que les femmes devaient recevoir le même salaire que les hommes pour le même travail :

«Finalement, dans le domaine des revendications féminines on ne doit pas oublier que si le travail est aussi efficace que celui de l'homme, il n'y a aucun motif pour que leur rémunération soit inférieure. Il est alors injuste que des inégalités soient établies dans le domaine économique. La femme doit être l'objet de considérations spéciales

\footnotetext{
211 « Hay espíritus pusilánimes y pesimistas, aún de mujeres cultas, que consideran que todavía no ha llegado el momento de que se les reconozca el ejercicio de los derechos políticos, como si para ello se requiriese una gran experiencia y un formidable bagaje de conocimientos. Olvidan tales personas, que la mujer boliviana, hace muchos años que se ha dedicado a la enseñanza y que hoy día suple satisfactoriamente al hombre en las actividades comerciales e industriales.

La guerra del chaco ha comprobado en forma elocuente que la mujer presta servicios eficientes, pues ha organizado asociaciones filantrópicas, encargadas de mitigar el dolor humano, ayudando a los prisioneros, inválidos y heridos proporcionándoles toda clase de recursos; ha hecho una campaña incesante para que la correspondencia se distribuya con oportunidad; distinguidas damas sirven de enfermeras en el mismo campo de batalla y han ido comisiones femeninas a visitar a nuestro valeroso ejército, llevándole el cariño y respetuoso saludo de los elementos de la retaguardia (...)

Estas circunstancias las deberían haber inducido al gobierno a otorgar sin mayor dilación a la mujer el ejercicio de sus derechos políticos; concedidos o reconocidos éstos sería muy fácil que el parlamento se preocupe de modificar la ley civil, corrigiendo las enormes injusticias relativas al régimen de bienes dentro del matrimonio.

He sido y soy ardiente propugnador de la emancipación jurídica y política de la mujer, creo firmemente que si se le reconoce el derecho a intervenir en los asuntos públicos del país, otorgándole la ciudadanía activa y pasiva ha de hacer un uso discretísimo de esa prerrogativa pues nunca olvidará que la sociedad y la familia reclaman de ella el cumplimiento de deberes sagrados e inexcusables y jamás dejará de ser la Reina del hogar. » La Razón, 21 octobre 1934, La Paz. Collection personnelle d'extraits de journaux de Zoila Viganó Castañón.
} 
dans certaines époques de la vie, dans lesquelles le travail peut altérer sa santé et compromettre celle de la progéniture. ${ }^{212}$

En plus de l'égalité des salaires, les femmes devaient pouvoir bénéficier d'une protection lorsqu'elles se trouvaient enceintes, même s'il n'est pas clair dans cette conférence quel était le type de protection proposé par José María Gutiérrez.

Quelques mois avant ce cycle de conférences organisées par le «Comité de Acción Feminista », des « Semaines féminines » avaient été organisées dans la radio « Illimani », dans lesquelles de conférences sur les femmes furent réalisées par plusieurs hommes intellectuels. Ainsi, le poète Raúl Jaimes Freyre qui parla au sujet de «La femme artiste», Alberto de Santa Cruz qui parla de «La femme intellectuelle », l'historien Luis S. Crespo qui réalisa une conférence au sujet de « La femme dans notre histoire ». Ces conférences furent réalisées dans le cadre du programme « La semaine féminine » de la radio « Illimani ». Ce programme incluait en outre des interventions de femmes intellectuelles, poétesses, musiciennes, chanteuses qui récitaient leurs poèmes, chantaient, jouaient au piano, etc. Des poétesses telles que Aida Ballón Sanjinés (voir annexe A n ${ }^{\circ 4}$ ), Olga Bruzzone (voir annexe $A n^{\circ} 38$ ), Yolanda Bedregal (voir annexe $\left.A n^{\circ} 45\right)$, Margarita Nuñez del Prado (voir annexe $\mathrm{A} \mathrm{n}^{\circ} 46$ ) et Aida Carvajal (voir annexe $\mathrm{A} \mathrm{n}^{\circ}$ 47) déclamèrent des poèmes. Des musiciennes telles que Yolanda Pando Zalles (voir annexe $\mathrm{A} \mathrm{n}^{\circ} 48$ ) réalisèrent des présentations de piano. Des femmes intellectuelles, telles que Julia Reyes Ortiz de Canedo (voir annexe A n49) et María Luisa Sánchez Bustamante de Urioste (voir annexe $\mathrm{A} \mathrm{n}^{\circ} 10$ ) prononcèrent des discours (voir annexe $\mathrm{C} \mathrm{n}^{\circ} 23$ ).

Il semblerait que ce programme eut du succès car la radio « Illimani » décida de le prolonger pendant plusieurs semaines. Un autre programme se tint à la radio « Illimani » pendant plusieurs semaines : «Hora patriótica femenina » dans lequel intervenaient plusieurs femmes intellectuelles, telles que Zoila Viganó chargée de la section "Lettres".

\footnotetext{
212 «Finalmente en el terreno de las reivindicaciones femeninas no ha de olvidarse que si el trabajo de la mujer es tan eficiente como el del hombre, no hay motivo alguno para que su remuneración sea inferior. Es pues injusto que se establezcan desigualdades en el campo económico y a aquella debe guardársele especiales consideraciones en ciertas épocas de la vida, en que el trabajo puede alterar su salud y comprometer la de la prole. » Idem.
} 
Le travail du «Comité de Acción Feminista » eut un certain succès car suite à la campagne réalisée dans les journaux et la radio et suite à la demande que les membres de cette organisation firent au gouvernement ${ }^{213}$, trois députés, Corveza, Zenteno et Herrera présentèrent un projet de loi pour accorder les droits civils et politiques aux femmes. Le travail et la campagne féministe du Comité eurent des échos dans la presse chilienne comme le démontre un article du journal La Razón:

«Le travail bien orienté du «COMITÉ DE ACCIÓN FEMINISTA » atteint une étendue divulgation dans la presse étrangère et son action pratique mérite des applaudissement avec des raisonnables arguments. Nous reproduisons ce que dit le Mercurio de Valparaíso à ce sujet :

\section{« LA FEMME BOLIVIENNE RÉCLAME LES DROITS CIVILS ET POLITIQUES »}

Des communiqués qu'on a reçus récemment nous apportent des informations sur la campagne qu'a entreprise la femme bolivienne pour les droits civils et politiques. Des articles de presse signés par des prestigieuses dames de La Paz, des présentations aux pouvoirs publics, des campagnes au sein de sociétés et de cercles intellectuels, et tout cela tend à l'heure actuelle à atteindre cette aspiration, qu'a déjà été réalisée dans d'autres pays, y compris en partie dans le nôtre. En faisant écho de cette campagne, les représentants nationaux, messieurs Corveza, Zenteno et Herrera ont présenté au Parlement bolivien un projet de loi pour accorder ces droits à la femme. En s'appuyant sur ce projet, le « Comité de Acción Feminista », par l'intermédiaire de ses secrétaires de relations et de gouvernement respectivement, mesdemoiselles Zoila Viganó Castañón et Etelvina Villanueva, ont fait une présentation aux pouvoirs publics en sollicitant le soutien au projet déjà mentionné.

Le Code Civil de la Bolivie, est similaire à celui de plusieurs pays de notre Amérique. Il laisse à la femme dans une évidente infériorité par rapport à l'homme, et aujourd'hui, dans ces heures pendant lesquelles une guerre maintient en tension à la société et aux éléments du gouvernement de l'Altiplano, la femme a donné des preuves de courage et d'abnégation, desquelles elles font un capital pour représenter aux congressistes leur situation d'égalité devant la loi et les droits.

La femme bolivienne, en réclamant la place qu'il lui correspond politiquement et civilement, met en relief encore une fois son aspiration d'amélioration sociale et élévation du concept d'égalité de droits avec l'homme. $\gg{ }^{214}$

\footnotetext{
${ }^{213}$ Universal, 4 septembre 1934, La Paz. Hemeroteca del Archivo del Congreso, La Paz-Bolivie.

214 « La labor bien orientada del COMITÉ DE ACCIÓN FEMINISTA alcanza amplia divulgación en la prensa extranjera y su acción práctica es aplaudible con razonables argumentos. Reproducimos lo que al respecto dice el Mercurio de Valparaíso:

"LA MUJER BOLIVIANA RECLAMA DERECHOS CIVILES Y POLÍTICOS"
} 
Dans le cadre de cette campagne, un Registre Civique Féminin fut ouvert à la fin du mois d'août 1934 par le «Comité » afin que les femmes puissent s'inscrire pour voter dans les élections de novembre.

En outre, un «Comité Feminista » fut formé également à Cochabamba. Il se joignit à son homologue de La Paz pour la pétition des droits civils et politiques au Parlement. Le message envoyé par cette organisation au «Comité de Acción Feminista » afin d'unir leurs idéaux, et celui envoyé à la Chambre des Députés furent publiés dans le journal El Diario :

« COMITÉ FÉMINISTA S'ADHÈRE À LA PÉTITION DU VOTE Il se dirigea au "Comité de Acción Feminista» et à la chambre de députés.

\section{DE COCHABAMBA}

Le «Comité Feminista » de Cochabama a envoyé les notes suivantes au comité similaire de La Paz et à la Chambre des députés :

Le «Comité Feminista » de Cochabamba, considère qu'il est d'une très grande importance unifier les idéologies et les aspirations de la femme consciente, orientant l'effort collectif vers une seule volonté, et s'adhère aux activités du Comité Central de La Paz, secondant l'œuvre de celui-ci pour les droits de la femme.

Avec ce motif nous vous prions d'agréer nos considérations les plus distinguées : Mercedes Anaya de Urquidi (voir annexe A n³1), María Quiroga (voir annexe A n³0), Cira Aguayo Moreno (voir annexe A $\mathrm{n}^{\circ} 51$ ), Flora de Calvimonte, Mercedes Rodríguez (voir annexe A $\left.\mathrm{n}^{\circ} 55\right)$, Elena Redón Mujía et Guinda Lina Loayza.

Comunicaciones que se han recibido últimamente, nos traen la noticia de la campaña que ha emprendido la mujer boliviana en pro de la conquista de derechos civiles y políticos. Artículos de prensa firmados por prestigiosas dama paceñas, presentaciones a los poderes públicos, campañas societarias y de círculos intelectuales, y todo ello tiende en la hora presente, a conseguir ese anhelo, que ya en otros países se ha plasmado, incluso en parte en el nuestro.

Haciéndose eco de esta campaña, los representantes nacionales, señores Corveza, Zenteno y Herrera han presentado al Parlamento boliviano un proyecto de ley para conceder aquellos derechos a la mujer. Apoyándose en ese proyecto, el Comité de Acción Feminista, por intermedio de sus secretarios de relaciones y gobierno respectivamente, señoritas Zoila Viganó Castañón et Etelvina Villanueva, han hecho una presentación a los poderes públicos solicitando el apoyo al ya mencionado proyecto.

El Código Civil de Bolivia, es como el de muchos países de nuestra América. Deja a la mujer en manifiesta inferioridad con relación al varón, y hoy, en estas horas en que una guerra mantiene en tensión a la sociedad y elementos del gobierno del Altiplano, la mujer ha dado prueba de coraje y abnegación, del cual hacen ellas caudal para representar a los congresales su situación de igualdad ante la ley y los derechos.

La mujer Boliviana, al reclamar el puesto que le corresponde política y civilmente, pone de relieve una vez más su anhelo de mejoramiento social y elevación en el concepto de la igualdad de derechos con el hombre. » La Razón, 9 décembre 1934, La Paz. Collection personnelle d'extraits de journaux de Zoila Viganó Castañón. 
Le «Comité de Acción Feminista» de Cochabamba, envoie à la Chambre des députés son adhésion à la protection des droits de la femme.

\section{CHAMBRE DE DÉPUTÉS DE LA PAZ}

«Comité de Acción Feminista » de Cochabamba prête résolument son soutien à la pétition de son homologue de La Paz, élevée devant le pouvoir Législatif, relative à la reconnaissance et déclaration des droits civils et politiques de la femme en Bolivie, en ouvrant la voie en justice aux idéaux avancés de la femme et à la stricte morale sociale et politique.

Signé. Présidente du Comité. » ${ }^{215}$

Le Comité de Cochabamba était rattaché à celui de La Paz. Parmi ses membres, on retrouve à Mercedes Anaya de Urquidi (voir annexe A n³1), et María Quiroga de Montenegro (voir annexe A ${ }^{\circ} 30$ ) fondatrices et directrices de la revue Anhelos.

Cependant, malgré toute la campagne réalisée par le «Comité de Acción Feminista » de La Paz, et le soutien que celui-ci reçut de son homologue de Cochabamba, il semblerait que le projet de loi présenté par les députés Corveza, Zenteno et Herrera afin d'accorder les droits civils et politiques aux femmes n'ait jamais été débattu au sein du Parlement. Ce sujet ne figure à aucun moment dans les débats parlementaires de l'époque. Il est probable que dans le contexte de guerre, les parlementaires aient considéré que la discussion sur ce projet de loi était d'une importance secondaire face aux problèmes liés à la guerre que le pays devait affronter.

\footnotetext{
215 «COMITÉ FEMINISTA QUE SE ADHIERE A PETICIÓN DEL VOTO.

Dirigióse al Comité de Acción Feminista y a la Cámara de Diputados.

DE COCHABAMBA.

El Comité Feminista de Cochabamba ha dirigido las siguientes notas al comité similar de La Paz y a la Cámara de Diputados:

El Comité Feminista de Cochabamba, considera que es de máxima importancia el unificar los ideales y aspiraciones de la mujer consciente, encauzando el esfuerzo colectivo a una sola voluntad, y se adhiere a las actividades del Comité Central de La Paz, secundando la obra de éste en pro de los derechos de la mujer.

Con este motivo les reiteramos nuestras más altas consideraciones. Atentamente: Mercedes Anaya Urquidi, María Quiroga, Cira Aguayo Moreno, Flora de Calvimonte, Mercedes Rodríguez, Elena Redón Mujía y Guinda Lina Loayza.

El Comité de Acción Feminista de Cochabamba, envía a la Cámara de Diputados su adhesión a la protección de los derechos de la mujer. CÁMARA DE DIPUTADOS DE LA PAZ.

Comité de Acción Feminista de Cochabamba, presta resueltamente su apoyo a la petición de su similar de La Paz, elevada ante poder Legislativo, relativa al reconocimiento y declaración de los derechos civiles y políticos de la mujer en Bolivia, dando paso en justicia a los ideales avanzados de la mujer y estricta moral social y política. (Fdo.). Presidenta Comité. »El Diario, 26 octobre 1934, La Paz. Collection personnelle d'extraits de journaux de Zoila Viganó Castañón.
} 
En outre, la campagne du «Comité de Acción Feminista » de La Paz ne reçut pas le soutien d'autres organisations féminines ni de certaines femmes intellectuelles et journalistes.

En octobre 1934 fut réalisée à la ville d'Oruro une Convention de Femmes organisée par 1'«Asociación Femenina Pro Defensores de la Patria» («ASFEDEPA»), organisation déjà mentionnée chargée de porter soutien et aider les soldats et leurs familles. A cette occasion, le «Comité de Acción Feminista» de La Paz fit parvenir un message de solidarité aux organisations présentes à la Convention dans lequel il demandait que la Convention proclame la revendication des droits civils et politiques pour les femmes. Ce message rédigé par Zoila Viganó et remis à Antonia Zalles de Careaga (voir annexe A $\mathrm{n}^{\circ} 40$ ) fut publié dans le journal La Razón:

« En cette heure de deuil pour la patrie et depuis l'Altiplano de La Paz nous vous envoyons ce message afin que vous l'accueillez avec les bras ouverts car il va de cœur à cœur de femme et avec le destin d'embrasser votre esprit.

La Convention qui se réalisera dans la ville sœur d'Oruro sera la consécration de la pratique appliquée du sentiment philanthropique féminin et signifiera le bilan des forces spirituelles et éthiques, qui se sont mises en évidence dans cet état de guerre souffert par le pays. Les vertus de la femme s'apprécient lorsque les nations sont soumises à rude épreuve, à des mauvais et désespérés moments, et dans cette circonstance douloureuse pour la patrie, vous démontrez la noble mission qui correspond à la femme (...)

Nous articulons dans la distance notre voix fraternelle et notre voix fervente de collaboration (...)

De votre convention solennelle doit naître la fusion grande et unique de l'âme de toutes les femmes boliviennes, lesquelles réclameront avec hauteur leurs droits, en témoignant au nom des conquêtes sociales que les femmes nous démontrons de l'intérêt pour ce problème qu'à la fois qu'il est un problème de culture est un problème social et politique (...) C'est à vous femmes de la première Convention, femmes de cœur et d'esprit qui revient d'accomplir le devoir de faire face de manière franche au problème féminin du droit.

Unissons-nous! Regroupées nous lancerons la voix hautaine de notre propre rédemption, et en Bolivie, au nord et au sud, en orient et en occident, se feront sentir les palpitations de solidarité et l'élan annonciateur de meilleurs jours.

Ce message envoyé avec des frémissement de foi repose dans les mains de la distinguée madame doña Antonia Zalles de Careaga qui étendra à la femme bolivienne la main sincère de la femme de La Paz, représenté par le Secrétariat du "Comité de Acción Feminista", mesdames Etelvina Villanueva, María Pardo de Vargas, María G. de Medinaceli, Herminia Carmona et María C. de Lara. 
Vous avez notre collaboration positive et immédiate.

Zoila Viganó Castañón » ${ }^{216}$

Cependant, la Convention de femmes réunie à Oruro rejeta la proposition de réclamer les droits civils et politiques pour les femmes en arguant que les sujets touchés par le Congrès étaient strictement liés à la Défense Nationale du pays :

«Il fut décidé d'envoyer une communication au «Comité de Acción Feminista » de La Paz, en niant la suggestion de demander vote et droit pour la femme, car le travail de la Convention concerne exclusivement des affaires en rapport avec la Défense Nationale. $»^{217}$

Effectivement, la Convention réunissait les organisations créées pour assister les soldats et leurs familles. Plusieurs organisations se trouvaient présentes, dont on peut citer : 1 “ «Asociación Femenina Pro Defensores de la Patria » («ASFEDEPA »), la «Liga Filial de Oruro », la « Juventud Católica Femenina » de La Paz, la « Sociedad Pro Prisioneros » d'Oruro, la « Asociación Educacionista », la Croix Rouge d'Oruro, entre autres. Les sujets débattus lors de cette Convention furent, entre autres : le paiement des appointements et des pensions aux familles des mobilisés car ils étaient en retard; les devoirs de l'arrière-garde; l'attention aux mutilés, aux malades, aux

\footnotetext{
216 « En esta hora de luto de la patria y desde el Altiplano de La Paz os enviamos este mensaje a fin de que lo acojáis con los brazos abiertos ya que él va de corazón a corazón de mujer y con el hado de abrazar vuestro espíritu (...)

La Convención a realizarse en la hermana ciudad de Oruro será la consagración de la práctica diligente del sentimiento filantrópico femenino y significará el balance de las fuerzas espirituales y éticas, que se ha venido evidenciando en este estado de guerra que sufre el país. Las virtudes de la mujer se aquilatan cuando las naciones se someten a pruebas rudas, a trances desesperantes, en nuestra noble misión que le corresponde a la mujer (...)

Os articulamos por sobre la distancia nuestra voz fraterna y nuestra decisión fervorosa de colaboración (...)

De vuestra convención solemne debe nacer la fusión grande y única del alma de todas las mujeres bolivianas, las cuales reclamarán altivamente sus derechos, atestiguando en nombre de las conquistas sociales, que las mujeres demostramos interés por este problema que a la vez que de cultura es problema social y político (...)

A vosotras mujeres de la Primera Convención, mujeres de corazón y espíritu, corresponde cumplir con el deber de encarar en forma franca el problema femenino derecho.

¡Unámonos! Agrupadas lanzaremos la voz altiva de nuestra propia redención, y en Bolivia, en norte y sud, en oriente y occidente, se sentirán las palpitaciones de solidaridad y el impulso augurador de mejores días.

Este mensaje enviado con estremecimientos de fe, queda en poder de la distinguida señora doña Antonia Zalles de Careaga, que tenderá a la mujer boliviana la mano sincera de la mujer paceña, representada por la secretaría del "Comité de Acción Feminista", señoras Etelvina Villanueva, María Pardo de Vargas, María G. de Medinaceli, Herminia Carmona y María C. v. de Lara.

Tenéis nuestra colaboración positiva e inmediata. Zoila Viganó Castañón. » La Razón, 21 octobre 1934, La Paz. Collection personnelle d'extraits de journaux de Zoila Viganó Castañón.

217 «Se resolvió dirigir una comunicación al Comité de Acción Feminista de La Paz, negando la sugerencia de pedir voto y derecho para la mujer por referirse las labores de la Convención a asuntos exclusivamente relacionados con la Defensa Nacional. » La Patria, 11 octobre 1934, Oruro. Collection personnelle d'extraits de journaux de Zoila Viganó Castañón.
} 
blessés ; la protection des familles des mobilisés ; l'alphabétisation des évacués dans les hôpitaux d'arrière-garde; les embusqués ; l'envoi des paquets et du courrier aux mobilisés ; la situation des prisonniers de guerre ; la fin de la guerre, etc ${ }^{218}$.

Les membres de la Convention d'Oruro n'étaient pas les seules à considérer qu'il était inopportun de demander les droits civils et politiques pour les femmes dans le contexte tragique de la guerre dans lequel d'autres problèmes devaient être prioritaires. En effet, un certain nombre d'autres organisations et de femmes journalistes et intellectuelles s'opposèrent à la campagne pour les droits civils et politiques des femmes en considérant qu'il s'agissait d'une demande égoïste et qu'il fallait donner la priorité à d'autres sujets.

Ce fut le cas de l'«Ateneo Femenino » qui considérait que les problèmes liés à la guerre devaient avoir la priorité dans les débats du Parlement et que les femmes pouvaient attendre quelques années pour redémarrer la campagne afin d'obtenir les droits civils et politiques. Dans la section féminine de La Semana Gráfica, dirigée par Zoila Viganó, fut posée aux lectrices la question : « Êtes-vous pour les droits civils et politiques des femmes ?» Emma Perez del Castillo de Carvajal (voir annexe A n ${ }^{\circ}$ ) alors présidente de l'« Ateneo Femenino » répondit ainsi :

« Je considère que le moment de douloureuse incertitude que traverse la femme bolivienne, dont le foyer a endeuillé la tragédie du Chaco, ne permet d'autre chose que de concentrer toutes nos énergies dans la défense de la Patrie, en cherchant par tous les moyens une paix honorable avec le Paraguay.

Et je pense aussi que l'actuel Parlement circonscrira son travail au chapitre fondamental qui nous accable, réduisant à sa minime expression le nombre de sessions.

L'impératif patriotique et le sens commun imposent laisser de côté les problèmes secondaires, qui en étant approuvés ou refusés, graviteront sur l'exigu Budget National.

Lorsque l' « Ateneo Femenino » adopta le Projet de Loi qui accordait la jouissance des droits civils et politiques à la femme, les circonstances, diamétralement opposées à celles d'aujourd'hui, permettaient l'énorme gaspillage de temps, d'argent et d'oratoire « au détail» qu'investit la Chambre de députés en ce temps-là.

Je crois alors que la femme bolivienne, fidèle à sa tradition glorieuse et stoïque, doit seulement souhaiter que les activités et l'argent ne soient pas distraits au détriment de nos soldats, reportant à une meilleure occasion, des questions secondaires.

${ }^{218}$ Idem. 
De plus : les corporations féminines doivent demander aux Chambres l'ajournement du projet qui pour le moment constitue une ruse politique détournant l'attention de l'opinion publique.

D'autre part, les projets anodins et brisés qu'ils présentent ne sont pas en accord avec les idéaux de la femme bolivienne qui lutte depuis dix ans pour l'approbation intégrale de ses droits civils et politiques.

Ça ne fait rien d'attendre deux ou trois années encore afin de ne pas devenir des complices inconscientes de l'objectif poursuivi par l'éternelle politique politicienne « criolla ».

Il y a quelque chose de plus noble et de sacré à quoi penser : toute une génération détruite, anéantie pour toujours, nous contemple depuis l'infini.

Et cette charge humaine que nous rend la guerre : des garçons maigres, jaunâtres exsangues, fiévreux comme si dans ses veines se fermentait toute la boue de la jungle, demandent notre aide.

La Paz, Septembre $1^{\text {er }}, 1933$. Emma Perez de Carvajal. »» ${ }^{219}$

L'«Ateneo Femenino » qui avait été le plus actif défenseur des droits civils et politiques des femmes dans les années 1920, décida de consacrer entièrement ses activités à l'assistance et au secours des mobilisés et de leurs familles, laissant pour plus tard leurs revendications féministes. Par ailleurs, selon Emma Perez Carvajal, le projet présenté n'était pas complet et ne répondait pas aux revendications pour

219 «Considero que el momento de dolorosa incertidumbre por el que atraviesa la mujer boliviana, cuyo hogar ha enlutado la tragedia del Chaco, no permite otra cosa que enfocar todas nuestras energías a la defensa de la Patria, buscando por todos los medios posibles una paz honrosa con el Paraguay.

Y pienso también que el actual Parlamento circunscribirá sus labores al capítulo fundamental que nos agobia, reduciendo a su mínima expresión el número de sesiones.

El imperativo patriótico y el sentido común, imponen dejar de lado problemas secundarios que al aprobarse o rechazarse, han de gravitar hondamente sobre el exiguo Presupuesto Nacional.

Cuando el Ateneo Femenino prohijó el Proyecto de Ley que acordaba el goce de los derechos civiles y políticos de la mujer, las circunstancias, diametralmente opuestas a las de hoy, permitían el enorme despilfarro de tiempo, dinero y oratoria al "por menor" que invirtió la Cámara de Diputados en aquel entonces.

Creo pues, que la mujer boliviana, fiel a su tradición gloriosa y estoica, solamente debe anhelar que no se distraigan actividades y dineros en detrimento de nuestros soldados, dejando para mejor ocasión, cuestiones secundarias.

Algo más: las corporaciones femeninas deben pedir a las Cámaras el aplazamiento del Proyecto, que por el momento sólo constituye un ardid político que desvía la atención de la opinión pública.

Por otra parte, los proyectos anodinos y tronchados que presentan no están de acuerdo con los ideales de la mujer boliviana que desde hace diez años viene luchando por la aprobación integral de sus derechos civiles y políticos.

Nada importa esperar dos o tres años más a fin de no hacernos cómplices inconscientes del objetivo perseguido por la eterna politiquería criolla.

Hay algo más noble y sagrado en qué pensar: toda una generación destruida y aniquilada para siempre, nos contempla desde el infinito.

Y esa cara humana que nos devuelve la guerra: muchachos flacos, amarillos, exangües, calenturientos, cual si en sus venas fermentase todo el cieno de la selva, pide nuestra ayuda.

La Paz, Septiembre 1ero, de 1933. Emma Perez de Carvajal. » La Semana Gráfica, septembre 1933, La Paz. Collection personnelle d'extraits de journaux de Zoila Viganó Castañón. 
lesquelles l'«Ateneo Femenino » avait lutté pendant 10 ans depuis la présentation du «Projet de réintégration des droits civils de la femme », et ne servait donc qu'à distraire la population des problèmes liés à la guerre. Malheureusement le projet de loi présenté par les députés Corveza, Zenteno et Herrera est introuvable ; il aurait été intéressant de le comparer avec le projet présenté au Parlement par l'«Ateneo » en 1925.

Les membres de l'«Ateneo » n'étaient pas les seules à estimer que demander les droits civils et politiques pour les femmes en période de guerre était inopportun. Des femmes journalistes publièrent plusieurs articles dans les journaux attaquant la position des membres du «Comité d'Acción Feminista» qu'elles considéraient comme égoïste en ce moment de guerre. Ce fut le cas de Gloria Serrano (voir annexe A $n^{\circ} 50$ ) et de Martha Mendoza (voir annexe $\mathrm{A} \mathrm{n}^{\circ} 34$ ).

Gloria Serrano commença un débat avec Zoila Viganó dans les journaux, en affirmant qu'il était «inhumain» de demander les droits des femmes alors que les soldats étaient en train de mourir au Front et argua que les femmes boliviennes n'étaient pas suffisamment préparées pour voter :

«En défiant le risque d'être accusée de « pasatista » et réactionnaire je n'approuverai pas la campagne féministe qui a commencé il y a quelques jours.

Non pas par être considérée comme une femme d'idées avancées qui lutte pour sa libération, elle sera déclarée propagandiste d'une cause qui n'est pas encore suffisamment mûrie.

Des expériences amères nous montrent quotidiennement que nous ne devons pas nous lancer à des aventures sans être suffisamment préparés. Et la femme bolivienne ne l'est pas pour le suffrage électoral. La moyenne culturelle de la femme est presque nulle. On ne va pas juger le total, de la minime proportion qu'offre le pourcentage d'un groupe de femmes intellectuelles qui occupent un élevé fauteuil de cérémonie dans le domaine des lettres et des arts. Ce groupe cultivé est réduit. Par contre, le nombre de femmes analphabètes et semi alphabètes est vaste. Car le fait de savoir lire et écrire n'est pas un taux qui marque un haut degré culturel (...)

Avant de penser à des triomphes électoraux, préparons-nous et préparons la camarade prolétaire. L'exclure parce qu'elle n'est pas munie du bagage culturel nécessaire, serait injuste. La lancer dans le suffrage, serait dangereux (...)

Les plis du drapeau sont empourprés avec le sang des combattants, humectés des larmes de femmes folles de douleur, et c'est inhumain de penser à nous et à nos droits. $\rangle^{220}$

\footnotetext{
220 «Desafiando el riesgo de ser tachada de pasatista y reaccionaria, no voy a corear la campaña feminista que se ha iniciado en los últimos días.
} 
A cet article, Zoila Viganó répondit ainsi :

«En conséquence du mouvement féministe que nous avons commencé, la presse a fait connaître des avis de nature diverse, entre eux celui de Gloria Serrano, dont les appréciations m'obligent à consolider mes idées exprimées dans un article antérieur publié à $L a$ Razón et à la Gaceta de Bolivia.

L'auteure de Jirones Kollavinos, commence en disant qu'elle ne peut pas se « déclarer propagandiste d'une cause qui n'est pas suffisamment mûrie ", ce qui veut dire qu'elle attend que le mouvement féministe, atteigne son développement maximal, pour se prononcer à sa faveur ; tandis que nous pensons d'une manière différente, nous croyons que toute doctrine, aspiration ou conquête, ne naît jamais «mûre », mais elle commence peu à peu jusqu'à atteindre sa plénitude à travers de la gestation de luttes ardues, en suivant un procès naturel et logique d'évolution qui a caractérisé tous les changements politiques, sociaux et économiques du monde. Même si pour beaucoup, notre mouvement semble improvisé et prématuré, nous croyons accomplir un devoir en organisant l'action franche et résolue pour la conquête des droits politiques et civils de la femme bolivienne, tenant en compte les caractéristiques et les problèmes que le pays présente pour cet aspect.

Elle affirme que : "La moyenne culturelle de la femme est presque nulle ». Probablement personne ne dira le contraire, mais c'est aussi une grande vérité, que toutes les conquêtes démocratiques ont été faites par des multitudes analphabètes qui se sont passionnées pour certains idéaux forgés par une minorité d'hommes, d'où il résulte que nous ne pouvons pas attendre des masses de femmes cultivées pour les conquêtes qu'elles soutiennent, alors, ce que nous devons faire c'est leur donner la consigne de l'idéal qui les passionnera pour lutter pour leur réalisation, et ceci n'est pas une question de culture, car les multitudes o collectivités œuvrent guidées plus par leurs sentiments que par le cerveau (...)

Nonobstant, le fait que notre Constitution Politique, dit que pour participer aux comices électoraux il suffit de savoir « lire et écrire »,

No por ser considerada como una mujer de avanzadas ideas que lucha por su liberación, ha de declararse propagandista de una causa que aún no está suficientemente madurada.

Amargas experiencias nos muestran a diario que nunca debemos lanzarnos a una aventura sin estar convenientemente preparados. Y la mujer boliviana no lo está para el sufragio electoral.

El promedio cultural de la mujer es casi nulo. No vamos a juzgar el total de la mínima proporción que ofrece el porcentaje un núcleo de mujeres intelectuales que ocupan un elevado sitial en el campo de las letras y el arte. Ese grupo culturizado es reducido. En cambio es vasto el de mujeres analfabetas y semialfabetas. Porque el hecho de saber leer y escribir no es índice que marque un alto grado cultural $(\ldots)$

Antes de pensar en triunfos electorales, preparémonos y preparemos a la compañera proletaria. Excluir a ésta por que no está munida del bagaje cultural necesario, sería injusto. Lanzarla en el sufragio, peligroso $(\ldots)$

Los pliegues de la bandera están enrojecidos con la sangre de los combatientes, humedecido con las lágrimas de mujeres enloquecidas de dolor y es inhumano pensar en nosotras y en nuestros derechos. " El Diario, 24 septembre 1934, La Paz. Collection personnelle d'extraits de journaux de Zoila Viganó Castañón. 
Gloria Serrano, affirme : «Car le fait de savoir lire et écrire n'est pas un taux qui marque un haut degré culturel», et qui croit que «savoir lire et écrire » est synonyme de culture ? Peut-on exiger aux masses un haut degré culturel? Nous comprenons qu'elles peuvent avoir une instruction relative, mais la culture peut seulement être exigée à un nombre déterminé d'hommes ou de femmes, qui l'ont acquise comme conséquence de leurs études et de leurs recherches (...)

Nous ne pouvons pas nous résigner à attendre que le période de post guerre consacre nos droits, pour lesquels nous n'aurions pas lutté, nous n'ignorons pas non plus que le période de post guerre amène probablement des changements politiques, sociaux et économiques, or, si elle consacre nos droits, que ce soit après que nous ayons accompli le devoir de lancer le cri d'alerte aux femmes boliviennes, avant que les évènements nous surprennent dans une heure imprévue.

Finalement nous plaidons pour toutes les femmes mères, épouses et filles qui souffrent la douleur et la misère de la guerre, à qui sont exigés tous les sacrifices et leur sont niés les droits. Nous luttons contre ces injustices ! ${ }^{221}$

221 «Como consecuencia del movimiento feminista que iniciamos, la prensa ha dado a conocer opiniones de diversa índole, entre ellas la de Gloria Serrano, cuyas apreciaciones me obligan a consolidar mis ideas expresadas en un artículo anterior publicado en LA RAZON y la Gaceta de Bolivia.

La autora de "Jirones Kollavinos", comienza diciendo que no puede "declararse propagandista de una causa que aún no está madurada", lo que quiere decir que espera que el movimiento feminista, llegue a su máximo desarrollo, para pronunciarse recién a su favor; en cambio pensamos nosotras de distinta manera, creemos que toda doctrina, aspiración o conquista de determinado ideal, nunca nace "maduro", sino que se inicia poco a poco hasta llegar a su plenitud a través de una gestación de luchar arduas, siguiendo un proceso natural y lógico de evolución que ha caracterizado a todos los cambios políticos, sociales y económicos del mundo. Nosotras, aunque para muchos parezca extemporáneo o prematuro nuestro movimiento, creemos cumplir un deber al iniciar la acción franca y decidida por la conquista de los derechos políticos y civiles de la mujer boliviana, teniendo muy en cuenta las características y problemas que el país presenta en este aspecto.

Afirma que: "El promedio cultural de la mujer es casi nulo". Seguramente que nadie le dirá lo contrario, pero también es una gran verdad, que todas las conquistas democráticas han sido hechas por multitudes analfabetas que se han apasionado de determinados ideales forjados por una minoría de hombres, de donde resulta que no podemos esperar masas de mujeres culturizadas para las conquistas que propugnan, entonces, lo que debemos hacer es darles la consigna del ideal que les ha de apasionar para luchar por su realización, y esto no es una cuestión de cultura porque las multitudes o colectividades obran más que con el cerebro guiadas por sus sentimientos (...)

No obstante que nuestra Constitución Política del Estado, dice que para tomar parte en los comicios electorales es suficiente saber "leer y escribir", Gloria Serrano expresa: "Porque el hecho de saber leer y escribir no es índice que marque un alto grado "cultural", ¿Y quién ha creído que "saber leer y escribir" es sinónimo de cultura? ¿Y se puede exigir a las masas "un alto grado cultural?", nosotras entendemos que pueden tener relativa instrucción, pero cultura solo se puede exigir a determinado número de intelectuales hombres o mujeres, que han llegado a adquirirla como consecuencia de sus estudios e investigaciones (...) No podemos resignarnos a esperar que la post - guerra consagre nuestros derechos, por los que nosotras no hubiéramos luchado, tampoco desconocemos que la postguerra posiblemente traiga cambios políticos, sociales y económicos; ahora bien, si ella consagra nuestros derechos que sea después de que nosotras hubiéramos cumplido con el deber de dar el grito de alerta a las mujeres bolivianas, antes de que los acontecimientos nos sorprendan en una hora desprevenida. Finalmente abogamos por todas las mujeres madres, esposas e hijas que sufren el dolor y la miseria de la guerra, a quienes se les exige todos los sacrificios y se les niega todos los derechos. ¡Por estas injusticias luchamos! » El Diario, 19 octobre 1934, La Paz. Collection personnelle d'extraits de journaux de Zoila Viganó Castañón. 
A cet article Gloria Serrano répondit en insistant sur l' "égoïsme » que signifiait demander les droits civils et politiques dans le contexte tragique de la guerre :

«Même si cela semble une redondance, je ne cesserai de répéter que dans l'heure que vit la patrie, c'est un crime d'égoïsme donner la préférence à des projets d'amélioration féministe très louables en temps de paix.

La femme qui est abnégation et oubli de soi même ne peut pas fermer les yeux devant la situation présente. Serait-il humain qu'en voyant le père, frère ou enfant mourir -au lieu d'aller mitiger avec sa présence l'agonie désespérante elle aille discuter avec la voisine de droits prétendus...

On ne voit nulle part le bienêtre - matériel et intellectuel - que l'obtention des droits civils pourrait apporter à la femme bolivienne. ${ }^{222}$

Gloria Serrano ne fut pas la seule femme journaliste s'opposant à la campagne féministe du «Comité de Acción Feminista », Martha Mendoza (voir annexe A n³4) publia plusieurs articles arguant que la femme n'était pas encore préparée pour voter, et que le vote d'ailleurs ne servait ni aux hommes ni aux femmes car les procès électoraux étaient extrêmement corrompus dans le pays. Cependant, Martha Mendoza considérait que la demande pour l'obtention des droits civils était légitime ${ }^{223}$.

L'éclatement de la guerre fut l'occasion, pour un groupe de femmes conscientes du rôle qu'elles étaient en train de jouer dans l'arrière garde, de réclamer leurs droits civils et politiques. La contribution des femmes à l'effort de guerre et le manque d'électeurs étaient les principaux arguments pour justifier la nécessité d'octroyer ces droits. Le débat autour de cette question fut ravivé depuis le début de la guerre et s'intensifia avec la campagne réalisée par le «Comité de Acción Feminista » à travers les journaux et la radio, ce qui poussa trois députés à présenter un projet de loi afin d'octroyer les droits civils et politiques aux femmes. Cependant, le projet ne fut pas débattu au sein de l'Assemblée et la campagne réalisée ne fut pas soutenue par toutes

\footnotetext{
222 «Aunque parezca redundancia no me cansaré de repetir que en esta hora que vive la patria, es un crimen de egoísmo dar preferencia a proyectos de mejoramiento feminista muy loables en tiempo de paz.

La mujer que es abnegación y olvido de sí misma no puede cerrar los ojos antes la situación presente. ¿Sería humano que viendo morir al padre, hermano o hijo - en vez de mitigar con su presencia la desesperación de la agonía- se vaya a discutir con la vecina sobre pretendidos derechos...

No se ve por ningún lado el bienestar - material e intelectual- que la obtención de derechos civiles puede reportar a la mujer boliviana. » El Diario, 25 octobre 1934, La Paz. Collection personnelle d'extraits de journaux de Zoila Viganó Castañón.

${ }^{223}$ Universal, 20 septembre 1934 et 29 octobre 1934, La Paz. Hemeroteca del Archivo del Congreso, La Paz-Bolivie.
} 
les organisations féminines qui considéraient qu'il était inopportun de demander ces droits en raison de la situation tragique qu'affrontait la Bolivie. L' « égoïsme » devait être laissé de côte pour se concentrer avec «abnégation » sur l'assistance et le secours aux mobilisés et à leurs familles. La question des droits civils et politiques était une question secondaire qui ne méritait pas d'être discutée dans de telles circonstances. La campagne féministe qu'eut lieu pendant la guerre ne connut pas de succès, mais elle contribua à raviver le débat dans l'opinion publique par rapport à cette question.

Dans la période de post guerre, les principales dirigeantes du «Comité de Acción Feminista » formèrent deux organisations beaucoup plus institutionnalisées avec d'autres objectifs et d'autres stratégies que celles développées pendant la guerre.

\section{b) Le mouvement féministe de post guerre}

Après leur expérience avec le «Comité de Acción Feminista » pendant la guerre, Etelvina Villanueva (voir annexe A $n^{\circ} 43$ ) et Zoila Viganó (voir annexe A $n^{\circ} 42$ ) fondèrent chacune en 1935, deux organisations différentes : la «Legión Femenina de Educación Popular América » («LFEPA ») et la «Unión de Mujeres Americanas » («UMA ») respectivement. Ces deux organisations étaient les satellites en Bolivie d'organisations internationales avec le même nom. À part l'obtention des droits civils et politiques, les objectifs de ces deux organisations étaient désormais plus larges et s'inscrivaient dans le contexte de changements politiques et sociaux déclenchés par la guerre. La structure, les objectifs et les stratégies de ces deux organisations étaient donc très différents de ceux présentés pendant la guerre.

\section{La «Legión Femenina de Educación Popular América »: un féminisme « socialiste »?}

La «Legión Femenina de Educación Popular América » («LFEPA») fut fondée à La Paz le 20 décembre 1935 par Etelvina Villanueva (voir annexe A n43), qui avait été nommée Déléguée à la Présidence Internationale, par la présidente de la Direction centrale de l'Institution, Rosa Borja de Icaza, qui se trouvait à GuayaquilÉquateur. Etelvina Villanueva fut ainsi autorisée à fonder les satellites de l'organisation dans d'autres villes de la Bolivie : Santa Cruz, Oruro, Trinidad, Sucre, 
Cochabamba, Potosí et Tarija. Il semblerait que la création de cette organisation en Bolivie eut comme origine la décision du «Comité de Acción Feminista» de s'affilier a la «Legión Femenina de Educación Popular América » de Valparaíso au Chili. En effet, en janvier 1935 un message fut envoyé par le «Comité de Acción Feminista » de La Paz à la «Legión » de Valparaíso lui informant de leur volonté de s'affilier à celle-ci afin d'arriver à une action féministe collective à l'échelle continentale. Ce message fut publié dans la revue Nosotras de Santiago du Chili ${ }^{224}$ :

«COMITÉ ACCIÓN FEMENISTA - LA PAZ, BOLIVIA.

Décembre 1934

Présidente de la « Legión Femenina de Educación Popular ».

- Valparaíso :

Par décision prise dans une assemblée du «Comité de Acción Feminista », fondé en Bolivie, avec siège à La Paz, j'ai l'honneur de m'adresser à vous pour mettre en votre connaissance le désir qu'ont les membres de déployer un effort collectif pour la défense sociale, économique et politique de la femme, jusqu'à culminer dans la rédemption complète de la situation dans laquelle elle a été placée jusqu'à aujourd'hui.

Avec cette fin et en reconnaissant les mérités prestiges dont jouit votre très noble institution, le "Comité de Acción Feminista » a décidé de s'affilier à la «Legión Femenina de Educación Popular » afin de parvenir à une action conjointe pour la défense de nos droits et procurer le rapprochement de toutes les femmes du continent américain.

Je remercie au nom des membres de mon organisation le fraternel accueil qui sera dispensé à notre résolution.

Je vous prie de recevoir mes salutations les plus distinguées.

Zoila Viganó Castañón, Secrétaire de Relations. » ${ }^{225}$

\footnotetext{
${ }^{224}$ La revue Nosotras était une revue féminine - féministe publiée à Santiago, Chili ayant pour objectif de présenter les avances des différentes organisations féministes du continent sud-américain. Elle était dirigée par Delia Ducoing de Arrate («Isabel Morel»), qui était la présidente de la « Legión Femenina de Educación Popular » au Chili. VILLANUEVA Etelvina, Acción Socialista de la mujer en Bolivia, Cooperativa de Artes Gráficas E. Burillo Ltda., La Paz -Bolivie, 1970.

225 « COMITÉ ACCIÓN FEMINISTA. - LA PAZ, BOLIVIA.

Diciembre de 1934.

Presidenta de la Legión Femenina de Educación Popular.

- Valparaíso:

Por resolución de una asamblea del Comité de Acción Femenina, fundado en Bolivia, con sede en La Paz, tengo el honor de dirigirme a usted para poner en su conocimiento el deseo que tienen las socias de desplegar un esfuerzo colectivo en pro de la defensa social, económica y política de la mujer, hasta culminar en la completa redención de la situación en que hasta hoy está colocada.

Con este fin, y reconociendo los merecidos prestigios de que goza vuestra nobilísima institución, el Comité de Acción Feminista, ha resuelto afiliarse a la Legión Femenina de Educación Popular a fin de lograr una acción conjunta en defensa de nuestros derechos y procurar el acercamiento de todas las mujeres del continente americano.

Agradezco en nombre de mis consocias la fraternal acogida que se dignará dispensar a nuestra resolución.

Saluda atentamente a usted. - Zoila Viganó Castañón, Secretaria de Relaciones. » Nosotras, $\mathrm{n}^{\circ} 61$, janvier 1935, Santiago, Chili. Collection personnelle d'extraits de journaux de Zoila Viganó Castañón.
} 
Il est probable que suite à ce message, les membres du «Comité de Acción Feminista » aient été mis en relation avec la Présidente de la «Legión Femenina de Educación Popular », Rosa Borja de Icaza qui désigna Etelvina Villanueva comme la Présidente de l'organisation en Bolivie. En effet. En août 1935, Rosa Borja de Icaza envoya une lettre à Etelvina Villanueva pour lui informer qu'elle avait pensé à elle pour fonder cette organisation en Bolivie :

« Guayaquil, 29 août 1935.

(...) En ces moments je commence mes relations avec le Venezuela, le Costa Rica et le Panamá, et j'aspire à la réalisation d'un Congrès International Féminin. Ainsi, en considérant la coopération de la Bolivie, j'ai pensé à vous comme la personne appelée à intervenir, par votre intelligence et vos prestiges, dans cette œuvre sociale, d'incalculables bénéfices pour l'orientation solidaire de nos peuples...

Maintenant qu'est finie la tragédie angoissante et inquiète de la guerre, commence la véritable, la plus intense, la plus douloureuse des tragédies pour ces pauvres nations qui sont abattues, épuisées, désarmées dans leur bagage matériel et intellectuel. Le moment est venu, ma chère amie Etelvina, de former une nouvelle humanité ; d'unifier la pensée vers des horizons plus vastes, plus chrétiens, plus humains. Faire de ce terrain en friche, qu'ont laissé la poudre, les rancœurs, le désespoir et la mort, un champ fécondé par les modernes orientations sociales.

Inculquer chez les enfants, guider les mères, dans les sentiers tracés par la justice et le droit. Enterrer sous l'énorme poids de la raison, de la logique, de la nécessité de vivre, en un mot, tout un échafaudage d'ambitions, d'impiétés, d' "inégalités », qui sont venues caractériser et caractérisent encore notre structure politique « criolla ».

C'est une opportunité brillante pour la Bolivie et pour le Paraguay, d'ériger notre nouvel édifice social avec l'expérience dure et amère, obtenue dans les tranchées, dans la jungle, et dans les précipices.

Que cette nouvelle Génération soit le Héraut Annonciateur de la Paix et de la Justice Sociale dans notre continent!

S'élever c'est vivre!

Rosa Borja de Icaza (Présidente Internationale de la L.F.E.P.A.) $»^{226}$

\footnotetext{
226 «En estos momentos inicio mis relaciones con Venezuela, Costa Rica y Panamá, y aspiro a la realización de un Congreso Internacional Femenino. Así pues, al considerar la cooperación de Bolivia, he pensado en Ud. como la persona llamada a intervenir, por su inteligencia y sus prestigios, en esta obra social, también de incalculables beneficios para la orientación solidaria de nuestros pueblos... Ahora que ha terminado la tragedia angustiosa e inquieta de la guerra, comienza la verdadera, la más intensa, la más dolorosa, para esas pobres naciones que quedan abatidas, exhaustas, inermes en su bagaje material e intelectual. Ahora es el momento, mi querida amiga Etelvina, de formar una nueva humanidad; de unificar el pensamiento hacia horizontes más amplios, más cristianos, más humanos. Hacer de este erial, que dejaron la pólvora, los rencores, la desesperación y la muerte, un campo fecundado por las modernas orientaciones sociales.
} 
Cette lettre nous laisse entrevoir les objectifs que la nouvelle «LFEPA » fondée par Etelvina Villanueva devait avoir. Rosa Borja parle d'« œuvre sociale», d'« orientations sociales », d'« inégalités », ce qui montre que la nouvelle organisation devait avoir des objectifs d'amélioration «sociale» dans le contexte de changements politiques, sociaux, culturels de post guerre.

En effet, la «LFEPA » de Bolivie avait une orientation sociale très marquée et ses objectifs étaient très vastes. C'est ce que laisse entrevoir son organisation et son règlement :

\section{« Finalité}

La «Legión Femenina de Educación Popular América », a pour fins basiques les postulats suivants :

a) - Les Liens Américains Féminins.

b) - Assistance Sociale.

c) - Développement de la culture Féminine.

d) - Défense Sociale de l'Enfant.

e) - Libération de la Femme.

f) - Postulats de paix nationale et internationale

Art. $1^{\circ}$ La «Legión Femenina de Educación Popular América », affirmera la création de réseaux et la création de solidarité avec les femmes du Continent Indo américain.

Art. $2^{\circ}$ Elle travaillera pour l'union et la compréhension des aspirations de la femme bolivienne, en faisant écho de ses initiatives et de son travail culturel et social.

Art. $3^{\circ}$ Il n'y aura pas de séparation de classes sociales, ni d'état civil, religieux ou doctrinaire.

Art. $4^{\circ}$ On essayera par tous les moyens de divulguer l'importance de la professionnalisation de la femme; dans les diverses activités sociales, artistiques, éducatives, commerciales, etc.

\footnotetext{
Inculcar en los niños, guiar a las madres, en los senderos trazados por la justicia y el derecho. Soterrar bajo el enorme peso de la razón, de la lógica, de la necesidad de vivir, en una palabra, todo un andamiaje de ambiciones, de impiedades, de "desigualdades", que han venido y siguen caracterizando nuestra estructura política criolla.

Es una oportunidad brillante para Bolivia y para el Paraguay, erigir nuestro nuevo edificio social con la experiencia dura y amarga, obtenida en las trincheras, en la manigua y en los despeñaderos. Sea esa nueva Generación el Heraldo Anunciador de la Paz y la Justicia Social en nuestro continente! ¡Ascender es vivir! Rosa Borja de Icaza. (Presidenta Internacional de la L.F.E.P.A.) » VILLANUEVA Etelvina, Acción Socialista de la mujer en Bolivia, Cooperativa de Artes Gráficas E. Burillo Ltda., La Paz-Bolivie, 1970.
} 
Art. $5^{\circ}$ La «Legión Femenina de Educación Popular América », s'étendra aux centres scolaires avec le nom de « Legión Femenina pour Enfants ». Un programme de coopération et mutualisme social-scolaire se développera, en accord avec les nécessités de l'environnement familial de l'enfant.

\section{Programme Idéologique}

Art. $6^{\circ}$ Le programme idéologique contient :

- Égalité des Droits Civils et Politiques avec l'homme.

- Ratification du Traité de Nationalisation Féminine.

- Défense de la Mère célibataire.

- Droits sociaux et juridiques de l'Enfant.

- Diffusion de la doctrine pacifiste.

- Université Populaire pour femmes.

- Établir et reconnaître la Journée de la femme de ménage.

- Rendre digne la mission de Mère et d'Épouse.

- Professionnalisation féminine qui rende digne l'indépendance économique de la femme.

- Abolition du Règlement de la prostitution, à travers de la collaboration médicale - sociale.

- Responsabilité sexuelle dans la défense des enfants.

- Combattre le jeu et l'alcoolisme.

- La mixité dans les Écoles et Lycées.

- Éducation Sexuelle.

- Enseignement pratique de puériculture et de premiers secours.

- Bibliothèque pour femmes.

- Syndicalisation féminine.

- Porte-parole féminin.

\section{Membres}

Art. $7^{\circ}$ Seront membres de la L.F.E.P.A. toutes les femmes qui souhaitent collaborer dans l'action sociale, dans n'importe quel champ ou activité de leur préférence.

Art. $8^{\circ}$ Las membres ont l'obligation de maintenir un journal, qui exprime les postulats du Programme Idéologique.

Art. $9^{\circ}$ Pour être membre, $1^{\prime}$ on doit solliciter son inscription dans le Livre de Registres de la «Legión" et offrir un texte à la Bibliothèque. Il y aura des membres Honoraires et des membres Actives.

\section{Direction}

Art. $10^{\circ} \mathrm{La}$ Direction sera composée d'une Présidente Nationale ; d'une Présidente Départementale ou Provinciale et ses respectives Vice-Présidentes, Secrétaires, Trésorières et onze Directrices 
d'organisation de : Art, Culture, Assistance Sociale, Défense Juridique, Ateliers, Sports, Bibliothèques, Réseaux Culturels et Légions pour enfants, Action Littéraire.

Art. $11^{\circ}$ Les Directrices sont autonomes dans leurs respectifs programmes de travail, en envoyant un informe annuel à la Présidence Nationale.

Art. $12^{\circ} \mathrm{La}$ Direction se réunira en sessions chaque semaine, elle convoquera 1'Assemblée Générale pour les résolutions importantes ou la rénovation de la Direction, Congrès, etc. $»^{227}$

227 « Finalidad.

La "Legión Femenina de Educación Popular América", tiene por fines básicos los siguientes postulados:

a) -Vinculación Femenina Americana.

b) - Asistencia social.

c) - Culturización Femenina.

d) - Defensa Social del Niño.

e) - Liberación de la Mujer.

f) - Postulados de paz nacional e internacional.

Art. $1^{\circ}$ La "Legión Femenina de Educación Popular América", afirmará la vinculación y solidaridad con las mujeres del Continente Indoamericano.

Art. $2^{\circ}$ Trabajará por la unión y comprensión de las aspiraciones de la mujer boliviana, haciendo eco de sus iniciativas y labores sociales y culturales.

Art. $3^{\circ}$ No habrá separación de clases sociales ni de estado civil, religioso o doctrinario.

Art. $4^{\circ}$ Se procurará por todos los medios, divulgar la importancia de la profesionalización de la mujer. dentro de las diversas actividades sociales, artísticas, educativas, comerciales, etc.

Art. $5^{\circ}$ La "Legión Femenina de Educación Popular América", se hará extensiva a los centros escolares con el nombre de Legión Femenina Infantil, debiendo desarrollarse un programa de cooperación y mutualismo social-escolar, acorde con las necesidades del ambiente familiar del niño.

Programa Ideológico.

Art. $6^{\circ} \mathrm{El}$ programa ideológico contiene:

- Igualdad de Derechos Civiles y Políticos con el hombre.

- Ratificación del Tratado de Nacionalización Femenina.

- Defensa de la Madre soltera.

- Derechos sociales y jurídicos del Niño.

- Difusión de la doctrina pacifista.

- Universidad Popular para mujeres.

- Establecer y reconocer el Día de la Empleada.

- Dignificación de la misión de Madre y Esposa.

- Profesionalización femenina que dignifique la independencia económica de la mujer.

- Abolición del Reglamento de prostitución por la colaboración médico-social.

- Responsabilidad sexual en defensa de los hijos.

- Combatir el juego y el alcoholismo.

- La coeducación en Escuelas y Colegios.

- Educación Sexual.

- Enseñanza práctica de Puericultura y Primeros Auxilios.

- Biblioteca para mujeres.

- Gremialización femenina.

- Vocero Femenino.

\section{Socias.}

Art. $7^{\circ}$ Serán socias de la L.F.E.P.A. todas las mujeres que sientan anhelo de colaborar en la acción social, en cualquier campo o actividad de su preferencia.

Art. $8^{\circ}$ Las socias tienen la obligación de sostener un periódico, que exprese los postulados del Programa Ideológico. 
Comme on peut le voir, le contenu des objectifs et du « Programme Idéologique » de la « LFEPA » était clairement voué à une action d'amélioration sociale des femmes et des enfants. L'un de ses objectifs principaux était la création de liens avec les autres femmes du continent américain ce qui était favorisé par la structure internationale de l'organisation. Il y a une nette orientation vers la défense et l'amélioration de conditions de vie des femmes et des enfants qui passe par la défense du travail de la mère en général et des mères célibataires. Les femmes des classes populaires occupent une place primordiale dans les objectifs d'assistance de l'organisation qui envisage la création d'Universités Populaires, de l'établissement de la journée de la femme de ménage, la syndicalisation féminine, et l'abolition du règlement qui règlementait la prostitution. Ce qui est nouveau est l'objectif de prendre en main l'éducation sexuelle, projet qu'aucune organisation féminine n'avait présenté auparavant. L'obtention des Droits Civils et Politiques pour les femmes apparaît comme un objectif parmi d'autres, même si cet celui-ci avait une importance prépondérante pour l'organisation comme on le verra plus tard.

Le programme de la «LFEPA » était très vaste et avait une orientation sociale très marquée. Cette organisation diffère ainsi de toutes les organisations des années 1920, et notamment de 1'«Ateneo Femenino », qui avait également des projets sociaux parfois similaires à ceux de la «LFEPA» (protection du travail de la femme, combat contre les vices et l'alcoolisme, Bibliothèque féminine, etc.) mais envisagés de manière paternaliste comme des œuvres de charité et non pas comme des mesures promouvant des changements sociaux plus profonds. L'« Ateneo Femenino » était une organisation beaucoup plus élitiste dont les projets sociaux et de bienfaisance se réalisaient sous l'impulsion de la valeur chrétienne de la charité que toute femme de la bourgeoisie devait réaliser, alors que la «LFEPA» avait une orientation sociale

\footnotetext{
Art. $9^{\circ}$ Para ser socia, debe solicitarse su inscripción en el Libro de Registro de la Legión, y obsequiar un texto a la Biblioteca. Habrán socias de Honor y Activas.

Directorio.

Art. $10^{\circ}$ El Directorio estará compuesto por una Presidenta Nacional; una Presidenta Departamental, Provincial y sus respectivas Vicepresidentas, Secretarias, Tesoreras y once Directoras de organización de: Arte, Cultura, Asistencia Social, Defensa jurídica, Talleres, Deportes, Bibliotecas, Vinculación Cultural y Legiones Infantiles. Acción Literaria.

Art. $11^{\circ}$ Las Directoras son autónomas en sus respectivos programas de trabajo, enviando un informe anual a la Presidencia Nacional.

Art. $12^{\circ}$ El Directorio sesionará semanalmente, convocará a Asamblea general para resoluciones de importancia o cambio de Directorio, Congresos, etc. » VILLANUEVA Etelvina, Acción Socialista de la mujer en Bolivia, Cooperativa de Artes Gráficas E. Burillo Ltda., La Paz -Bolivie, 1970.
} 
beaucoup plus claire qui intégrait les femmes des classes populaires tant dans ses objectifs sociaux que dans sa composition. Comme l'annonce le règlement « il n'y aura pas de séparation de classes sociales ». L' «Ateneo Femenino » en théorie acceptait les femmes de toutes les classes sociales et de tous les crédos religieux, cependant dans la pratique il était composé uniquement par des femmes des classes moyennes et élevées de la société en raison de conditions matérielles et culturelles requises pour devenir membre. La «LFEPA» avait également des conditions matérielles, mais beaucoup plus modestes telles que le maintient d'un journal, et la donation d'un texte pour la Bibliothèque. L'orientation plus sociale de la « LFEPA », qu'Etelvina Villanueva qualifia elle même de «socialiste » lors de la production de son livre Acción Socialista de la mujer en Bolivia (qui contient beaucoup de documents concernant le travail de l'organisation), s'inscrit dans le contexte de l'après guerre d'effervescence politique visant à répondre à la frustration de la société par la défaite et à la recherche de nouvelles orientations idéologiques. L'orientation sociale de la «LFEPA» est en effet un produit du contexte de changements politiques, sociaux et culturels qu'avait déclenché la guerre où le « socialisme » avait pris une place prépondérante dans les actions et les discours, même si de manière très diverse et parfois vide de contenu idéologique. L'amélioration de la société dans son ensemble était désormais un objectif annoncé par les gouvernements du « socialisme militaire », des nouveaux partis politiques, et des partis traditionnels tels que le «Partido Repúblicano Genuino » qui ajouta l'adjectif «socialista » à sa dénomination. L“" Ateneo Femenino » était une organisation de femmes appartenant à l'élite sinon économique, au moins intellectuelle du pays, qui soutenaient et légitimaient le gouvernement oligarchique. Leurs projets sociaux s'inscrivaient dans la mission de charité de leur position de classe, et non pas dans un projet de changements plus profonds de la société. La «LFEPA», qui était également composée de femmes des classes élevées, mais surtout de femmes des classes moyennes de la société, avait une orientation sociale plus marquée qui n'était pas envisagée comme une œuvre de charité mais était influencée par les courants idéologiques et politiques de l'époque qui recherchaient l'amélioration de la société dans son ensemble et qui remettaient surtout en question le régime oligarchique et les partis traditionnels. Ceux-ci avaient mené à la tragique défaite et n'avaient rien fait pour l'amélioration des conditions de vie de la plus grande partie de la population. Le contenu de l'idéologie et du programme de la «LFEPA» répondait au 
mécontentement social des secteurs populaires et des classes moyennes de la société, qui soutenaient des changements profonds dans l'exercice du pouvoir. Comme l'affirme Gloria Ardaya: «...el Ateneo Femenino reflejó, por una parte, la hegemonía política de los sectores dominantes y el nacimiento de los sectores medios algunos de los cuales se constituyeron en fuerzas de apoyo del Estado oligárquico; y por otra, un movimiento en sentido contrario, la rebeldía de sectores medios de mujeres profesionales por ingresar al ámbito público. La LFEPA fue una señal del divorcio de las capas medias con la clase dominante y de la constitución de éstas como factor de cambio ante el fracaso de la Guerra del Chaco (1932-1935). ${ }^{228}{ }_{\text {» }}$

Les femmes qui composaient les directions des différents satellites de la « LFEPA » étaient les suivantes ${ }^{229}$ :

\section{La Paz :}

Présidente : María Tubert de Estéban (voir annexe A n62).

Secrétaire : María Angélica Panozo (voir annexe A nº65).

Secretaria de Actas: Ana Rosa Vázquez (voir annexe A nº9).

Directrices :

D'action juridique : Josefa Rocabado.

D’action Sociale : Elvira Bedregal (voir annexe A n52)

D’Art et de Propagande : Leonor Díaz Romero (voir annexe A n¹6) et Alina Ballón (voir annexe $\mathrm{A} \mathrm{n}^{\circ} 23$ )

De Services Sanitaires: Antonieta de la Riva.

D’Assistance Sociale: Ana Miranda.

\section{Sucre :}

Présidente : Carmela Zuazo.

Secrétaire : Carmen Acebey.

\footnotetext{
${ }^{228}$ ARDAYA, Gloria, Política sin rostro: mujeres en Bolivia, Editorial Nueva Sociedad, Venezuela, 1992.

${ }^{229}$ VILLANUEVA Etelvina, Acción Socialista de la mujer en Bolivia, Cooperativa de Artes Gráficas E. Burillo Ltda., La Paz-Bolivie, 1970.
} 
Secrétaire d'Actes : Angélica Ramírez.

Trésorière : María Jesús Balcázar.

Directrices :

De Presse et de Propagande : Aurora de Miranda, Rebeca Salazar Brito (voir annexe A n ${ }^{\circ 53)}$ et Isabel Mendoza (voir annexe A n54).

D’Action Juridique : Agar Peñaranda.

D'Art et d'Action Sociale : Elena Paravicini.

\section{Cochabamba :}

Présidente : Cira Aguayo y Moreno (voir annexe A n51).

Secrétaire : Fidelia Corral de Sánchez (voir annexe A n²2)

Directrices :

D’Action Sociale : María Quiroga Vargas (voir annexe A n³0).

D’Action Juridique: Luisa Mendoza (voir annexe $A n^{\circ} 60$ ).

D’Action Mutualiste: Mercedes Rodríguez (voir annexe A n55).

D’Action Littéraire: Mercedes Anaya de Urquidi (voir annexe A n³1).

De Presse et Propagande: Aury Albornoz.

De Réseaux: Rosa Fernández de Carrasco.

De Bienfaisance : Lola Anaya et Sara Segaloski.

Bibliothèque : Rosa Morales Guillén (voir annexe $\mathrm{A} n^{\circ} 61$ ).

Sports : Elsa Anaya F.

Ateliers : María Martínez de Vargas.

\section{Oruro:}

Présidente: Amelia Chopitea (voir annexe A n56).

Secrétaire: Paz Nery Nava (voir annexe A n57).

Secrétaire de Correspondance: Neptalí Gallo Peñaranda.

Secrétaire de Bienfaisance : Emilia Cruz.

Trésorière : Carmen Deheza. 


\section{Santa Cruz :}

Présidente : Blanca C. de Herrera.

Vice-Présidente : Elena Tejada de Mercado.

Secrétaire : Romana Gutiérrez.

Secrétaire d'Actes : Adelaida S. Galvarro.

Directrices :

De Culture : María Vaca Díez et Peregrina Ortiz.

D’Assistance Sociale: María Luisa Castro et Rosa Suárez.

D’Action Juridique : Adela v. de Quintela et Rosa Gutiérrez.

D’Art : Rogelia Rojo et Hortensia Gutiérrez.

De Presse et de Propagande : Elvira de Chávez (voir annexe A n59).

De Sports : Edith Chávez (fille de Elvira de Chávez) et Olga Moreno.

Bibliothèque : Juana Mercado et Mary Justiniano.

Membres du Conseil : Aurora Arrien, Luz Castro, Manuela Galvarro, Elia Krutzfeld,

Elba Amelunge, Adriana Peredo, Eloísa Rivero, Alicia Rivero, Alicia Suárez.

\section{Trinidad:}

Présidente: Rosa T. Melgar

Vice-Présidente: Celia Monasterios.

Secrétaire d'Actes: Mary Rivero.

Secrétaire de Correspondance: Dory Aponte B.

Trésorière: Susana Bello L.

\section{Potosí:}

Présidente: Etelvina Villanueva (voir annexe $\mathrm{A} \mathrm{n}^{\circ} 43$ )

Secrétaire: Carmen Aurora Valda Cortez.

Trésorière: Rita del Río.

Directrices:

De Culture: Raquel Carmona (voir annexe $\mathrm{A} \mathrm{n}^{\circ} 58$ ).

D’Action Sociale : Marina Zuleta.

D’Art : María de Sehger.

D’Action Juridique: Nelly Parada. 
De Presse et Propagande: Inés Cortez.

De Sports: María Scheille de La Faye.

Bibliothèque: Casta Rivera.

\section{Tarija:}

Présidente: Adela Hoyos.

Secrétaire: N. Hoyos

Comme on peut le constater, on retrouve plusieurs femmes qui étaient membres des organisations de 1920, notamment de l'«Ateneo Femenino » dans les Directions des «LFEPA » en Bolivie. C'est le cas de Ana Rosa Vázquez (voir annexe A n9), qui avait été également membre du «Centro Ideal Femenino» et directrice de la revue Aspiración. C'est le cas également de Leonor Díaz Romero (voir annexe A n¹6), Alina Ballón (voir annexe A n²3), Fidelia Corral de Sánchez (voir annexe A n²2) et de Raquel Carmona (voir annexe A n58). Il est intéressant de constater également que la plupart de membres du «Comité de Acción Feminista » de Cochabamba font partie de la direction de la «LFEPA» de cette ville. C'est le cas de Cira Aguayo Moreno (voir annexe A n51), Mercedes Rodríguez (voir annexe A n55), María Quiroga Vargas (voir annexe A n³0) et Mercedes Anaya de Urquidi (voir annexe A $\mathrm{n}^{\circ} 31$ ), ces deux dernières ayant été les fondatrices et directrices de la revue Anhelos. Cela veut dire que la «LFEPA » de Cochabamba fut organisée en grande partie avec les membres du «Comité de Acción Feminista » de cette ville.

Les membres du «Comité de Acción Feminista» de La Paz et de Cochabamba recomposèrent en grande partie les «LFEPA» de la Bolivie sous la direction d'Etelvina Villanueva.

En outre, chaque direction de la «LFEPA » était relativement large en personnel et développement selon les villes. Ainsi, les directions des «LFEPA» des villes de La Paz, Sucre, Santa Cruz, Potosí et notamment Cochabamba étaient les plus développées avec plusieurs directrices couvrant un vaste champ d'activités (sports, culture, littérature, assistance sociale, bibliothèque). Ce développement pourrait s'expliquer par l'ancienneté de leur fondation, alors que les directions d'Oruro, Trinidad et Tarija sont moins développées et semblent avoir été fondées après les autres. La «LFEPA» de Bolivie était présente dans toutes les capitales de 
département à l'époque ${ }^{230}$, ce qui veut dire qu'elle avait une extension nationale très importante. Aucune autre organisation féministe n'avait eu une extension pareille auparavant.

La «LFEPA » de Bolivie disposait d'un journal nommé Despertar qui s'éditait à Potosí, qu'on n'a malheureusement pas pu consulter.

Les activités des «LFEPA » furent diverses et variées selon les villes. On connaît les activités de l'organisation dans les différentes villes pour l'année 1936. La «LFEPA » de Santa Cruz sous la direction de Blanca C. de Herrera se chargea de la création d'une École Nocturne pour femmes à laquelle assistaient des femmes ouvrières. Des cours de Morale, de Mathématiques basiques, d'Espagnol, d'Hygiène, de Puériculture et d'Instruction Civique y étaient enseignés. La «LFEPA » de Trinidad se chargea de réaliser plusieurs fêtes et kermesses afin de réunir des fonds pour la construction d'un Annexe Sanitaire à l'Hôpital Guadalupe de la ville, ainsi que la « LFEPA » de Potosí qui réalisa une séance de cinéma pour collecter des fonds. La «LFEPA » de Sucre, se chargea d'encourager la lecture dans la ville en créant une journée de lecture tous les samedis.

À Oruro, sous la direction d'Amelia Chopitea (voir annexe A n56), la « LFEPA » de cette ville se chargea de la construction du Pavillon pour enfants dans l'Hôpital Municipal de la ville. La «LFEPA » d'Oruro se chargea de même, de réaliser une enquête sur les Droits Civils et Politiques de femmes en juin 1936. L'enquête, semble-t-il, fut envoyée à des personnalités importantes de la ville par leur «prestige intellectuel ». Les questions de l'enquête furent les suivantes :

«Étant donné votre prestige intellectuel, nous sollicitons votre précieux avis, et nous vous invitons à prendre part de cette enquête pour répondre aux questions suivantes :

Première - D'après vos observations, est-ce que la femme bolivienne est suffisamment préparée pour qu'ils lui soient octroyés les Droits Civils et Politiques?

Deuxième - Est-ce que vous croyez qu'il est juste et équitable qu'elle soit encore exclue de ces droits, même en réunissant des conditions avantageuses pour le libre exercice de ceux-ci ?

\footnotetext{
${ }^{230}$ Le département de Pando fut créé en 1938 et la ville de Cobija fut déclarée sa capitale en 1945. MESA (de) José, GISBERT Teresa, MESA Gisbert Carlos D., Manual de Historia de Bolivia, Editorial Gisbert, La Paz, 2008.
} 
Troisième - $\grave{A}$ votre avis, doit-on accorder les Droits Civils et Politiques à la femme bolivienne?

Quatrième - Quelles seraient vos suggestions pour orienter l'initiative de ces droits?

Avec la sécurité d'obtenir votre importante réponse, qui orientera des activités sur un thème d'une palpitante actualité, nous vous prions de recevoir nos salutations distinguées.

(Signé) Docteure Amelia Chopitea, Présidente. - Paz Nery Nava, Secrétaire. $»^{231}$

On ne connaît malheureusement pas les réponses de cette enquête. Cependant, suite à cette action la «LFEPA » de Potosí se chargea d'envoyer une lettre vers juillet 1936 à la Junte Militaire dirigée par le Président de la République David Toro, en lui demandant l'octroi des droits civils et politiques aux femmes. Cette lettre, qui fut qualifiée par les membres de la «LFEPA » comme un «manifeste », laisse entrevoir comment la «LFEPA» s'inscrit dans le contexte de changements politiques de l'époque de post guerre où le socialisme avait pris une place importante dans les discours pour parler de l'amélioration de conditions de vie des plus défavorisés :

«"Plénitude de Droits Civils et reconnaissance des Droits Politiques pour la femme qui possède un titre Universitaire ou Professionnel ou un métier qui garantisse son indépendance économique.” »

(Du Programme d'Action Socialiste, Officiel.)

Messieurs très distingués membres de la JUNTE MILITAIRE DE GOUVERNEMENT :

L'évolution socio-économique qui s'est opérée dans la Nation comprend dans son idéologie l'avènement équitable du droit pur les intérêts collectifs.

\footnotetext{
231 «En vista de su prestigio intelectual, solicitamos su valiosa opinión, e invitamos a usted a tomar parte en dicha Encuesta, insinuando responder a las siguientes preguntas:

Primero - Según sus observaciones, ¿la mujer boliviana tiene suficiente preparación para que se le confiera Derechos Civiles y Políticos?

Segundo - ¿Le parece justo y equitativo, que siga excluida de esos derechos, aún reuniendo condiciones ventajosas para el libre ejercicio de ellos?

Tercero - En su concepto, ¿se debe o no conceder los Derechos Civiles y Políticos a la Mujer Boliviana?

Cuarto - ¿Qué sugerencias daría usted para orientar la iniciativa de estos derechos?

En la seguridad de obtener su importante respuesta, que orientará actividades sobre el tema de palpitante actualidad, nos suscribimos muy atentamente. - (Firmado) Dra. Amelia Chopitea, Presidenta. - Paz Nery Nava, Secretaria. » VILLANUEVA Etelvina, Acción Socialista de la mujer en Bolivia, Cooperativa de Artes Gráficas E. Burillo Ltda., La Paz -Bolivie, 1970.
} 
Dans ce sens, la personnalité féminine ne pouvait pas rester reléguée à un second plan, victime de préjugés, d'humiliations et d'inégalités au sein de l'agrégat social; pour ces raisons, en nous basant sur les postulats d'équité et de justice qu'envisage le programme du GOUVERNEMENT SOCIALISTE, la «Legión Femenina de Educación Popular América ", s'encadrant dans le réalisme défini par des aspirations de survie qui agitent l'âme nationale, déclare sa franche décision pour demander à l'actuel Gouvernement, la reconnaissance des Droits Civils et Politiques féminins.

La femme de post guerre, considère opportune sa participation comme un élément de formation juridique indiscutable, à la gestion des intérêts publiques, car la femme professionnelle et la femme universitaire, ont atteint un plan de nivellement avec le citoyen dépassant dans plusieurs cas l'élément électeur des masses du peuple, et si comme ce dernier, elle n'a pas mérité la protection des lois, en marchant dans le monde des luttes monétaires, sans autre bouclier que sa volonté, elle DEMANDE LA RECONNAISSANCE de ses droits légitimes; non pas pour grossir les rangs de politiciens fanatiques, mais pour coopérer à la réalisation d'une formule plus humaine, prenant soin d'une distribution équitable du travail, d'une rémunération juste, de l'implantation du salaire minimum pour la femme prolétaire, de l'interdiction du travail pour les enfants; en synthèse, de lutter pour abolir l'exploitation du capitalisme, pour protéger la Mère et l'Enfant.

Les articles de la législation de la bourgeoisie, qui a marqué son Régime d'absurdes contre-sens, n'a pas pensé à la femme, et ses lois ont été fabriquées par l'homme et pour l'homme ; mais, aujourd'hui avec le plus vaste sens de confraternité, la «Legión Femenina de Educación Popular América » aspire à ce que les éléments des deux sexes, marchent ensemble par des voies de dépassement, sans rivalités, sans haine, ni prépondérances, en reconnaissant uniquement l'être dans la champ juridique et social.

La femme ne contourne pas les responsabilités, mais elle ne veut pas être non plus la victime de lois égoïstes, qui lui ont légué uniquement la lutte inégale, plaçant dans l'horizon des obstacles invincibles et en faisant taire avec la fiction d'une fausse protection, la juste protestation arrachée par le poids de responsabilités et de devoirs. En raison de cela, et de plusieurs autres raisons, qui n'échappent pas à la clairvoyance et aux nobles fins que poursuit cette respectable Junte de gouvernement, la «Legión Femenina de Educación Popular América» au nom de la femme bolivienne, implore, que soit mise en pratique, la formule en tête de ce Manifeste, envisagé dans le PROGRAMME du Gouvernement Socialiste.

Pour l'Union Fraternelle de la Bolivie.

(Signé). Etelvina Villanueva, Présidente Nationale.- Aurora Valda Cortez, Secrétaire d'Action Juridique.- Nelly Parada, Secrétaire Générale. ${ }^{232}$

\footnotetext{
232 «"Plenitud de Derechos Civiles y reconocimiento de Derechos Políticos para la mujer que tenga título Universitario o Profesional u Oficio que garantice su independencia económica."

(Del Programa de Acción Socialista, Oficial).
} 
Pour demander les droits civils et politiques des femmes, les membres de la «LFEPA » s'appuyèrent sur le programme officiel du gouvernement dans lequel celui-ci annonçait l'octroi des droits civils aux femmes et du droit de vote restreint à celles qui possédaient un titre universitaire ou professionnel ou encore un métier qui leur permette d'être indépendantes économiquement. Elles firent appel au programme socialiste du gouvernement qui visait l'amélioration des conditions de vie des plus défavorisées, groupe dans lequel elles incluaient les femmes en accusant les lois des gouvernements oligarchiques antérieurs qui les avaient délaissées. Les membres de la « LFEPA » ne remirent pas en question les conditions imposées par le programme du

Excelentísimos Miembros de la JUNTA MILITAR DE GOBIERNO :

La evolución económico-social, que se ha operado en la Nación, abarca en su ideología el advenimiento equitativo del derecho en pro de los intereses colectivos.

En este sentido no podía quedar relegada a segundo plano la personalidad femenina, víctima de prejuicios y de humillaciones y desigualdades dentro del agregado social; para ellos basándonos en los postulados de equidad y justicia que contempla el Programa del GOBIERNO SOCIALISTA, la "Legión Femenina de Educación Popular América", encuadrándose al realismo definido por anhelos de supervida que agitan el alma nacional, declara su franca decisión para pedir al actual Gobierno, el reconocimiento de los Derechos Civiles y Políticos femeninos.

La mujer de post-guerra cree oportuna su concurrencia como elemento de capacitación jurídica indiscutible, al manejo de los intereses públicos, ya que la mujer profesional y la mujer universitaria, han alcanzado un plano de nivelación con el ciudadano superando en muchos casos al elemento elector de las masas del pueblo, y si como éste último, no ha merecido la protección de las leyes, caminando por el mundo de las luchas monetarias, sin más escudo que su voluntad, PIDE EL RECONOCIMIENTO de sus legítimos derechos; no para engrosar las filas de fanáticos politiqueros, sino para cooperar en la realización de una fórmula más humana, velando por una distribución equitativa del trabajo, por la remuneración justa de éste, por la implantación del salario mínimo para la mujer proletaria; por la prohibición del trabajo para los niños; en síntesis, luchando por abolir la explotación del capitalismo, amparar a la Madre y proteger al Hijo.

El articulado legislativo de la burguesía, que ha marcado su Régimen de absurdos contrasentidos, no ha pensado en la mujer, y sus leyes se han fabricado por el hombre y para el hombre; mas, hoy día con el más amplio sentido de confraternidad, anhela la "Legión Femenina de Educación Popular América" que el elemento de ambos sexos, conjuntamente marchen por rutas de superación, sin rivalidades, sin odios, ni preponderancias, reconociendo únicamente el ser, en el campo jurídico y social.

La mujer que no elude responsabilidades, pero que tampoco quiere ser víctima de leyes egoístas, que únicamente le han legado la lucha desigual, colocando en el horizonte, obstáculos invencibles y acallando con la ficción de mentido amparo, la justa protesta arrancada por peso de responsabilidades y deberes. Por esto, y muchas otras razones, que no escapan a la clarividencia y nobles fines que persigue esa respetable Junta de Gobierno, la "Legión Femenina de Educación Popular América", en nombre de la Mujer boliviana, impetra, se lleve a la práctica, la fórmula dispositiva con la que encabezamos el presente Manifiesto, contemplado en el PROGRAMA del Gobierno Socialista.

Por la Unión Fraternal de Bolivia.

(Firmado). Etelvina Villanueva, Presidenta Nacional.- Aurora Valda Cortez, Secretaria de Acciónn Jurídica.- Nelly Parada, Secretaria General. » Idem. 
gouvernement pour accorder le droit de vote (possession de titre universitaire, professionnel ou métier). Elles acceptaient ainsi que le droit de vote soit accordé à un secteur restreint de la population féminine. Le programme du gouvernement était assez vague car ne définissait pas clairement ce qui était entendu par «métier». Si avoir un «métier» signifiait travailler, une grande partie des femmes des classes populaires (qui travaillaient en tant qu'ouvrières, femmes de ménage, dans le commerce, les marchés, etc.) seraient des potentielles électrices. Dans tous les cas la «LFEPA » acceptait ces conditions requises qui n'étaient pas les mêmes pour les hommes, puisque ceux-ci devaient savoir lire et écrire pour pouvoir voter.

Le ton et le contenu de ce «manifeste » s'inscrivent complètement dans le contexte de post guerre de dénonciation des gouvernements oligarchiques et de mise en avant $\mathrm{du}$ « socialisme » comme doctrine visant à pallier les inégalités sociales à laquelle se rattachait, au moins théoriquement, la «LFEPA » par ce manifeste.

En réponse à cette lettre le président David Toro, par le décret-loi du 21 octobre 1936, accorda les Droits Civils aux femmes. Cependant, ce décret, dont on parlera plus en détail ultérieurement, ne fut jamais appliqué.

Une des actions les plus importantes de la «LFEPA» fut l'organisation d'un Congrès National de « legionarias » en novembre 1936 à Cochabamba. Des ouvriers représentant des syndicats de la ville de Cochabamba se trouvèrent présents. Le Docteur José Macedonio Urquidi se trouvait également dans le Congrès ${ }^{233}$.

Dans ce Congrès furent discutés plusieurs thèmes et approuvés plusieurs projets concernant le pacifisme, l'éducation de la femme, la nécessité de créer de cours d'éducation sexuelle pour les jeunes femmes, la création d'orphelinats, la nécessité d'établir les recherches en paternité, la protection de mères célibataires avec la création d'ateliers et d'agences d'emploi pour celles-ci, la création de Bibliothèques populaires, la création de Maisons de bienfaisance pour les sans-abris, la création de maisons de réhabilitations morale pour les enfants délinquants, subventions pour les femmes de ménage, les ouvrières et les femmes enceinte, la création de réseaux avec

\footnotetext{
233 José Macedonio Urquidi était un avocat, intellectuel et écrivain, auteur de plus d'une vingtaine d'ouvrages, dont on peut citer Bolivianas Ilustres (1919). Il était marié à Mercedes Anaya de Urquidi (voir annexe A n³1). En 1932, il devint membre titulaire de l'Institut Américain de Droit International. Cette institution et la Commission Internationale de Femmes ${ }^{233}$ lui demandèrent de répondre à une enquête sur la condition juridique des femmes en Bolivie. Ce travail fut publié en Bolivie en 1937 : MACEDONIO Urquidi José Antonio, La Condición Jurídica o Situación legal de la mujer en Bolivia, 3e Edition, Cochabamba, 1937.
} 
les femmes d'Amérique, l'égalité de salaire entre les femmes et les hommes pour le même travail, la création de crèches dans les lieux de travail des femmes, l'égalité des enfants devant la loi, l'abolition de la peine de mort, entre autres. Cependant, le Congrès fut également le lieu où se révélèrent les contradictions et les conflits de l'organisation par la composition hétérogène de ses membres. En effet, les conflits surgirent à propos d'une attaque qu'avait réalisé le clergé de la ville de Sucre dans le journal catholique El Lábaro contre la « LFEPA ». La présidente de cette organisation se plaignit de ces attaques qui furent condamnées par la plupart des membres présentes qui affirmèrent que le «cléricalisme était la perversion de la femme » et qu'elles devaient se «défaire des soutanes ». Fidelia Corral Zambrana de Sánchez (voir annexe $\mathrm{A} \mathrm{n}^{\circ} 22$ ) s'opposa à ces condamnations et se mit à défendre la religion catholique et le clergé. Finalement, Fidelia Corral se retira du Congrès avec d'autres femmes en dénonçant les orientations «communistes » du Congrès et le fait qu'elle avaient été « trompées » car elle croyait que le Congrès ne toucherait pas des sujets religieux ni politiques. La question de l'obtention des droits politiques fut également une question controversée. Certains membres des « Légions » s’opposaient au droit de vote des femmes car elles considéraient que la femme bolivienne n'était pas encore préparée pour participer aux élections. Ce fut le cas de Luisa Mendoza (voir annexe A n60), Cira Aguayo (voir annexe A n51), Fidelia Corral de Sánchez (voir annexe A $\mathrm{n}^{\circ} 22$ ), et Angélica Panozo de Videa (voir annexe A n65). Cira Aguayo argua que les femmes n'étaient pas encore préparées à assumer les droits politiques car elles étaient encore sous la tutelle de leur parents, frères, et amoureux ${ }^{234}$. En réponse à cet argument, Elodia Ballivián de Ligerón (voir annexe A n¹2) affirma qu'elle se sentait blessée dans sa propre dignité de femme libre, qui n'admettait l'aide de personne ${ }^{235}$.

Ces conflits et divergences qui provoquèrent le désordre et les disputes au sein du Congrès, révèlent que la composition de la «LFEPA » était assez hétérogène et que les conceptions des femmes qui composaient les légions, étaient très différentes. Les réactions d'hommes de gauche dans la presse concernant les disputes de la Convention sont très intéressantes. Plusieurs hommes applaudirent le travail de

\footnotetext{
${ }^{234}$ La position de Cira Aguayo (voir annexe A n ${ }^{\circ 51)}$ résulte un peu surprenante car elle faisait partie du «Comité de Acción Feminista de Cochabamba » qui se joignit à son homologue de La Paz pour la pétition des droits civils et politiques en 1934. Il est probable qu'elle considérât que les femmes devaient d'abord obtenir les droits civils et plus tard les droits politiques.

${ }^{235}$ VILLANUEVA Etelvina, Acción Socialista de la mujer en Bolivia, Cooperativa de Artes Gráficas E. Burillo Ltda., La Paz -Bolivie, 1970.
} 
Etelvina Villanueva et d'autres membres de la «LFEPA» arguant que finalement s'était crée un bloc de femmes « socialistes » qui combattirent de manière légitime les bigotes qui avaient « inventé le mot “charité" pour humilier» au lieu d'agir sous le verbe «servir ». Ainsi, par les conflits surgis au sein du Congrès, deux positions furent signalées par l'opinion publique et notamment par les secteurs de gauche, l'une « conservatrice » des membres de la bourgeoisie qui représentait le gouvernement oligarchique déchu, et l'autre «socialiste» luttant pour le progrès social de l'ensemble de la société et notamment des plus défavorisés, non pas pour faire de la charité mais par la loi du « service » et les droits humains.

La «LFEPA » n'eut pas une durée de vie assez longue car ses actions se limitèrent aux années 1930 après la guerre. La «LFEPA » fut le produit du contexte de l'après guerre d'effervescence politique où les classes populaires et moyennes de la société cherchaient des nouvelles orientations politiques, dont le «socialisme » qui fut utilisé de manière très diverse par le gouvernement, par les partis politiques et même par la «LFEPA » dont les objectifs et le programme idéologique concernaient l'amélioration des conditions de vie des femmes. Malgré cette orientation, la «LFEPA » était une organisation très hétérogène dans sa composition et par conséquent dans les tendances et orientations qu'elle poursuivait. Elle était composée de femmes des classes élevées de la société ayant appartenu à l'« Ateneo Femenino » par exemple, et aussi de femmes des classes moyennes de la société. Tandis que dans les organisations des années 1920 les femmes des classes moyennes soutenaient politiquement le gouvernement oligarchique, en même temps qu'elles essayaient de se frayer un chemin dans la vie publique, dans la «LFEPA», dans le contexte d'après guerre, les femmes des classes moyennes s'opposaient au gouvernement oligarchique et cherchaient d'autres orientations politiques. D'où les divergences surgies au sein de la « LFEPA » à l'occasion de leur Congrès.

La «LFEPA » ne fut pas la seule organisation qui surgit après la guerre du sein des «Comités de Acción Feminista » de La Paz et de Cochabamba, Zoila Viganó fonda en même temps le satellite en Bolivie de la « Unión de Mujeres Americanas ». 


\section{La « Unión de Mujeres Americanas »}

Malheureusement, on dispose de beaucoup moins d'informations sur cette organisation. Elle fut fondée par Zoila Viganó vers septembre 1935 à La Paz en tant que section bolivienne de l'organisation internationale «Unión de Mujeres Americanas » («UMA ») qui avait son siège à New York. L' «Unión de Mujeres Americanas » avait été fondée par la mexicaine, Margarita Robles, qui avait participé à la Conférence Internationale de femmes réalisée en 1933 à Montevideo. Des sections de cette organisation s'étaient déjà formées dans plusieurs pays de l'Amérique Latine ${ }^{236}$.

Lors de sa visite à Buenos Aires en novembre 1935 Zoila Viganó fut interviewée dans le journal Crítica. À la question «quels sont les buts de l'Association de Femmes d'Amérique ? » elle répondit :

« Le but de la société est d'intensifier l'éducation et la culture de la femme, en favorisant en même temps toutes ses revendications tant de nature politique que civile. En même temps nous maintenons un programme d'ibéro américanisme, car nous luttons ardemment pour l'union politique et économique de nos nations et, par conséquent, nous combattons l'impérialisme étranger qui est la cause de plusieurs de leurs tragédies et qui réduit considérablement son indépendance politique. $\gg{ }^{237}$

La «UMA» de Bolivie tout comme la «LFEPA» était donc rattachée à une organisation internationale plus vaste dont l'un des objectifs principaux était la création de liens entre femmes latino-américaines afin d'organiser une lutte commune pour leurs revendications. L'éducation et la culture de la femme apparaissent comme un des objectifs principaux de l'organisation ainsi que l'obtention des droits civils et politiques des femmes. La lutte contre «l'impérialisme» à laquelle se réfère ZoilaViganó est liée à la thèse la plus courante pour expliquer les motifs qui déclenchèrent la guerre contre le Paraguay. Selon cette thèse, le conflit aurait été promu par l'impérialisme, qui se reflétait dans l'affrontement entre la Compagnie

\footnotetext{
${ }^{236}$ El Diario, 16 novembre 1935, La Paz. Collection personnelle d'extraits de journaux de Zoila Viganó Castañón.

237 «El propósito de la sociedad es intensificar la educación y cultura de la mujer, propiciando al mismo tiempo todas sus reivindicaciones tanto de índole política como civil. Al mismo tiempo sostenemos un programa de iberoamericanismo práctico, pues luchamos ardientemente por la unión político económica de nuestras naciones y, consecuentemente combatimos el imperialismo extranjero que es causa de muchas de sus tragedias y que merma considerablemente su independencia política. » Idem.
} 
pétrolière Standard Oil qui opérait en Bolivie et l'anglo-hollandaise Royal Dutch Shell, dont la compagnie subsidiaire allait opérer dans le Chaco Boréal car l'on supposait que des puits de pétrole se trouvaient dans cette région. La Standard Oil se serait trouvée bloquée car elle ne pouvait pas exporter le pétrole bolivien par la rivière Paraguay, bloquée par les paraguayens, et parce que l'Argentine prétendait exploiter elle même le pétrole situé au nord du pays. La présence de la Standard gênait donc les argentins qui se nièrent à la construction d'un pipeline entre la Bolivie et l'Argentine. La Standard Oil aurait donc poussé à la guerre entre la Bolivie et le Paraguay pour satisfaire ses intérêts ${ }^{238}$.

Les objectifs de la «UMA » s'inscrivaient ainsi dans le contexte d'après guerre dans lequel les femmes boliviennes voulaient développer des liens avec les autres pays pour favoriser le pacifisme entre nations.

L'on ne connaît pas la structure et l'organisation de l'«UMA » à La Paz, mais si de son homologue fondé à Cochabamba en mars 1936. L'on peut supposer que l'organisation et la structure de 1' «UMA » de La Paz étaient similaires à celles de l'«UMA » de Cochabamba. Celle-ci comptait d'une Secrétaire de gouvernement, Maritza Cuadros Quiroga; de Secrétaires de liens et réseaux continentaux, María Teresa Urquidi (voir annexe $A \mathrm{n}^{\circ}$ ) et Julia Villazón. L'organisation comptait également de plusieurs sections couvrant diverses activités : Pro Paix, Pro Éducation des indigènes, Pro orphelins de guerre, Pro prisonniers de guerre, Propagande, Culture de la femme, Droits féminins (charge tenue par Lily Cámara Ugarte et Cira Aguayo (voir annexe A n ${ }^{\circ 51}$ ), Pro défense de l’enfance déshéritée, Beaux Arts, Pro Morale, Liens avec les ouvriers (charge tenue par Rosa Morales (voir annexe A n61), Presse, Pro législation sociale de la femme (charge tenue par Luisa Mendoza (voir annexe A $\mathrm{n}^{\circ} 60$ ), Bibliothèque, Bienfaisance, Actes, Économie, Statistique, Présentations littéraires et artistiques ${ }^{239}$.

Les champs couverts par l'organisation étaient très divers et liés au contexte de guerre. Ainsi les sections Pro Paix, Pro orphelins de guerre, Prisonniers. Tout comme la «LFEPA» elle couvrait un champ social avec les sections de liens avec les ouvriers, Pro défense de l'enfance déshéritée, Pro législation Sociale de la femme.

\footnotetext{
${ }^{238}$ MESA (de) José, GISBERT Teresa, MESA Gisbert Carlos D., Manual de Historia de Bolivia, Editorial Gisbert, La Paz, 2008.

${ }^{239}$ La Patria (supplément pour Cochabamba), 14 mars 1936, Cochabamba. Collection personnelle d'extraits de journaux de Zoila Viganó.
} 
L'organisation avait des projets semblables à ceux de l'« Ateneo Femenino » avec l'existence de sections Pro éducation indigène et de Bienfaisance. Il est difficile de savoir de quelle manière les projets sociaux étaient envisagés par l'organisation, avec le peu d'informations dont on dispose. Il est difficile de savoir également si l'organisation avait une orientation «socialiste» comme la «LFEPA » dans le contexte d'après guerre ou s'il s'agissait d'une organisation plus «bourgeoise » comme l'«Ateneo Femenino ». Dans tous les cas, les sections existantes laissent entrevoir que le contexte d'après guerre avait fortement influencé l'organisation de la société avec les sections consacrées à affronter les problèmes liés à l'après guerre, la volonté de créer des liens avec les classes populaires et la préoccupation pour la législation sociale de la femme.

Des membres de la «LFEPA» de Cochabamba telles que Cira Aguayo, Luisa Mendoza et Rosa Morales étaient également membres de l'«UMA» de cette ville. On ignore quelles étaient les relations que les deux organisations entretenaient: si elles étaient de collaboration ou de concurrence. Il est probable que les deux organisations aient collaboré ensemble par la présence de membres dans les deux, et par le fait qu'Etelvina Villanueva et Zoila Viganó avaient travaillé ensemble dans le «Comité de Acción Feminista » de La Paz (sauf dans le cas d'une éventuelle dispute entre ces deux dirigeantes).

Zoila Viganó fonda d'autres satellites de l' «UMA » à Oruro et à Santa Cruz.

Le journal El Diario accorda une section féminine à l'organisation, dirigée par Zoila Viganó où se publiaient des articles relatifs aux droits des femmes, ainsi que des textes littéraires.

La guerre du Chaco signifia un bouleversement majeur pour la Bolivie; la défaite catastrophique fut la source de frustrations et d'amertumes d'une génération qui remit en question le régime de gouvernement oligarchique qui existait dans le pays depuis la fin du XIX ${ }^{\mathrm{e}}$ siècle. Les classes moyennes de la société qui avaient soutenu le gouvernement avant la guerre, se mirent à chercher de nouvelles orientations politiques pour répondre aux frustrations et mécontentements surgis suite au conflit avec le Paraguay. Une effervescence politique suivit ainsi la fin de la guerre; les bases du régime de gouvernement oligarchique commencèrent à s'écrouler. 
La guerre signifia également un bouleversement majeur dans la vie des femmes. Elles contribuèrent à l'effort de guerre de manière importante avec les organisations de secours et d'assistance aux mobilisés et à leurs familles. Le rôle qu'elles jouèrent dans la guerre permit à un certain groupe de femmes de prendre conscience de l'importance de la contribution des femmes en ce moment de crise. Le mouvement féministe se raviva avec une campagne menée afin d'obtenir les droits civils et politiques des femmes. Cependant, la campagne fut considérée comme une expression d'égoïsme dans les circonstances tragiques de la guerre, et n'eut pas de résultats. Les stratégies des femmes qui l'avaient lancé, changèrent donc après la guerre. Des organisations rattachées à des institutions internationales furent créées avec des objectifs beaucoup plus larges comprenant des inquiétudes sociales. Les stratégies et objectifs de ces nouvelles organisations féministes s'inscrivaient dans le contexte d'après guerre où il fallait s'affilier à des organisations internationales pour promouvoir le pacifisme, il fallait répondre aux problèmes sociaux aggravés avec la crise économique et avec la guerre et, où des nouvelles doctrines comme le « socialisme» apparaissaient comme des réponses possibles servant à la reconstruction du pays. L' «UMA » et surtout la «LFEPA» furent les produits de ce contexte d'après guerre où les féministes durent adapter leurs stratégies et objectifs au contexte social et politique. Il ne suffisait plus de réclamer les droits civils et politiques comme elles l'avaient fait pendant la guerre, il fallait créer des organisations de structure internationale comprenant aussi des objectifs d'amélioration des conditions de vie de l'ensemble de la société.

Le débat créé par les féministes pendant et après la guerre sur l'obtention des droits civils et politiques eut une répercussion dans la sphère politique. Les droits civils et politiques des femmes furent débattus et considérés par les hommes politiques... sans résultats. 


\section{C) Quelques pas vers l'octroi des droits civils et politiques aux femmes... qui ne menèrent nulle part.}

\section{a) Le décret-loi de David Toro octroyant les droits civils aux femmes jamais mis en application}

Suite à la lettre envoyée par la «LFEPA » à la Junte militaire du gouvernement réclamant l'octroi des droits civils et politiques aux femmes en accord avec le programme officiel du gouvernement, le président à l'époque, David Toro répondit favorablement par l'envoi d'une lettre à la «LFEPA» en leur assurant que le gouvernement «socialiste» se chargerait d'octroyer les droits civils aux femmes ${ }^{240}$. Des commissions furent formées en juillet et août pour étudier les droits civils de la femme. Finalement, un décret-loi octroyant les droits civils aux femmes fut proclamé le 21 octobre 1936. Cependant, pour des raisons qui nous sont inconnues, ce décretloi ne fut jamais appliqué.

Le « Projet de réintégration des droits civils de la femme » réalisé par Benjamín H. Gallardo et présenté au Parlement par l'«Ateneo Femenino» en 1925 servit de base pour la réalisation du décret de Toro. Celui-ci reprit presque tous les articles du projet de Gallardo de manière presque identique, avec de légères modifications et quelques suppressions.

Ainsi, le décret de Toro étant presque identique au projet de Benjamín H. Gallardo déjà étudié dans la première partie de ce travail, on se limitera ici à présenter uniquement les modifications apportées au projet original par ce décret.

La présentation des considérations du décret fut exprimée ainsi dans le décret :

« DÉCRET SUPRÊME DU 21 OCTOBRE 1936.

Furent légiférés les droits civils de la femme et le régime juridique et économique de la société conjugale.

Le colonel David Toro R.

Président de la Junte Militaire de Gouvernement.

\footnotetext{
${ }^{240}$ VILlANUEVA Etelvina, Acción Socialista de la mujer en Bolivia, Cooperativa de Artes Gráficas E. Burillo Ltda., La Paz -Bolivie, 1970.
} 


\section{CONSIDÉRANT :}

Que l'incapacité civile de la femme répond seulement à une fiction juridique, tendant à la protéger sous l'autorité du mari en discréditant sa personnalité.

Que de tels droits de la femme, contemplés dans les codes en vigueur, comme personne membre de la société conjugale, ont été soumis à une révision générale.

Que l'évolution du droit civil a incorporé des réformes radicales dans le régime conjugal, reconnues par les principales nations.

Que des réputés jurisconsultes nationaux, comme Aspiazu, Canedo, Toro et d'autres en s'occupant d'une matière si importante, ont déjà fait des précieuses études, parmi lesquelles se distingue celle du docteur Benjamín H. Gallardo tirée de la législation brésilienne du $1^{\mathrm{er}}$ janvier 1916.

Que de cette étude a été éliminé tout ce qui peut être objet de confusion, en examinant le texte même de la réforme brésilienne et en faisant une étude sur les conditions et capacités du pays ;

Qu'un des postulats du gouvernement socialiste, est de reconnaître à la femme bolivienne le libre exercice de ses droits civils. ${ }^{241}$

Le projet de Gallardo établissait dans l'article 7 que les futurs mariés devaient apporter un certificat médical pour prouver qu'ils n'avaient pas de maladies contagieuses. Cet article fut éliminé dans le décret de Toro.

Le décret de Toro reprenait l'article selon lequel le mari était le chef de la famille conjugale avec toutes les prérogatives que cela impliquait (représentation légale de la famille, administration de biens communs et patrimoniaux de la femme, le droit de fixer et changer le domicile de la famille, la charge de subvenir aux besoins de la famille) cependant le décret de Toro éliminait l'article du projet de Gallardo selon

241 «DECRETO SUPREMO DE 21 DE OCTUBRE DE 1936.

Legíslóse sobre los derechos civiles de la mujer y sobre el régimen jurídico y económico de la sociedad conyugal.

El Coronel David Toro R.

Presidente de la Junta Militar de Gobierno.

CONSIDERANDO:

Que la incapacidad civil de la mujer sólo responde a una ficción jurídica, tendiente a protegerla bajo la autoridad del marido, con menoscabo de su personalidad;

Que tales derechos de la mujer, contemplados en los códigos vigentes, como persona miembro de la sociedad conyugal, han sido sometidos a una revisión general;

Que la evolución del derecho civil ha incorporado reformas radicales en el régimen conyugal, reconocidas por las principales naciones;

Que reputados jurisconsultos nacionales, como Aspiazu, Canedo, Toro y otros, al ocuparse de tan importante materia, han hecho ya valiosos estudios, entre los cuales se destaca el del doctor Benjamín H. Gallardo, tomado de la legislación brasileña de $1^{\circ}$ de enero de 1916 ;

Que del referido estudio se ha eliminado cuanto puede ser objeto de confusión, examinando el texto mismo de la reforma brasileña y haciendo un estudio de las condiciones y capacidad del país;

Que es uno de los postulados del actual Gobierno Socialista, reconocer a la mujer boliviana el libre ejercicio de sus derechos civiles. » Tiré de tiré de MACEDONIO Urquidi José Antonio, La Condición Jurídica o Situación legal de la mujer en Bolivia, 3e Edition, Cochabamba, 1937. 
lequel le mari avait le droit d'autoriser la profession de la femme et sa résidence hors du foyer conjugal.

L'article du projet de Gallardo selon lequel en cas d'absence d'un des conjoints la patria potestad correspondait au conjoint présent, fut remplacé par «En cas d'absence, d'empêchement, interdiction ou mort du mari, l'exercice de la patria potestad et l'administration des biens correspond à la femme ».

Concernant la licence uxoriale, le décret de Toro reprenait tous les articles du projet de Gallardo, à exception de l'article qui établissait que le mari ne pouvait sans le consentement de la femme faire des donations avec des biens communs sauf s'il s'agissait d'une donation rémunératrice ou de petite valeur. Cet article étai remplacé par «(Quel que soit le régime des biens, le mari ne peut sans le consentement de la femme) : faire des donations avec les biens communs ».

L'article selon lequel la femme ne pouvait exercer profession sans le consentement du mari, fut éliminé par le décret de Toro.

L'article $12 \mathrm{du}$ projet de Gallardo selon lequel la femme qui exerçait profession, industrie ou acte lucratif, ou qui travaillait en tant qu'ouvrière, avait le droit de pratiquer tous les actes inhérents à son exercice et à sa défense, tout comme le droit de disposer librement du produit de son travail, fut remplacé par « La femme qui exerce profession, industrie ou acte lucratif, ou travaille comme ouvrière a le droit de faire usage de toutes les actions inhérentes à son exercice ».

Dans le projet de Gallardo la femme mariée pouvait sans l'autorisation de son mari libérer ou revendiquer les immeubles du mariage que le mari ait mit en garantie ou aliéné, sans le consentement de sa femme ou du juge. Dans le décret de Toro la femme pouvait « libérer ou revendiquer les immeubles du mariage que le mari ait mit en garantie ou aliéné ». De même, si dans le projet de Gallardo la femme pouvait revendiquer les biens communs, meubles ou immeubles donnés ou transférés par le mari à sa concubine, dans le décret de Toro la femme pouvait réaliser cette action pour les biens communs, meubles ou immeubles transférés par le mari à quiconque.

Le reste du décret concernant les types de régimes matrimoniaux est presque identique au projet de Gallardo, avec l'ajout de quelques précisions concernant surtout le régime dotal ${ }^{242}$.

\footnotetext{
${ }^{242}$ MACEDONIO Urquidi José Antonio, La Condición Jurídica o Situación legal de la mujer en Bolivia, 3e Edition, Cochabamba, 1937.
} 
Comme on le voit les modifications apportées par le décret-loi de Toro au projet original élaboré par Benjamin H. Gallardo sont minimes. Les modifications principales concernent l'exercice professionnel de la femme. Dans le décret de Toro, celle-ci n'avait plus besoin de l'autorisation de son mari pour exercer une profession et faire usage de toutes les actions qu'impliquait cet exercice.

Le décret, protégeait encore plus les biens communs et les biens de la femme ne permettant pas au mari de faire des donations ou de les transférer sans l'autorisation de la femme.

Ce décret fut critiqué par des jurisconsultes telles que José Macedonio Urquidi et José María Gutierrez qui avaient été des défenseurs des droits civils et politiques des femmes. Ils considéraient qu'ayant été réalisé en 1916, le Code Civil brésilien sur lequel se basait ce décret était archaïque pour l'époque, qu'il était complexe et long, et qu'il ne libérait pas véritablement la femme de la dépendance maritale ${ }^{243}$. Le docteur José María Gutierrez invité par l' "UMA» réalisa une conférence en novembre 1936 pour discuter de la Loi du Divorce Absolu qu'il soutenait mais qu'il considérait était l'objet d'abus de la part de la population, et pour discuter des modifications qui devraient se réaliser au décret-loi de Toro ${ }^{244}$. Il est probable que ce décret n'ait pas bénéficié du soutien suffisant et que pour cette raison il n'ait jamais été appliqué.

Cependant, même si ce décret ne fut jamais appliqué, que le gouvernement ait pris en compte les demandes des membres de la «LFEPA » pour élaborer un décret de loi octroyant les droits civils aux femmes, montre bien que dans le contexte de changements d'après guerre, la question d'accorder les droits civils et politiques aux femmes fut une question débattue non seulement dans la société mais aussi dans la sphère politique. C'est ce qui fut aussi révélé dans la Convention de 1938 où la question d'accorder le droit de vote aux femmes fut une question polémique au sein de l'Assemblée.

\footnotetext{
${ }^{243}$ Idem.

${ }^{244}$ El Diario, 9 novembre 1936, La Paz. Hemeroteca del Archivo del Congreso, La Paz - Bolivie.
} 


\section{b) La Convention de 1938 et le débat sur le suffrage féminin}

Les changements politiques, culturels et économiques qu'était en train de subir la Bolivie impliquaient des changements d'une plus grande profondeur dans le gouvernement et dans les principes qui régissaient le pays pour répondre à la soif de demandes et d'aspirations nouvelles de la société bolivienne d'après guerre. Ainsi, la question de réunir une Assemblée Constituante se posa dans le gouvernement de Toro. Cependant, cette Assemblée Constituante se réunit finalement sous le gouvernement de Busch au milieu de l'année 1938.

La convocation à la Convention Nationale de 1938 représenta un moment historique dans le développement politique de la Bolivie. Comme l'affirme Herbert Klein : «Por una parte representaba la cristalización del pensamiento de post-guerra y echó los cimientos para el crecimiento de la izquierda nacional y la elaboración de su programa. $»^{245}$

Cette Convention eut lieu du 24 mai à la fin du mois d'octobre 1938, après que la Bolivie ait vécu trois ans de gouvernement sans Parlement. Jusqu'à cette date elle avait été régie par la Constitution de 1880 : une Constitution typiquement libérale du XIX siècle, qui faisait de la propriété privée un droit sacré et où l'Etat intervenait très peu dans la sphère économique et sociale sous la prémisse du «laisser-faire ». La Constitution de 1938 était le signe que le pays affrontait une nouvelle période de son histoire et qu'on voulait tourner la page du libéralisme de 1880. Cette nouvelle Constitution était très importante en ce qu'elle modifiait quelques principes essentiels restés inchangés depuis 1826. Ces changements venaient en partie des courants du « constitutionnalisme social » qui s'inspiraient de la Constitution mexicaine de 1917. L'ère du « constitutionnalisme social » en Amérique Latine fut marquée par la rupture avec les principes des constitutions du $\mathrm{XIX}^{\mathrm{e}}$ qui prônaient un gouvernement limité et la protection des droits individuels contre l'intervention de l'État, et surtout la protection de la propriété privée. Une grande partie de pays latino-américains rédigea des nouvelles constitutions au début $\mathrm{du} \mathrm{XX}^{\mathrm{e}}$ siècle qui stipulaient les responsabilités sociales du capital, les droits économiques du travailleur, et la responsabilité de l'État pour le bien-être de l'ensemble de ses citoyens. Le droit à la propriété privée n'était plus sacré et était compris désormais comme un droit social en liaison directe avec

\footnotetext{
${ }^{245}$ KLEIN, Herbert S., Orígenes de la revolución nacional boliviana. La crisis de la generación del Chaco, Librería Editorial G.U.M, s.d.
} 
son utilité pour la collectivité. L'Etat était désormais responsable de la société : il était obligé d'éduquer et de garantir la santé des citoyens ainsi que de protéger les femmes et les enfants. Il s'agissait d'un interventionnisme d'Etat, qui s'opposait au « laisserfaire », de l'époque antérieure. La plupart de ces idées furent héritées du radicalisme et du socialisme européen, mais aussi du mouvement indigéniste latino-américain du $\mathrm{XX}^{\mathrm{e}}$ siècle, au moins dans les pays indo américains qui cherchèrent à travers de leurs constitutions à détruire les liens féodaux qui maintenaient les indigènes exclus de la vie nationale. Telle fut l'expérience de la Bolivie en 1938 qu'inaugurait une nouvelle période de son histoire avec cette Constitution.

Les parlementaires réunis à cette Convention venaient de tous les bords : des représentants très conservateurs de l'oligarchie minière et des propriétaires fonciers ; quelques uns des plus grands intellectuels de gauche de l'époque; des communistes qui n'avaient jamais occupé une fonction publique; des dirigeants ouvriers qui occupaient pour la première fois dans l'histoire Bolivienne la charge de députés, et même un paysan indigène. La presse des partis traditionnels attaqua durement la composition hétéroclite de cette Convention, qu'elle qualifia de «populace illettrée ». Parmi les intellectuels présents à cette Convention, on peut mentionner à Augusto Guzmán qui était un écrivain, critique littéraire, historien et homme politique de gauche. Il fut professeur de littérature, de droit minier, et d'histoire de l'art dans les Universités de La Paz et de Cochabamba. Il était membre de l'Académie de la Langue et d'Histoire. Il avait participé à la Guerre du Chaco et avait été prisonnier de guerre au Paraguay, fait qui lui inspira l'écriture de son chef-d'œuvre Prisionero de Guerra (1937). Augusto Céspedes se trouvait également présent à la Convention. Écrivain et homme politique de gauche, il avait participé à la Guerre du Chaco. Son expérience dans la guerre lui inspira la rédaction d'un livre de contes intitulé Sangre de Mestizos (1936). Carlos Medinaceli était aussi un des grands intellectuels présents à cette Assemblée. Écrivain et homme politique de gauche né à Potosí, il avait fondé la revue et le groupe littéraires Gesta Bárbara dans cette ville. Son ouvrage le plus célèbre fut La Chaskañawi, publié en 1947 mais rédigé à la fin des années 1920. On peut citer également la présence de Nazario Pardo Valle, écrivain, journaliste et intellectuel qui collaborait dans le journal La Calle.

Les principaux dirigeants de la gauche socialiste et radicale à cette Convention étaient Carlos Medinaceli, Augusto Céspedes, Balcázar, Eguino Zaballa, Renato Riverín, 
Arriata, Siñani, Alvarez (ces deux derniers étant des dirigeants ouvriers) Victor Paz Estenssoro et Walter Guevara Arze. Ces deux derniers, furent plus tard les principaux dirigeants du Mouvement Nationaliste Révolutionnaire (MNR) ${ }^{246}$.

Une fois réunis dans la Convention les parlementaires exprimèrent la mission et les objectifs qu'ils accordaient à la nouvelle Constitution qu'ils s'apprêtaient à rédiger, avec une claire conscience du moment tournant et historique qu'ils étaient en train de vivre. Pour eux, il s'agissait de créer un monde nouveau pour la génération du Chaco et la nouvelle Constitution serait un acte de remise en question de l'ordre ancien. Ainsi, le ministre du gouvernement, le colonel César B. Menacho, exprima ce sentiment lorsqu'il salua la Convention lors de la première session en affirmant :

« Nous sommes en train de vivre, messieurs les députés, un moment indubitablement historique. La Guerre du Chaco a créé une nouvelle conscience collective et une claire réflexion de cette évolution doit être le travail que vous allez réaliser dans cette Chambre... Nous sommes dans un point où les événements semblent hésiter perplexes, pour prendre une nouvelle impulsion avec une renaissance totale de ses forces spirituelles et matérielles. (...) N'oubliez pas qu'à travers le principe idéologique que vous allez découvrir, sûrement, la Convention de 1938, guidera les générations des cinquante ans à venir. » 247

Une des questions essentielles que l'Assemblée législative de 1938 débattit fut celle d'accorder la citoyenneté aux femmes en leur octroyant le droit de vote. En juin 1938 le gouvernement envoya des projets avec des changements importants en relation à la citoyenneté, à la nationalité et à la famille. Concernant la citoyenneté le pouvoir exécutif proposa que le droit de vote soit accordé aux femmes ${ }^{248}$. Les débats par rapport à cette question commencèrent le 11 août 1938 et durèrent quatre jours. Pendant les jours où eurent lieu les débats, la question fut débattue dans les journaux avec la publication d'articles divers d'hommes qui considéraient que les femmes perdraient leur féminité et qu'elles laisseraient de côte leurs obligations familiales en

\footnotetext{
${ }^{246}$ Idem.

247 «Estamos viviendo, señores convencionales, un momento incuestionablemente histórico. La Guerra del Chaco ha creado una nueva conciencia colectiva y una clara reflexión de esa evolución debe ser el trabajo que ustedes realizarán en esta Cámara... Estamos en un punto en el cual los acontecimientos parecen vacilar perplejos, para tomar nuevo impulso con un rejuvenecimiento total de sus fuerzas espirituales y materiales. (...) No olviden que por el fundamento ideológico que ustedes descubrirán, seguramente la Convención Nacional de 1938, orientará a las generaciones de los cincuenta años venideros."

Convención Nacional de 1938, Redactor de la Convención Nacional, tome I, p. 3. (désormais on citera la source comme "Redactor de 1938"), repris de KLEIN, Herbert S., Orígenes de la revolución nacional boliviana. La crisis de la generación del Chaco, Librería Editorial G.U.M, pas daté, p. 322.

${ }^{248}$ REVOLLO QUIROGA, Marcela, Mujeres bajo prueba. La participación electoral de las mujeres antes del voto universal (1939 - 1949), Eureka Ediciones, La Paz - Bolivia, 2001.
} 
s'immisçant dans les luttes politiques ${ }^{249}$. Il y avait d'autres journalistes qui, en voulant faire de l'humour sur la question arguaient que les femmes voteraient pour le candidat le plus «beau» ou le plus «bigot ${ }^{250}$. Le débat s'intensifia avec la publication d'articles de femmes qui attendaient que justice soit enfin faite aux femmes en leur accordant le suffrage ${ }^{251}$. Plusieurs femmes de La Paz, Cochabamba et Oruro envoyèrent des pétitions à l'Assemblée demandant aux députés que le droit de vote leur soit accordé ${ }^{252}$. Les institutions culturelles de femmes de La Paz, dont la «Comisión Interamericana Pro Derechos de la Mujer », la « Unión Femenina Social» et la «Unión Femenina de Fraternidad Pro Cultura de la Mujer», envoyèrent un message aux députés de l'Assemblée arguant que les lois étaient dictées sans distinction de sexe et que les députés devaient accomplir les devoirs «socialistes » auxquelx ils s'étaient engagés ${ }^{253}$. L' «UMA » envoya également une pétition qui mentionnait les avances des autres pays par rapport à la question, le travail des femmes dans l'Administration Publique, et le fait que l'intervention des femmes dans les élections servirait à les « moraliser». Plusieurs femmes se trouvaient présentes à l'Assemblée pour écouter les débats, mais il semblerait que vers la fin du débat la présence de femmes fut moins importante ${ }^{254}$. Ayant entendu et lu dans les journaux les arguments s'opposant au suffrage féminin, plusieurs femmes dénoncèrent les arguments utilisées par les parlementaires opposants dans la radio et dans les journaux $^{255}$. La question ne passa donc pas inaperçue dans l'opinion publique où la mesure à être débattue provoqua diverses réactions.

Plusieurs furent les thèmes et les arguments mis en avant dans la Convention, pour défendre, ou pour s'opposer au suffrage féminin.

Parmi les arguments en faveur du suffrage féminin, un des plus cités fut celui selon lequel les femmes devaient avoir le droit de vote car par leur travail elles contribuaient à l'économie et à la richesse du pays. Elles étaient présentes dans l'administration publique, dans les entreprises privées, dans le commerce, dans

\footnotetext{
${ }^{249}$ La Razón, 14 août 1938, La Paz. Hemeroteca del Archivo del Congreso, La Paz-Bolivie.

${ }^{250}$ REVOLLO QUIROGA, Marcela, Mujeres bajo prueba. La participación electoral de las mujeres antes del voto universal (1939 - 1949), Eureka Ediciones, La Paz - Bolivia, 2001.

${ }^{251}$ El Diario, 16 et 19 août 1938, La Paz. Hemeroteca del Archivo del Congreso, La Paz-Bolivie.

${ }^{252}$ El Diario, 19 et 20 août 1938, La Paz. Hemeroteca del Archivo del Congreso, La Paz-Bolivie.

${ }^{253}$ Última Hora, 16 août 1938, La Paz. Hemeroteca del Archivo del Congreso, La Paz-Bolivie.

${ }^{254}$ La Calle, 16 août 1938, La Paz. Hemeroteca del Archivo del Congreso, La Paz-Bolivie.

${ }^{255}$ La Calle, 18 août 1938, La Paz. Hemeroteca del Archivo del Congreso, La Paz-Bolivie.
} 
l'éducation, dans un très grand nombre de secteurs où elles avaient réussi à s'implanter. En effet, les parlementaires avaient conscience de la présence massive des femmes dans le marché du travail, ce qui posait de nouveaux enjeux sociaux et politiques. Ainsi, comme le dit le parlementaire Rodríguez Vázquez :

«Dans notre pays, l'influence qu'a réussi à avoir la femme dans l'ordre social et dans d'autres activités, est très grande $»^{256}$.

Les femmes ne pouvaient plus être comprises uniquement dans la sphère familiale et privée puisque visiblement et concrètement elles étaient rentrées à la sphère publique par l'accès massif au marché du travail et par le fait d'avoir pris des postes qu'auparavant seuls les hommes occupaient. La société et les hommes politiques de l'époque s'affrontaient à une réalité indéniable de post guerre qu'ils devaient affronter avec toutes les conséquences sociales et politiques que cela impliquait, comme la reconnaissance des droits civils et politiques des femmes, en vertu de leur participation à la richesse de l'Etat. Comme l'explique le parlementaire Fajardo :

«La femme contribue au maintien de l'Etat avec le paiement des impôts et avec le travail dans les fonctions publiques : par conséquent elle a des responsabilités envers la société et envers la patrie. Même si l'homme fait le service militaire, en revanche la femme donne des enfants, desquels elle se détache en cas de guerre. D'où le fait qu'elle mérite d'être bien considérée, et qu'elle mérite aussi le droit à la citoyenneté. Nous devons prendre en compte le fait que les femmes ont atteint non seulement les postes publiques, mais aussi le commerce et l'industrie, car il y a une grande quantité d'ouvrières et d'employées dans ces domaines. $)^{257}$

Ou encore, comme le dit le parlementaire Villarroel Claure :

«Un autre aspect est celui lié à la participation de la femme comme facteur économique au sein de l'organisation de l'Etat. En observant l'environnement dans lequel nous vivons, on voit que la femme, surtout celle de la classe moyenne, ne contribue pas seulement avec sa production personnelle, mais elle a aussi réussi à déplacer l'homme dans quelques activités; et s'il y a des femmes qui ont des intérêts

\footnotetext{
256 « En nuestro país, la influencia que ha llegado a tener la mujer en el orden social y otras actividades es muy grande." Redactor de 1938, p. 114.

257 « La mujer contribuye al sostenimiento del Estado con el pago de impuestos y con el trabajo en las reparticiones públicas: por consiguiente, tiene responsabilidades para con la sociedad y para con la patria. Si bien el hombre hace el servicio militar, en cambio la mujer da hijos, de los cuales se desprende en caso de guerra. De ahí que merezca ser considerada y merezca también el derecho de ciudadanía. Debemos tener en cuenta que las mujeres no solamente han llegado a los puestos públicos, sino también al comercio y la industria, pues hay una cantidad de obreras y empleadas en estos ramos". Redactor de 1938, t. III, p. 122. Archivo del Congreso de La Paz, La Paz - Bolivie.
} 
économiques, que ce soit dans leurs propriétés, leur travail et offices, il est logique qu'on ne puisse pas les priver de défendre leurs droits, en leur niant l'intervention dans la formation des pouvoirs de la nation. $»^{258}$

La guerre avait changé profondément la réalité du pays car les femmes avaient été obligées à accéder massivement au marché du travail, à contribuer à l'effort de guerre et à souffrir les tragédies de la guerre. Les difficultés que certaines femmes avaient dû affronter pendant et après la guerre, à travers le travail et les conséquences du conflit leur donnait une certaine légitimité à vouloir s'intéresser à la chose publique puisque désormais, comme résultat de la guerre, elles faisaient partie de la sphère publique avec leurs spécificités et nécessités propres. Ainsi, comme l'affirme le parlementaire Flores Jiménez :

«Les femmes ont un indice de nécessités, qui doit être interprété avec un critère et une sensation propres à elles-mêmes. Les employées d'Etat qui forment déjà une catégorie de mille cinq-cents ou plus, avec une capacité acquise dans des activités de fonction publique ou autres, sont en condition d'apprécier les phénomènes sociaux avec un critère propre, même si pas identique à celui de l'homme. Les veuves, les mères de famille, celles qui ont un diplôme universitaire, et finalement les mères d'ex combattants morts pendant la guerre; forment quatre catégories de femmes qui ont, non seulement une parfaite raison pour intervenir, mais aussi une capacité pour participer avec l'homme dans l'entreprise de construction du gouvernement, non pas comme éligibles, mais comme électrices. (...) Je formule la modification suivante: "Auront le droit politique ou le vote, les catégories de femmes suivantes : $1^{\circ}$., celles qui ont un diplôme universitaire $; 2^{\circ}$., les employées d'Etat, de commerce et des industries urbaines qui soient syndicalisées; $3^{\circ}$., les veuves qui soient mères de famille; $4^{\circ}$., les mères d'anciens combattants morts pendant la guerre. » » ${ }^{259}$

\footnotetext{
258 «Otro punto es el referente a la participación de la mujer como factor económico dentro de la organización estatal. Haciendo una observación del ambiente en que vivimos, vemos que efectivamente la mujer, sobre todo la de la clase media, no solamente contribuye con su producción personal, sino también ha llegado a desplazar al hombre en algunas actividades; y si hay mujeres que tienen intereses económicos, ya sea en su propiedad, en su trabajo u oficio, es pues lógico que no se les puede privar de defender sus derechos, negándoles que intervengan en la formación de los poderes de la nación.” Idem, p. 154.

259 «Las mujeres tienen un índice de necesidades, que requiere ser interpretado con criterio propio y sensación específica de ellas. Las empleadas de Estado, que ya forman una categoría de mil quinientas o más, con capacidad adquirida en actividades de función pública u otras, están en condición de apreciar los fenómenos sociales con criterio propio, aunque no igual al hombre. Las viudas, madres de familia, las que tengan título universitario y finalmente, las madres de los ex combatientes fallecidos en la campaña; forman cuatro categorías que, no solamente tienen perfecta razón para intervenir, sino también, capacidad para coparticipar con el hombre en la empresa de constituir el gobierno, no como elegibles, sino como electoras. (...) Formulo la siguiente modificación: "Tendrán el derecho político o el voto, las siguientes categorías de mujeres; $1^{\circ}$., las que tienen título universitario; $2^{\circ}$., las empleadas del Estado, del comercio y de las industrias urbanas que se sindicalicen; $3^{\circ}$., las viudas que sean madres de familia, y $4^{\circ}$., las madres de los excombatientes fallecidos en la campaña." Idem, p. 120.
} 
La réalité de l'accès massif des femmes au travail était claire et les parlementaires en avaient bien conscience. Pour certains, cette entrée massive des femmes dans le marché du travail avait forcément des conséquences politiques et sociales, puisque certains considéraient que si la femme travaillait, que ce soit dans l'administration publique, le commerce, l'industrie, etc., il était juste que les femmes puissent participer à la sphère politique pour faire connaître leurs nécessités propres liées à leurs activités professionnelles. Pour d'autres encore, à part le travail, l'éducation et le fait d'avoir subi directement les conséquences de la guerre (être veuve mère de famille, ou mère d'un ex combattant), leur accordait une légitimité certaine à pouvoir participer en politique. En travaillant, les femmes s'intégraient de fait dans la sphère publique, ce qui leur donnait légitimement le droit d'être rattachées à la sphère politique et de participer à la formation des pouvoirs publics, d'autant plus que, seuls les citoyens pouvaient travailler dans l'administration publique; les femmes bénéficiaient de ce droit sans pour autant être citoyennes, il y avait donc une inconsistance dans la loi qu'il faillait corriger.

Si une grande partie des femmes avaient accédé de manière massive au marché du travail surtout suite à la guerre du Chaco, c'était parce qu'une grande partie d'entre elles possédaient la culture et la formation nécessaires pour exercer leur profession et avoir une vie indépendante. L'éducation des femmes fut également un argument très utilisé pour justifier leur inclusion à la vie politique, d'autant plus qu'une des conditions nécessaires pour être citoyen était celle de savoir lire et écrire. Il semblait donc absurde d'écarter de l'exercice de ce droit les femmes qui remplissaient cette condition. Ainsi, comme le dit le parlementaire Ayala Gamboa :

« Il n'est pas possible qu'un domestique, par exemple, ait plus de droit qu'une demoiselle cultivée, qui a suivi tous les cycles de l'instruction. Pourquoi celle qui a plus de capacités ne peut pas participer avec son vote à la formation des pouvoirs publics ? Avoir le baccalauréat devrait être une condition exigible pour la femme, ainsi, elle pourrait intervenir dans l'exercice du droit de la citoyenneté. La femme peut montrer sa capacité non seulement dans cet aspect-là, car nous sommes tous témoins que la femme comme facteur économique, produit parfois plus que l'homme. En résumé, je désire ardemment et je voterai pour que la Convention accorde le droit de suffrage à la femme pour qu'elle 
participe comme électrice et éligible aux charges municipales, au moins. ${ }^{260}$

Ou encore comme l'affirme le parlementaire Pardo Valle :

«Elles ne sont pas, comme on l'a manifesté dans cette salle, très peu nombreuses les dames et demoiselles avec une aptitude pour le bon usage des droits politiques en question. Au contraire, les femmes mieux capacités que les hommes s'élèvent à des milliers. Il y a des femmes professionnelles, avec des diplômes universitaires et académiques, qui, néanmoins, se trouvent marginalisées de ce droit, tandis que plusieurs des électeurs actuels lisent à peine et gribouillent avec difficulté leur nom propre. En relation à la moralité et à la compréhension des devoirs civiques il n'y a pas de parallélisme possible. $\gg{ }^{261}$

Le parlementaire Burgoa va dans le même sens :

« Je ne trouve aucune raison pour nier l'exercice de ce droit légitime à la femme qui sait lire et écrire, à savoir, à celle qui est suffisamment apte à pouvoir intervenir comme électrice et comme éligible et prendre part ainsi dans les intérêts de la chose publique. Sans aucun doute, il existe dans le pays environ 20.000 femmes qui ont les capacités d'exercer les droits politiques, parfois dans des meilleures conditions que plusieurs hommes. (...) Cette mesure qui est pour moi indispensable à l'heure actuelle, viendra augmenter le pourcentage d'éléments conscients parmi l'électorat du pays, puisque je suis convaincu qu'il y a plus de 20.000 électeurs du sexe masculin, qui savent à peine dessiner leurs noms et n'ont pas de conscience de ce qu'ils font; par conséquent il n'est pas possible que cette grande partie d'éléments capables et préparés soient subordonnés à d'autres qui peuvent à peine signer. $)^{262}$

\footnotetext{
260 « No es posible que un criado, por ejemplo, tenga mayor derecho que una señorita que tiene cultura, que ha cursado todos los ciclos de la instrucción. ¿Por qué la que tiene más capacidad no ha de concurrir con su voto a formar los poderes públicos? Condición exigible para la mujer sería la del bachillerato, así podría intervenir en el ejercicio del derecho de la ciudadanía. No solamente en este aspecto la mujer puede mostrar su capacidad, pues a todos nos consta que como factor económico, produce en muchas ocasiones más que el hombre. En resumen deseo ardientemente y hago votos por que la $\mathrm{H}$. Convención otorgue el derecho de sufragio a la mujer para que concurra como electora y elegida para cargos municipales, por lo menos.” Idem, p. 117.

261 « No son, como se ha manifestado en esta H. Sala, que son muy contadas las señoras y señoritas con aptitud para el buen uso de los derechos políticos en cuestión. Al contrario: suman miles las mujeres mejor capacitadas que otros tantos miles de hombres. Las hay profesionales, con títulos universitarios y académicos, que, no obstante, se hallan marginadas de este derecho, en tanto que muchos de los actuales electores apenas leen y muy difícilmente garabatean su propio nombre. En cuanto a la moralidad y comprensión de los deberes cívicos, no hay paralelismo posible.” Idem, p. 133.

262 «No encuentro razón ninguna para negar el ejercicio de este legítimo derecho a la mujer que sabe leer y escribir, es decir, a aquella que es suficientemente apta para poder intervenir como electora o como elegida y tomar parte así en los intereses de la cosa pública. Indudablemente, existen en el país unas 20, 000 mujeres que se encuentran capacitadas para ejercer los derechos políticos, acaso en mejores condiciones que muchos hombres. (...) Esta medida que para mí es indispensable en la hora actual, vendrá a aumentar el porcentaje de elementos conscientes en el electorado del país, porque estoy convencido que existen más de 20.000 electores del sexo masculino, que apenas saben dibujar su
} 
Ainsi, pour certains parlementaires, c'était le critère d'éducation (et donc celui de classe) qui devait primer devant le critère de sexe, même si les ambiguïtés ne manquaient pas. En effet, la plupart de ceux qui défendent la capacité des femmes à participer à la vie politique sont d'accord pour qu'on accorde le droit de vote uniquement aux femmes ayant un diplôme universitaire ou ayant suivi l'instruction secondaire ou primaire ; c'est-à-dire, que les critères à devoir remplir pour voter étaient tout de même plus élevés que ceux exigés aux hommes qui devaient seulement savoir lire et écrire. Comme l'exprime le parlementaire Anaya:

« Je suis pour l'octroi du droit de vote à la femme, mais de manière restreinte, en le limitant à celles qui, en raison de leur culture soient dignes de ce droit, qui implique la liberté de critère, la liberté de raisonnement et la liberté de conviction. (...) Alors il est convenable qu'il y ait une conscience civique capable d'influer et de modifier telle ambiance, d'une manière progressive, jusqu'à atteindre le vrai concept de souveraineté nationale. Nous y réussirons si nous accordons le droit de citoyenneté aux femmes qui sont universitaires, avec un diplôme professionnel et celles qui ont la renommée de femmes cultivées, comme les écrivaines, poétesses, etc. $»^{263}$

En plus de constituer une mesure juste et légitime, puisque les femmes par leur présence dans le marché du travail et leurs capacités, méritaient le droit de vote, la mesure serait utile car elle permettrait de «moraliser» les élections si corrompues dans le pays par les pratiques de fraude. En effet, une grande partie des parlementaires considérait que les femmes étaient un élément moralisateur, car par nature elles étaient plus respectueuses des valeurs morales que les hommes. Les inclure dans la vie politique serait donc utile pour finir enfin avec les pratiques de violence, de fraude et de corruption qui caractérisaient la participation à la vie politique bolivienne. Ainsi comme l'affirme le député Nazario Pardo Valle :

«Il est nécessaire d'admettre cette vérité : dans la majorité des cas, la femme révèle des qualités peu fréquentes chez l'homme, telles que

nombre y que no tienen conciencia de lo que hacen; por consiguiente, no es posible que esa gran porción de elementos de capacidad y preparación estén supeditados por otros que escasamente pueden firmar." Idem, p. 177.

263 «Soy partidario de conceder el voto a la mujer, pero en forma restrictiva, limitándolo a aquellas que, por razón de su cultura sean acreedoras a este derecho, que importa libertad de criterio, libertad de razonamiento y libertad de convicción. (...) Entonces, nos conviene que haya una conciencia cívica capaz de influir y modificar tal ambiente en forma progresiva, hasta alcanzar el verdadero concepto de soberanía nacional. Lo conseguiremos si damos derecho de ciudadanía a las mujeres que son universitarias, con título profesional y a aquellas que tengan patente de cultas, por ser escritoras, poetisas, etc. » Idem, p. 139. 
l'honnêteté, la ponctualité, l'honnêteté et l'absence de vices. Tandis que le nombre de citoyens qui souffrent de graves défauts moraux qui les font inaptes au bon exercice des droits politiques est innombrable, il existe de manière notable plusieurs femmes qui pourraient remplacer ceux -ci avec avantage. ${ }^{264}$

Ou encore comme le dit le député Fajardo :

«On ne doit pas oublier que les luttes politiques, comme toute manifestation sociale, sont susceptibles d'humanisation. Si nous accordons l'intervention à la femme dans les luttes politiques, il est très probable que ces manifestations s'humaniseront par le respect que mérite la femme. $\rangle^{265}$

Les avances à l'étranger par rapport à la question étaient également présentes dans l'esprit d'une partie de parlementaires qui considéraient que la plupart des nations civilisées avaient déjà franchi le pas en octroyant le droit de vote aux femmes. C'est ce qu'exprime le parlementaire Pardo Valle :

« Dans le monde il n'y a aucun pays civilisé dans lequel la femme soit exclue de la fonction publique. Et si en Bolivie, on lui reconnaît des aptitudes et de l'efficacité, pourquoi le droit de vote lui sera nié ? ${ }^{266}$

Les résultats du suffrage féminin dans ces pays avaient eu des résultats satisfaisants. Il s'agissait donc d'une mesure positive pour la vie politique des différentes nations. C'est ce qu'entend démontrer le député Jordán Cuellar en citant l'exemple des EtatsUnis :

«Aux Etats-Unis, où le vote féminin existe on a vu qu'il y a des femmes gouverneurs, parlementaires, etc., qui exercent leurs hautes fonctions avec toute habileté, et la présence de la femme américaine dans les campagnes électorales de cette nation a eu véritablement la vertu d'apaiser les violences politiques et le socialisme a été mis en place grâce à son efficace intervention dans les affaires de l'État. ${ }^{267}$

\footnotetext{
264 «Preciso es convenir en esta verdad: en la mayoría de los casos, la mujer revela cualidades poco frecuentes en el hombre, tales como la honradez, la puntualidad, la honradez y la ausencia de vicios. Mientras es incontable el número de ciudadanos que adolecen de graves defectos morales que les inhabilitan para el buen ejercicio de los derechos políticos, existen notoriamente muchísimas mujeres que podrían reemplazar con ventaja a aquellos. » Idem, p. 112.

265 «No debemos olvidar que las luchas políticas, como toda manifestación social, son susceptibles de humanización. Si nosotros damos intervención a la mujer en las luchas políticas, es muy posible que estas manifestaciones se humanicen por respeto que nos merece la mujer. » Idem, p. 122.

266 «No hay en el mundo ni un solo país civilizado en el cual la mujer estuviera excluida de la función pública. Y si, como en Bolivia, se le reconoce aptitudes y eficiencia, ¿por qué se le va a negar el derecho al voto? », Idem, p. 111.

267 «En Estados Unidos, donde existe el voto femenino, hemos visto que hay mujeres gobernadoras, parlamentarias, etc., que desempeñan sus altas funciones con todo acierto, y verdaderamente la presencia de la mujer americana en las campañas electorales de esa gran nación, ha tenido la virtud de
} 
Pourtant, nombreuses furent les interventions pour s'opposer à cette mesure jugée, «prématuré » et «dangereuse ». Parmi les arguments contre le suffrage féminin, un des plus cités était celui selon lequel les femmes appartenaient à la « nature » et les hommes à «l'histoire ». Il s'agissait de deux sphères complètement distinctes par nature ; vouloir les dépasser était une atteinte dangereuse à l'ordre de choses, contre l'« harmonie » des sexes, qui avait déjà été troublée pendant la Guerre du Chaco, où les femmes dans l'urgence du moment avaient dû accéder aux espaces exclusivement dévolus aux hommes auparavant. Comme l'affirme Augusto Guzmán :

«L'humanité est divisée en deux sexes qui jouent des rôles absolument distincts, même s'ils se complémentent dans l'histoire, ils sont essentiellement différents, non pas par la volonté des législateurs, mais parce que la nature établit fatalement la différentiation sexuelle. Si nous allons accorder les droits politiques à la femme on continuera à accentuer cette décentration de la sensibilité féminine opérée à l'occasion de la guerre du Chaco (...) Je parle fondamentalement du projet d'accorder les droits politiques à la femme dans les mêmes conditions que l'homme, ce qui me parait absolument dangereux pour les institutions du pays. Je ne nie pas que les auteurs du projet soient inspirés par un esprit généreux, mais ils sont dans l'erreur en pensant que la femme peut s'identifier à l'homme (...) La femme ne peut pas intervenir en politique parce que l'on introduirait la méconnaissance dans les mariages, la perturbation la plus profonde dans les relations de deux êtres de sexe différent. Si dans la vie conjugale se produisent fréquemment des discordes, qu'est ce qui se passerait si on amenait la femme aux luttes des partis, à l'exacerbation des passions politiques? Si telle chose arrivait, on aurait tout simplement conspiré contre la fonction sociale de la femme, on l'aurait transformé en un être qui a perdu sa qualité naturelle, pour acquérir une personnalité artificielle masculinisée. » 268

apaciguar las violencias políticas y se ha hecho socialismo gracias a su eficaz intervención en los asuntos del Estado. » Idem, p. 161.

${ }^{268}$ « La humanidad está dividida en dos sexos, que juegan papeles absolutamente distintos, aunque se complementan en la historia son esencialmente diferentes, no por voluntad de los legisladores, sino porque la naturaleza establece fatalmente la diferenciación sexual. Si nosotros hemos de conceder derechos políticos a la mujer, no haremos más que continuar acentuando esa descentración de la sensibilidad femenina, operada con motivo de la Guerra del Chaco (...) A lo que quiero referirme en forma fundamental es al proyecto de conceder derechos políticos a la mujer en las mismas condiciones que al hombre, lo que me parece absolutamente peligroso para la institucionalidad del país. No niego que los proyectistas estén inspirados en un espíritu generoso, pero están profundamente equivocados al considerar que la mujer pudiera identificarse con el hombre (...) La mujer no puede intervenir en la política, porque introduciríamos el desconocimiento en los matrimonios, la perturbación más honda en las relaciones de dos seres de distinto sexo. Si en la vida conyugal se producen frecuentemente discordias, qué no ocurriría si llevásemos a la mujer a las luchas partidistas, a la exacerbación de las pasiones políticas? Si tal cosa sucediera, sencillamente habremos conspirado contra la función social de 
Que la femme veuille transgresser les limités de la sphère qui lui était dévolue, c'està-dire, la sphère privée de la famille, du foyer, de la maisonnée, était inacceptable pour certains parlementaires. Que la femme envahisse l'espace masculin, c'est-à-dire, l'espace public, celui de la politique et de l'Histoire était considéré comme une aberration. D'où les attaques nombreuses à la figure qu'incarnait cette transgression et ce brouillage de sphères et d'identités masculine et féminines : la «flapper» ou la « garçonne », icône de la femme «moderne ». La figure de la «garçonne » était apparue en France avec le roman de Victor Margueritte, intitulé «La Garçonne », publié en 1922, qui présentait une femme décidant de mener une vie libre avec des partenaires multiples. Cette figure était devenue une mode dans ce qu'on appelle les « années folles » qui vont du sortir de la Première Guerre Mondiale, jusqu'en 1929. Le terme devient synonyme de femme émancipée, active et autonome, qui fume, boit, a des pratiques sportives, conduit des voitures, et a des mœurs libérées, en affichant des liaisons hors mariage, voire son homosexualité ou bisexualité. Dans la mode, le look de la «garçonne» émergea à Paris, sous l'impulsion de Coco Chanel principalement. L'allure de la «garçonne» se caractérisait par une silhouette androgyne et longiligne, où n'étaient plus marquées ni la poitrine, ni la taille, et par le port des cheveux courts. L'équivalent de la «garçonne» dans le monde Etats-Unien était la figure de la « flapper», qui se caractérisait également par la liberté de mœurs, la mobilité, l'autonomie, la fréquentation des clubs de jazz. Cette figure était apparue en 1920 avec le film « The Flapper» de Frances Marion. La figure de la «garçonne » et de la « flapper » étaient diffusées au cinéma, et plusieurs actrices incarnaient cette figure comme Louise Brooks, Clara Bow et Joan Crawford. D'ailleurs, en 1936 sortit l'adaptation cinématographique du roman de Victor Margueritte, «La Garçonne », sous la direction de Jean de Limur.

En 1938 on était en plein dans cette mode et les figures de la « flapper» et de la «garçonne» étaient bien présentes dans les esprits de l'époque. Ainsi, les parlementaires ne manquent pas d'y faire référence à plusieurs reprises pour décrire le comportement immoral et transgressif des femmes des classes élevées principalement qui, d'après eux, ne méritaient pas le droit de vote. Dans l'esprit des parlementaires, si les femmes voulaient participer en politique c'était dans un désir de personalidad artificial masculinizada. » Idem, p.117-118. 
« masculinisation » déjà exprimée par leur comportement. C'est ce qu'exprime en partie le député Augusto Guzmán :

« Si telle chose arrivait, on aurait tout simplement conspiré contre la fonction sociale de la femme, on l'aurait transformé en un être qui a perdu sa qualité naturelle, pour acquérir une personnalité artificielle masculinisée... » ${ }^{269}$

Le parlementaire Flores Jiménez qui avait très bien compris la référence à laquelle Augusto Guzmán faisait allusion, répondit:

«Un autre aspect qui semble alarmer le conventionnel Guzmán, peutêtre très touché par la littérature de Victor Margueritte, avec « La Garçonne » qui raconte les modifications de l'esprit de la femme après $1918 \ldots \gg$

Cette figure incarnée dans le comportement des femmes des classes moyennes et élevées est produite d'après le parlementaire Araúz, par les changements liés à la « modernité », qui scandalisent le député à tel point qu'il affirme :

«La vie moderne nous envahit avec fureur, avec cet ensemble de coutumes qui s'appelle modernisme, et qui s'est assimilé au foyer Bolivien, par la facilité avec laquelle les peuples qui n'ont pas une civilisation avancée assimilent les défauts et les vices. La seule chose que la femme Bolivienne a appris, de la société appelée moderne, sont les vices des hommes, de façon qu'elle va les dépasser bientôt. Jadis, dans les foyers une jeune fille de 15 ans devait se cacher pour fumer; aujourd'hui, une jeune fille de cet âge fume dans les rues et chez elle avec ses parents, la seule chose qu'on ne lui pardonne pas est qu'elle fume sans grâce. (...) Auparavant, aucune femme ne visitait des bars ; aujourd'hui on voit des filles de 15 ans, dans des sites d'amusement, fumant et buvant des cocktails, et faisant des blagues qui feraient rougir même un carabinier. Auparavant, la femme ne voulait pas s'égaler à l'homme, nos mères se contentaient d'êtres femmes de foyer, la vie politique leur était égale, mais pas la vie domestique; maintenant, nous arrivons à l'extrême où la femme a appris tous les vices masculins, par ce désir d'imitation, et en plus elle veut se plonger dans les luttes politiques. (...) De nous jours, les mères, au lieu de se préoccuper de l'éducation de leurs enfants, préfèrent se consacrer à jouer au «baccara », au bridge, fumer et boire; aucune maison ne manque de salle de jeux. (...) Lorsqu'un mari veut mettre fin à ces excès, la femme a recours au simple dossier du divorce, pour se libérer de l'obstacle qui s'oppose à ses caprices.» ${ }^{270}$

\footnotetext{
269 « Si tal cosa sucediera, sencillamente habremos conspirado contra la función social de la mujer, la habremos convertido en ser, que ha perdido su cualidad natural, para adquirir una personalidad artificial masculinizada...” Idem, p. 118.

${ }^{270}$ « La vida moderna nos invade con furor, con ese conjunto de costumbres que se llama modernismo, y que se ha asimilado al hogar boliviano, por la facilidad que asimilan los pueblos, que no tienen civilización avanzada, los defectos y los vicios. La mujer boliviana de la sociedad que se llama
} 
A la fin de cette intervention la plupart des parlementaires semblent avoir été touchés par les paroles du député Araúz, parce qu'ils répondirent avec des applaudissements. Le parlementaire Liendo fait également référence à la figure de la «flapper» pour exprimer son opposition à ce que l'on accorde le droit de vote aux femmes des classes moyennes et élevées qui incarnent cette figure :

«Et pour ne pas perdre plus de temps, je me limite à exprimer, brièvement, mon avis contre le vote féminin, car, en réalité, les seules qui pourraient avoir ce droit seraient les «cholas » et les « indias", comme éléments de production, et pas les «flappers » qui perdent leur temps entre cocktails et volutes de fumée. $»^{271}$

Faire appel aux figures de la « garçonne » et de la « flapper» pour justifier leur opposition au suffrage féminin servait à disqualifier moralement le comportement des femmes éduquées des classes moyennes et élevées de la société, qui ne méritaient pas de devenir citoyennes parce qu'elles transgressaient les lois morales, et voulaient entrer dans une sphère qui ne leur était pas réservée : la sphère publique qui était celle des hommes. La figure de la «garçonne » et de la « flapper» représentait les craintes d'une partie des hommes politiques de voir les femmes hors de la sphère privée et familiale. Ces deux figures représentaient également le désir des femmes de sortir de l'espace privé pour entrer dans l'espace public : en allant dans les bars, en fumant, en buvant, en conduisant des voitures, etc., elles entraient dans la sphère publique de l'homme, et se «masculinisaient». Ces deux figures étaient le résultat des transformations produites par la Première Guerre Mondiale en Europe, où les femmes entrèrent massivement au marché du travail et par conséquent dans la sphère publique. Le même phénomène s'était opéré en Bolivie avec la guerre du Chaco.

moderna, lo único que ha aprendido son los vicios de los hombres, en forma que los aventajarán muy pronto. En el hogar de ayer, una muchacha de 15 años tenía que cuidarse y ocultarse para fumar; hoy, una muchacha de esa edad fuma en las calles y en su hogar con sus padres, lo único que no se le perdona es que no fume sin gracia. (...) Antes, la mujer no se preocupaba de igualar al hombre, nuestras madres se contentaban con ser mujeres del hogar, no les importaba la vida política, sino la vida doméstica; ahora, llegamos al extremo de que la mujer ha aprendido todos los vicios masculinos, por ese su afán de imitación, y aún quiere enfrascarse en las luchas políticas. (...)Hoy por hoy, las madres en lugar de preocuparse de la educación de los hijos, como es su deber, prefieren dedicarse a jugar bacará, bridge, fumar y beber; ninguna casa deja de tener su sala de juegos. (...) Cuando hay un marido que quiere poner coto a estos desmanes, la mujer recurre al sencillo expediente del divorcio, para librarse del obstáculo que se opone a sus caprichos. » Idem, p. 137-138.

271 "Y, para no perder más tiempo me limito a expresar, brevemente, mi opinión contra el voto femenino, porque, en realidad, las únicas que podrían tener este derecho serían las cholas y las indias, como elementos de producción, y no las flappers que pierden su tiempo entre cocktails y volutas de humo." Idem, p. 166. 
Attaquer la «garçonne» et la «flapper» était une manière d'attaquer les femmes de la bourgeoisie, dont non seulement leurs modes de vie étaient discrédités par les parlementaires mais aussi leur travail. En effet, pour contrer les arguments en défense du suffrage féminin qui mettaient en avant la présence des femmes dans le marché du travail, les parlementaires, surtout de gauche, disqualifièrent le travail exercé par les femmes des clases moyennes et élevées. En effet, plusieurs parlementaires considéraient que les femmes des classes moyennes et élevées qui travaillaient le faisaient par pure « frivolité » et non pas par nécessité. Ils utilisaient des arguments qui étaient liés à une disqualification morale du travail, mais ils ne nièrent jamais la présence des femmes dans l'espace public à travers le travail comme une réalité claire et absolue. Ils confirmèrent la présence des femmes dans l'espace public et leur présence massive dans le marché du travail en citant le travail des femmes des classes populaires, les femmes métisses («cholas ») et les indigènes, qui d'après eux, réalisaient le «vrai » travail. Or, comme ils le comprenaient bien, la plupart des femmes des classes populaires qui travaillaient, ne savaient ni lire ni écrire, et donc ne pouvaient pas, de toutes les façons, devenir citoyennes. Celles qui potentiellement pouvaient avoir le droit de vote (car elles savaient lire et écrire), ne réalisaient pas un «vrai » travail et ne méritaient donc pas de devenir citoyennes. Telle fut la logique des arguments de parlementaires qui se prononçaient contre le suffrage féminin. L’explication du parlementaire Araúz O. va dans ce sens :

« Je vais expliquer au parlementaire Rodríguez Vázquez, pourquoi les femmes occupent des postes publiques. Dans d'autres endroits, le travail rend digne, parce qu'il répond à la satisfaction de nécessités supérieures, essentielles, par exemple, au maintien du foyer. En Bolivie la femme est en train de discréditer le travail, parce que les papas et les mamans qui ont besoin d'argent pour le jeu, pour les cigarettes, pour les boissons et pour toutes ces frivolités, ont résolu le problème en faisant en sorte que ses filles occupent des postes publiques, où avec commodité et aisance, elles reçoivent ce dont elles ont besoin, pas pour les nécessités de la vie mais pour ses frivolités. ${ }^{272}$

\footnotetext{
272 « Voy a explicarle al H. Rodríguez Vázquez, por qué las mujeres ocupan puestos públicos. En otras partes el trabajo es dignificador, porque responde a la satisfacción de necesidades superiores, imprescindibles, por ejemplo, el sostenimiento del hogar. En Bolivia la mujer está desacreditando el trabajo, porque los papás y las mamás que necesitan dinero para el juego, para los cigarrillos, para las bebidas y para todas esas frivolidades, han resuelto el problema, haciendo que sus hijas ocupen puestos públicos, donde con, comodidad y holgura, ganan lo que precisan, no para necesidades de la vida sino para sus frivolidades." Idem, p. 145.
} 
Le parlementaire Céspedes suit cette ligne de pensée en faisant référence au travail des femmes des classes populaires et en confirmant l'importance du travail et de la production pour la citoyenneté:

«Dans l'aspect économique il faut partir d'un principe : la citoyenneté n'est fondée que dans la capacité productrice à travers laquelle tout élément qui contribue à l'économie a droit à surveiller son rangement à partir de l'Etat. (...) La femme Bolivienne - celle de la classe dominante - a atteint cette capacité seulement en proportion relative, mais en échange, cette vertu de travail et de production est atteinte par les classes métisses et indigènes féminines de notre pays. Le type Bolivien de la «chola» est admirable par sa force productrice, son dynamisme social et son sens de la vie. La "chola » a réalisé, sans théories, la parfaite émancipation sexuelle et économique de la femme. La métisse est indépendante dans son économie, comme elle est indépendante dans l'élection de son compagnon, elle élève et prend soin de ses enfants, et dans certaines occasion, il entretient même l'homme.(...) En ce qui concerne « la india », bien qu'elle ne soit pas socialement émancipée, elle conserve une solidarité communautaire avec l'homme dans la société indigène, dans laquelle elle travaille en proportion égale à l'homme, en constituant un facteur économique irremplaçable $\mathrm{du}$ foyer. Ces deux types de femmes sont économiquement émancipées, alors que la femme blanche ne l'est pas. (...) Alors : s'il s'agit d'adopter le suffrage féminin, il arriverait qu'on donnerait le droit de vote précisément à la femme non émancipée, et qu'on le nierait de fait à celle qui est réellement libre, à savoir, à la métisse et à « la india ». » ${ }^{273}$

Cette intervention valut à Céspedes les huées des femmes qui se trouvaient présentes dans la Convention.

Le parlementaire Liendo s'exprima brièvement sur la question ainsi :

«Et pour ne pas perdre plus de temps, je me limite à exprimer, brièvement, mon avis contre le vote féminin, car, en réalité, les seules qui pourraient avoir ce droit seraient les «cholas» et les « indias»,

\footnotetext{
273 « En el aspecto económico partamos de un principio: la ciudadanía no se funda en otra cosa que en la capacidad productora por la cual todo elemento que contribuye a la economía, tiene derecho a fiscalizar su ordenación desde el Estado. (...) A aquella capacidad no ha llegado la mujer boliviana me refiero a la clase dominante- sino en proporción relativa, pero, en cambio esa virtud de trabajo y producción la llenan eficientemente las clases mestiza e indígena femenina de nuestro país. El tipo boliviano de la chola es admirable por su fuerza productora, por su dinamismo social y por su sentido de la vida. La chola ha realizado, sin teorías, la perfecta emancipación sexual y económica de la mujer. La mestiza es independiente en su economía así como es independiente en la elección del compañero, ella cría y educa sus hijos y, en ocasiones, hasta mantiene al varón. (...) En cuanto a la india, si bien no está socialmente emancipada, conserva una solidaridad comunaria con el varón en la sociedad indígena, en la cual trabaja también en proporción igual a la del hombre, constituyendo un insustituible factor económico del hogar. Estas dos clases de mujeres están económicamente emancipadas, en cambio la mujer blanca no lo está (...) Pues bien: si se trata de aprobar el voto femenino, ocurriría que, precisamente se daría voto a la mujer no emancipada, y se lo negaría de hecho a la realmente libre, es decir, a la mestiza y a la india. » Idem, p. 148.
} 
comme éléments de production, et pas les «flappers » qui perdent leur temps entre cocktails et volutes de fumée. $»^{274}$

On comprend bien que ces attaques qui provenaient pour la plupart de parlementaires de gauche servent à discréditer les femmes des élites qui représentaient la « décadence » de l'oligarchie qui avait mené le pays à la défaite catastrophique. Il y a une défense des femmes des classes populaires telles que l'indigène et surtout la métisse qui étaient considérées comme les «véritables » forces productrices de la nation. Cependant, le système électoral étant restreint à ceux qui savaient lire et écrire, la plupart des femmes des classes populaires ne seraient pas qualifiées pour voter. Dans ce cas la question n'avait plus besoin de discussion, aucune femme ne pouvait voter.

En ce qui concerne le développement de l'éducation et de la formation des femmes, la plupart des parlementaires ne nient pas l'existence des femmes cultivées qui mériteraient le droit de vote, mais ils considèrent qu'elles représentent une infime minorité pour qu'on leur accorde le droit de vote.

Ainsi, le parlementaire Balcázar affirme :

«Bien que dans notre pays existent des dames et des demoiselles cultivées qui peuvent très bien exercer la citoyenneté, il est vrai aussi qu'on ne peut pas légiférer pour vingt ou trente personnes. $»^{275}$

Pour nier le droit de vote aux femmes et démontrer que les femmes cultivées étaient une très petite minorité, les parlementaires s'appuyèrent aussi sur une sorte de pessimisme en relation au développement éducatif et culturel de la Bolivie en général. Ils essayèrent de démontrer que si la plus grande partie de la population et des hommes n'était pas suffisamment éduquée, la situation était encore pire pour les femmes puisque le développement de leur éducation était tout récent. C'est ce qu'essaye de démontrer le parlementaire Echazú :

«Maintenant nous voyons ce qui se passe dans la réalité de notre pays. L'élément privilégié, dans tous les domaines et même pour acquérir de la culture en Bolivie a toujours été l'homme ; la femme a commencé à assister aux universités et lycées récemment, depuis vingt ans. Avant elle ne le faisait pas à cause des préjugés sociaux et religieux, c'est

\footnotetext{
274 «Y, para no perder más tiempo me limito a expresar, brevemente, mi opinión contra el voto femenino, porque, en realidad, las únicas que podrían tener este derecho serían las cholas y las indias, como elementos de producción, y no las flappers que pierden su tiempo entre cocktails y volutas de humo." Idem, p. 166.

275 «Si bien en nuestro país existen damas y señoritas cultas que muy bien pueden ejercer la ciudadanía, también es cierto que no podemos legislar para veinte o treinta personas. » Idem, p. 130.
} 
pourquoi la plupart des femmes, même celles de la race blanche, ne sont pas en conditions de concurrencer l'homme. (...) Si la femme Bolivienne est encore dans un retard considérable, et a commencé à se cultiver et à se préparer pour l'exercice de ses droits tout récemment, nous ne pouvons pas nous mettre en avance en leur accordant la citoyenneté, car, loin de lui faire du bien, on lui fera un mal positif, parce qu'on pourrait même arriver à la dissolution du foyer. » ${ }^{276}$

Le parlementaire Landívar Zambrana présente le même type d'argument :

« Une des raisons attribuées au retard dans lequel se trouve la Bolivie, est le niveau culturel très bas de ses hommes. Si cela est une vérité, dont la cause nous la trouvons dans le manque d'universités, d'écoles et d'éducation à la maison, qu'est-ce qu'on pourrait dire de la femme qui réclame des droits politiques ? $»^{277}$

Comme on l'a déjà mentionné auparavant, il n'y a pas de chiffres concernant la quantité de femmes professionnelles et présentes dans le marché du travail pour les années qui précédent 1950. Il est donc très difficile d'avancer des chiffres pour la fin des années 1930. Cependant, en 1950, sur une population de 3.019.031 habitants, 75.94\% avait comme occupation principale l'agriculture et l'élevage, c'est-à-dire, 440.371 femmes ; 8.98\%, entraient dans la catégorie «Professionnelles, services domestiques et personnels », c'est-à-dire 52.074 femmes; $7.76 \%$ travaillait dans l'industrie de transformation, notamment dans les secteurs textiles et alimentaires, c'est-à-dire 44.999 femmes; 4.19\% s'occupait du commerce, des crédits et des assurances, c'est-à-dire, 24.297 femmes. Et seulement 268,758 femmes de tous les âges, savaient lire et écrire, c'est-à-dire, $9 \%$ de la population totale. L'on peut imaginer qu'à la fin des années 1930 ces chiffres étaient encore plus réduits. Sans aller jusqu'à affirmer comme le fait le parlementaire Balcázar en exagérant, que le nombre de femmes cultivées se réduisait à 20 ou 30 personnes, il est clair que le

\footnotetext{
276 « Ahora vemos lo que ocurre en la realidad en nuestro país. El elemento privilegiado, en todo orden y aún para adquirir cultura en Bolivia ha sido el hombre; la mujer recién ha comenzado a asistir a universidades y colegios desde hace veinte años, antes no lo hacía por prejuicios sociales y religiosos, por eso, la mayoría de las mujeres, aún las de raza blanca, no están en condiciones de competir con el hombre. (...) Si la mujer boliviana está aún en un atraso considerable y recién comienza a culturizarse y a habilitarse para el ejercicio de sus derechos, no podemos adelantarnos nosotros otorgándoles la ciudadanía, porque, lejos de beneficiarla le haremos un mal positivo, porque, incluso se puede llegar a la disolución del hogar. » Idem, p. 164.

277 «Una de las razones atribuidas al atraso en que está Bolivia, es el bajo nivel cultural de sus hombres. Si esta es una verdad, cuya causa la encontramos en la falta de universidades, de escuelas y de educación en el hogar, ¿qué podríamos decir de la mujer que reclama derechos políticos?” Idem, p. 146.
} 
secteur de femmes cultivées et professionnelles en Bolivie était très réduit par rapport au reste de la population.

Cependant, au delà de ces arguments, une des raisons principales pour s'opposer à octroyer le droit de vote aux femmes, était la famille. Si la femme obtenait le droit de vote les familles seraient dissoutes car la femme laisserait de côté ses obligations au sein de la famille et du foyer. Face à « l'invasion » progressive de l'espace public par la femme, surgissait la peur de la plupart des parlementaires de voir la femme quitter l'espace qu'ils considéraient qui leur était réservée : l'espace privée, à savoir, l'espace de la famille et de la maisonnée. La «mission » de la femme au sein de la famille fut ainsi exaltée par une grande partie de parlementaires. C'est sous cette logique que s'exprima le parlementaire Ardaya :

« Mon vote par conséquent, monsieur le Président, sera négatif avec le pardon de la femme, que je veux toujours voir, après tout, dans le sanctuaire du foyer, vénérée. ${ }^{278}$

Le parlementaire García Agreda alla dans le même sens :

«En ce qui concerne le suffrage féminin je suis contre, car la femme exerce dans la terre la haute mission de former le foyer, prendre soin des enfants, former son esprit, etc. (...) Si on va permettre que la femme intervienne dans les luttes des partis, les disputes électorales, on ne fera que perturber les foyers et provoquer leur dissolution. Il n'est pas possible que les mères se mêlent de politique et que pour cela elles abandonnent leurs enfants et leur foyer. Des pays comme le Brésil, l'Argentine, le Chili, n'ont pas osé introduire dans leur législation cette réforme. L'œuvre de tout législateur est de ne pas créer des éléments de perturbation pour le foyer et l'ordre social ; au contraire cette œuvre doit se caractériser par leur renforcement. En accord avec ce qu'exprimait le conventionnel Araúz, je ne crois pas qu'il y ait un seul conventionnel qui soit chef de famille, qui permette que sa femme et ses enfants assistent à des bars ou à des hôtels pour jouer, fumer et boire, encore moins qu'ils prennent part aux élections. $»^{279}$

\footnotetext{
278 « Mi voto en consecuencia, señor Presidente, ha de ser por la negativa con perdón de la mujer, a quien quiero siempre verla, después de todo, sólo en el santuario del hogar, venerada.” Idem, p. 163.

279 «En cuanto al sufragio femenino estoy en contra, porque la mujer ejerce en la tierra la alta misión de formar el hogar, cuidar a los hijos, modelar su espíritu, etc. (...) Si vamos a permitir que la mujer intervenga en las luchas partidistas, en las contiendas electorales, no haremos más que perturbar los hogares y provocar su disolución. No es posible que madres tengan que mezclarse en la política candente y que para ello tengan que abandonar a sus hijos y su hogar. Países como la Argentina, Chile, Brasil no se han atrevido a introducir en su legislación esta reforma. La obra de todo legislador es la de no crear elementos de perturbación para el hogar y el orden social; al contrario, esa obra tiene que caracterizarse por su mayor afianzamiento. De acuerdo con lo que expresaba el H. Araúz, no creo que haya un Convencional, que sea jefe de familia, que permita que su esposa e hijos concurran a cantinas u hoteles a jugar, fumar y beber, ni menos que tomen parte en elecciones.” Idem, p. 163.
} 
La place des femmes n'était pas dans les sphères publique et politique, même si elles avaient les capacités de les intégrer, car par nature leur place était dans la sphère familiale. C'est ce qu'exprime le parlementaire Quiroga :

« Il est vrai que dans la composition d'un peuple existent, comme dans le notre, des éléments féminins avec une haute capacité, qui se rendent dignes d'exercer des fonctions comme celle de Président de la République, Ministres d'Etat, députés, charges diplomatiques, membres de la Cours Suprême, de la Cour de District, etc.; mais la place de la femme n'est pas dans les bureaux publics, ni dans le Parlement, ni dans la magistrature, ni dans les comices politiques, mais dans la maison, où elle est appelée à accomplir la belle mission que lui a montré la nature, et où, au contraire, elle manque de temps pour remplir son devoir en s'occupant de son conjoint et de ses enfants, surtout pour remplir le gouvernement intelligent de l'économie domestique. " ${ }^{280}$

En même temps que l'on exaltait la mission «sacrée » et «naturelle » au sein du foyer, s'exprimait la crainte non seulement de voir les femmes hors de leur propre espace, mais aussi la crainte que cela provoquerait la dissolution des familles. Les femmes devaient avoir des enfants pour défendre le pays en cas de guerre. Cette crainte de la dissolution des familles s'exprimait d'autant plus fortement qu'en 1932 fut proclamée la Loi du Divorce Absolu, qui était, d'après certains parlementaires, la cause principale de la séparation et de la «destruction» des familles. Ceux qui dénonçaient cette loi redoutaient toujours la dissolution de familles à laquelle elle contribuait. Le parlementaire Vargas Soto s'attarde à attaquer cette loi en même temps qu'il exprime la crainte de voir les femmes abandonner leurs familles :

«Ensuite, une autre erreur des dernières années à été la loi du divorce absolu. Depuis qu'elle a été sanctionnée, les foyers Boliviens ont commencé à se dissoudre. Qui en sont les victimes? Les pauvres femmes qui restent trompées sous l'abri de tous les subterfuges de pauvres lois qu'utilisent les hommes afin de faire paraître justes ses déviations. (...) Et pour conclure, si la Convention va donner accès à la femme aux fonctions politiques, je présenterai un projet de loi dans le sens où l'Etat prenne en charge l'éducation des enfants, parce que sûrement il n'y aura plus personne dans les foyers pour prendre soin de

\footnotetext{
280 «Es verdad que dentro de la composición de un pueblo existen, como en el nuestro, elementos femeninos de alta capacidad, que se hacen dignos para ejercer funciones como las de Presidente de la República, Ministros de Estado, diputaciones, cargos diplomáticos, vocalías de Corte Suprema, de Cortes de Distrito, etc.; pero, el lugar de la mujer no está en las oficinas públicas, en el Parlamento, en la judicatura ni en los comicios políticos, sino, en la casa, donde está llamada a cumplir la hermosa misión que le ha señalado la naturaleza, y donde más bien, le falta tiempo para llenar su deber atendiendo a su consorte y a sus hijos, y sobre todo, para desempeñar el gobierno inteligente de la economía doméstica." Idem, p. 177.
} 
ces besoins. Nous voyons dans nos habitudes détendues que la plupart des parents de famille passent généralement ses heures dans les clubs et dans les bars, et si en plus on va arracher la femme du foyer pour la mêler aux luttes politiques, les enfants seront complètement abandonnés, et par conséquent, viendra le bouleversement total de la famille. $»^{281}$

L'exaltation de la mission de la femme au sein du foyer vient soutenir l'idée traditionnellement admise selon laquelle la femme doit rester dans la sphère privée, du foyer et de la famille. Pour certains parlementaires, il était inconcevable de voir la femme participer en politique et transgresser la loi de la nature qui la reléguait au sein de la famille pour exercer sa mission la plus « sacrée » : la maternité.

Ce furent les derniers arguments qui l'emportèrent au sein de l'Assemblée car le droit de vote fut finalement nié aux femmes. A la fin du débat, sur un total de 86 députés présents, 31 votèrent pour l'octroi du suffrage féminin et 55 contre celui-ci. Pendant les débats, sur un total de 32 parlementaires qui se prononcèrent sur le suffrage féminin, 15 se prononcèrent pour le suffrage féminin (partiel ou total), et 17 se prononcèrent contre celui-ci. Malgré le caractère « révolutionnaire » accordé à la Convention de 1938, celle-ci n'osa pas adopter le suffrage féminin.

Les années 1930 marqués par la guerre furent une période de profondes mutations en Bolivie tant dans le domaine culturel et économique que dans le domaine politique où les partis traditionnels commencèrent une période de décadence. La vie de femmes fut également transformée par leur contribution à l'effort de guerre et leur entrée massive au marché du travail. Les femmes occupaient une nouvelle place dans la société et dans la sphère publique, dont étaient conscientes les féministes qui s'occupèrent d'élaborer une campagne pour l'obtention des droits

\footnotetext{
281 «Luego, en los últimos años otro error ha sido la inconsulta ley del divorcio absoluto. Desde que ella fue sancionada, los hogares bolivianos han comenzado a disolverse. Quiénes son las víctimas? Las pobres mujeres que quedan burladas al amparo de todas las triquiñuelas leguleyescas de que se valen los hombres para cohonestar sus desvíos. (...) Y para terminar, si la H. Convención ha de dar acceso a la mujer a las funciones políticas, yo he de presentar un proyecto de ley en sentido de que el Estado se haga cargo de la educación y crianza de los hijos, porque seguramente ya no habrá en los hogares quienes cuiden de estos menesteres. Estamos viendo en nuestras costumbres relajadas que la mayoría de los padres de familia generalmente pasan sus horas en los clubes o en las cantinas, y si también se ha de arrancar del hogar a la mujer para mezclarla en las luchas políticas, los hijos quedarán completamente abandonados, y como consecuencia, vendrá el desquiciamiento total de la familia. » Idem, p. 164.
} 
civils et politiques. Une fois la guerre finie, les stratégies et les objectifs qu'adoptèrent ces mêmes féministes devaient s'accorder au contexte de post guerre où régnait le mécontentement social surtout des classes moyennes en quête de nouvelles orientations politiques. Les nouvelles organisations féministes ne pouvaient plus se contenter de réaliser des activités culturelles, d'exiger leurs droits civils et politiques et d'envisager les problèmes sociaux sous le prisme de la charité comme dans les années 1920. Elles devaient embrasser des objectifs plus larges qui s’inscrivent sous les auspices du « socialisme » revendiqué à l'époque et qui visent à l'amélioration des conditions de vie des plus défavorisés, des éternels laissés pour compte sous les gouvernements oligarchiques. Le rapprochement avec les femmes des classes populaires et la prise en compte de revendications sociales des femmes furent partie intégrante des programmes de ces organisations qui avaient une structure internationale. Les mutations produites par la guerre et la nouvelle place occupée par les femmes dans la société provoquèrent un vrai débat au sein de la société sur la question de leur accorder ou non les droits civils et politiques; la polémique sur ce sujet ayant atteint deux points culminants en 1934 et en 1938. Ni la société ni le gouvernement de post guerre furent indifférents aux demandes des féministes. Ainsi, le gouvernement de Toro proclama un décret de loi visant à leur octroyer les droits civils en 1936. Cependant, ce décret ne fut jamais appliqué. Le suffrage féminin fut débattu pendant 4 jours au sein de la Convention Nationale de 1938, sans être adopté à la fin. La seule mesure favorable aux femmes adoptée dans cette Convention fut celle de l'article 41 établissant que la femme mariée avec un étranger ne perdait plus sa nationalité.

Les années 1940 marqués par l'écroulement final du régime de gouvernement oligarchique furent des années apportant certains triomphes dont la première participation politique des femmes au sein des élections municipales, et l'intégration des femmes dans les partis politiques, tels que le MNR. 


\section{III) Les premières expériences des femmes en politique (années 1940)}

Après le suicide de Germán Busch en août 1939, la question de la succession présidentielle se posa. Enrique Baldivieso avait été élu Vice-président par la Convention de 1938, mais étant donné que Busch s'était déclaré dictateur, la légitimité de sa charge fut remise en question. Ce fut l'armée qui prit la décision de la succession et qui choisit Carlos Quintanilla comme président du pays. Pendant son court gouvernement qui signifia un virage à droite, furent révoquées les mesures les plus radicales de Busch dont le décret-loi du 7 juin 1939 déclarant que le 100\% des divises obtenues par les exportations des minéraux devaient être données à l'État. Des élections présidentielles furent réalisées en 1940, où se présentèrent comme candidats Enrique Peñaranda qui représentait l'armée et les partis traditionnels et José Antonio Arze représentant la gauche du pays. Enrique Peñaranda remporta les élections, mais la gauche réussit à avoir un nombre important de sièges au Parlement.

Au début des années 1940, se forgèrent les partis politiques les plus importants de la décennie créés par les hommes qui composaient la "génération du Chaco », frustrée par la guerre et visant à transformer le pays de manière radicale. Ce fut le cas du «Partido de Izquierda Revolucionaria » («PIR») fondé par José Antonio Arze et Ricardo Anaya, le 26 juillet 1940 dans un congrès de gauche réalisé à Oruro. D'orientation marxiste le «PIR » fut le parti de gauche le plus influent des années 1940. Il proposait la révolution démocratique-bourgeoise comme étape préalable au socialisme, la réforme agraire et de manière moins claire le contrôle de l'État sur les revenus miniers. L'autre parti à être formé au début des années 1940 fut le « Movimiento Nacionalista Revolucionario » (MNR) fondé en janvier 1941, même si sa fondation officielle est reconnue en juin 1942. Les fondateurs de ce parti furent Victor Paz Estenssoro, Hernán Siles Zuazo, Wálter Guevara Arze, Carlos Montenegro, Augusto Céspedes, Germán Monroy Block et Rafael Otazo. Le « MNR » ne disposait pas d'un programme clair et défini à ses débuts, ce qui le rapprocha des orientations fascistes d'Europe à l'époque. Dans les années qui suivirent, le MNR allait se définir comme un parti politique réunissant plusieurs classes («policlasista ») en défense des intérêts populaires. 
Le climat politique fut très tendu pendant le gouvernement de Peñaranda en raison de l'opposition des divers partis politiques dont celle du PIR et du MNR. Après une période d'amnistie, les demandes du secteur de chemins de fer, et un nouvel triomphe de la gauche aux élections législatives de 1942, le gouvernement opta pour la répression et la censure des journaux. La répression du gouvernement atteignit son point culminant avec le massacre de plusieurs miniers réclamant une hausse de salaires dans le complexe minier Catavi-Siglo XX en décembre 1942 (voir annexe A $\mathrm{n}^{\circ} 73$ ). Ce massacre fut fortement dénoncé par l'opposition et surtout par le MNR qui réussit une grande convocation populaire. L'image des «barons de l'étain » fut fortement discréditée suite à cet événement et le gouvernement de Peñaranda fut affaibli.

À la fin de la guerre, des loges militaires furent formées telles que la loge «Santa Cruz » qui était connue publiquement et la loge «RADEPA » («Razón de Patria ») qui fonctionnait de manière sécrète. Ces loges n'avaient pas une idéologie ou un programme clairs et définis; elles s'appuyaient sur une obsessive moralisation $\mathrm{du}$ pays, la discipline stricte et la nécessité d'imposer de l'ordre. Elles étaient sympathisantes du modèle national-socialiste allemand. Entre septembre et décembre 1943, RADEPA et le MNR réalisèrent un accord secret, pendant que le gouvernement de Peñaranda était de plus en plus affaiblit. Un coup d'État fut réalisé en décembre 1943 par RADEPA et par le MNR. Gualberto Villarroel devint ainsi président du pays.

Le gouvernement de Villarroel arrivât en pleine Deuxième Guerre Mondiale où la polarisation produite par le conflit était très forte. Les sympathies qu'éprouvaient les membres du MNR et de RADEPA pour le national-socialisme allemand, contribuaient à donner l'image d'un gouvernement pronazi. Les Etats-Unis se nièrent à reconnaître le nouveau gouvernement. Après 6 mois de négociations, ils le reconnurent avec la condition que soient bannis du gouvernement Carlos Montenegro, Augusto Céspedes et tous les membres du MNR. La sortie du MNR fut temporaire, car les membres du parti revinrent peu de temps après et leur influence dans les décisions du gouvernement fut très importante.

Le nouveau gouvernement convoqua aux élections pour la formation d'une nouvelle Assemblée Constituante. 


\section{A) La Convention de 1944-1945: réformes dans la législation de la famille et obtention du suffrage féminin limité}

\section{a) Les réformes dans la législation de la famille}

Le MNR gagna la plupart des sièges dans les élections pour l'Assemblée Constituante, mais le PIR obtint aussi une représentation importante. La gauche dominait donc cette Assemblée. L'écrivain, intellectuel, et homme politique Franz Tamayo, fut élut président de l'Assemblée. Celle-ci se réunit en deux temps en août 1944 et en juillet 1945.

La Constitution de 1944-1945 ne modifia presque pas celle de 1938, elle ne fit que la compléter et l'élargir en particulier dans le domaine économique, social et familial.

Plusieurs réformes furent approuvées dans la législation de la famille qui amélioraient la condition des femmes: l'égalité des enfants devant la loi, l'autorisation de recherches en paternité, et l'égalité juridique des conjoints.

La question de l'égalité des enfants devant la loi et de l'autorisation de recherches en paternité fut un sujet assez débattu depuis janvier 1945. L'égalité des enfants devant la loi avait déjà été établie dans l'article 132 de la Constitution de 1938 Cependant, cet article fut interprété par la jurisprudence de telle manière qu'il concernait uniquement les enfants légitimes et naturels légalement reconnus pour l'égalité dans la succession héréditaire. Dans la Convention de 1945 il s'agissait donc d'établir l'égalité devant la loi de tous les enfants (légitimes, naturels, illégitimes, adultérins, sacrilèges, incestueux) légalement reconnus ou pas, leur accordant le droit à une succession héréditaire égale pour tous. Pour que cette mesure puisse être appliquée il fallait que l'État autorise les enquêtes en paternité. Ce projet fut débattu en juillet 1945 avec une certaine polémique. Pendant que les débats se tenaient dans l'Assemblée, des organisations féminines et catholiques telles que la «Acción Católica Boliviana », la Croix Rouge, la « Liga de la Moral», la « Unión de Madres Católicas », la « Acción Social del Apostolado », la « Beneficiencia de Señoras », le « Consejo Arquidiócesano de La Paz », et des associations regroupant des féministes telles que l'«Ateneo Femenino» et la «Federación de Sociedades Culturales Femeninas », envoyèrent une lettre aux députés de l'Assemblée en demandant que 
l'égalité des enfants devant la loi, mesure «monstrueuse », ne soit pas adoptée car elle constituerait « une atteinte contre la moralité de la famille et produirait le chaos le plus absolu ». Contrairement à la «LFEPA» (dont un des objectifs était l'obtention de l'égalité des enfants et l'autorisation des enquêtes en paternité) les membres de l'«Ateneo Femenino » et de la «Federación de Sociedades Culturales Femeninas » s'opposèrent à cette mesure avec les organisations catholiques du pays par des raisons religieuses et de «morale ». On n'a pas beaucoup d'informations sur la « Federación de Sociedades Culturales Femeninas ». Elle fut fondée au début des années 1940 avec le but d'harmoniser les actions des sociétés culturelles féminines. Les membres composant l'institution étaient organisés de la manière suivante : ${ }^{282}$

\section{Direction :}

Présidente : Emma Perez del Castillo de Carvajal (voir annexe A n¹2).

Vice-Présidente : Isabel B. v. de Haillot (voir annexe A n²0).

Secrétaire Générale : Emiliana Cortéz Villanueva.

Trésorière Générale : Germaine Haillot B.

Pro Secrétaire : Margot Silva.

\section{Représentations :}

«Ateneo Femenino»: María Luisa Sánchez Bustamante (voir annexe A n¹0). « Asociación Pro Paz » : Victoria Velasco de Tejada Fariñas.

«Asociación de Mujeres Universitarias »: María Josefa Saavedra (voir annexe A $\left.\mathrm{n}^{\circ} 61\right)$.

«Comité Cívico Departamental del Servicio Auxiliar Femenino de la Pre Militar »: Carmen Rosa Torrez Ballivián.

«Comité Femenino Pro Cultura »: María Tubert de Estebán (voir annexe A n62). «Centro Femenino de Cooperación Americana »: Marina Lijerón Baldivia (voir annexe $\mathrm{A} \mathrm{n}^{\circ} 63$ ).

\footnotetext{
${ }^{282}$ El Diario, 2 septembre 1944, La Paz. Hemeroteca de los Archivos del Congreso de La Paz, La PazBolivie.
} 


\section{Commissions :}

Assistance Sociale : Antonieta Suarez (voir annexe A n64) et Margarita Nuñez del Prado (voir annexe A n46).

Prévision Sociale : Angélica Panozo de Videa (voir annexe A nº65).

Presse et Propagande : María Virginia Estenssoro de Cusicanqui, Cristina de Zalles (voir annexe $\mathrm{A} \mathrm{n}^{\circ} 21$ ) et Yolanda Bedregal de Conitzer (voir annexe $\mathrm{A} \mathrm{n}^{\circ} 45$ ).

Art: Ada Carvajal Perez del Castillo.

Droits Civils et Politiques: Josefa Rocabado de Zeballos et Azunta Bozo de Bitrot.

Professeurs de Secondaire : Raquel Carmona (voir annexe A n ${ }^{\circ} 8$ ).

Professeurs de Primaire : María Frontaura Argandoña (voir annexe A nº6).

Comission Civique: Ana Rosa Tornero (voir annexe A nº7) et Elodia Ballivián de Ligerón (voir annexe $\mathrm{A} \mathrm{n}^{\circ} 12$ ).

Liens avec les ouvriers: Angélica Azcui (voir annexe A n²4)

Comme on peut le constater, l'«Ateneo Femenino» faisait partie de cette fédération avec une grande partie de ses membres à la tête de plusieurs charges: Emma Perez del Castillo de Carvajal (voir annexe A n²), María Luisa Sánchez Bustamante (voir annexe A $n^{\circ} 10$ ), Isabel B. v. de Haillot (voir annexe A $n^{\circ} 20$ ), Marina Lijerón Baldivia (voir annexe A n63), Cristina de Zalles (voir annexe A $\mathrm{n}^{\circ} 21$ ), Raquel Carmona (voir annexe A n58), María Frontaura Argandoña (voir annexe $A n^{\circ} 66$ ), Ana Rosa Tornero (voir annexe A n7), Elodia Ballivián de Ligerón (voir annexe $\mathrm{A} \mathrm{n}^{\circ} 12$ ), et Angélica Azcui (voir annexe $\mathrm{A} \mathrm{n}^{\circ} 24$ ). L’on retrouve également des anciens membres de la «LFEPA » tels que María Tubert de Estebán (voir annexe $\mathrm{A} \mathrm{n}^{\circ} 62$ ), Angélica Panozo de Videa (voir annexe A ${ }^{\circ} 65$ ), ce qui confirme l'idée que la «LFEPA » était une organisation très hétérogène car, malgré le fait qu'un des ses objectifs était l'obtention de l'égalité des enfants et de l'autorisation des enquêtes en paternité, ses anciens membres s'opposèrent à cette mesure quelques années plus tard au sein de la «Fédération de Sociétés Culturelles Féminines ». Cependant, malgré ces différences, la «Fédération», qui regroupait plusieurs organisations (dont toutes n'étaient pas féministes), adopta une structure similaire à celle des organisations des années 1930 avec des sections qui couvraient plusieurs champs sociaux: assistance sociale, prévision sociale, liens avec les ouvriers, ce qui montre que la «Fédération » essaya de créer des liens avec les secteurs populaires de 
la société, ainsi qu'avec les secteurs moyens consacrés à l'éducation (commissions de professeurs de primaire et de secondaire). On ne connaît pas quelles furent les actions de la «Fédération » à part l'envoi de cette lettre aux députés de l'Assemblée. L'on sait cependant que ses membres organisèrent une « Semaine Féminine » du 25 au 30 septembre 1944, à laquelle furent invités des hommes politiques et à laquelle participèrent les femmes ouvrières. Des conférences furent réalisées pendant cette semaine sur des thèmes tels que : Assistance Sociale, Hygiène, Salubrité, Prévision Sociale, travail de la femme, situation de la femme ouvrière, Universités Populaires, Littérature et Arts, Droits Civils et Politiques de la femme. Suivant l'exemple, des organisations des années 1930 comme la «LFEPA » ou l'«UMA », l'« Ateneo » rejoignit une fédération de sociétés féminines avec des objectifs plus étendus englobant des inquiétudes sociales pour les secteurs populaires de la société. Ces objectifs incluaient des stratégies de formation de liens et d'alliances avec les femmes ouvrières. Les temps avaient changé après la guerre et l' « Ateneo Femenino » trouva les moyens de s'y adapter. Cependant, ces nouveaux objectifs et stratégies ne changeaient pas la position de classe conservatrice de la plupart de ses membres et de ceux de la «Fédération » car elles s'opposèrent à l'égalité des enfants devant la loi et de l'autorisation de recherches en paternité.

Cette mesure fut finalement adoptée par la Convention à la fin du mois de juillet 1945. L'article 132 de la nouvelle Constitution instituait que les inégalités entre enfants n'était pas reconnues, que tous avaient les mêmes droits et devoirs et que les recherches en paternité étaient autorisées. Cet article reconnaissait en outre le mariage de fait entre les concubins après deux ans de vie conjointe ou après la naissance d'un enfant. Cette mesure était d'importance pour la Bolivie car la plus grande partie de la population du pays, composée d'indigènes, ne se mariait pas. Suivant leurs coutumes, les couples aymaras et quechuas vivaient ensemble sans légaliser leur union devant l'État. Cette mesure visait donc à légaliser et régulariser cette coutume très répandue dans le pays.

Par l'article 131 de la nouvelle Constitution, l'État se portait protecteur du mariage, de la famille et de la maternité. Ce même article établissait l'égalité juridique des conjoints. Par cet article, les conjoints avaient les mêmes droits et devoirs au sein du mariage. Les femmes recevaient ainsi tous les droits civils. Cependant, cette mesure devait être suivie d'une réforme dans le Code Civil pour qu'elle soit vraiment appliquée et le Code Civil bolivien ne fût réformé qu'en 1976. Ainsi, même si la 
Constitution de 1945 octroya les droits civils aux femmes, celles-ci durent attendre l'année 1976 pour que cette mesure soit véritablement mise en place. Malgré tout, la Convention de 1945 accorda aux femmes le suffrage limité.

\section{b) L'obtention du suffrage féminin limité}

La Convention de 1944-1945 débattit la question du suffrage féminin dans un climat différent de celui de 1938. D'abord, si en 1938 plusieurs féministes et femmes des villes comme La Paz, Santa Cruz et Oruro avaient demandé aux députés de l'Assemblée que le droit de vote leur soit accordé, ainsi qu'elles avaient réalisée des communiqués dans la radio en dénonçant les arguments tenus par les députés qui s'opposaient à la réforme, et avaient également publié des articles dans les journaux pour que la mesure soit enfin adoptée, en 1945 presque rien de cela n'eut lieu. On ne trouve pas d'articles rédigés par des femmes réclamant le droit de vote, ou encore d'articles mentionnant les actions des femmes dans ce but dans les journaux de l'époque. Au contraire, les articles qui parlent du sujet soulignent l'indifférence des femmes face à la question :

"Quelque chose qu'il faut souligner ici est la parfaite indifférence des femmes par rapport à la discussion d'hier, et celle qui eut lieu il y a longtemps dans les sessions de la commission législative. En dehors de peu, très peu d'avis, il n'y a pas eu de mouvement d'inquiétude féminine par la possibilité du vote qu'on essaye de leur donner. Et ce fait révélateur est une mesure des véritables aspirations féminines. En nous souvenant simplement de nouvelles reçues par câble, l'on peut assurer que dans d'autres pays où fut également discutée le cas de la citoyenneté pleine pour la femme, des sociétés féminines, des groupes suffragistes, des institutions culturelles féminines s'efforcèrent pour créer un climat propice afin d'atteindre ce droit. Ici ne s'est pas produit un mouvement du même type. $»^{283}$

\footnotetext{
283 «Algo que hay que subrayar es la perfecta indiferencia de la mujer frente a la discusión de ayer y a la que se efectuó hace tiempo, en las sesiones de la Comisión Legislativa. Fuera de pocas, poquísimas opiniones no ha habido un movimiento de inquietud femenina por la posibilidad del voto que se trata de darles. Y este hecho revelador es índice de las verdaderas aspiraciones femeninas. Recordando simplemente noticias cablegráficas, puede asegurarse que en otros países donde también se discutió el caso de la ciudadanía plena de la mujer, sociedades femeninas, agrupaciones sufragistas, instituciones culturales femeninas se esforzaron por crear un clima propicio para conseguir ese derecho. Aquí no se ha producido un movimiento de ese linaje. »El Diario, 14 juillet 1945, La Paz. Hemeroteca del Archivo del Congreso, La Paz-Bolivie.
} 
Un autre article va dans le même sens :

«Les femmes reçoivent cette réforme dans un environnement de pleine indifférence. On pourrait affirmer que la plupart d'entre elles à qui l'on veut bénéficier, persiste à se montrer à l'écart de ces inquiétudes. Les manifestations à faveur du suffrage ont été trop petites, insignifiantes. On aurait pu attendre, véritablement, une autre attitude, un mouvement d'enthousiaste adhésion au projet. Il n'y eut rien de cela. » ${ }^{284}$

Les modestes démonstrations de femmes en faveur de la réforme provenaient probablement de l'«Ateneo Femenino» et de l'«UMA», seules organisations féministes dont on connaît l'existence dans la première moitié des années 1940. Il semblerait que l'effervescence politique propice aux changements des années 1930 avait disparu dans les années 1940. On ignore les raisons de cette indifférence. Étaitelle liée à un certain pessimisme ressenti par les féministes en relation aux décisions à être prises dans l'Assemblée? Après tout, des campagnes et des actions pour l'obtention des droits civils et politiques avaient été réalisées en 1934 et 1938, sans résultats. Quoi qu'il en soit, à juger par les informations procurées par les journaux il semblerait que les organisations féministes connurent un certain effacement au début des années 1940.

Les discussions sur le suffrage féminin de la Convention de 1944-1945 ne se tinrent donc pas dans le même climat et ambiance que celles de 1938. D'ailleurs, l'ambiance de discussion entre les parlementaires fut beaucoup moins polémique qu'en 1938.

Lorsque le suffrage féminin fut discuté il s'agissait d'approuver, refuser ou modifier la formule proposée par la commission législative qui avait déjà discuté la question et avait décidé de proposer à la Convention la formule suivante : «Le droit de vote sera octroyé à la femme de nationalité bolivienne, qui ait fini l'instruction primaire et ait au moins 21 ans, pour la formation des Municipalités ». Le vote et la discussion se fit en deux temps : il s'agissait d'abord d'approuver ou de refuser cette formule, et si elle était approuvée il s'agirait de voter pour les projets modificateurs proposés par les députés.

\footnotetext{
284 «Reciben las mujeres esta reforma en un ambiente de plena indiferencia. Podría afirmarse que la mayoría de ellas, a quienes precisamente se quiere beneficiar, persiste en mostrarse marginada de estas inquietudes. Las manifestaciones a favor del sufragio han sido demasiado pequeñas, insignificantes. Podía, en verdad, haberse esperado otra actitud, un movimiento de entusiasta adhesión al proyecto. No hubo pues, nada de eso. » Idem.
} 
La plupart des parlementaires qui s'exprimèrent se prononcèrent à faveur du suffrage féminin. En effet sur 27 parlementaires qui s'exprimèrent dans les débats sur la question, 19 se prononcèrent à faveur du suffrage féminin et seulement 8 contre. Il y avait donc un consensus beaucoup plus important au sein de l'Assemblée par rapport à ce sujet, que dans la Convention de 1938.

Plusieurs furent les arguments utilisés pour défendre le suffrage féminin. La participation des femmes dans la Guerre du Chaco prit une signification plus importante à cette époque, surtout dans le contexte de la Deuxième Guerre Mondiale où les députés étaient conscients du rôle joué par les femmes dans celle-ci. Des députés tels que Otero Reiche firent appel à la contribution des femmes à l'effort de guerre tant en Europe comme en Bolivie pendant la Guerre du Chaco pour arguer qu'il n'y avait pas de raison de leur nier le droit de vote :

« Et si elle est un facteur social pondérable et efficace, si sur ce point personne ne peut discuter déjà, après son contingent social mis au service de la patrie dans la dernière guerre mondiale, si nous avons vérifié cette même pondération dans la guerre contre le Paraguay, je ne vois pas pourquoi on pourrait lui nier ses droits politiques... ${ }^{285}$

Le député Tovar va dans le même sens en arguant que les femmes avaient joué et pouvaient jouer un rôle prépondérant en cas de guerre :

« ... Pendant la guerre avec le Paraguay, la femme souffrit les calamités inhérentes au conflit et fut utilisée par les services d'arrière garde, alors qu'il y eut des hommes qui désertèrent abandonnant le pays par peur, en évitant de participer au moment du danger national, et, nous les voyons, malgré cela en train de légiférer confortablement... Nous travaillons pour l'avenir, la preuve de cela est que la femme reçoit l'enseignement pré militaire. Nous sommes en train de la former pour profiter de ses conditions spéciales, pour l'employer comme le facteur primordial de la défense nationale. Il est logique qu'elle n'accède pas à la caserne, car les lois militaires la considèrent inhabilitée pour ce service, cependant on ne méconnaît pas sa potentialité adaptative pour le combat et les services spéciaux exigés par un conflit de guerre, assurant ainsi la potentialité militaire de l'État. » ${ }^{286}$

\footnotetext{
${ }^{285}$ «Y si es un factor social ponderable y eficiente, si sobre este punto nadie puede discutir ya después de su contingente social puesto al servicio de la patria en la última guerra mundial, si nosotros comprobamos estas misma ponderación en la guerra contra el Paraguay, no creo por qué se le puede negar sus derechos políticos... » Redactor de 1945, t. I (sesión extraordinaria), La Paz. Archivo del Congreso de La Paz, La Paz - Bolivie.

286 «...Durante la guerra con el Paraguay, la mujer sufrió las calamidades inherentes a la contienda y fue utilizada en los servicios de retaguardia, pero han habido hombres que desertaron abandonando el país por miedo, rehuyendo su concurso en el momento de peligro nacional y, los vemos, a pesar de ello cómodamente legislando...Estamos trabajando para el porvenir, prueba de ello es que la mujer
} 
En effet, le Ministère de la Défense établit par le décret-loi du 26 juillet 1943, le service militaire obligatoire pour toutes les jeunes femmes étudiantes afin de les former comme un groupe auxiliaire de l'Armée. Il s'agissait de former des « Brigades Féminines » en cas de guerre : elles devaient être chargées de la conduction de voitures, des services de communication, de porter secours et assistance, et des services auxiliaires d'aviation. Des cours de pilotage pour femmes furent organisés dans cet objectif. Le Service Auxiliaire féminin avait été créé par Etelvina Villanueva (voir annexe A n ${ }^{\circ} 43$ ), ancienne présidente de la « LFEPA».

La présence des femmes dans le marché du travail et dans divers secteurs de l'économie était considérée également comme une raison inattaquable pour accorder le droit de vote aux femmes. La présence des femmes dans le marché du travail n'était plus considérée comme un phénomène exceptionnel et anormal lié à la guerre $\mathrm{du}$ Chaco. Comme l'affirme Marcela Revollo Quiroga : «A diferencia de los argumentos propuestos en 1938, esta participación laboral dejó de ser considerada como una usurpación de los espacios de trabajo masculinos para pasar a ser vista como un aporte al desarrollo, la modernización y un avance en la formación de las mujeres. En este sentido, es posible advertir un reconocimiento a la participación y aporte social de ellas, además de una valoración más allá de su rol de madres y esposas. » ${ }^{287}$ C'est ce que laisse entrevoir le parlementaire Bravo :

« Il y a dans ce pays des milliers de femmes qui dirigent leurs activités dans des délicates fonctions. Ainsi, nous avons les professeures d'écoles, les employées de bureaux publics et privés. Il y a beaucoup de femmes avec un haut degré de compréhension de leurs droits et devoirs et qui contribuent de manière brillante dans les arts et les lettres. Alors il n'est pas possible de leur nier ce droit, afin qu'elles contribuent à la formation des Pouvoirs Publics avec les lumières de leur intellect en faisant usage de cette liberté. ${ }^{288}$

\footnotetext{
boliviana, recibe enseñanza pre militar. La estamos capacitando aprovechando de sus condiciones especiales, para emplearla en el factor primordial de la defensa nacional. Es lógico que no entre al cuartel, porque las leyes militares la consideran inhábil para dicho servicio, empero, no se desconoce su potencialidad adaptativa para el combate y servicios especiales que requiera una contienda bélica, asegurando así, la potencialidad militar del Estado. » Idem.

${ }^{287}$ REVOLLO QUIROGA, Marcela, Mujeres bajo prueba. La participación electoral de las mujeres antes del voto universal (1939 - 1949), Eureka Ediciones, La Paz - Bolivia, 2001.

288 «Existen en este país millares de mujeres que dirigen sus actividades en delicadas funciones. Así tenemos a las maestras de escuelas; así tenemos a las empleadas de oficinas públicas y particulares. Aún existen demasiadas mujeres con un alto espíritu de comprensión de sus derechos y deberes y que contribuyen brillantemente en las artes y en las letras. Entonces no es posible negarles este derecho, para que con luces de su intelecto contribuyan a la formación de los Poderes Públicos, en uso de esa libertad. » Idem.
} 
D’après le député Trigo Paz, la présence des femmes dans la sphère publique et dans le marché du travail était un fait indéniable qui devait être pris en compte :

«En Bolivie, la participation de la femme dans la vie active est un fait, nous le savons tous et nous le reconnaissons, c'est ainsi qu'aujourd'hui la femme est à l'Université, dans l'exercice professionnel, dans les bureaux publics, dans les sociétés particulières, dans l'atelier et dans la mine, et dans toutes les activités qui constituent la vie même de la nation. Alors, si cela est ainsi, lui nier sa participation à la formation des Pouvoirs de l'État serait vraiment injuste. $\gg{ }^{289}$

Pour le député Morales Carlos, marxiste, le vote devait être octroyé aux secteurs de la population qui jouaient un rôle important dans la production. De par leur participation à l'économie du pays, les femmes devaient obtenir le suffrage :

« D'autre part, le vote ne se donne pas en fonction sentimentale, mais en fonction de la production ; car lorsque le vote est octroyé, c'est pour que les classes qui occupent un rôle déterminé dans la production, aient le droit de faire prévaloir la part qui leur correspond dans la distribution. Dans ce sens, dans le sens éminemment économique, on doit accorder le droit de vote à la femme... » ${ }^{290}$

Les avances des pays par rapport au suffrage féminin furent très souvent citées par les parlementaires comme la preuve que la Bolivie devait rentrer dans le groupe de nations civilisées ayant accordé le suffrage féminin, et que de toutes les façons, tôt ou tard ce droit allait devoir leur être octroyé. Cet argument fut utilisé avec beaucoup plus de fréquence et avec beaucoup plus de poids qu'en 1938, car pour 1944, beaucoup plus de pays avaient accordé le droit de vote aux femmes.

Ainsi, le député Mendoza López ${ }^{291}$ fait référence à la France qui venait d'accorder le droit de vote aux femmes :

« On argue que dans notre environnement la femme n'est pas suffisamment évoluée pour prendre part aux activités politiques et qu'elle n'a pas la maturité de la femme saxonne ou de la femme

\footnotetext{
289 «En Bolivia, la participación de la mujer en la vida activa es un hecho; todos lo sabemos y lo reconocemos y así hoy tenemos a la mujer en la Universidad, en el ejercicio profesional, en las oficinas públicas, en entidades particulares, en el taller y en la mina, y en todas las actividades que constituyen la vida misma de la nación. Entonces, si esto es así, negarle su participación en la formación de los Poderes del Estado sería verdaderamente injusto. » Idem.

290 « Por otra parte, el voto no se da en función sentimental, sino en función de la producción; porque cuando se concede un voto, es para que las clases que ocupan un rol determinado en la producción, tengan derecho a hacer prevalecer la parte que les corresponde dentro de la distribución. En este sentido, en el sentido eminentemente económico, se debe conceder el voto a la mujer...» Idem.

${ }^{291}$ Alberto Mendoza López avait été le dirigeant du Parti Socialiste et du Parti Travailliste de préguerre.
} 
d'autres pays. Cela même était argué en France, mais, hier on a annoncé que les femmes françaises prendront partie dans les activités politiques qui vont déterminer la marche future de la quatrième république française probablement, ou de la survivance de la troisième république. Alors ce problème est réglé en France. ${ }^{292}$

Le député Trigo Paz s'attarde à citer les constitutions de pays modernes qui accordent le suffrage féminin:

« En plus, monsieur le président, je citerai, comme une simple référence, que la plupart des constitutions modernes acceptent et accordent le vote féminin dans l'organisation des Pouvoirs Publics. Ainsi par exemple, l'accordent, sans restrictions, les constitutions de l'Autriche, l'Allemagne, la Bavière, l'Espagne, la Finlande, la Lettonie, la Pologne, la Russie, la Norvège, le Danemark, la Tchécoslovaquie, l'Angleterre, les Etats-Unis d'Amérique du Nord, l'Équateur, et le Chili, comme on le sait, accorde le vote municipal; la Constitution uruguayenne l'admet pourvu qu'il soit approuvé par les deux tiers de leur Représentation Nationale. ${ }^{293}$

De plus, la Bolivie ne devait pas tarder à octroyer le suffrage féminin car elle s'était engagée à accorder les droits civils et politiques aux femmes dans la Conférence de Chapultepec tenue au Mexique en février 1945 $5^{294}$. C'est ce que rappelle le parlementaire Tovar :

« Il existe un compromis international à ce sujet, je ne pense pas que la Bolivie essaie de le violer, je parle de l'Acte de Chapultepec, que notre pays a signé, en s'engageant avec les autres États signataires, à faire effectives ses recommandations, se trouvant parmi elles, dans une place prédominante, le point 31 concernant les droits civils et politiques de la femme, que la Nation sœur du Brésil vient d'accomplir. De plus, le Gouvernement démocrate de la Grande Bretagne a fait un pas en avant, en incorporant la femme dans les

\footnotetext{
292 «Se arguye que en nuestro ambiente la mujer no está suficientemente evolucionada para tomar parte en las actividades políticas y que no tiene la madurez como la mujer sajona o la mujer de otros pueblos. Esto mismo se argüía en Francia, mas, ayer se ha anunciado que las mujeres francesas tomarán parte en las actividades políticas que han de determinar la marcha futura de la cuarta república francesa, seguramente, o la superexistencia de la tercera república. Entonces este problema ha quedado liquidado en Francia. » Idem.

293 « Además, señor Presidente, citaré, como una simple referencia, que la mayoría de las constituciones modernas, aceptan y otorgan el voto femenino en la organización de los Poderes Públicos. Así por ejemplo, las otorgan, sin restricción, las constituciones de Austria, Alemania, Baviera, España, Finlandia, Letonia, Polonia, Rusia, Noruega, Dinamarca, Checoslovaquia, Inglaterra, Estados Unidos de Norte América, Ecuador y Chile, como se sabe, da el voto municipal; la Constitución uruguaya lo admite siempre que lo apruebe los dos tercios de su Representación Nacional.» Idem.

${ }^{294}$ El Diario, 9 février 1945, La Paz. Hemeroteca del Archivo del Congreso, La Paz - Bolivie.
} 
services de Police, avec les mêmes attributions et obligations que pour les policiers hommes. ${ }^{295}$

Le gouvernement de Gualberto Villarroel était conçu par une grande partie des parlementaires comme un moment révolutionnaire. Les décisions prises dans l'Assemblée devaient obéir au moment révolutionnaire qu'ils étaient en train de vivre. Le suffrage féminin était compris comme une mesure révolutionnaire qui devait être prise dans cette Assemblée. C'est ce qu'exprime le député Arana Peredo:

«Pourquoi considérer que la femme suffragiste va inverser le rôle matrimonial en allant aux élections ou au Parlement? Non, messieurs. Nous voulons faire usage d'un critère plus radical. Ce Parlement est le produit d'une révolution idéologique, non seulement d'une révolution de fait. Comme fins de la révolution, se trouvent des postulats que, s'ils ne sont pas approuvés par les nations du Continent, la Bolivie qui s'est caractérisée par le pessimisme avec lequel on juge notre situation politique, la Bolivie qui va à l'avant-garde parmi les nations les plus avancées, peut faire ce pas révolutionnaire. » 296

Pour le parlementaire Mendoza López, le sens révolutionnaire de la mesure concernait le fait d'élargir la participation politique à une plus grande partie de la population :

«...(que) cela se fasse aussi pour (l'aspect) féminin, par des raisons révolutionnaires, Monsieur le Président, profondément révolutionnaires. Et quelles sont ces raisons révolutionnaires ? Ces raisons révolutionnaires résident dans le fait de donner participation pour délibérer sur les destins du pays au plus grand pourcentage d'éléments qui puissent délibérer. ${ }^{297}$

\footnotetext{
295 «Existe un compromiso internacional al respecto, no creo que Bolivia trate de violarlo, me refiero al Acta de Chapultepec, que nuestro país ha suscrito, comprometiéndose conjuntamente con los otros Estados signatarios, hacer efectivas sus recomendaciones, estando entre ellas, en lugar predominante, el punto 31 concerniente a los derechos civiles y políticos de la mujer, a la que la Nación hermana del Brasil acaba de dar cumplimiento. Además, el Gobierno demócrata de la Gran Bretaña, ha dado un paso más adelante, me refiero a que la mujer ha sido incorporada a los servicios de Policía, con las mismas atribuciones y obligaciones que el policía Hombre. » Idem.

296 « ¿Por qué considerar que la mujer sufragista ha de invertir el papel matrimonial, yendo a las elecciones o al Parlamento? No, señores. Nosotros queremos ir con un criterio más radical. Este Parlamento es el producto de una revolución ideológica, no solamente de una revolución de hecho. Como fines de la revolución, están los postulados que si no están aprobados en las naciones del Continente; Bolivia que se ha caracterizado por el pesimismo con que juzgamos nuestra situación política, Bolivia que va a la vanguardia entre las naciones más avanzadas, puede dar este paso revolucionario. » Idem.

297 «...(que) se lo haga también en el (aspecto) femenino, por razones revolucionarias, Sr. Presidente, hondamente revolucionarias. ¿Y cuáles son estas razones revolucionarias? Estas razones revolucionarias radican en dar participación para deliberar sobre los destinos del país, al mayor porcentaje de elementos que pueda deliberar. » Idem.
} 
Une grande partie des parlementaires qui défendaient le suffrage féminin, considéraient que la formule proposée par la Commission législative était trop restreinte en voulant accorder le droit de vote uniquement aux femmes qui avaient fini l'instruction primaire d'abord, et ensuite en limitant le suffrage féminin aux élections municipales. Ainsi, plusieurs parlementaires proposèrent des nouvelles formules en proposant que le droit de vote soit accordé aux femmes qui savaient lire et écrire dans le cadre des élections municipales. D'autres proposèrent encore que le droit de vote soit accordé aux femmes qui savaient lire et écrire dans les élections nationales, c'està-dire, dans les mêmes conditions que les hommes.

Le député Pardo considérait que le projet était trop restreint car il concernait uniquement le droit d'élire et pas le droit d'être élue, et que restreindre le droit uniquement aux femmes qui avaient fini l'instruction primaire était injuste car cela excluait des femmes qui enseignaient comme professeures sans pour autant avoir assisté à l'école primaire :

« Je voudrais ne pas être dans l'erreur, mais comme l'a déjà remarqué un représentant, la réforme constitutionnelle telle qu'elle est proposée par la Commission Législative, est trop restreinte dans le droit qu'est en train d'être reconnu à la femme pour prendre part dans la vie civile dans sa qualité de citoyenne (...) Ici on ne parle pas du droit d'être élue. De plus, je me permets de remarquer une autre légère déficience dans la rédaction de cet article. Apparemment, l'intention est très bonne : accorder seulement le droit d'être électrice à la femme qui ait atteint le cycle primaire et qui ait 21 ans, mais il arrive dans la pratique, et je peux l'attester, qu'il y a des femmes qui n'ont pas fini le cycle d'instruction primaire, et malgré cette circonstance, elles sont professeures. Ce cas arrive monsieur le Président, et il arrive car la femme, avec le noble désir de se dépasser, a réussi à se former, de telle manière qu'actuellement elle enseigne dans les écoles. » ${ }^{298}$

Plusieurs parlementaires considéraient qu'accorder le droit de vote uniquement aux femmes qui avaient fini l'instruction primaire était créer un «privilège » pour

\footnotetext{
298 «Quisiera no estar equivocado, pero tal como propone la Comisión Legislativa la reforma constitucional, y como ya lo hizo notar algún $\mathrm{H}$. Representante, es demasiado restrictivo el derecho que se está reconociendo a la mujer para tomar parte en la vida civil en su calidad de ciudadana. (...) Aquí no se está hablando del derecho de ser elegida. Además, me permito hacer notar otra pequeña defíciencia en la redacción de ese artículo. Aparentemente, la intención es muy buena: otorgar solamente el derecho de ser electora a la mujer que haya cumplido el ciclo primario y tenga 21 años de edad, pero ocurre en la práctica, y esto me consta particularmente, que hay mujeres que no han vencido el ciclo de instrucción primaria, y sin embargo de tal circunstancia, son maestras. Ocurre este caso Sr. Presidente, y ocurre por razón de que la mujer, en el noble afán de superarse, ha llegado a capacitarse de tal manera, que actualmente enseña en las escuelas. » Idem.
} 
certaines en excluant injustement les femmes travailleuses. Il fallait donc élargir la proposition. C'est ce qu'exprime le député Arce Armando :

« Je ne pense pas que l'initiative de l'Honorable député pour Tarija qui accorde la citoyenneté à la femme, soit retenue, car elle contient des privilèges injustes, parce que le projet concerne uniquement les femmes qui ont assisté aux cours d'instruction primaire. On dit que la femme va à l'Université, aux charges publiques et privées, ce qui est très respectable; mais on oublie la femme du peuple qui vit chez elle en s'occupant de son mari, de ses enfants, de ses parents et qui porte réellement tout le poids du foyer, elle doit avoir aussi les mêmes droits. La pauvreté n'est pas une raison pour qu'on accorde ce privilège seulement aux femmes qui arrivent à l'Université. »" 299

Le député Morales Carlos s'exprime dans le même sens :

« Nous qui nous appelons révolutionnaires, on ne peut pas continuer à maintenir une contradiction de systèmes, contradiction qui se manifeste ici, car la majorité du peuple bolivien, peuple producteur, est en contradiction avec nos systèmes juridiques, qui ne donnent pas de participation aux majorités dans la formation des pouvoirs publics; et les majorités populaires, les majorités travailleuses, ne sont pas seulement les hommes, mais aussi les femmes. Alors, si nous voulons faire une véritable révolution, nous ne devons pas juger avec un critère étroit pour donner le droit de vote uniquement aux femmes qui ont fini l'instruction primaire, secondaire ou universitaire, car dans ce cas on ne donnerait pas le vote à la femme bolivienne, mais à une petite minorité. » ${ }^{300}$

La formule proposée n'était pas uniquement trop restreinte en ce qu'elle concernait une minorité de femmes, mais aussi en ce qu'elle concernait uniquement les élections municipales. Les femmes devaient avoir le droit de vote pour les élections nationales.

\footnotetext{
${ }^{299}$ « No creo que prospere la iniciativa del H. Convencional por Tarija, que proporciona ciudadanía a la mujer, pues contiene privilegios injustos, porque el proyecto solo se hace extensivo a las mujeres que han cursado la instrucción primaria. Se dice que la mujer va a la Universidad, a los cargos públicos y privados, lo que es muy respetable; pero se olvida de la mujer del pueblo que vive en su casa atendiendo a su marido y sus hijos, a sus padres y llevan realmente el peso de todo el hogar, debe tener también iguales derechos. La pobreza no es razón alguna para que se conceda ese privilegio sólo a las mujeres que llegan a la Universidad. » Idem.

300 « Nosotros que nos llamamos revolucionarios, no podemos seguir manteniendo una contradicción de sistemas, contradicción que se manifiesta aquí, ya que la gran mayoría del pueblo boliviano, pueblo productor, está en contradicción con nuestros sistemas jurídicos, que no dan participación a las mayorías en la formación de los poderes públicos; y las mayorías populares, las mayorías trabajadoras, no son solamente los hombres, sino también las mujeres. Entonces, si queremos hacer una verdadera revolución, no tenemos que juzgar con criterio estrecho, para dar el derecho de voto sólo a las mujeres que han cursado la instrucción primaria, secundaria o universitaria, porque así estaríamos dando voto no a la mujer boliviana, sino a una pequeña minoría. » Idem.
} 
Comme l'affirme le député Arana Peredo :

« Dans ce concept je ne vois pas de raison pour que soit restreint le droit politique de la femme seulement au suffrage dans les élections municipales, dans le projet de la formule rédigée par la Commission Législative. Quelle différence il y a t-il entre les élections municipales et les élections pour les représentants législatifs ou mandataires ? Quelle supériorité intellectuelle est requise pour faire cette différentiation, pour limiter ce droit à la femme? $»^{301}$

Le député Ayala Gamboa va dans le même sens en soulignant l'effet positif que signifierait la présence des femmes dans le Parlement :

«Le projet qui réduit simplement le vote de la femme seulement pour la formation des municipalités, est trop restreint, car la femme n'exercera pas son droit de suffrage comme un moment de distraction ou comme un acte d'apparence, mais avec le désir de contribuer à la formation des Pouvoirs Publics pour obtenir des lois pratiques et intelligentes, car, le jour où l'on verra la femme bolivienne ici dans le Parlement, sans doute qu'avec sa participation, les lois seront sages et intelligentes, comme par exemple les lois protectrices des enfants et d'autres de caractère social. ${ }^{302}$

Cependant, il y avait des députés qui tout en étant à faveur du suffrage féminin considéraient qu'il devait être limité car il s'agirait de réaliser un « essai » pour voir si les femmes étaient suffisamment capables d'exercer le droit de vote. Dans ce sens, si l'épreuve était positive ils pourraient considérer ultérieurement l'élargissement du suffrage féminin aux élections nationales. Comme l'exprime Marcela Revollo Quiroga, il s'agissait bien de faire un « test »: « Era una ciudadanía parcial restringida al gobierno municipal, y de prueba porque exponía a las mujeres al examen de su capacidad política, y dejaba abierta la posibilidad de que fuera revertida si ellas no pasaban. » Accorder le droit de vote aux femmes uniquement pour les municipalités ne représenterait pas un danger car les Municipalités n’étaient que des établissements

\footnotetext{
301 « En este concepto yo no veo razón para que se restrinja en el proyecto de la fórmula redactada por la Comisión Legislativa, el derecho político de la mujer solamente al sufragio en las elecciones municipales. Qué diferencia hay entre las elecciones municipales y las elecciones para representantes? Legislativos o de Mandatarios? ¿Qué superioridad intelectual se necesita, para hacer esta diferenciación, para limitar este derecho a la mujer? » Idem.

302 «El proyecto que reduce simplemente el voto de la mujer para solo la formación de las municipalidades, es muy restringido, pues la mujer no ejercitará su derecho de sufragio como un momento de distracción o como un acto de apariencia, sino con el deseo de contribuir a la formación de los Poderes Públicos para obtener leyes prácticas e inteligentes, pues, el día que veamos aquí en el Parlamento a la mujer boliviana, indudablemente que, con su concurrencia, las leyes serán sabias e inteligentes, como por ejemplo leyes protectoras de los niños y otras de carácter social. » Idem.
} 
d'administration et non de pouvoir. C'est ce qui laisse entrevoir l'intervention du parlementaire Bravo :

« Ce dernier droit semblera inopportun pour beaucoup, irréalisable et prématuré, mais il est nécessaire que ce droit soit circonscrit à son intervention dans les Municipalités. Les Municipalités ne signifient pas des organismes appartenant aux Pouvoirs de l'État. Elles sont simplement des noyaux d'Administration. Dans d'autres endroits, le droit de citoyenneté n'est pas nécessaire pour participer à la formation des Municipalités. $»^{303}$

En ce qui concerne les arguments contre le suffrage féminin, ceux qui s'y opposaient exprimèrent la même inquiétude que les parlementaires de 1938, à savoir, que les femmes allaient laisser de côté leurs devoirs au sein de leurs familles et de leurs foyers. Comme en 1938, le rôle de la femme au sein du foyer et de la famille fut exalté. C'est ce que démontre le parlementaire Fernández:

« Je me trouve alarmé avec le projet de réforme qui se discute car je considère -avec le pardon des messieurs défenseurs du projet - qu'il s'agit d'un attentat contre la famille qui est la pierre angulaire de la patrie...

H. Tovar.- Je demande à l'Honorable député, la citoyenneté de l'individu est aussi un attentat contre la famille?

H. Fernández.- Je dis tout simplement que la famille est la pierre angulaire de la Patrie, et celle qui dirige la famille, qui modèle l'âme des enfants est la femme. Elle a une mission plus importante que l'homme dans la vie, celle de créer l'âme des enfants, l'âme des citoyens qui doivent diriger la patrie. Si on la fait sortir de son foyer et nous l'emmenons aux luttes mesquines de la politique, qu'arrivera-t-il avec ce foyer et avec l'éducation des enfants ? Il est très probable que mon avis soit discordant ou un peu étrange dans cette matière, mais je crois que la vérité m'assiste quant à la consolidation de la famille. $\gg{ }^{304}$

\footnotetext{
303 «Este derecho último, para muchos parecerá inoportuno, impracticable y prematuro, pero es necesario dejar constancia de que este derecho está circunscrito a su intervención en las Municipalidades. Las Municipalidades no significan organismos pertenecientes a los Poderes del Estado. Simplemente son núcleos de Administración. En otras partes inclusive, no es necesario el derecho de ciudadanía para concurrir a la formación de las Municipalidades. » Idem.

304 «Yo me encuentro alarmado con el proyecto de reforma que se está discutiendo porque considero con perdón de los señores defensores del proyecto- que es un atentado contra la familia que es la piedra angular de la patria...

H. Tovar.- Pregunto al H. Diputado: ¿la ciudadanía del individuo es también un atentado contra la familia?

H. Fernández.- Yo digo simplemente que la familia es la piedra angular de la Patria, y quien dirige la familia, quien hace el alma de los hijos es la mujer. Tiene una misión más importante que el hombre en la vida, cual es la de crear el alma de los hijos, el alma de los ciudadanos que deben dirigir la patria. Si sacamos a la mujer de su hogar y la llevamos a las luchas mezquinas de la política, ¿qué sucederá de ese hogar y de la educación de los hijos? Es muy posible que mis opiniones sean un poco discordantes o extrañas en esta materia, pero creo que me asiste la verdad en cuanto a la consolidación de la familia.» Idem.
} 
C'est ce qu'exprime de même le député Finot ${ }^{305}$ :

«Et je vais donner un exemple qui a sûrement toute la force et l'efficacité. Un homme qui travaille dans l'usine, depuis 6 ou 8 heures $\mathrm{du}$ matin, retourne chez lui, avec l'intention de trouver du repos, espérant que sa femme lui ait préparé la nourriture et il se trouve avec la triste réalité que sa compagne du foyer, est dans un comité politique, discutant sur les affaires d'importance de l'État. Sauf si l'on créé des restaurants populaires, où nous devrions tous aller déjeuner, ou manger, si l'on multiplie les crèches en grandes quantités pour que les enfants des prolétaires et des travailleurs soient reçus, pendant que la femme délibère, comme je le dis, autour d'importantes affaires politiques. (Applaudissements). $»^{306}$

La religion fut également utilisée comme argument pour prouver que les femmes, conservatrices dans leur majorité, voteraient pour les forces cléricales en bloquant tout effort révolutionnaire dans le pays. Cet argument fut utilisé par le parlementaire Finot :

« Malheureusement, Monsieur le Président et messieurs les députés, la femme en Bolivie est dans les mains du cléricalisme des Actions Catholiques, qui sont parfaitement organisées dans le territoire de la Bolivie et composées d'un groupe select de dames et de demoiselles et de jeunes femmes cultivées, et cela j'ai pu le constater en faisant une enquête sur elles. »»

Le député Carvajal s'exprime dans le même sens :

« Je me permets de demander à l'honorable collègue, s'il ne pense pas que la femme, par tradition et par tempérament, est conservatrice et s'il ne pense pas que cet environnement de conservatisme de l'élément féminin, viendrait au moment du débat politique à être un jouet, un instrument dans les mains d'un certain secteur d'influence, par

\footnotetext{
${ }^{305}$ Enrique Finot était un journaliste, historien, pédagogue et diplomate bolivien né à Santa Cruz. Il fut le fondateur du journal El País, et collabora également dans les journaux El Diario et El Fígaro de La Paz, et El Oriente de Santa Cruz. Il fut également le directeur de la revue pédagogique La Educación Moderna. En tant que diplomate, il participa aux négociations frontalières entre la Bolivie et le Paraguay après la guerre du Chaco.

${ }^{306}$ «Y voy a poner por ejemplo que seguramente tiene toda la fuerza y eficacia. Un hombre que trabaja en la fábrica, desde las 6 u 8 de la mañana, regresa a su hogar, con el ánimo de encontrar descanso y reposo, esperando que su mujer le haya preparado el alimento y se encuentra con la triste realidad, que su compañera de hogar, está en un comité político, sesionando sobre las altas cuestiones del Estado. A no ser que creemos restaurantes populares, donde todos tengamos que ir a almorzar, a comer o en su defecto, tengamos que multiplicar las Casas Cuna en grandes cantidades para que los hijos de los proletarios y trabajadores, estén en ellas, mientras la madre delibere, como digo, en torno a las altas cuestiones políticas. (Aplausos). » Idem.

307 « Desgraciadamente, H. Sr. Presidente, y HH. Convencionales, la mujer en Bolivia está en manos del clericalismo de las Acciones Católicas, que están perfectamente organizadas en el territorio de Bolivia y constituidas por un selecto grupo de señoras y de señoritas y muchachas cultas y esto lo he podido constatar haciendo una encuesta sobre ellas. » Idem.
} 
exemple, le secteur clérical. Alors, ne serait-il pas une stagnation de la Révolution accorder le suffrage féminin ? ${ }^{308}$

Concernant les avances sur les droits politiques des femmes dans les autres pays, les parlementaires s'opposant au suffrage féminin arguèrent que la Bolivie ne se trouvait pas dans les mêmes conditions que ces pays, et qu'il fallait prendre en compte les réalités du pays pour prendre des décisions à ce sujet. Avec un certain sens de l'humour le député Fernández s'exprima ainsi sur la question :

«L'on dit aussi que ces droits politiques leur sont accordés dans des pays civilisés comme l'Angleterre et l'Allemagne, la Yougoslavie, etc., mais la Bolivie n'est pas dans la même situation que l'Allemagne et l'Angleterre.

H. Tovar.- Si nous ne sommes pas dans un pays civilisé, alors vous êtes un barbare. (Sifflets de la barre).

H. Fernández .- Vous ne m'avez pas compris, Monsieur le député. J'ai dit que notre pays n'est pas dans les mêmes conditions que ces pays et vous n'allez pas croire que l'on est supérieurs.

H. Tovar.- Je ne suis pas un caméléon, qui légifère en pensant à l'odeur de la nourriture. (Sifflets de la barre).

H. Fernández .- Je vais vous répondre, Monsieur le député. Je vais dans ce sens. J'ai entendu l'avis d'un député qui disait: (Il lit l'avis sur le travail du Ministre de Travail aux Etats-Unis, Madame Perkins). Effectivement, il est très probable que Madame Perkins, ait réussi, grâce à son intelligence, une augmentation des salaires pour les ouvriers, mais pas parce qu'elle ait réussi cela aux Etats-Unis, nous allons donner le vote à tout l'élément féminin formé ou non formé dans le pays. L'on disait aussi que la fille du Commissaire de la Russie, Molotoff, s'était distinguée en tant que parachutiste...

H. Tovar.- Les expressions que vous m'attribuez d'avoir exprimé dans la Commission Législative, ne sont pas les miennes monsieur le député...

H. Président.- On est priés de ne pas interrompre.

H. Fernández.- Je ne parle pas de vous, Monsieur le député, sinon d'un autre Représentant. On disait que la fille de Molotoff s'était distinguée comme une grande parachutiste. Je ne crois pas que cela soit un motif prématuré pour que l'on donne le vote politique aux femmes de la Bolivie, qui ne sont pas des parachutistes. (Rires dans les tribunes et dans la barre.) Que Madame Chanh Kai Shek, était une dame de grandes conditions intellectuelles, cela dans la Chine. » 309

\footnotetext{
308 « Me permito preguntar al H. colega, si no piensa que la mujer, por tradición y temperamento, es conservadora y si no piensa que ese ambiente de conservadurismo del elemento femenino, vendria en el momento de un debate político, a ser un juguete, un instrumento en manos de cierto sector de influencia, por el ejemplo el sector clerical. Entonces, no sería un estancamiento de la Revolución conceder el voto femenino?» Idem.

309 « También se dice que se le otorgan estos derechos políticos en países civilizados como Inglaterra, Alemania, Yugoslavia, etc., pero Bolivia no está en la misma situación de Alemania e Inglaterra. H. Tovar.- Si no estamos en un país civilizado, usted es un bárbaro. (Silbidos de la barra).
} 
Les arguments pour démontrer que le nombre de femmes éduquées et cultivées qui mériteraient le droit de vote en Bolivie était infime allaient dans le même sens : prouver que la Bolivie n'était pas dans les mêmes conditions que les autres pays. Finot exprime cet argument ainsi:

« Des mentalités intellectuelles parmi les femmes boliviennes, nous en avons trouvé en grandes quantités, qui ont donné, pour le dire ainsi, la mesure de la valeur intellectuelle de la femme depuis les héroïnes de la Coronilla (voir annexe A n ${ }^{\circ 35)}$, depuis Juana Azurduy de Padilla (voir annexe A $n^{\circ} 36$ ), Adela Zamudio (voir annexe $A n^{\circ} 28$ ), plusieurs poétesses actuelles et d'autres intellectuelles de grand poids, qui nous donnent la preuve de la valeur intellectuelle de la femme, mais messieurs les députés, celle-ci est une minorité sélecte de femmes. Le pourcentage de femmes ainsi, qui existent en Bolivie, n'est pas supérieur à un pour mille, messieurs les députés, qui soit dans les conditions de ces dames distinguées que je me permets de nommer. $»^{310}$

Le député Lazo de la Vega essaie de démontrer le même phénomène:

« Faire participer la femme dans l'organisation des pouvoirs publics est louable; mais du point de vue de la réalité bolivienne, nous devons considérer un fait qui peut passer inaperçu pour le critères des députés ; la femme bolivienne n'a pas atteint une culture appréciable, en ce qui concerne la densité même de la population féminine bolivienne, c'està-dire, que la femme bolivienne instruite qui a reçu l'instruction primaire n'atteint qu'un degré minime de la population. De sorte que, si on lui accorde amplement ce droit, sans considérer la nécessité lente

H. Fernández.- No me ha entendido el Sr. Diputado. He dicho que nuestro país no está en las mismas condiciones que esos países y tampoco crea el Sr. Diputado que somos superiores.

H. Tovar.- Yo no soy un camaleón. que legislo pensando en el olor de la comida. (Silbidos de la Barra). H. Fernández.- Voy a contestarle, Sr. Diputado. A eso voy. He oído la opinión de algún H. Diputado que decía: (Lee la opinión sobre la labor del Ministro de Trabajo de Estados Unidos, Sra. Perkins). Evidentemente, es muy posible que la Sra. Perkins, hubiera conseguido, gracias a su inteligencia, un aumento de salarios para los obreros, pero no porque ella haya obtenido esto en Estados Unidos, vamos a dar el voto a todo el elemento femenino sea capacitado o no sea capacitado en el país. También se decía que la hija del Comisario de Rusia, Molotoff, se había distinguido como paracaidista...

H. Tovar.- Las expresiones que me atribuye haber yo vertido, en la Comisión Legislativa, no son mías Sr. Diputado.

H. Presidente.- Se ruega no interrumpir.

H. Fernández,- No me refiero a usted, Sr. Diputado sino a otro Representante. Se decía que la hija de Molotoff se había distinguido como una gran paracaidista. Esto tampoco me parece que sea un motivo prematuro para que nosotros demos el voto político a las mujeres de Bolivia, que no son paracaidistas. (Risas en tribunas y barra). Que Madame Chanh Kai Shek, era una dama de grandes condiciones intelectuales, esto en China. » Idem.

310 «Mentalidades intelectuales entre las mujeres bolivianas, hemos encontrado por cantidades, que han dado, diré así, la pauta del valor intelectual de la mujer, desde las heroínas de la Coronilla, desde Juana Azurduy de Padilla, Adela Zamudio, muchas poetisas actuales y otras intelectuales de gran fuste, nos dan prueba del valor intelectual de la mujer, pero HH. señores Convencionales, es esta una minoría selecta de mujeres. El porcentaje de mujeres así, existentes en Bolivia, yo creo que no será del uno por mil, HH. Convencionales, que está en las condiciones de aquellas distinguidas damas que me permito nombrar. » Idem. 
des choses en Bolivie, je crois que nous commettrions une erreur qui serait critiquée postérieurement. Le législateur pour les minorités infimes s'écarte des postulats du Droit Public. Les législateurs doivent toujours être dans le cadre de la généralité, et la généralité de la femme bolivienne ne peut pas être considérée pour un vote d'une telle étendue. $»^{311}$

Le manque de références au mouvement féministe tant dans les débats de 1938 que dans les débats de 1945 est notable. Dans la Convention de 1938, le mouvement féministe de Bolivie fut mentionné une seule fois, tandis que dans la Convention de 1945 il ne fut pas mentionné du tout. En 1938 certaines organisations envoyèrent des messages aux représentants et des articles furent publiés dans la presse, ainsi que des communications réalisées dans la radio, cependant soit parce que ces actions n'eurent pas assez d'impact, soit parce qu'elles ne furent pas aussi importantes, la plupart des parlementaires ne les mentionnèrent pas. En 1945, il semblerait que les manifestations du mouvement féministe furent très modestes, ce qui expliquerait qu'elles ne soient pas mentionnées du tout. Dans tous les cas, l'on peut affirmer que le moment où le mouvement féministe fut le plus actif, fut dans les années qui vont de 1934 à 1936, avec la campagne féministe de 1934 et la création de la «LFEPA » et de l' «UMA » en 1935. En 1938 on n'a pas d'informations sur les actions de ces deux dernières organisations ; il semblerait qu'à ce moment le mouvement féministe commençait déjà un certain déclin qui fut accentué au début des années 1940.

Malgré le fait qu'il y avait un grand nombre de députés dans l'Assemblée de 1945 qui voulaient élargir la formule proposée aux élections nationales, la manière de procéder pour la votation ne le permettait pas ainsi. En effet, un premier vote fut réalisé pour accepter ou refuser la proposition de la commission législative sachant qu'on pouvait la modifier dans le détail après en votant pour les projets de modification proposés par les parlementaires. Si la proposition était refusée le vote ne serait pas octroyé aux femmes. Dans cette première votation, sur 74 votes, 58 étaient

\footnotetext{
311 «Hacer participar a la mujer en la organización de los poderes públicos, es encomiable; pero desde el punto de vista de la realidad boliviana, debemos considerar un hecho que puede pasar desapercibido para el criterio de los HH. convencionales; la mujer boliviana no ha alcanzado una cultura apreciable, en cuanto se refiere a la densidad misma de la población femenina boliviana, es decir, que la mujer boliviana instruida, la que ha recibido la instrucción primaria, alcanza apenas a un grado mínimo de la población. De modo, entonces. que si a la mujer se le otorga ampliamente ese derecho, sin considerar la necesidad paulatina de las cosas en Bolivia, yo creo que cometeríamos un error que posteriormente sería criticado. El legislador para minorías ínfimas se aparta de los postulados del Derecho Público. Los legisladores deben estar siempre dentro del marco de la generalidad, y la generalidad de la mujer boliviana no puede estar considerada para un voto de tanta amplitud. » Idem.
} 
en faveur du suffrage féminin et 16 contre. Lorsque la formule proposée fut ainsi votée on ne pouvait plus la modifier dans ces principes essentiels, c'est-à-dire que l'on ne pouvait pas proposer que le vote soit accordé aux femmes pour les élections nationales, car d'après le président de l'Assemblée ça serait modifier le principe essentiel de la formule qui avait déjà été approuvé. Il s'agissait donc de voter pour les projets de modification qui modifiaient uniquement les conditions requises aux femmes pour voter. Le projet qui fut finalement approuvé accordait le droit de vote (avec la possibilité d'élire et d'être élue) aux femmes qui savaient lire et écrire dans le cadre des élections municipales. Sur un total de 73 votes, 43 se prononcèrent à faveur de ce projet de modification et 30 contre. Il est probable que l'augmentation du nombre de députés qui votèrent contre le projet soit due au fait que plusieurs députés s'opposaient à la restriction faite aux élections municipales.

Les femmes qui savaient lire et écrire obtinrent ainsi un droit de suffrage limité aux élections municipales. L'occasion pour exercer ce droit pour la première fois se présenta dans les années 1947 et 1949.

\section{B) La première participation électorale des femmes : les élections municipales de 1947 et de 1949}

Le contexte dans lequel les femmes exercèrent leur droit de vote pour la première fois, n'était pas du tout le même de celui dans lequel elles l'avaient obtenu. En effet la fin du gouvernement de Gualberto Villarroel, en 1946, fut assez tragique. Plusieurs évènements contribuèrent à cette fin. Des actes de violence furent réalisés contre les membres de la «rosca» (membres de l'oligarchie qui soutenaient les « barons de l'étain »). Ainsi, par exemple Mauricio Hoschild, un des barons de l'étain fut séquestré par les membres de «RADEPA » et libéré avec beaucoup de difficultés sous l'intervention directe du président. Une conspiration contre le gouvernement eut lieu en novembre 1944 à Cochabamba et Oruro dirigée par Ovidio Quiroga. Une fois cette conspiration réprimée, 10 rebelles furent tués. Quatre d'entre eux furent assassinés dans des conditions terrifiantes: Luis Calvo, Félix Capriles, Rubén Terrazas et Carlos Salinas Aramayo furent criblés de balles et puis poussés dans le vide à Chuspipata, dans le chemin entre Los Yungas et La Paz. L'impact de cette 
brutalité fut très fort surtout dans les secteurs des classes moyennes et élevées de la société. Cet événement constitua le début de la fin du gouvernement de Villarroel.

Des manifestations contre le gouvernement se réalisèrent vers juillet 1946 en s'appuyant sur les revendications de salaires de travailleurs de chemins de fer, de constructeurs et surtout de professeurs et d'étudiants universitaires. Pendant ces jours, María Teresa Solari Ormachea (voir annexe A n²9) présidente de 1'« Unión Cívica Femenina Boliviana $»^{312}$, réalisa un intense travail d'agitation dans la rue, avec d'autres femmes réunies dans le «Frente Democrático Antifascista ». Le 15 juillet, les professeurs et les étudiants se déclarèrent en grève générale. Le 20 juillet, Gualberto Villarroel nomma un cabinet militaire et retira les membres du MNR de son gouvernement. Le 21 juillet la foule d'agitateurs et de manifestants contre le gouvernement prit la Plaza Murillo. À midi, Gualberto Villarroel signa sa démission mais cela ne fut pas suffisant. Un groupe d'activistes attaqua le Palais de Gouvernement et assassina le président, et ses collaborateurs les plus proches. Le cadavre de Villarroel fut lancé d'un balcon à la place et accroché à un réverbère au milieu d'une foule enflammée qui vexa le corps.

Après quelques heures de confusion, une junte civile fut formée et présidée par le président de la Cour Suprême de La Paz, Tomás Monje.

Des élections eurent lieu en janvier 1947. Enrique Hertzog, candidat du «Partido de la Unión Republicana Socialista » («PURS») fut élu président avec une marge très réduite et dans des circonstances de discrédit car très peu d'électeurs participèrent à ces élections. Son élection représentait un retour des partis traditionnels et leur dernier essai pour s'imposer au pouvoir avant la révolution de $1952^{313}$. Cette période de retour des partis traditionnels et d'essai de restauration du pouvoir oligarchique qui va de 1947 à 1952 fut appelé le « Sexenio », et ce fut dans ce contexte que les premières élections municipales dans lesquelles participèrent les femmes eurent lieu.

Les informations dont on dispose sur les organisations féministes de cette époque sont malheureusement très peu nombreuses. L'on connaît l'existence du

\footnotetext{
${ }^{312}$ L'« Unión Cívica Femenina Boliviana » édita un numéro de la revue Tribuna Cívica en décembre 1944. La directrice était María Teresa Solari et ses objectifs étaient « unifier l'opinion féminine autour des problèmes de la patrie, de la famille et de la tradition», ainsi que «diriger l'action des femmes boliviennes vers un travail noble et démocratique des normes de civisme». Il ne s'agissait pas d'une organisation féministe, car les droits civils et politiques des femmes n'étaient pas revendiqués.

${ }^{313}$ MESA (de) José, GISBERT Teresa, MESA Gisbert Carlos D., Manual de Historia de Bolivia, Editorial Gisbert, La Paz, 2008.
} 
«Comité Feminista Democrático » dont les secrétaires étaient María Luisa Sánchez Bustamante de Urioste (voir annexe A n 10 ), Carmen I. v. de Bedregal, Mercedes de Nardín Rivas, Rosa Santa Cruz de Cartesegna, Ana María Calvo de Etchenique. Ce comité se réunit en Assemblée le 19 août 1946 afin d'unifier ses objectifs par rapport au droit de vote des femmes. Le Comité se prononça pour l'obtention des droits civils des femmes et des droits politiques sans restrictions pour les femmes qui savaient lire et écrire. Il fut décidé qu'une Convention Nationale de femmes devait se réunir à la fin de l'année. Le Comité se déclara également contre l'« apolitisme » et confirma son union avec le «Frente Democrático Antifascista » pour combattre les « fascistes» « totalitaires » qui restaient dans le pays même après la « révolution libératrice » du 21 juillet $1946^{314}$. Les membres du Comité étaient donc des claires opposantes du gouvernement de Villarroel et avaient sûrement participé à sa chute avec le « Frente Democrático Antifascista » de femmes. L' «apolitisme» dont elles parlent est une claire référence aux hommes politiques qui se déclaraient « apolitiques » et qui étaient suspects de faire partie du « MNR » et de « RADEPA ».

L'autre organisation féministe qui était active à cette époque était la «Asociación Interamericana de Mujeres ». Elle fut fondée par Etelvina Villanueva (voir annexe $\mathrm{A} \mathrm{n}^{\circ} 43$ ) en 1945 ; il s'agissait donc d'une organisation très similaire à la «LFEPA » tant par ses objectifs que par sa structure internationale. Un programme d'objectifs fut présenté aux candidats présidentiels pour les élections de janvier 1947. Ces objectifs étaient entre autres : droits civils et politiques pour les femmes sans restrictions, égalité des salaires entre hommes et femmes, aide à la femme travailleuse, aide à la mère célibataire, création de crèches pour les femmes travailleuses, défense juridique et sociale des enfants illégitimes, reconnaissances des droits de l'enfant, enquêtes en paternité, droit de la maternité, combattre l'alcool et les vices, réunions annuelles de féministes et des syndicats féminins, protection des mères et des enfants, assistance et coopération aux femmes paysannes et travailleuses des mines, interdiction du travail nocturne ou exigeant un grand effort physique, sécurité sociale obligatoire, législation juridique sociale pour la femme travailleuse, création d'écoles techniques et d'écoles nocturnes pour femmes, création d'Universités Populaires, formation professionnelle pour les femmes de ménage,

\footnotetext{
${ }^{314}$ La Razón, 21 août 1946, La Paz, Hemeroteca del Archivo del Congreso, La Paz - Bolivie.
} 
développement de la culture, etc ${ }^{315}$. Elvira Delgado Mantilla de Bedregal (voir annexe A n ${ }^{\circ 52)}$ appartenait à cette organisation. Comme son prédécesseur, la « LFEPA » des années 1930, la «Asociación Interamericana de Mujeres » insistait sur les droits sociaux des femmes travailleuses et la protection des femmes et des enfants. Malheureusement on n'a pas d'autres informations sur cette association. Le «Comité Feminista Democrático » et la «Asociación Interamericana de Mujeres 》 se déclaraient pour l'obtention du suffrage féminin sans restrictions, c'est-à-dire pour la participation des femmes aux élections nationales et pas seulement municipales. . Le « Comité Feminista Democrático », qui semble être composé surtout de femmes des classes élevées de la société, insistait sur l'obtention des droits civils et politiques sans restrictions et sur l'opposition contre les membres du gouvernement de Villarroel; tandis que la deuxième avait des objectifs beaucoup plus larges qui prenaient en compte des revendications sociales pour les femmes des classes populaires et la protection des enfants. Dans le programme de gouvernement de Hertzog le suffrage féminin sans restrictions apparaissait comme une mesure convenable qui devait être mise en place. Cependant, il n'était pas clair quand et sous quelles modalités le suffrage féminin allait mis en place.

A l'approche des élections municipales à la fin de l'année 1947 les femmes appartenant à ces organisations ainsi que d'autres s'organisèrent pour préparer leur première participation électorale.

\section{a) La préparation pour les comices ${ }^{316}$}

Les élections municipales dans lesquelles les femmes votèrent pour la première fois eurent lieu dans les mois de décembre de 1947 et 1949.

Les élections de 1947 furent très importantes historiquement pour deux raisons : l'élection démocratique de gouvernements municipaux depuis 15 ans d'interruption et la participation des femmes en tant qu'électrices, éligibles et membres des jurys électoraux.

\footnotetext{
${ }^{315}$ El Diario, 14 décembre 1946, La Paz. Hemeroteca del Archivo del Congreso, La Paz - Bolivie.

${ }^{316}$ Une grande partie des informations sur la participation électorale des femmes dans les élections municipales de 1947 et 1949 a été tirée de REVOLLO QUIROGA, Marcela, Mujeres bajo prueba. La participación electoral de las mujeres antes del voto universal (1939 - 1949), Eureka Ediciones, La Paz - Bolivia, 2001.
} 
L'histoire municipale en Bolivie est marquée par l'instabilité et par les changements dans le pouvoir des municipalités et les formes d'élection de leurs membres. Cette histoire est due à une permanente tension entre des processus de décentralisation et de centralisation. Depuis le XIX ${ }^{\mathrm{e}}$ jusqu'aux gouvernements militaires de Toro et Busch les conseillers municipaux et les maires exerçaient des charges ad honorem, c'est-àdire, sans aucune rétribution monétaire. Les membres des municipalités étaient élus par leur prestige et leur honorabilité au sein de la communauté. Le gouvernement de Toro réalisa des réformes importantes. D'après celles-ci le maire devait recevoir un salaire et être élu par un Collège Électoral. Le Conseil municipal devait être composé de membres des Chambres d'Industrie, de la Fédération Ouvrière, des collèges professionnels, et de la Ligue de propriétaires. Les responsabilités sur la santé publique et l'éducation ne dépendaient plus des municipalités mais de l'administration centrale. Dans la Convention de 1938 furent introduites d'autres réformes, appliquées en 1942 avec la promulgation de la Loi organique des Municipalités, qui établissait que l'élection des conseilleurs municipaux devait se faire à travers des listes incomplètes, et que le maire devait être élu par le Président de la République. En 1945, cette modalité fut modifiée : le maire devait désormais être choisi par le Conseil municipal parmi trois personnes désignées. Le Président devait accepter cette élection. Le gouvernement de Enrique Hertzog maintint ce schéma électoral mais le maire devait désormais être élu par le Conseil Municipal pour une période de deux ans et les conseillers municipaux devaient être élus par suffrage populaire, ce qui instaurait l'autonomie municipale, car depuis 15 ans les conseilleurs municipaux avaient été élus par le Pouvoir Éxécutif.

Les élections de 1947 se réalisèrent dans un climat de crise politique où l'image du gouvernement avait été fortement détériorée. Il s'agissait alors pour le gouvernement, de tourner à son avantage cette participation démocratique en même temps qu'il s'agissait de mesurer le vrai poids des partis politiques opposants.

La présence des femmes dans les élections provoqua beaucoup d'expectatives dans la société. Certains considéraient que les connaissances pratiques des femmes dans le domaine du foyer leur seraient utiles dans les municipalités qui étaient vues comme une « grande maison » où l'hygiène, l'ordre et la bonne administration étaient primordiaux. Comme l'affirme Marcela Revollo Quiroga: «En cuanto a la administración comunal, significaba incorporar en ella la intuición y la experiencia cotidiana femenina, bajo el criterio de que las mujeres eran más aptas para resolver las 
necesidades domésticas de la población... ${ }^{317}$ L'on considérait également que les femmes serviraient d'élément modérateur des élections qui étaient le plus souvent marquées par la violence et la corruption. La présence des femmes servirait ainsi à éviter les vices électoraux, « humanisant» et «moralisant» les pratiques électorales. En outre, les femmes devaient faire preuve de leurs capacités et de leur responsabilité dans ces élections car, comme on l'a vu, les députés de 1945 leur avaient accordé le droit de vote comme un «test». Les femmes devaient donc passer cette épreuve en démontrant qu'elles étaient bien préparées pour participer aux comices.

Les élections municipales auraient dû avoir lieu avant décembre 1947, cependant elles furent repoussées jusqu'à décembre, car le Parlement n'avait pas encore validé les réformes constitutionnelles de 1945; ceci provoqua le retard quant aux inscriptions des femmes dans les registres civiques ${ }^{318}$. Ces derniers furent ouverts exclusivement pour les femmes en octobre $1947^{319}$. D'après le décret du 3 octobre 1947, les femmes voteraient dans les mêmes conditions que les hommes. Les conditions que les femmes durent remplir pour voter alors étaient : être bolivienne par naissance ou par naturalisation, avoir 21 ans si célibataire et 18 ans si mariée, et savoir lire et écrire en castillan. Au lieu d'apporter le Bulletin de Service Militaire exigé aux hommes pour l'inscription, les femmes devaient apporter leur carte d'identité ${ }^{320}$.

Les conseils municipaux devaient être élus par suffrage populaire selon un système de listes incomplètes. Les électeurs devaient voter pour 8 candidats dans les capitales de département, 4 dans les capitales de province, et 2 dans les sections municipales. D'après le système des listes incomplètes, une partie des conseils municipaux était élue par majorité et l'autre par minorité. Ainsi, par exemple les membres d'un Conseil municipal de capitale de département étaient 12. L'on votait uniquement pour 8 et les 4 restants étaient les candidats qui suivaient les 8 premiers. Dans les capitales de province la minorité était composée de deux membres, et dans les sections municipales par 1 seul membre ${ }^{321}$.

\footnotetext{
${ }^{317}$ REVOLLO QUIROGA, Marcela, Mujeres bajo prueba. La participación electoral de las mujeres antes del voto universal (1939 - 1949), Eureka Ediciones, La Paz - Bolivia, 2001, p.91.

${ }^{318}$ Décret Suprême du 19 juin 1947, Anuario de 1947, Archivo del Congreso, La Paz - Bolivie.

${ }^{319}$ Décret Suprême du 4 octobre 1947, Anuario de 1947, Archivo del Congreso, La Paz - Bolivie.

${ }^{320}$ La carte d'identité avait été accordée aux femmes en 1945.

${ }^{321}$ La Razón, 12 décembre 1947, La Paz. Hemeroteca del Archivo del Congreso, La Paz - Bolivie.
} 
Suite à la convocation électorale, plusieurs organisations féminines furent réorganisées et créées pour participer aux élections avec les partis politiques.

Trois types de candidatures étaient acceptés dans les élections de 1947 et 1949 : celles qui appartenaient à un parti politique, les «populaires » qui avaient le soutien de juntes de voisinage, de syndicats et d'associations professionnelles, et les candidatures proprement féminines qui avaient le soutien d'institutions féminines. Cependant, ces deux dernières candidatures finirent par réaliser des alliances avec les partis ; aucune organisation féminine ne participa de manière indépendante.

Les organisations féminines qui participèrent dans les élections furent diverses : ainsi participèrent des associations anciennes comme 1'«Ateneo Femenino », des organisations catholiques comme l'«Asociación Cristiana Femenina », et des nouvelles organisations comme l'«Asociación Femenina Boliviana » ${ }^{322}$, 1'«Unión Cívica Femenina Boliviana », l'«Unión Femenina Universitaria » de La Paz, et l'«Acción Católica de Mujeres » parmi les organisations les plus actives. Les trois dernières organisations étaient les plus conservatrices et soutenaient ouvertement le gouvernement. Elles cherchèrent à convoquer les femmes, proposèrent des candidates et réalisèrent des conférences dans lesquelles elles essayèrent de concilier leur « mission sacrée » de mères avec leur participation politique.

Lorsque les candidatures furent décidées, les femmes appartenant aux institutions et aux partis politiques réalisèrent une intense campagne électorale mettant beaucoup d'insistance sur l'inscription des femmes dans les registres civiques, ce qui contribua à ce que la police étende l'octroi des cartes d'identité pour les femmes en province ${ }^{323}$. Cochabamba fut la ville où les campagnes électorales des femmes furent les plus actives.

Parmi les femmes se portant candidates à La Paz en 1947 l'on peut citer à María Luisa Sánchez Bustamante de Urioste (voir annexe A $n^{\circ} 10$ ) et à Matilde Carmona Rodo de Busch (voir annexe $\mathrm{A} \mathrm{n}^{\circ} 8$ ) toutes les deux appartenant à « La Candidatura del Pueblo » à laquelle participèrent plusieurs candidats sans affiliation politique et d'autres appartenant au « PIR » (« Partido de Izquierda Revolucionaria »), raison pour laquelle le «PIR» soutenait ces candidatures. Elodia Ballivián de Ligerón (voir

\footnotetext{
${ }^{322}$ Organisation féminine importante à l'époque, ses objectifs n'étaient pas du tout liés au féminisme. Il s'agissait d'une organisation conservatrice avec une identité purement civique. Elle soutenait le gouvernement de Hertzog et établit des filiales dans les principales villes du pays.

${ }^{323}$ La Razón, 3 novembre 1947, La Paz. Hemeroteca del Archivo del Congreso, La Paz - Bolivie.
} 
annexe $\mathrm{A} \mathrm{n}^{\circ} 12$ ) se présenta comme candidate du «PURS ». Natty de Guillén Pinto (voir annexe $\mathrm{A} \mathrm{n}^{\circ} 67$ ) se présenta en tant que candidate de la «Federación de las Juntas Vecinales ».

Les discours des candidates avant les élections mettaient en avant leur rôle maternel pour exercer leurs fonctions politiques. Ainsi par exemple, María Luisa Sánchez Bustamante de Urioste affirma :

« Je crois que la maternité est le plus haut signe de la femme, raison pour laquelle nous devons toutes nous consacrer à protéger, de manière maternelle, les enfants du peuple. $\gg{ }^{324}$

L'importance de la participation des femmes dans les élections à venir fut exprimée par María Angélica Panozo de Videa (voir annexe A n65) qui réalisa une conférence intitulée «L'évolution de la femme dans le champ intellectuel » à l'Université Mayor de San Andrés à La Paz en octobre 1947, dans laquelle elle déclara :

«La femme doit intervenir dans les activités civiques, elle doit contribuer avec son effort à donner plus de solidité aux institutions de la patrie : à dépurer les procédés électoraux, à affirmer la paix sociale et de cette manière la paix des nations. $)^{325}$

D'autre part, Natty Guillén Pinto s'attarda à annoncer son programme de travail ainsi :

«Je travaillerai intensément pour la culture du peuple et pour le bienêtre, pour l'hygiène des quartiers habités par les ouvriers, pour la baisse du prix de la vie et pour anoblir l'intervention de la femme bolivienne dans la politique active. ${ }^{326}$

La participation aux élections était également considérée comme un devoir patriotique pour certaines femmes. Alicia D’Arlach de Blanco Galindo (voir annexe A n 70 ) de Cochabamba s'exprima dans ce sens:

\footnotetext{
324 «Creo que la maternidad es el más alto signo de la mujer por lo que todas debemos dedicarnos a proteger, maternalmente a los hijos del pueblo.» La Razón, 12 décembre 1947, La Paz. Tiré de REVOLLO QUIROGA, Marcela, Mujeres bajo prueba. La participación electoral de las mujeres antes del voto universal (1939 - 1949), Eureka Ediciones, La Paz - Bolivia, 2001.

325 «La mujer debe intervenir en las actividades cívicas, debe concurrir con su esfuerzo a dar mayor solidez a las instituciones patrias: a depurar los procedimientos electorales, a afirmar la paz social y, de este modo, la paz de las naciones. » La Razón, 24 octobre 1947, La Paz. Hemeroteca del Archivo del Congreso, La Paz - Bolivie.

326 «Trabajaré intensamente por la cultura del pueblo y por el bienestar, por la higiene de los barrios habitados por obreros, por el abaratamiento de la existencia y por ennoblecer la intervención de la mujer boliviana en la política activa. " La Razón, 12 décembre 1947, La Paz. Tiré de REVOLLO QUIROGA, Marcela, Mujeres bajo prueba. La participación electoral de las mujeres antes del voto universal (1939 - 1949), Eureka Ediciones, La Paz - Bolivia, 2001.
} 
«J'ai accepté d'intervenir dans cette campagne nonobstant mes multiples occupations, car je considère que la loi a donnée le droit de vote à la femme ; celle-ci a le devoir de répondre de forme très étendue et patriotique. $»^{327}$

Isabel Ugarte de Morató (voir annexe $\mathrm{A} \mathrm{n}^{\circ} 69$ ) candidate à Cochabamba également exprima la même idée :

« J'ai accepté ma candidature avec un étendu esprit patriotique, car je considère que toute personne a le devoir de servir son pays de manière résolue et ample. $»^{328}$

En ce qui concerne les élections municipales de 1949, la présence d'organisations féminines fut moins importante qu'en 1947. Par contre, les sections féminines créées au sein des partis prirent de l'importance. L'intégration des femmes dans les partis politiques s'était renforcée à la fin des années 1940, en même temps que le rôle des organisations féminines et féministes s'effaçait.

Une preuve de l'importance et l'autonomie prise par les sections féminines des partis politiques est illustrée dans le cas du «Control Femenino» du «PURS» et du «Centro Liberal Femenino» de Cochabamba qui décidèrent de continuer leur alliance politique malgré le fait que les partis auxquels elles appartenaient avaient rompu leur pacte :

«Étant donné que les secteurs masculins de ces deux partis avaient rompu le pacte pour participer ensemble dans les élections, l'on crut qu'il en était de même entre les fractions féminines, mais aussi étrange que cela puisse paraître et de manière qui honore la femme de Cochabamba et qui donne une leçon d'honneur à tous les hommes politiques, Madame Fidelia Corral Zambrana de Sánchez (voir annexe A $n^{\circ} 22$ ) affirma que le pacte se maintenait comme prévu car les descendantes des héroïnes de la Coronilla (voir annexe $A n^{\circ} 35$ ) l'avaient signé. $\gg{ }^{329}$

\footnotetext{
327 «He aceptado de intervenir en esta campaña no obstante mis muchas ocupaciones, pues considero que la ley ha dado el voto a la mujer; ésta tiene el deber de responder en forma amplia y patriótica. » Los Tiempos, 13 décembre 1947, Cochabamba. Tiré de REVOLLO QUIROGA, Marcela, Mujeres bajo prueba. La participación electoral de las mujeres antes del voto universal (1939 - 1949), Eureka Ediciones, La Paz - Bolivia, 2001.

328 «He aceptado mi candidatura con un amplio espíritu patriótico, pues considero que toda persona tiene el deber de servir a su país en forma decidida y holgada. "Los Tiempos, 13 décembre 1947, Cochabamba. Tiré de REVOLLO QUIROGA, Marcela, Mujeres bajo prueba. La participación electoral de las mujeres antes del voto universal (1939 - 1949), Eureka Ediciones, La Paz - Bolivia, 2001.

329 «Como los sectores masculinos de estos dos partidos rompieron el pacto para concurrir juntos a las elecciones, se creyó que había ocurrido lo mimso entre las fracciones femeninas, pero por extraño que parezca y en forma que honra a la mujer cochabambina y da una lección de honor a todos los políticos, la señora Fidelia Corral Zambrana de Sánchez dijo que todo se mantenía en pie ya que lo habían firmado descendientes de las Heroínas de la Coronilla. La Razón, 23 décembre 1949, La Paz. Tiré de
} 
Les sections féminines des partis politiques commencèrent à jouer un rôle important dans la revendication des droits politiques des femmes, rôle qui auparavant était uniquement détenu par les organisations féministes. Ainsi, la section féminine $d u$ «PURS » demanda l'octroi des droits politiques dans les mêmes conditions que les hommes dans la deuxième Convention du parti en novembre $1949^{330}$.

La préparation pour les élections municipales de 1947 et 1949 permit l'intégration des femmes dans les divers partis politiques avec la création des sections féminines dont les objectifs s'élargirent car il ne s'agissait plus seulement de proposer des candidates pour les élections municipales mais aussi de revendiquer de droits en tant que femmes comme les droits politiques sans restrictions. La création de ces sections féminines permit à certaines candidates d'être élues pour la première fois à une charge politique dans le pays.

\section{b) La participation des femmes aux élections municipales et la réception de cet événement par la société}

Les élections de 1947 eurent lieu le 14 décembre 1947 et celles de 1949 eurent lieu le 27 décembre 1949. Les deux élections furent marquées par une grande indifférence de la part des électeurs, car une grande partie d'entre eux ne votèrent pas. Ces élections furent marquées aussi par la «tranquillité » dans l'environnement où ne se produisirent presque pas d'actes de violence. Dans les élections de 1947 environ $60 \%$ des inscrits ne votèrent pas $^{331}$. En 1949, l'abstention fut encore plus importante, car seulement $10 \%$ de la population en âge et en conditions de voter s'était inscrit pour voter, c'est-à-dire, 29.665 hommes et femmes. ${ }^{332}$ Cette abstention fut plus importante chez les femmes dans les deux élections (voir tableau B). Les raisons de l'abstention générale étaient liées au contexte politique de plus en plus tendu où les gouvernements de Hertzog (en 1947) et de Mamerto Urriolagoitia (en 1949), et l'État oligarchique en général, se trouvaient en pleine crise politique.

REVOLLO QUIROGA, Marcela, Mujeres bajo prueba. La participación electoral de las mujeres antes del voto universal (1939 - 1949), Eureka Ediciones, La Paz - Bolivia, 2001.

${ }^{330}$ La Razón, 3 novembre 1949, La Paz. Hemeroteca del Archivo del Congreso, La Paz - Bolivie.

${ }^{331}$ La Razón, 15 décembre 1947, La Paz. Hemeroteca del Archivo del Congreso, La Paz - Bolivie.

${ }^{332}$ La Razón, 14 décembre 1949, La Paz. Hemeroteca del Archivo del Congreso, La Paz - Bolivie. 
Tableau B $\mathbf{B}^{333}$

Número de mujeres inscritas, por capital de
departamento, según año de elección

\begin{tabular}{|l|l|l|l|l|l|l|}
\hline & \multicolumn{3}{|c|}{1947} & \multicolumn{3}{c|}{1949} \\
\hline Ciudad & Total & Mujeres & Hombres & Total & Mujeres & Hombres \\
\hline La Paz & & 2.150 & & 24.773 & & \\
\hline Cochabamba & 11.188 & 2.480 & 8.708 & 8.075 & 1.635 & 6.440 \\
\hline Santa Cruz & & & & 5.445 & 1.625 & 3.820 \\
\hline Oruro & & & & & & \\
\hline Sucre & & 750 & & & & \\
\hline Tarija & 2.996 & 411 & 2.585 & & & \\
\hline Potosí & & 420 & & 8.830 & 1.500 & 7.330 \\
\hline Trinidad & & 453 & & & & \\
\hline Cobija & 445 & 81 & 364 & & & \\
\hline
\end{tabular}

Fuente: Elaboración propia, en base a La Razón y El Diario de 1947 y 1949

En las casillas vacias se debe leer: Sin datos.

L'abstention des femmes s'explique par des raisons subjectives et objectives. Comme on le verra un peu plus tard, une grande partie des femmes considéraient que les femmes n'étaient pas préparées pour voter et qu'elles ne devaient pas participer en politique car leur véritable place était au sein du foyer. Il est probable que par ces considérations, plusieurs femmes ne se soient pas inscrites pour voter. D'autre part, les femmes avaient reçu pour la première fois leurs cartes d'identité, en 1945, et en 1947 une grande partie des femmes, surtout des provinces, ne l'avaient pas encore, ce qui les empêchait de s'inscrire au registre civique et par conséquent de participer aux élections. En regardant le tableau B, on peut constater que le nombre de femmes inscrites pour voter passe de 420 en 1947 à 1500 en 1949 à Potosí. Il est probable que cette explosion soit due à l'extension de l'octroi des cartes d'identités en province

\footnotetext{
${ }^{333}$ Ce tableau a été tiré de REVOLLO QUIROGA, Marcela, Mujeres bajo prueba. La participación electoral de las mujeres antes del voto universal (1939 - 1949), Eureka Ediciones, La Paz - Bolivia, 2001.
} 
pour l'année 1949. La ville où la participation des femmes fut la plus importante en 1947 fut Cochabamba. Sur le nombre total d'inscrits, 22\% étaient des femmes.

Les hommes et les femmes votaient dans des enceintes et des amphores séparées. Les élections nationales et municipales du pays étaient presque toujours marquées par le désordre et la confusion par rapport à l'emplacement des bureaux de vote. Cet aspect s'aggrava avec l'extension du vote aux femmes et l'installation d'enceintes séparées, raison pour laquelle ce désordre affecta surtout les enceintes féminines. Les journaux publièrent les plaintes de plusieurs femmes des villes de $\mathrm{La}$ Paz, Trinidad, Santa Cruz, et Potosí, qui durent se déplacer plusieurs fois pour chercher leurs bureaux de vote, et une grande partie d'entre elles ne put pas voter car elles ne trouvèrent jamais le bureau où elles devaient voter. Parfois les enceintes électorales de femmes fermèrent avant l'heure prévue, ouvrirent plus tard que prévu, ou simplement ne furent jamais ouvertes car les membres du jury ne se présentèrent pas. En réaction à cette désorganisation en 1949, Rosa Nava de Mendoza López, élue conseillère municipale pour le «PURS » à La Paz, décida de renoncer à sa charge en signe de protestation puisqu'une grande partie des femmes n'avait pas pu voter. En mettant en avant les droits des femmes elle demanda que des élections complémentaires soient mises en place pour que les femmes qui n'avaient pas pu voter puissent le faire ${ }^{334}$. Ces circonstances contribuèrent à réduire le nombre de femmes votantes.

Malgré ces adversités concernant le vote des femmes des conseillères municipales femmes furent élues dans certaines villes. Les tableaux suivants nous permettent de connaître quelles furent les femmes candidates aux élections municipales dans chaque capitale de département et quelles furent les candidates élues $^{335}$.

\footnotetext{
${ }^{334}$ La Razón, 28 décembre 1949, La Paz. Hemeroteca del Archivo del Congreso, La Paz - Bolivie.

${ }^{335}$ Ces tableaux ont été tirés de REVOLLO QUIROGA, Marcela, Mujeres bajo prueba. La participación electoral de las mujeres antes del voto universal (1939 - 1949), Eureka Ediciones, La Paz - Bolivia, 2001.
} 
Tableau C : Élections municipales de 1947

Oruro

\begin{tabular}{|c|c|c|c|}
\hline Partido & Candidata & Estado civil & Electas \\
\hline Liberal & $\begin{array}{l}\text { Sra. Raquel Aguirre } \\
\text { Vásquez } \\
\end{array}$ & soltera & \\
\hline PURS & $\begin{array}{l}\text { Sra. Lola Cardona } \\
\text { Torrico } \\
\text { Sr.Elvira Bustillos de } \\
\text { Aranibar } \\
\end{array}$ & $\begin{array}{l}\text { soltera } \\
\text { casada }\end{array}$ & \\
\hline PIR & Sra. Leonila Bernal & soltera & \\
\hline FOS & Leticia Fajardo & $\mathrm{s} / \mathrm{d}$ & \\
\hline Total & 5 & & $\mathbf{0}$ \\
\hline
\end{tabular}

$\mathrm{s} / \mathrm{d}:$ Sin datos

Cochabamba

\begin{tabular}{|c|c|c|c|}
\hline Partido & Nombre & $\begin{array}{c}\text { Estado } \\
\text { civil }\end{array}$ & Electas \\
\hline Liberal-PURS & Isabel Ugarte de Morató & casada & sí \\
\hline \begin{tabular}{|l|} 
Unión Cívica \\
Cristiana \\
(Asociación \\
Femenina \\
Boliviana, FSB y \\
Liga Electoral \\
Cristiana) \\
\end{tabular} & \begin{tabular}{|l|} 
Alicia D'Arlach de \\
Blanco Galindo \\
Lindaura Sainz de \\
Ferrufino \\
\end{tabular} & $\begin{array}{l}\text { casada } \\
\text { casada }\end{array}$ & sí \\
\hline MNR & Rosa Morales Guillen & $\mathrm{s} / \mathrm{d}$ & \\
\hline Total & 4 & & 2 \\
\hline
\end{tabular}

- Leticia Fajardo (voir annexe A nº8).

- Isabel Ugarte de Morató (voir annexe A n69)

- Alicia D’Arlach de Blanco Galindo (voir annexe A n 70 )

- Lindaura Sainz de Ferrufino (voir annexe A n ${ }^{\circ} 71$ )

- Rosa Morales Guillén (voir annexe A nº61) 
Tarija

\begin{tabular}{|l|l|c|c|}
\hline Partido & Nombre & Estado civil & Electas \\
\hline PURS & Graciela de Gainza & casada & si \\
\hline PIR & $\begin{array}{l}\text { Emma Mogro de } \\
\text { Navajas } \\
\text { Aurora Peñeiros de } \\
\text { Zamora }\end{array}$ & casada & \\
\hline Total & 3 & & 1 \\
\hline
\end{tabular}

s/d. Sin datos

\section{Santa Cruz}

\begin{tabular}{|l|c|c|c|}
\hline Partido & Nombre & Estado civil & Electas \\
\hline MNR & Bella de Menacho & s'd & \\
\hline Total & I & & 0 \\
\hline
\end{tabular}

Dato recogido del tibro de Isabel Arauco, 1984 s/d: Sin datos

\section{Beni}

\begin{tabular}{|l|l|c|c|}
\hline Partido & Nombre & Estado civil & Electas \\
\hline PURS & Petrona de Terán & casada & \\
\hline PIR & $\begin{array}{l}\text { Clara Parada de } \\
\text { Pinto }\end{array}$ & casada & \\
\hline Total & 2 & & 0 \\
\hline
\end{tabular}


La Pax

\begin{tabular}{|c|c|c|c|}
\hline Partido & Nombre & $\begin{array}{c}\text { Estado } \\
\text { civil }\end{array}$ & Electas \\
\hline MNR & $\begin{array}{l}\text { Sra Matilde Olmos y } \\
B^{* *} \text {. }\end{array}$ & $\mathrm{s} / \mathrm{d}$ & \\
\hline PLRS & Elodia de Lijeron & casada & sí \\
\hline \multirow[t]{2}{*}{$\begin{array}{l}\text { Candidatura } \\
\text { del pocblo }\end{array}$} & $\begin{array}{l}\text { Matilde Carmona de } \\
\text { Buch } \cdots\end{array}$ & & \\
\hline & $\begin{array}{l}\text { Ma Luisa Sánchez } \\
\text { Bustamante de } \\
\text { Urioste* }\end{array}$ & casada & \\
\hline Juncas Vecinales & Natty de Guillen Pinto & casada & \\
\hline FSB & $\begin{array}{l}\text { Mary Arteaga de } \\
\text { Candia ** }\end{array}$ & casada & \\
\hline Total & 6 & & 1 \\
\hline
\end{tabular}

"lnacialmente candidara del PLR, pero este partido no se presentó en La Paz y apoyo a la "Candidatura del Pueblo", sutodefinida como agrupación de insenocioes revolucionarias, civicas y culturales.

*Primers en la lisha.

sit: Sin danos

Sucre

\begin{tabular}{|l|c|c|c|}
\hline Partido & Nombre & Estado civil & Electas \\
\hline Liberal & $\begin{array}{c}\text { Clotilde Urioste de } \\
\text { Villa* } \\
\text { Marina Sánchez }\end{array}$ & casada & sí \\
& 2 & & sí \\
\hline Total & 2 & 2 \\
\hline
\end{tabular}

*Primera en la lista

- Elodia de Lijerón (voir annexe A n¹2)

- Matilde Carmona de Busch (voir annexe $\mathrm{A} \mathrm{n}^{\circ} 8$ )

- M. Luisa Sánchez Bustamante (voir annexe A nº 10)

- Natty de Guillén Pinto (voir annexe A n67)

- Clotilde Urioste de Villa (voir annexe A n 72 ) 
Cobija

\begin{tabular}{|l|c|c|c|}
\hline Partido & Nombre & Estado civil & Electas \\
\hline PURS & $\begin{array}{c}\text { Teodosia de } \\
\text { Pereira* }\end{array}$ & casada & sí \\
\hline PIR & Carmen Vargas* & s/d & sí \\
\hline Total & $\mathbf{2}$ & & $\mathbf{2}$ \\
\hline
\end{tabular}

*Primera en la lista

Potosí

\begin{tabular}{|l|c|c|c|}
\hline Partido & Nombre & Estado civil & Electas \\
\hline $\begin{array}{l}\text { Lista } \\
\text { Populares }\end{array}$ & Laura Llanos & s/d & \\
\hline Total & 1 & & 0 \\
\hline
\end{tabular}




\section{Tableau D : Élections municipales de 1949}

\section{La Paz et Potosí}

Les tableaux des candidates et élues aux élections municipales de 1949 à La Paz et Potosi présentés dans l'ouvrage de Marcela Revollo Quiroga Mujeres bajo prueba. La participación electoral de las mujeres antes del voto universal (1939 - 1949, présentent une erreur car ils sont les mêmes que pour 1947. C'est pour cette raison que l'on se permet de ne pas les reproduire ici. En nous basant sur le journal La Razón du 28 décembre 1949, l'on sait que Rosa Nava de Mendoza López (voir annexe A $\mathrm{n}^{\circ} 73$ ) candidate $\mathrm{du}$ PURS fut élue conseillère municipale et qu'elle renonça à sa charge. Si l'on se base sur le tableau E, l'on sait qu'elle fut la seule candidate élue parmi 5 autres. Ce sont malheureusement les seules informations dont on dispose quant aux candidates et élues de 1949 à La Paz. Par des informations proportionnées en annexe dans l'ouvrage de Marcela Revollo et par le tableau E, l'on sait que Catalina de Chacón fut la seule candidate à se présenter aux élections de 1949 à Potosí et qu'elle fut élue. 
Cochabamba

\begin{tabular}{|c|c|c|c|}
\hline Partido & Nombre & $\begin{array}{c}\text { Estado } \\
\text { civil }\end{array}$ & Electas \\
\hline Liberal-PURS & Isabel Ugarte de Morató & casada & si \\
\hline $\begin{array}{l}\text { Unión Civica } \\
\text { Cristiana } \\
\text { (Asociación } \\
\text { Femenina } \\
\text { Boliviana, FSB y } \\
\text { Liga Electoral } \\
\text { Cristiana) } \\
\end{array}$ & $\begin{array}{l}\text { Alicia D'Arlach de } \\
\text { Blanco Galindo } \\
\text { Lindaura Sainz de } \\
\text { Ferrufino }\end{array}$ & $\begin{array}{l}\text { casada } \\
\text { casada }\end{array}$ & sí \\
\hline MNR & Rosa Morales Guillen & $\mathrm{s} / \mathrm{d}$ & \\
\hline Total & 4 & & 2 \\
\hline
\end{tabular}

Santa Cruz

\begin{tabular}{|l|c|c|c|}
\hline Partido & Nombre & Estado civil & Electas \\
\hline MNR & Bella de Menacho & s/d & \\
\hline Total & 1 & & 0 \\
\hline
\end{tabular}

Primera en la lista

s/d: Sin datos

\section{Oruro}

\begin{tabular}{|c|c|c|c|}
\hline Partido & Candidata & Fstando civil & Flectins \\
\hline Liberal & $\begin{array}{l}\text { Sra. Raquel Aguirro } \\
\text { Visquez }\end{array}$ & soltera & \\
\hline PUTRS & $\begin{array}{l}\text { Sra. Lolia Cardona } \\
\text { Torrico } \\
\text { Sr. Elvira Bustillos de } \\
\text { Mramibar }\end{array}$ & $\begin{array}{l}\text { soltera } \\
\text { casada }\end{array}$ & \\
\hline PIR & Sra. Leonila Bernal & soltern & \\
\hline FOS & Leticia Fajardo & $\mathbf{s} d$ & \\
\hline Total & 5 & & 0 \\
\hline
\end{tabular}


Cobija

\begin{tabular}{|l|c|c|c|}
\hline Partido & Nombre & Estado civil & Electas \\
\hline PURS & $\begin{array}{c}\text { Teodosia de } \\
\text { Pereira }\end{array}$ & casada & si \\
\hline PIR & $\begin{array}{c}\text { Carmen Vargas } \\
\text { Total }\end{array}$ & s/d & si \\
\hline
\end{tabular}

Trinidad

\begin{tabular}{|l|c|c|c|}
\hline Partido & Nombre & Estado civil & Electas \\
\hline Total & 0 & & 0 \\
\hline
\end{tabular}

\section{Sucre}

\begin{tabular}{|l|c|l|c|}
\hline Partido & Nombre & Estado civil & Electas \\
\hline Total & 0 & & 0 \\
\hline
\end{tabular}

\section{Tarija}

\begin{tabular}{|c|c|c|c|}
\hline TPardidio: & Nomithre & Fustadio elwil & Flactas \\
\hline Fups & Chrediela de Coinir: & ensada & ai \\
\hline FIR & 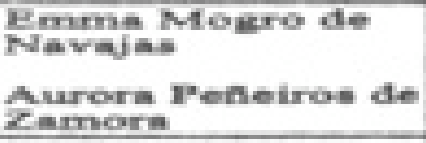 & $\begin{array}{l}\text { onsodia } \\
\text { onsadia }\end{array}$ & \\
\hline Totind & 3 & & 1. \\
\hline
\end{tabular}

-Primen en la lista 
Tableau E

Candidatas y concejalas, por año, según ciudad

\begin{tabular}{|l|c|c|c|c|}
\hline & \multicolumn{2}{|c|}{1947} & \multicolumn{2}{c}{1949} \\
\hline & Candidatas & Concejalas & Candidatas & Concejalas \\
\hline La Paz & 6 & 1 & 5 & 1 \\
\hline Cochabamba & 3 & 2 & 2 & 2 \\
\hline Santa Cruz & 1 & - & 1 & 1 \\
\hline Sucre & 2 & 2 & - & - \\
\hline Potosí & 1 & - & 1 & 1 \\
\hline Oruro & 5 & - & 1 & 1 \\
\hline Trinidad & 2 & - & - & - \\
\hline Tarija & 2 & 1 & 1 & 1 \\
\hline Cobija & 2 & 2 & 2 & 2 \\
\hline Total & $\mathbf{2 4}$ & $\mathbf{8}$ & $\mathbf{1 3}$ & $\mathbf{9}$ \\
\hline $\begin{array}{l}\text { \% de unTotal } \\
\text { de 108 }\end{array}$ & - & $\mathbf{7}$ & - & $\mathbf{8}$ \\
\hline Concejales & & & & \\
\hline
\end{tabular}


Tableau F

Candidatas y concejalas, por año, según partido u organización (1947)

\begin{tabular}{|l|c|c|}
\hline Partido u organización & Candidatas & Concejalas \\
\hline Liberal & 4 & 3 \\
\hline PURS & 6 & 3 \\
\hline PIR & 4 & 1 \\
\hline MNR & 3 & \\
\hline FSB & 1 & \\
\hline JuntasVecinales & 1 & \\
\hline FOS & 1 & \\
\hline Candidatura del Pueblo & 2 & \\
\hline Unión Cívica Cristiana & 1 & 1 \\
\hline Lista Popular & 1 & \\
\hline Total & 24 & 8 \\
\hline
\end{tabular}


Tableau G

\section{Candidatas y concejalas, por año, según partido u organización (1949)}

\begin{tabular}{|l|c|c|}
\hline Partido u organizacion & Candidatas & Concejalas \\
\hline Liberal & 2 & \\
\hline PURS & 4 & 3 \\
\hline $\begin{array}{l}\text { Frente Ant Totalitario } \\
\text { (Liberal, PURS, PASD) }\end{array}$ & 3 & 3 \\
\hline FSB & 1 & 1 \\
\hline Independiente & 1 & 1 \\
\hline POR & 1 & \\
\hline MNR* & & \\
\hline PSD & 1 & 1 \\
\hline Total & 13 & 9 \\
\hline
\end{tabular}

"No se presento a las elecciones municipales 
Comme on peut le voir dans le tableau E, le nombre de femmes candidates s'était réduit considérablement en 1949 puisque seulement 13 candidates se présentèrent aux élections, tandis qu'en 1947 le nombre de candidates était de 24. Pourtant, le nombre de conseillères municipales élues fut un peu plus élevé en 1949 : 9 femmes élues en 1949 ; 8 femmes élues en 1947. Ceci pourrait s'expliquer par le fait qu'après la première expérience réalisée en 1947, la société était peut-être plus disposée à voter pour des femmes en 1949. En observant les tableaux G, on constate qu'à l'exception du POR, aucun parti de gauche (PIR et MNR) ne se présenta aux élections de 1949. La répression contre le MNR (dont les dirigeants étaient en exil depuis 1946) s'était renforcée avec la « guerre civile » d'août 1949 dont on parlera un peu plus tard.

Le nombre de femmes candidates et élues est assez réduit pour les deux années. Le pourcentage de femmes élues fut de 7\% et de 8\% pour les années 1947 et 1949 sur un total de 108 conseillers municipaux. Cependant, ces sommes paraissent tout à fait normales pour des premières élections où les femmes participèrent et furent élues pour la première fois dans des postes politiques.

Mais quel fut l'avis de la société par rapport à cette première participation des femmes en politique?

Dans tous les journaux, le bilan de la participation féminine apparaît comme très positif. La participation des femmes fut considérée comme responsable et même exemplaire. Ainsi, un article de La Razón du 15 décembre 1947 fut intitulé «Les femmes donnèrent un exemple de maturité civique et politique ». L'environnement « tranquille » dans lequel se déroulèrent les élections fut expliqué par la présence des femmes, face à qui les agitateurs n'osèrent pas faire de démonstrations de violence. C'est ce qu'exprime un article de La Razón :

\section{« Le rôle des femmes}

(...) D'autre part, leur conduite servit pour que les élections d'hier aient la hiérarchie qu'elles atteignirent en raison de l'absence absolue d'incidents contraires à la démocratie. »" 336

\footnotetext{
336 « El desempeño de las mujeres.

(...) Su conducta, por otra parte, ha servido para que las elecciones de ayer tengan la jerarquía que alcanzaron por la absoluta ausencia de incidentes contrarios a la democracia. » La Razón, 15 décembre 1947, La Paz. Hemeroteca del Archivo del Congreso, La Paz - Bolivie.
} 
Les femmes semblaient donc avoir passé de manière satisfaisante l'épreuve envisagée par les députés de 1945 qui leur octroyèrent le droit de vote pour les élections municipales. Cependant, si plusieurs hommes considéraient désormais que les femmes pouvaient et devaient participer en politique, plusieurs femmes n'étaient pas du même avis. En effet, plusieurs femmes furent interviewées avant et pendant les élections. À la question «Que pensez-vous de la participation des femmes dans les élections municipales?», une grande partie d'entre elles répondirent qu'elles n'étaient pas d'accord et qu'elles considéraient que les femmes n'étaient pas encore préparées pour voter, ou que les femmes ne devaient participer en politique car leur véritable place était au sein du foyer. L'épouse de l'ex-président Monje Gutierrez, Raquel Soria Galvarro, considérait que les femmes n'étaient pas encore préparées pour voter:

« Je pense que la femme ne doit pas intervenir encore dans les activités politiques. Pour le faire, il est indispensable que sa préparation soit plus consistante et vigoureuse pour stimuler avec une efficacité positive les problèmes difficiles qui doivent s'affronter. L'improvisation dans les aspects politiques a en effet, des résultats déplorables. » ${ }^{337}$

L'épouse de l'ex président de la junte de gouvernement Nestor Guillén, Raquel Riveros, considérait que la politique était un domaine exclusivement dévolu aux hommes et que les femmes qui participaient en politique perdaient leur « féminité » :

« Je ne suis pas d'accord avec la participation de la femme dans un acte électoral de ce type. La femme ne doit pas participer dans ces luttes qui correspondent seulement aux hommes. La femme doit se conserver toujours dans un plan d'élévation et de sérénité. La politique fait que la femme perde sa vertu la plus excellente : la féminité. $\gg{ }^{338}$

\footnotetext{
337 «Pienso que la mujer no ha debido aún intervenir en actividades políticas. Para hacerlo es indispensable que su preparación sea más consistente y vigorosa para impulsar con positiva eficiencia los difíciles problemas que deben encararse. La improvisación en el aspecto político, es pues de resultados deplorables. » El Diario, 14 décembre 1947, La Paz. Hemeroteca del Archivo del Congreso, La Paz - Bolivie.

338 «No estoy de acuerdo con la participación de la mujer en un acto electoral de esta naturaleza. La mujer no debe participar en estas luchas que solo corresponden a los hombres. La mujer debe conservarse siempre en un plano de elevación y de serenidad. La política hace que la mujer pierda su más excelente virtud: la feminidad. » Idem.
} 
L'épouse du chef de l'État Major, Betty de Terrazas, considérait que les femmes ne devaient pas participer en politique directement, mais qu'elles devaient le faire à travers du foyer :

«Je ne suis pas d'accord avec le fait que la femme intervienne avec son vote ni avec son action directe dans les luttes politiques. Mais je considère que depuis le foyer, depuis ce sacré bastion de spiritualité matrimoniale, la femme est, et peut continuer à être la noble conductrice qui oriente l'activité publique : c'est-à-dire, être comme une belle fleur qui répand son arôme pour parfumer l'environnement politique et l'adoucir. » ${ }^{339}$

D'autres femmes furent interviewées lorsqu'elles se trouvaient dans les enceintes électorales pour voter. L'une d'entre elles, Frida Claussen s'exprima ainsi :

« Je crois que la femme ne doit pas intervenir encore dans des actes politiques de ce type. D'après mon avis, la femme doit rester à la maison consacrée entièrement à son foyer. ${ }^{340}$

Une autre femme interviewée, Yolanda S. de Llanos à cette occasion déclara ne pas avoir voté pour aucune candidate car les femmes n'étaient pas préparées pour participer à la chose publique. Elle avoua avoir participé dans les élections par « invitation » de son époux:

« Je n'ai voté pour aucune des candidates car je crois que la femme ne peut pas encore répondre aux délicates fonctions de diriger la chose publique. Les femmes à la cuisine ! Voilà ma devise, même si j'ai dû participer pour voter, invitée gentiment par mon époux. $\rangle^{341}$

D'autres femmes exprimèrent un certain enthousiasme par la participation des femmes dans les élections mais étaient du même avis sur celles qui s'opposaient en considérant que les femmes n'étaient pas encore préparées pour diriger les affaires politiques.

\footnotetext{
339 « No estoy de acuerdo con que la mujer intervenga con su voto ni con su acción directa en las luchas políticas. Pero sí, considero que desde el hogar, desde este sagrado reducto de la espiritualidad matrimonial, la mujer es y puede seguir siendo, la noble conducta que oriente la actividad pública: es decir, ser como bella flor, que difunde su aroma para perfumar el ambiente político y suavizarlo. » Idem.

340 «Creo que la mujer aún no debe intervenir en actos de esta naturaleza. Mi opinión es que debe permanecer en su casa dedicada íntegramente a su hogar. » La Razón, 15 décembre 1947, La Paz. Hemeroteca del Archivo del Congreso, La Paz - Bolivie.

${ }^{341}$ «No he votado por ninguna de las candidatas porque creo que la mujer aún no puede responder a las delicadas funciones de dirigir la cosa pública. ¡Las mujeres a las cocinas! Ese es mi lema, aunque he tenido que concurrir a sufragar invitada gentilmente por mi esposo. » Idem.
} 
C'est le cas de Frida S. de Villanueva qui affirma :

« Je suis touchée et contente car une grande partie des citoyennes a participé dans ces comices qui se déroulent normalement. Ça me rend très heureuse que la femme puisse aussi intervenir dans l'élection pour les dirigeants des fonctions publiques, cependant, je n'ai voté pour aucune femme parce que je pense que nous n'avons pas encore une capacité suffisante pour diriger ces fonctions. » ${ }^{342}$

Cependant, à part celles qui se portaient candidates et qui appartenaient aux organisations féministes, il y eut d'autres femmes qui considéraient que la femme était à sa place en participant en politique et qu'elle était tout à fait capable de diriger les affaires publiques. Quelques unes des interviewées exprimèrent combien cette participation était importante, car la femme contribuerait à la politique et au pays de diverses façons. Ainsi, la sœur du président Hertzog considérait que les femmes « humaniseraient » les élections :

«Je pense qu'avec l'intervention de la femme dans ces élections, celles-ci atteindront une expression d'exceptionnelle élévation et je considère aussi que leur réalité sera humanisée. ${ }^{343}$

María Teresa Solari Ormachea (voir annexe A n²9) se montra à faveur du suffrage féminin et de l'exercice de la charge de maire par une femme :

- « Considérez-vous prudent qu'une femme occupe la mairie dans l'année du centenaire, c'est-à-dire en 1948 ?

- Je crois que les femmes comme les hommes peuvent exercer correctement la plus haute charge municipale. Il est juste nécessaire d'avoir plus d'esprit civique que politique pour y réussir. Le futur Maire doit, avant tout, défendre les intérêts du peuple.

- Croyez-vous que la femme est préparée pour la lutte politique?

- Oui. Et avec cet acte je crois que s'est assis le droit politique de la femme.

- Voulez-vous ajouter un message personnel ?

- Au nom de 1' «Unión Cívica Femenina » je félicite l'élément féminin qui avec beaucoup d'enthousiasme affronte sa fonction patriotique d'élire de représentants pour la Commune. »>344

\footnotetext{
342 «Estoy emocionada y contenta porque una gran parte de las ciudadanas ha concurrido a estos comicios que se desarrollan normalmente. Me complace en grado sumo que la mujer pueda también intervenir en la elección para dirigentes de las funciones públicas, empero no he votado por ninguna mujer porque creo que todavía no tenemos suficiente capacidad para dirigir estas funciones. » Idem.

343 «Pienso que con la intervención de la mujer en este acto eleccionario, éste ha de adquirir una expresión de excepcional elevación, y considero asimismo que su realidad se ha de humanizar. »El Diario, 14 décembre 1947, La Paz. Hemeroteca del Archivo del Congreso, La Paz - Bolivie.

344 «- Considera Ud. .prudente que una mujer ocupe la Alcaldía en el año del centenario, es decir en $1948 ?$
} 
Ces témoignages nous montrent à quel point les femmes des classes moyennes et élevées de la société, presque les seules à pouvoir voter en raison des conditions capacitaires exigées, avaient des avis très différents sur le rôle qu'elles devaient jouer dans la société. Une grande partie d'entre elles considérait que les femmes ne méritaient pas ce droit qu'elles exerçaient, et si quelques unes d'entre elles considéraient qu'elles le méritaient, elles pensaient que les femmes n'étaient pas suffisamment préparées et formées pour exercer des charges publiques. Ainsi, plusieurs d'entre elles refusèrent de voter pour une femme. Les femmes qui considéraient que le vote était véritablement un droit et que la femme devait participer en politique appartenaient pour la plupart à des organisations féminines ou féministes telles que 1'« Ateneo Femenino » qui luttait pour l'obtention du droit de vote depuis les années 1920, et à d'autres organisations culturelles, sociales ou civiques, même si l'on ne connaît pas quels étaient les avis de tous les membres de ces organisations par rapport à la question, mais leur participation dans les campagnes électorales nous laisse supposer qu'elles acceptaient ce droit comme légitime.

La deuxième moitié de la décennie des années 1940 permit aux femmes de s'intégrer dans les partis politiques non seulement pour présenter des candidates aux élections municipales de 1947 et 1949 mais aussi par conviction politique et pour soutenir les membres de leurs familles qui se trouvaient dans l'opposition. Ce fut le cas des femmes qui s'intégrèrent au MNR après que celui-ci fut chassé du pouvoir et banni en 1946 avec la chute de Villarroel.

\footnotetext{
- Creo que tanto los varones como las mujeres pueden desempeñarse correctamente en el máximo cargo municipal. Sólo se requiere tener más espíritu cívico que político para lograrlo. El futuro Alcalde debe, ante todo. defender los intereses del pueblo.

- Cree Ud. que la mujer boliviana está capacitada para la lucha política?

- Sí. Y con este acto considero que se ha fundamentado el derecho el derecho político de la mujer.

- Desea agregar algo personal?

- A nombre de la Unión Cívica Femenina, felicito al elemento femenino que con mucho entusiasmo encara su función patriótica de colegir representantes para la Comuna. » La Razón, 15 décembre 1947, La Paz. Hemeroteca del Archivo del Congreso, La Paz - Bolivie.
} 


\section{c) Les femmes du MNR, la Révolution et le suffrage universel}

Le gouvernement de Hertzog se déroula sous un climat de tensions et mécontentements politiques et sociaux très importants qui étaient des éléments révélateurs de la crise du régime oligarchique qui vivait les derniers moments de son écroulement. Hertzog dut affronter une crise économique qui provoqua un processus d'inflation important contribuant au mécontentement social et politique. Le gouvernement dut s'affronter constamment aux miniers et ouvriers ainsi qu'à une conspiration presque constante des membres du MNR qui travaillaient dans la clandestinité pour renverser le gouvernement. En 1949, le MNR obtint un triomphe important dans les élections parlementaires ce qui provoqua une crise au sein du gouvernement. Arguant qu'il souffrait de problèmes de santé, Enrique Hertzog renonça à la présidence du pays en mai 1949, même s'il le fit officiellement le 22 octobre 1949. Mamerto Urriolagoitia son vice-président devint ainsi président intérimaire en mai 1949 et président constitutionnel en octobre 1949.

En mai 1949, à l'issue d'une grève générale se produit un conflit dans les mines «Siglo XX» de Simón I. Patiño, (le plus important «baron de l'étain »). Urriolagoitia décida d'arrêter les principaux dirigeants. En représailles les miniers prirent en otage deux employés étrangers de la mine et les tuèrent. La réaction du gouvernement fut l'intervention militaire et la tuerie de plusieurs miniers dans ce que fut appelé plus tard la « Massacre de Siglo XX ». C'était le prélude de la rébellion.

Le 27 août 1949 se produit un soulèvement dirigé par le MNR dans quatre villes du pays. Un gouvernement parallèle fut créé et l'on proclama Victor Paz Estenssoro président du pays. Urriolagoitia envoya l'armée qui reprit les villes de Cochabamba et Santa Cruz où se trouvait le foyer rebelle principal. Le 14 septembre le gouvernement reprit le contrôle de tout le territoire. Ce soulèvement, qui fut une sorte de préliminaire à la révolution de 1952, fut appelé la « Guerre Civile » de 1949.

Le 18 mai 1950, la convocation à une grève générale provoqua des émeutes populaires surtout dans les quartiers ouvriers du nord de La Paz sous la direction du 
MNR. L'armée attaqua la zone de «Villa Victoria » avec plusieurs régiments tuant plusieurs ouvriers et manifestants ${ }^{345}$.

Pendant toute cette période du «Sexenio » le MNR fonctionnant dans la clandestinité, prit une force jamais eu auparavant car il réussit à convoquer et organiser un mouvement national composé de secteurs très divers de la société dont les classes moyennes, les ouvriers, les miniers, les paysans, mais aussi les femmes qui s'intégrèrent au parti et contribuèrent dans toutes les actions de celui-ci pendant cette période.

\section{a) Les « Barzolas » : les commandos féminins du $\mathrm{MNR}^{346}$}

Dans ses premières années, le MNR ne fit pas appel aux femmes comme des sujets de transformation de la société. Cependant, après la chute de Villarroel le MNR entra dans un type de fonctionnement différent, car il devait endurer la persécution et la répression du gouvernement. Il était donc impossible pour les militants du parti de lutter ouvertement. Dans ce contexte, le parti fit appel à la solidarité et participation des femmes en tant que mères, épouses et filles des victimes de la « révolution » $d u$ 21 juillet 1946 et des persécutions politiques qui s'ensuivirent. Les femmes passèrent ainsi à jouer un rôle important dans l'organisation des actions clandestines du parti pendant le « Sexenio ».

L'entrée des premières femmes dans le parti fut assez spontanée, car comme le remarque María Isabel Arauco, la plupart de ces femmes étaient des membres de la famille des militants et dirigeants du parti (voir annexe $\left.C \mathrm{n}^{\circ} 24\right):$ «... es posible que entre las motivaciones que indujeron a las primeras movimientistas a ingresar en la política probablemente estaba la relación de parentesco que las vinculaba con militantes y dirigentes del MNR. $\gg{ }^{347}$ Cependant, comme le dit Arauco cela ne veut pas dire que leur engagement politique était d'une moindre valeur: «...esta suposición no quiere en ningún modo negar el valor de una decisión tal, considerando el nivel de la lucha política del momento y las dificultades que debía vencer una

\footnotetext{
345 MESA (de) José, GISBERT Teresa, MESA Gisbert Carlos D., Manual de Historia de Bolivia, Editorial Gisbert, La Paz, 2008.

${ }^{346}$ La plupart des informations sur les « Barzolas » ont été tirées de ARAUCO, María Isabel, Mujeres en la Revolución Nacional: Las Barzolas, Distribución CINCO, La Paz, 1984 et de ARDAYA, Gloria, Política sin rostro: mujeres en Bolivia, Editorial Nueva Sociedad, Venezuela, 1992.

${ }^{347}$ ARAUCO, María Isabel, Mujeres en la Revolución Nacional: Las Barzolas, Distribución CINCO, La Paz, 1984.
} 
mujer que optaba por tal camino. ${ }^{348}$ Ainsi, une partie des premières femmes qui accédèrent dans les luttes politiques du MNR était constituée de membres de la famille des dirigeants et militants de ce parti. Parmi les premières femmes intégrant le parti, l'on peut citer à Ela Campero, Matilde Olmos, Carmen Eguez, Luisa Z. de Caballero, Etelvina de Peña Córdova, Emma Gutierrez de Bedregal, Benita Villanueva de Bedregal, Teófila Cossío, Adriana S. de Cuadros, Graciela de Rodríguez, Marina Pinto de Alvarez Plata, Rosa Uriarte de Sanjinés, Blanca Peña de Sandóval Morón, Isabel Zuazo Rosa Lema Dolz de Lluch (voir annexe A n74), entre autres.

Ces premières femmes commencèrent à s'organiser et à recevoir des instructions, des consignes et des ordres d'action du Comité Politique du Parti. La première apparition publique du MNR et des groupes des femmes qui deviendraient les «commandos féminins » eut lieu le 15 décembre 1946 à l'occasion d'une cérémonie religieuse qui devint une marche en l'honneur de Gualberto Villarroel. Cette manifestation fut réprimée par le gouvernement.

À la fin de 1946 les femmes réalisèrent des actions de propagande pour les candidats du MNR dans les élections de janvier 1947, dans lesquelles Victor Paz Estenssoro réussit à avoir 18.000 votes et deux membres du MNR furent élus députés.

Petit à petit les organisations de ces femmes prirent la forme de commandos féminins intégrés aux structures du parti. Les femmes appartenant à ces commandos féminins choisirent le nom de « Barzolas » en honneur à María Barzola (voir annexe A nº73).

En janvier 1948 le MNR organisa la IV Convention du Parti à La Paz. Formant partie des délégations de Cochabamba et du Beni se trouvaient Rosa Morales Guillén (voir annexe $\mathrm{A} \mathrm{n}^{\circ} 61$ ) et Sabina Vargas de Rivero en représentation des Commandos Féminins de ces villes. En 1948, d'autres femmes s'intégrèrent aux Commandos Féminins, telles que Lydia Gueiler Tejada (voir annexe A $\mathrm{n}^{\circ} 75$ ). Jusqu'alors la plupart des femmes avaient été des parentes des membres du parti. Ainsi : « el ingreso de Lydia Gueiler al MNR significó la expresión individual de la incorporación masiva de las mujeres al partido. $\rangle^{349}$

Postérieurement des femmes célibataires ou chefs de foyer intégrèrent massivement les rangs du parti. Les « Barzolas » participèrent activement dans toutes les tentatives

\footnotetext{
${ }^{348}$ Idem.

349 ARDAYA, Gloria, Política sin rostro: mujeres en Bolivia, Editorial Nueva Sociedad, Venezuela, 1992.
} 
du MNR pour renverser les gouvernements du « Sexenio », dont la « Guerre Civile » de 1949. La répression politique qui suivit cet événement fut très importante, des centaines de militants furent arrêtés ou envoyés dans des zones tropicales et inhospitalières. Cette répression obligea les femmes à jouer un rôle très important en prenant soin des prisonniers et en réalisant de la propagande politique.

L'année 1950 fut consacrée à la préparation des élections générales du 6 mai 1951 où Victor Paz Estenssoro et Hernán Siles Zuazo allaient être présentés comme candidats. Au début de 1951, le gouvernement arrêta des centaines de militants du MNR avec l'objectif de les invalider comme candidats aux élections. Vingt-sept femmes du MNR réalisèrent alors une grève de faim le 20 avril 1951 dans le Palais de Justice en demandant au gouvernement la libération des prisonniers. Cette grève eut beaucoup de succès car elle provoqua la mobilisation de plusieurs secteurs de la population et le gouvernement fut obligé à libérer les prisonniers.

Les actions de violence réalisées par le gouvernement de Mamerto Urriolagoitia telles que la «massacre de Siglo XX» et celle de «Villa Victoria» avaient affaibli considérablement le gouvernement. La grève de faim réalisée par les femmes du MNR provoqua les mobilisations de la population. La popularité du MNR s'était accrue de manière retentissante entre 1949 et 1951 et le gouvernement avait perdu le soutien des classes moyennes, qui était décisif lors des élections.

\section{b) La Révolution Nationale et le Suffrage Universel}

Le MNR gagna les élections du 6 juin 1951 avec une majorité relative de 54.129 (43\%) votes. La candidature du gouvernement avait obtenu 40.381 (32\%) votes. Le résultat des élections surprit Mamerto Urriolagoitia qui refusa de les accepter. Sous prétexte que le résultat de ces élections était un danger pour le pays, puisque le MNR était suspecté d'être affilié au Parti Communiste de la Bolivie, Mamerto Urriolagoitia réalisa un « auto-coup » d'Etat, qui fut qualifié plus tard comme « Mamertazo », en renonçant à la présidence et en transférant illégalement la charge au chef de l'État Major, qui, à son tour, nomma comme président Hugo Ballivián. Le nouveau gouvernement annula les élections et mit le MNR hors la loi. La possibilité de prendre le pouvoir démocratiquement ayant échoué, il ne restait qu'une seule solution: prendre le pouvoir par la force. 
Au début de mars 1952, un des ministres du gouvernement chargé de l'administration interne et de la police nationale, Antonio Seleme prit contact avec les dirigeants du MNR pour planifier un coup d'État contre le gouvernement. Le 9 avril commença une tentative de coup d'État qui finit par devenir une insurrection populaire massive (voir annexe $\mathrm{B} \mathrm{n}^{\circ} 9$ et $\left.\mathrm{n}^{\circ} 10\right)$. Le gouvernement tenta de la réprimer avec les forces armées sous la direction du général Humberto Torres Ortiz. Les luttes, qui eurent lieu surtout à La Paz et à Oruro, durèrent 3 jours pendant lesquels les femmes du MNR jouèrent un rôle important en secourant les blessés, en transportant des armes, en prenant les moyens de communication tels que la radio, et en soutenant émotionnellement et logistiquement les militants du MNR. Le 11 avril le général Torres décida de négocier une trêve avec Hernán Siles Zuazo. La révolution avait triomphé (voir annexe B $\left.\mathrm{n}^{\circ} 11\right)$.

Hernán Siles présida la junte révolutionnaire qui dirigea le pays entre le 11 et le 14 avril pendant l'organisation du retour de Victor Paz Estenssoro de l'exil. Le 15 avril celui-ci arriva à La Paz après six ans d'exil en Argentine et en Uruguay.

La révolution de 1952 fut l'événement politique le plus important et marquant de l'histoire de la Bolivie car elle transforma radicalement la société, le régime politique et l'économie, à tel point qu'il est difficile de comprendre la Bolivie d'aujourd'hui sans comprendre la signification de la Révolution. Trois réformes principales contribuèrent à ces transformations de profondeur: l'octroi du suffrage universel (décret-loi du 21 juillet 1952), la nationalisation des mines (décret loi du 31 octobre 1952), et la réforme agraire (décret loi du 2 août 1953). La minuscule élite politique qui dirigeait le pays fut supplantée par une «classe moyenne » (difficile à cerner sociologiquement) au niveau du pouvoir politique. Les intérêts de l'élite furent profondément affectés avec l'expropriation des grandes exploitations agricoles et la nationalisation des mines. Les secteurs paysans et ouvriers s'intégrèrent à des organisations qui avaient un véritable poids au sein du gouvernement. Les ouvriers et miniers participèrent directement dans les décisions économiques et politiques du pays. Une importante législation du travail fut élaborée ainsi que des lois sociales avancées. D’une économie semi féodale (où le secteur primaire était prépondérant) contrôlée et dépendante de capitaux privés (pour l'industrie minière principalement) l'on passa à une économie contrôlée principalement par l'État (70\%). Une nouvelle bourgeoisie émergea qui tenta d'industrialiser le pays. Il y eut une certaine diversification de l'économie et une plus grande intégration territoriale. Dans les 
campagnes, la réforme agraire élimina les grandes exploitations et permit le début du procès d'intégration des paysans à la vie nationale ${ }^{350}$. Avec l'octroi du suffrage universel, le monopole de la politique par une petite minorité d'hommes blancs et métis, sachant lire et écrire et ayant une situation économique relativement aisée, fut finalement brisé. Il faut rappeler que dans les élections de 1951, seuls 204.649 électeurs étaient inscrits pour voter, c'est-à-dire, $6,78 \%$ de la population ${ }^{351}$. Désormais la plus grande partie de la population hommes et femmes pouvaient participer dans la vie politique du pays non seulement en tant qu'électeurs mais aussi en tant que potentiels éligibles aux charges politiques nationales.

Le rôle joué par les femmes dans la société et dans la lutte contre le régime oligarchique du « Sexenio » fut reconnu dans les considérations prises en compte pour établir le suffrage universel dans le pays. Le décret-loi du 21 juillet 1952 s'exprima sur ce rôle ainsi :

\section{« (...) CONSIDÉRANT :}

Que la mentalité féodale, caractéristique des organisateurs d'un tel régime politique ne pouvait pas reconnaître l'importante participation que la femme a dans la vie de toute la société organisée, participation qui fut manifeste dans la courageuse lutte du peuple de la Bolivie, dans les six dernières années, contre l'oligarchie (...)

(Victor Paz Estenssoro, Président Consitutionnel de la République) DÉCRÈTE :

Article $1^{\circ}$ - Auront le droit de vote pour la formation des pouvoirs publiques, tous les boliviens, hommes et femmes, âgés de plus de 21 ans si célibataires et de plus de 18 ans si mariés, n'importe quel soit leur degré d'instruction, leur occupation ou leur rente. $»^{352}$

Toutes les femmes boliviennes obtinrent ainsi le droit de vote et participèrent pour la première fois dans les élections nationales en 1956. L'élargissement de la démocratie

\footnotetext{
${ }^{350}$ MESA (de) José, GISBERT Teresa, MESA Gisbert Carlos D., Manual de Historia de Bolivia, Editorial Gisbert, La Paz, 2008.

${ }^{351}$ LEAÑO ROMÁN Eduardo, Sistemas electorales en Boliva. La Conversión de votos del Ejecutivo y Legislativo, Unidad de Análisis e Investigación del Area de Educación Ciudadana de la Corte Nacional Electoral, Corte Nacional Electoral, La Paz - Bolivia, 1ère édition février 2005, p. 37.

352 «(...) CONSIDERANDO:

Que la mentalidad feudal, característica de los organizadores de tal régimen político, no podía reconocer la importante participación que la mujer tiene en la vida de toda sociedad organizada, pariticipación que se hizo patente en la valerosa lucha del pueblo de Bolivia, en los últimos seis años contra la oligarquía (...)

(Victor Paz Estenssoro, Presidente Constitucional de la República) DECRETA:

Artículo $1^{\circ}$ - Tendrán el derecho al voto para la formación de los poderes públicos, todos los bolivianos, hombres y mujeres, mayores de veintiún años de edad siendo solteros o de dieciocho siendo casados, cualquiera que sea su grado de instrucción, su ocupación o renta.» Décret-loi du 21 juillet 1952, Anuario de 1952, Archivos del Congreso, La Paz - Bolivie.
} 
en 1952 dans le cadre d'une révolution concerna tant les femmes que les hommes. La question de l'intégration des femmes dans la vie politique se dissout ainsi dans la question de l'intégration de la majorité de la population dans la vie politique du pays. Les questions de genre furent dissoutes dans les questions de transformations sociales, politiques et économiques du pays que le gouvernement de la Révolution implanta. Ce même phénomène eut lieu dans les organisations des « Barzolas » qui s'intégrèrent aux structures du parti mais de manière subordonnée. Intégrées aux structures du parti dans des fonctions secondaires et subordonnées, les femmes du MNR ne mirent pas en avant leurs demandes de genre, telles que l'accession des femmes dans les charges les plus importantes du gouvernement. Les affaires et problèmes que devait affronter le parti furent toujours prioritaires aux questions de genre au sein du parti et $d u$ gouvernement. À part quelques femmes telles que Lydia Gueiler (voir annexe A $\mathrm{n}^{\circ} 75$ ), Rosa Lema Dolz (voir annexe A ${ }^{\circ}{ }^{\circ 4}$ ) et Zoila Viganó (voir annexe A n42) qui réussirent à devenir députés pendant les années 1950 et le début des années 1960, la plupart des femmes appartenant au MNR, furent reléguées dans des postes secondaires et subordonnés. Comme 1'affirme Gloria Ardaya : « En el sistema político emergente, las mujeres se reinsertaron de manera subordinada y no tuvieron un espacio cualitativo diferenciado de acción y de representación. Las militantes que tuvieron acciones extraordinarias y de mucho valor durante el sexenio y en la propia insurrección, no recuperaron estas acciones para su propio potenciamiento posterior. Se comprobó a través de ellas lo que ya había ocurrido en varias experiencias históricas, en que las mujeres suelen ser extraordinarias en la resistencia, clandestinidad e insurrección, pero carecen de entrenamiento o no son incorporadas a la gestión política en tiempos de vigencia de la democracia. Ello porque, como ya se ha reiterado, probablemente la experiencia histórica de las mujeres es el mundo “privado-doméstico" en el cual está vedada una participación igualitaria en el mundo de la política. »" 353

Les années 1940 qui connurent un certain déclin des organisations féministes, illustrée par le peu de manifestations réalisées lors de la discussion du suffrage féminin dans la Convention de 1945, signifièrent l'intégration des femmes dans la vie politique par l'octroi du droit de vote restreint et limité aux élections municipales.

\footnotetext{
${ }^{353}$ ARDAYA, Gloria, Política sin rostro: mujeres en Bolivia, Editorial Nueva Sociedad, Venezuela, 1992.
} 
Même si les organisations féminines et féministes pouvaient participer dans celles-ci de manière indépendante, aucune d'entre elles ne se présenta ainsi. Toutes les organisations s'allièrent aux partis politiques dans lesquels des sections féminines furent créées. En permettant l'intégration des femmes en politique, la fin des années 1940 signifia un changement dans le mode à travers lesquels les femmes accédaient à l'espace public pour faire valoir leurs demandes. Les partis politiques devinrent les principales plateformes et moyens que devaient utiliser les femmes pour revendiquer leurs droits. Les organisations féministes commencèrent donc à perdre leur raison d'être dans ce nouveau contexte. S'il y eut donc un processus dans lequel les femmes mirent en avant leurs demandes de genre au sein des partis politiques, comme par exemple la section féminine du «PURS» qui demanda le droit de vote pour les femmes dans les mêmes conditions que les hommes dans la deuxième convention $d u$ parti en novembre 1949, la donne générale fut la subordination des questions de genre aux priorités du parti politique, comme par exemple les actions des « Barzolas » pour la prise du pouvoir pendant la période du «Sexenio ». Ainsi, les femmes qui intégrèrent les partis et surtout celles qui intégrèrent le MNR mirent de côté leurs demandes de genre et participèrent aux actions du parti de manière auxiliaire et toujours subordonnée. Une fois la Révolution accomplie, les femmes qui avaient intégré le MNR (dont plusieurs féministes telles que María Luisa Sánchez Bustamante (voir annexe $\mathrm{A} \mathrm{n}^{\circ} 10$ ), Zoila Viganó (voir annexe A n42), Aida Carvajal (voir annexe A n ${ }^{\circ} 47$ ), Rosa Morales Guillén (voir annexe A n61)), ne réussirent pas à intégrer leurs demandes en tant que femmes au sein du gouvernement de type corporatiste qu'avait créé le MNR. Après l'octroi du suffrage universel en 1952 et l'intégration des femmes au sein du MNR et d'autres partis politiques, les organisations féministes perdirent complètement leur raison d'être. L'«Ateneo Femenino », la seule organisation qui perdurait depuis les années 1920 et la seule à avoir eu une durée de vie longue, continua à fonctionner jusqu'au début des années 1980, non plus en tant qu'organisation féministe, mais en tant qu'organisation culturelle réunissant toujours des femmes des classes moyennes et élevées de la société. Le mouvement féministe qui avait commencé dans les années 1920 se dissout ainsi dans un contexte où les femmes intégrèrent les partis politiques sans pour autant faire valoir leurs revendications de genre, car elles durent se subordonner aux priorités du parti qui étaient beaucoup plus générales et concernaient, sous une logique de classe et non de 
genre, des secteurs de la population beaucoup plus larges, dont les nouveaux acteurs politiques d'importance à l'époque : les ouvriers, les miniers et les paysans. 


\section{$\underline{\text { Conclusion }}$}

Les organisations féministes qui composaient le mouvement féministe né en Bolivie dans les années 1920 et dissout après l'obtention du suffrage universel avec la révolution de 1952, furent chacune le produit du contexte social, politique et culturel dans lequel elles étaient apparues et auquel elles devaient s'affronter. Ainsi, les premières organisations féministes qui surgirent à l'issue du développement de l'éducation des femmes par le gouvernement libéral du début du $\mathrm{XX}^{\mathrm{e}}$ siècle, constituées tout d'abord comme des centres culturels où les premières générations de femmes éduquées et cultivées appartenant aux classes moyennes de la société trouvèrent un espace pour s'exprimer autour de l'art, de littérature, de peinture, etc. Ce fut dans la première de ces organisations, le «Centro Artístico e Intelectual de Señoritas de Oruro », que naquit une conscience de genre parmi les femmes qui le composaient. En tant que femmes bénéficiaires d'une éducation privilégiée, les membres de cette organisation ne comprenaient pas pourquoi les femmes devaient rester reléguées hors de la vie publique et politique du pays, d'autant plus qu'elles remplissaient une des conditions essentielles pour devenir citoyennes à l'époque, savoir lire et écrire. Elles avaient connu une première émancipation à travers de l'éducation, il fallait que celle-ci soit traduite dans les lois et dans les droits dont ces femmes devaient disposer : droit à l'éducation et droits civils. Le « Centro Artístico e Intelectual de Señoritas de Oruro » fut l'étincelle qui raviva cette prise de conscience dans d'autres villes du pays. Sous son exemple, plusieurs autres organisations furent créées dans les principales villes de la Bolivie: La Paz, Cochabamba, Potosí. Ces organisations qui reprirent la structure d'organisation du «Centro Artístico e Intelectual de Señoritas de Oruro », naquirent comme des organisations culturelles mais aussi comme des organisations féministes destinées à défendre la culture des femmes et leurs droits. Ce fut le cas de «Iris » à Cochabamba, le «Centro Ideal Femenino » et 1'《Ateneo Femenino » à La Paz, qui, comme principal moyen de communication de leurs idées et de leurs revendications publièrent des revues féminines - féministes dans lesquelles étaient publiées non seulement leurs travaux culturels tels que des poèmes et des essais littéraires, mais aussi des informations sur les actions de l'organisation, des réflexions sur l'éducation des femmes, des informations sur les avances du féminisme à l'étranger, et des réflexions sur la 
définition même du féminisme. «Feminiflor», «Eco Femenino », «Indice », « Venas de Plata », « Aspiración » et « Anhelos » furent les moyens à travers lesquels ces femmes firent connaître leurs désirs, inquiétudes et revendications. Ce fut dans ces revues que les organisations féministes des années 1920 exprimèrent ce qu'elles entendaient pour féminisme et comment se définissaient elles mêmes en tant que féministes. En critiquant le féminisme anglo-saxon, qu'elles qualifièrent de « violent », « excessif » et « masculin » elles proposèrent un type de féminisme plus modéré mettant en avant les qualités essentiellement féminines de « la femme » et son rôle de reproductrices dans la société à travers l'exaltation de la maternité et de l'éducation des enfants, futurs citoyens de la patrie. Dans ce sens, elles insistèrent sur le rôle que les femmes devaient jouer pour le progrès de la «patrie » avec la formation des citoyens responsables, moraux, et cultivés. Elles essayèrent de démontrer ainsi l'importance du rôle joué par les femmes dans la société et dans le pays : les femmes en tant que mères permettaient la reproduction de la société et en tant qu'éducatrices de leurs enfants, permettaient la formation de citoyens de valeur qui seraient des facteurs de « progrès » pour le pays. C'est pour cette raison, que ces organisations insistaient particulièrement sur l'éducation des femmes. Les femmes devaient bénéficier d'une bonne éducation qui leur permettrait d'êtres de bonnes épouses, mères et surtout de bonnes éducatrices des hommes qui changeraient le destin de la nation par le « progrès » et l'accession de la Bolivie au rang des nations « civilisées ». Les droits civils devaient également être accordés aux femmes car le Code Civil qui régissait leur vie civile était archaïque et n'était plus adapté aux conditions de vie des femmes du début du $\mathrm{XX}^{\mathrm{e}}$ siècle. Le droit de vote était également envisagé par ces organisations. Cependant une grande partie de celles-ci le voyaient comme un objectif à atteindre à long terme: les femmes devaient s'éduquer et obtenir leurs droits civils d'abord pour ensuite envisager l'obtention des droits politiques. La seule organisation qui envisagea l'obtention du droit de vote de manière plus immédiate était l'« Ateneo Femenino ». Pourtant, les membres de cette organisation tout comme les membres des autres organisations, considéraient qu'il fallait procéder par étapes avec l'éducation des femmes et les droits civils d'abord pour ensuite obtenir le droit de vote.

Par leur composition sociale (femmes éduquées (proviseures, professeures) des classes moyennes et élevées de la société) et le type de féminisme qu'elles revendiquaient, les organisations féministes boliviennes ne se distinguaient pas de 
celles surgies dans d'autres pays de l'Amérique Latine où les processus de développement de l'éducation des femmes permirent le surgissement des premières organisations féministes agissant le plus souvent dans un cadre légal et pacifiste. Dans ce sens, le mouvement féministe de la Bolivie ne diffère pas du tout de ceux des autres pays.

Toutes les organisations des années 1920 à exception de l' «Ateneo Femenino » eurent une durée de vie assez courte. Elles disparurent assez vite avec leurs revues et ne connurent donc pas une organisation assez solide et durable qui leur aurait permis de réaliser des actions plus importantes, à part la publication de revues féminines féministes. La seule organisation par sa durée de vie et sa solidité qui put réaliser des actions plus concrètes en vue de l'obtention des droits civils et politiques fut l'«Ateneo Femenino »: ses membres participèrent à des Congrès internationaux de femmes, furent à l'origine d'un projet de modification du Code Civil octroyant les droits civils aux femmes en 1925 avec l'aide du jurisconsulte Benjamin H. Gallardo, et organisèrent le premier Congrès National de femmes dans le pays. Cependant, par l'indifférence exprimée par les hommes politiques de l'époque à l'égard du projet présenté, et l'abîme social et culturel qui existait entre les femmes de l' « Ateneo » et celles de syndicats réunies dans la Congrès des femmes de 1929, ces actions furent un échec. Faisant partie de l'élite économique et intellectuelle du pays, les féministes des années 1920 soutenaient le régime oligarchique qui gouvernait le pays depuis la fin du $\mathrm{XIX}^{\mathrm{e}}$. La manière dont elles envisageaient l'amélioration des conditions de vie des plus défavorisés comme par exemple les indigènes et les femmes des classes populaires, était structurée par leur origine sociale et leur position de classe. Ainsi, elles envisageant les œuvres sociales sous le prisme de la charité chrétienne, et ne proposaient en aucun cas des changements sociaux plus profonds. Ce fut pour cette raison qu'elles ne s'entendirent pas avec les femmes des classes populaires appartenant à des syndicats d'idéologie marxiste et anarchiste durant le Congrès de femmes de 1929, et qu'elles ne purent pas former des alliances avec les femmes des classes populaires sous une bannière de genre. Les manières dont les féministes des années 1920 et les femmes syndiquées comprenaient le rôle et la place que «la femme » devait avoir dans la société étaient ainsi structurées par leur position de classe.

Cependant, la Guerre du Chaco dans les années 1930 transforma complètement la manière dont les féministes envisageaient leur rôle dans la société et transforma par 
conséquent ses stratégies ainsi que les objectifs à atteindre. Bouleversement majeur dans la vie politique, sociale, économique et culturelle du pays, il le fut également pour la vie des femmes qui durent contribuer de manière très importante à l'effort de guerre. Leur participation dans cet événement en tant que secouristes, marraines de guerre apportant de l'aide aux mobilisés et à leurs familles, fut reconnue par la société et surtout par un groupe de femmes qui considérait que c'était l'occasion idéale pour demander les droits civils et politiques. Par leur contribution à l'effort de guerre et leur accès massif au marché du travail, les femmes avaient démontré toutes leurs capacités et habiletés pour s'affronter aux problèmes qu'endurait le pays. Dans un contexte où les hommes étaient absents et avec des élections présidentielles qui approchaient, un groupe de femmes organisa le «Comité de Acción Feminista » qui se chargea de l'organisation et réalisation d'une intense campagne pour l'obtention des droits civils et politiques des femmes avant les élections présidentielles de 1934. Si les femmes étaient capables de prendre en charge la société pendant que les hommes étaient au Front, elles seraient aussi capables de diriger le pays dans une situation aussi critique. En outre, si les femmes remplissaient leurs devoirs pour la patrie de manière exceptionnelle, elles méritaient l'obtention des droits. Tels furent les arguments exprimés dans cette campagne qu'eut lieu à travers les journaux et la radio. Si les féministes des années 1920 revendiquaient ses droits en tant que femmes (féminines, mères, épouses) les féministes actives pendant la guerre envisageaient les droits en tant qu'individus: d'après les dirigeantes de cette campagne, lorsque la Constitution parlait des hommes, elle se référait aux hommes et aux femmes en tant qu'individus et non pas en tant qu'hommes, c'est-à-dire, en tant que sujets masculins. Malgré le gros effort mis dans cette campagne qui reçut le soutien d'hommes intellectuels et politiques, tels que José María Gutiérrez, chef du Parti Libéral, et les parlementaires qui présentèrent un projet de loi au parlement pour l'octroi des droits civils et politiques aux femmes, les objectifs ne furent pas atteints. D'autres femmes, (dont les membres de l' «Ateneo Femenino ») s'opposèrent à la campagne en accusant les membres du «Comité Feminista » d'être «égoïstes », car le pays avait d'autres priorités beaucoup plus urgentes à régler que l'octroi des droits civils et politiques aux femmes. Leurs revendications devaient donc attendre le retour des temps de paix. Lorsque ce moment arriva avec tous les changements de l'après guerre dans une société complètement frustrée par la défaite et cherchant désespérément des nouvelles orientations politiques, les féministes qu'avaient dirigé la campagne 
féministe de 1934 s'organisèrent d'une toute autre manière et s'adaptèrent au nouveau contexte politique et social d'après guerre. Elles créèrent en Bolivie des organisations qui avaient des bases dans d'autres pays latino-américains, en quête de pacifisme et de liens avec les femmes des autres pays pour harmoniser une lutte féministe continentale. Ainsi, surgirent la «LFEPA » et la «UMA » quelques mois après la fin du conflit. Dans un contexte où le socialisme se constituait comme le nouveau phare idéologique revendiqué par plusieurs partis politiques, même par les plus traditionnels («PURS »), et par le nouveau gouvernement dans les mains des militaires, qualifié de « socialisme militaire », ces deux organisations devaient prendre en compte dans leurs objectifs et revendications les principes du « socialisme » entendu comme la quête de l'amélioration de conditions de vie des plus défavorisés. Ainsi, ses objectifs en plus d'inclure l'obtention des droits civils et politiques, s'élargirent pour inclure des inquiétudes sociales telles que l'amélioration des conditions de vie des femmes des classes populaires. Il fallait désormais penser à la protection des mères célibataires, des prostituées, et des enfants en général. L'égalité des enfants devant la loi et l'autorisation des enquêtes en paternité étaient désormais des nouveaux objectifs à atteindre. Cependant, comme le révéla la Convention des membres de la «LFEPA », la composition de cette organisation était très hétérogène : même si les femmes des classes moyennes cherchant des nouvelles orientations politiques en constituaient la majorité, l'organisation se composait aussi de femmes des classes élevées de la société qui s'opposaient à ces objectifs, comme le démontra dans les années 1940 la présence d'anciennes membres de la «LFEPA » parmi les femmes qui demandaient aux parlementaires de ne pas voter pour l'égalité des enfants devant la loi et l'autorisation des enquêtes en paternité. Les changements survenus après la guerre dans le domaine politique qui promettait des changements à la population, la reconnaissance du rôle que les femmes avaient joué pendant la guerre et leur entrée massive au marché du travail, ainsi que les actions de la «LFEPA » favorisèrent les initiatives prises par les gouvernements $d u$ « socialisme militaire » pour octroyer les droits civils (décret de Toro en 1936) et les droits politiques (débats sur le suffrage féminin dans la Convention de 1938) aux femmes. Cependant, les résistances à ces changements étaient encore trop importantes : le décret de Toro ne bénéficia pas du soutien nécessaire pour être appliqué, la majorité des parlementaires de 1938 s'opposèrent au suffrage féminin car ils considéraient que la place des femmes était au sein du foyer et que les femmes n'étaient pas suffisamment préparées pour 
participer en politique. Les promesses des changements radicaux à venir avec le « socialisme militaire » ne furent pas suffisamment « radicales » pour octroyer les droits civils et politiques aux femmes.

La décennie des années 1940 plus silencieuse à l'égard des organisations féministes, fut marquée par l'écroulement final du régime oligarchique avec le gouvernement composé par les membres du MNR et RADEPA de Gualberto Villarroel et le retour en réaction des forces traditionnelles qui tentèrent de s'imposer au pouvoir une dernière fois avant leur explosion finale. La Convention de 1945, qui compléta et élargit celle de 1938, accorda certains droits qui amélioraient la condition de vie des femmes. La Constitution élaborée à cette occasion proclama l'égalité juridique des conjoints (pas appliquée) ainsi que la légalité des mariages de fait. Des objectifs recherchés par les membres de la «LFEPA» (dissoute déjà à l'époque) telles que l'égalité des enfants devant la loi et l'autorisation des enquêtes en paternité furent également proclamés, malgré l'opposition d'organisation féminines catholiques et d'organisations féministes telles que l'«Ateneo Femenino » et la «Federación de Sociedades Culturales Femeninas », qui en outre, se manifestèrent peu par rapport aux débats sur le suffrage féminin. Les avances d'autres pays par rapport à cette dernière question, les accords signés par la Bolivie, la mise en valeur de la participation des femmes dans la Guerre du Chaco ainsi que leur accès massif au marché du travail déjà confirmé dans le temps, permirent que les débats par rapport au droit de vote des femmes se réalisent dans un climat de consensus différent à celui de 1938. Les parlementaires de cette époque octroyèrent ainsi le droit de vote restreint aux femmes qui savaient lire et écrire dans le cadre des élections municipales. Les femmes des classes moyennes et élevées de la société purent exercer ce droit pour la première fois en 1947 et en 1949 sous la période du « Sexenio ». L'octroi de ce droit permit aux organisations féminines et féministes de s'organiser pour y présenter leurs candidates et réaliser une campagne électorale. Cependant, les partis politiques commencèrent à s'imposer comme la plateforme privilégiée pour les femmes afin d'accéder en politique. Les organisations féministes commençaient donc à perdre leur raison d'être car les revendications de genre se réalisaient aussi au sein des partis politiques. Une fois le droit de vote restreint ayant été obtenu, il ne restait qu'à demander le droit de vote sans restrictions. Ces demandes se réalisèrent au sein d'organisations féministes qui avaient hérité des objectifs et de l'organisation de la «LFEPA », comme la «Agrupación Interamerciana de Mujeres », mais aussi au sein des partis politiques. 
En même temps que le processus où les partis politiques apparaissaient comme des espaces privilégiés pour la revendication des demandes de genre, un autre processus eut lieu: celui de l'intégration des femmes aux partis politiques par leurs liens familiaux et par leur conviction politique afin de contribuer à la réalisation des objectifs du parti. Ce fut le cas des femmes qui intégrèrent le MNR pour contribuer à la prise du pouvoir de celui-ci avant et après la Révolution. Ces femmes s'intégrèrent aux structures du parti, mais de manière subordonnée et ne réussirent pas à faire valoir leurs demandes en tant que femmes surtout lorsque le parti avait déjà pris le pouvoir en 1952. La question d'intégration des femmes à la vie politique du pays fut dissoute dans la question de l'intégration des majorités nationales à la nation, d'où la proclamation du suffrage universel qui octroyait le droit de vote tant aux femmes comme aux hommes. Les hommes qui avaient formé partie des subordonnés, à savoir, les ouvriers, les miniers, et les paysans devinrent des acteurs essentiels dans un État révolutionnaire corporatiste. Dans cette structure la place donnée aux femmes, qui ne constituaient pas une classe en soi, mais qui traversaient toutes les classes sociales en occupant toujours une place subordonnée, était subalterne. Dans ce contexte le mouvement féministe qui avait eu comme un de ses objectifs principaux depuis les années 1920, l'obtention du droit de vote, n'avait plus raison d'être. Après 1952 et l'obtention du suffrage universel, les modalités pour l'accession des femmes en politique et surtout aux plus hautes sphères du pouvoir n'étaient plus les mêmes qu'avant, mais cela relève d'une toute autre histoire. 


\section{Annexes}

\section{A) Biographies de femmes ${ }^{354}$}

\section{1.- Smith Peñaranda Elena}

Professeure prestigieuse née à La Paz. Elle fut une des élèves boursières qui partit étudier à l'Ecole Normale Supérieure du Chili. Elle commença à enseigner à son retour en 1911 au « Colegio de Niñas » de La Paz, nommé «Liceo de Señoritas » en 1912. Elle y enseigna la Grammaire, la Littérature, l'Histoire et l'Education Civique. A partir de 1919 et jusqu'en 1938, elle devint Proviseur de ce lycée qui désormais était nommé «Liceo de Señoritas Venezuela» où elle réalisa un travail culturel et éducatif important pour les jeunes femmes étudiantes.

\section{2.- María Gutierrez de Medinaceli}

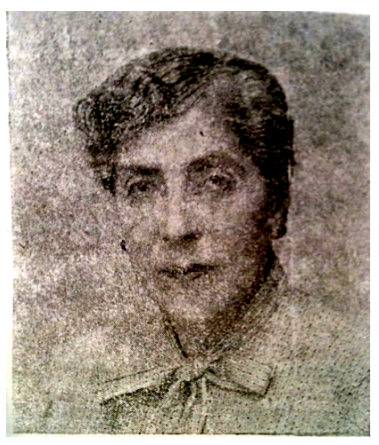

Poète et professeure normalienne née à Sucre. Elle étudia à l'Ecole Normale Supérieure de Sucre et obtint son diplôme en 1910. Elle fut une des promotrices de l'instauration du cycle d'éducation secondaire pour les filles à Sucre, Oruro et Potosí. Ainsi, elle fut une des fondatrices du «Liceo de Señoritas María Josefa Mujía ». En 1914 elle devint Proviseur de cet établissement. Elle fut également la fondatrice de la première brigade de «Girls Scouts" à Oruro le 25 mai 1915. Le Ministère d'Education honora ce travail en lui attribuant un diplôme. En 1917, elle partit à Potosí où elle fonda le "Liceo de Señoritas".

\footnotetext{
${ }^{354}$ La plupart de ces biographies ont été réalisées sur la base d'informations tirée de PAREDES de Salazar Elssa, Diccionario biográfico de la Mujer Boliviana, Ediciones « Isla », La Paz, 1965.
} 
Son travail littéraire en tant que poète fut fécond à Potosí où elle était le seul membre féminin du groupe et de la revue littéraires Gesta Bárbara. Elle fonda également les revues «Atenhea » et «Claridad» qui appartenaient au «Liceo de Señoritas ». Elle fut de la même manière une active correspondante à Potosí du «Ateneo Femenino » de La Paz, et du « Círculo Hispano Americano » de femmes. Elle organisa des débats et des conférences sur la Loi du Divorce Absolu et les avantages qu'elle signifiait pour l'émancipation des femmes. Elle fonda à Potosí la "Fête des Mères".

Elle fut membre du «Comité de Acción Feminista » à La Paz en 1934. Pendant la Guerre du Chaco elle fut Secrétaire ad honorem de l'Association Pro-Prisonniers de Guerre de 1934 à 1936.

En reconnaissance à son travail éducatif, la société de Potosí lui attribua le titre de "Maestra de la Juventud Femenina de Potosí” le 3 février 1936.

Le 10 novembre 1944 le Gouvernement lui remit la décoration « Orden del Mérito al Maestro » avec le grade d'Officier.

\section{3.- Nelly López Rosse ${ }^{355}$}

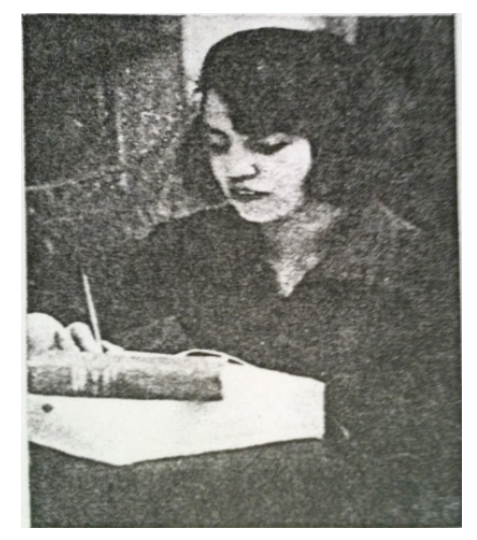

Née l'année 1900 à Oruro, elle réalisa ses études au «Colegio Nacional Bolívar ». Elle fut la première bachelière femme de Oruro. Elle forma partie d'un groupe de jeunes femmes qui envoya une pétition signée au Recteur du «Colegio Nacional Bolívar » et au Ministère de 1'Education pour qu'il leur soit permit d'assister en cours dans ce lycée avec les garçons, puisque il n'existait pas encore de Lycée

\footnotetext{
${ }^{355}$ Les informations et la photographie de Nelly López Rosse ont été tirées de ALEXANDER de Alvéstegui Bertha « Memoria de la administradora Nelly López de Fernández » dans BELTRAN Luis Ramiro (comp.), "Feminiflor" Un hito en el periodismo femenino de Bolivia", CIMCA, Círculo de Mujeres Periodistas, CIDEM, (n.d.).
} 
pour filles proposant des études secondaires. La permission leur fut finalement accordée.

En compagnie de Laura Graciela de la Rosa Torres (voir annexe A n ${ }^{\circ}$ ) et de Betshabé Salmón Fariñas (voir annexe $\mathrm{A} \mathrm{n}^{\circ} 4$ ) elle fonda le «Centro Artístico e Intelectual de Señoritas de Oruro ». En 1921 elle fut chargée de l'administration de la revue « Feminiflor » publiée par ce Centre.

\section{4. - Bethsabé Salmón Fariñas de Beltrán ${ }^{356}$}

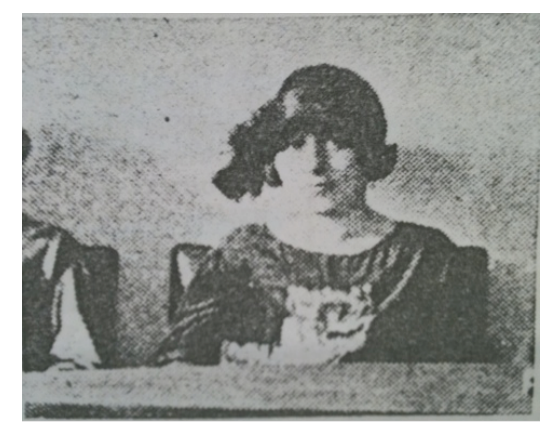

Née en 1899 à la ville de La Paz, elle forma partie des premières générations de bachelières du « Liceo de Señoritas » de cette ville et par conséquent du pays. Elle fut membre intégrant de la brigade de «Girls Scouts» et de la Croix Rouge Bolivienne. Partie à Oruro en 1919, elle fut une des premières femmes à travailler dans un bureau dans cette ville en tant que Secrétaire correspondante dans une entreprise (Isabel Barrenechea fut l'autre pionnière à travailler dans un bureau au sein de la Banque Centrale). Elle s'inscrivit en tant qu'auditrice au lycée de garçons « Colegio Bolívar » pour soutenir les quelques femmes qui assistaient en cours malgré les restrictions.

En 1920 elle fonda le «Centro Artístico e Intelectual de Señoritas de Oruro » avec Laura Graciela de la Rosa Torres et Nelly López Rosse. Un an après, en 1921, elles

\footnotetext{
${ }^{356}$ Les informations sur la vie de Bethsabé Salmón ont été tirées d’un entretien réalisé avec son fils Luis Ramiro Beltrán à $\mathrm{La} \mathrm{Paz}$ en août 2010, et des documents fournis et produits par celui-ci: "Resumen biográfico de Betshabe Salmón viuda de Beltrán"; "Mujer y prensa en Bolivia: la experiencia precursora de "Feminiflor" de Oruro en 1921-1923", conférence réalisée le 10 avril 1995 au Musée d'Ethnologie et de Folklore; "Palabras de Luis Ramiro Beltrán Salmón en memoria de sus padres en la presentación del libro Testimonio: Memoria Fotográfica en Homenaje a los Beneméritos de la Guerra del Chaco en La Paz en septiembre de 2008"; "Doña Becha y la Revista "Feminiflor" de Oruro"; BELTRAN Luis Ramiro (comp.), "Feminiflor" Un hito en el periodismo femenino de Bolivia”, CIMCA, Círculo de Mujeres Periodistas, CIDEM, (n.d.). Les photographies de Bethsabé Salmón ont été tirées de ce dernier ouvrage.
} 
fondèrent la revue féminine du Centre : «Feminiflor» qui circula jusqu'en 1923. Betshabé était la rédactrice en chef, Laura Graciela de la Rosa Torres la directrice de la revue, et Nelly López était chargée de l'administration. Ce fut la première revue féminine - féministe à être fondée dans le pays.

Pendant le Guerre du Chaco elle travailla dans la «Liga Filial » d'Oruro avec Laura Graciela de La Rosa Torres, association vouée à prêter des services divers aux soldats et à leurs familles. Avant de partir au Front son mari lui demanda de lui promettre que s'il mourait dans la guerre, sa dépouille mortelle serait transportée à Oruro pour reposer près de ses proches. Avec beaucoup d'efforts, Bethsabé réussit à tenir sa promesse en 1940 lorsqu'elle ramena du Paraguay jusqu'à Oruro la dépouille mortelle de son mari.

\section{5.- Laura Graciela de La Rosa Torres ${ }^{357}$}

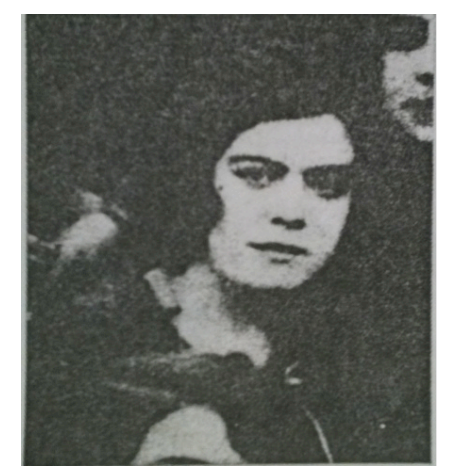

Fondatrice du «Centro Artístico e Intelectual de Señoritas de Oruro » avec Bethsabé Salmón Fariñas et Nelly López Rosse, elle fut également la Directrice de la revue « Feminiflor » produite par ce Centre. Après avoir passé un long séjour au Chili en tant qu'adjointe culturelle de l'Ambassade de Bolivie à la fin des années 1920, elle retourna dans son pays lorsque la Guerre du Chaco éclata contre le Paraguay en 1932. Elle fonda la «Liga Filial» d'Oruro, association qui se chargeait de la rédaction de lettres (pour les familles qui ne savaient pas écrire) et de leur envoi aux soldats qui se trouvaient dans le Front. Cette association se chargeait aussi de donner des vêtements

\footnotetext{
${ }^{357}$ Les informations et les photographies de Laura Graciela de la Rosa Torres ont été tirées de l'entretien réalisé avec Laura Graciela de la Rosa Torres à Cochabamba - Bolivie en 1987 par Sandra Aliaga Bruch, et inclus sous le titre de «"Eramos audaces" Testimonio de la Directora Laura G. de La Rosa Torres » dans l'ouvrage de BELTRAN Luis Ramiro (comp.), "Feminiflor" Un hito en el periodismo femenino de Bolivia”, CIMCA, Círculo de Mujeres Periodistas, CIDEM, (n.d.).
} 
et le petit-déjeuner aux enfants des combattants. De même, les membres de cette association étaient marraines de guerre des soldats. Elles créèrent la première bibliothèque militaire à Villamontes.

Partie au Front avec d'autres femmes membres de la Liga Filial pour emmener des aliments et des vêtements aux soldats, elle écrivit un livre sur son expérience dans le Front: «Mi visita a las trincheras y zanjas del velo », dont la plus grande partie du contenu fut censurée par le gouvernement.

Le 4 mars 1934 elle fonda l'école «Luis Llosa » dans sa maison pour les enfants des combattants qui n'assistaient pas à l'école. Elle soutint cette école pendant plusieurs années, en même temps qu'elle fut la directrice ad honorem de la «Liga Filial» d'Oruro pendant dix ans.

En reconnaissance de son travail réalisé pendant la Guerre, le Premier et Second Corps de l'Armée de la Bolivie décida de la nommer «Héraut de l'Armée » en juin 1934.

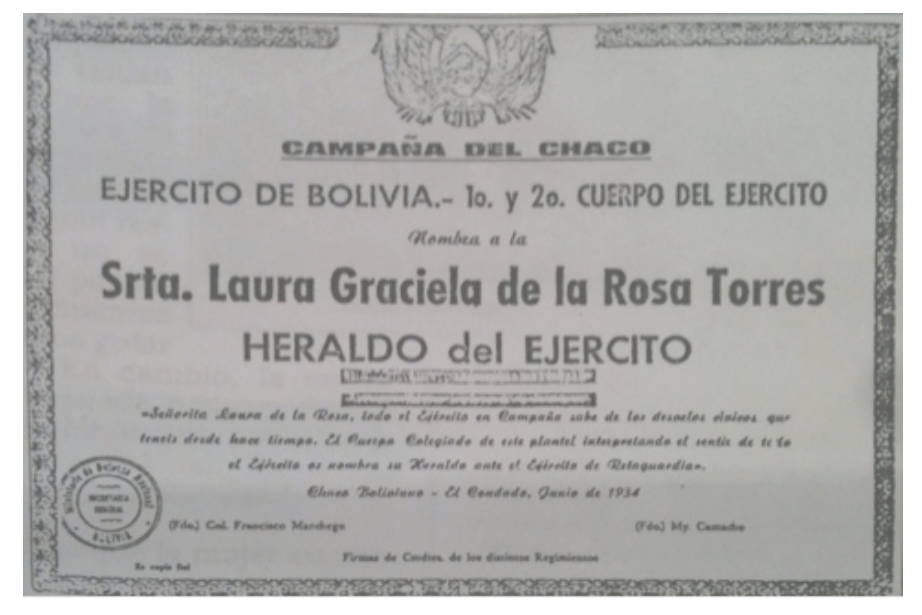

En 1938, elle réalisa avec Ricardo López Nosse (directeur à l'époque de la «Liga Filial » d'Oruro) un congrès anti - régionaliste. Pour l'occasion et en symbole de l'union de la Bolivie, ils fondèrent le «Parc de l'Union » dans lequel chaque délégué présent versa un peu de terre emmené du département d'où il venait. 


\section{6.- María Teresa Urquidi R.}

Née à Cochabamba, elle était l'épouse d'un des fondateurs et principaux dirigeants du MNR, Walter Guevara Arze. Elle fut une des élèves d'Adela Zamudio (voir annexe $\mathrm{A} \mathrm{n}^{\circ} 28$ )

Elle étudia en Californie et devint ingénieure agronome. Elle fut d'ailleurs, la première femme en Bolivie à avoir cette profession.

Elle fut une des fondatrices de la revue Iris et de l'association féministe qui la publiait à Cochabamba, organisation féministe créée en 1921 sous l'exemple du «Centro Artístico e Intelectual de Señoritas » d'Oruro.

Elle fut de la même manière membre et correspondante de «l'Ateneo Femenino » à Cochabamba.

Elle fut la Secrétaire de relations et liens continentaux de la «Unión de Mujeres Americanas » en 1935.

De même, elle fut fondatrice et première Présidente du «Comité Cívico Femenino » de Cochabamba (1936).

\section{7.- Ana Rosa Tornero ${ }^{358}$}

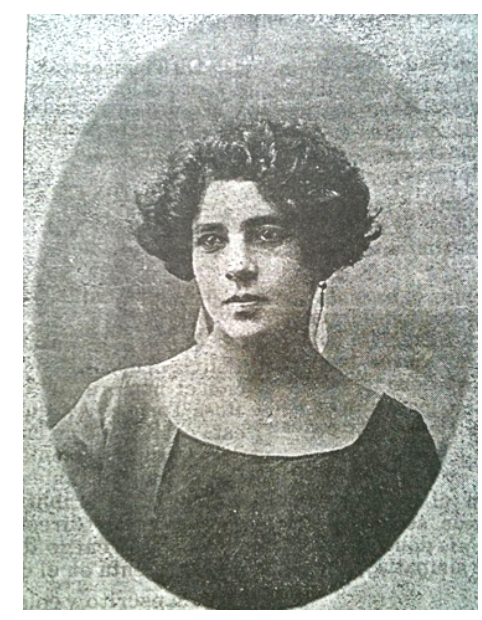

Née à La Paz, professeure et journaliste, elle voua plusieurs années de sa vie à essayer de réformer l'éducation du pays. Professeure de Philosophie et de Littérature, elle fut également Proviseure du Lycée « María Josefa Mujía » de Sucre, de l'Ecole

\footnotetext{
358 Photographie prise de la revue Eco Femenino, n¹3 mai 1925, La Paz, Hemeroteca de la Universidad Mayor de San Andrés, La Paz - Bolivie.
} 
Professionnelle de la même ville, de l'Ecole Professionnelle « Uruguay » à La Paz et du Lycée « Zamudio » à Cochabamba. Elle fut la directrice de l'association « Centro Ideal Femenino » de La Paz, et de sa revue Ideal Femenino. Elle fut l'une des membres fondatrices de "l'Ateneo Femenino », ainsi que la fondatrice et directrice de la revue éditée par ce centre: «Eco Femenino». Elle assista en tant que représentante de «l'Ateneo Femenino » et de la Bolivie à la Seconde Conférence Panaméricaine de femmes à Lima en 1924 et à la «Liga Ibérica Hispanoamericana » au Mexique en 1925. Elle participa également à la Conférence Internationale de femmes réunie à Montevideo en 1933.

Lorsque la Guerre du Chaco fut déclarée, en tant que Proviseure de l'Ecole Professionnelle «Uruguay », elle organisa une manifestation contre le Paraguay qui se rendit jusqu'à la Plaza Murillo (place principale de la ville de La Paz) où depuis le balcon présidentiel, elle prononça des fervents discours patriotiques avec d'autres femmes. Pendant tout le conflit, elle travailla en tant que secouriste. Elle se rendit plusieurs fois dans la zone d'opérations pour secourir les blessés et leur apporter des aliments et des articles de première nécessité. Elle organisa des «Brigadas Femeninas » dans plusieurs villes du pays qui remplissaient le travail de secouristes dans le Front. Lorsqu'elle retournait de ses voyages au Chaco, elle faisait part publique de ses expériences et de l'état des soldats à travers la radio, le journal et des conférences qu'elle réalisait au théâtre municipal. Elle organisa en outre, plusieurs conférences sur des thèmes patriotiques avec le but de collecter des fonds pour les familles pauvres des mobilisés. Pour honorer son travail, le gouvernement lui attribua la décoration du Mérite Militaire avec le grade de Chevalier. De même, l’État-Major lui octroya un diplôme.

Elle fut également une des fondatrices du « Centro Hispano Americano ».

En 1944 elle était chargée de la Commission Civique de la «Fédération de Sociétés Culturelles Féminines ».

\section{8.- Matilde Carmona Rodo}

Née à Potosí, elle était mariée à Germán Busch, héros de la Guerre du Chaco et président de la Bolivie de 1938 à 1939. Elle réalisa ses études secondaires à La Paz, et commença à étudier le Droit à l'Université Mayor de San Andrés. Au bout d'un an, elle arrêta ses études pour se marier. Membre du « Centro Ideal Femenino », elle fut 
une des fondatrices des revues Ideal Femenino et ensuite d'Aspiración, revue de laquelle elle était la rédactrice en chef.

Elle fut également membre de «l'Ateneo Femenino ».

Lorsque son mari était président elle réalisa plusieurs œuvres sociales dont la construction de la « Casa Cuna » (orphelinat à Cochabamba) qui porte son nom.

Une fois veuve, après le suicide de son mari alors qu'il était Président, elle partit habiter à Washington, Etats-Unis.

En 1947 elle fut candidate aux élections municipales pour «La Candidatura del Pueblo ».

Elle fut attachée culturel ad honorem à l'Ambassade de Bolivie à Washington en 1963. Elle participa en tant que déléguée de la Bolivie au Congrès du Conseil International de la Femme à Washington en 1963.

\section{9.- Ana Rosa Vázquez ${ }^{359}$}

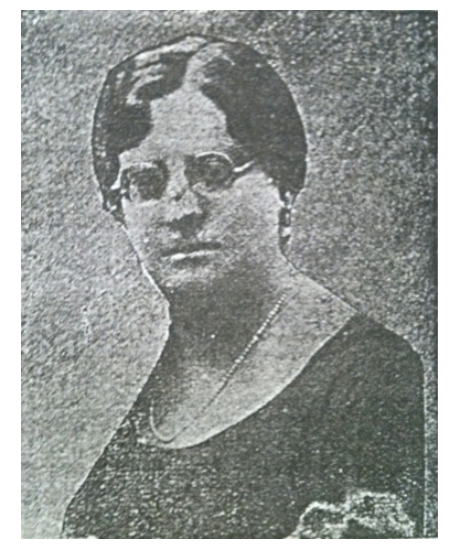

Née à La Paz, elle fut membre du «Centro Ideal Femenino », ainsi que fondatrice, administratrice et directrice de la revue Aspiración. De même, elle publiait des articles dans l'hebdomadaire La Paz.

Elle fut également membre actif de «l'Ateneo Femenino ».

En 1925 elle fut déléguée de La Paz au Premier Congrès de « Protection à l'Enfance » à La Paz. Elle participa également au Premier Congrès des femmes à La Paz, organisée par « l’Ateneo Femenino ».

\footnotetext{
359 Pothographie prise de la revue Eco Femenino n², octobre 1923, La Paz. Hemeroteca de la Universidad Mayor de San Andrés, La Paz - Bolivie.
} 
Membre de la «Legión Femenina de Educación Popular de América » en 1936, elle y avait la charge de Secrétaire d'Actes à La Paz. A ce titre, elle participa du Congrès de Femmes réalisée par cette organisation en novembre 1936 à Cochabamba.

De la même manière elle fut membre de la Direction de la Conférence de dames de San Vicente de Paul, ainsi que membre fondatrice du « Centro Hispano Americano de Señoras ».

\section{0.- María Luisa Sánchez Bustamante de Urioste ${ }^{360}$}
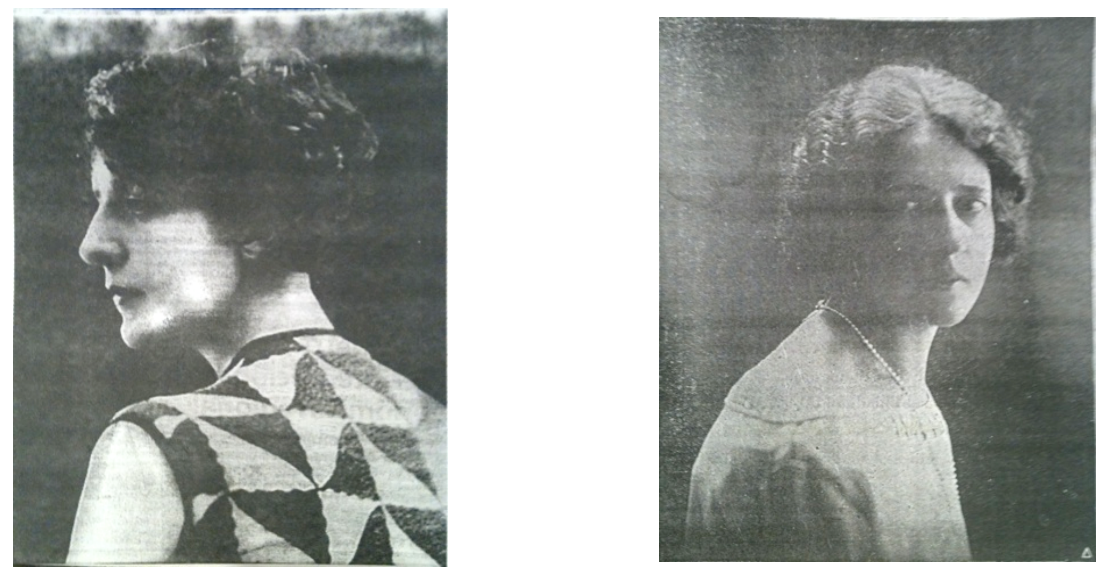

Née à Sucre, elle était partie vivre à La Paz très jeune. Elle était la fille de Daniel Sánchez Bustamante, homme politique d'une très grande importance en Bolivie. Ce dernier contribua à la fondation de l'Ecole Normale Supérieure de Sucre en 1909 sous le gouvernement de Ismael Montes, et finança pour ce projet, l'arrivée de la mission éducative belge «Rouma» en Bolivie, avec la vente de l'une de ses maisons. Il fut Ministre de Relations Extérieures et Ministre de l'Education.

Il organisait tous les dimanches des «tertulias » avec les plus grands intellectuels du début du XXe siècle en Bolivie: Alcides Arguedas, Juan Francisco Bedregal, Armando Chirveches et Franz Tamayo. Avec ce dernier, il fonda le parti radical dans la deuxième décennie du XX ${ }^{\mathrm{e}}$ siècle. Lors de la « Révolution de 1930 » dans laquelle

\footnotetext{
${ }^{360}$ Les informations et les photographies sur la vie de María Luisa Sánchez Bustamante de Urioste ont été tirées de PAREDES de Salazar Elssa, Diccionario biográfico de la Mujer Boliviana, Ediciones «Isla », La Paz, 1965, ainsi que de HUBER ABENDROTH Hans, Pequeña biografía de María Luisa Sánchez Bustamante (Malú), Editores: Ministerio de Desarrollo Humano, Secretaría de Asunto Étnicos, de Género y Generacionales, Subsecretaría de Asuntos de Género, La Paz - Bolivia, 1997.
} 
fut renversé le président Hernando Siles, il présida le Cabinet qui dirigea le pays de manière transitoire.

Il s'assura que ses enfants fréquentent les meilleurs lycées du pays à l'époque. Ainsi, María Luisa réalisa ses études au « Liceo de Señoritas » de La Paz.

En mai 1923, elle fonda «l'Ateneo Femenino », l'organisation féministe la plus importante de la première moitié du $\mathrm{XX}^{\mathrm{e}}$ siècle en termes d'actions et de durée de vie. Elle fut la directrice de cette organisation pour plus de 28 ans, pendant des périodes différentes. Elle fonda les deux revues féminines - féministes publiées par cette organisation : Eco Femenino et Indice. Elle organisa le Premier Congrès de Femmes en 1929 à La Paz.

De 1933 à 1936 elle fut nommée Directrice du Musée National d'Archéologie «Palacio Tiahuanacu», en raison de la vaste collection personnelle coloniale et archéologique qu'elle possédait.

Elle fut militante du «Partido Izquierdista Revolucionario » (PIR) dans les années 1940 en tant que Secrétaire Générale du parti. Un peu plus tard, à la dissolution du PIR, elle rejoignit le MNR.

En 1947 elle fut candidate aux élections municipales pour « La Candidatura del Pueblo ». 


\section{1.- Rosa Infante ${ }^{361}$}

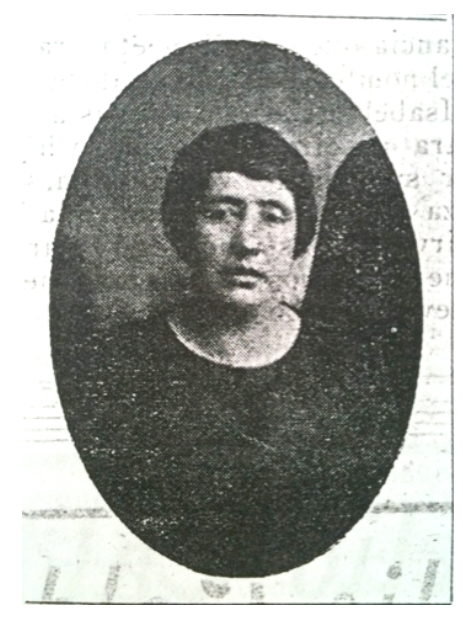

Professeure normalienne, elle enseignait l'Histoire au «Liceo de Señoritas » de La Paz. Elle participa à la fondation de la Croix Rouge Bolivienne.

Elle fut une des membres fondatrices de l'«Ateneo Femenino » ainsi que la VicePrésidente (1923-1925) et Présidente (1925-1927) de celui-ci.

${ }^{361}$ Photographie tirée de Eco Femenino ${ }^{\circ} 14$, juillet 1925. Hemeroteca de la Universidad Mayor de San Andrés, La Paz - Bolivie. 


\section{2.- Elodia Ballivián de Ligerón ${ }^{362}$}
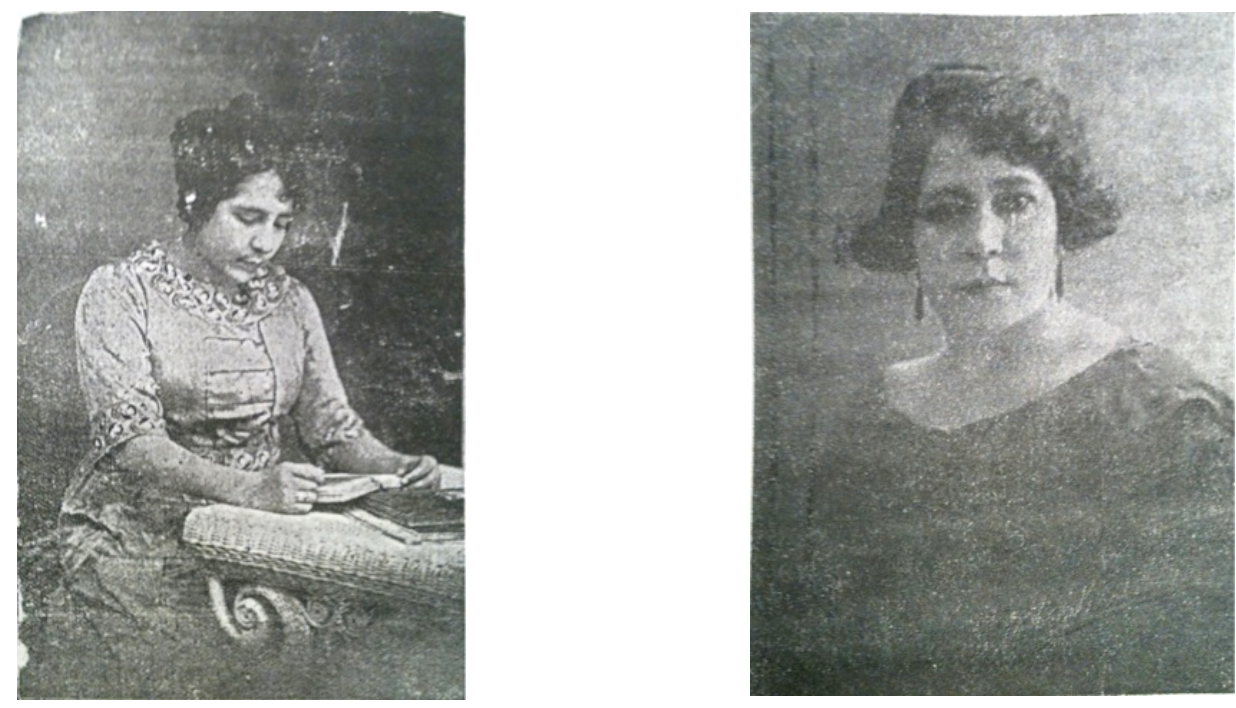

Professeure normalienne née à $\mathrm{La} \mathrm{Paz}$ en 1892, elle travailla en tant que Proviseure dans un lycée à Oruro. Plus tard, le travail réalisé dans l'école « Vicenta Juaristi Eguino » en tant que Proviseure fit sa renommée. Elle fut une des membres fondateurs de l'«Ateneo Femenino », ainsi que d'autres organisations telles que l' «Unión Femenina de Educadoras », et le « Centro Hispano Americano ».

Le 27 mai 1928 en hommage aux héroïnes de la «Coronilla» (voir annexe A n³5), elle présenta un projet à l'Assemblée à travers le député Corvera Zenteno, por créer la « Fête des Mères ».

Elle fonda une «École Nocturne pour ouvriers », et travailla dans celle-ci pendant quatre ans.

Pendant la Guerre du Chaco, elle organisa le « Courrier au soldat» afin d'envoyer des lettres d'encouragement aux soldats du Front.

Elle fonda deux revues féminines : « Aclis » et « La Paz ».

La médaille « Inca de Oro » lui fut attribuée par son travail « Devoirs de la Femme Bolivienne », ainsi que la médaille d'or de l' « Union Panaméricaine » à Lima, Pérou en raison de son travail américaniste.

Elle publia quelques livres de théâtre pour enfants.

Elle contribua également à la fondation de plusieurs bibliothèques.

\footnotetext{
${ }^{362}$ La première photographie a été tirée de Eco Femenino ${ }^{\circ} 7$, juin 1924, La Paz. Hemeroteca de la Universidad Mayor de San Andrés, La Paz - Bolivie ; et la deuxième de PAREDES de Salazar Elssa, Diccionario biográfico de la Mujer Boliviana, Ediciones « Isla », La Paz, 1965.
} 
Elle fut élue conseillère municipale en décembre 1947 à La Paz.

\section{3.- Elvira Benguria de Knaudt}

Née à La Paz, elle fut chroniqueuse de la revue Ideal Femenino en 1922. Elle étudia à l'Université Mayor de San Andrés, et elle obtint une licence en Pharmacologie.

Elle fut membre de l' « Ateneo Femenino ».

\section{4.- Carmen Sánchez Bustamante ${ }^{363}$}

Sœur de María Luisa Sánchez Bustamante, elle fut un des membres fondateurs de l'« Ateneo Femenino ». En juin 1924 elle partit en voyage pour l'Europe, et devint par conséquent membre correspondant de l'organisation avec la mission de mettre en contact l' «Ateneo Femenino » avec les féministes européennes. En septembre 1924, alors qu'elle se trouvait à Buenos Aires avant son départ en Europe, elle contacta les dirigeantes des sociétés féminines argentines qui réalisaient des œuvres de charité et les mit en contact avec l'« Ateneo Femenino ».

\section{5.- Eduviges Garaizabal v. De Hertzog ${ }^{364}$}

Proviseure de l'Ecole Normale Supérieure de Sucre, elle fut également professeure du « Liceo de Señoritas » de La Paz.

Membre fondateur et actif de l' «Ateneo Femenino », elle était un des membres les plus dynamiques de ce dernier. Elle participa avec Ana Rosa Tornero (voir annexe A $\left.n^{\circ} 7\right)$ à la Seconde Conférence Panaméricaine de femmes à Lima en 1924 où elle présenta quatre projets : développement de l'éducation secondaire des femmes, le

\footnotetext{
${ }^{363}$ Les informations sur la vie de Carmen Sánchez Bustamante ont été tirées des revues Eco Femenino (1923-1925) et Indice (1927-1928). Hemeroteca de la Universidad Mayor de San Andrés, Centro de Informaciôn y Desarrollo de la Mujer (CIDEM), La Paz - Bolivie, collection personnelle de Martha Nardín Rivas.

${ }^{364}$ Les informations sur la vie Eduviges Garaizabal v. De Hertzog ont été tirées des revues Eco Femenino (1923-1925) et Indice (1927-1928). Hemeroteca de la Universidad Mayor de San Andrés, Centro de Informaciôn y Desarrollo de la Mujer (CIDEM), La Paz - Bolivie, collection personnelle de Martha Nardín Rivas et de OPORTO ORDOÑEZ, Luis, Las mujeres en la Historia de Bolivia. Imágenes y realidades del siglo XX (1900-1950), Antología, Anthropos, La Paz - Bolivia, 2001.
} 
droit de vote des femmes, la création d'une Banque Protectrice des femmes travailleuses et l'alphabétisation des indigènes.

Elle était la mère de Enrique Hertzog président de la Bolivie (1947-1949) pendant la période du « Sexenio » (dernier essai de l'oligarchie pour prendre le pouvoir avant la révolution de 1952).

\section{6.- Leonor Díaz Romero ${ }^{365}$}

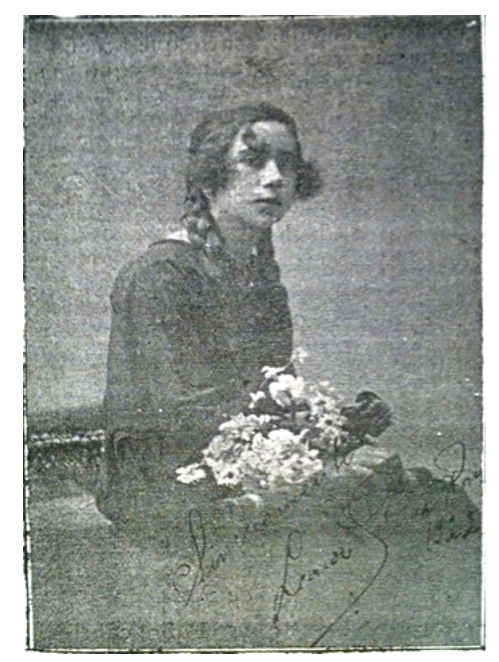

Poétesse née à La Paz. Elle laissa beaucoup de poèmes qui sont encore inédits, ainsi qu'un livre intitulé Los poemas de la espera.

Son poème le plus connu fut « Ambition » dont la dernière strophe finit ainsi :

« No hallaste tregua, ni hallaste límite.

Más que ambición, tu empuje te elevó tanto

Que para soñar de nuevo, juntas morirían

Fuerza, libertad, ambición y gloria.

Hasta allí corazón, llegaste al límite! »

Elle fut membre de 1'« Ateneo Femenino » et publia plusieurs de ses poèmes dans la revue de cette organisation : Eco Femenino.

\footnotetext{
${ }^{365}$ La photographie a été prise de la revue Eco Femenino nº 15 septembre 1925, La Paz. Hemeroteca de la Universidad Mayor de San Andrés, La Paz - Bolivie.
} 
Membre de la «Legión Femenina de Educación Popular América» en 1936, elle était, avec Alina Ballón (voir annexe A n²3) la Directrice d'Art et de Publicité de cette organisation à La Paz de 1936 à 1938.

\section{7.- Quica Estenssoro}

Poétesse et écrivaine née à La Paz, elle était mariée à Carlos Salinas Aramayo, homme politique qui fut assassiné dans des conditions tragiques à Chuspipata le 20 novembre 1944 suite à sa participation dans une conspiration contre le gouvernement de Gualberto Villarroel.

En 1925, elle publia un livre de contes Violetas de Oro.

Elle publia plusieurs articles et poèmes dans diverses revues et journaux du pays dont Eco Femenino, revue publiée par l'« Ateneo Femenino » organisation à laquelle elle appartenait.

\section{8.- Amalia Villa de La Tapia}

Première aviatrice bolivienne, elle naquit à Potosí et s'éduqua à Lima, Pérou. Elle obtint sa licence de professeure normalienne en 1917. En 1921 elle accéda à l'école d'aviation civile dans un village près de Lima alors que dans la plupart des pays de l'Amérique l'aviation se trouvait encore en pleine période d'essai. Après un an d'apprentissage elle obtint son permis d'aviatrice le 16 mars 1922. Pour cette occasion, les membres du «Centro Artístico e Intelectual de Señoritas de Oruro » et rédactrices de Feminiflor lui vouèrent plusieurs articles pour la féliciter et faire ressortir son exploit, puisqu'elle était la première aviatrice femme du cône $\mathrm{Sud}^{366}$.

En 1923, elle retourna en Bolivie où elle réalisa une campagne de démonstrations et d'enseignement sur l'aviation militaire, civile et sportive.

Elle fut membre intégrant de l'« Ateneo Femenino ».

En 1927, elle perfectionna ses études d'aviation à Paris à l'école «Le Crotoy ». De retour en Amérique, elle s'arrêta à Buenos Aires où elle fonda le premier Club de planeurs « Jorge Nuvery ».

\footnotetext{
${ }^{366}$ Feminiflor $n^{\circ} 18$, décembre 1922, Oruro. Hemeroteca de la Universidad Mayor de San Andres, La Paz - Bolivie.
} 
De retour en Bolivie à partir de 1931, elle commença une campagne pour que l'aéromodélisme soit enseigné dans les écoles. Ainsi, au début des années 1940 elle présenta une première exposition d'aéromodélisme, qui le 16 juillet 1944 fut exposée dans tout le pays.

Elle fonda et finança avec ses propres moyens le premier Club d'aéromodélisme «Rafael Pabón ».

Le 18 juin 1958 elle fut incorporée à l'armée de l'air avec le grade de capitaine. En 1965 elle acquit le grade d'officier majeur.

En dehors de toutes ces activités, elle était professeure de langues, de musique et d'apiculture. Elle contribua à la fondation du premier musée d'aéronautique.

Elle publia les livres Aeromodelismo, Simón Bolívar y Bolivia, et Horas Cívicas.

\section{9.- Emma Perez del Castillo de Carvajal}

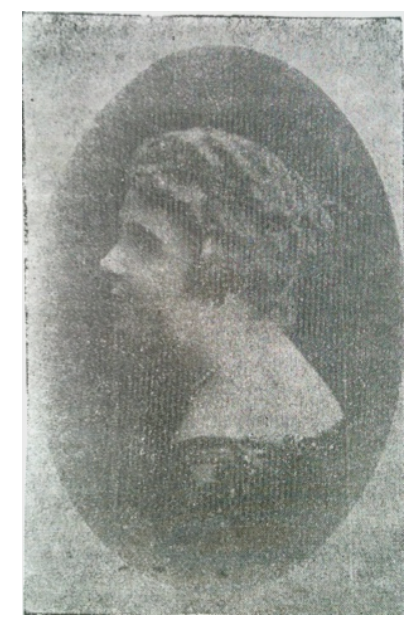

Journaliste née à La Paz en 1891, elle voyagea beaucoup. Elle fit des études de littérature et de sociologie à La Sorbonne.

Lorsqu'elle se trouvait en Bolivie elle habitait à la campagne où elle fonda plusieurs écoles dans lesquelles elle donnait des cours aux paysans.

En 1911 elle fut la première femme admise à la Société Géographique de La Paz. En 1912, lorsqu'elle se trouvait à Buenos Aires, elle participa dans un concours littéraire où elle présenta plusieurs contes pour lesquels elle gagna le premier prix. En 1923 elle obtint dans cette même ville la distinction honorifique « La Flor Natural ». En 1920 elle eut à sa charge la section féminine de la revue argentine Atlántida. 
Elle fut un des membres fondateurs de l'«Ateneo Femenino » et présidente de celuici pendant plusieurs périodes. Elle fut une des fondatrices et directrices de la revue Eco Femenino. Elle écrivit également dans plusieurs revues boliviennes telles que Campanas y campanadas, Bohemia et dans les revues argentines Lea, Charlas Femeninas, Monde Argentin et Vida Nueva.

En 1924 elle participa en tant que déléguée de la Bolivie à la Second Conférence Panaméricaine de femmes à Lima.

Pendant la Guerre du Chaco elle organisa des cours de secourisme.

Elle était membre de la « Société de Bienfaisance de dames ». Elle fut la fondatrice de la «Société San Vicente de Paul» de Cochabamba et d'une société littéraire nommée «El puñado de rosas » (« La poignée de roses »).

En 1944 elle fut élue présidente de la «Federation de Sociétés Culturelles Féminines ».

\section{0.- Isabel B. v. de Haillot}

Professeure née à La Paz, elle fut l'organisatrice et proviseure de l'école «Lindaura Campero». Elle fut un des membres fondateurs de l'«Ateneo Femenino », sa secrétaire de 1925 à 1927, et collaboratrice de la revue Eco Femenino. Elle assista en tant que déléguée au Premier Congrès de femmes à La Paz en 1929.

En 1944 elle fut élue Vice-Présidente de la «Federation de Sociétés Culturelles Féminines ».

\section{1.- Cristina Iturralde de Zalles}

Intellectuelle et écrivaine née à La Paz, elle était membre actif de l'« Ateneo Femenino ». Elle collabora également dans la revue Aspiración.

Elle assista au Premier Congrès de « Protection à l'Enfance » à La Paz en 1925.

Elle fut chargée de la commission Presse et Propagande de la «Federación de Sociedades Culturales Femeninas » en 1944. 


\section{2.- Fidelia Corral Zambrana de Sánchez}

Educatrice et écrivaine, née à Cochabamba, elle fut fondatrice et Proviseure de plusieurs écoles : « Sucre » et « Heroínas » à Quillacollo (province du département de Cochabamba), «Sara Ugarte », «Mariano Baptista » et «San Alberto » à Cochabamba.

Elle fut membre de 1' «Ateneo Femenino» dont elle fut la représentante dans le Premier Congrès de Protection à l'Enfance en 1925. En tant que journaliste, elle collabora dans plusieurs journaux de La Paz et de Cochabamba.

Elle fut la Directrice de la revue Por la Raza, organe de diffusion de la Croix Rouge départementale de Cochabamba, de laquelle elle était membre. Elle était également présidente des « Legiones Juveniles » et directrice du journal Opinión Nacional fondé en 1929.

Membre de la «Legión Femenina de Educación Popular América », elle était la secrétaire de cette organisation à Cochabamba. Elle participa au Premier Congrès de cette institution en novembre 1936. A l'occasion de cet événement elle se retira du Congrès ainsi que de l'institution en raison des désaccords qui étaient surgis par rapport aux orientations anti - cléricales que le Congrès avait pris. En effet, la présidente de la «Legión » de Sucre s'était plainte des attaques qu'avait reçu l'institution dans cette ville de la part des curés dans le journal catholique El Lábaro. L'ensemble du Congrès vota pour la condamnation de ces attaques. Fidelia Corral, se montra en désaccord avec cette condamnation et se mit à défendre la religion catholique et le clergé. Des conflits surgirent dans le Congrès, d'où finalement elle se retira en condamnant l'orientation soi-disant «communiste » que le Congrès avait pris, en faisant référence à la présence de la dirigeante ouvrière Angélica Azcui (voir annexe $\left.\mathrm{A} \mathrm{n}^{\circ} 24\right)^{367}$.

En 1949, elle était la présidente du «Control Femenino» du «Partido Unión Republicana Socialista »(PURS).

\footnotetext{
${ }^{367}$ VILLANUEVA Y Saavedra Etelvina, Acción socialista de la mujer en Bolivia, Cooperativa de Artes Gráficas E. Burillo Ltda., La Paz - Bolivia, 1970.
} 


\section{3.- Alina Ballón}

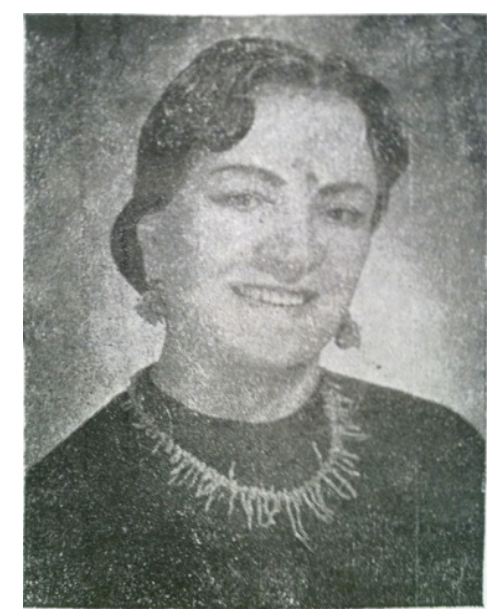

Artiste née à La Paz, elle étudia au Conservatoire National de Musique de La Paz obtenant le titre de professeure de piano et de violon. Elle continua ses études à Buenos Aires où elle obtint le titre de concertiste.

Poétesse, écrivaine et critique d'art elle obtint plusieurs prix de poésie dans des concours nationaux et internationaux.

Elle fut membre de l'«Ateneo Femenino », du «Conseil National de Femmes » de Bolivie, membre honoraire de la Société d'Artistes et Écrivains du Pérou, membre fondateur de la «Peña de Artistas y Escritores » de La Paz, membre fondateur du Centre Culture bolivien-égyptien.

Sportive, elle obtint le titre de championne de tennis pendant 10 années consécutives de 1932 à 1942.

En 1934 elle était partie intégrante du « Comité de Acción Feminista ».

Membre de la «Legión Femenina de Educación Popular América» en 1936, elle était, avec Leonor Díaz Romero (voir annexe $A n^{\circ} 16$ ) la Directrice d'Art et de Publicité de cette organisation à La Paz de 1936 à 1938.

Elle publia deux livres de poèmes : Adolescencia et Vestigios de sombra.

\section{4.- Angélica Azcui}

Artiste et intellectuelle, elle fut l'une des premières dirigeantes ouvrières femme. Elle commença sa carrière artistique en 1922 avec la déclamation et plus tard, en 1930 elle continua avec le théâtre. En 1941 elle travailla dans la compagnie 
« Tiahuanacu » de Francisco Alvarez García y Gandelman, qui réalisa une tournée dans tous les pays sud-américains

En 1929 elle participa en tant que déléguée de la « Fédération du Travail » au Premier Congrès de Femmes à La Paz. A cette occasion, elle présenta un travail sur les organisations ouvrières.

Elle fut membre de l'« Ateneo Femenino » et de la «Legión Femenina de Educación Popular América » de La Paz.

Elle fut une grande défenseure des droits ouvriers et des droits des femmes en général.

\section{5.- Laura Córdova}

Membre correspondant de l'«Ateneo Femenino » à Potosí, elle fut également la Directrice de la revue féminine - féministe Venas de Plata en 1924.

\section{6.- Modesta Sanjinés}

Née à La Paz en 1832, elle étudia depuis très jeune la musique et les lettres, et se consacra au piano. Elle publia deux ouvrages littéraires Las dos caras et El Hijo del Cóndor. Elle composa de même plus de 50 pièces musicales: de compositions pour piano et des chansons dont la plus célèbre est « La brisa de Uchumachi ».

Elle fut professeure de langues ; elle maîtrisait l'anglais et l'italien.

Elle dirigea la revue pour femmes El Jardincito de María de 1874 à 1876.

Elle voua une grande partie de son temps à la bienfaisance: elle s'occupait des malades dans les hôpitaux, les hospices, et les asiles. Une section de l'hôpital «Loayza » fut financée par elle. Elle visitait également les prisonniers.

Elle mourut à Pau en France en 1887. Ses restes furent déplacés à Paris. Le Ministre Plénipotentiaire de l'époque, Aniceto Arce et la colonie bolivienne de la France honorèrent ses obsèques.

\section{7.- Carolina Jaimes Freyre}

Écrivaine et poétesse péruvienne née en 1849, elle devint bolivienne par son mariage avec Julio Lucas Jaimes. Elle est la mère des poètes boliviens Ricardo et Raúl Jaimes Freyre. 
Elle publia plusieurs ouvrages dont : Pizarro et Carmen Silva. Elle obtint un premier prix littéraire à Lima pour le premier. Elle collabora dans le journal publié par son père El Tacora, et dans la revue féminine argentine La Mujer.

Elle dirigea la revue féminine El Album à Sucre à partir de 1889.

\section{8.- Adela Zamudio ${ }^{368}$}

Née en 1854, elle est une des poétesses les plus célèbres du pays. Elle se forma de manière autodidacte et fut professeure dans plusieurs écoles et lycées du pays.

Son poème le plus connu s'intitule « Nacer Hombre» (« Naître Homme ») et dénonce l'injustice des différences des conditions entre les hommes et les femmes. Une des strophes les plus célèbres dénonce le fait que les femmes cultivées ne pouvaient pas participer dans la vie politique du pays, alors que les hommes analphabètes le pouvaient:

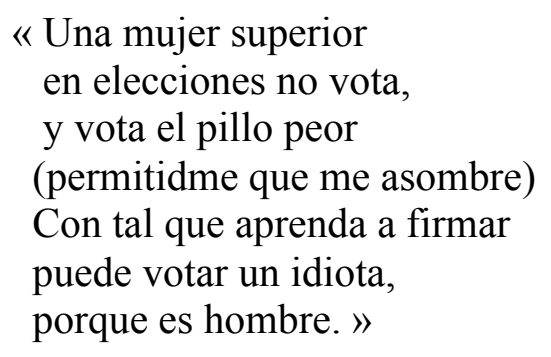

Elle signait tous ses poèmes et ouvrages avec le pseudonyme de « Soledad ».

En 1887 fut publié à Buenos Aires un tome de ses premiers poèmes Ensayos Poéticos. Ensuite fut publiée à Paris la collection de poèmes Ráfagas.

Elle écrivit et publia également des livres de contes et de nouvelles dont on peut citer parmi d'autres: Intima, Noche de Fiesta, Inundación, El vértigo, El Diablo Químico, etc.

Elle se voua également au domaine de la peinture en tant que peintre.

En 1926, elle fut couronnée publiquement par le gouvernement de Hernando Siles comme une grande intellectuelle et illustre poétesse de la Bolivie et des Amériques.

\footnotetext{
${ }^{368}$ Les informations sur la vie de Adela Zamudio ont été tirées de CAJÍAS de Villa Gómez Dora, Adela Zamudio. Transgresora de su tiempo, Serie "Protagonistas de la Historia", Editores: Ministerio de Desarrollo Humano, Secretaría de Asunto Étnicos, de Género y Generacionales, Subsecretaría de Asuntos de Género, La Paz - Bolivia, 1997; et PAREDES de Salazar Elssa, Diccionario biográfico de la Mujer Boliviana, Ediciones « Isla », La Paz, 1965.
} 
Elle mourut le 2 juin 1928. Le premier numéro de juillet 1929 de la revue Anhelos lui fut dédié en hommage.

Elle rédigea son propre épitaphe dans lequel on lit : «Vuelvo a morar en ignorancia estrella libre ya del suplicio de la vida, allá os espero; hasta seguir mi huella, lloradme ausente pero no perdida. »

\section{9.- María Teresa Solari Ormachea}

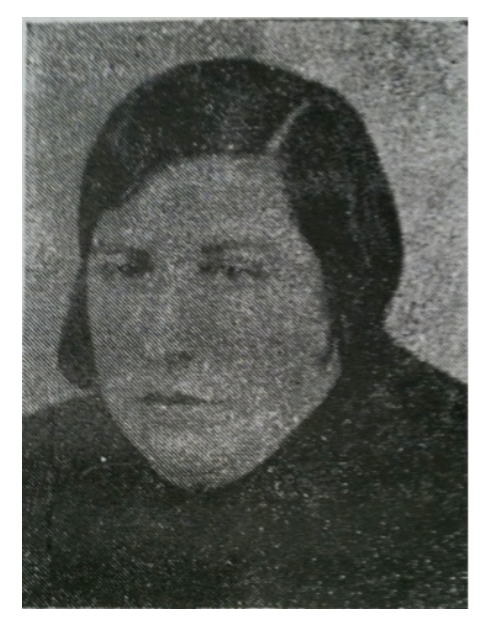

Professeure et poétesse née à La Paz, elle se voua à la littérature depuis très jeune en publiant ses travaux dans la presse.

Elle fut membre de 1' «Ateneo Femenino » et directrice de la revue Eco Femenino pendant quelques mois en 1925.

En 1946 elle fut conseillère civique et puis présidente de l’«Unión Cívica Femenina Boliviana ». En tant que telle, elle réalisa en juillet 1946 un intense travail d'agitation dans la rue, avec d'autres femmes réunies dans le «Frente Democrático Antifascista » contre le gouvernement de Gualberto Villarroel (1943-1946).

Lorsque le MNR était au pouvoir elle l'attaqua souvent dans la presse, ce qui lui valut la persécution politique et la ruine économique. Elle évita la prison en se cachant dans 1'asile San Ramón qui lui offrit refuge. 


\section{0.- María Quiroga Vargas de Montenegro}

Poétesse et écrivaine née à Cochabamba en 1905. Elle fut une des élèves de Adela Zamudio (voir annexe A $\mathrm{n}^{\circ} 28$ ). Elle travailla pendant longtemps en tant que professeure de Littérature et de Philosophie.

Elle remporta un des premiers prix dans les Jeux Floraux de 1923 à Cochabamba, le deuxième prix dans le concours de contes de la revue Vanguardia en 1930, le premier prix du concours poétique organisé par l'association féminine «Pro-Madre » avec le poème « Hymne à la mère », et le prix «Jasmin d'argent» fut attribué à son poème « Séparation » par la Société d' Écrivains et d'Artistes de Cochabamba.

Elle fut fondatrice et directrice de la revue Anhelos avec Mercedes Anaya de Urquidi (voir annexe $\mathrm{A} \mathrm{n}^{\circ} 31$ ).

Elle fut membre du «Comité d'Action Féministe» à Cochabamba en 1934 et Directrice de Culture de la «Legión Femenina de Educación Popular América » de Cochabamba en 1935.

Elle collabora de même dans la presse nationale et dans des revues culturelles à l'étranger. Elle publia le livre Transverberación, dont le prologue fut rédigé par Gregorio Reynolds, et le livre Véspero.

Elle appartenait à la Société d'Écrivains et d'Artistes de Cochabamba et à la Société Géographique de cette ville. 


\section{1.- Mercedes Anaya de Urquidi}

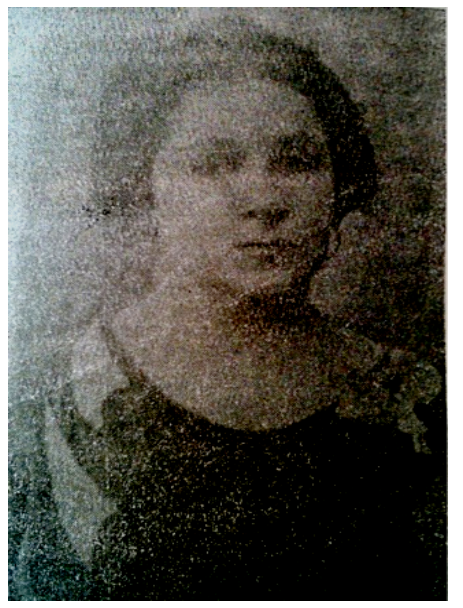

Écrivaine et spécialiste de folklore, née à Cochabamba en 1888. Elle était mariée à José Macedonio Urquidi, avocat, intellectuel et écrivain, auteur de plus d'une vingtaine d'ouvrages dont on peut citer Bolivianas Ilustres (1919). En 1932, il devint membre titulaire de l'Institut Américain de Droit International. Cette institution et la Commission Internationale de Femmes ${ }^{369}$ lui demandèrent de répondre à une enquête sur la condition juridique des femmes en Bolivie. Ce travail fut publié en Bolivie en 1937 : MACEDONIO Urquidi José Antonio, La Condición Jurídica o Situación legal de la mujer en Bolivia, 3e Edition, Cochabamba, 1937.

Mercedes Anaya fut fondatrice et directrice de la revue Anhelos avec María Quiroga de Montenegro (voir annexe $\mathrm{A} \mathrm{n}^{\circ} 30$ ).

Elle fut membre du «Comité d'Action Féministe» à Cochabamba en 1934 et Directrice d'Action Littéraire de la «Legión Femenina de Educación Popular » de Cochabamba en 1935.

Elle collabora également dans le journal La Prensa de Buenos Aires, et dans des revues culturelles d'Espagne et du Pérou. Elle est l'auteure des ouvrages : Poemas de Hogar, Evocaciones (1936), Tradiciones y Leyendas del Folklore Boliviano (1937) et Indianismo (1947) qui fut adopté par le Gouvernement comme texte officiel pour les écoles.

Le village de Sipe-Sipe dans le département de Cochabamba, qu'elle décrit dans ses ouvrages, la nomma sa « Hija Predilecta » («Fille préférée ») et demanda que le nom

\footnotetext{
${ }^{369}$ Organisme spécialisé de l'OEA (Organisation des États Américains) elle fut établie par la Sixième Conférence Panaméricaine à La Havane, Cuba, en 1928. Elle fut le premier organe intergouvernemental créé pour la reconnaissance des droits civils et politiques des femmes.
} 
du village prenne le nom de Mercedes en son honneur. L'école principale du village porte son nom.

Elle remporta un des premiers prix dans le huitième Salon du Livre réalisée au Mexique.

Elle fut membre de la Société Géographique et de la Société d'Histoire de la ville de Cochabamba.

\section{2.- Sara Ugarte de Salamanca}

Poétesse née à Cochabamba en 1866, elle était mariée à Daniel Salamanca, qui fut président du pays de 1931 à 1934 et qui mena la Bolivie à la Guerre du Chaco (19321935) contre le Paraguay.

Elle écrivait sous le pseudonyme de « Clora ».

Elle fonda et dirigea le journal féminin Nueva Aurora à Cochabamba.

\section{3.- Leticia Antezana de Alberdi}

Née à Cochabamba, elle fut membre fondateur de 1' "Ateneo Femenino ", et Présidente de la Conférence de Dames de San Vicente de Paul depuis 1923, ayant été réélue à cette charge de manière périodique pendant 42 ans. Elle participa au Congrès sur la Protection de l'Enfance en 1925. Elle fut fondatrice de la «Liga de la Defensa de la Moral» en 1940, fondatrice et Présidente Honoraire à vie de la « Fédération de femmes de ménage Catholiques », présidente de l'Action Catholique Bolivienne de 1948 à 1950. Elle fut également la deuxième Vice-Présidente de la Confédération Nationale d'Institutions Féminines de 1958 à 1960, et sa Présidente de 1960 à 1961. Elle fut également membre actif de la Croix Rouge Bolivienne.

\section{4.- Martha Mendoza}

Journaliste, poétesse et professeure, née à Llallagua près de Potosí, elle était la fille du poète Jaime Mendoza. Elle passa la plus grande partie de son enfance à Sucre. Elle se forma dans l'École Normale Supérieure de Sucre, où elle obtint le titre de professeure normalienne. Elle fut la fondatrice de la première école à Villamontes, et fut également Proviseure de plusieurs écoles à Vallegrande, Santa Cruz, Potosí et La Paz, 
où elle fonda l'école "Natalia Palacios". Elle fut également la Directrice du District Scolaire.

Elle fut une journaliste très active. Ses articles furent publiés dans les journaux de Sucre La Industria et La Capital, et dans plusieurs journaux de La Paz.

\section{5.- « Hérö̈nes de la Coronilla »}

Les «héroïnes de la Coronilla» furent un groupe de femmes de Cochabamba qui sacrifièrent leur vie pour défendre leur ville contre les troupes royalistes dirigées par Goyeneche le 12 mai 1812 lorsque celui-ci et ses troupes décidèrent de réprimer le soulèvement qui avait eu lieu dans cette ville. Des négociations furent tentées avant l'arrivée de Goyeneche, qui réclama les principaux dirigeants de la rébellion. La ville et surtout les femmes nièrent cette offerte et s'organisèrent pour la résistance. Elles se réunirent dans la colline de San Sebastián et attendirent l'arrivée de troupes qu'elles affrontèrent en périssant toutes au combat.

Un monument fut érigé dans cette colline à l'initative de Sara Ugarte de Salamanca (voir annexe $\mathrm{A} \mathrm{n}^{\circ} 32$ ). En hommage à ces femmes, la Fête des Mères en Bolivie fut fixée le 27 mai à l'initiative de Elodia Ballivián de Ligerón (voir annexe A n¹2).

\section{6.- Juana Azurduy de Padilla}

Née à Chuquisaca le 8 mars 1781, elle fut admise au Monastère «Santa Teresa » de Sucre en 1797 à l'âge de 16 ans, par volonté de sa mère. Cependant, elle quitta le Monastère assez vite. Elle se maria avec Manuel Ascencio Padilla en 1805. Elle participa des guerres d'Indépendance en luttant dans les combats comme n'importe quel homme. Elle combattit dans les batailles, accompagnée de 25 autres femmes.

Le 13 août 1816, le gouvernement de Buenos Aires lui attribua le grade de « Teniente Coronel».

\section{7.- Simona Josefa Manzaneda}

Femme issue des classes populaires, née à La Paz en 1770. Elle participa du soulèvement produit à La Paz le 16 juillet 1909 et du soulèvement parti du Cuzco à La Paz en 1814. A la fin de l'année 1816 elle fut condamnée à mort par le 
Commandant espagnol Mariano Ricaforte envoyé par le nouveau Vice-roi Enrique Pezuela pour réprimer le peuple de La Paz en raison des soulèvements. Ses cheveux furent coupés et elle fut obligée de monter dans un âne qui fit le tour de la place où elle fut flagellée par 50 coups de fouets dans les quatre coins de la place. Ensuite elle fut attachée à un poteau où elle mourut par un coup de feu dans le dos.

\section{8.- Olga Bruzzone de Bloch ${ }^{370}$}

Écrivaine et poétesse née en 1909, elle gagna plusieurs prix littéraires. Elle fut la directrice de la revue féminine Superación, porte-parole de la «Confederación Nacional de Instituciones Femeninas » (« CONIF ») fondée le 11 juillet 1958.

\section{9.- Esther Villalobos Vidal de Carrasco}

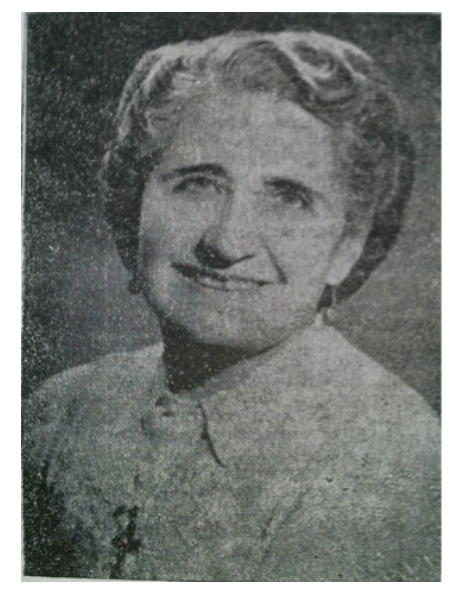

Née à La Paz, elle était la sœur de poète bolivien Rosendo Villalobos. Elle se maria avec le journaliste et homme de lettres José Carrasco Jiménez.

Elle réalisa ses études d'abord à Tacna - Pérou et les acheva au «Colegio Inglés Católico » de La Paz.

Elle fut la présidente de la «Sociedad Protectora de la Infancia » dans laquelle elle réalisa un travail important au bénéfice des enfants abandonnés. Aux côtés de Antonia Zalles de Careaga (voir annexe $\mathrm{A} \mathrm{n}^{\circ} 40$ ) et en tant que Vice-Présidente de la Croix Rouge Bolivienne, elle déploya une activité permanente pendant la Guerre du Chaco.

\footnotetext{
${ }^{370}$ Les informations sur la vie de Olga Bruzzone de Bloch ont été tirées du Diccionario cultural Boliviano, de l'éditoriale «El Aparapita », publié en ligne par le directeur de cet établissement Elías Blanco Mamani dans le site http://elias-blanco.blogspot.com/2011/04/olga-bruzzone-de-bloch.html.
} 
Elle forma partie de 1'«Asociación Femenina Pro Defensores de la Patria» («ASFEDEPA ») avec d'autres femmes.

Elle fut également membre de l' « Ateneo Femenino », occupant la charge de chef de la section de la Protection au Travail de la femme en 1935 et celle de Trésorière en 1948.

Elle travailla pour l'amélioration de son ancien lycée, à travers la réalisation de conférences et de discussions instructives.

\section{0.- Antonia Zalles de Careaga}

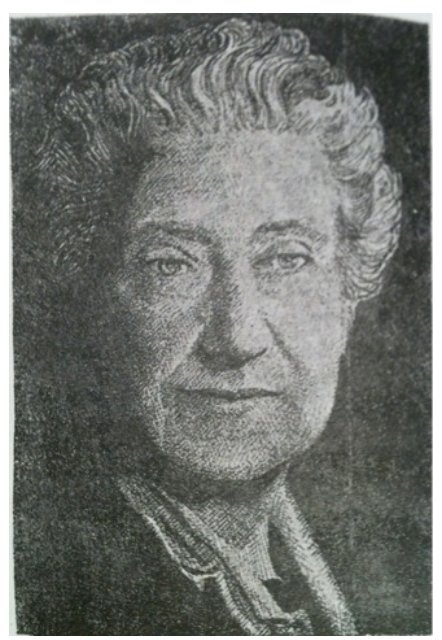

Née à La Paz, elle fut Présidente en 1927 de la « Sociedad Protectora de la Infancia ». En 1933 elle fonda 1'«Asociación Femenina Pro Defensores de la Patria» («ASFEDEPA »). Un comité de cette institution se rendit à la ligne d'opérations et de combats pour donner de l'aide morale et matérielle aux soldats. Ce comité était formé par Raquel Goytia de Sanjinés, Sara de Gutiérrez, Raquel Ichazo de Adriázola, Laura Iturralde, parmi d'autres. De même, elle travailla intensément au sein de la Croix Rouge bolivienne. En 1935, dans une Convention réalisée à Oruro par l'«ASFEDEPA », la réorganisation de la Croix Rouge fut décidée car elle avait été dissoute sans justifications. Elle fut élue présidente du Comité Inter-départemental de la Croix Rouge à La Paz, mais suite à des incompréhensions elle renonça en laissant la charge au Dr. Juan Manuel Balcázar.

En 1937, elle fut élue présidente du Conseil National de la Croix Rouge bolivienne, charge qu'elle eut jusqu'en 1952, date à laquelle le MNR décida la réorganisation de 
la Croix Rouge en concordance avec les Ministères d'Hygiène et Salubrité, Travail et Prévision Sociale récemment créés.

\section{1.- Jael Oropeza de Perez}

Poétesse née à Potosí, elle publia beaucoup de poèmes dans des journaux et des revues culturelles. Elle fut professeure d'anglais. Elle fut la représentante en Bolivie de la revue Mujeres de América fondée et dirigée par Nelly Merino Carvalho à Buenos Aires de 1930 à 1935.

\section{2.- Zoila Viganó Castañón ${ }^{371}$}

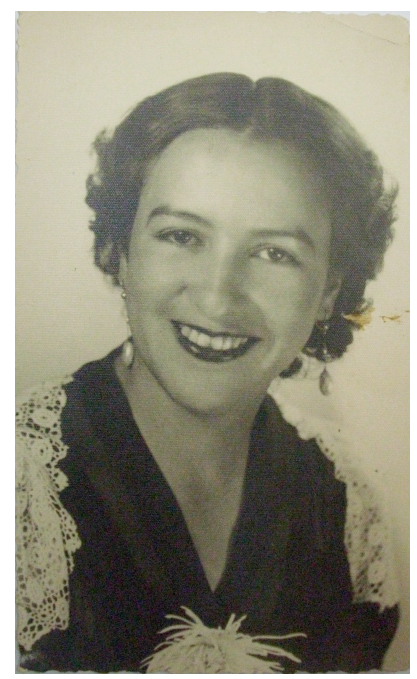

Née à La Paz, elle obtint sa Licence de Droit et de Sciences Politiques à l’Université Mayor de San Andrés à La Paz en 1933. Elle participa en tant qu'étudiante à la «Révolution de $1930 »$ qui renversa le président Hernando Siles. Elle fut décorée de la médaille «Défenseur de la Constitution» par le «Centro Hispano - Americano de Señoras » en tant que dirigeante du mouvement universitaire qui contribua à ce renversement. En tant que déléguée universitaire au début des années 1930, elle réalisa plusieurs communications sur la situation des femmes à

\footnotetext{
${ }^{371}$ Les informations sur la vie de Zoila Viganó Castañón ont été tirées de PAREDES de Salazar Elssa, Diccionario biográfico de la Mujer Boliviana, Ediciones «Isla », La Paz, 1965 ; de Zoila Viganó de Antezana. Mujer de las Américas 1983 1986, MINISTERIO de Educación y Cultura, n.d.; et d'un entretien réalisé en janvier 2010 avec l'un de ses fils, Guido Antezana, qui nous procura les photographies utilisées.
} 
Sucre et Potosí. Elle participa également au mouvement universitaire qui conquit la réforme universitaire en 1930.

En 1931 elle organisa un mouvement de jeunesse universitaire à La Paz, pour demander au pouvoir législatif que les droits civils et politiques soient octroyés aux femmes.

Elle devint membre de l'«Ateneo Femenino» en 1932, et occupa la charge de déléguée de cette organisation devant la Fédération d'étudiants universitaires pour demander au Parlement l'approbation de la Loi de Réintégration de Droits de la Femme.

En 1933 elle devint la directrice de la section féminine du journal La Semana Gráfica, ainsi que des sections "Crónicas heroicas", "Problemas nacionales" et "Cuestiones Sociales". Elle collabora également avec des articles dans d'autres revues et journaux du pays tels que La Gaceta de Bolivia, Apuntes à La Paz, Arte y Trabajo à Cochabamba, la revue Nosotras de Santiago - Chili (1935), la revue Mujeres de América de Buenos Aires (1935). Elle signait souvent ses articles avec les pseudonymes « Kora » et « Zetavece ».

Pendant la Guerre du Chaco elle publia le livre Conflicto Boliviano - Paraguayo à La Paz en 1935, dans lequel elle présenta les droits historiques de la Bolivie sur le territoire du Chaco, ainsi q'une réclamation pour que les prisonniers de guerre boliviens soient libérés. La vente de cette publication fut destinée au bénéfice de l'école des orphelins de guerre. Invitée par le Ministère des Affaires Étrangères, elle réalisa également des conférences sur les droits de la Bolivie sur le Chaco. De même, pendant le conflit avec le Paraguay elle contribua en tant que secouriste dans les hôpitaux d'arrière-garde.

Pendant la guerre, elle forma avec d'autres femmes telles que Etelvina Villanueva (voir annexe A ${ }^{\circ} 43$ ), María Gutierrez de Medinaceli (voir annexe A n²), le «Comité de Acción Feminista», organisation qui réalisa une campagne pour l'obtention des droits civils et politiques des femmes vers la fin de l'année 1934.

Elle réalisa un travail important à Buenos Aires pour la libération de prisonniers de guerre à travers la Confédération de la Paix Américaine et du Congrès Pro Paix.

En 1935 elle fut la fondatrice de 1' «Unión de Mujeres Americanas » («UMA ») en Bolivie, dans les villes de La Paz, Cochabamba et Santa Cruz. 
De 1952 à 1955 elle fut la présidente de l'«Ateneo Femenino », organisation de laquelle elle avait occupé la charge de Secrétaire d'Affaires Juridiques pendant plusieurs périodes auparavant.

Lorsque le droit de vote fut octroyé aux femmes le 21 juillet 1952 elle organisa une première manifestation féministe honorée par l'épouse du président.

Elle collabora à la réalisation d'un Dictionnaire de femmes avec la collaboration de la Suisse.

Elle participa au « Congreso Femenino Hispano - Americano » à Madrid en 1951, où elle présenta une communication sur la situation juridique des femmes boliviennes.

Elle fut députée nationale du département de La Paz en 1961 pour le MNR.

En 1963, elle réorganisa 1' «Unión de Mujeres Americanas » («UMA »). Elle y fut nommée présidente honoraire à vie.

En 1966, elle fut nommée membre honoraire du Conseil Interaméricain par l'«UMA » à New York en reconnaissance de son travail en tant que représentante et fondatrice de l'organisation en Bolivie.

En 1971 elle fut invitée à la Première Convention de 1' «Unión de Mujeres Americanas » à Porto Rico, où elle présenta une communication sur la situation légale des femmes en Bolivie.

En 1972 elle fut proclamée «Femme bolivienne américaniste», et l'«Ateneo Femenino » lui attribua un diplôme d'honneur en reconnaissance de son travail pour le progrès des femmes et l'union des pays d'Amérique.

En 1983 elle fut nommée «Femme des Amériques » par l'«UMA » à New York.

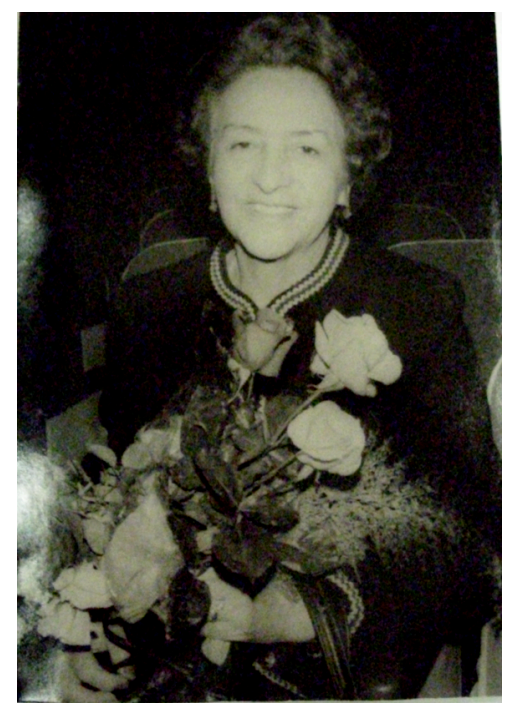

Zoila Viganó, lorsqu'elle reçut le titre de «Femme des Amériques » à l'hôtel Waldorf - Astoria à New York en 1983. 


\section{3.- Etelvina Villanueva ${ }^{372}$}

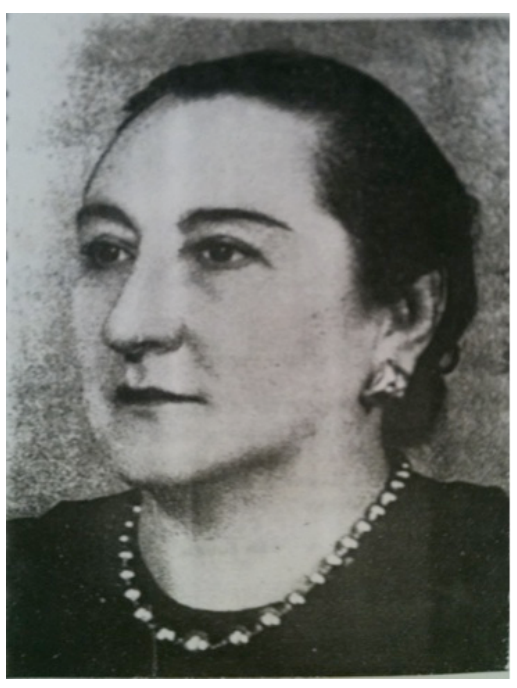

Bolivienne par mariage et par sa mère, elle habita en Bolivie pendant plus de 49 ans. Née à Lima en 1897, elle réalisa ses études à l'École Normale Supérieure de cette ville et arriva en Bolivie en 1916. Elle devint professeure et proviseure de plusieurs écoles et lycées, à Potosí et Oruro.

Elle forma partie du «Comité de Acción Feminista » en 1934 avec María Gutierrez de Medinaceli (voir annexe $A n^{\circ}$ 2) et Zoila Viganó Castañón (voir annexe A n42) entre autres.

En 1935 elle fut la fondatrice et présidente de la «Legión Femenina de Educación Popular América » en Bolivie. Elle présida le premier Congrès de cette institution à Cochabamba le 12 novembre 1936. Elle fut la directrice de la revue de cette organisation : Despertar.

Elle fut membre de l'«Ateneo Femenino» et de plusieurs autres organisations féminines.

En 1943 elle fonda le Service Auxiliaire Féminin, dépendant du Ministère de Défense. En 1946, elle fut nommée Chef National du Service Auxiliare Féminin (SAF), et réalisa un travail technique et éducatif de formation dans les lycées secondaires et professionnels de jeunes femmes. Il s'agissait de former des « Brigades Féminines » en cas de guerre : elles devaient être chargées de la conduction de voitures, des services de communication, de porter secours et assistance, et des

\footnotetext{
${ }^{372}$ Les informations sur la vie d'Etelvina Villanueva ont été tirées de PAREDES de Salazar Elssa, Diccionario biográfico de la Mujer Boliviana, Ediciones « Isla », La Paz, 1965, et de
} 
services auxiliaires d'aviation. Des cours de pilotage pour femmes furent organisés dans cet objectif.

En 1945 elle fonda la « Asociación Interamericana de Mujeres ».

En 1945 son travail à faveur des femmes fut reconnu par l'attribution du titre «Custodia de los Derechos de la Mujer Americana » par l'institution « Custodia de América » du Panamá.

En 1953, elle publia une anthologie de poésie féminine intitulée Ronda Femenina de América. Elle publia également un livre de poèmes, Siembra, en 1939.

\section{4.- Aida Ballón Sanjinés}

Poétesse née à La Paz, elle était très célèbre dans le pays pour ses déclamations.

\section{5.- Yolanda Bedregal de Conitzer}

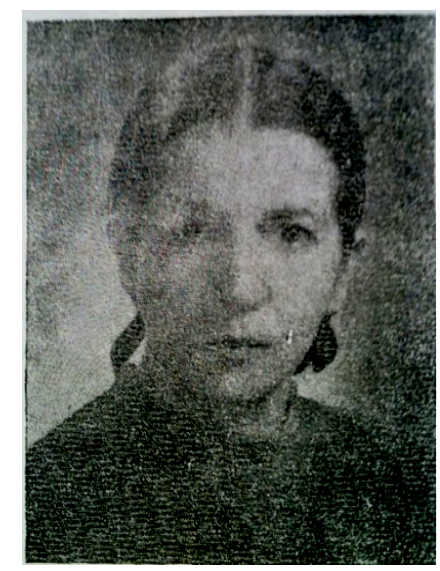

Née à La Paz, elle fut une des poétesses les plus célèbres de la Bolivie. Elle était fille de l'écrivain Juan Francisco Bedregal et de Carmen Iturry.

Dans sa jeunesse elle se consacra à la sculpture.

Elle fut professeure d'histoire de musique à l'université et au Conservatoire National de Musique.

Plusieurs de ses poèmes ont été traduits à l'anglais, à l'allemand, au portugais au bengali, à l'hongrois, au suédois et au norvégien.

Yolanda fut également une spécialiste du folklore bolivien et publia plusieurs articles dans des revues culturelles sur les coutumes typiques de la Bolivie. Elle publia 
plusieurs livres: Naufragio, Poemar, Ecos, Almadia, Del mar y la ceniza, Alegatos y Antología et Nadir. D'eux d'entre eux furent traduits à l'allemand par son époux.

\section{6.- Margarita Nuñez del Prado}

Née à La Paz, poétesse célèbre par ses déclamations. Le gouvernement lui offrit une bourse pour qu'elle aille perfectionner ses études de déclamation en Europe alors qu'elle était très jeune.

Elle étudia à l'Ecole de Services Sociaux de La Paz et se diplôma en tant que travailleuse sociale.

Elle laissa de côté la déclamation pour se consacrer entièrement à son travail.

En 1944 elle fut chargée de la Commission d'Assistance Sociale de la « Fédération de Sociétés Culturelles Féminines ».

\section{7.- Aida Carvajal}

Poétesse née à Cochabamba, elle étudia dans l'Institut de Commerce de sa ville et devint secrétaire commerciale. Elle devint présentatrice de radio, mais elle était surtout célèbre par ses déclamations.

Elle fut militante au sein du MNR.

En 1964 elle fut la première femme à former partie de la direction de la Banque Centrale.

\section{8.- Yolanda Pando Zalles}

Concertiste et professeure de piano née à La Paz.

Elle réalisa ses premières études de piano sous la direction de Pietro Burno. En 1924 elle réalisa un cours de spécialisation à New York sur l'enseignement du piano aux enfants. En 1926 elle partit étudier en France à l'Ecole Normale Supérieure de Musique obtenant le titre de professeure de piano. Elle retourna en Bolivie en 1930, où elle créa une école. En 1942 elle obtint une bourse du « Institute of International Education » pour réaliser des cours de spécialisation au «Teacher's College » de l’Université de Columbia et dans la « Juilliard School of Music » de New York. 


\section{9.- Julia Reyes Ortiz de Canedo ${ }^{373}$}

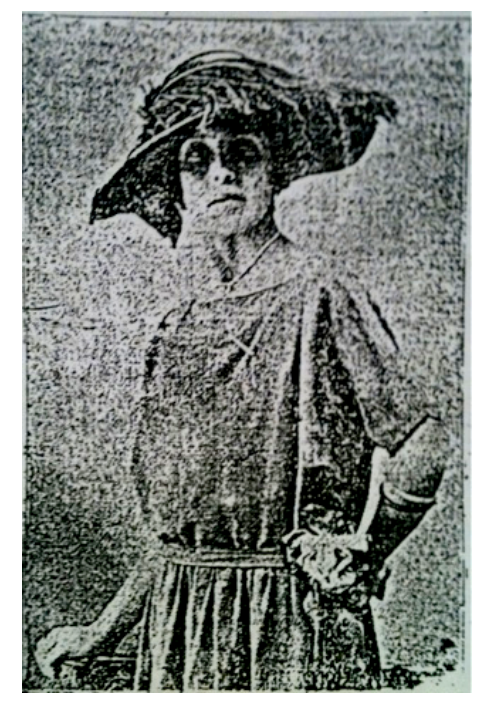

Professeure et journaliste née à La Paz en 1881. Elle était fille de l'écrivain Félix Rosa Reyes Ortiz et de Adela Cabrera, sœur du docteur Ladislao Cabrera un des principaux défenseurs de la ville de Calama pendant la Guerre du Pacifique (1879 1883).

Elle commença sa carrière de journaliste dans le journal de La Paz El Siglo Industrial. Elle fonda et dirigea la section féminine du journal La República, et fut chargée de la section «Inquietudes Femeninas » du journal La Razón en 1925. Elle collabora dans les journaux El País et Los Tiempos de Cochabamba.

Elle fut professeure de Philosophie à l'université de Cochabamba.

Elle fut également fondatrice du Lycée « La Paz » avec Lola Ruck.

Elle fut un des membres fondateurs de l'« Ateneo Femenino ».

A Cochabamba elle fut la première femme à être membre du conseil de la Société d'Écrivains et d'Artistes. Elle fut la fondatrice de l'Académie « Man Césped» dans cette ville.

En 1926 elle fonda la revue culturelle Ilustración Artística et plus tard, en 1930, la revue Las Horas.

Elle fut invitée à plusieurs congres internationaux dont on peut citer entre autres : le Congrès International de journalistes qu'eut lieu à Génève en 1959, au Congrès « Pro

\footnotetext{
${ }^{373}$ Photographie tirée de Eco Femenino, n 9 , septembre 1924, La Paz. Hemeroteca de la Universidad Mayor de San Andrés, La Paz - Bolivie.
} 
Paix Universelle » réalisé à Lausanne, et au Congrès de Paris qui traita du problème de la destruction de la bombe atomique.

\section{0.- Gloria Serrano (Rosenda Caballero de Crespo Gastelú)}

Rosenda Caballero de Crespo Gastelú, plus connue par son pseudonyme "Gloria Serrano", était une journaliste et écrivaine née à La Paz. Elle avait fait ses études à l'Ecole Normale Supérieure de Sucre et obtint le titre de professeure normalienne.

Elle collabora depuis 1929 dans la section littéraire du journal La Razón, dans les revues Mujeres de América, La Gaceta de Bolivia, Variedades, Mundo Uruguayo de Montevideo et dans les journaux El Comercio et El Sol de Cuzco.

Elle publia plusieurs livres dont : Jirones Kollavinos, Tierras del Kosko.

Elle réalisa plusieurs conférences et discussions culturelles.

\section{1.- Cira Aguayo ${ }^{374}$}

Membre du «Comité de Acción Feminista de Cochabamba » en 1934. Elle fut également la présidente de la « Legión Femenina de Educación Popular América » de Cochabamba en 1935, et la Directrice des «Droits féminins» de l'«Unión de Mujeres Americanas » de Cochabamba.

\footnotetext{
${ }^{374}$ Les informations sur Cira Aguayo ont été tirées de VILLANUEVA Etelvina, Acción Socialista de la mujer en Bolivia, Cooperativa de Artes Gráficas E. Burillo Ltda., La Paz -Bolivie, 1970; et de El Diario, 26 octobre 1934, La Paz. Collection personnelle d'extraits de journaux de Zoila Viganó Castañón.
} 


\section{2.- Elvira Delgado Mantilla de Bedregal}

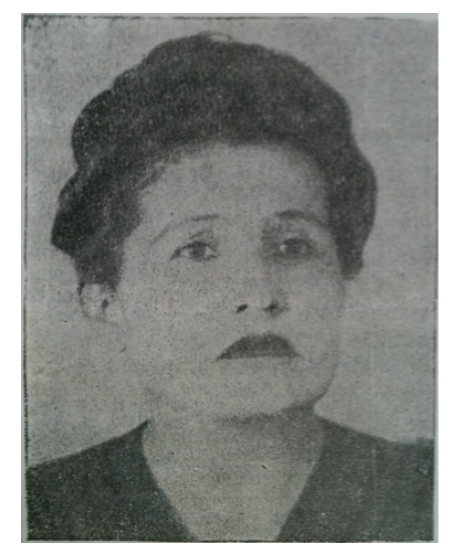

Professeure normalienne et écrivaine née à $\mathrm{La} \mathrm{Paz}$, elle fut Proviseure de plusieurs écoles. Elle fut la fondatrice et Proviseure de l'école «Víctor Muños Reyes » en 1944.

Elle participa en 1929 au premier Congrès National de femmes organisé par l'« Ateneo Femenino », en présentant un communiqué sur le « Sentimentalisme ».

Elle fut membre de la «Legión Femenina de Educación Popular América » ( LFEPA ») et rédactrice en chef du journal de cette organisation Despertar.

En 1948, elle fut déléguée de l'«Ateneo Femenino devant l'Assemblée des Sociétés Culturelles, présentant un travail d'études sur les « Droits Politiques de la Femme ».

Elle appartint et collabora dans plusieurs institutions civiques et culturelles. Elle fut Présidente du Comité Féminin «Pro Cultura»; Vice-Présidente de l' «Ateneo Pedagógico Boliviano »; ancienne présidente de l'«Ateneo Femenino »; membre actif de la "Agrupación Interamericana de Mujeres »; ancienne Secrétaire de la «Legión Femenina de Educación Popular América » et directrice de l'Action Sociale de cette organisation ; membre de la «Unión Sindical de Maestros », promotrice de la «Oficina de la Mujer », membre de la « Peña de Escritores y Artistas de Bolivia », et fondatrice de la «Unión Femenina de Educacionistas » en 1933.

Elle publia plusieurs livres d'éducation et de Droit International, ainsi que des ouvrages littéraires tels que Mi Verdad (1945) et Huellas (1950). 


\section{3.- Rebeca Brito Salazar}

Écrivaine née à Sucre. En 1930 elle publia des articles sur les droits des femmes.

Elle fut membre de la Société Géographique de Sucre. Elle fut Directrice de la Bibliothèque Nationale, du Musée de Sucre, et membre de l'Association de journalistes de cette ville.

\section{4.- Isabel Mendoza}

Poétesse née à Sucre, elle était la sœur du poète Jaime Mendoza. À la mort de ses parents il habita avec lui en se consacrant à la littérature et à l'éducation de sa nièce Martha Mendoza (voir annexe A n ${ }^{\circ} 34$ ).

Elle mourut en 1944.

\section{5.- Mercedes Rodríguez ${ }^{375}$}

Membre du «Comité de Acción Feminista de Cochabamba » en 1934, elle fut également la Directrice de l'Action Mutualiste de la « Legión Femenina de Educación Popular América » de Cochabamba en 1935.

\section{6.- Amelia Chopitea}

Née à Colquechaca dans la province de Potosí, elle s'éduqua à Sucre. Elle réalisa des études de médecine à l'Université San Francisco Xavier de Sucre. Elle fut la première femme en Bolivie à obtenir le titre de médecin chirurgien en 1925. Le gouvernement bolivien lui octroya une bourse pour qu'elle réalise sa spécialisation à Paris.

Elle participa à la Convention organisée par la 1'«Asociación Femenina Pro Defensores de la Patria » («ASFEDEPA ») réunie à Oruro en octobre 1934.

En tant que présidente de la « Legión Femenina de Educación Popular América » à Oruro en 1935, elle fit construire le Pavillon pour Enfants dans 1'Hôpital Municipal d'Oruro en 1936.

\footnotetext{
${ }^{375}$ Les informations sur Mercedes Rodríguez ont été tirées de VILLANUEVA Etelvina, Acción Socialista de la mujer en Bolivia, Cooperativa de Artes Gráficas E. Burillo Ltda., La Paz -Bolivie, 1970; et de El Diario, 26 octobre 1934, La Paz. Collection personnelle d'extraits de journaux de Zoila Viganó Castañón.
} 


\section{7.- Paz Nery Nava Bohorquez}

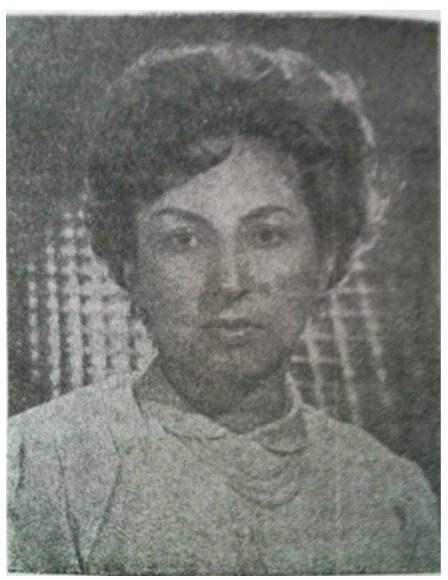

Poétesse, spécialiste de l'éducation, et travailleuse sociale, née à Uncía dans la province de Potosí. Elle réalisa ses études primaires et secondaires à Oruro. Elle étudia à l'Institut des Sciences de l'Éducation dépendant de l'Université San Francisco Xavier de Sucre et devint professeure normalienne en 1934. Elle étudia également à l'Ecole Nationale de Service Social en étant une des premières élèves de cet établissement et obtenant le titre de travailleuse sociale en 1948.

Elle prit des cours de spécialisation en Psychologie, Sociologie et Diététique.

En 1960 elle reçut une bourse de Nations Unies pour étudier à Santiago, Chili dans le « Centro de Formación de Especialistas de la Educación ».

Elle fut présidente de l' «Unión Femenina de Educadoras », présidente conseillère de l'«Ateneo Femenino », membre fondateur du groupe «Fuego de Poesía », présidente de la «Asociación Nacional de Asistentes Sociales » en 1963. Elle fut membre de la Direction de la « Asociación de Autores de Textos Didácticos ». Elle fut également la fondatrice du «Círculo Femenino de Cultura» en 1963, et des «Centros de Intercambio Cultural Boliviano-Uruguayo » et « Boliviano-Guatemalteco ».

Elle publia plusieurs livres dont on peut citer : Silabario de Sueños (1957), Lenguaje funcional en la escuela primaria (1959). Elle fut correspondante de la revue Lírica Hispánica de Caracas, Venezuela.

Elle reçut des diplômes en reconnaissance de son travail par l' « Ateneo Femenino », la «Unión Femenina de Educadoras », et de l'école «Guatemala » où elle était Proviseure. 


\section{8.- Raquel Carmona ${ }^{376}$}

Membre fondateur de 1'«Ateneo Femenino », elle fut fut la Pro Secrétaire de cette organisation en 1924, et la Trésorière en 1925.

Elle fut également la Directrice de Culture de la « Legión Femenina de Educación Popular América » de Potosí en 1935.

Elle fut chargée de la commission de professeurs de secondaire dans la «Federación de Sociedades Culturales Femeninas » en 1944.

\section{9.- Elvira Ortiz de Chávez ${ }^{377}$}

Poétesse, professeure de musique et femme d'une vaste culture, née à Trinidad, elle vécut toute sa vie à Santa Cruz.

Elle était la mère de Nuflo Chávez, un des principaux dirigeants du MNR et VicePrésident de la Bolivie en 1956.

"Santa Cruz" est l'un de ses poèmes les plus célèbres pour lequel elle remporta un prix dans un concours littéraire.

Elle est l'auteure de plusieurs écrits en prose et de pièces de théâtre dont El Orgullo y la Humildad, pièce en vers qui fut représentée dans les théâtres.

Elle fut également Proviseure de la «Escuela Profesional de Señoritas » de Santa Cruz, et professeure de piano au Conservatoire de Musique.

Elle fut également la fondatrice et directrice pendant plusieurs années, de l'école de Beaux Arts de l’Université « Gabriel René Moreno » de Santa Cruz.

Elle publia le livre Poesías y canciones escolares. Elle dirigea également la section féminine du Diario Popular (1936).

Membre de la «Legión Femenina de Educación Popular América» de Santa Cruz, elle était la directrice de Presse et de Propagande de cette organisation en 1935.

Elle fut co-fondatrice de la «Liga Femenina Internacional» avec Blanca Catera de Herrera.

\footnotetext{
${ }^{376}$ Les informations sur la vie de Raquel Carmona ont été tirées de Feminiflor n ${ }^{\circ}$ 25, novembre 1923, Oruro, et de VILLANUEVA Etelvina, Acción Socialista de la mujer en Bolivia, Cooperativa de Artes Gráficas E. Burillo Ltda., La Paz -Bolivie, 1970.

${ }^{377}$ Les informations sur la vie de Elvira Ortiz de Chávez ont été tirées de PAREDES de Salazar Elssa, Diccionario biográfico de la Mujer Boliviana, Ediciones « Isla », La Paz, 1965 et d'un entretien réalisé avec le petit-fils de celle-ci, Gonzalo Alvarez Chávez, en mai 2011.
} 


\section{0.- Luisa Mendoza ${ }^{378}$}

Membre de la «Legión Femenina de Educación Popular América » de Cochabamba en 1935, elle était la Directrice d'Action Juridique de l'organisation.

Elle fut également membre de l'«Unión de Mujeres Americanas » («UMA») de Cochabamba en 1935, où elle était chargée de la section «Pro législation sociale de la femme ».

\section{1.- Rosa Morales Guillén ${ }^{379}$}

Membre de la «Legión Femenina de Educación Popular América » de Cochabamba en 1935, elle était la Directrice de la Bibliothèque de l'organisation.

Elle fut également membre de l'«Unión de Mujeres Americanas » («UMA ») de Cochabamba en 1935, où elle était chargée de la section « Liens avec les ouvriers ».

En tant que membre des Commandos Féminins du MNR, elle se présenta candidate du parti aux élections municipales de la ville de Cochabamba en 1947.

\footnotetext{
${ }^{378}$ Les informations sur Luisa Mendoza ont été tirées de La Patria (supplément pour Cochabamba), 14 mars 1936, Cochabamba ; et de VILLANUEVA Etelvina, Acción Socialista de la mujer en Bolivia, Cooperativa de Artes Gráficas E. Burillo Ltda., La Paz -Bolivie, 1970.

${ }^{379}$ Les informations sur Rosa Morales ont été tirées de La Patria (supplément pour Cochabamba), 14 mars 1936, Cochabamba; de VILLANUEVA Etelvina, Acción Socialista de la mujer en Bolivia, Cooperativa de Artes Gráficas E. Burillo Ltda., La Paz -Bolivie, 1970; et de REVOLLO QUIROGA, Marcela, Mujeres bajo prueba. La participación electoral de las mujeres antes del voto universal (1939 - 1949), Eureka Ediciones, La Paz - Bolivia, 2001.
} 


\section{1.- María Josefa Saavedra ${ }^{380}$}

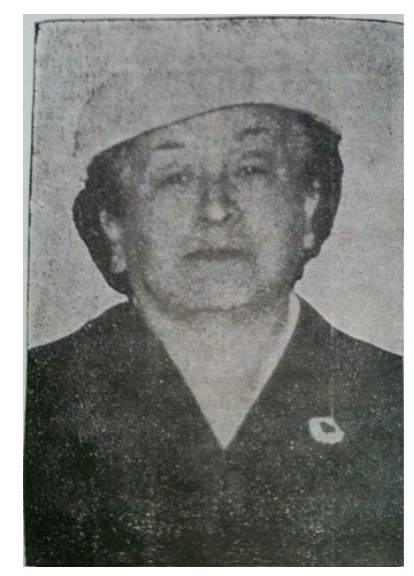

Professionnelle Bolivienne née à La Paz. Nièce de Bautista Saavedra, président de la Bolivie de 1920 à 1925. Elle réalisa ses études supérieures à l'Université Mayor de San Andrés de La Paz, obtenant la licence de Droit en 1925.

Elle fut professeure de Droit Romain à cette même Université et publia un Manuel de Droit Romain, ainsi que plusieurs articles dans la presse.

Elle appartint à plusieurs institutions culturelles féminines, dont l'« Asociación de Mujeres Universitarias ».

\section{2.- María Tubert de Estebán ${ }^{381}$}

Présidente de la «Legión Femenina de Educación Popular América » de La Paz en 1935, elle fut présidente du «Comité Femenino Pro Cultura» et représentante de celui-ci dans la «Federación de Sociedades Culturales Femeninas » en 1944.

\footnotetext{
${ }^{380}$ Les informations sur María Josefa Saavedra ont été tirées de PAREDES Oviedo Martha, María Josefa Saavedra, Serie "Protagonistas de la Historia", Editores: Ministerio de Desarrollo Humano, Secretaría de Asunto Étnicos, de Género y Generacionales, Subsecretaría de Asuntos de Género, La Paz - Bolivia, 1997 et de PAREDES de Salazar Elssa, Diccionario biográfico de la Mujer Boliviana, Ediciones « Isla », La Paz, 1965

${ }^{381}$ Les informations sur María Tubert de Estebán ont été tirées de El Diario, 2 septembre 1944, La Paz; et de VILLANUEVA Etelvina, Acción Socialista de la mujer en Bolivia, Cooperativa de Artes Gráficas E. Burillo Ltda., La Paz-Bolivie, 1970.
} 


\section{3.- Marina Lijerón Baldivia}

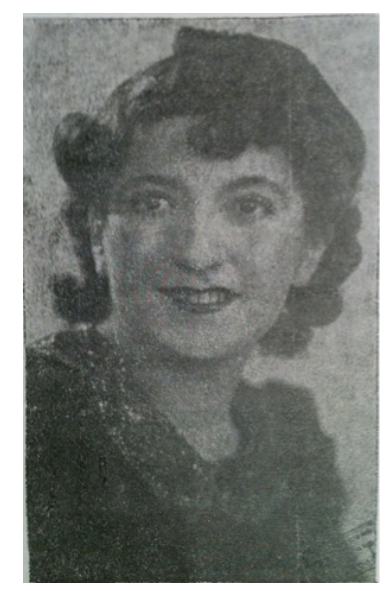

Née à La Paz, elle étudia le Droit à l'Université Mayor de San Andrés, et obtint la licence de Droit en 1943.

Elle fut secrétaire générale du « Ateneo Femenino » en 1936.

Elle fut déléguée universitaire au IV Congrès Universitaire réuni à Sucre en 1938. Elle collabora à la radio «Illimani » de La Paz pendant les années 1930 et 1940 en créant le programme « Paroles à la Femme ». Elle fut de même présidente du Comité Permanent «Pro Derechos Políticos de la Mujer» à La Paz en 1938. Elle fut également fondatrice de la revue Nosotras en 1939.

Elle participa en tant que représentante de la Bolivie à la Commission Interaméricaine de Femmes réunie à Buenos Aires en 1949.

\section{4.- Antonieta Suarez Dupleich de Taechsler}

Née à Oruro, elle fut la fondatrice de la première école d'aveugles dans le pays.

Depuis son adolescence elle montra une inquiétude envers les aveugles. Elle étudia le système Braille pour apprendre à lire et à écrire aux aveugles. Elle apprit à jouer au piano, à la guitare et à d'autres instruments à travers le tact.

Avec l'aide de la société d'Oruro elle fonda la première école pour aveugles en Bolivie en avril 1932 où se donnaient des cours gratuitement. Plus tard, la Préfecture du Département et la Municipalité lui accordèrent des subsides pour soulager la mauvaise situation économique de l'école. 


\section{5.- María Angélica Panozo de Videa ${ }^{382}$}

Secrétaire de la «Legión Femenina de Educación Popular América » de La Paz en 1935. En 1944, elle était chargée de la commission de Prévision Sociale dans la « Federación de Sociedades Culturales Femeninas ».

\section{6.- María Frontaura Argandoña de Illanes}

Née à Potosí, elle fut éduquée à Sucre. Elle était mariée avec l'artiste Mario Alejandro Illanes. Elle étudia à l'École Normale Supérieure de Sucre devenant professeure normalienne en 1917.

Éducatrice, journaliste et écrivaine elle fut professeure dans plusieurs écoles et se consacra également au folklore bolivien.

Elle fut membre de l'« Ateneo Femenino » à partir de 1935.

Elle réalisa plusieurs conférences sur l'importance des indigènes pour le progrès de la Nation.

\section{7.- Natty Peñaranda de Guillén Pinto}

Écrivaine, professeure normalienne et spécialiste du folklore née à La Paz. Elle était mariée avec Alfredo Guillén Pinto, professeur et écrivain.

Elle fut Proviseure de plusieurs écoles et lycées, dont les écoles pour indigènes « Núcleo Indigenal de La Paz», « Núcleo Indigenal de Caquiaviri Alfredo Guillén Pinto ». Elle fut également la fondatrice et proviseure de l'école « $1^{\circ}$ de Mayo ». Elle partit vivre à Buenos Aires, où elle fut professeure de psychopédagogie à l'école « Jesús María ».

Elle publia plusieurs ouvrages dont Utama qui reçut le prix de meilleur roman de l'année, Mina roman social, Pacha Ajayu roman folklorique, et El Cerebro Instrumento Creador, ouvrage didactique.

Elle collabora dans plusieurs journaux de La Paz, et dans El Universal de Caracas, Venezuela. Elle collabora également aux revues féminines Superación et Nuestra Revista.

\footnotetext{
${ }^{382}$ Les informations sur María Angélica Panozo de Videa ont été tirées de El Diario, 2 septembre 1944, La Paz; et de VILLANUEVA Etelvina, Acción Socialista de la mujer en Bolivia, Cooperativa de Artes Gráficas E. Burillo Ltda., La Paz-Bolivie, 1970.
} 
Elle fut membre de plusieurs institutions féminines culturelles dont l'«Ateneo Femenino », la « Unión Femenina de Educadoras », le « Círculo Femenino de Cultura Hispánica », «Mesa Redonda Panamericana », «Círculo Cultural Boliviano Americano de Damas ». Elle fut également membre d'organisations féminines à l'étranger telles que 1'«Ateneo Paula Albarracín de Sarmiento » et 1' «Asociación Democrática Latino-Americana » de Buenos Aires.

\section{8.- Leticia Fajardo de Perelman}

Écrivaine et poétesse née à Oruro, elle étudia à l'Université Technique où elle obtint la licence de Droit. Elle travailla comme conseillère juridique dans la Fédération Nationale d'Avocats de Bolivie.

Elle publia plusieurs livres dont l'ouvrage Pampa, metal y sangre où elle décrit la vie des femmes dans les mines.

\section{9.- Isabel Ugarte de Morató ${ }^{383}$}

Conseillère municipale de 1948 à 1949 à Cochabamba. Elle fut candidate du Parti Libéral et du PURS qui avaient formé une coalition.

Elle était liée à la vie culturelle et civique de sa ville.

Elle étudia en France et postérieurement elle travailla dans les activités de l'Alliance Française de Cochabamba.

\section{0.- Alicia D'Arlach de Blanco Galindo ${ }^{384}$}

Élue conseillère municipale à Cochabamba en 1947 pour la «Candidatura CívicoCristiana » composée par 1' « Asociación Femenina Boliviana », « Falange Socialista Boliviana » et la « Liga Electoral Femenina Cristiana ».

\footnotetext{
${ }^{383}$ Les informations sur la vie de Isabel Ugarte de Morató ont été tirées de REVOLLO QUIROGA, Marcela, Mujeres bajo prueba. La participación electoral de las mujeres antes del voto universal (1939 - 1949), Eureka Ediciones, La Paz - Bolivia, 2001.

${ }^{384}$ Les informations sur la vie de Alicia D'Arlach de Blanco Galindo ont été tirées de REVOLLO QUIROGA, Marcela, Mujeres bajo prueba. La participación electoral de las mujeres antes del voto universal (1939 - 1949), Eureka Ediciones, La Paz - Bolivia, 2001.
} 
Pendant la Guerre du Chaco elle fonda le « Comité Pro Huérfanos de Guerra » et sous sa présidence avec la collaboration des sœurs de la «Cruzada Pontificia » et les mères de «Santa Ana» furent fondés deux orphelinats en 1935 pour filles et garçons respectivement.

En 1947, elle fut déclarée «Fille Prédilecte » du Beni par l'aide qu'elle avait apporté aux sinistrés des inondations que subit le département cette année.

Elle reçut un diplôme par la Municipalité de Cochabamba par son travail humanitaire.

\section{1.- Lindaura Sainz de Ferrufino ${ }^{385}$}

Militante du parti d'extrême droite «Falange Socialista Boliviana », elle fut élue conseillère municipale à Cochabamba en 1949. Elle avait été une des fondatrices de la Croix Rouge de Santa Cruz.

En tant que conseillère municipale elle travailla pour l'amélioration des prisons et l'alimentation dans les orphelinats.

Elle fut fondatrice de la «Unión Cristiana Femenina» et du «Comité Pro Cochabamba Femenino ».

Elle reçut en 1985 le prix « Orden del Sol de Septiembre » en reconnaissance de son travail en tant que conseillère municipale.

\section{2.- Clotilde Urioste de Villa}

Conseillère municipale élue en 1947 à Sucre, elle appartenait à une des familles les plus aisées de Sucre. Elle consacra sa vie et son argent à des œuvres sociales : elle fit don des terrains pour la construction de la maison d'aliénés de Sucre, et d'autres à l'Église Catholique. Sa participation dans la vie civique, culturelle et d'assistance sociale dans la ville fut très intense.

\footnotetext{
${ }^{385}$ Les informations sur la vie de Lindaura Sainz de Ferrufino ont été tirées de REVOLLO QUIROGA, Marcela, Mujeres bajo prueba. La participación electoral de las mujeres antes del voto universal (1939 - 1949), Eureka Ediciones, La Paz - Bolivia, 2001.
} 


\section{3.- María Barzola}

María Barzola était une femme des classes populaires qui travaillait en tant que «palliri » ${ }^{386}$ dans les mines de Catavi. Lors de la grève pour l'augmentation des salaires dans le complexe minier Catavi-Siglo XX en décembre 1942, elle se mit à la tête des ouvriers pendant la grève et mourut sous les coups des mitrailleuses. Elle devint un symbole de la lutte pour les droits du prolétariat. Les commandos féminins du MNR formés pendant la période du «Sexenio» (1946-1952) étaient appelés «Barzolas ». Le décret de Nationalisation de Mines après la révolution de 1952 fut signé dans le champ où María Barzola mourut qui porte son nom.

\section{4.- Rosa Lema Dolz}

Professionnelle et femme politique, née à Tarija elle réalisa des études de Droit. Membre du MNR depuis la fin des années 1940, elle fut élue député nationale en 1962.

\section{5.- Lydia Gueiler Tejada ${ }^{387}$}

Née à Cochabamba, elle réalisa des études de Commerce. Pendant la guerre du Chaco elle rencontra son premier époux, un officier paraguayen qui avait été fait prisonnier. Elle partit vivre au Paraguay pendant quelques années, et retourna ensuite en Bolivie. Elle commença à travailler à la Banque Centrale où elle rencontra quelques membres du MNR. Luis Peñaloza, collègue de travail l'invita à se joindre aux rangs du MNR en 1948. Elle commença ainsi sa militance au sein de MNR et fut désignée chef des « Grupos de Honor », groupes secrets d'action dans les conspirations et soulèvements. Elle participa dans une grève de faim réalisée par 27 femmes du MNR le 20 avril 1951 afin que les prisonniers politiques soient libérés. Cette grève eut beaucoup de

\footnotetext{
${ }^{386}$ Les « palliris » sont les femmes qui sélectionnent les minéraux extraits des mines.

${ }^{387}$ Les informations sur la vie de Lydia Gueiler ont été tirées de PAREDES de Salazar Elssa, Diccionario biográfico de la Mujer Boliviana, Ediciones «Isla », La Paz, 1965 ; MESA (de) José, GISBERT Teresa, MESA Gisbert Carlos D., Manual de Historia de Bolivia, Editorial Gisbert, La Paz, 2008 ; CRESPO Alfonso, Lydia, Una Mujer en la Historia, Plural Editores, La Paz, 1998 ; Entretien réalisé par Maria René Duchén avec Lydia Guiler, dans la série Mujeres Políticas en la Tierra Prohibida. Testimonios de mujeres protagonistas de la política boliviana, Nuestra Esperanza, Konrad Adenauer Stiftung, La Paz, Décembre 2008.
} 
succès car elle provoqua la mobilisation de plusieurs secteurs de la population et le gouvernement fut obligé à libérer les prisonniers.

Lydia Gueiler participa également de la Révolution du 9 avril 1952 avec d'autres femmes du MNR en secourant les blessés, transportant des armes, etc. En 1953, elle partit à Hambourg en Allemagne comme secrétaire du Consulat de la Bolivie. Elle retourna en Bolivie quelques années plus tard, et devint député suppléante entre 1956 et 1960. En 1960 elle fut Officier Majeur du Ministère d'Affaires Paysannes, et fut député titulaire entre 1960 et 1964.

Elle fut nommée déléguée permanente de la Bolivie à la Commission Interaméricaine de femmes dont le siège se trouve à Washington.

Lorsque le MNR se divisa en 1964 elle devint membre du « Partido Revolucionario de la Izquierda Nacionalista » («PRIN ») dirigé par Juan Lechín. Elle milita dans ce parti jusqu'aux années 1970 où elle se sépara et forma une fraction propre avec laquelle elle s'allia à nouveau avec le MNR. Député de l'alliance avec le MNR, elle fut élue présidente de la Chambre de députés et en tant que telle elle fut élue Présidente intérimaire du pays en 1979. Elle fut la première et unique femme présidente de la Bolivie. Cependant, son gouvernement dura peu de temps car en 1980 elle fut renversée par García Mesa, et dut s'exiler. 


\section{B) Photographies}

\section{1.- Femmes boursières qui partirent étudier au Chili en 1906}

$(1910)^{388}$

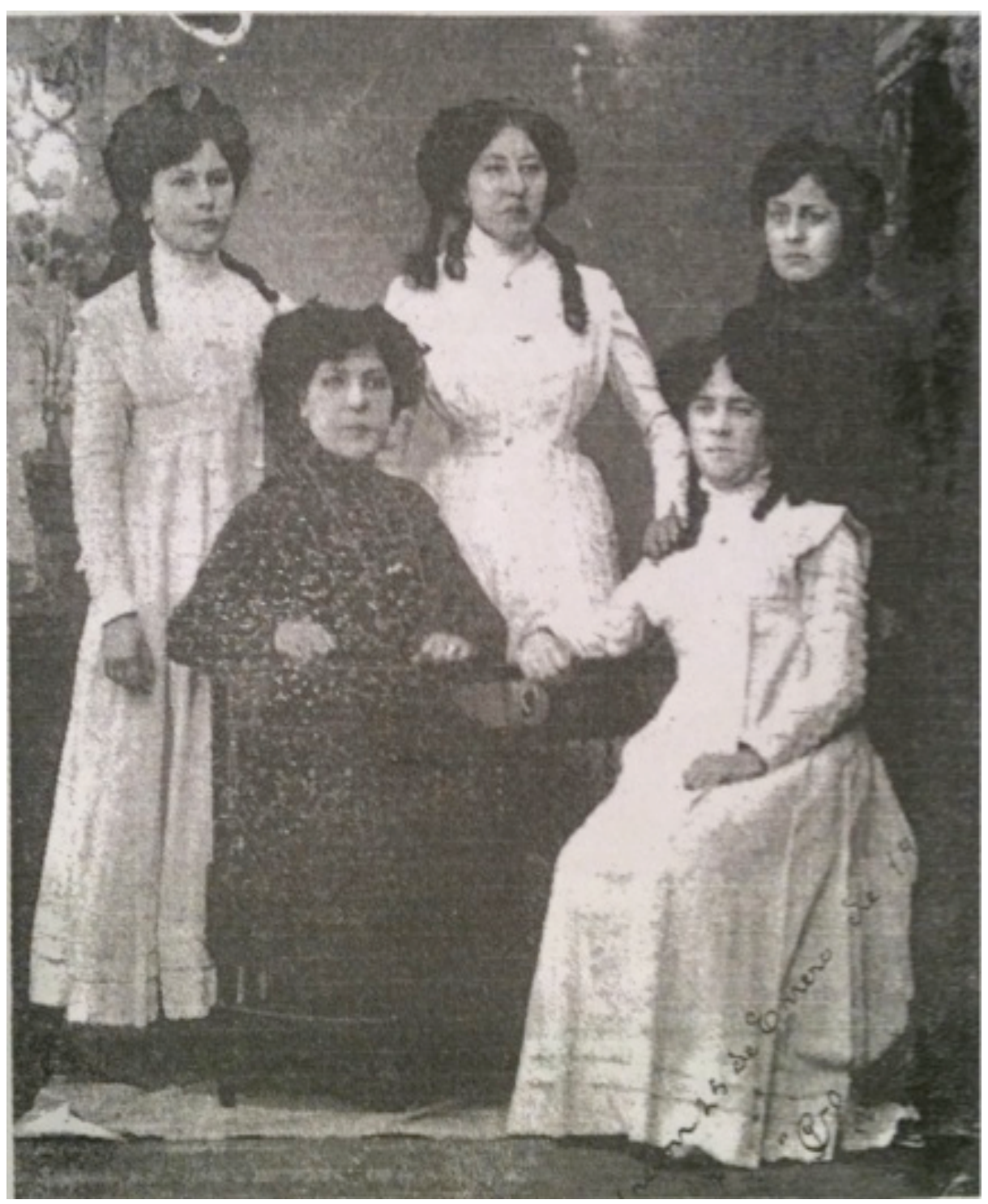

388 Photographie prise de l'ouvrage MEDINACELLI, Ximena, Alterando la rutina. Mujeres en las ciudades de Bolivia 1920 - 1930, CIDEM, La Paz - Bolivia, 1989, p. 33. 


\section{2.- Fondatrices du «Centro Artístico e Intelectual de Señoritas de Oruro » et rédactrices de la revue « Feminiflor » ${ }^{389}$}

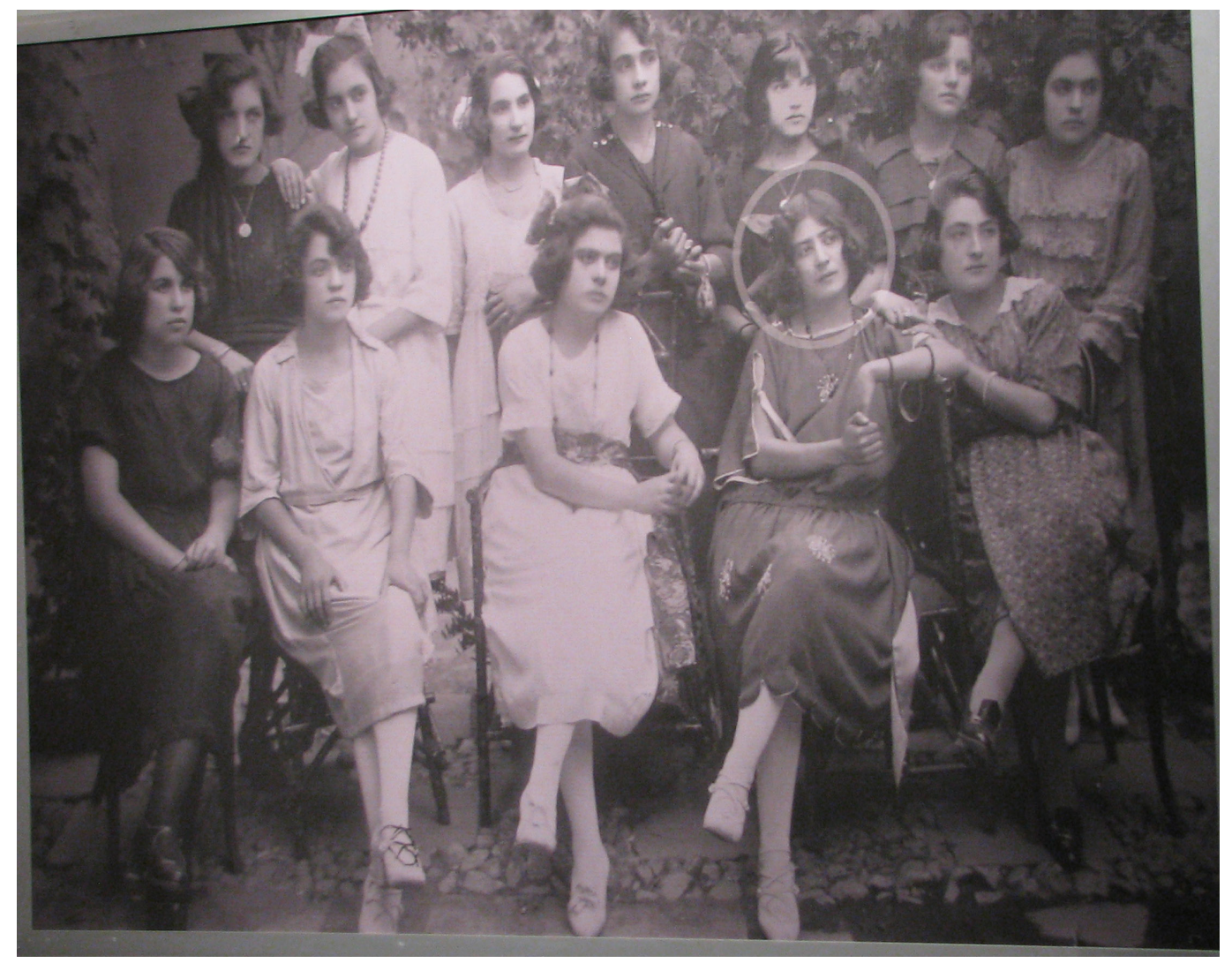

Devant au centre: (de gauche à droite) $2^{\mathrm{e}}$ Nelly López Rosse, Laura de La Rosa et Bethsabé Salmón (encerclée).

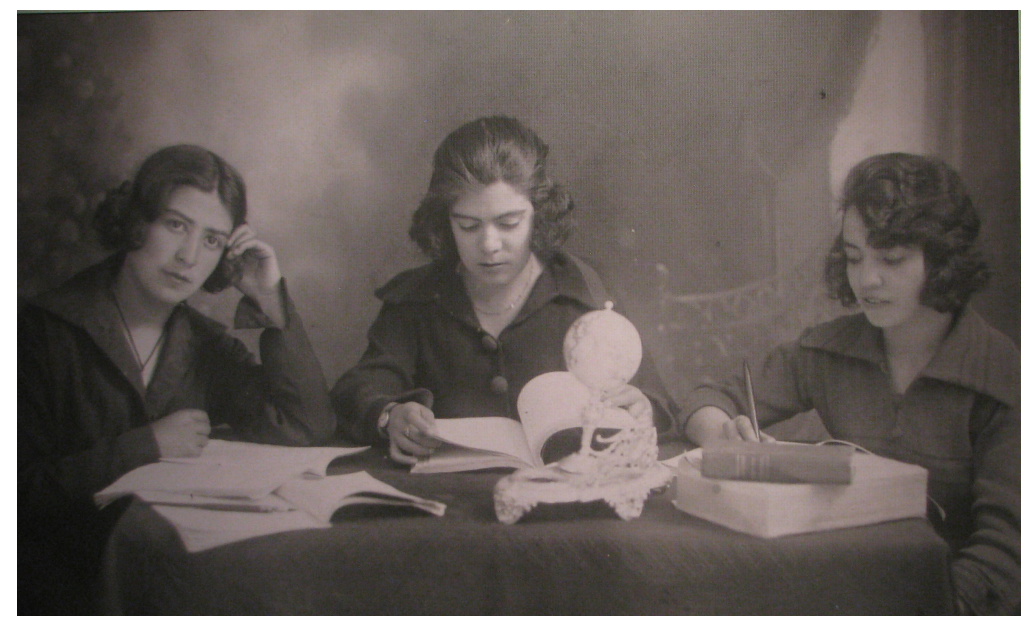

De gauche à droite Bethsabé Salmón, Laura de La Rosa et Nelly López Rosse.

${ }^{389}$ Photographies tirées de l'exposition « Bethsabé Salmón, Precursora del pensamiento femenino en Bolivia » qui eut lieu du 24 août au 10 septembre 2010 à la Fundación Simón I. Patiño à La Paz, Collection de Luis Ramiro Beltrán. 
3.- Membres du «Centro Artístico e Intelectual de Señoritas de Oruro" avec leurs amis pendant le Carnaval (début des années 1920) ${ }^{390}$

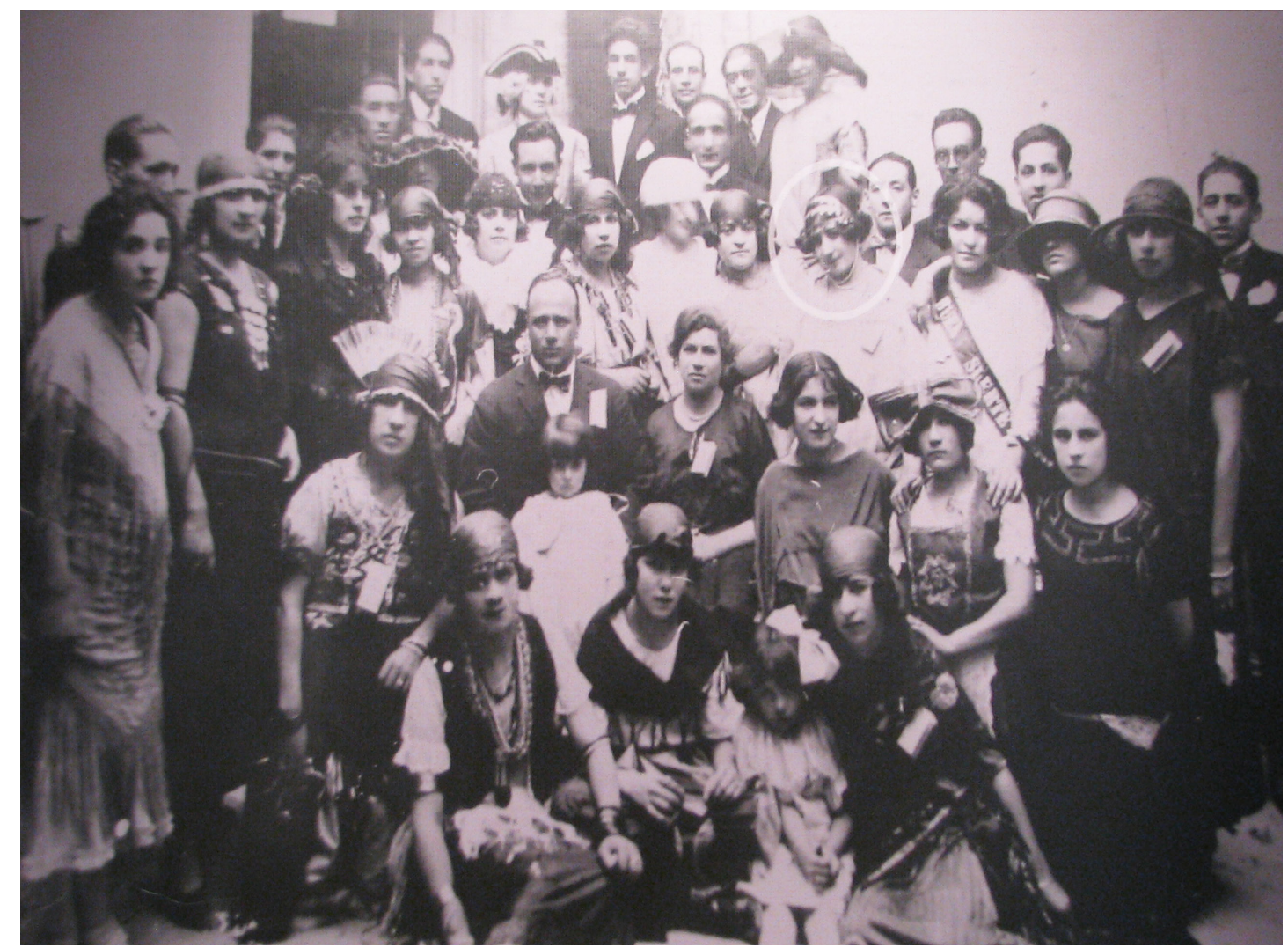

\footnotetext{
${ }^{390}$ Photographie tirée de l'exposition «Bethsabé Salmón, Precursora del pensamiento femenino en Bolivia » qui eut lieu du 24 août au 10 septembre 2010 à la Fundación Simón I. Patiño à La Paz, Collection de Luis Ramiro Beltrán.
} 
4.- Une partie des membres de la Direction de l'« Ateneo Femenino » $\left(\right.$ mai 1925) ${ }^{391}$

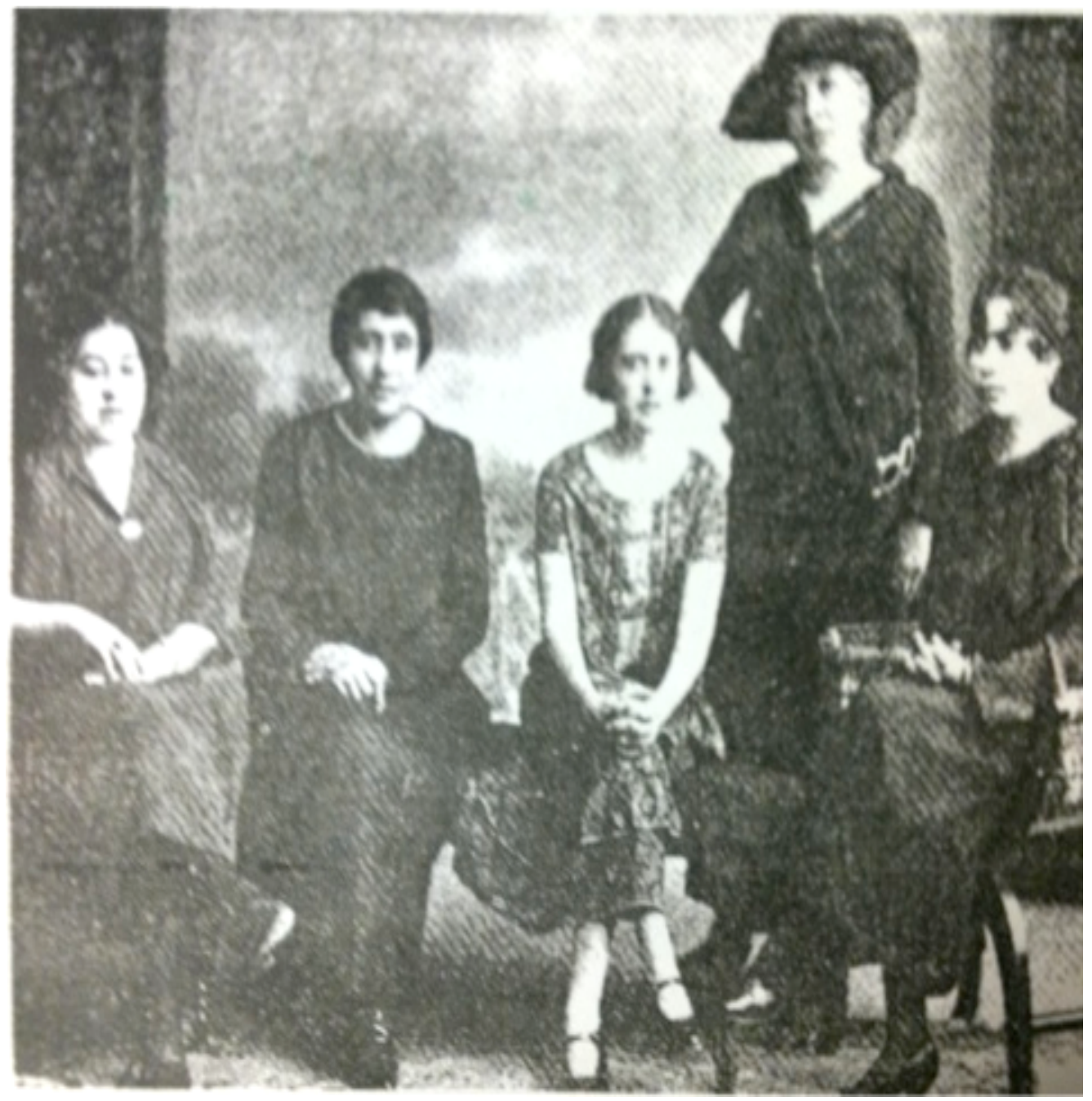

${ }^{391}$ Eco Femenino n 13 , mai 1925, La Paz. Hemeroteca de la Universidad Mayor de San Andrés, La $\mathrm{Paz}$ - Bolivie. 
5.- Allégorie représentée dans la fête d'inauguration du nouveau local de l'« Ateneo Femenino » (octobre 1923) ${ }^{392}$

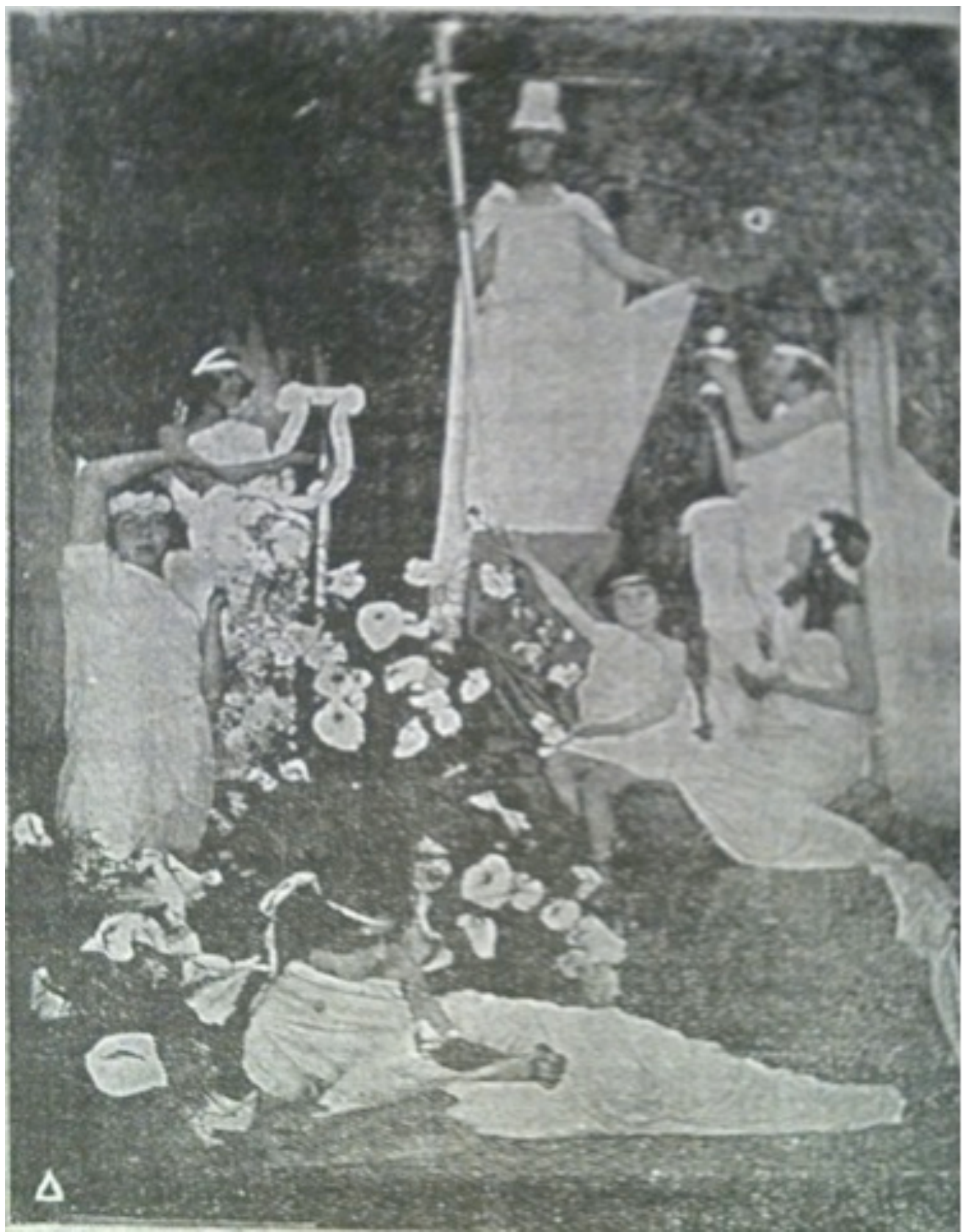

\footnotetext{
${ }^{392}$ Eco Femenino ${ }^{\circ}{ }^{2}$, octobre 1923, La Paz. Hemeroteca de la Universidad Mayor de San Andrés, La
} $\mathrm{Paz}$ - Bolivie. 
6.- Photographies des "Evocations historiques" pièces de théâtre historiques réalisées par l'« Ateneo Femenino " avec l'« Ateneo de la Juventud ${ }^{393}$

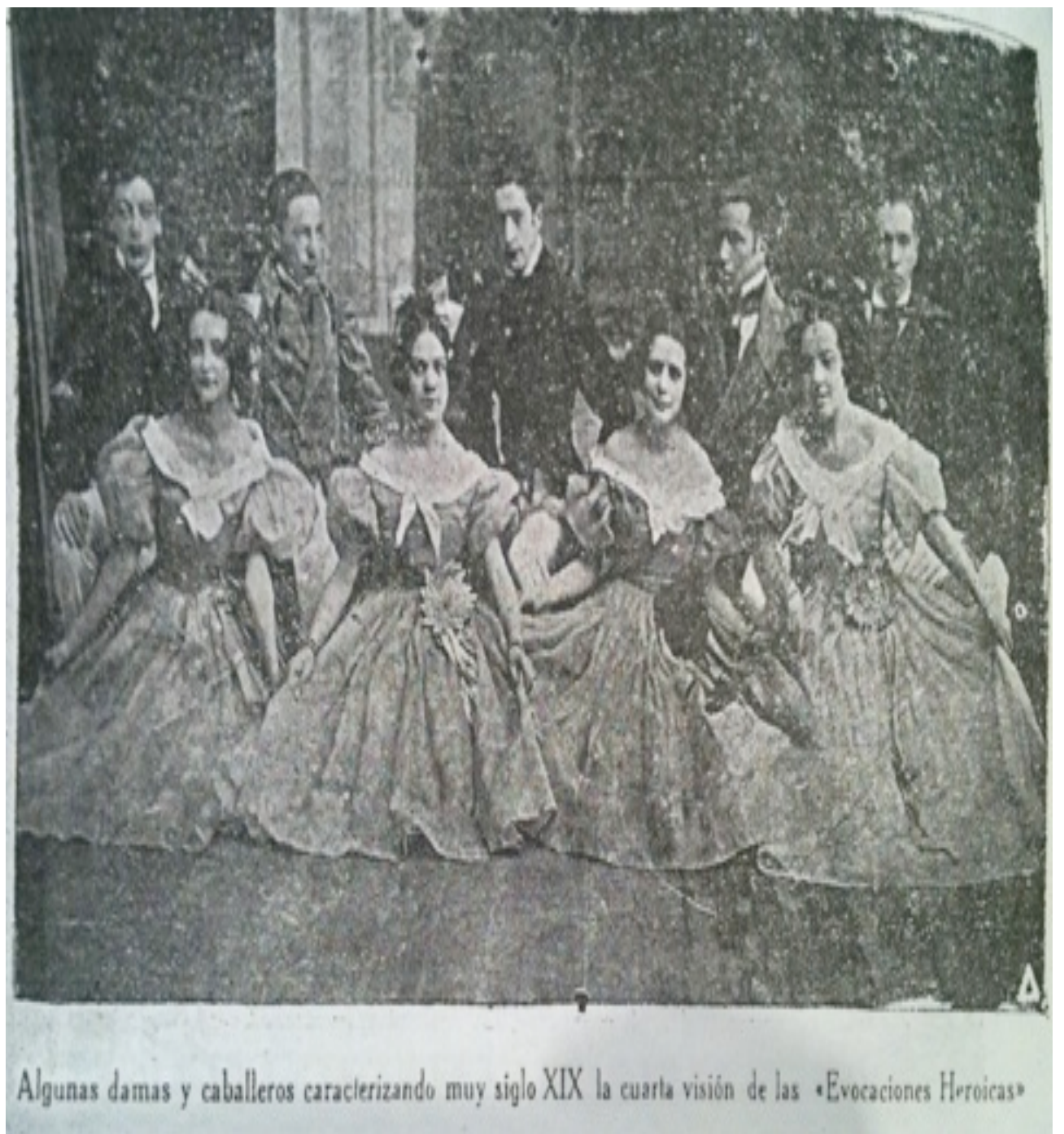

${ }^{393}$ Eco Femenino, n7, juin 1924, La Paz. Hemeroteca de la Universidad Mayor de San Andrés, La Paz - Bolivie. 
7.- Fête sociale offerte par le «Centro Artístico e Intelectual de Señoritas de Oruro » en l'honneur de la représentante de l' "Ateneo Femenino » de La Paz, Ana Rosa Tornero (novembre 1923) ${ }^{394}$

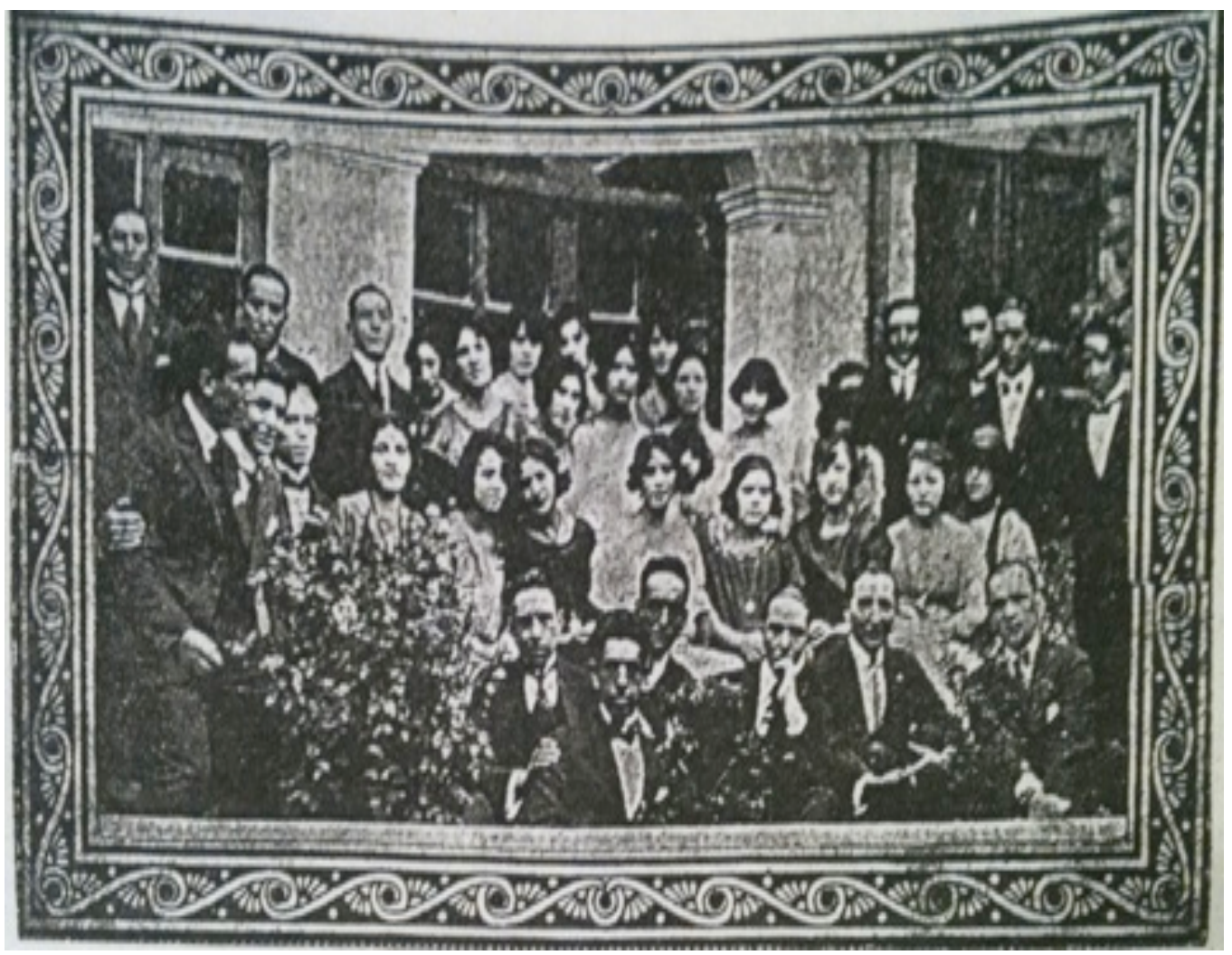

\footnotetext{
${ }^{394}$ Eco Femenino n`4, janvier 1924, La Paz. Hemeroteca de la Universidad Mayor de San Andrés, La $\mathrm{Paz}$ - Bolivie.
} 
8.- Dr. Benjamín H. Gallardo, jurisconsulte qui sous l'appel de l' "Ateneo Femenino", réalisa un projet de réforme du Code Civil en 1925 afin que les femmes puissent obtenir les droits civils ${ }^{395}$

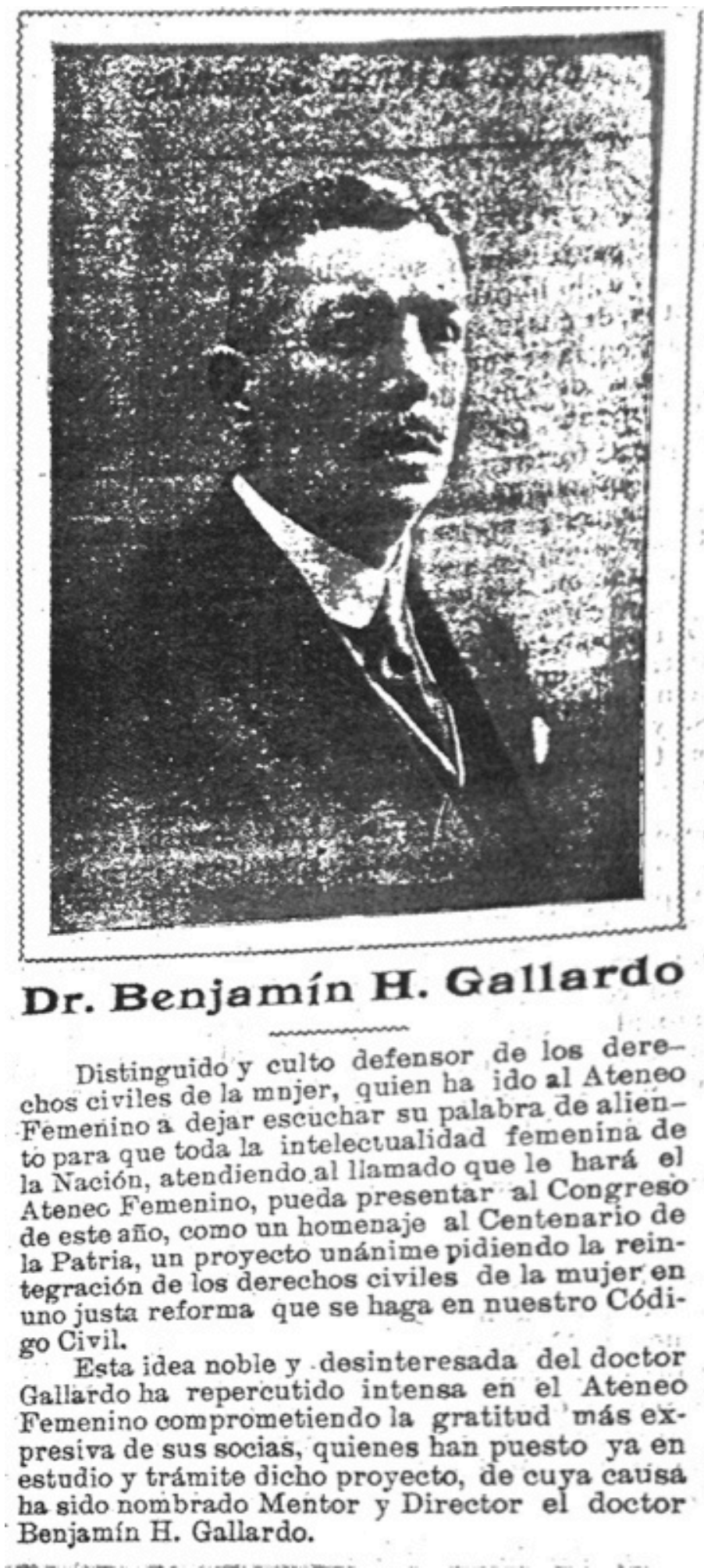
${ }^{395}$ Eco Femenino, n ${ }^{\circ} 4$, juillet 1925, La Paz. . Hemeroteca de la Universidad Mayor de San Andrés, La
Paz - Bolivie. 
9.- Miliciens dans les rues de La Paz lors de la Révolution de $1952^{396}$

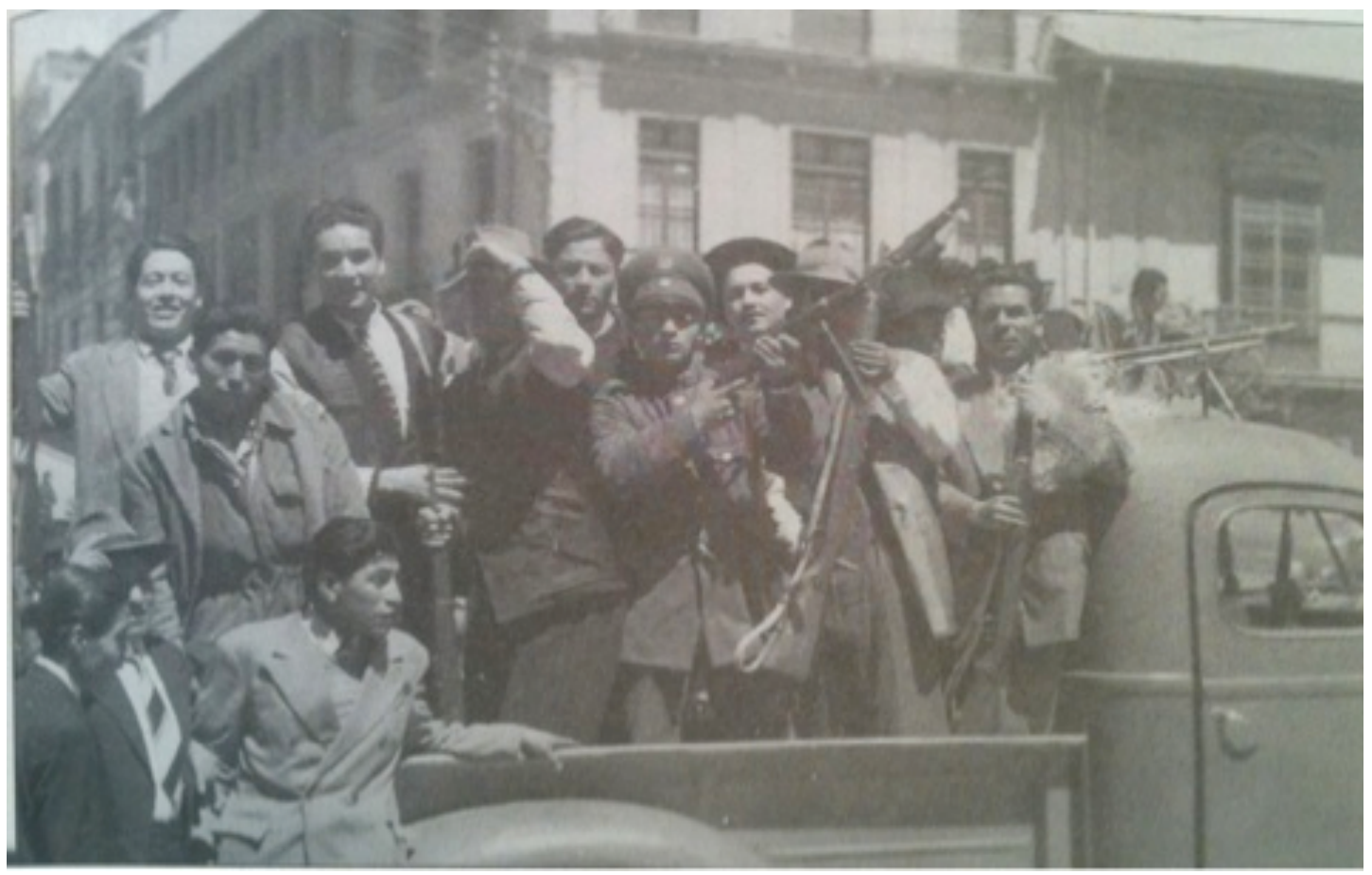

10.- Paysans mobilisés pour l'insurrection de $1952^{397}$

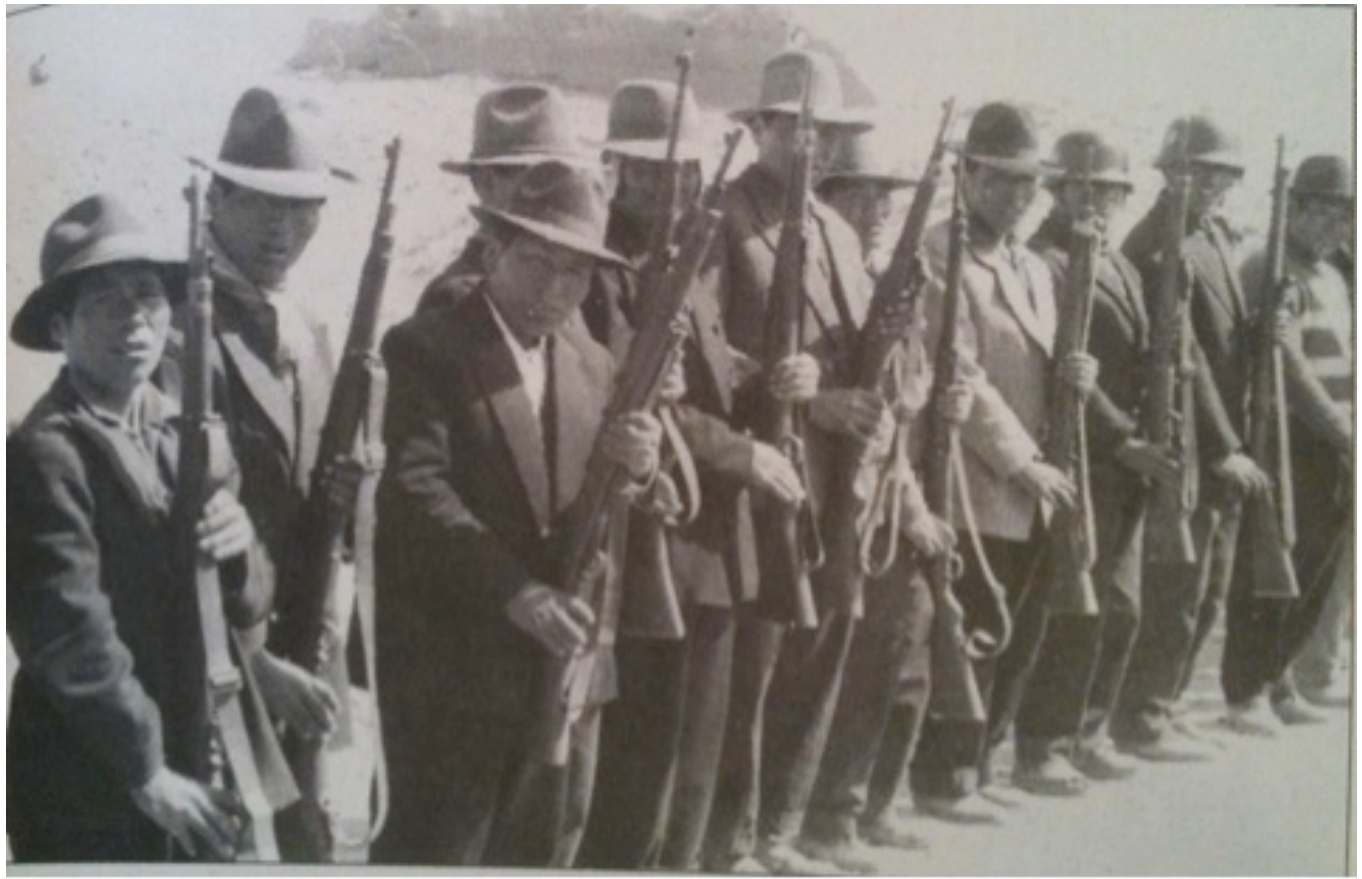

\footnotetext{
${ }^{396}$ Photographie tirée de DUNKERLEY, James, Rebelión en las venas, Trad. Rose Marie Vargas Jastram, Plural Editores, La Paz - Bolivia, 2003.

${ }^{397}$ Idem.
} 
11.- Dirigeants du MNR saluent la foule située dans la Plaza Murillo de La Paz après le triomphe de la Révolution de $\mathbf{1 9 5 2}^{398}$
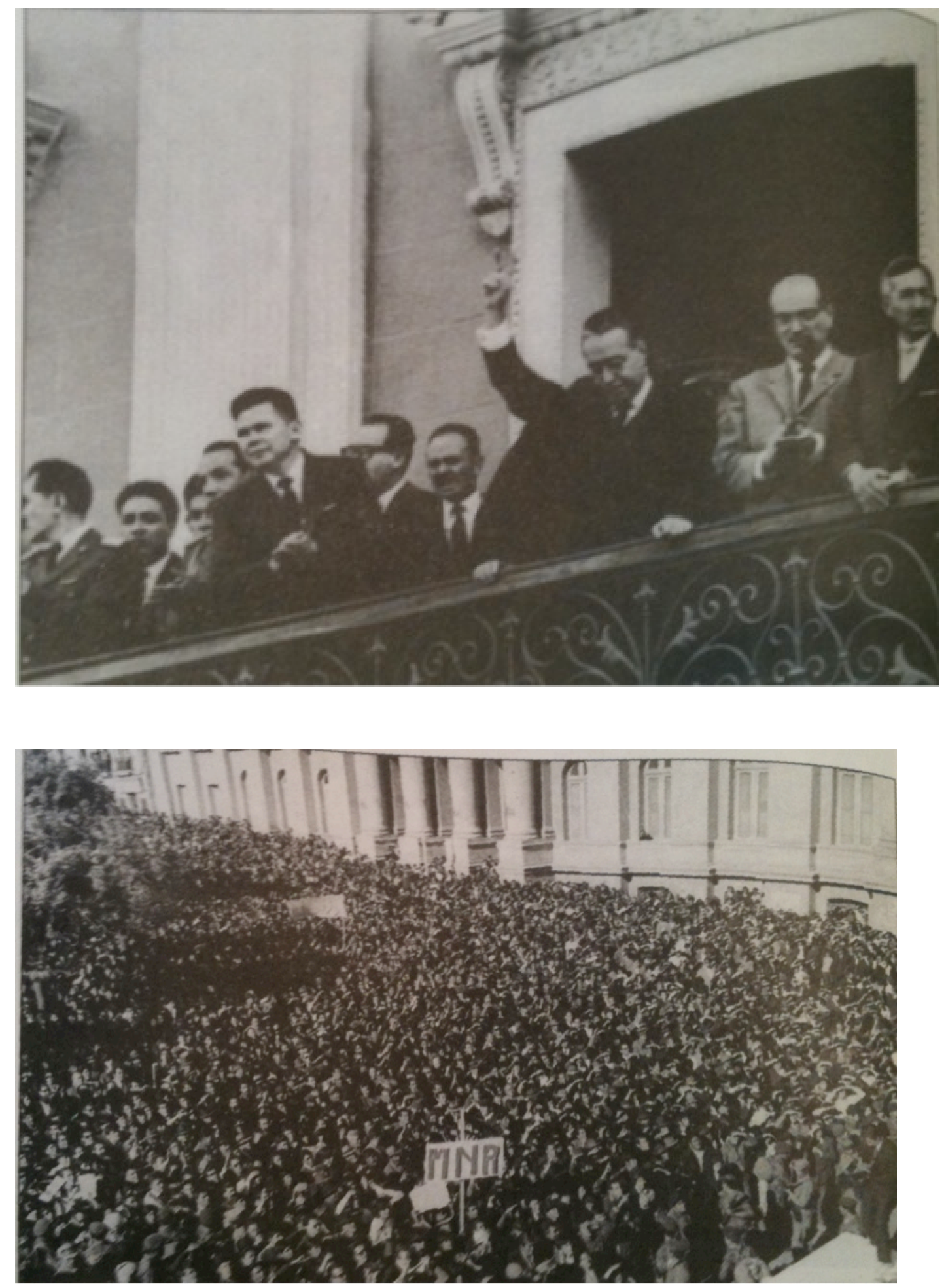

${ }^{398}$ Idem. 


\section{C) Documents}

\section{1.- Rénovation de la Direction et Convocation du «Centro Artístico e Intelectual de Señoritas de Oruro $»{ }^{399}$}

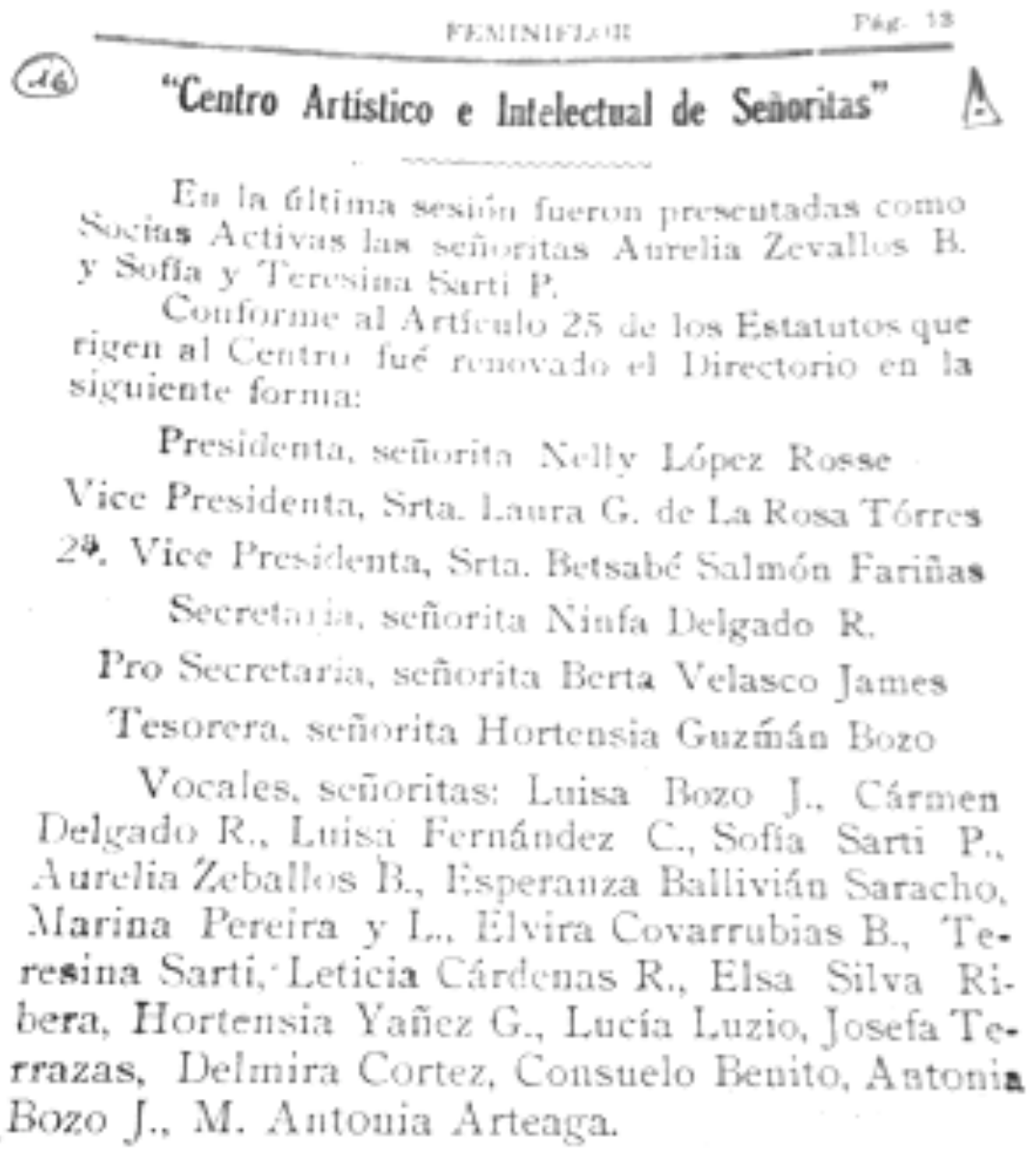

(1)

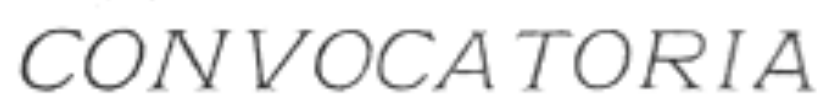

Se corvoca a las Sacias del * Centro Artístico e Intelectual de Seforitasy a Sesión Extraordintaria para el dia Lunes 30 de Óctubre de 1922, a horas 4 p. m., en casa de la Presidenta señorita Na. tiy Lopez . Rosse,

\section{La Secretaria}

${ }^{399}$ Feminiflor $\mathrm{n}^{\circ} 16$, octobre 1922, Oruro. Hemeroteca de la Universidad Mayor de San Andrés, La Paz - Bolivie. 
2.- Lettre de remerciement de la poétesse uruguayenne Juana de Ibarbourou pour sa nomination et tant que membre honoraire de $l ' \ll$ Ateneo Femenino ${ }^{400}$
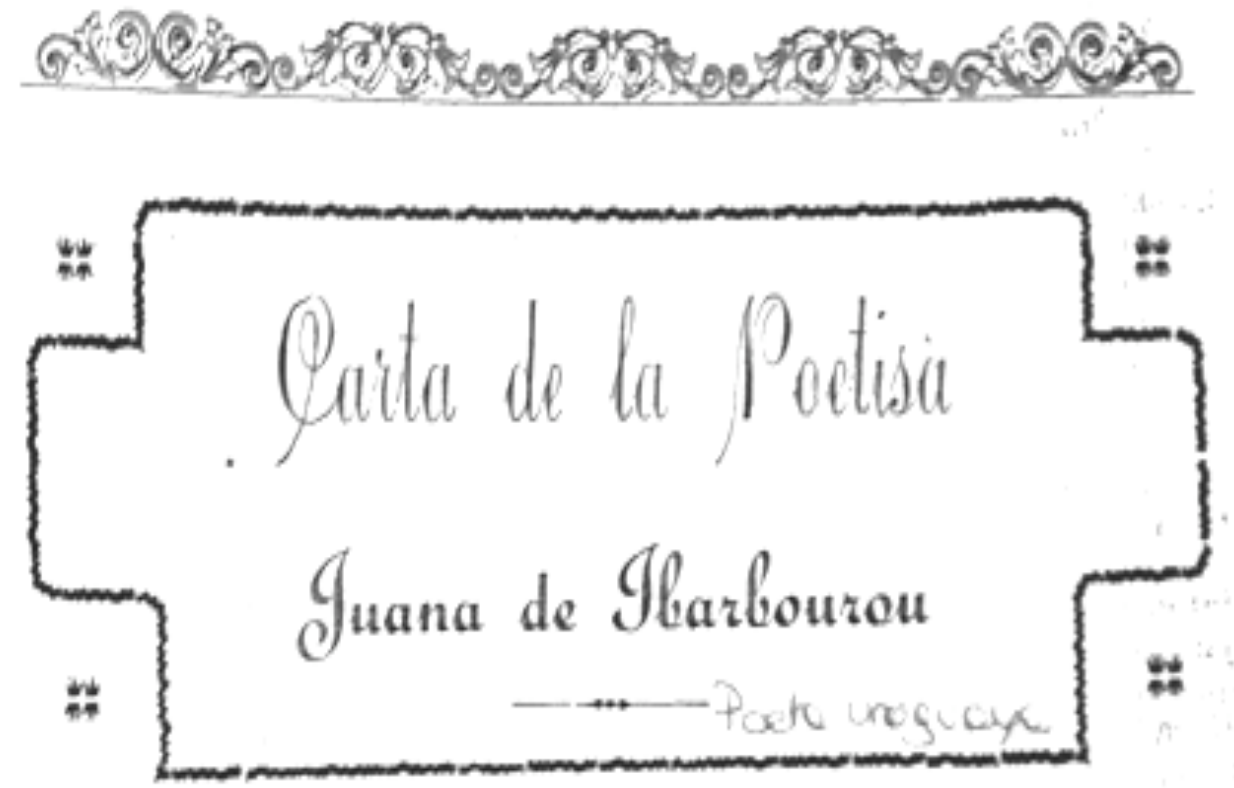

Habiendo sido nombrada socis Honoraria del Ateneo Femenino la eminente escritora, Juana de Ibarbourou, tuvo la gentileza de contes. tar a nuestra comunicación con la siguiente carta:

\section{Montevideo, Enero 7 de 1925.}

A las sefioras que forman la comisión

dol Ateneo Femenino de $\mathrm{La} \mathrm{Paz}_{\mathrm{a}}$

Bolivia.

\section{Seந̃oras:}

La distinción de que me hacen Uds.objeto al honrarme con el título de socia bonoraria del Ateneo Femeni. no me llena de satisfaccion y orgu. llo y al agradecerla a Uds., les ruego dispongan de mi como tal, en es. te país que es amigo del vuestro y donde quiera que las circunstancia me lleven.

Hago votos por la prosperidad de la hermosa institución que honra a la mujer americana y envio a todas las que son desde ya mis compafe. ras un atento saludo y toda $\mathrm{mi}$ sim. patia:

\section{Guana de Sharbourou.}

\footnotetext{
${ }^{400}$ Eco Femenino ${ }^{\circ} 13$ mai 1925, La Paz. Hemeroteca de la Universidad Mayor de San Andrés, La Paz - Bolivie.
} 


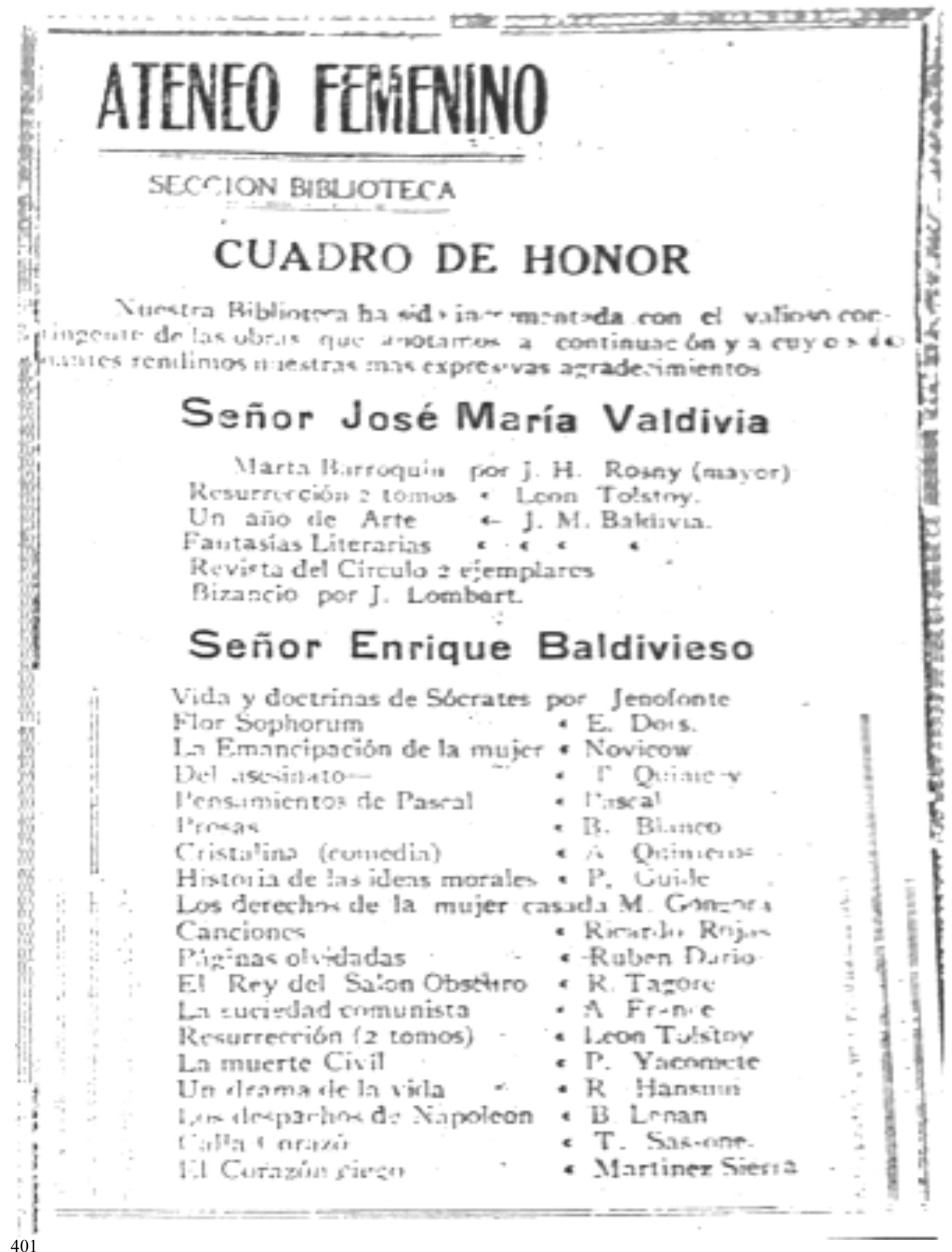

${ }^{401}$ Eco Femenino n ${ }^{\circ}$ 9, septembre 1924, La Paz. Hemeroteca de la Universidad Mayor de San Andrés, La Paz - Bolivie. 
5.- Croquis de la façade du local de l'« Ateneo Femenino » réalisé par l'artiste Emilio Amoretti (1928) ${ }^{402}$

\author{
Fachada del local del Ateneo Femenino
}

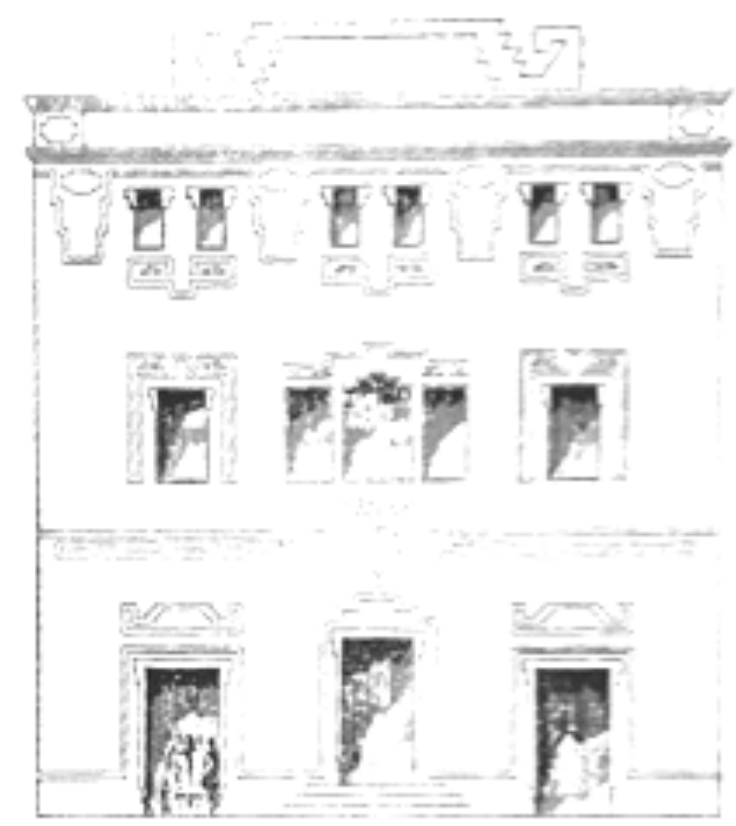

Insertamos el grupo central de la fachada del Ateneo Femenino El edificio tendra un teatro pequeño para las fiestas del Ateneo, un vestibulo amplio; salas de conferencias y cur sos, y una Biblioteca Pública Los cuerpos las terales del edificio serán construidos pose teriormente.

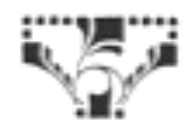

${ }^{402}$ Indice ${ }^{\circ}$ 2, janvier 1928, La Paz. Centro de Informaciôn y Desarrollo de la Mujer (CIDEM), La Paz - Bolivie. 
6.- Carte de salutation envoyée par le «Centro Artístico e Intelectual de Señoritas de Oruro" à l'«Ateneo Femenino» de La Paz (novembre 1923) ${ }^{403}$

\section{Carscta reilida por al Atute}

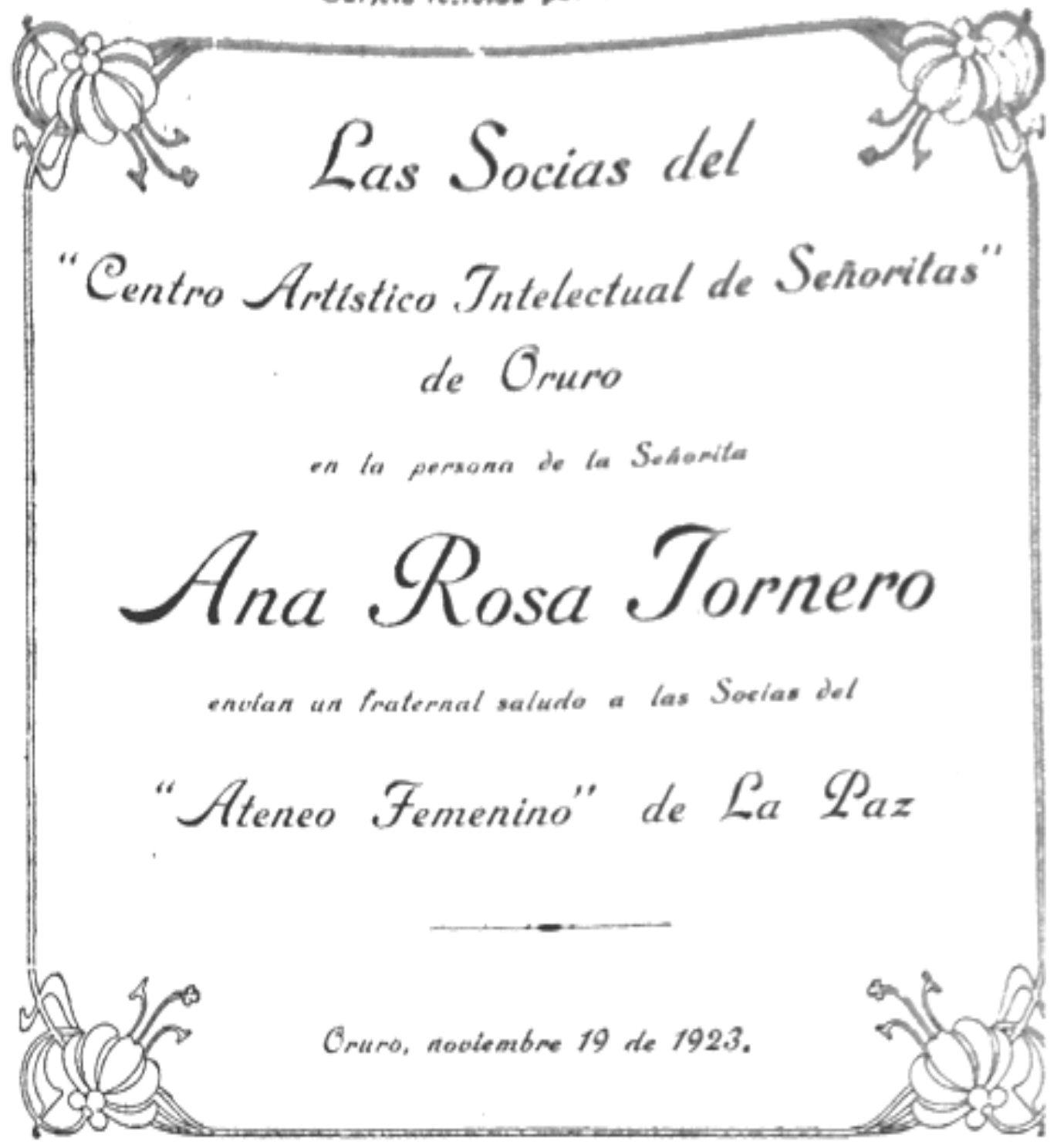

\footnotetext{
${ }^{403}$ Eco Femenino n ${ }^{4}$, janvier 1924, La Paz. Hemeroteca de la Universidad Mayor de San Andrés, La Paz - Bolivie.
} 
7.- Couvertures de la revue Feminiflor
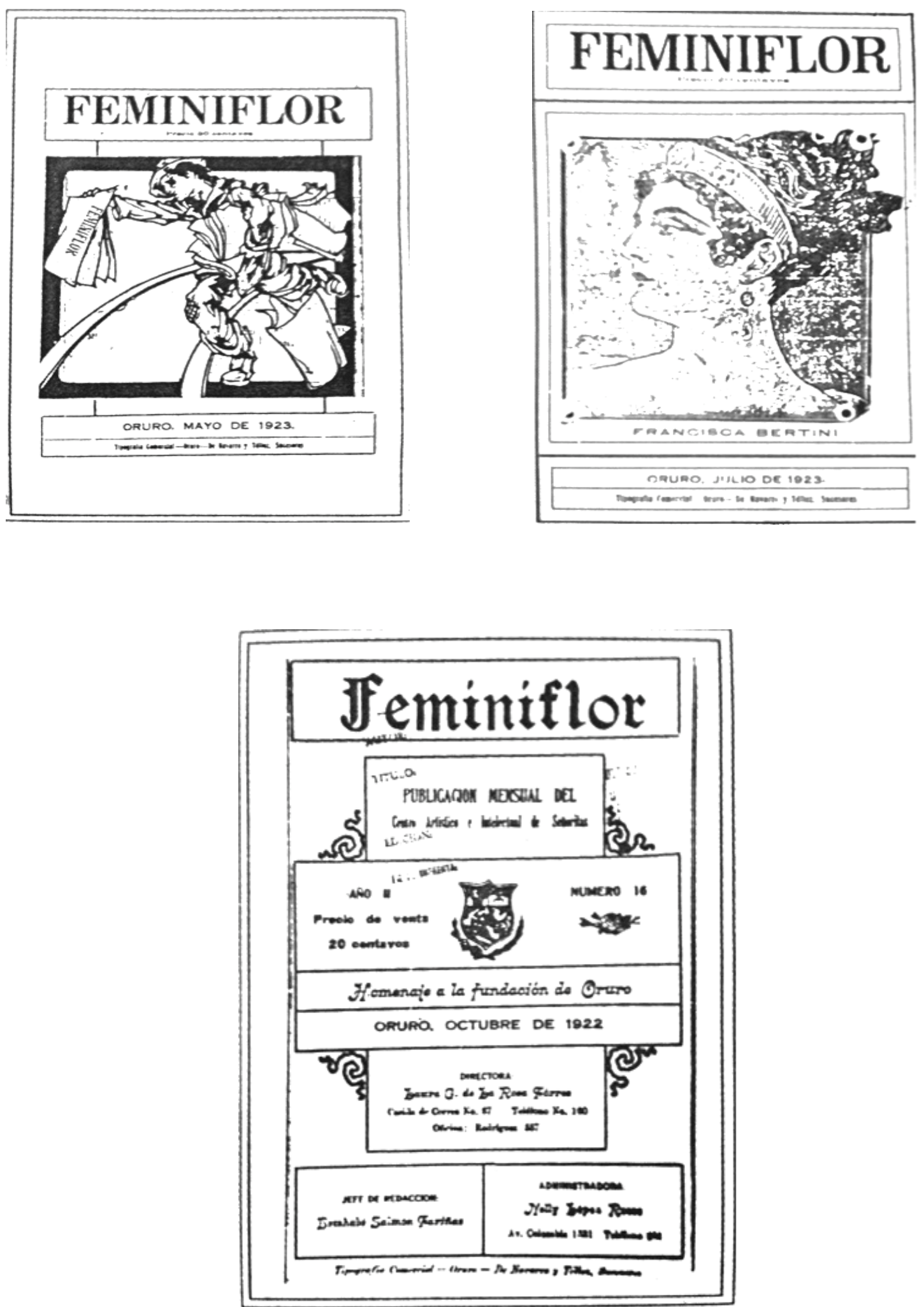
8.- Sommaire du contenu des numéros disponibles de la revue Feminiflor404

\section{AÑo I \\ $N^{2}$ 10.- Oruro, 10 de Febrero de 1922}

KGlorla a mi Pueblo! „Gloria a Oruro! Laura Graciela de la

1785-3 de Febrero de 1922. Nelly López Rosse.

Magdalena de Scudery. Betshabé Salmón Farnas.

A mi pueblo. María Ninga Delgado Rodriguez.

En el campo. (Poesia) Adela Zamudio.

Poemas. Sra. Hubner (Escritora y Poetisa Chilena)

Fue perfidia? a ti... (Poema) Alma

Para Enriqueta Bohrt. Emma Bohrt.

Soñar... A Elsa Silva Rivera. Silvia.

Mi hogar paterno. Nelly.

De mi diario (Pasajes de ml infancia en Santiago Chile.) Nina.

El Patriotismo. Maria Llanque.

Recetas de cocina. Menú de Comida. Cakes y panecillos para el té.

"Carnaval Alegre" Para Bethsabé Salmon Farinas. Laura Graciela de la Rosa Paz. 


\section{$\overline{\text { AÑO II }}$}

$N^{2}$ 16. Oruro, Octubre de 1922

"Homenaje a la Fundación de Oruro"

La Critica. Betshabé Salmón Farinas.

"La paja en el ojo ajeno"... Al "Caballero Pladosamente".

Psicología de la coquetería de la Mujer. Transcripción de "El Hogar". M. Antonia Martinez.

Carldad. Nelly López Rosse.

"De mi Diario". Pasajes de mi infancla escritos en Santiago-Chile. Nina.

Página literaria

La Princesita enferma. Sylvia.

Fragmentos. Las vacaciones. Iry.

Contraste. Maria Luisa Bozo.

Campo.

Colaboración masculina

Los sonetos del Olvido. A la que primero ame. para la Amada. Jorge Sempértegui.

Colcha, Invierno 1922. Laura Graciela de la Rosa Torres

Encontrê. Maria Josefa Terrazas.

Cantar de los Cantares (Para Feminiflor). A. Sarmiento. 
De nuestras colaboradoras. Paginas Intimas. Decepolon. M.E.V.

"Centro Artistico e Intelectual de Señoritas". Directorio.

Página del hogar

Mená de Almuerzo.

El alma huérfana (Poema) R.E.L.

La fundacion de Oruro. Aurora

El Telefono.

"El colmo de un neurasténico".

$N^{2} 18$ Oruro diciembre de 1922.

Homenaje a la primera aviadora Nacional

sef̂orita Amalia Villa de La Tapla.

Autografo. Amalia Villa de la Tapia.

Homenaje a la primera Aviadora nacional. Betshabé Salmón Farinas.

Criticas extranjeras de examen en los vuelos de la señorita Amalla villa de la Tapia. De la revista ilustrada MUNDIAL.

La primera Aviadora Sudamericana. Del periódico "El Comercio". 16.III. 1922.

Colaboraciones

Los exponentes de la literatura potosina. Ledi

Ojos Negros...! Zobeida. 
Gue esperanzal Pelargonla

Página masculina

Noche Buena. Juan Maragall

Faltan págs. $11,12,13$ y 14 .

Discurso. Pronunclado por la sefiorlta Laura de La Rosa Torres en la funcion Literaria-musical preparada por el "Centro Artistico e Inelectual de Sentoritas" 22 de diefembre en pro de los huerfanos de Chile.

Productos de los fondos. Liquidacion.

A la memoria de la distingulda Señorita Amella $R$. Duarte A. (Poesía)

En familia (Transcripción). Santlago, Noviembre.

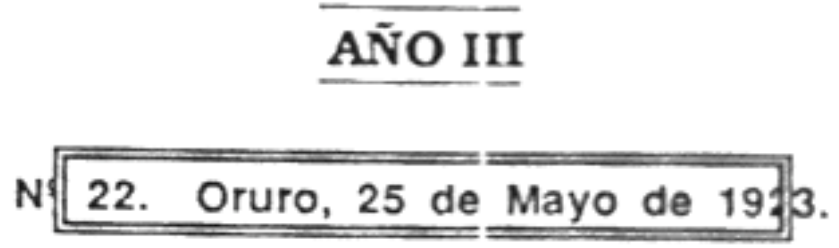

Hoy. Renovando energías. Bet:shabé Salmón Farinas.

La redaccion de Feminiflor (Foto)

Efeméride de América. Laura (iraciela de la Rosa Torres.

Falta pág. 6

...Maria Ringa Delgado R. Sucre "17 de abril de 1982" B.S.La Unidad Moral. Angélica

Para "Feminiflor" Ana Rosa Tornero A. Directora de "Ideal Femenino".

Homenaje al 25 de mayo de $18(19$. M.P. de Vargas. 
La Mujer de ayer y la Mujer de Hoy, Nelly Lopez Rosse.

"Feminflor" y su segundo Antversarto, Laura 0 . de la
Rosa Torres.

Caridad. Luisa Bozo Yantzen

\section{Página masculina}

La Aldea (poema). Antonio José de Sainz.

Soledad. Para "Feminiflor". (joema) Humberto Landa

Ser Bardo. Para "Feminiflor" en su segundo Antversarto. (poema) Manuel Agullar.

La hoja Escrita para Feminiflor en su aniversarto. (Del Director de "La Patria") Luis Gutierrez Monje.

reminismo y Feminidad. Para "Feminiflor". Nolo Beas.

Feminismo para "Feminiflor". Del director de "El Diario de La Paz" Fablán Vaca Chávez.

M1 estrella. Para "Feminflor". (poema) Damaso Eduardo Delgado.

Para vuestro Epistolario. E. Zżpcovic Lizárraga.

La reaccion Femenina. De la oficina de "El Mercurto" en Nueva York. E. Montenegro.

Un mal cllente. Max Et Alex Fischer.

Para los Jugadores de Ajedrez. Jaque y Mate.

Chistes para Feminiflor. Davir Pérez Alacón.

Primer concurso de Feminiflor. Quién es el hombre más feo de Oruro?

Concurso $\mathrm{N}^{\circ} 2$ de Feminiflor. 
Colaboracion artistica para Femintifor (arafleol del Ar. tista Orureno senor David Luna.

\section{Página literaria}

Canclones de Madres. Para Bscuelas Bogares de Mexico (poemas) Gabriela Mistral.

\section{La mujer que trabaja}

Anuncios gratuitos.

Para "Feminiflor" (poema). María guiroga Vargas.

Para un amigo (poema) Isolda.

La Mujer en la Literatura Nacional. Maria Josefa Mujia. Betshabé Salmón.

V1da. Zobeida.

Heroinas de la Historia. E1 Sacrificio de la condesa Lavalette.

Venganza Ultratumba. Cuento vivido. Fresia

Te Acuerdas? Zobeida.

Momentos de meditación (Para mi querida amiga Hortensla de La Riva) Haydeé.

Página del hogar

Cosas utlles y curlosas. Madame de Lys

Conocimientos fitiles para el hogar. La hospitalidad. Femina

25 de Mayo. Maria Josefa Terrızas.

Aniversario. Bertha Velasco James. 
La mujer cochabambina. Concepto moral y fisico. Marna Pereira y Lanza.

Grupo de sobrevivientes del Alto de la Alianza. Foto.

La batalla del Alto de la Allanza. L.S.B.

Mayo. Naida.

El Trabajo. Emi Morató A.

Alegria. Thelina.

Feminiflor. Emma Luz Monje.

La señorita Ana Rosa Tornero y la promoción del cargo que desempeñaba en el Liceo de Señoritas.

Un año más. Para "Feminiflor" de Oruro. Emma Alina Ballón V.

Plegaria. Para Feminiflor (poema) Jorge Palenque.

Invernal... Emma Luz Monje.

Tened compasión de los mendigos! Ernestina Fernández Castonas.

La sesion del Ateneo en honor de don Ricardo Jaimes. Freire. Sussana de Lyz.

E1 deporte en Oruro

De redaccion. Varias notas informativas.

№23. Oruro Julio de 1923.

16 đe jullo María Josefa Terrazas

In Memorlan. Directora del Círculo Artístico e Intelectual de Señoritas.

Plegaria. En recuerdo de la señora Arminda Salmón de Veintemillas. L.G.L.T. 
Prosa Dollente en la Triste fecha del 10 de fullo de 1922. Betshabe Salmon Fartnas.

"Remember". En el primer aniversarto de la muerte de la señora Arminda Salmon de Velntemillas. Laura Graclela de La Rosa Torres.

Orando. M.J.T.

A la sentora Arminda Salmon de Velntemillas. En el aniversario de su muerte (poesia). Emma Luz Monje.

A la memorla de la señora Arminda Salmon de Velntemillas. María Josefa Terrazas.

Cinerarias. Ernestina Fernández Castanes

Una palabra de recuerdo. Para la que fue señora Arminda de Veintemillas. Maria Luz Ballón $\mathrm{M}$.

En su Sarcofago. Depositare la flor de mil recuerdo a la Sra. Arminda Salmon. Nelly López Rosse.

Educación Fisica. Arminda Salmón de Vetntemillas.

Los Clpreses. (Poesia) E. Carrere.

Temas đel dí. Bertha Hernández Castaños.

Página literaria

En el Album. (Poesia). Lindaura de Campero

La mujer en la literatura nacional. Lindaura Anzostegui de Campero B. Salmón Farinas.

Página del hogar

Para las madres Verdad y sencillez en los niños. Dely.

Conocimientos atiles para el hogar. Modo de recoger las 
semillas cabezas y raices de las flores. La rabla o hldiro fobla. Femina.

Cartas frivolas. Algo sobre la crisis domestica. Madame Lys.

\section{La Mujer que Trabaja}

\section{Anunctos}

\section{Concurso $\mathrm{N}^{0} 2$ de Feminiflor.}

La aviacion en Bollvia y la Muerte Conde Aldo Barbaro Cornaro. Flor de Sombra.

Escena Muda (fotografia)

La mujer. Amado Nervo.

La directora del "Ideal Femenino".

La efemeride paceña. Adela Reyes Ortiz.

$$
\mathrm{N}^{2} 24 \text {. Oruro, Octubre de } 1923
$$

E1 dia de la Raza. Laura Graciela de la Rosa Torres

La Conferencia Panamericana de Mujeres en México. De N.D.

Algo sobre Feminismo L.L.R.T.

Escuchad a vuestras almas. Zobeida.

Artes y Letras.

Canciones de Cuna. Me tuviste. Suavidades. Rondas de niños. Los que no danzan (poemas) Nelinca.

Página del hogar

Cartas Frivolas. La manera de culdar al pobre baby Ma- 
dame de Lyz.

Conocimientos atiles al hogar. El arte de ser agradable. Preparacion del Cafe. Femina.

Página literaria

Un Bohemio. Floralba

Sueña. M. Luisa Bozo Yantzen.

La mujer que trabaja

Anuncios

Página masculina

Souvenir, Manuel Aguilar.

E1 Hbro "Elevacion". Amado Nervo

Al Pasar. Para Feminiflor. Roberto Guzmán Tellez.

Pensamiento.

Concurso $N^{*} 2$ de "Feminiflor".

En memoria de la que fue señora Casimira Carmona v. de Fernández.

№25. Oruro Noviembre de 1923

El "Ateneo Femenino" de La Paz. Y el Mensaje de Fraternidad. Enviado a la Sociedad Femenina de Oruro.

Mensaje. La Paz diciembre de 1923. A la Sociedad Femenina de Oruro. 
Respuesta al Mensaje del "Ateneo Femenino" Leido por la señorita Betshabe Salmón Fariñas.

Alguien dijo.

Enseñanza profesional para señortas. Maria V. V. de Estivariz.

Las siervas de Maria. Sucre. Mary Emma Velasco y Bla. cutt.

El Comercio. Femina.

Pensamiento

Página Intima. María Lutsa Bozo Yantzen.

Página masculina

E1 Feminismo. Betshabé Salmón Fariñas. Jullo César Fernândez y $\mathrm{P}$.

La Oración del Visionario. (Poema) Julio César Fernández y $P$.

Concurso $\mathrm{N}^{\mathbf{2}} 2$ de "Femintflor".

Página literaria

De Nuestras Poetlsas Ayer y Hoy. Hercilia F. de Mujia

Cain. (Poema) Adela Zamudio.

De nuestros Poetas. El Periodista. (Poema) Rasendo V1llalobos

Juventud y Esperanza (Poema)

La mujer que trabaja

Anuncios 
9.- Feminiflor : Article «Algo sobre Feminismo » ${ }^{405}$

FEMINIFLOR

Pág. 5

\begin{tabular}{|c|c|}
\hline 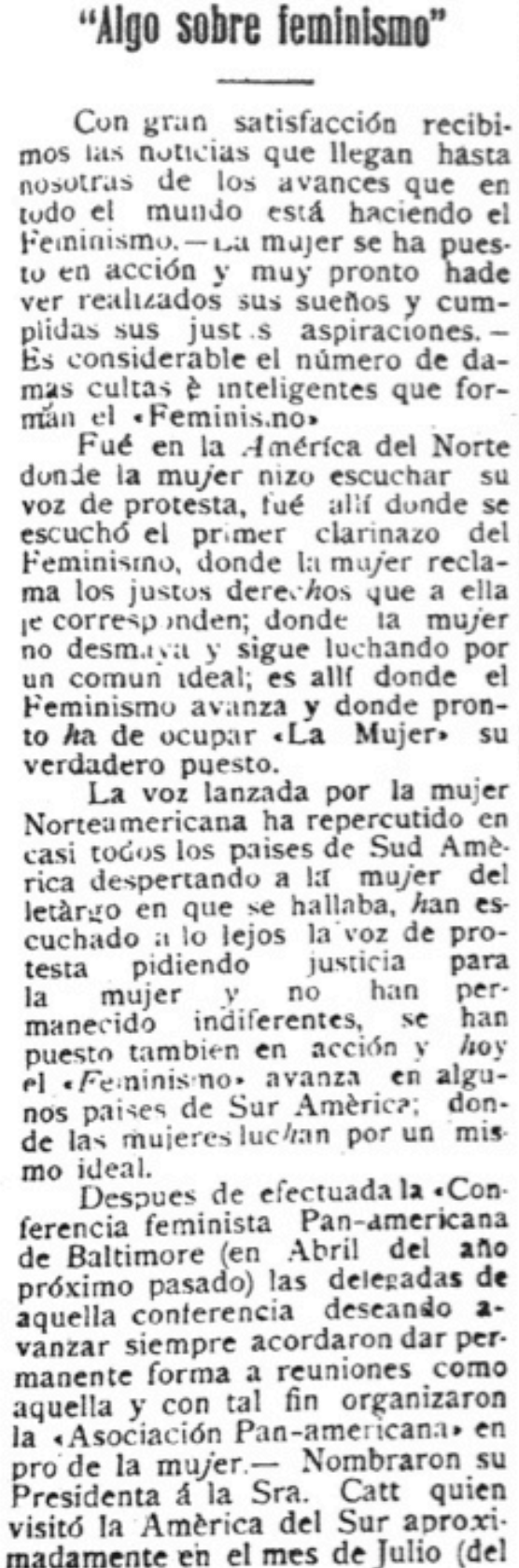 & 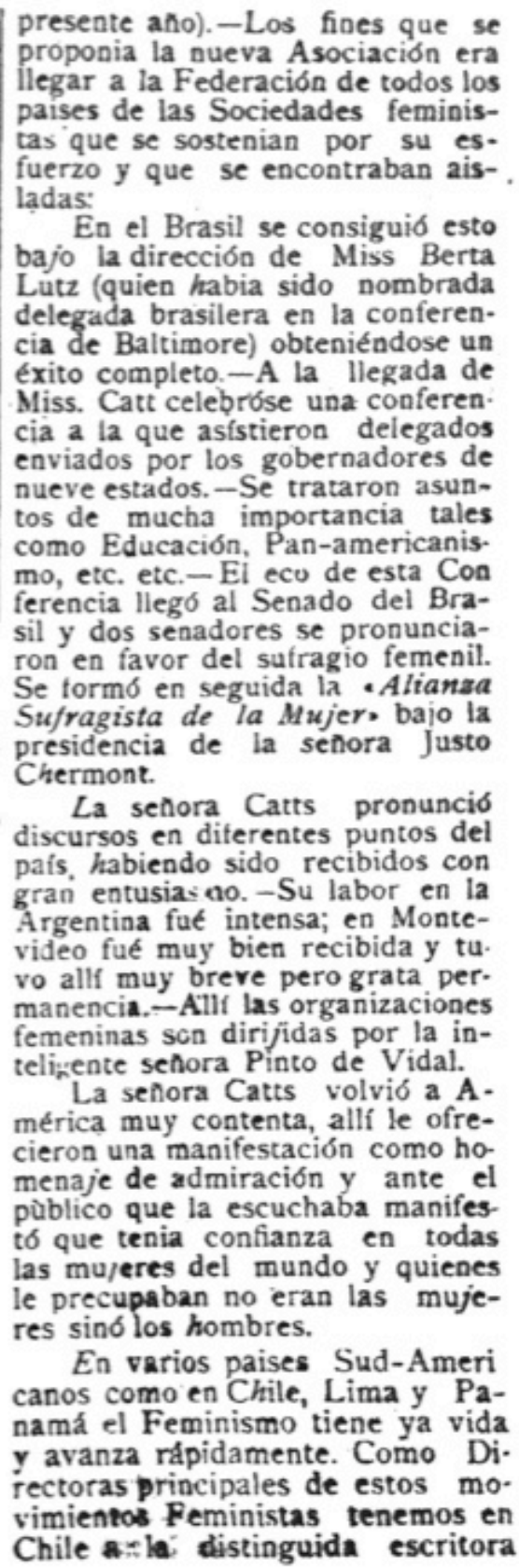 \\
\hline
\end{tabular}

-111 -

${ }^{405}$ Feminiflor, n²4, octobre 1923, Oruro. Hemeroteca de la Universidad Mayor de San Andrés, La Paz - Bolivie. 
señora Amanda Labarca Hubers. ton, en Lima a la señora María T. Olvarado Rivera y se ha abierto allí una sucursill de la Asociación Pan-americana bajo la dirección de la Sra Luisa Daumonst. En Panamá dirige la senora $E$ sther Niera de Calvo.

En Bolivia el Feminismo viene orientandose decididamente, aun falta mucho por hacer, pero se conseguira, día llegará en que triunfe el Heminismo, no ese $\mathrm{Fe}$ minismo batallador y politico $\sin \theta$ el verdadero teminismo; conscierte de deberes y derechos que coloca a la mujer en el verdadero pues. to que a ella le corresponde. Has: ta hace pocos años la mujer Boliviana ha vivido en interioridad mental con respecto del hombre; permanecia indiferente.-Hoy la juventud temenina se ilustra, lucha por un ideal, reclama para la mujer sus derechos. Y dia llegará en que la mujer Boliviana rea cumplidas sus $j$ ustas aspiraciones.

Oruro, octubre de 1923.

L. L. R. T. 


\section{0.- Feminiflor: Page d'annonces gratuits pour les femmes travailleuses d'Oruro ${ }^{406}$}

\section{"La Mujer que Trabaja"}

Ponemos en conocimiento del sexo remenino que dedicamos esta sección para las personas que deseén poner sus anuncios en nuestra Revista. Los avisos serán publicadus gratuitamente cuantas veces lo deseen las interenadas. Si son enviados por correo dirigir a Revísta

-Feminitlor ., Casilla 87-Oruro y en caso contrario dirigirse a la Administración: Avenida Colombia 1531. Telefono 251.
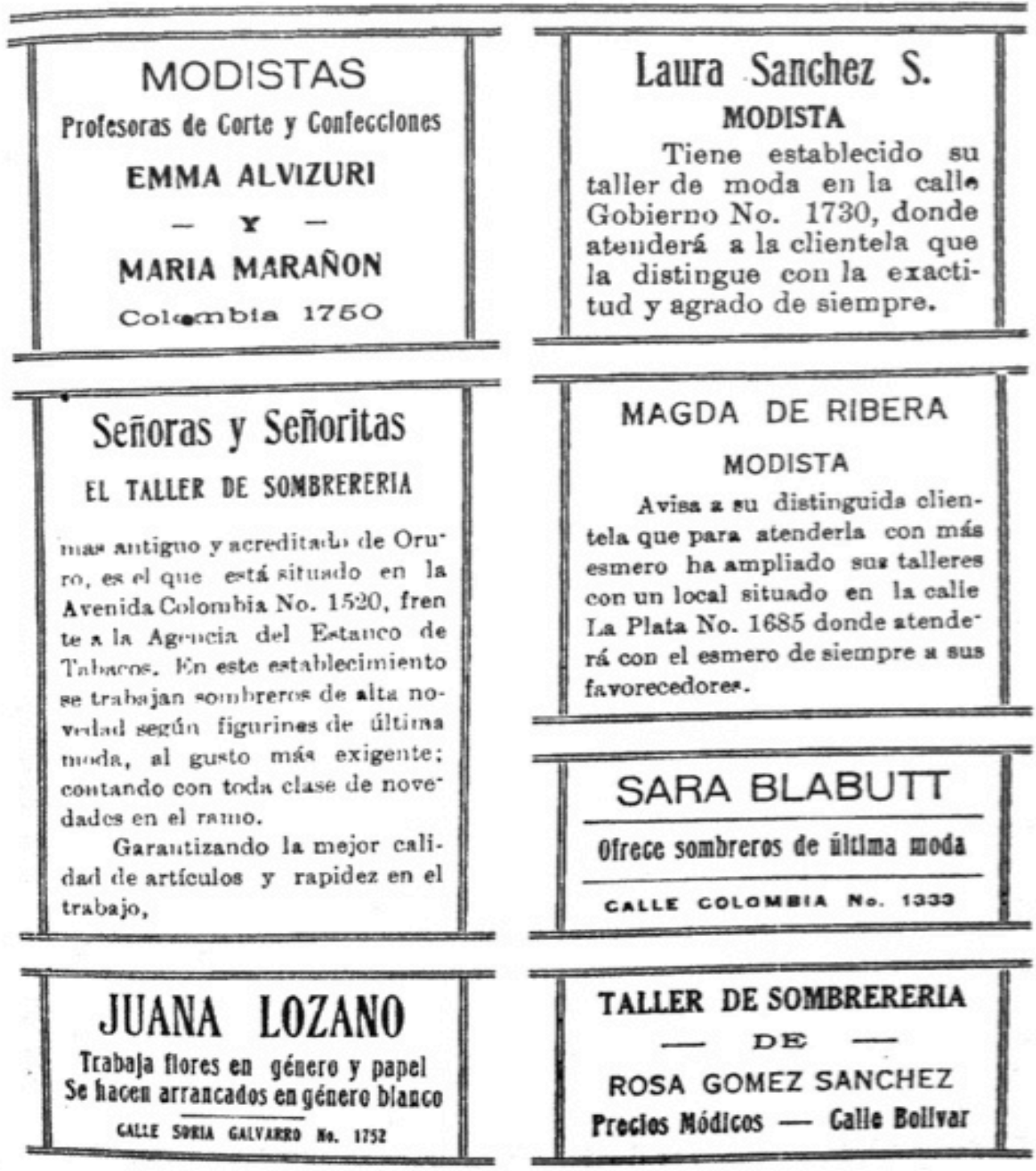

\footnotetext{
${ }^{406}$ Feminiflor, n²4, octobre 1923, Oruro. Hemeroteca de la Universidad Mayor de San Andrés, La Paz - Bolivie.
} 


\section{Couvertures de la revue Aspiración}
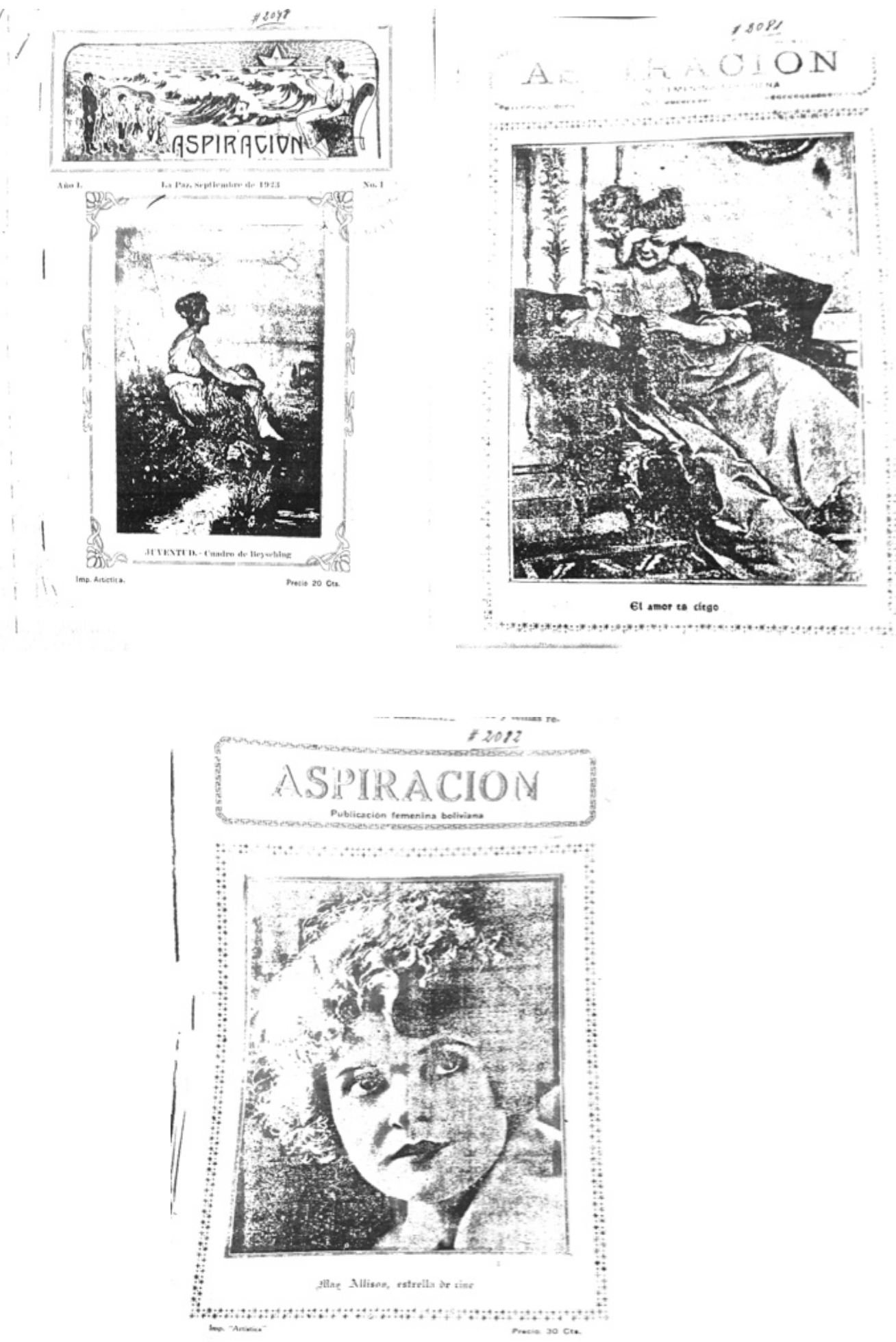
12.- Couvertures de la revue Eco Femenino
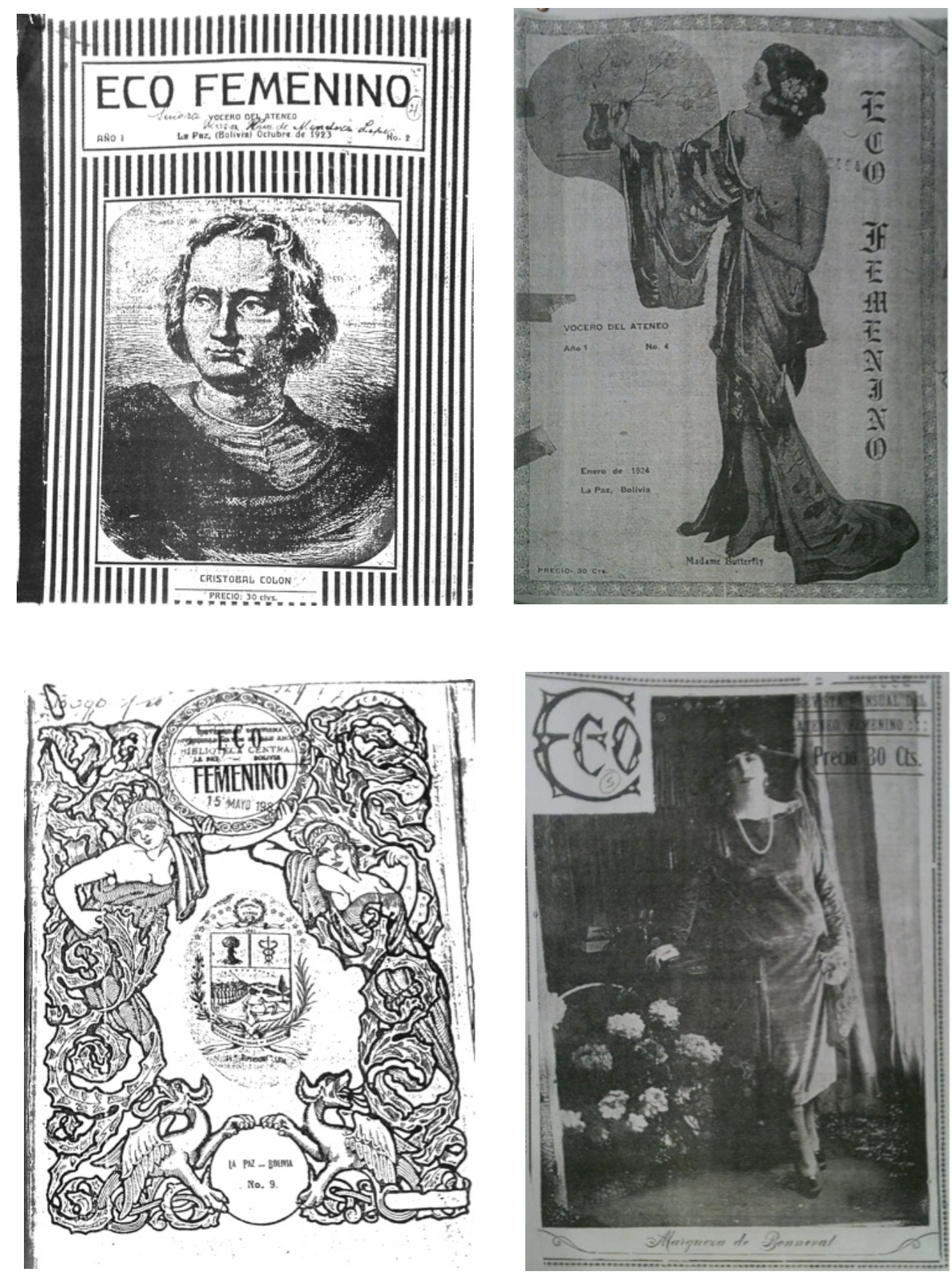


\section{TDOtasta SUSCRIPCION a "ECO"}

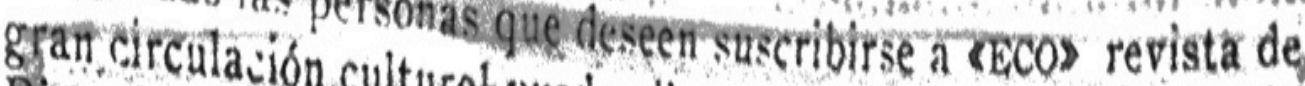
Dirección de culturoh pueden llenaresteocupón:

Rerista.

Señorita Directora de «ECo: Envío a UUd. los siguientes da. tos para una suscripción a esta revista:

Nombre

Tient

Domicilio

Dirección particular

Incluyo Bs.

Los pagos a'la suscripción se bacen adelantados de acuerdo a la siguiente tarifa:

Trimestral en la ciudad Bs. 0.90 Fuera Bs. 1.50 Semestral: >> > 180 in $>3.00$

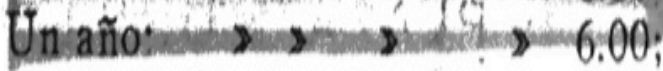

Las suscripciones fuera cuestan más por el derecho de certificación que importa el envío de ellas.

Se publican toda clase delanuncios comerciales y profesiona. les a precios sumamente módicos:

Dirección: Ateneo Femenino--Casilla 296

\footnotetext{
${ }^{407}$ Eco Femenino ${ }^{\circ}$ 14, juillet 1925, La Paz. Hemeroteca de la Universidad Mayor de San Andrés, La Paz-Bolivie.
} 


\section{4.- Eco Femenino: Articles sur l'obtention des droits civils et politiques des femmes ${ }^{408}$}

\section{Derecho del voto para la mujer}

7. " la revlon tez del globo nada es 1. utópico, muchu mús si be tra ta de reformas sociales: utópico (1) seila ir contra viento y marea. 1. :cuando los climentos se destrncialenin.

Los hombres son seres racionales. dotadus de pasiunes, sí, pero:émbién Ie razún y ven con claridad meridianit, que es una reforina muy necesaria. para la vida de a humanidad, el derecho que tiene la inu er de ir a las anloras a depositar su voto.

No se comprende que los hombres juzguen a mujeres: el corazón de la 4 mujer pura emotividad y el cerebro del hambre egoísmo, erudición.

Sryuraniante los padres de la pa. tria, estuvieron reñidos con su amable y cara mitad. cuando dictarón la lev de la MtNORIUAD para la mujer casada No se comprende de otro mndo: 'a esposia tiene que ser fiel, trabajitora, económica, amante, heIla, ilustrada, prudente y todo lo dem.ís... En el niatrimónio el FUERTF. debe dispuner !os bienes de su consortc si lleva diote, debe la pobrecita pedirle autorización para gastat, lo que sus padres economizarón para la felicidad de la hija. No debe intervinit en los negocios buenos 0 malcs del marido. Debe silenciar las faltas morales de su esposo.

Que contra-sentido:muerc elfUERIE, y de golpc, cruelmentc, tiene que responder con sus bienes atesorados en el matrim: inio, sin que ella hubierd tenido participación de los malos manejos; la ley to dice, hay que pagar lo que no le consta.

Se me imasina ๆุue 4 matrimonio cs tm RARCO. en if cmlsavido mat st: la existenria : el caprtan d marido: ei TIMONEL la mujer, en loई dos está barco. para llegar a puerto segure? ¿Cómo no intervenir, cómo la ley no recun-ice a la esposa el derecho de disponer. de su dote o de su trabajo? y cuando é esposn falta!, es mayor dE EDAD. esta niujer menor sojuzgada po: la autoridad marital núnca podrá ser buen timonel, si no ha sabido pensar ni discurrir, en asuntos. extraños al hogar.

Se dirá que la ley lo ha previsto. todo, pero esta ley es muy elastica en manos dei FUERTE, dueñò de su. mujer. El!a por tímida, por. el que dirán, por amor a su esposo, a sus hijos no recurre a los estrados judiciales. Sufre en si'encio, pierde su personalidad $\mathrm{y}$ su derecho.

Se hace necesario que la mujer. tenga el derecho del voto para-mejorar la condición de las mujeres oprimicas per el esposo. y votar por personcros, que prosenten leyes racionales.

Tieue la mujes el derecho del vo-. To, porque en verso y prosa llamanlàs inspiradoras-de grandes hechos, e ideales: los hombres nunca han silenciado, que mujeres fueron las que dieron hombres grandes a la Histo: ria; nó : ólo por la maternidad natural.

Es justo que la Mujer tenga el de. recho del voTO, porque si es delincuente se la considera CIUDADANO, para que sufra el castigo; un menor no vuede ni debe ir a pres:dio o al patíbulo; y la mujer. cascili menor soltera. joven o. vicin. purga su delitosntonces es MaYOR. CIUDADANO: purque clla. cu lo civi!, .

${ }^{408}$ Eco Femenino ${ }^{\circ}$ 9, septembre 1924, La Paz. Hemeroteca de la Universidad Mayor de San Andrés, La Paz-Bolivie. 
en lo penla' y hasta en lo militar, ez" si hay neccridad de recurrinia la ley.

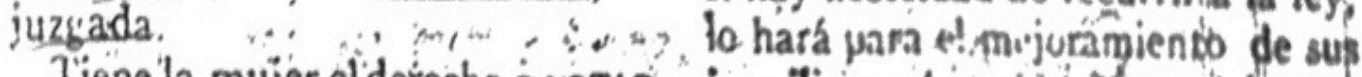

Tiene la muier elderechoa voTAR, inquilinos, nimca parti' usar del/ DEs. porque es esposa, madre. hija y her" Puju.

mana del hombre; a quien directa. Tienen derecho al voto todas las o indirectamente cuntribuye a for- mujeres cabezas de famillar au? mar la personalidad del FUERTE. ... proveen el pan en el hogar, aunque

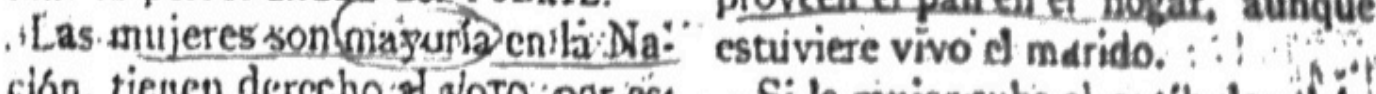
ción, tienen derecho al Nors; por es: "Si la mujer sube al patibula debe ta mayoría y porque las'leyes no de subir a la Tribuna a dictar la ley'sule ben dictarse sin su : coádurso, por la la jodrá juztar: entonces, tienedere:

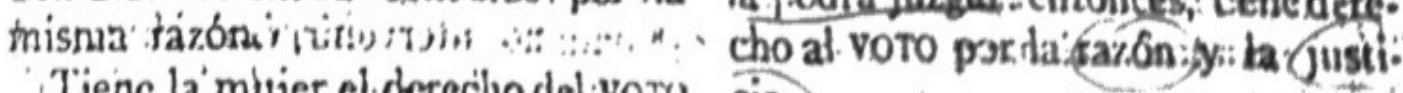

Tienc la mujer el derecho del:voro cia,

porjucen la haciendaula patrona es Alguien dijosare la mujer aprenmis ilustrada que el ILACATA, y. es- da a ser novia, esposa y madres;me, te aunque no sepa nadalide cicnicid; jor señores tio discutir: sobre estó ni tenga conciencia dello qué es Mo. RAL, $y$ haga:jeroglificos en lugar de nombresimarcha a emitir su voto, porque es hombre que se deja comprar por un obsequio. La dueña del fundo estudiará las masculino, todas estas sin razo. puntos, porque temo que salgais po cu airosos, i vamos a comproba con hechos las proezas del'FUERTE. Todos tos argumentos de los hom-i bres, sun sinrazcnes del eyoismo necesidades de sus colonos $y$. nes son sin base. $y$ nü pueden. Agosto 28 de $1921^{\prime} \quad \therefore$ sostenerse por disiquilibradas EDUVIJESS v. de HERTZOG 


\section{LA MUJER ANTE NUESTRAS LEYES}

Lin destacado intelectual en cuyo cerebro "juvenil y rigoroso se siente cl alctear de reneraciones radicales muy siglo XX; (Theddy Hartman de cimos, bien conocido ya por su es. piritu libre e independiente de traba. zones convencionalistas, nos da estas bellas y luggicas lineas preámbulo, cn verdad, de grandes tesis que nos haran pensar muy hondo y muy de verass subre lia trascendencia de ellas. por (que cada letra que con mano firme traza es un predazo de dinamita (ralga la paradoja) que al destruir ron sul estillido, construye estrellas...

Bendito sea simure el lervor de (ales plumas.)

(ue ciertos individuos - con arres los de inteleçlud les - sostengan a brazo partido que la mujer no debe ser simo la esposa humilde y buena que se resigna a vivir enclaustrada en el hogar junto a los hijos y muy cerca de los potes. sin otras preten. siones, sin olros idealss, sin ntra fe advierte que sus afectos no están mo. ni otra esperanza, es tolerable si se

vidos por olro interés que no sea el egoismo, y q' aun se estiman como los rejes de la crcación, los únicos scñores de la tierra; pero, que estos nismos pensamientos aniden en los cerebros de algunas mujeres que se jrecian y ufanan de cultas, es incon. cebible.

Si la mujer ilustrada y culta no lucha por elevar al mismo nivel del lombre su condición social y legal, confirma la crecencia baslanle urratfida de su inferioridad: y, contribuir a gine se accontie esse prejuicio, es contribuir al propio desprestigio.

Para lodes los conservadores de la tradición apolillada; para todos los espiritus egoistas, la mujer que sc vergue contra el feminismo, la que traiciona a sul sexo y entrega voluntariamente sus pies y sus manos para (pire se los agarrolen, es la verdadera untrjer, es ta esjosa, la compañera de la Iutc les hablio Pablo a los Corintios $y$ a los Efesios en sus conocidas epistolus. Mas, csla esposa biblica, si ha ganado un puesto allá en ultratumba, 
ha perdido en este mundo donde 10 to es fucha y donde resurgen a la wido los yue no han caidn, tos que no idu lon resignado...

La mujer que acepta la potestad del varón como to fatal, sufre un procel so de metamorfosis y se convjeroce la mariposa Kallima, en es lepide en tero intitil que hace ticm es 'lepidóp. ra extinguido, a no ticmpo se hubietencia valiendose del miner su exismeia valiendose del mimetismo.

Mientras la mujer vive de ensoñ ciones en el hogar paterno ensona. cnparse del mundo oxterior in preo. nocer la durezo de exterior, sin cohaber custadeza de fa vida real, sin eura no se a culiz de la amarclira. no se da cuenta de que para de cue coucerrados muclios caminos, de que contra ella se levantan muchos nisma ley que contra ella está la

AC dictio la ley? si, la ley es el principal enemigo de $\sqrt{a}$ muer. La ley consigra muchos abusos, y la ley permite muchas injusticins. Anle la ciencia que se afana por demostrar la irualdad mental de la mujer $y$ del hombre, ze opone la ley que no se af ana menos por demostrar la infe. rioridad de aquella; si la coereión social priva al hombre de cierta potestad. la ley se la devuelve. La ley $y$ la razón están en pugna. La razón portue sigue ef proceso evolutivo del Derfeccionamientu; la lev porque se lia quedado un centenar de años atrús $y$ en vano se exfuerza por unir el pasado con el presente.

Dejando a un lado fodo sentimentalismo o lucubracion especulativa. he de exponer cúmo la ley se halla contru la mujer. Comonzare por ha. blar de los derechos y delieres de Jos copjosos.

Art, 130 del Condiso Civil. "Hl maridu dele pROTECCION a su muier, $\checkmark$ ista O13FDIENCIA AL MARIDO". Li mujer debe obediencia al marido; jüzocse este mandamiento $v$ counblemintesele con el de que el marido debe vrotección a su muier y se verá me ella sioue aun en la rondicion de sierva. La protección del marido e la sumerioridad de $\dot{j l}$ sobre sul es. posa: v la obediencia al esposo no es cino ol mandato imperativo de nue la muier debe someterse a sn dneño. Poco ha variado la condición de la mujer: sione considerads momo en el Derecho Romano en calidad de mamut piri (en mano del varón), y en su ns.
Decto tienico conforme a este mismo su marido". Art. 132 .

comparecer - "La mujer no puede su maridor en juício sin licencia de ta al oppso remarca la ley, $y$ faculcsposo a autorizar o nó a su esposa para un acta judicial; pero esta faculiad que realmente pudiera ser vir de prolección, si asi se quiere, que da desvirluada con el $\mathrm{Art} .133$ que tinade: "No se neccaita la licencia del marido cuando la muier es persegui. da en materia criminal o de polieia". Fs decir, aue para catos cnsos graves $y$ a veces denigrantea. la mujer ya no cslí protegida por el csposo....

Y. después de todo żde qué sirve que el marido p i-ta o nn "utorizar un acto judiclal, si junto a ed y con la misma faculfad calá el juez? La mujer ya no depende sólo de su esposo, sino también de un extraño como es el juez. El, asimismo, tiene potestad sobre ella, lo dicen los Arts. 135,136 y 138, este -1timo que además faculta al juez para conceder autorización a la mujer que desea realizar un acto de libre y expontánea volunta، como es el de contratar.

La mujer que es el ejo del. hogar. ave es la que ayuda a amasar ta fortuna $y$ o hacer menos pesada la lucha por la vida. no puede, de acuer. do con el Art. 134, ni enajenra. ni vender, ni dar sus biencs sin la concirrencia del esposo, que sigue a la exposa como la sombra al cuerpo: d citado articulo va más lejos: nrohibe, ivualmente, a la mujer. adquirir lienes ya sca a titulo gratuito u one. roos, sin la autorizacion del marido. o, sin la autorizaci tal vez en otro Aqui me detento espacio suficiente numero encuentre espacindo la des-

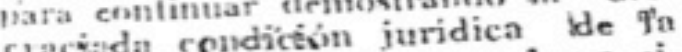
fracita condicen an nuestras leyes civiles mereantiles $v$ penales

THEDDY HARTMANN.

\section{EMPRESA EDITORA}

\section{"MARINONI"}

\author{
Andres Chiocchetti y Co.
}

PICHINCHA $28-30$ 
15.- Couvertures de la revue Indice

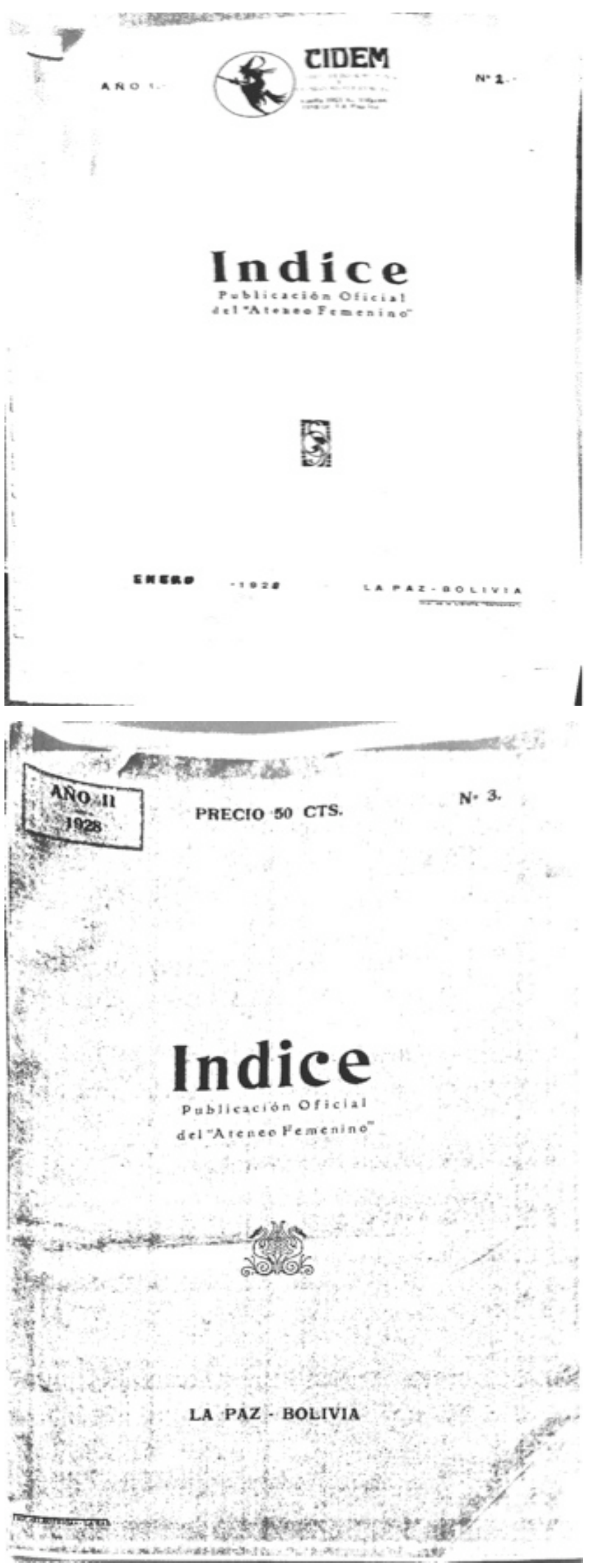




\section{6.- Publicité de la revue Indice I09 $^{409}$}

NO DEJE DE LEER TODOS LOS MESES LA RE:
VISTA DE PROPAGANDA CULTURAL FEMENINA "INDICE"

Editada por el Directorio del Ateneo Femenino y Concejo de Cooperación Nacional

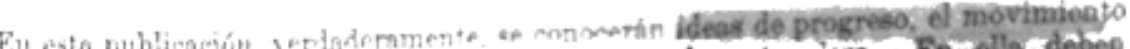

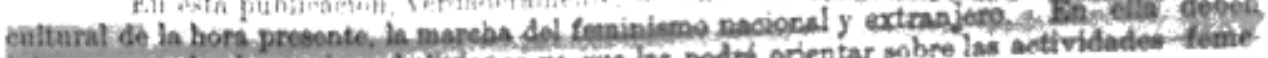

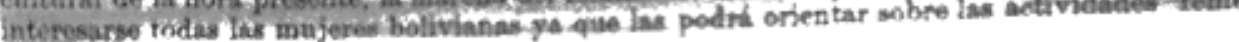
ninas del mutodo entero

D. Ateneo Bemenino, Fedwado al Concejo Internactobal de Mujeres y al Nacional dy

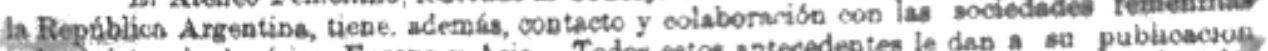
y feministas do América, Europa y Asis. Todos estos antecedeotes le das a su pubtucaciogs

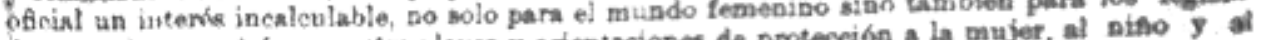

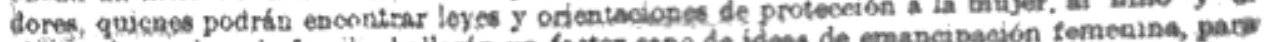

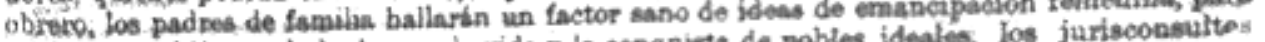

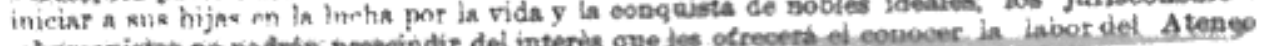
y hamanistas no podrin presciodiz del interve gue les ocreocts

INDICE no es una publicación de negocio, por esto se realizaran grandes gastos para que su edlclón sea elegante

MDICE no paga a sus Directoras y cuerpo de Redacción

IMDICE divulga ideas de progreso y bienestar social.

IXDICE reune en su centro propagandista, un núcleo de mujeres trabajadoras, que no omite esfuerzo y sacrificio para hacer de esta REVISTA una publicación importante.

La servión de avisos de INDICE servizá de manera especial y como ninguna otra de su genem los interuss del comercio, para efectuar uns propaganda de grandes aleances.

pues no olvide usted que

INDICE circulara profusamente en la República y en el Extranjero

WDič tiene agentes en todas las capitales de Departamento

INDICE agotará sus ediciones porque ellas serán distribuidas en su totalidad, como todas las publicaciones que efectúa el Ateneo Femenino.

El Directorio de la Institución será responsable de la Revista INDICE

Presidenta

Vice-presidentas

Secretaria de actas

Socretaria de prensu

Secretaria de correspondencia

Tesorera

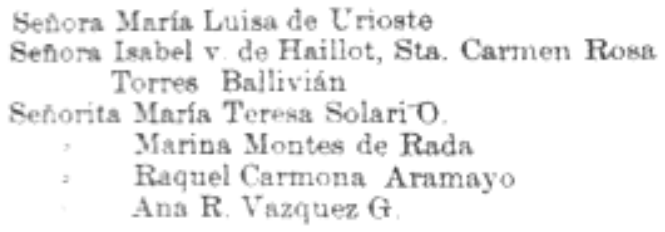

AGENTE COMERCIAL: Emilia Carmona Aramayo DIRECCION: Calle Recreo 173. Casilla 515. La Paz-Bolivia

${ }^{409}$ Indice, ${ }^{\circ}{ }^{1}$, décembre 1927, La Paz. Centro de Informaciôn y Desarrollo de la Mujer (CIDEM), La $\mathrm{Paz}$ - Bolivie. 
17.- Couvertures de la revue Venas de Plata
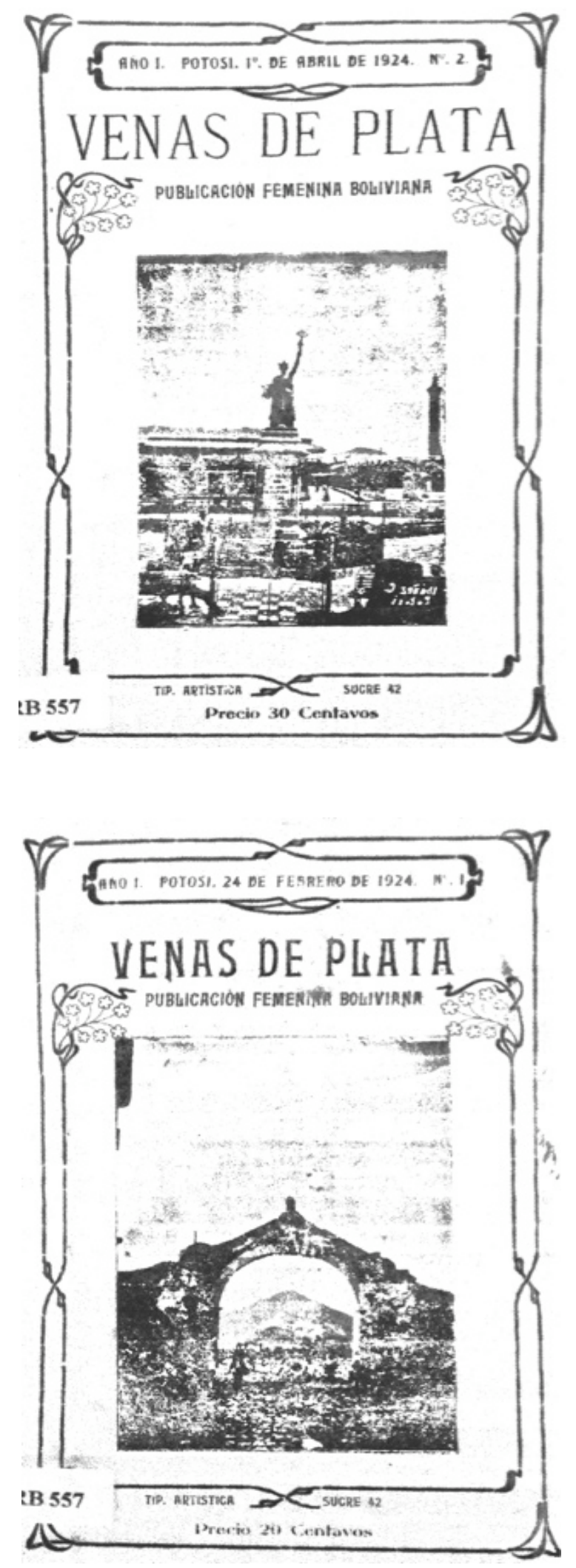


\section{8.- Couvertures de la revue Anhelos}
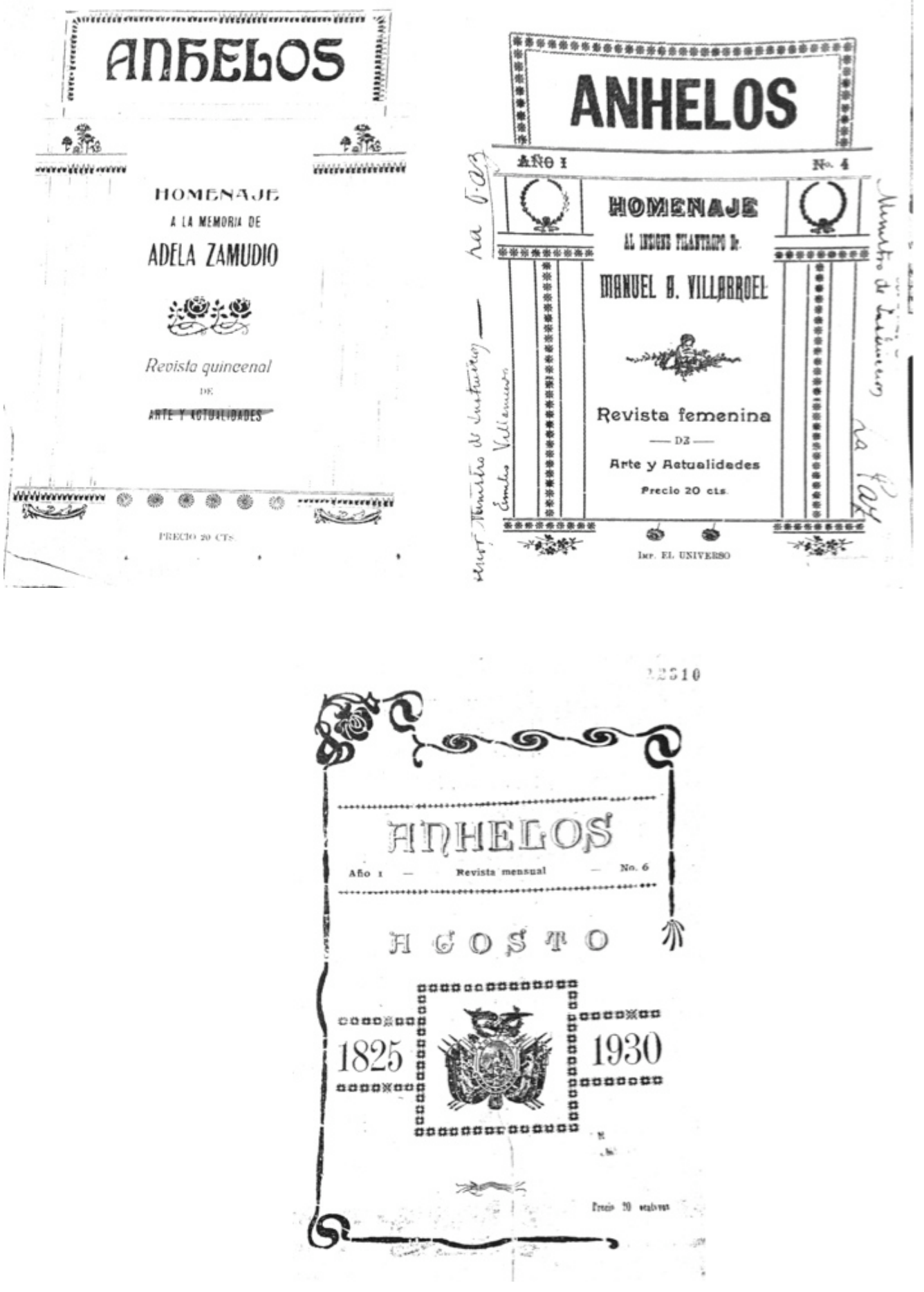
19.- Caricature dans la revue Indice II0 $^{410}$

\section{I $\mathrm{R} \mathrm{O} \mathrm{N} \mathrm{I} \mathrm{A}$}

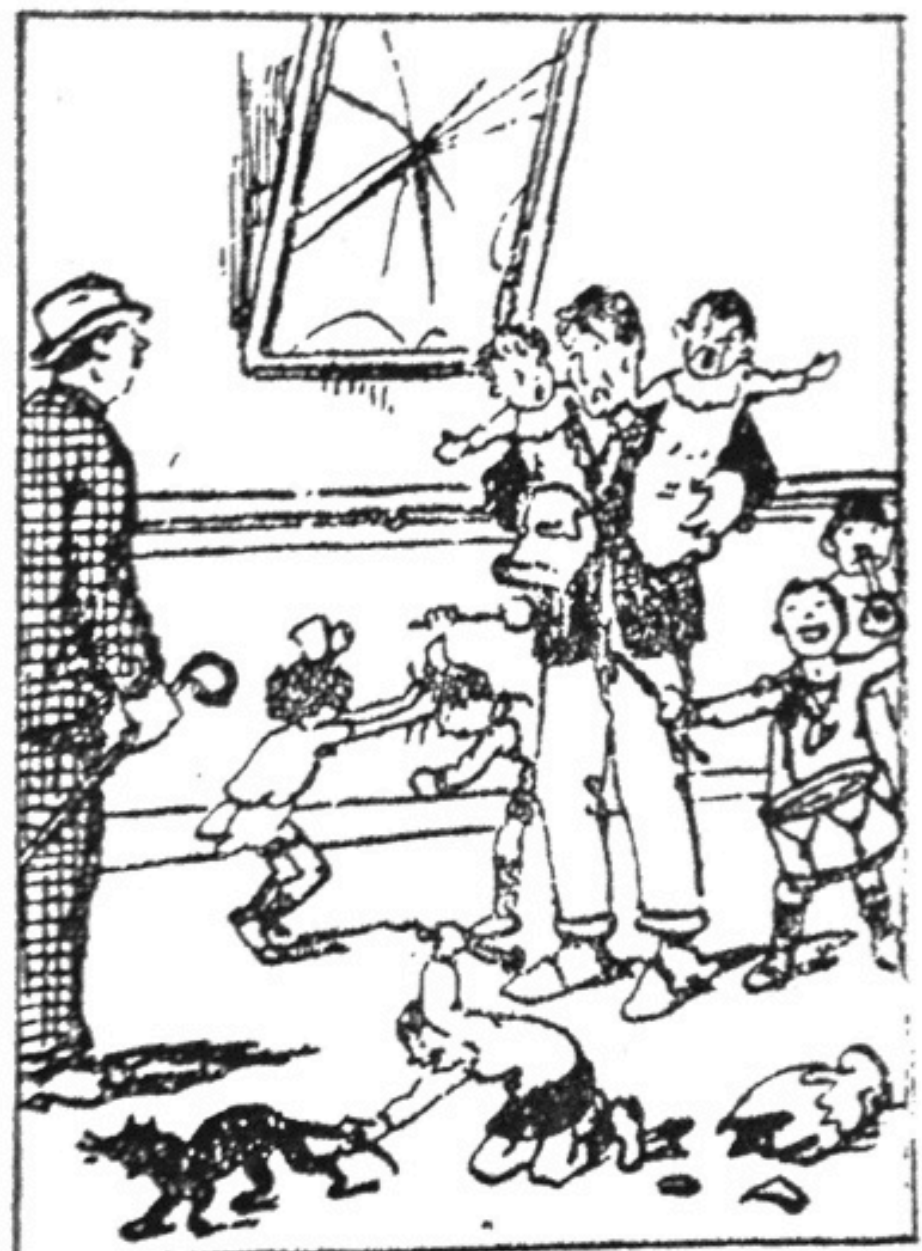

--pobre amigo mío! ¿Y tu mujer?

-Ha ido al Ateneo a dictar una conferencia sobre los deberes de la madre de familia.

${ }^{410}$ Indice, n², janvier 1928, La Paz. Centro de Informaciôn y Desarrollo de la Mujer (CIDEM), La Paz - Bolivie. 


\section{0.- Plan du « Chaco boréal ${ }^{411}$}

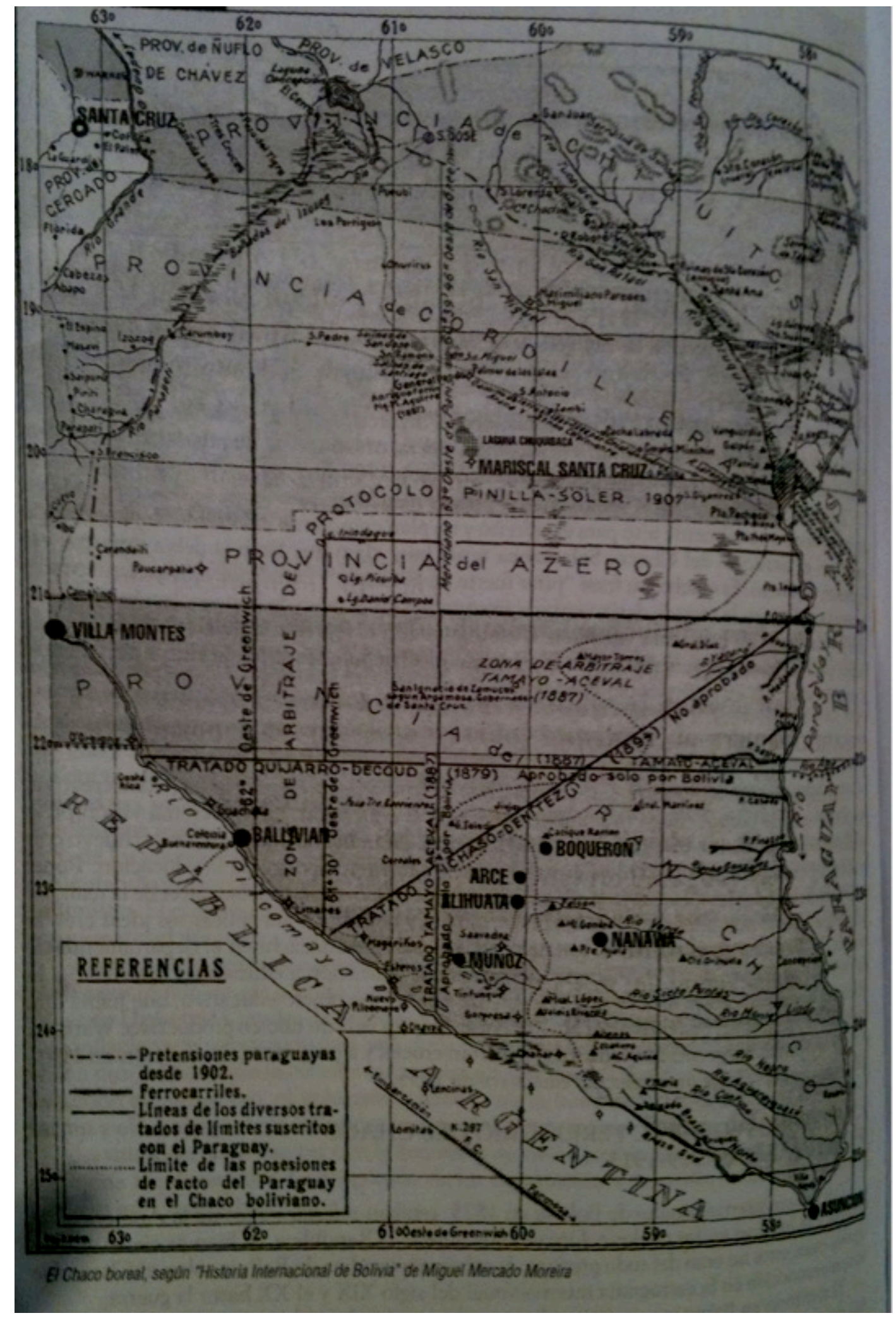

411 Tiré de MESA (de) José, GISBERT Teresa, MESA Gisbert Carlos D., Manual de Historia de Bolivia, Editorial Gisbert, La Paz, 2008. 
21.- Paroles de la cueca "Infierno Verde» composée par Alberto Ruiz Lavadenz évoquant l' " enfer » que signifia la Guerre du Chaco et les adieux entre les soldats et les femmes

Infierno Verde

Si aún queda llanto en tus ojos

Para llorar mi partida

No llores mientras la vida

Deja un minuto al amor

Ese minuto de vida

A la orilla de la muerte

Tiene el encanto de verte

Resignada ante el dolor

Llorarás cuando mañana

Ya nadie de mí se acuerde

Porque del infierno verde

Sólo Dios se acordará. 


\section{2.- « Soldados Adelante " poème écrit par la poétesse Olga Bruzzone dédié aux soldats boliviens partant à la guerre pour la défense du Chaco $^{412}$}

\section{Soldados Adelante}

Ha sonado ya el grito,

horrísono y fatídico

La sombra de la Guerra quitó

el sueño pacífico. Entusiasmadas,

locas, las turbas se levantan

al sentir el ultraje a la Patria inferido

La madre ha contemplado

con orgullo y dolor a ese

pedazo amado, pedazo de su ser

La poesía continúa expresando el sentir de la

mujer, esposa, hija, novia, hermana y termina:

La mujer boliviana, heroica y altanera

con el pecho partido y el corazón sangrante,

con el sollozo amargo a los suyos espera...

y aunque el dolor abraza con una llama quemante

mezclado en sus plegarias, lanza con voz entera

el grito de, Adelante.

\footnotetext{
412 Tiré de DURÁN JORDÁN Florencia et SEOANE F. Ana María, El complejo mundo de la mujer durante la Guerra del Chaco, Editores: Ministerio de Desarrollo Humano, Secretaría de Asunto Étnicos, de Género y Generacionales, Subsecretaría de Asuntos de Género, La Paz - Bolivia, 1997.
} 


\section{LUNES 4}

D 20 a 21 bions. Noticioso de guerra. Folklore nacional én grapaciö. nes. Cantante, Emmo Reyes. Orquesta de baile de la salla. Informativos, nacional $\mathrm{y}$ exterior.

De 20 a 21 Loras. - Profesor Eduardo Calderón en música pro pia.

Mañana, mado dia y noche, 0 . bertura de Supee por la orquesta Radio nomanis

sñor Raúl Jalmes freyre (Ia) mujer artista). Conferencia. Señor Alberto de Santa Cruz. (La mujer intelectual). Señor Inis S. Crespo, (La mujer en meestra historia). De 22 a 23 horas. - Noticioso de guerra.

Sopranor señora Ana Palma de Aguirre. Colaboracion. Onquesta de balle de la salá. Conjunto típlco Andes.

La Bayadera. Opereta de

Kallman. Ornuesta Kana Wara
MARTES 5-

De 20 a 21 hora6. Noticloso

de guedra.

Canciones mexicanas en grabactones.

Pablo de la Riva en imitacio. nes de keans.

Orquesta de balle de la sala. Informativos, nacional $y$ ex-

terior

De 21 a 22 foras. - Noticioso

de guerra.

Gantante, señorita Claudetté. Egmont. Overtura de Bectho

ven, Orquesta clásican. Programa de la semana feme.

nina.

I.-Señora, Juclla Flores de

Tejada Sorzino.

II.-Discurso y lectura del

mnsaje de $\mathrm{la}^{7}$ mujer espaflola, a

a mier buliviana. Sefiorlta Co

rinia de la Rocbr.

II. - Soprano, señora Ana Pal

ma de Agnirie.

IV. - Recitación, señorita Afda

Bailón Sanjiness.

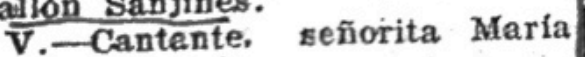

Teresa Rivas.

VI. - Piano; señora Elena $\mathrm{Sa}_{\text {. }}$

gurnasa de Ernst.

De 22 a 23 horas. - Orquesta

de baile de la sala.

La hora del vals, pianista se-

nor Luis Fores L.

Trio folklórico Slas. Katari.

Betzo.

Cadiz-de Valverde. Orquesta

Kana Wara.

${ }^{413}$ El Diario, juin 1934, La Paz. Collection personnelle d'extraits de journaux de Zoila Viganó. 


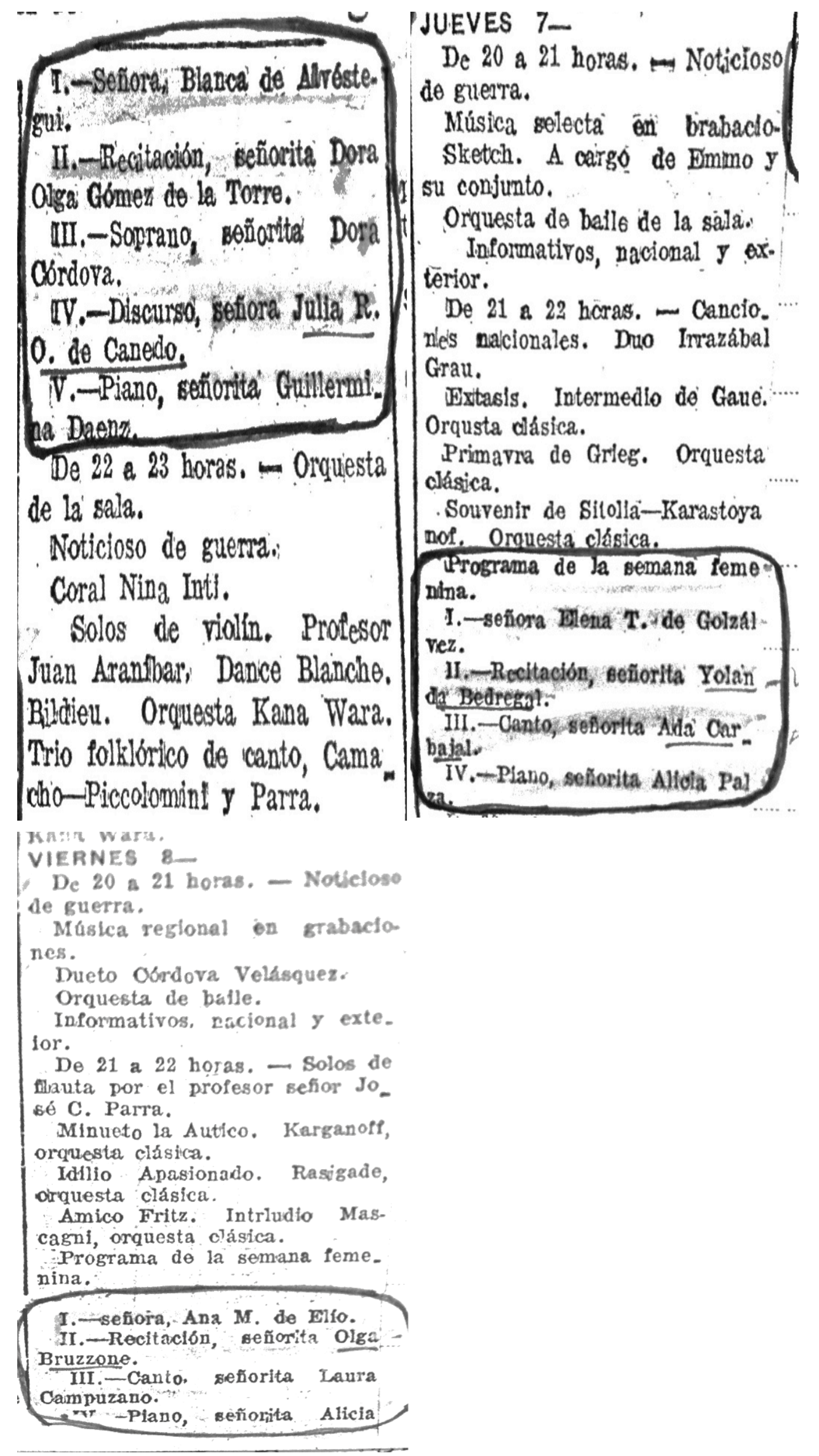




\section{Radio Allimani calizarán durante CP4 y. CP5}

Trio Salas Katari. Betzo. Trozos selectos en srabaclones. Doná canta la Alondra. Pot potirit de wehar. Por $1 \mathrm{a}$ orques ta Kana Wara.

SABADO 9

De 20 a 21 horas. Noticioso de guerra.

Canciones mexicanas en graba ciones.

(Planista, señorita Cira Villalo bos.

Orquesta de bajle.

Informativos, nacional $y$ exterior.

Do 21 a 22 honas. Suite faponesa. Yoshitomo. Orquesta clástan

Programa de la semina femo nina.

I. - Seña, Maria Luisa $S$. đo

Nota. - In vista del entuela mo patribtico con que han $r f$ pnodido al Departamento de Pr paganda, las señoras $y$ señorita invitadas por el para tomar pra is en la hora ferienina de la $\mathbf{R}$ dio Ilfimani, se ha resuelto ex! tender el programa fermenino. varias semanas, para 10 crat 5 ha hecho una distribucion gue permita mantemer el interés de
discho programa sin que el decal

ga en días sucesivos.

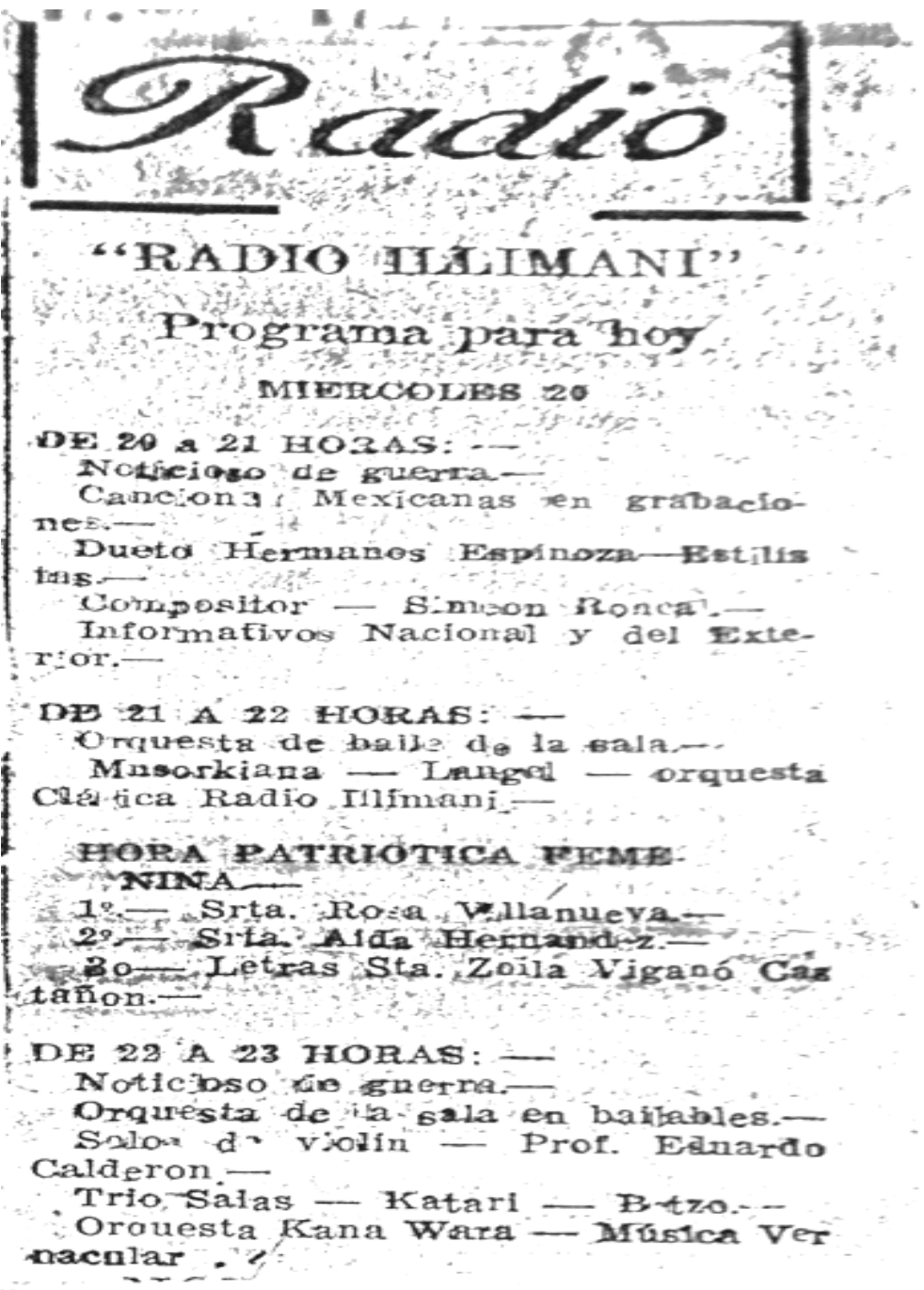


24.- Liens de parenté entre les militantes « Barzolas » et les membres du MNR M14 $^{414}$

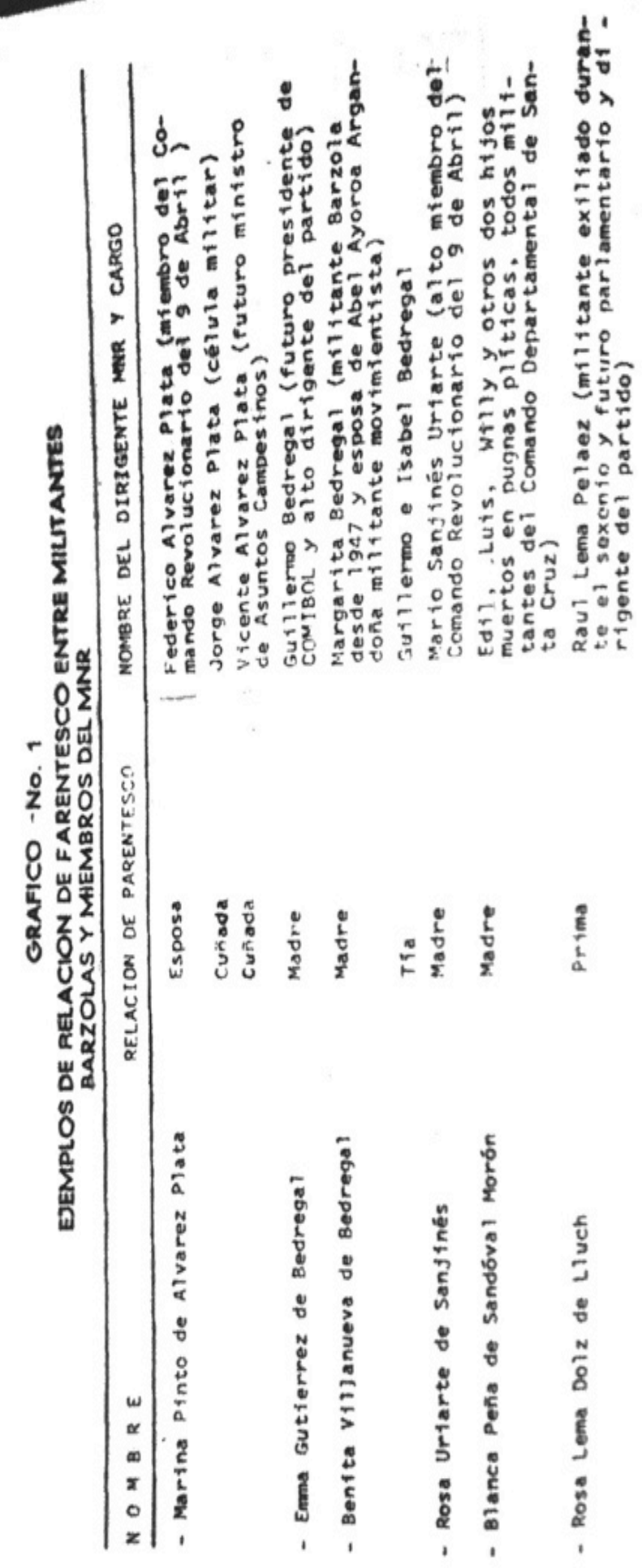

${ }^{414}$ Tiré de ARAUCO, María Isabel, Mujeres en la Revolución Nacional: Las Barzolas, Distribución CINCO, La Paz, 1984. 


\section{$\underline{\text { Sources }}$}

\section{$\underline{\text { Lois, décrets de loi, constitutions, études juridiques, projets de loi }}$}

Archivos del Congreso de La Paz - Bolivia.

- Anuario de 1932.

- Ley de Divorcio Absoluto, 15 de abril de 1932, p. 260-266.

- Anuario de 1947.

- Decreto Supremo, Elecciones municipales, 13 de marzo de 1947, p. 411.

- Decreto Supremo, Elecciones municipales, 10 de abril de 1947, p. 421422.

- Decreto Supremo, Elecciones municipales, 19 de junio de 1947, p. 465466.

- Decreto Supremo, Elecciones Municipales, 4 de octubre de 1947, p. 613614.

- Anuario de 1949.

- Decreto Supremo, Elecciones, 21 de octubre de 1949, p. 857-858.

- Anuario de 1952.

- Decreto Supremo No 3128, 21 de Julio de 1952, p. 122-124.

- Anuario Administrativo de 1944.

- Decreto Supremo, Trabajo Femenino Nocturno, 22 de Enero de 1944, p. 189-191.

- Decreto Supremo, Trabajo extraordinario para mujeres y niños, 31 de marzo de 1944 , p. 522-524. 
- TRIGO Ciro Félix, Las Constituciones de Bolivia, Editora Atenea S.R.L., La Paz Bolivia, 2003.

- Constitución de 1880.

- Constitución de 1938.

- Constitución de 1945.

Archivo Nacional, Sucre - Bolivia.

- MACEDONIO Urquidi José Antonio, La Condición Jurídica o Situación legal de la mujer en Bolivia, 3e Edition, Cochabamba, 1937.

Centro de Información y Desarrollo de la Mujer (CIDEM), La Paz - Bolivie.

- Exposición de motivos y proyecto de ley de Reintegración de los Derechos Civiles de la Mujer. Conferencia que tuvo lugar en el Ateneo Femenino, en el mes de Julio de 1925, por el jurisconsulto y Civilista Dr. Benjamín H. Gallardo, Rector de la Universidad Mayor de San Andrés. Talleres "La República", La Paz - Bolivia.

\section{Débats parlementaires}

\section{Archivos del Congreso de La Paz - Bolivia.}

- Redactor del Senado, sesiones extraordinarias, 1932, p. 188-679.

- Convención Nacional de 1938, Redactor de la Convención Nacional, tomo III, p. 106-186.

- Convención Nacional de 1944, Redactor de la Convención Nacional, tomo II., p. 765-781.

- Convención Nacional de 1945, Redactor de la Convención Nacional, tomo I., p. 226-296. 


\section{Presse}

Hemeroteca de la Universidad Mayor de San Andrés, La Paz - Bolivia.

Hemeroteca de los Archivos del Congreso de La Paz - Bolivia.

Collection personnelle d'extraits de journaux de Zoila Viganó de Antezana.

- La Razón (1932, 1936, 1938, 1944, 1946, 1947, 1949)

- El Diario (1932, 1934, 1935, 1936, 1938, 1945, 1946, 1947, 1949, 1950, 1952)

- La Calle $(1936,1938,1945)$

- Última Hora (1936, 1938, 1944, 1947, 1952, 1956)

- Los Tiempos (1947)

- Universal $(1933,1934)$

- La República $(1940,1941)$

- La Noche (1948)

- La Semana Gráfica $(1933,1934)$

- La Gaceta de Bolivia (1934)

- La Patria $(1934,1936)$

\section{Presse féminine et féministe}

Hemeroteca de la Universidad Mayor de San Andrés, La Paz - Bolivia.

- Eco Femenino, La Paz, 1923-1925: n², 4, 7, 9, 13, 14 et 15.

- Feminiflor, Oruro 1921-1923, n, 10, 16, 18, 22, 23, 24 et 25.

Archivo Nacional, Sucre - Bolivia.

- Venas de Plata, Potosí, 1924, nº1 et 2.

Centro de Información y Desarrollo de la Mujer (CIDEM), La Paz - Bolivie.

- Anhelos, Cochabamba, 1929-1930, n²1, 2, 3, 4 et 6 .

- Aspiración, La Paz, 1923-1924, n¹, 2, 3, 4 et 5.

- Indice, La Paz, 1927-1928, n¹, 2.

Collection personnelle de Martha Nardín de Urioste.

- Indice, La Paz, 1927-1928, n³. 


\section{Collection personnelle de Zoila Viganó de Antezana.}

- Nosotras, Santiago-Chile, $1935, \mathrm{n}^{\circ} 61$.

\section{Entretiens}

\section{Collection personnelle de Luis Ramiro Beltrán}

- Entretien vidéo Dos Mujeres en la Historia, avec Bethsabé Salmón et de María Luisa Sánchez Bustamante réalisé par Eva Urquidi, CIMCA, 1987.

- Entretien vidéo avec Bethsabé Salmón réalisé par Eva Urquidi, filmé et édité par Miriam Ernst et Miguel Cusicanqui à Quito - Equateur à la fin des années 1980. Transcription partielle de l'entretien réalisée par C. de Vega Magalí et FLORES Bedregal Teresa, incluse sous le titre de « Con el periodismo en las venas. Testimonio de la jefe de redacción Bethsabé Salmón de Beltrán », dans l'ouvrage de BELTRAN Luis Ramiro (comp.), "Feminiflor" Un hito en el periodismo femenino de Bolivia", CIMCA, Círculo de Mujeres Periodistas, CIDEM, (n.d.).

- Entretien réalisé à María Luisa Sánchez Bustamante par Mariana Baptista Alvarez à La Paz, en 1979 et inclus dans l'article « Evolución de la mujer boliviana en los últimos 50 años » dans l'édition «Bodas de Oro » du journal Ultima Hora, avril 1979.

- Entretien réalisé par María René Duchén avec Lydia Gueiler dans la série Mujeres en la Tierra Prohibida.Testimonios de Mujeres protagonistas de la politica boliviana, Nuestra Esperanza, Konrad Adenauer Stiftung, La Paz, décembre 2008.

- Entretien réalisé avec Luis Ramiro Beltrán, fils de Bethsabé Salmón, janvier 2010.

- Entretien réalisé avec Martha Nardín de Urioste, belle fille de María Luisa Sánchez Bustamante, janvier 2010.

- Entretien réalisé avec Guido Antezana, fils de Zoila Viganó de Antezana, janvier 2010.

- Entretien réalisé avec Gonzalo Alvarez Chávez, petit-fils de Elvira Ortiz de Chávez, mai 2011. 


\section{Livres utilisés comme sources}

- VILlanUEVA Etelvina, Acción Socialista de la mujer en Bolivia, Cooperativa de Artes Gráficas E. Burillo Ltda., La Paz-Bolivie, 1970.

- GUEILER, Lydia, La Mujer y La Revolución, Editorial Los Amigos del Libro, La Paz - Bolivie, 1983.

- VIGANÓ Castañón Zoila, Conflicto Boliviano - Paraguayo, Editorial “AMERICA”, La Paz, 1935.

- MINISTERIO de Educación y Cultura, Zoila Viganó de Antezana. Mujer de las Américas 1983 1986, n.d 


\section{Bibliographie}

\section{Bibliographie générale}

- DEMÉLAS, Marie - Danielle, L'invention politique - Bolivie, Équateur, Pérou au XIX siècle, Éditions Recherches sur les Civilisations, Paris, 1992.

- DUNKERLEY, James, Rebelión en las venas, Trad. Rose Marie Vargas Jastram, Plural Editores, La Paz - Bolivia, 2003.

- KLEIN, Herbert S., Historia de Bolivia, Librería Editorial Juventud, La Paz, 1982 (3e édition augmentée et corrigée 2002).

- KLEIN, Herbert S., Orígenes de la revolución nacional boliviana. La crisis de la generación del Chaco, Librería Editorial G.U.M., La Paz, (n.d.)

- LAVAUD, Jean-Pierre, El embrollo boliviano. Turbulencias sociales y desplazamientos políticos (1952 - 1982), CESU-IFEA-hisbol, Bolivia, 1998.

- MESA (de) José, GISBERT Teresa, MESA Gisbert Carlos D., Manual de Historia de Bolivia, Editorial Gisbert, La Paz, 2008.

- OCAMPO Moscoso Eduardo, Historia del periodismo boliviano, Librería editorial “Juventud", La Paz - Bolivia, 1978.

\section{Histoire des femmes et du genre}

- BRANCHE, Raphaëlle et VOLDMAN, Danièle (dir.), «Histoire des femmes, histoire des genres $», \mathrm{~N}^{\circ}$ spécial de la revue Xxe siècle, $\mathrm{n}^{\circ} 75$, Paris, Presses de Sciences Po, 2002.

- BRIAN Isabelle, LETT Didier, Sebillote Violaine, VERDO Geneviève, « Le genre comme démarche », dans Genre et Histoire, Hypothèses, 2004, Paris 2005, p. 277 295.

- BARD, Christine, BAUDELOT, Christian, MOSSUZ-LAVAU Janine, Quand les femmes s'en mêlent. Genre et pouvoir, Editions de la Martinière, 2004.

- BOURDIEU, Pierre, La domination masculine, Le Seuil, 1998.

- CAPDEVILLA, Luc, « L’Histoire des femmes dans les sociétés espagnole et latinoaméricaines », dans "Amériques métisses", CLIO. Histoire, femmes et sociétés, $\mathrm{N}^{\circ}$ $27,2008$.

- DIGNEFFE, Françoise, « La reconnaissance de droits spécifiques aux femmes : une question de justice ou de responsabilité ?”, dans Déviance et société, Année 1992, 
Volume 16, $\mathrm{N}^{\circ} 3$, p. 279-286.

- DUBY, Georges et PERROT, Michelle, Femmes et histoire, Plon, 1993.

- GRANSAC, Ariane, «Les femmes dans les luttes sociales en Bolivie», dans Matériaux pour l'histoire de notre temps, Année 1985, Volume 1, $\mathrm{N}^{\circ}$ 1, p. 31-32.

- JELIN, Elizabeth, "Igualdad y diferencia: dilemas de la ciudadanía de las mujeres en América Latina", en Ágora, Cuadernos de estudios políticos, año 3, № 7: Ciudadanía en el debate contemporáneo, 1997, pp. 189-214.

- MONTAÑO VIRREIRA, Sonia, «Actuar por otras: La representación política de las mujeres », dans Partidos políticos y representación en América Latina, Thomas Manz et Moira Zuazo (coord.), Editorial Nueva Sociedad, Caracas,1998.

- MOLLER OKIN, Susan, «Feminismo y multiculturalismo: algunas tensiones », dans Feminaria, año XV, Nr. 28/29, Julio 2002.

- MORANT Isabel (Coord.), Historia de las mujeres en España y América Latina, T. $I V$, Ediciones Cátedra, S.A., 2005.

- PERROT, Michelle (dir.), Une histoire des femmes est-elle possible?, Marseille, 1994.

- PERROT, Michelle, Les femmes ou les silences de l'histoire, Flammarion, 1998

- RIOT-SARCEY, Michèle, La démocratie à l'épreuve des femmes. Trois figures critiques du pouvoir, Albin Michel, 1994.

- SCOTT W., Joan, La citoyenne paradoxale. Les féministes françaises et les droits de l’homme, Traduit de l'anglais par Marie Bourdé et Colette Pratt, Albin Michel, 1998

- SCOTT W., Joan, “Gender: A Useful Category of Historical Analysis”, American Historical Review, vol. 91, n5, décembre 1986.

- SCOTT W., Joan, « Gender and the Politics of History », 1988, traduit en français sous le titre de "Genre, une catégorie utile de l'analyse historique", numéro spécial des Cahiers du GRIF intitulé Le genre de l'histoire, $n^{\circ} 37-38,1988, p .141$.

- SOHN Anne Marie et THÉLAMON Françoise (sous la direction de), L'Histoire sans les femmes est-elle possible?, Perrin, Rouen, 1997.

- THÉBAUD, Françoise (sous la direction de), DUBY, Georges, PERROT, Michelle, Histoire des femmes en Occident, T. V, Le Xxe siècle, Perrin, 2002.

- THÉBAUD, Françoise, Écrire l'histoire des femmes et du genre, 2e édition revue et augmentée, ENS (Éditions), 2007.

- VERJUS, Anne, Le cens de la famille. Les femmes et le vote, 1789-1848, Belin, 2002. 


\section{Les femmes en Bolivie}

- ARAUCO, María Isabel, Mujeres en la Revolución Nacional: Las Barzolas, Distribución CINCO, La Paz, 1984.

- ARDAYA, Gloria, Política sin rostro: mujeres en Bolivia, Editorial Nueva Sociedad, Venezuela, 1992.

- ARDAYA, Gloria, «La mujer en la lucha del pueblo boliviano: las Barzolas y el comité de amas de casa », dans Nueva Sociedad, Nr. 65, marzo-abril 1983, p. $112-$ 126.

- ARTEAGA Vivian et LÓPEZ Beatriz, El feminismo boliviano de principios de siglo. El Ateneo Femenino y su lucha por la mujer, pas d'éditeur, La Paz, 1986.

- BELTRÁN Luis Ramiro (comp.) «Feminiflor» Un hito en el periodismo de Bolivia, CIMCA, Círculo de Mujeres Periodistas, CIDEM, n.d.

- BARRAGÁN Rossana, QAYUM Seemin, SOUX María Luisa, De terratenientes a amas de casa. Mujeres de la élite de La Paz en la primera mitad del siglo XX, Serie "Protagonistas de la Historia", Editores: Ministerio de Desarrollo Humano, Secretaría de Asunto Étnicos, de Género y Generacionales, Subsecretaría de Asuntos de Género, La Paz - Bolivia, 1997.

- CAJÍAS de Villa Gómez Dora, Adela Zamudio. Transgresora de su tiempo, Serie "Protagonistas de la Historia", Editores: Ministerio de Desarrollo Humano, Secretaría de Asunto Étnicos, de Género y Generacionales, Subsecretaría de Asuntos de Género, La Paz - Bolivia, 1997

- CRESPO, Alfonso, Lydia. Una mujer en la historia, Plural Editores, La Paz Bolivia, 1999.

- DURÁN JORDÁN Florencia et SEOANE F. Ana María, El complejo mundo de la mujer durante la Guerra del Chaco, Editores: Ministerio de Desarrollo Humano, Secretaría de Asunto Étnicos, de Género y Generacionales, Subsecretaría de Asuntos de Género, La Paz - Bolivia, 1997.

- DURÁN Zuleta Marlene, Mujeres Orureñas, Biblioteca del Trabajador Universitario, La Paz, 2003.

- HUBER ABENDROTH, Hans, María Luisa Sánchez Bustamante (Malú), Serie "Protagonistas de la Historia", Editores: Ministerio de Desarrollo Humano, Secretaría de Asunto Étnicos, de Género y Generacionales, Subsecretaría de Asuntos de Género, La Paz - Bolivia, 1997. 
- MEDINACELLI, Ximena, Alterando la rutina. Mujeres en las ciudades de Bolivia 1920 - 1930, CIDEM, La Paz - Bolivia, 1989.

- MONTAÑO Virreira Sonia (travail collectif), Bibliografia de la Mujer Boliviana (1920 - 1985), La Paz, Sucre, Cochabamba y Santa Cruz, CIDEM, La Paz, 1986.

- OPORTO ORDOÑEZ, Luis, Las mujeres en la Historia de Bolivia. Imágenes y realidades del siglo XX (1900-1950), Antología, Anthropos, La Paz - Bolivia, 2001.

- PAREDES de Salazar Elssa, Diccionario biográfico de la Mujer Boliviana, Ediciones « Isla », La Paz, 1965.

- PAREDES Oviedo Martha, María Josefa Saavedra, Serie "Protagonistas de la Historia”, Editores: Ministerio de Desarrollo Humano, Secretaría de Asunto Étnicos, de Género y Generacionales, Subsecretaría de Asuntos de Género, La Paz - Bolivia, 1997.

- REVOLLO QUIROGA, Marcela, Mujeres bajo prueba. La participación electoral de las mujeres antes del voto universal (1939 - 1949), Eureka Ediciones, La Paz Bolivia, 2001.

- ROSSELS, Beatriz, Las mujeres en la Historia de Bolivia. Imágenes y realidades del siglo XIX, Anthropos, La Paz - Bolivia, 2001.

- ROSSELS, Beatriz, La Mujer : Una Ilusión. Ideologías e imágenes de la mujer en Bolivia en el siglo XIX, CIDEM, n.d.

- SEOANE F., Ana Maria, Resistencia e insurgencia: la mujer paceña (1936 - 1952), Tésis de Maestría, Universidad Internacional de Andalucía, La Paz - Bolivia, 2001.

- SEOANE F., Ana Maria, «La conquista de los derechos políticos para la mujer », Historias de procesos électorales, Revista de la Coordinadora de Historia, n ${ }^{\circ}$, La Paz, 2001.

\section{Histoire des élections et de la citoyenneté}

- ANNINO Antonio Historia de las elecciones en Iberoamérica, Siglo XIX, Fondo de Cultura Económica de Argentina, S.A., 1995.

- ANNINO Antonio, ROMANELLI Raffaele (coord.), "Notabili, Elettori, Elezioni”, dans Quaderni Storici, n ${ }^{\circ}$, 1988.

- HEATER Dereek, Citizenship: the Civic ideal in the World History. Politics and Education. New York, Logman Inc., 1990. 
- MALAMUD Carlos (coord.), Partidos politicos y elecciones en América Latina y la Península Ibérica, 1830-1930, Papeles de Trabajo del Instituto Universitario Ortega y Gasset, Madrid 1995.

- MANIN Bernard, The principles of Representative Government. Cambridge, Cambridge University Press, 1997.

- O’GORMAN Frank, “Campaign Rituals and Ceremonies: The Social Meaning of Elections in England, 1780-1860”. Past and present, n¹35, 1992.

- POSADA CARBO Eduardo (coord.), Elections before Democracy. The History of Elections in Europe and Latin America, , Macmillan, Londres, 1996.

- ROSANVALLON Pierre, Le sacre du citoyen. Histoire du suffrage universel en France, Paris, Ed. Gallimard, 1992.

- TILly Charles (ed.), Citizenship, Identity and social history. Cambridge, Cambridge University Press, 1996.

- TOURAINE Alain, Qu'est-ce que la démocratie?, Fayard, Paris, 1994;

\section{Vote, élections et citoyenneté en Bolivie}

- BARRAGAN Rossana, Indios, mujeres y ciudadanos. Legislación y ejercicio de la ciudadanía en Bolivia (siglo XIX), La Paz, Fundación Diálogo-Embajada del reino de Dinamarca en Bolivia, 1999.

- CORDERO CARAFFA Carlos Hugo, Historia electoral de Bolivia, 1952 - 2007, Unidad de Análisis e Investigación del Area de Educación Ciudadana de la Corte Nacional Electoral, Corte Nacional Electoral, La Paz - Bolivia, $1^{\text {ère }}$ édition février 2007.

- COSTA Arduz Rolando, Desarrollo electoral en Bolivia (1825-1880) tomo I, La Paz, Corte Nacional Electoral, 1998.

- COSTA Arduz Rolando, Desarrollo electoral en Bolivia (1880-1930) tomo II, La Paz, Corte Nacional Electoral, 2001.

- IRUROZQUI VICTORIANO, Marta, A bala, piedra y palo. La Construcción de la ciudadanía política en Bolivia, 1826 - 1952, Diputación de Sevilla, 2000.

- IRUROZQUI VICTORIANO, Marta, “Sobre leyes y transgresiones: reformas electorales en Bolivia, 1826 - 1952”, dans Legitimidad, representación y alternancia en España y América Latina: las reformas electorales (1880 - 1930), Carlos 
Malamud (Coordinador), Colegio de México, Fideicomiso Historia de las Américas, México, 2000.

- IRUROZQUI VICTORIANO Marta, «Ebrios, vagos y analfabetos. El Sufragio restringido en Bolivia, 1826 - $1952 »$, Revista de Indias, 1996, vol. 56, N²08, p. $697-742$

- IRUROZQUI VICTORIANO Marta, « ¿Que vienen los mazorqueros! Usos y abusos discursivos de la corrupción y la violencia en las elecciones bolivianas, 1884 1925 », dans SABATO HILDA (Coord.) Ciudadanía política y formación de las naciones. Perspectivas históricas de América Latina, Colegio de México, Fideicomiso Historia de las Américas, México, 1999

- IRUROZQUI VICTORIANO Marta, « La amenaza chola. La participación popular en las elecciones bolivianas, 1900-1930 », Revista Andina, Año 13, º2, décembre 2005

-LEAÑO ROMÁN Eduardo, Sistemas electorales en Boliva. La Conversión de votos del Ejecutivo y Legislativo, Unidad de Análisis e Investigación del Area de Educación Ciudadana de la Corte Nacional Electoral, Corte Nacional Electoral, La Paz - Bolivia, $1^{\text {ère }}$ édition février 2005.

- SABATO, Hilda, (Coordinadora), Ciudadanía politica y formación de las naciones. Perspectivas históricas de América Latina, Colegio de México, Fideicomiso Historia de las Américas, México, 1999.

- ZAMORA Kathia, "Ciudadanía plural y descentrada. Una aproximación a los derechos políticos en la Constitución Boliviana", Contrapuntos al debate constituyente. Ciudadanía y Estado de Derecho, Instituto Prisma, Bolivie, décembre 2009.

- ZEGADA María Teresa C., FARAH H. Ivonne, ALBÓ Xavier, Ciudadanías en Bolivia, Unidad de Análisis e Investigación del Area de Educación Ciudadana de la Corte Nacional Electoral, Corte Nacional Electoral, La Paz - Bolivia, Décembre 2006. 